Prepared for the

U.S. Nuclear Regulatory Commission under a Related Services Agreement

with the U.S. Department of Energy

Contract DE-AC05-76RL01830

\title{
Ultrasonic Evaluation of Two Dissimilar Metal Weld Overlay Specimens
}

\author{
SL Crawford \\ AD Cinson \\ TL Moran \\ MS Prowant \\ MT Anderson
}

June 2012 


\title{
DISCLAIMER
}

This report was prepared as an account of work sponsored by an agency of the United States Government. Neither the United States Government nor any agency thereof, nor Battelle Memorial Institute, nor any of their employees, makes any warranty, express or implied, or assumes any legal liability or responsibility for the accuracy, completeness, or usefulness of any information, apparatus, product, or process disclosed, or represents that its use would not infringe privately owned rights. Reference herein to any specific commercial product, process, or service by trade name, trademark, manufacturer, or otherwise does not necessarily constitute or imply its endorsement, recommendation, or favoring by the United States Government or any agency thereof, or Battelle Memorial Institute. The views and opinions of authors expressed herein do not necessarily state or reflect those of the United States Government or any agency thereof.

\author{
PACIFIC NORTHWEST NATIONAL LABORATORY \\ operated by \\ BATTELLE \\ for the \\ UNITED STATES DEPARTMENT OF ENERGY \\ under Contract DE-AC05-76RL01830 \\ Printed in the United States of America \\ Available to DOE and DOE contractors from the \\ Office of Scientific and Technical Information, \\ P.O. Box 62, Oak Ridge, TN 37831-0062; \\ ph: (865) 576-8401 \\ fax: (865) 576-5728 \\ email: reports@adonis.osti.gov

\footnotetext{
Available to the public from the National Technical Information Service, U.S. Department of Commerce, 5285 Port Royal Rd., Springfield, VA 22161 ph: (800) 553-6847 fax: (703) 605-6900

email: orders@ntis.fedworld.gov online ordering: http://www.ntis.gov/ordering.htm
}

This document was printed on recycled paper. 


\title{
Ultrasonic Evaluation of Two Dissimilar Metal Weld Overlay Specimens
}

\author{
SL Crawford \\ TL Moran \\ AD Cinson \\ MT Anderson \\ MS Prowant
}

June 2012

Prepared for

U.S. Nuclear Regulatory Commission under a Related Services Agreement with the U.S. Department of Energy

Contract DE-AC05-76RL01830

Pacific Northwest National Laboratory

Richland, Washington 99352 



\section{Summary}

Pacific Northwest National Laboratory has been conducting studies for the NRC on systems susceptible to pressurized water stress corrosion cracking (PWSCC). Weld overlays with resistant materials are being used to mitigate PWSCC found in reactor components. This study addressed the inspection of weld overlays.

Two specimens with a dissimilar metal weld (DMW) between a 516 Grade 70 carbon steel nozzle and a CASS pressurizer (PZR) surge-line pipe segment were implanted with thermal fatigue cracks (TFCs). In the first specimen, four TFCs were implanted in the weld-to-butter region with flaw depths ranging from $13 \%$ to $31 \%$ through-wall. The second specimen contained five circumferentially oriented IDconnected TFCs (flaw depths ranging from $49.8 \%$ to $89.9 \%$ through-wall) implanted in the center of the weld during the welding process to minimize implantation artifacts that could show in the ultrasonic data. The specimens were ultrasonically evaluated with phased-array probes having center frequencies of 0.8 , 1.0, 1.5, and 2.0 megahertz (MHz). An Alloy 82/182 weld overlay (WOL) was applied and the specimens were ultrasonically re-evaluated for flaw detection and characterization. The Post-WOL flaw depths were approximately $10 \%$ to $56 \%$ through-wall.

The WOL specimens were approximately $53 \mathrm{~mm}(2.1 \mathrm{in}$.) thick and with this thicker material suggested that a lower inspection frequency, on the order of 0.8 or $1.0 \mathrm{MHz}$, was needed to detect and size flaws from the cast austenitic stainless steel (CASS) pipe side of the weld. However, the longer wavelengths of the two lower frequency probes prevented them from detecting the two smallest flaws (10\% and 14\% through-wall deep). Accordingly, $1.5-$ and $2.0-\mathrm{MHz}$ probes were then used and it was shown that microstructures in the cast pipe and overlay materials were amenable to higher frequencies as all of the flaws were detected and characterized. It should be cautioned that these results were obtained after removal of the weld crown as it limited access to the flaws and thus prevented full flaw detection.

The detected flaws had SNR values of approximately $15 \mathrm{~dB}$ which are well above a minimal level of 8 to $10 \mathrm{~dB}$ for good detection. The depth sizing errors as calculated RMSEs were within the ASME requirements of $3.2 \mathrm{~mm}(0.125 \mathrm{in}$.) for the line scan data and a subset of the raster data where the analyst emphasized tip diffraction sizing. The remaining raster data, based more on specular reflection analyses, were above the ASME required RMSE level. Length sizing RMSEs were generally within the ASME requirements of $19 \mathrm{~mm}(0.75 \mathrm{in}$.) except when including the shallow flaws. The presence of a strong weld root signal that was not always separated from the flaw ID corner response contributed to the error in length sizing.

This study has shown the effectiveness of ultrasonic examinations of Alloy 82/182 overlaid DMW specimens. Phased-array probes with center frequency in the 0.8 - to $1.0-\mathrm{MHz}$ range provide a strong coherent signal but the greater ultrasonic wavelength and larger beam spot size prevent the reliable detection of small flaws. These small flaws had nominal through-wall depths of less than $15 \%$ and length in the 50-60 $\mathrm{mm}(2-2.4$ in.) range. Flaws in the $19 \%$ and greater through-wall depth range were readily detected with all four probes. At the higher frequencies, the reflected signals are less coherent but still provide adequate signal for flaw detection and characterization. A single inspection at $2.0 \mathrm{MHz}$ could provide adequate detection and sizing information but a supplemental inspection at 1.0 or $1.5 \mathrm{MHz}$ is recommended. 



\section{Acronyms and Abbreviations}

BW

CASS

$\mathrm{dB}$

DMW

GDC

ID

LBB

LOS

$\mathrm{MHz}$

NRC

NRR

OD

PA

PNNL

PWSCC

PZR

RES

RMSE

SNR

TFC

TRL

WNP

WOL

WSS

xLPR bandwidth

cast austenitic stainless steel

decibel

dissimilar metal weld

General Design Criteria

inner diameter

leak-before-break

loss of signal

megahertz

U.S. Nuclear Regulatory Commission

Office of Nuclear Reactor Regulation

outer diameter

phased array

Pacific Northwest National Laboratory

pressurized water stress corrosion cracking

pressurizer

Office of Nuclear Regulatory Research

root mean square error

signal-to-noise ratio

thermal fatigue crack

transmit-receive longitudinal

Washington Public Power Supply System Nuclear Power Plant

weld overlay

wrought stainless steel

extremely low probability of risk 



\section{Contents}

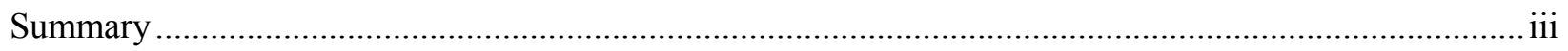

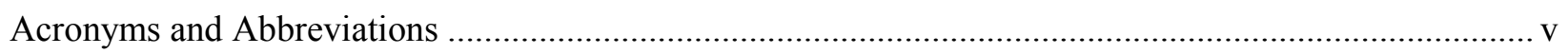

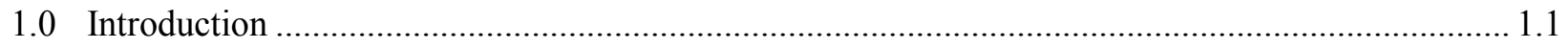

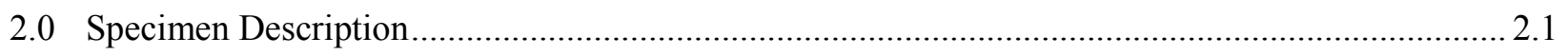

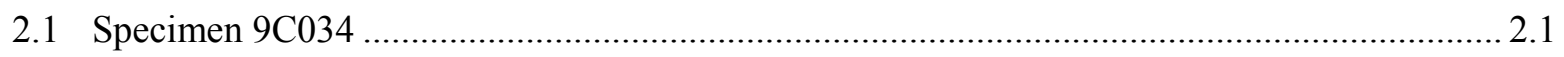

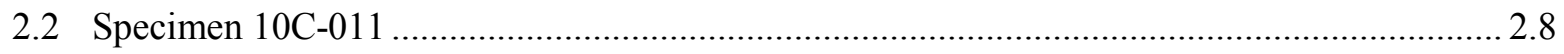

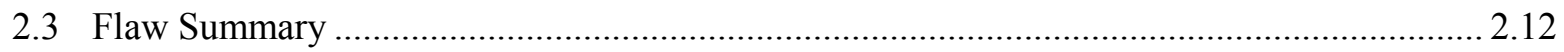

3.0 Phased-Array Probes and Focal Law Development ............................................................... 3.1

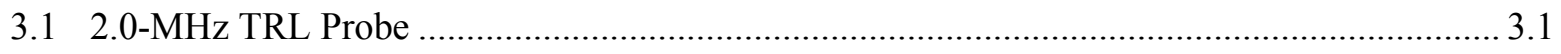

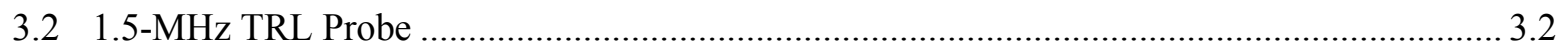

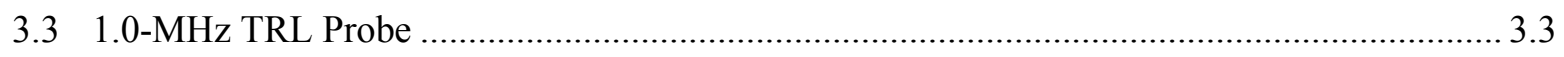

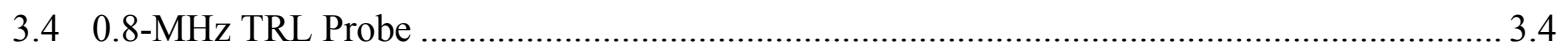

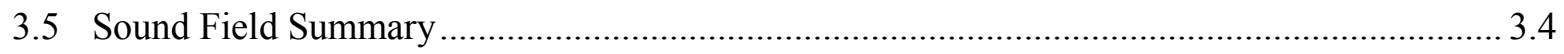

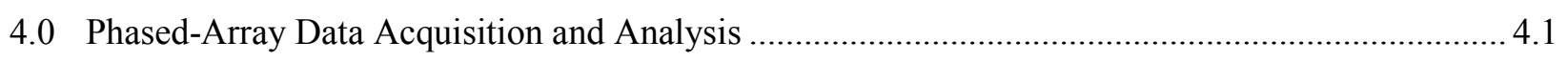

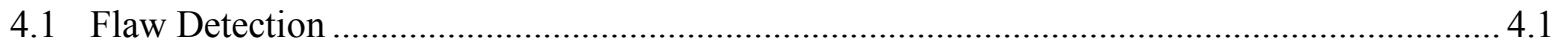

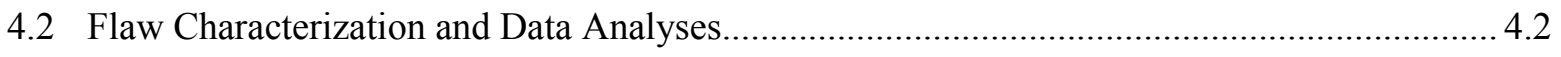

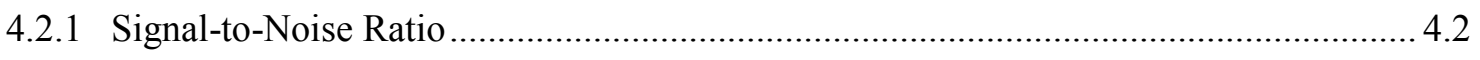

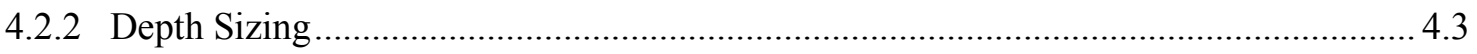

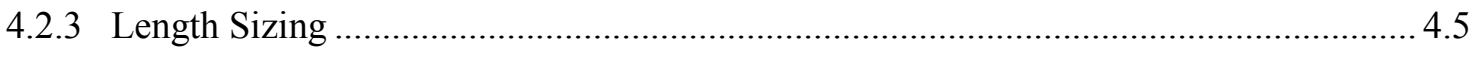

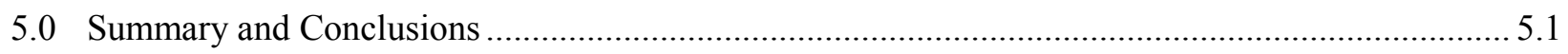

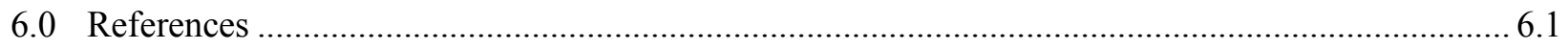

Appendix A - Dissimilar Metal Weld Specimen 9C-034 Phased-Array Data, Pre-WOL...................... A.1

Appendix B - Dissimilar Metal Weld Specimen 9C-034 Phased-Array Data, Post-WOL ........................1

Appendix C - Dissimilar Metal Weld Specimen 10C-011 Phased-Array Data, Pre-WOL ........................1

Appendix D - Dissimilar Metal Weld Specimen 10C-011 Phased-Array Data, Post-WOL ................... D.1

Appendix E - Length and Depth Sizing and Signal-to-Noise Ratio Tables ............................................ 1 


\section{Figures}

2.1 Dissimilar Metal Weld Profile for Specimen 9C-034 ............................................................. 2.2

2.2 Photographs of the Original OD Surface of DMW Mock-up Specimen 9C-034 .......................... 2.2

2.3 Polished and Etched Surface of Specimen 9C-034 Showing a Columnar Microstructure ............. 2.3

2.4 Photographs of the ID Surface of DMW Mock-up Specimen 9C-034 Depicting Various ID

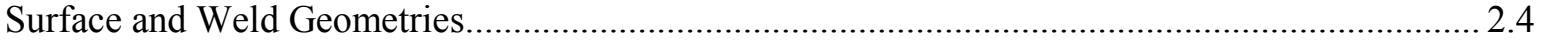

2.5 Side-View Illustration of All Four Thermal Fatigue Cracks Implanted into DMW Mock-Up

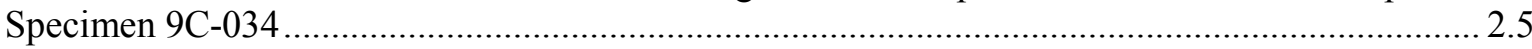

2.6 End-View Illustration of All Four Thermal Fatigue Cracks Implanted into DMW Mock-up

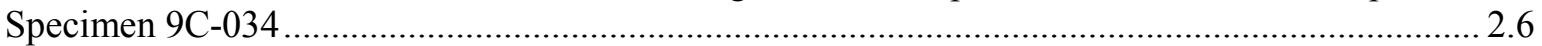

2.7 Photograph of Specimen 9C-034 with Water Backing During the Application of the Weld

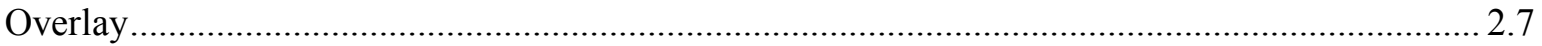

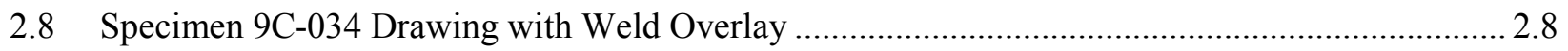

2.9 Photograph of Specimen 10C-011 with a Weld Overlay ............................................................ 2.9

2.10 Specimen 10C-011 Flaw Side View, showing Axial Position and Through-wall Depth ............. 2.10

2.11 Specimen 10C-011 Flaw End View, showing Circumferential Position and Length ................... 2.11

2.12 Drawing of Specimen 10C-011 with Weld Overlay and Dimensions ........................................ 2.12

3.1 Photograph of the 2.0-MHz, Phased-Array Probe, Originally Developed for Inlays, Onlays,

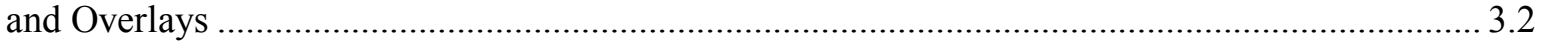

3.2 Photograph of the 1.5-MHz TRL Probe Originally Designed for Wrought Stainless Steel

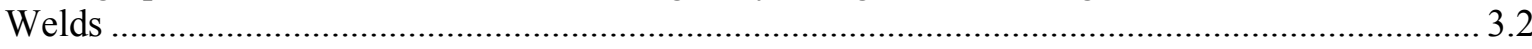

3.3 Photograph of the 1.0-MHz, Phased-Array Probe, Originally Developed for Inlays, Onlays,

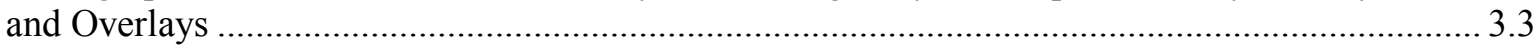

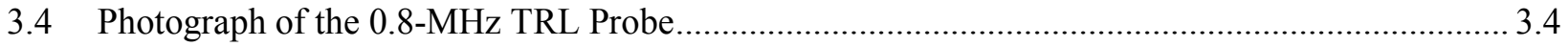

4.1 Signal-to-Noise Ratios for Raster Data from the Specimen Pipe Side and the Nozzle Side ........... 4.3

4.2 Measured Flaw Depths from Raster Data Acquired from the Pipe Side and the Nozzle Side......... 4.4

4.3 Measured Flaw Depths from Line Data Acquired from the Pipe Side and the Nozzle Side ........... 4.5

4.4 Length Sizing Results from Raster Data Acquired from the Pipe Side at the $-6 \mathrm{~dB}$

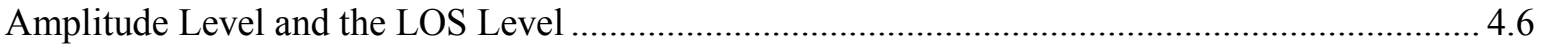

4.5 Length Sizing Results from Raster Data Acquired from the Nozzle Side at the $-6 \mathrm{~dB}$ Amplitude Level and the LOS Level..... 


\section{Tables}

2.1 Flaw Length and Depth Summary

2.13

3.1 Phased Array Ultrasonic Transducer Physical Specifications ....

3.2 Theoretical Focal Spot Dimensions at the $-3 \mathrm{~dB}$ Level for Probes Used in this Study for

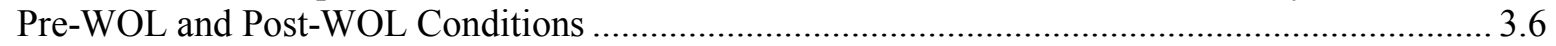

4.1 Flaw Detection Table for Specimen 9C-034 Post-WOL ........................................................... 4.2

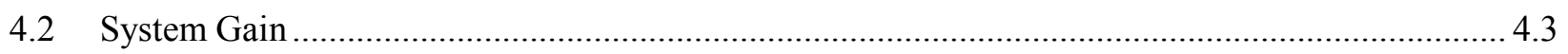

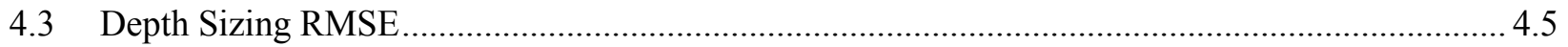

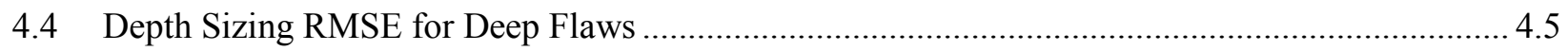

4.5 Length Sizing RMSE Values Acquired from the Pipe Side Data ................................................. 4.6

4.6 Length Sizing RMSE Values Acquired from the Nozzle Side Data.............................................. 4.7 



\subsection{Introduction}

Pacific Northwest National Laboratory (PNNL) has been conducting studies through the U.S. Nuclear Regulatory Commission's (NRC's) Office of Nuclear Regulatory Research (RES) to support the Office of Nuclear Reactor Regulation (NRR) in determining: (1) what combination of strategies are needed to assure continued compliance with General Design Criteria (GDC)-4 given that many systems approved for leak-before-break (LBB) are evidently susceptible to pressurized water stress corrosion cracking (PWSCC); (2) a position on whether inspections alone or inspections plus mitigation are needed to provide this assurance; (3) a unified LBB position on the need for inspection plus mitigation in systems affected by stress corrosion; (4) what regulatory actions are needed, if any, on PWSCC in Alloy $82 / 182 / 600$ butt weld configurations; and (5) review criteria needed for future LBB applications involving Alloy 82/182/600 materials.

This report addresses the material replacement issue under the larger project, Degradation in xLPR (extremely low probability of risk) Systems. Industry has been replacing Alloy 82/182/600 materials with the more resistant Alloy 52/152/690 as a means of corrective action for PWSCC. The material replacement task addresses three areas: (1) determine the effectiveness of weld overlays with resistant materials to mitigate PWSCC; (2) determine the inspectability of these modified configurations; and (3) develop criteria for determining long-term inspection frequencies for these modified configurations. The narrow focus of this report addresses the second area, to determine the inspectability in terms of ultrasonic nondestructive evaluation of weld overly specimens.

To conduct this study, thermal fatigue cracks were implanted in two dissimilar metal weld (DMW) specimens. The specimens were composed of a cast austenitic stainless steel pipe welded to a carbon steel nozzle with Alloy 82/182 weld material. Each specimen was evaluated with phased-array ultrasonic testing to determine flaw detection and characterization capabilities. An Alloy 82/182 weld overlay (WOL) was added to the specimens, and they were again evaluated ultrasonically for flaw detection and characterization. A WOL made of Alloy 52/152 was cost-prohibitive so the Alloy 82/182 was selected instead. Flaw characterization included length and depth measurements as well as a signal-to-noise ratio (SNR) determination. Objectives of this work included determining ultrasonic detection capabilities in DMW specimens with a WOL and to assess ultrasonic examinations through cast austenitic stainless steel (CASS) material. The following sections include a description of the specimens, a description of the ultrasonic phased-array probes, and a presentation of the ultrasonic results and conclusions. 



\subsection{Specimen Description}

Two specimens were evaluated in this study. The first (Specimen 10C-011) contained five circumferentially oriented ID-connected TFCs implanted in the center of the weld with flaw depths ranging from $49.8 \%$ to $89.9 \%$. These flaws were easily detected with ultrasound so a second specimen with shallower flaws was evaluated. The second specimen (9C-034) contained four TFCs implanted in the weld-to-butter region with flaw depths ranging from $13 \%$ to $31 \%$ through-wall.

\subsection{Specimen $9 \mathrm{C034}$}

Specimen 9C-034 contains a DMW between a 516 Grade 70 carbon steel nozzle and a CF8-M CASS pipe. The nozzle side butter and weld consisted of Alloy 182 material. The weld profile and components are diagramed in Figure 2.1. Four thermal fatigue cracks (TFCs) were implanted in the weld-to-butter region with flaw depths ranging from $13 \%$ to $31 \%$ through-wall. The flaws are vertical, have no tilt, are circumferentially oriented, and are inner-diameter (ID) surface connected. The specimen was first ultrasonically examined with the weld crown in place (Figure 2.2). It was determined that the presence of the weld crown limited access to the flaws and thus prevented full flaw detection, so the crown was removed and the specimen rescanned. Data were acquired from the CASS piping side of the weld as this is the accessible side in many plant configurations. The CASS pressurizer (PZR) surge-line pipe segment has an approximate $325-\mathrm{mm}$ (12.81-in.) outer diameter (OD), and is approximately $32.6 \mathrm{~mm}$ (1.28 in.) in wall thickness. This pipe portion of the DMW specimen was cut from a longer segment of a CASS PZR surge line from WNP-3 (Washington Public Power Supply System Nuclear Power Plant). A photograph of the polished and etched surface of the end of the pipe showing the CASS microstructure is displayed in Figure 2.3. The individual section of CASS pipe was sent to FlawTech where it was welded to a carbon steel nozzle segment and the four TFCs were implanted into the butter region on the nozzle side of the welded specimen, eliminating any excavation and implantation artifacts. This DMW mock-up specimen is approximately $325 \mathrm{~mm}$ (12.81 in.) in diameter at the flaw position, and $584.2 \mathrm{~mm}$ (23.00 in.) in length, with a nominal $32.6 \mathrm{~mm}$ (1.28 in.) wall thickness at the flaw location within the DMW.

This specimen also contained a substantial weld root as seen in Figure 2.4. This produced a strong ultrasonic signal that sometimes impacted flaw detection and characterization.

The four TFCs were inserted via a coupon-implant technique and were all circumferentially oriented flaws. An axial side-view illustration of the four flaws depicting flaw position relative to the DMW geometry and flaw depth is provided in Figure 2.5. A full circumferential view of all flaw positions and extents on Specimen 9C-034 is displayed in Figure 2.6. This pipe end-view depicts the circumferential extent or length of the implanted ID surface-connected cracks. 


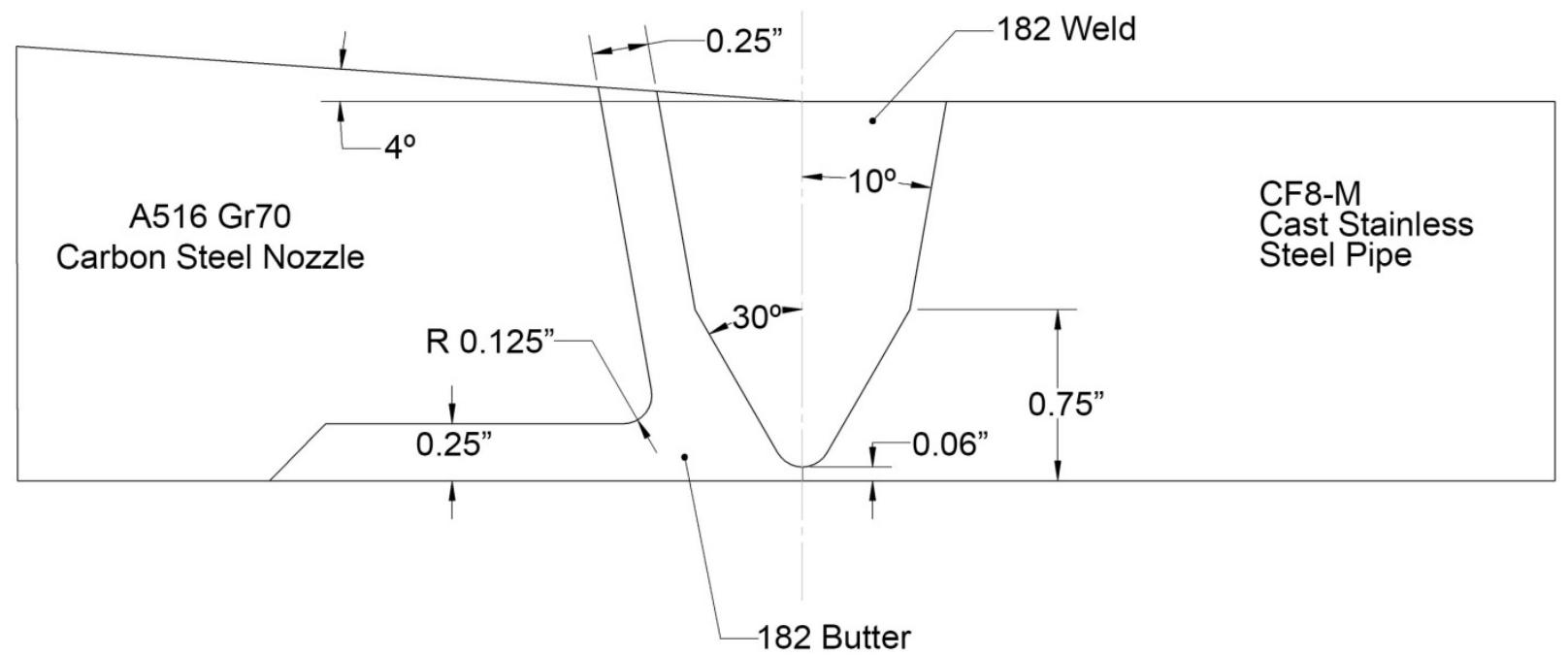

Figure 2.1. Dissimilar Metal Weld Profile for Specimen 9C-034
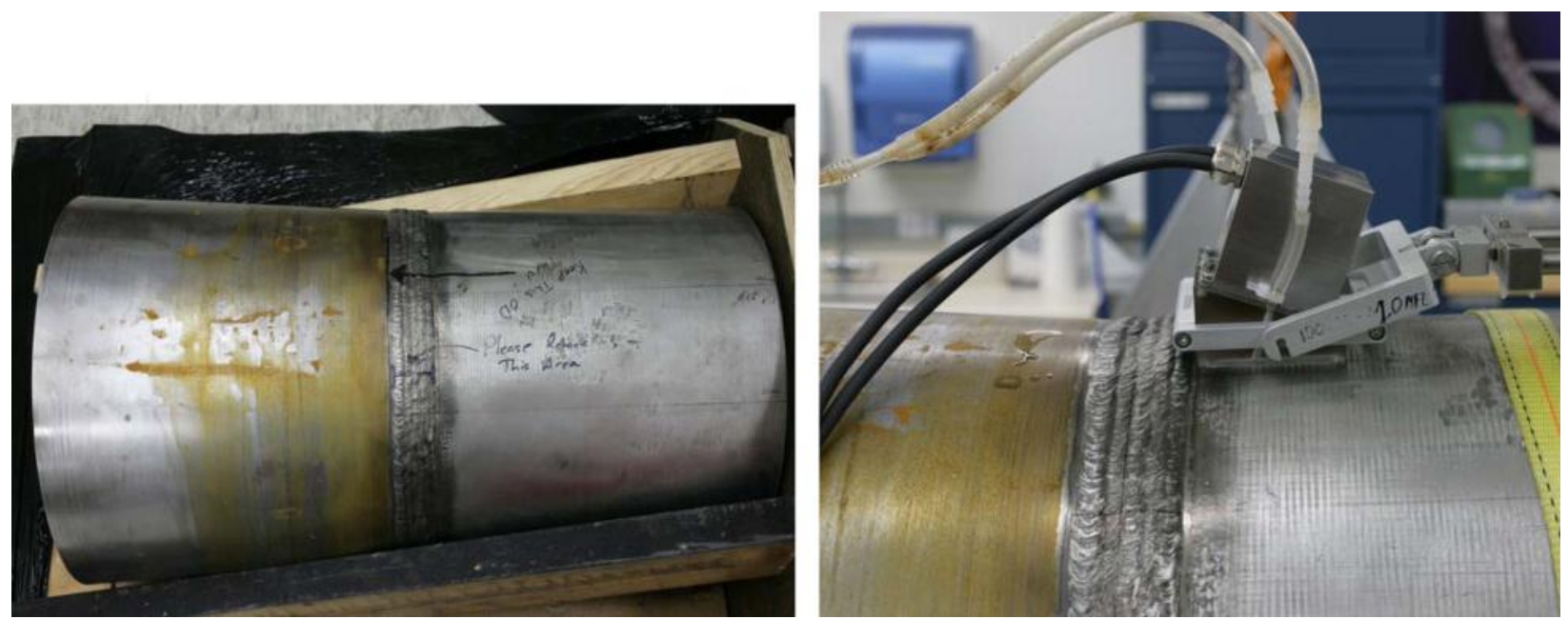

Figure 2.2. Photographs of the Original OD Surface of DMW Mock-up Specimen 9C-034 


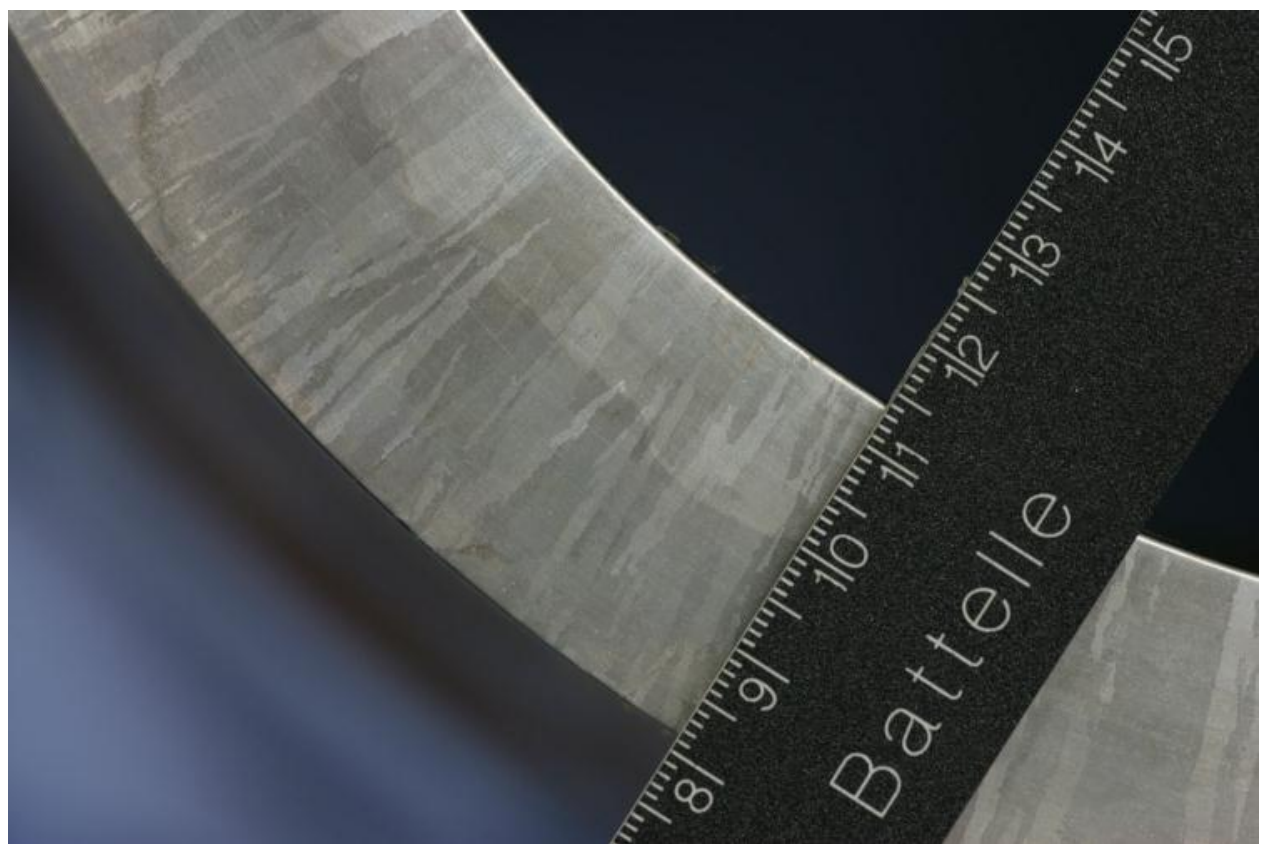

Figure 2.3. Polished and Etched Surface of Specimen 9C-034 Showing a Columnar Microstructure 

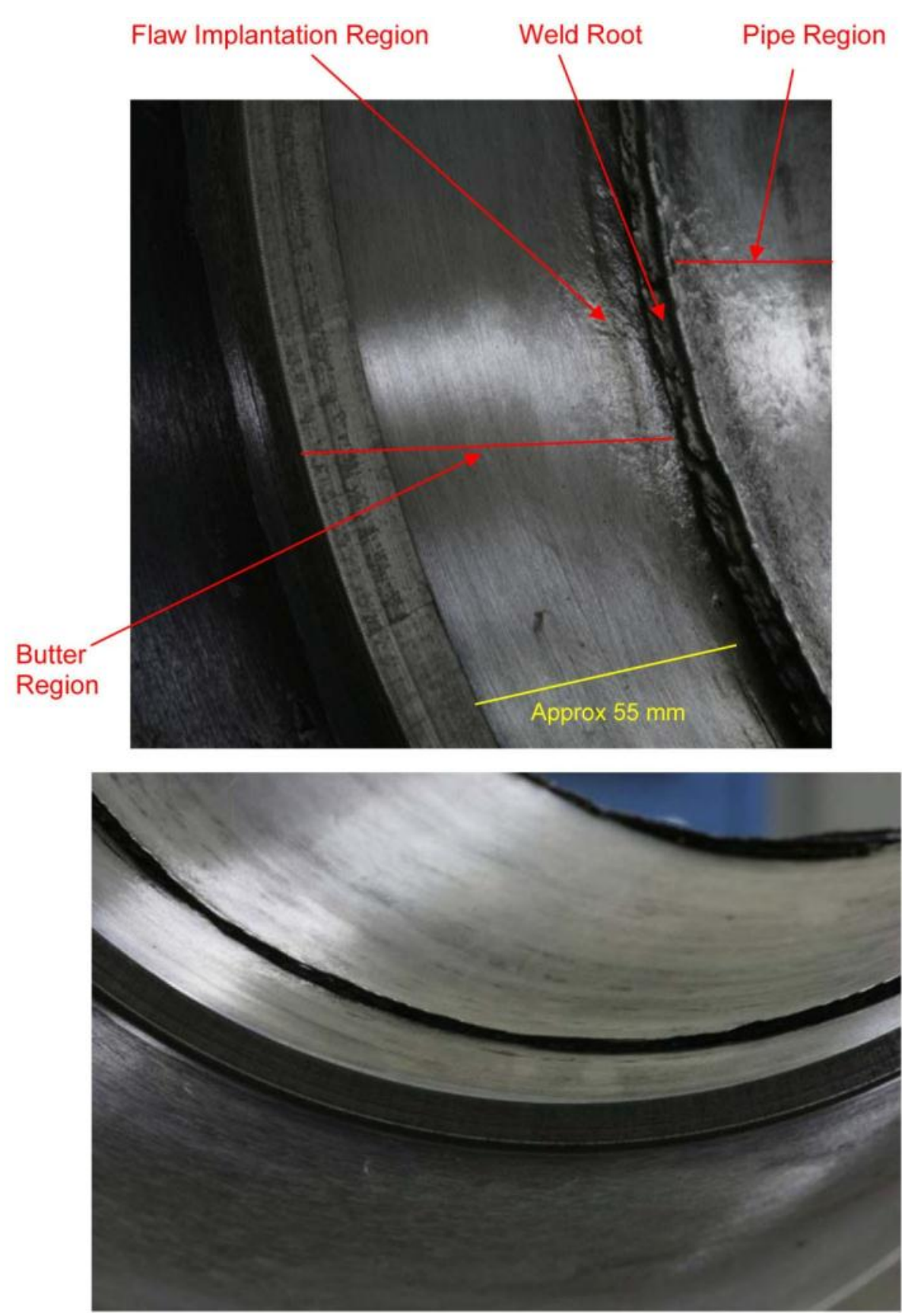

Figure 2.4. Photographs of the ID Surface of DMW Mock-up Specimen 9C-034 Depicting Various ID Surface and Weld Geometries 


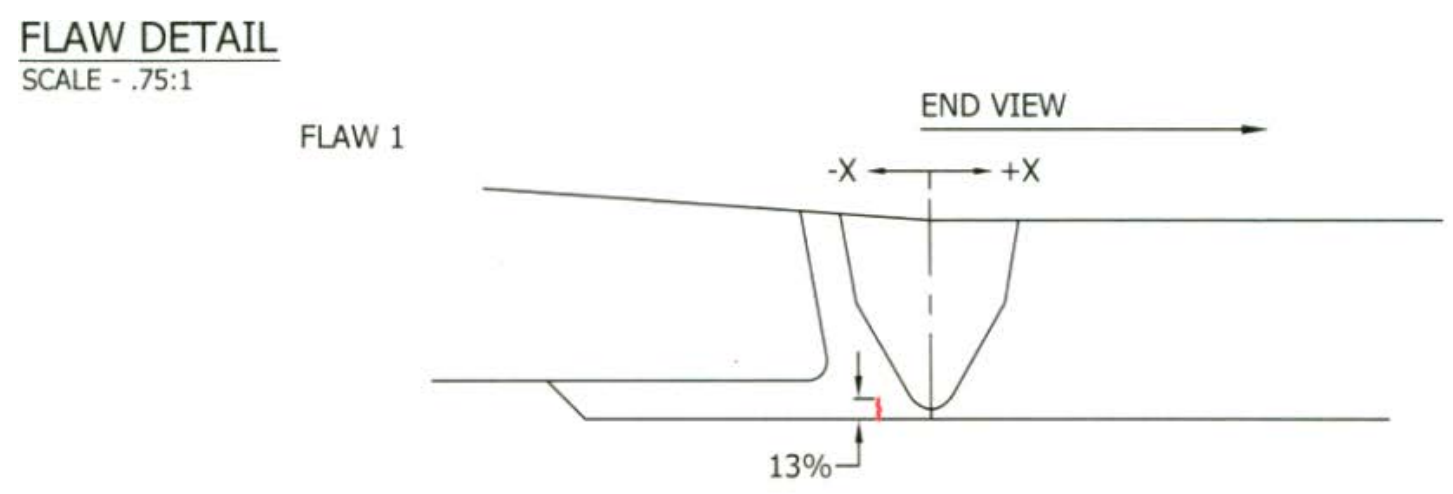

FLAW 2

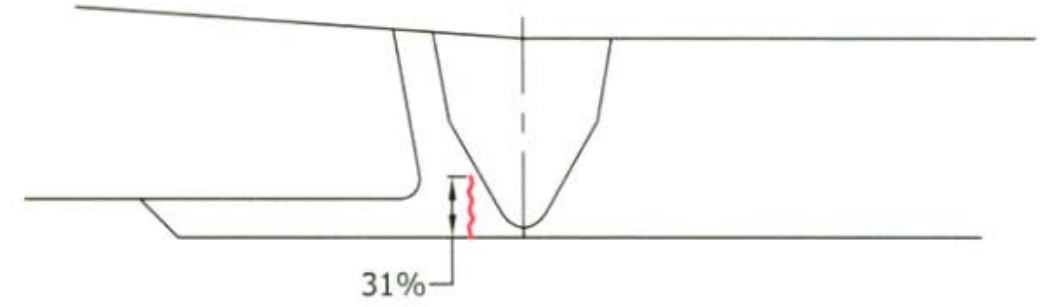

FLAW 3

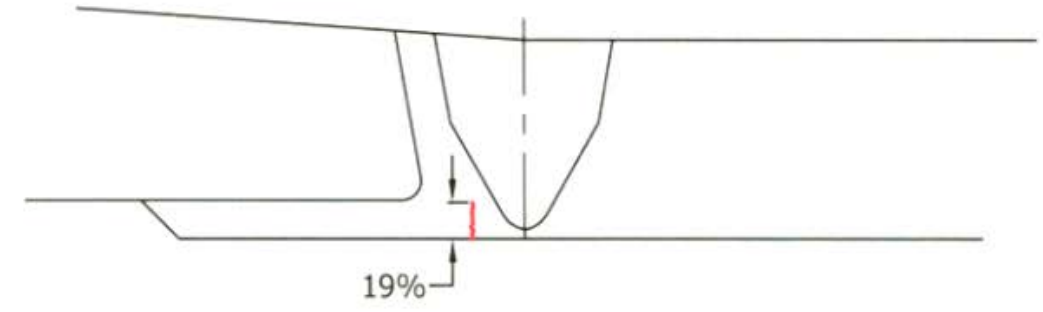

FLAW 4

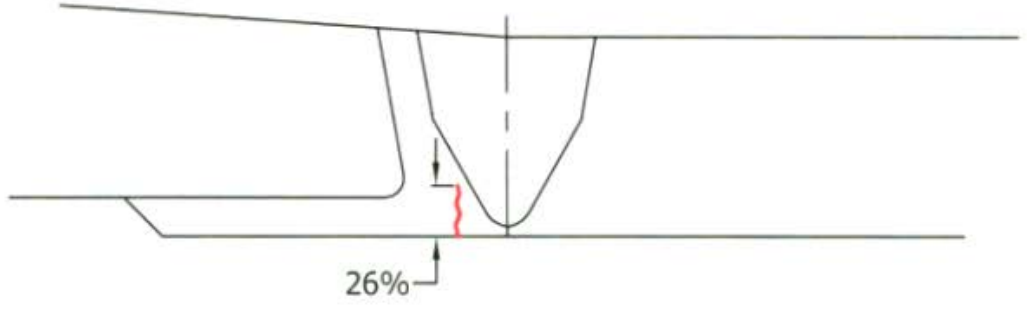

Figure 2.5. Side-View Illustration of All Four Thermal Fatigue Cracks Implanted into DMW Mock-Up Specimen 9C-034 


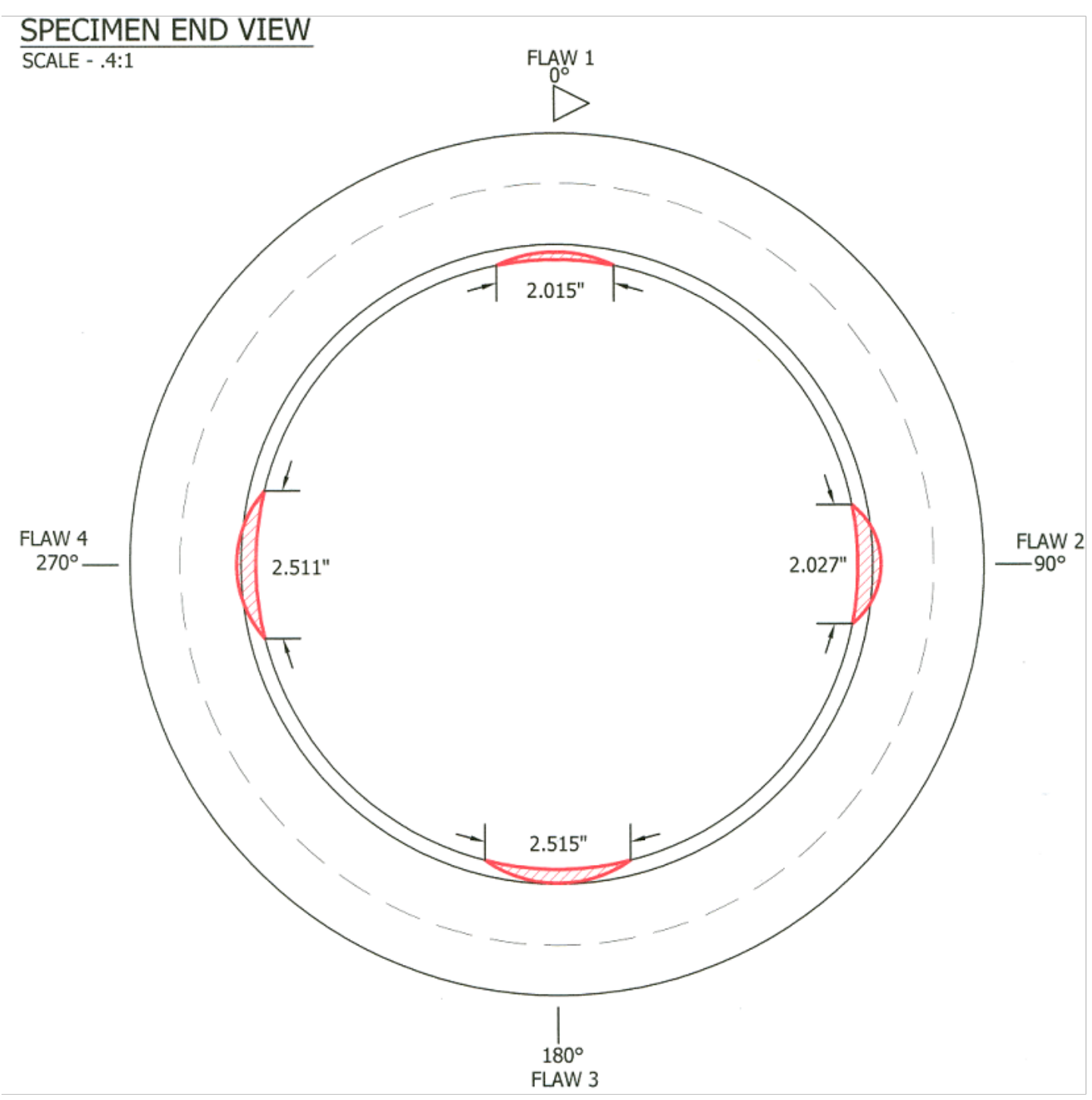

Figure 2.6. End-View Illustration of All Four Thermal Fatigue Cracks Implanted into DMW Mock-up Specimen 9C-034

The specimen was overlaid with Alloy 82 in a water-backed overlay process. A photo of the setup at FlawTech is shown in Figure 2.7. The polished and etched pipe surface is visible in the foreground. Finally, a drawing of the overlaid specimen with dimensions is shown in Figure 2.8. 


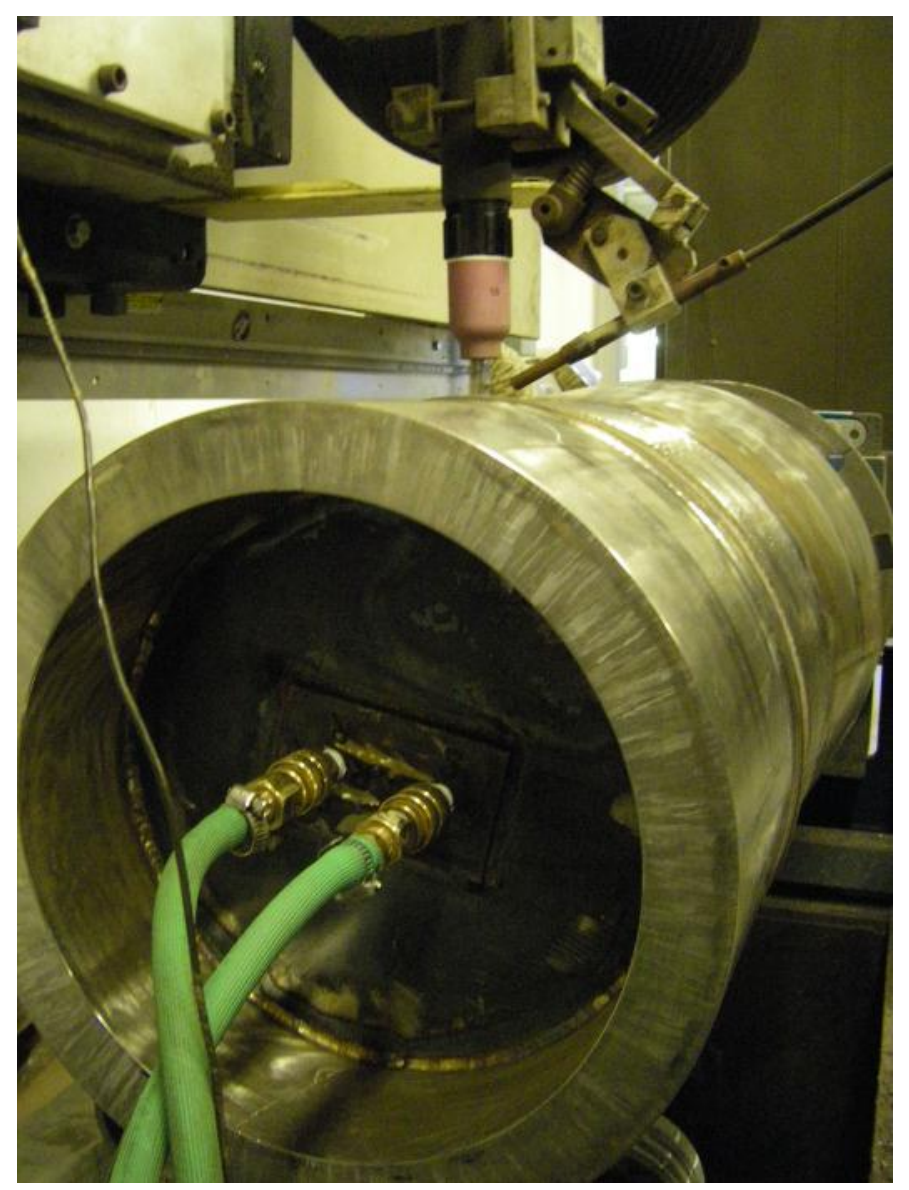

Figure 2.7. Photograph of Specimen 9C-034 with Water Backing During the Application of the Weld Overlay 


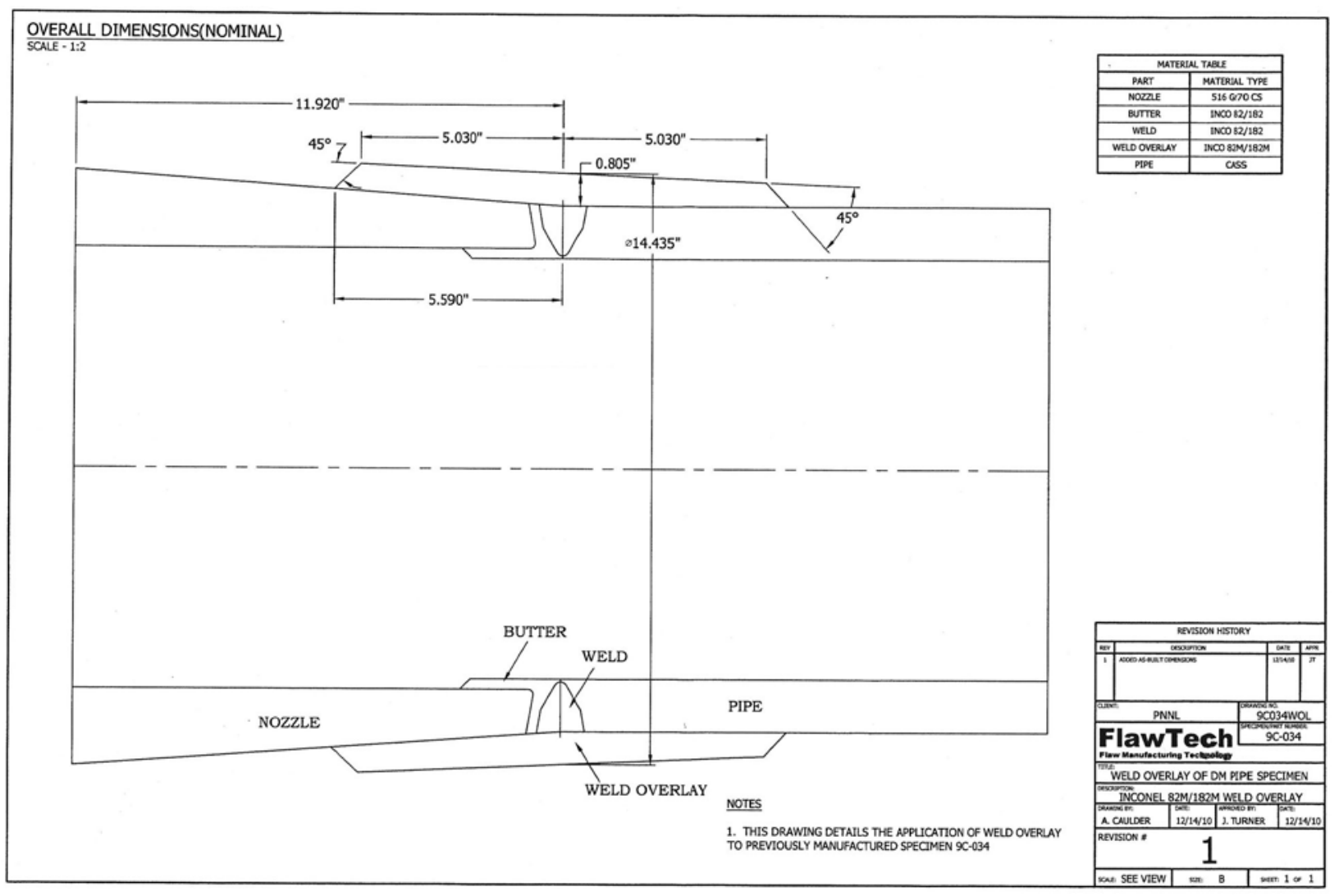

Figure 2.8. Specimen 9C-034 Drawing with Weld Overlay

\subsection{Specimen 10C-011}

Specimen 10C-011 is a 516 Grade 70 nozzle and Alloy 82 butter section welded to a CF8-M CASS pipe. The weld profile is similar to that shown for Specimen 9C-034 in Figure 2.1 except that the weld and butter material for Specimen 10C-011 is Alloy 82, rather than Alloy 182 used in Specimen 9C-034. A photograph of the specimen with a full structural weld overlay (Alloy 82) is shown in Figure 2.9. Five circumferentially oriented ID-connected TFCs were implanted in the center of the weld during the welding process to prevent implantation artifacts that could show in the ultrasonic data. The weld crown was removed for ultrasonic evaluations. However a weld root signal was often ultrasonically detected and precluded a strong corner response from the flaw itself. The presence of a strong weld root signal that could not be separated from the flaw signal complicated flaw length sizing. The flaw depths range from $49.8 \%$ to $89.9 \%$ through-wall deep and are tilted by 2 or 3 degrees. The flaw lengths vary from 38.15-63.86 mm (1.502-2.514 in.). A schematic of the flaw axial cross sections are shown in Figure 2.10, and a schematic of the full flaw circumferential cross section or end view is shown in Figure 2.11. These two figures show the through-wall extent and length of the cracks, respectively. The specimen has an approximate through-wall thickness at the location of the flaws of $32.9 \mathrm{~mm}$ (1.30 in.) with the weld crown removed. Lastly, a specimen drawing with the weld overlay is displayed in Figure 2.12 and shows the specimen dimensions. The full specimen is $684 \mathrm{~mm}$ (26.94 in.) long. 


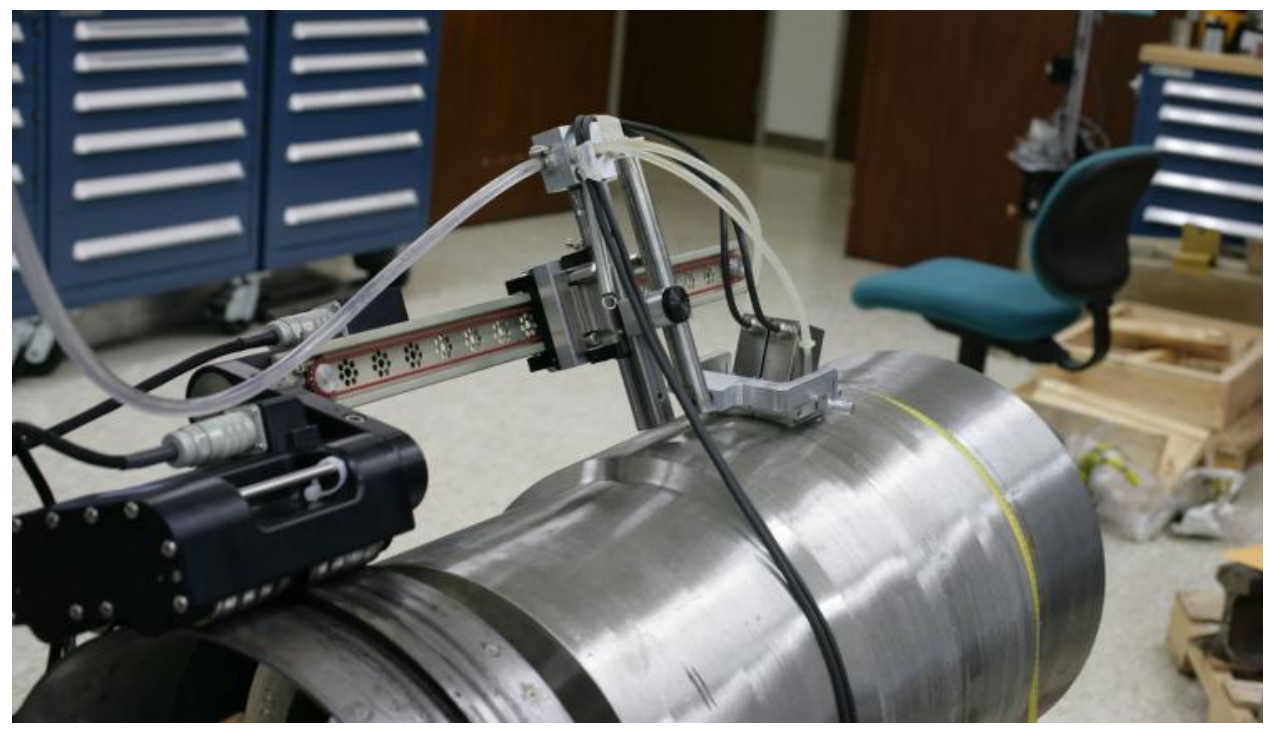

Figure 2.9. Photograph of Specimen $10 \mathrm{C}-011$ with a Weld Overlay 

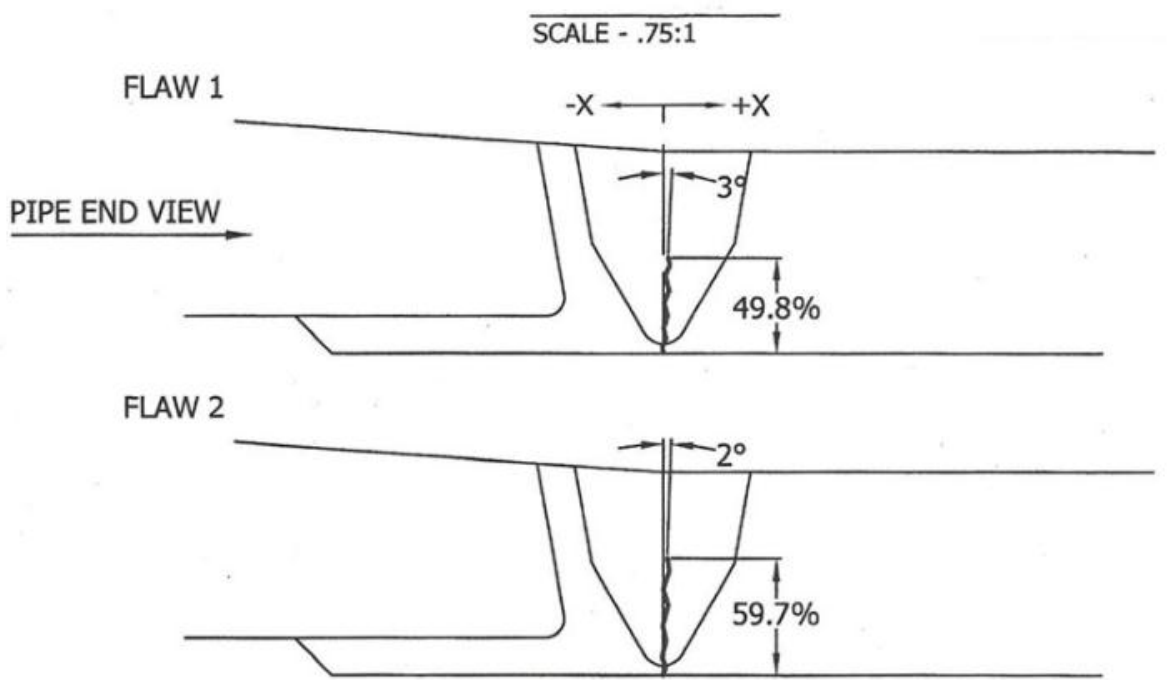

FLAW 3
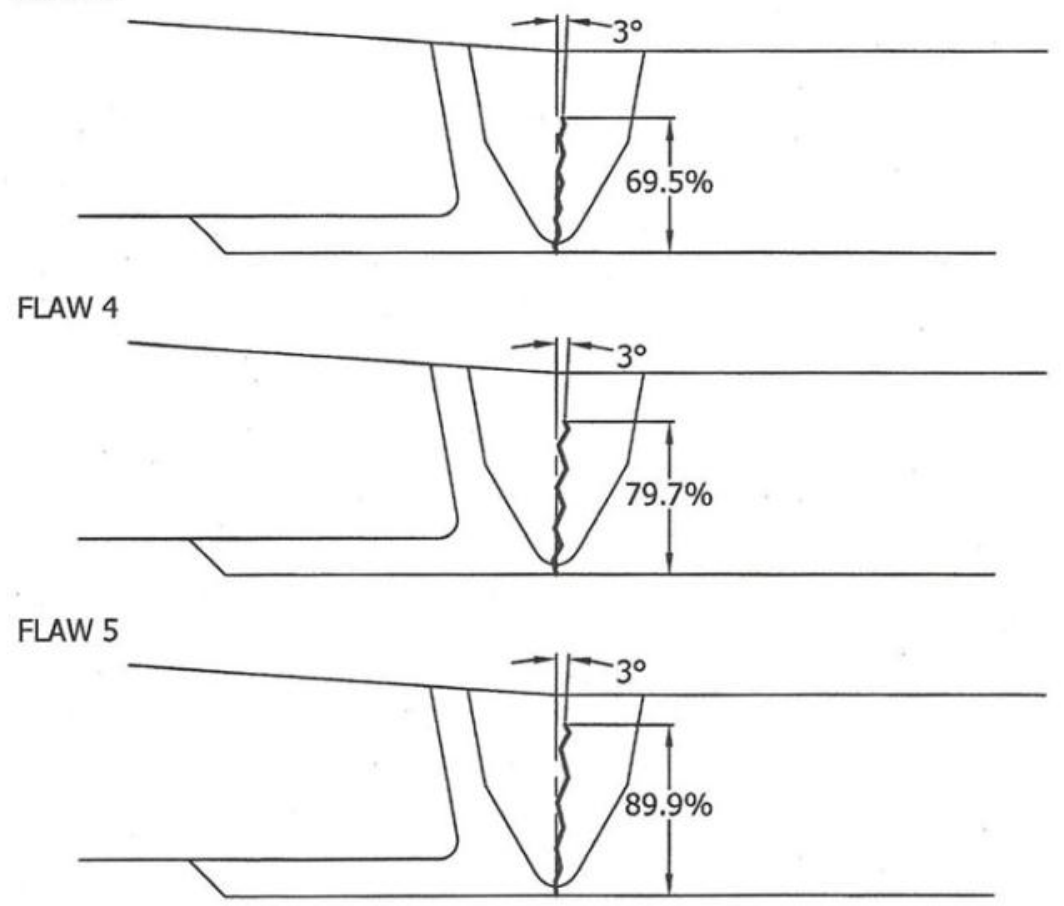

Figure 2.10. Specimen 10C-011 Flaw Side View, showing Axial Position and Through-wall Depth 


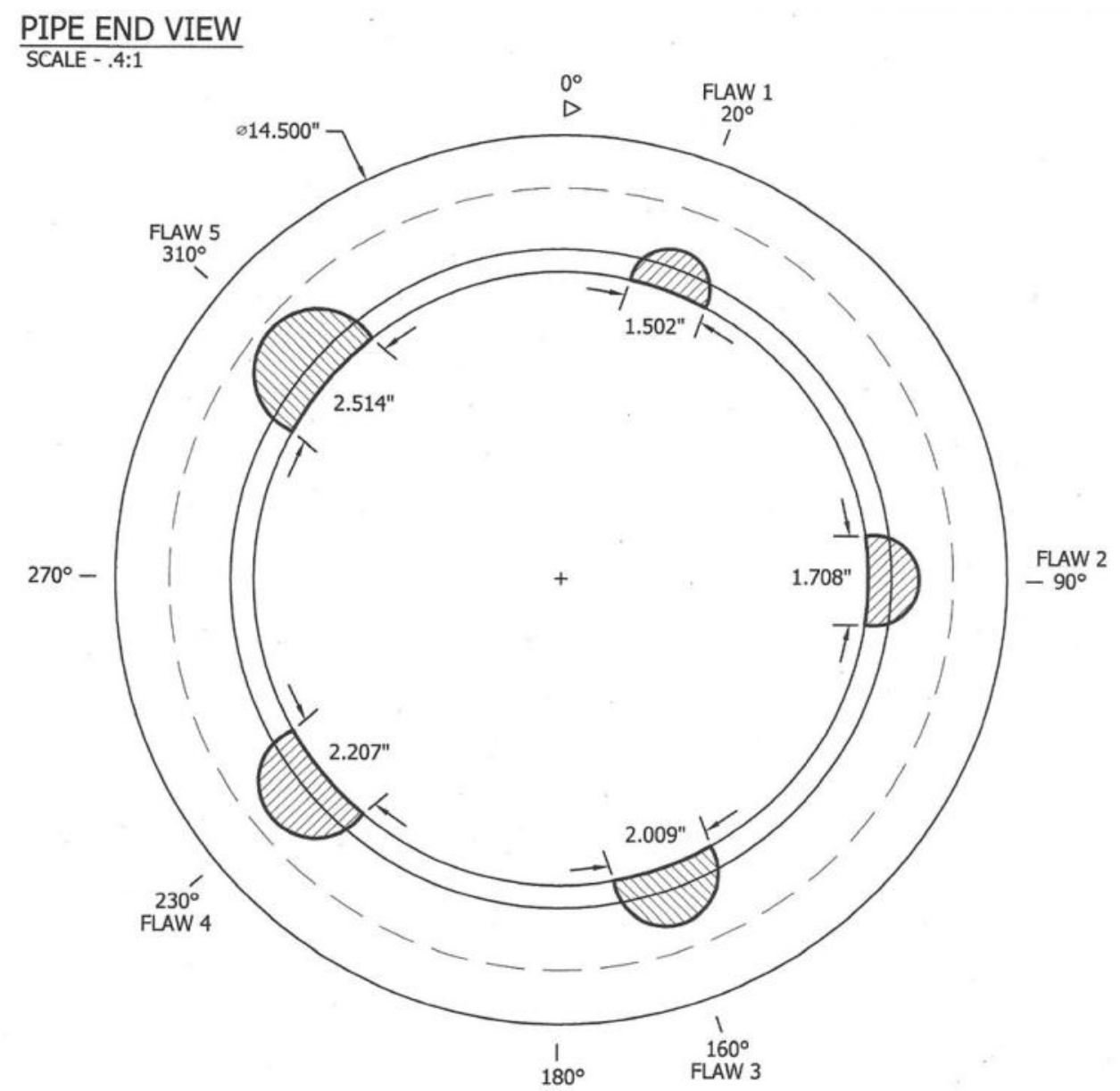

Figure 2.11. Specimen 10C-011 Flaw End View, showing Circumferential Position and Length 


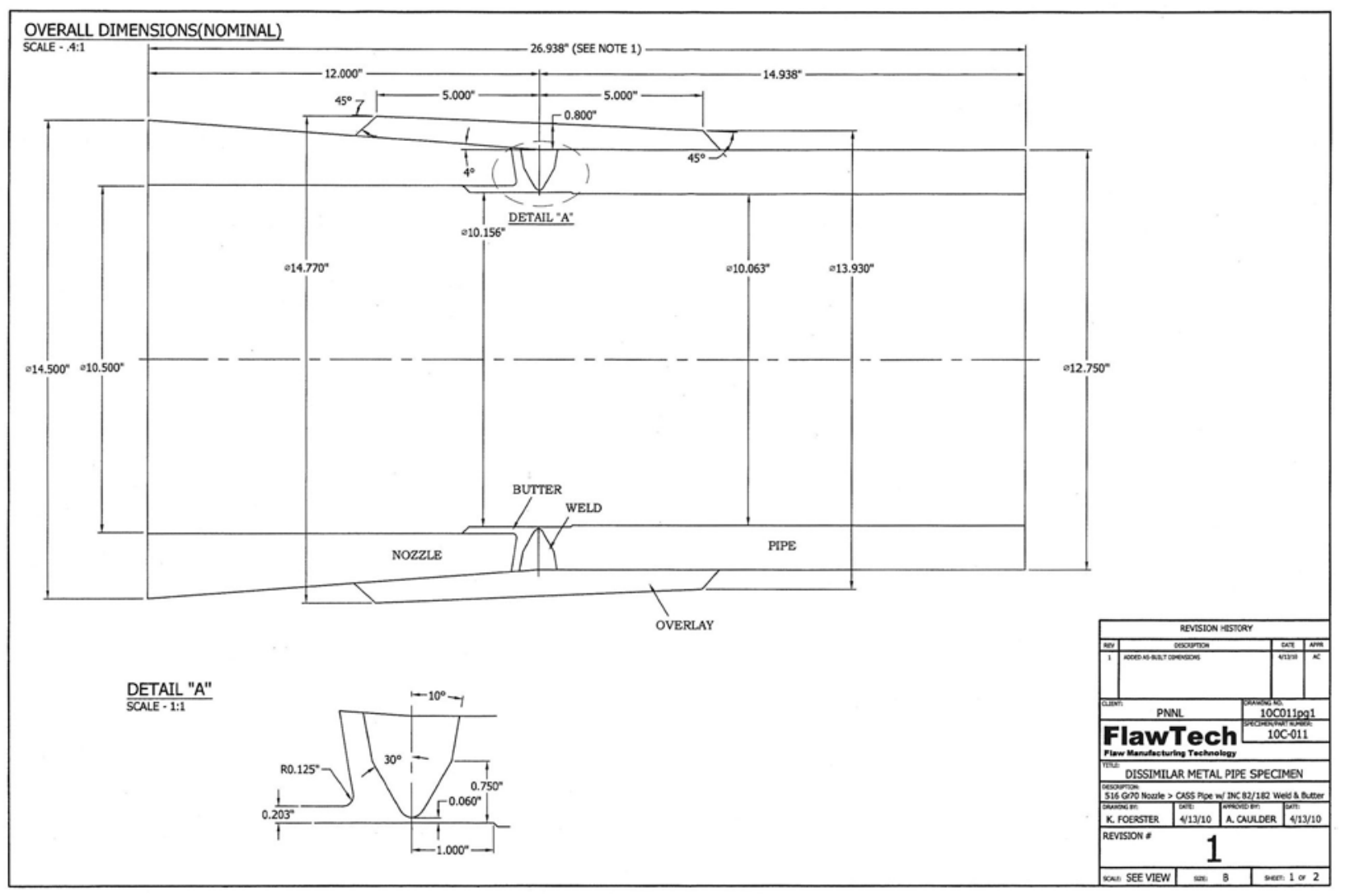

Figure 2.12. Drawing of Specimen 10C-011 with Weld Overlay and Dimensions

\subsection{Flaw Summary}

A summary listing of the nine flaw lengths and depth true-state values are given in Table 2.1. An assumed Pre-WOL specimen thickness at the flaw location for Specimen 9C-034 was $32.6 \mathrm{~mm}$ (1.28 in.) and for 10C-011 was $32.9 \mathrm{~mm}$ (1.30 in.). Calculating through-wall depths with these specimen thickness values produced results that were within $2 \%$ of the reported depths as a percentage of through-wall depth. The assumed Post-WOL thickness was $53.1 \mathrm{~mm}$ (2.09 in.) for Specimen 9C-034 and $47.9 \mathrm{~mm}$ (1.89 in.) for Specimen 10C-011. These thickness values were used to calculate the Post-WOL depths as a percentage of through-wall depth. Also added as a note to the table are the wavelengths $(\lambda)$ for the four probes. These values will be discussed in the later acquisition, analysis, and conclusions sections as they relate to flaw detection and characterization.

In accordance with ASME Code, Section XI, Appendix VIII, Supplement 11 requirements for full structural weld overlays (FSWOLs), the new overlay material as well as the outer $25 \%$ of the original base material must be inspected for flaws. For an optimized weld overlay (OWOL) the new overlay material and the outer $50 \%$ of the original material must be inspected for flaws. All of Specimen 10C011 flaws would be within the inspection volume for an OWOL (flaw 1 marginally so) and the deeper two flaws would be required to be detected during a FSWOL inspection. Smaller flaws were implanted in Specimen 9C-034 to demonstrate the capabilities of the examination techniques, thus any conclusions drawn with respect to FSWOL or OWOL inspection requirements are beyond the intended purpose of this 
report. Having stated this, it should be noted that even the smallest flaws implanted into Specimen 9C-034 were very detectable post application of the FSWOL, given the array designs employed during this work. One could therefore argue that examination volumes required by ASME Code are minimums, and that current technology could be brought to bear such that shallower flaws located within the inner $50 \%$ of the original base materials could be detected, if required.

Table 2.1. Flaw Length and Depth Summary

\begin{tabular}{|c|c|c|c|c|}
\hline Flaw & $\begin{array}{l}\text { Length, } \\
\text { mm (in.) }\end{array}$ & $\begin{array}{l}\text { Depth, } \\
\text { mm (in.) }\end{array}$ & $\begin{array}{l}\text { Pre-WOL Depth } \\
\text { (\% Through-wall) }\end{array}$ & $\begin{array}{l}\text { Post-WOL Depth } \\
\text { (\% Through-wall) }\end{array}$ \\
\hline 1: 9C-034-1 & $51.18(2.015)$ & $4.55(0.179)$ & 13.0 & 9.5 \\
\hline 2: 9C-034-2 & $51.49(2.027)$ & $10.74(0.423)$ & 31.0 & 22.4 \\
\hline 3: 9C-034-3 & $63.88(2.525)$ & $6.48(0.255)$ & 19.0 & 13.5 \\
\hline 4: 9C-034-4 & $63.78(2.511)$ & $9.19(0.362)$ & 26.0 & 19.2 \\
\hline 5: $10 \mathrm{C}-011-1$ & $38.15(1.502)$ & $16.51(0.650)$ & 49.8 & 31.1 \\
\hline 6: $10 \mathrm{C}-011-2$ & $43.38(1.708)$ & $19.86(0.782)$ & 59.7 & 37.4 \\
\hline $7: 10 \mathrm{C}-011-3$ & $51.03(2.009)$ & $23.11(0.910)$ & 69.5 & 43.5 \\
\hline 8: $10 \mathrm{C}-011-4$ & $56.06(2.207)$ & $26.42(1.040)$ & 79.7 & 49.7 \\
\hline 9: $10 \mathrm{C}-011-5$ & $63.86(2.514)$ & $29.72(1.170)$ & 89.9 & 55.9 \\
\hline \multicolumn{5}{|c|}{$\begin{array}{l}\text { Note } \lambda=7.1,5.7,3.8 \text {, and } 2.8 \mathrm{~mm}(0.28,0.22,0.15 \text { and } 0.11 \mathrm{in} \text {.) for the } 0.8-, 1.0-, 1.5-\text {, and } 2.0 \text {-megahertz } \\
\text { (MHz) probes, respectively. }\end{array}$} \\
\hline
\end{tabular}





\subsection{Phased-Array Probes and Focal Law Development}

The specimens were examined using four phased-array (PA) probes: a 2.0-megahertz (MHz) transmit-receive longitudinal (TRL) arrangement, a 1.5-MHz TRL probe, a 1.0-MHz TRL probe, and a $0.8-\mathrm{MHz}$ TRL probe. The 1.5-MHz transducer was chosen based on frequencies commonly used in reactor inspections of stainless steels. The additional 0.8-, 1.0-, and 2.0-MHz probes were employed to more fully evaluate the entire frequency spectrum and provide data to better assess lower and higher frequency limits for inspecting the various DMW components. The two lower frequencies were particularly applicable for evaluations in the increased specimen thickness in the Post-WOL condition. A set of custom wedges were fabricated for use in this study. Each set of wedges was curved to match the approximate 325-mm (12.8-in.) diameter of the DMW specimens. The same wedges were employed in the Post-WOL examinations. The change in specimen OD was considered to be minor and water coupling filled any gaps between the wedge and specimen OD surface during data acquisition. General specifications for the four models of transducers are described in Table 3.1. Each probe is described in more detail in the following subsections.

Table 3.1. Phased Array Ultrasonic Transducer Physical Specifications

\begin{tabular}{lcccc}
\hline \multicolumn{1}{c}{ Probe } & $\begin{array}{c}\mathbf{0 . 8}-\text { MHz TRL, } \\
\text { mm (in.) }\end{array}$ & $\begin{array}{c}\text { 1.0-MHz TRL, } \\
\text { mm (in.) }\end{array}$ & $\begin{array}{c}\text { 1.5-MHz TRL, } \\
\text { mm (in.) }\end{array}$ & $\begin{array}{c}\text { 2.0-MHz TRL, } \\
\text { mm (in.) }\end{array}$ \\
\hline Active Aperture & $44(1.7)$ & $40(1.6)$ & $35(1.4)$ & $22(0.9)$ \\
Passive Aperture & $22(0.9)$ & $20(0.8)$ & $17.5(0.7)$ & $11(0.4)$ \\
Active Aperture Elements & 10 & 10 & 10 & 10 \\
Passive Aperture Elements & 5 & 5 & 3 & 5 \\
\hline
\end{tabular}

\subsection{0-MHz TRL Probe}

The 2.0-MHz TRL array was originally designed for evaluating inspection effectiveness of PA methods on components with inlays, onlays, and overlays. It consists of two 10 -element by 5 -element matrix arrays and is shown in Figure 3.1. One array is used for transmitting, the other for receiving ultrasonic signals. This probe has a $62 \%$ bandwidth (BW) at -6 decibels (dB) and an approximately $30-\mathrm{mm}^{2}\left(1.2\right.$-in. $\left.{ }^{2}\right)$ footprint with a customized wedge for data collection in tight geometrical configurations. The probe was designed at PNNL and built by Imasonic. This smaller size generally allows insonification of the far side of a specimen even with a weld crown present. The probe's nominal wavelength in stainless steel is $2.8 \mathrm{~mm}(0.11 \mathrm{in}$.) at its average center frequency of $2.0 \mathrm{MHz}$. Skew angles of \pm 20 degrees are possible with this array.

Specific focal laws were generated for the DMW specimens based on the thickness of each specimen and the width of the welds in each specimen. While a frequency of 2.0-MHz would normally be considered too high for use on some stainless steel specimens, inspection work at 1.5-MHz (Diaz et al. $2009 \mathrm{~b}$ ) indicated that even at higher frequencies, detection and sizing of flaws in smaller bore piping could be achieved. Based on the focal laws and the results of the simulation, it was determined that the 2.0-MHz probe was capable of effectively insonifying the region surrounding the weld in the DMW samples. 


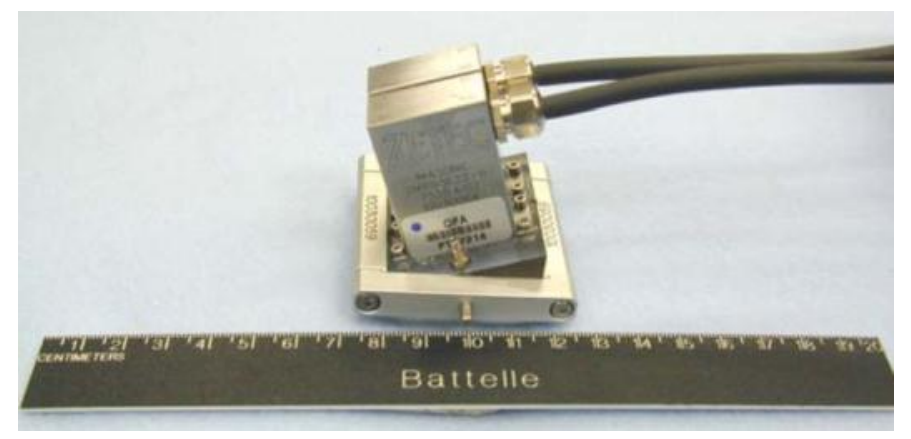

Figure 3.1. Photograph of the 2.0-MHz, Phased-Array Probe, Originally Developed for Inlays, Onlays, and Overlays

The 2.0-MHz probe was found to produce a beam with a horizontal width of $4.72 \mathrm{~mm}(0.19 \mathrm{in}$.) by vertical width of $4.18 \mathrm{~mm}\left(0.16 \mathrm{in}\right.$.) at $45^{\circ}$ at the $-3 \mathrm{~dB}$ points. The $2.0-\mathrm{MHz}$ probe is able to provide an effective sound field at distances from almost directly under the probe to a distance approximately $45 \mathrm{~mm}$ (1.8 in.) in front of the wedge. The ability of the probe to accurately measure crack width and depth improves with proximity between the probe focal spot and the flaw, as this is the location of tightest focusing and highest sensitivity.

\subsection{5-MHz TRL Probe}

This 1.5-MHz TRL probe was originally designed by PNNL for examinations of wrought stainless steel (WSS) components, and consisted of two 1.5-MHz PA transducers mounted side-by-side on a Rexolite wedge. The $1.5-\mathrm{MHz}$ probes operated in the pitch-catch mode with one transducer operating in the transmit mode and the other in the receive mode. The total wedge dimensions were $49 \times 50 \mathrm{~mm}$ $(1.93 \times 1.97$ in. $)$ and were held together by an aluminum frame. Both transmit and receive probes were identical in design with a $10 \times 3$ element array, an active area of $35 \times 17.5 \mathrm{~mm}(1.38 \times 0.69 \mathrm{in}$.), and a greater than $60 \%$ bandwidth at $-6 \mathrm{~dB}$. The $1.5-\mathrm{MHz}$ probe was used in previous examinations of flaws on the near and far sides of austenitic welds in WSS (Crawford et al. 2009) and in PZR surge-line CASS components (Diaz et al. 2009b). Skew angles of \pm 10 degrees are possible with this array. The probe is shown in Figure 3.2.

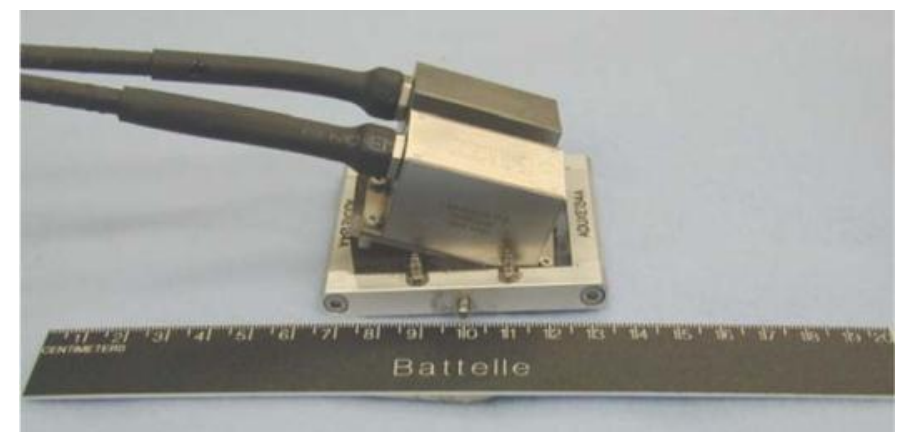

Figure 3.2. Photograph of the 1.5-MHz TRL Probe Originally Designed for Wrought Stainless Steel Welds 
Beam simulations indicated that the 1.5-MHz probe would be able to produce a well-focused beam at distances from directly below the probe to approximately $45 \mathrm{~mm}$ (1.8 in.) in front of the wedge. The probe produced a sound field that works best for detecting and sizing flaws on the near side of the weld, but was also capable of detecting flaws from the far side of most welds in thinner materials, assuming that the microstructure allows the waves to form and propagate appropriately. A half-path style of focusing was used to insonify the weld region. The higher angle laws exhibit a lower level of insonification thereby reducing the ability to size deep flaws. The wavelength for a $1.5-\mathrm{MHz}$ probe is $3.8 \mathrm{~mm}(0.15 \mathrm{in}$.). The $1.5-\mathrm{MHz}$ probe was found to produce a beam with a horizontal width of $5.01 \mathrm{~mm}(0.20 \mathrm{in}$.) by vertical width of $3.81 \mathrm{~mm}\left(0.15 \mathrm{in}\right.$.) at $45^{\circ}$ at the $-3 \mathrm{~dB}$ points.

\subsection{0-MHz TRL Probe}

The 1-MHz TRL array (Figure 3.3) was originally designed for evaluating inspection effectiveness of PA methods on components with inlays, onlays, and overlays. It consists of two 10-element by 5-element matrix arrays. One array is used for transmitting, the other for receiving ultrasonic signals. This probe has a $58 \% \mathrm{BW}$ at $-6 \mathrm{~dB}$ and an approximately $50-\mathrm{mm}^{2}\left(1.97 \mathrm{in}^{2}\right)$ footprint. This probe size generally allows insonification of the far side of a specimen even with a weld crown present, but can be prohibitive if the weld crown is too large. The probe's nominal wavelength in stainless steel is $5.7 \mathrm{~mm}(0.22 \mathrm{in}$.). Skew angles of \pm 20 are possible with this array.

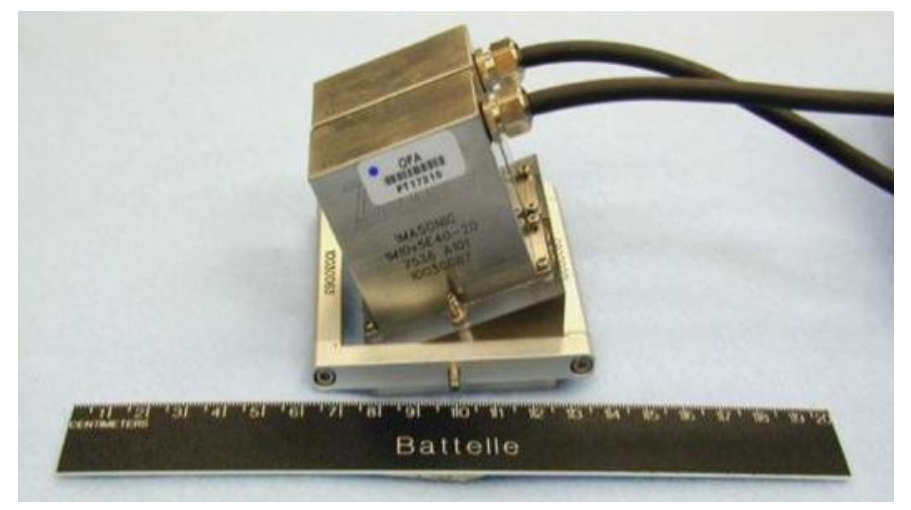

Figure 3.3. Photograph of the 1.0-MHz, Phased-Array Probe, Originally Developed for Inlays, Onlays, and Overlays

Based on the focal laws generated for this probe and the results of a beam simulation, it was determined that the 1.0-MHz probe was capable of effectively insonifying the region surrounding the weld in the DMW samples. The 1.0-MHz probe was found to produce a beam with a horizontal width of $6.16 \mathrm{~mm}\left(0.24 \mathrm{in}\right.$.) by vertical width of $4.94 \mathrm{~mm}\left(0.19 \mathrm{in}\right.$.) at $45^{\circ}$ at the $-3 \mathrm{~dB}$ points. The $1.0 \mathrm{-MHz}$ probe is able to provide an effective sound field at distances from almost directly under the probe to a distance approximately $45 \mathrm{~mm}$ (1.8 in.) in front of the wedge. The probe was designed at PNNL and built by Imasonic. As with the 1.5-MHz probe, the ability of the probe to accurately measure crack width and depth improves with proximity between the probe focal spot and the flaw, as this is the location of tightest focusing and highest sensitivity. 


\subsection{8-MHz TRL Probe}

The $0.8-\mathrm{MHz}$ probe was designed to provide a more optimal wavelength to allow ultrasonic penetration in the large grain structure of CASS, while maintaining suitable flaw resolution. The probes are mounted on a Rexolite wedge side-by-side to operate in a pitch-catch mode and are shown in Figure 3.4. The wedge dimensions were $63 \times 63 \mathrm{~mm}(2.48 \times 2.48 \mathrm{in}$.). The transmit-and-receive probes are identical in design and consisted of a $10 \times 5$ element array with an active area of $43.2 \times 21.2 \mathrm{~mm}$ $(1.70 \times 0.84 \mathrm{in}$.) and a greater than or equal to $50 \%$ bandwidth at $-6 \mathrm{~dB}$. The wedges are curved to match the approximate $325-\mathrm{mm}$ (12.8-in.) diameter of the DMW specimens.

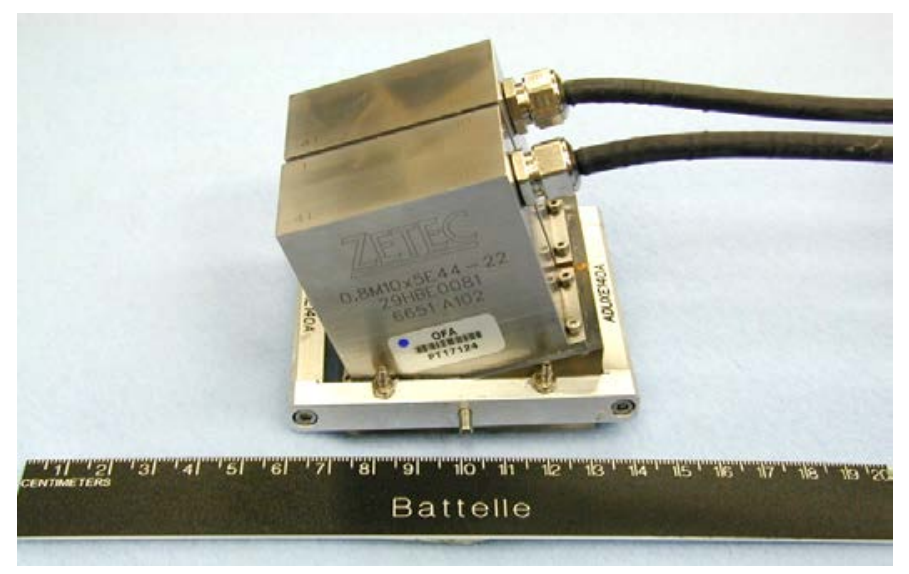

Figure 3.4. Photograph of the $0.8-\mathrm{MHz}$ TRL Probe

The 0.8-MHz probe produces a 7.1-mm (0.28-in.) wavelength in stainless steels, almost twice the wavelength of the 1.5-MHz probe. Beam simulations for this probe suggested that this probe was capable of insonifying the entire weld region and surrounding material in the DMW specimens.

The $0.8-\mathrm{MHz}$ probe is able to provide an effective sound field at distances from directly under the probe to a distance of $36 \mathrm{~mm}$ (1.42 in.) in front of the wedge. Because the $0.8-\mathrm{MHz}$ beam focal zone does not extend as far out in front of the probe as the other frequencies used in this study, it needs to be positioned axially closer to the flaw for optimal performance. The $0.8-\mathrm{MHz}$ probe was found to produce a beam with a horizontal width of $7.19 \mathrm{~mm}\left(0.28 \mathrm{in}\right.$.) by vertical width of $5.58 \mathrm{~mm}(0.22 \mathrm{in}$. $)$ at $45^{\circ}$ at the $-3 \mathrm{~dB}$ points.

\subsection{Sound Field Summary}

Using the modeling and simulation capabilities of the Ultravision software, the focal dimensions of the sound field as a function of frequency (for the four probes used in this study) and incident angle were computed for the dimensions corresponding to the DMW specimens. A half-path focusing style, which maintains a focus at a constant sound path from the probe, was used in all data acquisitions. The focus was set to $50 \mathrm{~mm}$ (1.97 in.) for the Pre-WOL condition (the only exception was in 10C-011 raster data where a 40-mm (1.58-in.) focus was used). The half-path focal depth was increased to $70 \mathrm{~mm}$ (2.76 in.) for the Post-WOL data acquisition. The focal spot size was computed at both the $-3 \mathrm{~dB}$ and $-6 \mathrm{~dB}$ points 
in both horizontal and vertical planes for the Pre-WOL condition. Table 3.2 summarizes the $-3 \mathrm{~dB}$ focal spot size data. The first dimension represents the primary axis of the probe (pipe axial direction) and the second is the secondary axis of the probe (the pipe circumferential direction). The sound field dimensions at $30^{\circ}$ were calculated at the ID surface rather than at the actual focal spot because the dimensions of the sound field extended well past the ID for the $30^{\circ}$ sound beam. As anticipated, the sound field focal dimensions generally decreased with increasing frequency. Note that the focal spots are not symmetric even though the probe apertures are nearly symmetric. A review of Table 3.2 shows the resultant PreWOL sound beam spot sizes for the $0.8 \mathrm{-MHz}$ probe at $45^{\circ}$ as $7.2 \mathrm{~mm}$ by $5.6 \mathrm{~mm}(0.28 \mathrm{in}$. by $0.22 \mathrm{in}$.). The spot size for the $1.5-\mathrm{MHz}$ probe at $45^{\circ}$ was 5.0 by $3.8 \mathrm{~mm}$ ( $0.20 \mathrm{in}$. by $0.15 \mathrm{in}$.). While the spot size in the circumferential direction is approximately $50 \%$ greater in the $0.8-\mathrm{MHz}$ probe than in the $1.5 \mathrm{-MHz}$ probe, this represents only a $1.8-\mathrm{mm}(0.070$-in.) difference. A smaller spot size will give a more accurate length measurement, assuming the entire crack is detected. However, length sizing measurements should be similar for the four probes.

The Post-WOL sound beams as measured at the $-3 \mathrm{~dB}$ level are larger than the Pre-WOL sound beams, as expected. These probes are focusing beyond their natural focal depths and thus are operating in the far field. As a result, the sound fields are diverging from the optimum or minimal spot size. A decrease in spot size is seen with increasing frequency, as was evident in the Pre-WOL sound beam, from the $0.8-\mathrm{MHz}$ probe to $1.5 \mathrm{-MHz}$ probe. However, the $2.0-\mathrm{MHz}$ probe has a spot size similar to the $1.5-\mathrm{MHz}$ probe spot size. This relates to the probe aperture as well as probe frequency. The apertures of the 0.8-, 1.0-, and 1.5-MHz probes are more similar in the 44-35 mm (1.7-1.4 in.) range while the smaller aperture of the $2.0-\mathrm{MHz}$ probe at $22 \mathrm{~mm}(0.9 \mathrm{in}$.) will naturally produce a larger beam. Nevertheless, the beam sizes in the specimen circumferential direction differ only by $3.6 \mathrm{~mm}(0.14 \mathrm{in}$.) between the four probes. These larger beam spot sizes in the Post-WOL data should increase the flaw length sizing error as compared to the Pre-WOL data. 
Table 3.2. Theoretical Focal Spot Dimensions at the $-3 \mathrm{~dB}$ Level for Probes Used in this Study for PreWOL and Post-WOL Conditions

\begin{tabular}{lcccc}
\hline \multicolumn{5}{c}{ Theoretical Sound Field Spot Size for CASS PZR Specimens } \\
\cline { 2 - 5 } PA Probe and & \multicolumn{2}{c}{$\mathbf{- 3 ~ d B}$ point Pre-WOL } & \multicolumn{2}{c}{$\mathbf{- 3 ~ d B}$ point Post-WOL } \\
\cline { 2 - 5 } Incident Angle & $\begin{array}{c}\text { Horizontal, } \\
\text { mm (in.) }\end{array}$ & $\begin{array}{c}\text { Vertical, } \\
\text { mm (in.) }\end{array}$ & $\begin{array}{c}\text { Horizontal, } \\
\text { mm (in.) }\end{array}$ & $\begin{array}{c}\text { Vertical, } \\
\text { mm (in.) }\end{array}$ \\
\hline 0.8-MHz TRL & & & & \\
30 deg. @ ID & $7.02(0.28)$ & $4.06(0.16)$ & $9.15(0.36)$ & $14.12(0.56)$ \\
45 deg. & $7.19(0.28)$ & $5.58(0.22)$ & $12.12(0.48)$ & $14.55(0.57)$ \\
60 deg. & $6.11(0.24)$ & $7.7(0.30)$ & $17.44(0.69)$ & $14.03(0.55)$ \\
\hline 1-MHz TRL & & & & \\
30 deg. @ ID & $5.89(0.23)$ & $3.46(0.14)$ & $7.42(0.29)$ & $12.52(0.49)$ \\
45 deg. & $6.16(0.24)$ & $4.94(0.19)$ & $10.48(0.41)$ & $13.07(0.51)$ \\
60 deg. & $5.61(0.22)$ & $7.4(0.29)$ & $15.77(0.62)$ & $11.89(0.47)$ \\
\hline 1.5-MHz TRL & & & & \\
30 deg. @ ID & $4.99(0.20)$ & $2.86(0.11)$ & $5.94(0.23)$ & $10.55(0.42)$ \\
45 deg. & $5.01(0.20)$ & $3.81(0.15)$ & $8.57(0.34)$ & $9.83(0.39)$ \\
60 deg. & $4.94(0.19)$ & $6.33(0.25)$ & $13.59(0.54)$ & $9.66(0.38)$ \\
\hline 2-MHz TRL & & & & \\
30 deg @ ID & $4.2(0.17)$ & $2.62(0.10)$ & $6.34(0.25)$ & $10.53(0.41)$ \\
45 deg. & $4.72(0.19)$ & $4.18(0.16)$ & $9.46(0.37)$ & $10.51(0.41)$ \\
60 deg. & $4.02(0.16)$ & $2.4(0.09)$ & $14.88(0.59)$ & $10.43(0.41)$ \\
\hline
\end{tabular}




\subsection{Phased-Array Data Acquisition and Analysis}

Phased-array data were acquired on the nine flaws in the two specimens with the phased-array probes. In general, line scan and raster data were acquired from both sides of the flaw. The next subsection, Flaw Detection, gives the specific details while the following subsection discusses flaw characterization and data analyses.

\subsection{Flaw Detection}

Phased-array data were acquired on Specimen 9C-034 prior to the application of the WOL as part of an earlier study (Diaz et al. 2009a) on evaluating DMW specimens. These Pre-WOL data were acquired from the CASS pipe side of the weld with the 1.5- and 2.0-MHz phased-array probes in both the line and raster styles of scanning. All four flaws were detected in this data. Data were not acquired from the carbon steel nozzle side of the specimen. Post-WOL data on Specimen 9C-034 were acquired from both the nozzle and pipe sides of the weld overlay with the 0.8-, 1.0-, 1.5-, and 2.0-MHz probes in the line and raster styles of scanning with one exception. Line scan data were not acquired at $0.8 \mathrm{MHz}$ from the pipe side of the overlay.

The four flaws in 9C-034 were detected in the Post-WOL raster data at 1.5 and $2.0 \mathrm{MHz}$ from the pipe side of the overlay. From the nozzle side of the overlay, the smallest flaw was marginally detected at 1.5 $\mathrm{MHz}$ but detected in the 2.0-MHz raster data. The other three flaws were detected in the 1.5- and 2.0-MHz raster data, nozzle side of the overlay. A summary of the Post-WOL detection results is shown in Table 4.1 with yes, no, and marginal detection calls.

Marginal or no detection calls were found in the 0.8 - and 1.0-MHz Post-WOL data for the smallest flaw, \#1. This small flaw is only 4.55-mm (0.179-in.) deep and is smaller than the ultrasonic wavelengths of 7.1 and $5.7 \mathrm{~mm}(0.28$ and $0.22 \mathrm{in}$.) for the 0.8 - and $1.0-\mathrm{MHz}$ probes, respectively. It is not surprising that this flaw is not detected at the lower frequencies. In addition to the large wavelength relative to the flaw depth, the beam spot sizes are also large. Therefore, in an interaction with a small flaw there is insufficient energy reflected from the flaw face for a detection call. The other three flaws had a mixture of yes, no, and marginal detections as shown in the table for the 0.8 - and $1.0-\mathrm{MHz}$ data.

Similarly, phased-array line and raster data were acquired on Specimen 10C-011 prior to the application of the weld overlay with the 0.8-, 1.0-, 1.5-, and 2.0-MHz probes from both the nozzle and pipe sides. The exception was that no raster data were acquired from the nozzle side with the $0.8 \mathrm{-MHz}$ probe. All five of the implanted TFCs were detected in both Pre- and Post-WOL datasets. In both the line and raster data, a weld root signal was often evident in the data and prevented the identification of an isolated flaw corner response. Upper specular reflections and flaw tips were evident allowing good flaw detection and characterization.

The phased-array data are displayed in Appendices A through D. Appendix A contains Pre-WOL data from Specimen 9C-034 while Appendix B contains Post-WOL data from this specimen. Appendices C and D contain Pre- and Post-WOL data from Specimen 10C-011 data, respectively. Additionally, tables of the ultrasonic length and depth sizing values are shown in Appendix E. 
Table 4.1. Flaw Detection Table for Specimen 9C-034 Post-WOL

\begin{tabular}{ccccccccccc}
\hline Frequency, & Side: & \multicolumn{4}{c}{ Nozzle } & \multicolumn{4}{c}{ Pipe } \\
\cline { 2 - 9 } MHz & Flaw: & $\mathbf{1}$ & $\mathbf{2}$ & $\mathbf{3}$ & $\mathbf{4}$ & $\mathbf{1}$ & $\mathbf{2}$ & $\mathbf{3}$ & $\mathbf{4}$ \\
\hline 0.8 & Line & $\mathrm{M}$ & $\mathrm{M}$ & $\mathrm{N}$ & $\mathrm{Y}$ & --- & -- & -- & -- \\
& Raster & $\mathrm{N}$ & $\mathrm{Y}$ & $\mathrm{M}$ & $\mathrm{Y}$ & $\mathrm{N}$ & $\mathrm{M} / \mathrm{N}$ & $\mathrm{Y}$ & $\mathrm{Y}$ \\
1.0 & Line & $\mathrm{M}$ & $\mathrm{Y}$ & $\mathrm{M}$ & $\mathrm{Y}$ & $\mathrm{N}$ & $\mathrm{N}$ & $\mathrm{M}$ & $\mathrm{N}$ \\
& Raster & $\mathrm{N}$ & $\mathrm{Y}$ & $\mathrm{M}$ & $\mathrm{Y}$ & $\mathrm{N}$ & $\mathrm{M}$ & $\mathrm{Y}$ & $\mathrm{M}$ \\
1.5 & Line & $\mathrm{N}$ & $\mathrm{Y}$ & $\mathrm{Y}$ & $\mathrm{Y}$ & $\mathrm{N}$ & $\mathrm{Y}$ & $\mathrm{Y}$ & $\mathrm{Y}$ \\
& Raster & $\mathrm{M}$ & $\mathrm{Y}$ & $\mathrm{Y}$ & $\mathrm{Y}$ & $\mathrm{Y}$ & $\mathrm{Y}$ & $\mathrm{Y}$ & $\mathrm{Y}$ \\
2.0 & Line & $\mathrm{Y}$ & $\mathrm{Y}$ & $\mathrm{Y}$ & $\mathrm{Y}$ & $\mathrm{N}$ & $\mathrm{M}$ & $\mathrm{Y}$ & $\mathrm{Y}$ \\
& Raster & $\mathrm{Y}$ & $\mathrm{Y}$ & $\mathrm{Y}$ & $\mathrm{Y}$ & $\mathrm{Y}$ & $\mathrm{Y}$ & $\mathrm{Y}$ & $\mathrm{Y}$ \\
\hline $\mathrm{M}=$ marginal, N N $=$ No, Y=Yes & & & & & & & \\
\hline
\end{tabular}

\subsection{Flaw Characterization and Data Analyses}

Detected flaws were characterized by length and depth sizing. Length sizing was conducted at the -6 $\mathrm{dB}$, half amplitude, and loss of signal (LOS) levels. Signal-to-noise ratios were also calculated to provide an indication of the strength of the flaw response relative to background noise.

\subsubsection{Signal-to-Noise Ratio}

Detected flaws were evaluated for SNR, which gives an indication of the peak flaw response relative to the mean background noise from the material. In general, these flaw responses were well above the background noise levels but flaw discrimination was sometimes a problem due to strong geometrical reflectors. The SNR data as determined from raster data, pipe and nozzle sides, are shown in Figure 4.1 for the four flaws from Specimen 9C-034 (flaws 1-4) and the five flaws from Specimen 10C-011 (flaws 5-9). Average SNRs for the pipe side data are 15.8 and 15.1 dB for the Pre-WOL and Post-WOL data, respectively. Average SNRs for the nozzle side data are 16.2 and 14.7 dB for the Pre-WOL and Post-WOL data, respectively. These values are well above a minimal level of approximately $8-10 \mathrm{~dB}$ for a good detection and show that the flaws were readily detected. Signal degradation (attenuation) expected with the longer part path (distance to the flaw) in the presence of the WOL material was offset by using a different set of focal laws for the post-WOL evaluation. As was previously discussed, the pre-WOL evaluations were conducted with a method that focused along a constant part path (for all angles) at a focal depth of 40 or $50 \mathrm{~mm}$. This is known as half path focusing. The post-WOL evaluations were conducted with a half path focusing at a focal depth of $70 \mathrm{~mm}$ to account for the longer part paths.

While signal quality in terms of SNR did not change appreciably, a slight alteration in the system gain was required. A table of the system gain values required to produce a nearly $100 \%$ of full screen height amplitude response is shown in Table 4.2 for the different probes. The 2.0-MHz data are most influenced by the added WOL material. From the nozzle side, the gain difference is $9 \mathrm{~dB}$ and on the pipe side, $4 \mathrm{~dB}$, showing more gain required in the Post-WOL evaluation. The higher frequency data are expected to be more affected by attenuation and scattering and the longer part path in the WOL will emphasize this effect. 

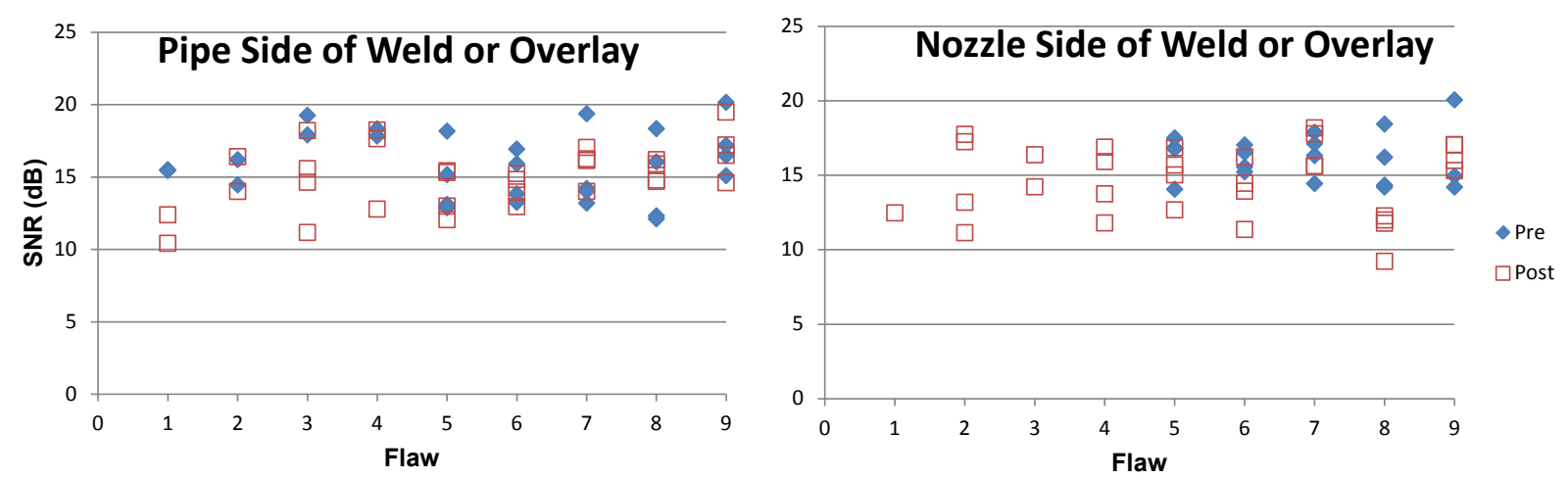

Figure 4.1. Signal-to-Noise Ratios for Raster Data from the Specimen Pipe Side (left) and the Nozzle Side (right). Pre-WOL raster data was not acquired from the nozzle side on the 9C-034 specimen, flaws $1-4$.

Table 4.2. System Gain (dB)

\begin{tabular}{ccccc}
\hline & \multicolumn{2}{c}{ Nozzle Side } & \multicolumn{2}{c}{ Pipe Side } \\
\cline { 2 - 5 } Frequency (MHz) & Pre-WOL & Post-WOL & Pre-WOL & Post-WOL \\
\hline 0.8 & 37.9 & 43.6 & 44.4 & 44.6 \\
1.0 & 37.4 & 40.1 & 41.9 & 42.2 \\
1.5 & 29.6 & 30.9 & 34.4 & 33.2 \\
2.0 & 39.6 & 48.8 & 43.4 & 47.7 \\
\hline
\end{tabular}

\subsubsection{Depth Sizing}

The flaw depth sizing results for the raster data from pipe and nozzles sides are shown in Figure 4.2. Shallower flaws, when detected are better depth sized than the deeper flaws. The probes were configured for specimen evaluation in an approximate 30- to 60-degree refracted angle range. These angles adequately insonify the specimen ID through the mid-wall area but do not focus well on the outer approximately $20 \%$ of the specimen thickness (nearest the probe beam-forming area). As a result, the full extents of the flaws at $80 \%$ and $90 \%$ through-wall depths in the Pre-WOL condition were not captured; thus, these flaws were undersized. The errors in depth sizing measurements as calculated by a root mean square error (RMSE) for the pipe side data were 3.9 and $4.0 \mathrm{~mm}(0.154$ and $0.157 \mathrm{in}$.) for the Pre- and Post-WOL data, respectively. RMSE values for the nozzle side data were 6.6 and $3.3 \mathrm{~mm}(0.260$ and 0.130 in.) for the Pre- and Post-WOL data, respectively. While the fine-grained carbon steel nozzle side data was expected to exhibit better, or at least similar, responses as data collected from the CASS pipe side, the opposite was observed in the Pre-WOL examination. In general, the CASS pipe side data showed stronger and more continuous specular responses, and weld root signals from flaws, than were observed in the Pre-WOL nozzle side data on Specimen 10C-011. The nozzle side data was likely being adversely influenced by the nozzle OD surface taper. This added angle re-directs the ultrasonic beam downward and further restricts the sound from reaching the upper part of the deep flaws in Specimen 10C-011, potentially leading to more sizing error. 

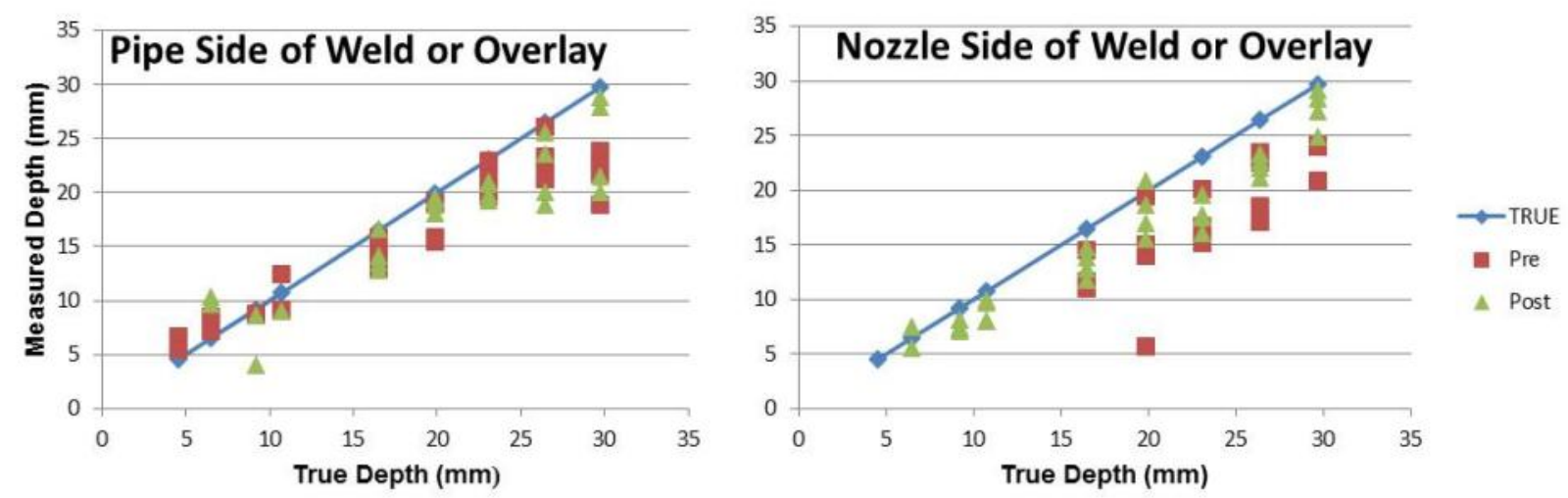

Figure 4.2. Measured Flaw Depths from Raster Data Acquired from the Pipe Side (left) and the Nozzle Side (right). The shallower first four flaws are from Specimen 9C-034. Pre-WOL raster data were not acquired from the nozzle side on the 9C-034 specimen, flaws $1-4$.

Line scan data provided better depth sizing results with the data presented in Figure 4.3. The errors in depth sizing as calculated by an RMSE for the pipe side data were 1.8 and $1.9 \mathrm{~mm}(0.071$ and $0.075 \mathrm{in}$.) for the Pre- and Post-WOL data, respectively. RMSE values for the nozzle side data were $2.7 \mathrm{~mm}$ (0.106 in.) for both the Pre- and Post-WOL data. These values are within the ASME Code Section XI requirements of $3.2 \mathrm{~mm}$ (0.125 in.) for depth sizing error unlike the raster data shown above. Both line scan and raster data were acquired in the 30 to 70 or 87 degree range. However, raster data were acquired with a 3-degree increment while line scan data were acquired with a 1-degree increment; that is, data were collected during line scanning at every one-degree. This difference contributes to the larger error seen in the raster depth sizing data. Ideally, raster data provides better sizing results as it captures data over many axial positions.

A summary of the depth sizing RMSE results is displayed in Table 4.3. Additionally the error from the flaws that were $50 \%$ and greater in through-wall extent of the original material were considered. These flaws are of interest because only these flaws are contained within the required inspection volume for OWOLs. These results are displayed in Table 4.4. The error values did not change appreciably, which illustrates the ability of the techniques used to depth size flaws smaller than required by ASME Code. Furthermore, a second analyst examined the Post-WOL raster data from the flaws 50\% deep and greater. These RMSE results are displayed in the third column of Table 4.4 and show RMSE errors within the ASME requirements for depth sizing (3.2 $\mathrm{mm}$ [0.125 in.] or less). The second analyst emphasized tip-diffraction sizing when tip signals were present whereas the first analyst relied on specular reflections from the upper parts of a flaw. This difference and the greater experience of the second analyst likely resulted in the better sizing results. 

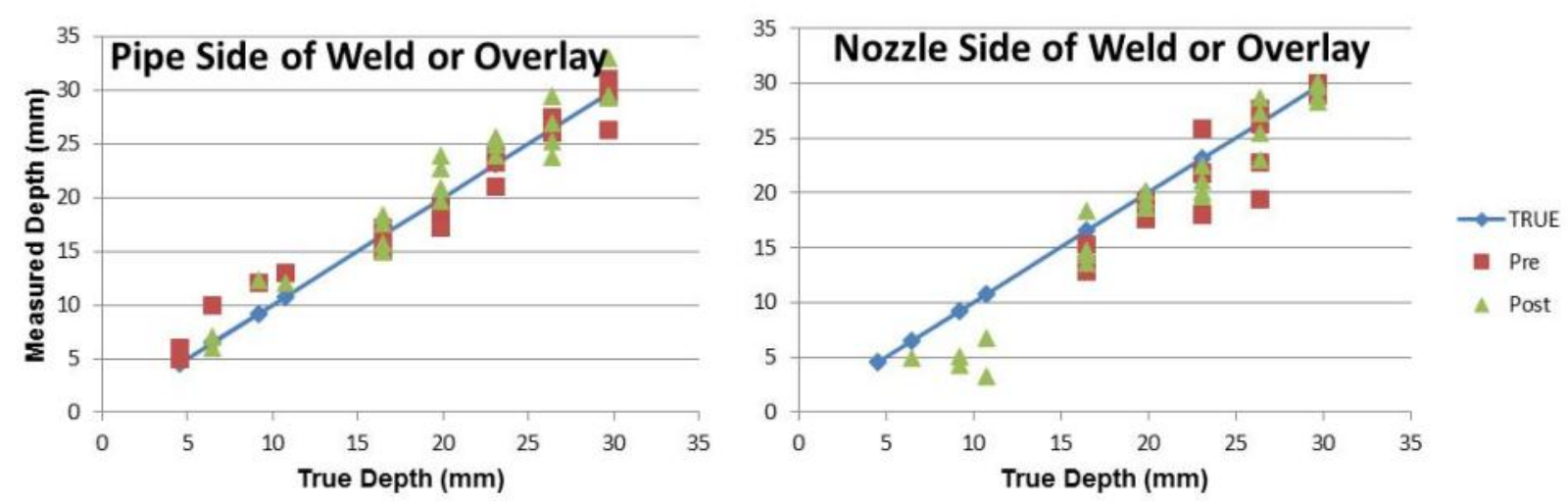

Figure 4.3. Measured Flaw Depths from Line Data Acquired from the Pipe Side (left) and the Nozzle Side (right). The shallower first four flaws are from Specimen 9C-034. Pre-WOL line data were not acquired from the nozzle side on the 9C-034 specimen, flaws 1-4.

Table 4.3. Depth Sizing RMSE

\begin{tabular}{lcccc}
\hline & \multicolumn{3}{c}{ All Flaws } \\
\cline { 2 - 5 } & $\begin{array}{c}\text { Pre-WOL } \\
\text { mm (in.) }\end{array}$ & $\begin{array}{c}\text { Post-WOL } \\
\text { mm (in.) }\end{array}$ & $\begin{array}{c}\text { Pre-WOL } \\
\text { mm (in.) }\end{array}$ & $\begin{array}{c}\text { Lost-WOL } \\
\text { mm (in.) }\end{array}$ \\
\hline Pipe Side & $3.9(0.15)$ & $4.0(0.16)$ & $1.8(0.071)$ & $1.9(0.075)$ \\
Nozzle Side & $6.6(0.26)$ & $3.3(0.13)$ & $2.7(0.11)$ & $2.7(0.11)$ \\
\hline
\end{tabular}

Table 4.4. Depth Sizing RMSE for Deep Flaws

\begin{tabular}{lccccc}
\hline & \multicolumn{4}{c}{$\geq \mathbf{5 0 \%}$ Deep } \\
\cline { 2 - 6 } & $\begin{array}{c}\text { Pre-WOL } \\
\text { mm (in.) }\end{array}$ & $\begin{array}{c}\text { Post-WOL } \\
\text { mm (in.) }\end{array}$ & $\begin{array}{c}\text { Post-WOL } \\
\text { mm (in.) }\end{array}$ & $\begin{array}{c}\text { Pre-WOL } \\
\text { mm (in.) }\end{array}$ & $\begin{array}{c}\text { Post-WOL } \\
\text { mm (in.) }\end{array}$ \\
\hline Pipe Side & $4.5(0.18)$ & $4.1(0.16)$ & $2.3(0.091)$ & $1.4(0.055)$ & $2.0(0.079)$ \\
Nozzle Side & $6.6(0.26)$ & $3.9(0.15)$ & $2.7(0.11)$ & $2.7(0.11)$ & $1.8(0.079)$ \\
\hline (a) Data analyzed by second operator & & & & \\
\hline
\end{tabular}

\subsubsection{Length Sizing}

Length sizing was measured at both the $-6 \mathrm{~dB}$ level and the loss-of-signal (LOS) level when possible. The LOS level equates to an approximate $-12 \mathrm{~dB}$ level. Raster data from the pipe side of the weld or weld overlay at the two measurement levels are shown in Figure 4.4. Length sizing errors were greatest in the 9C-034 Post-WOL data. This specimen has the shallower flaws. Error values for the pipe side data as acquired with both line scan and raster data are listed in Table 4.5. RMSE values at the $-6 \mathrm{~dB}$ sizing level for the 9C-034 Pre- and Post-WOL raster data and the 10C-011 Pre- and Post-WOL raster data were 8.1, 39.6, 9.0, and $14.9 \mathrm{~mm}(0.32,1.56,0.35$, and $0.59 \mathrm{in}$.), respectively. All but the Post-WOL 9C-034 data fall within the ASME guidelines for allowable error of $19.1 \mathrm{~mm}(0.75 \mathrm{in}$.). RMSE values at the LOS 
sizing level, raster data, for the 9C-034 Pre- and Post-WOL data and the 10C-011 Pre-and Post-WOL data were 5.8, 26.1, 7.9, and $10.5 \mathrm{~mm}(0.23,1.03,0.31$, and $0.41 \mathrm{in}$.$) , respectively. Again, all but the Post-$ WOL 9C-034 data at the LOS sizing level fell within the ASME requirements. Line scan data showed similar trends to those observed in the raster data. Overall the LOS sizing produces the lowest error as compared to the $-6 \mathrm{~dB}$ sizing. The improvement was as much as $6 \mathrm{~mm}(0.24 \mathrm{in}$.).
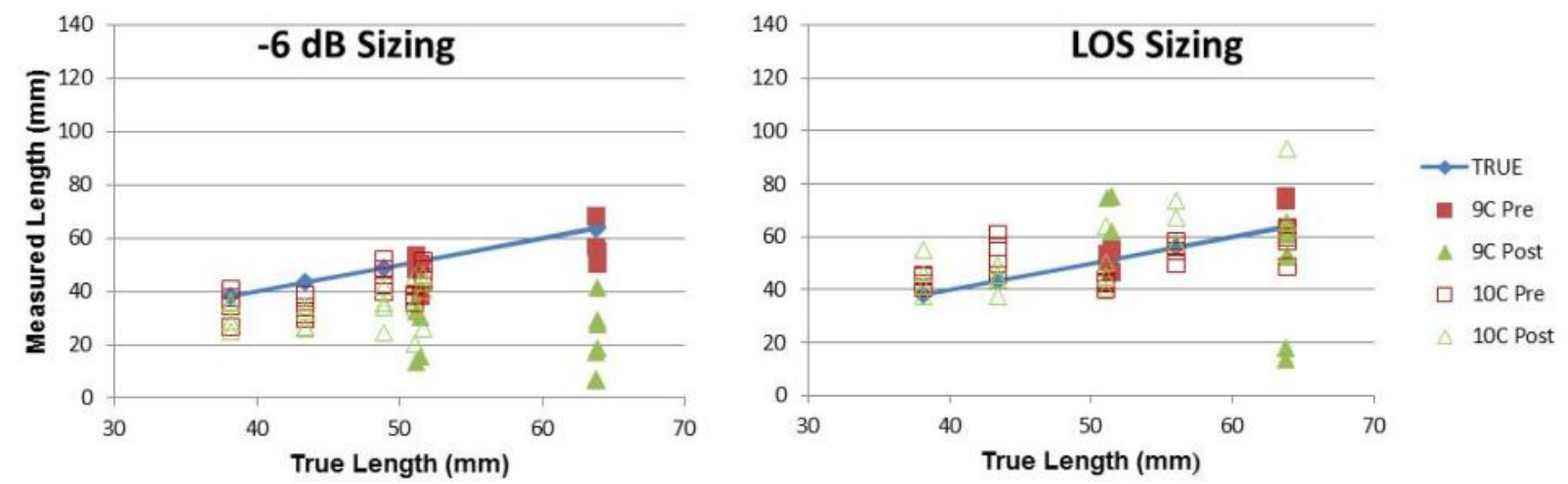

Figure 4.4. Length Sizing Results from Raster Data Acquired from the Pipe Side at the $-6 \mathrm{~dB}$ Amplitude Level (left) and the LOS Level (right)

Table 4.5. Length Sizing RMSE Values Acquired from the Pipe Side Data

\begin{tabular}{lrrrr}
\hline & \multicolumn{2}{c}{$-\mathbf{6 ~ d B}$} & \multicolumn{2}{c}{ LOS } \\
\cline { 2 - 5 } & Line, mm (in.) & Raster, mm (in.) & Line, mm (in.) & Raster, mm (in.) \\
\hline 9C Pre & $9.9(0.39)$ & $8.1(0.32)$ & $5.4(0.21)$ & $5.8(0.23)$ \\
9C Post & $44.9(1.77)$ & $39.6(1.56)$ & $22.8(0.90)$ & $26.1(1.03)$ \\
10C Pre & $13.9(0.55)$ & $9.0(0.35)$ & $8.2(0.32)$ & $7.9(0.31)$ \\
10C Post & $13.8(0.54)$ & $14.9(0.59)$ & $14.6(0.57)$ & $10.5(0.41)$ \\
\hline
\end{tabular}

Length sizing data from the nozzle side of the weld or weld overlay, raster data, are shown in Figure 4.5 with the error in length sizing for both raster and line scan data shown in Table 4.6. Pre-WOL data were not acquired on the 9C-034 specimen from the nozzle side. Again, length sizing errors are greatest in the Post-WOL data from Specimen 9C-034. RMSE values for the 9C-034 Post-WOL and the Pre- and Post-WOL 10C-011 raster data at the $-6 \mathrm{~dB}$ level were $27.8,13.4$, and $19.6 \mathrm{~mm}(1.09,0.53$, and 0.77 in.). At the LOS level, the RMSE values for the 9C-034 Post-WOL and the Pre- and Post-WOL 10C-011 data were 29.9, 15.0, and $10.7 \mathrm{~mm}(1.18,0.59$, and $0.42 \mathrm{in}$.). These results lead to an indeterminate best sizing level. Line scan data was similar to the raster data in that the Post-WOL 9C-034 data fell outside of the ASME requirements of $19.1 \mathrm{~mm}(0.75 \mathrm{in}$.) RMSE but so did the line scan data for 10C-011 Pre-WOL LOS data and 10C-011 Post-WOL at $-6 \mathrm{~dB}$. A likely reason for the poorer performance of line scan data was due to the strong weld root signal present in much of the data. The inherent axial limitation of line scan data prevented the full separation of weld root signal and flaw ID corner response, therefore misrepresenting the true flaw length. 

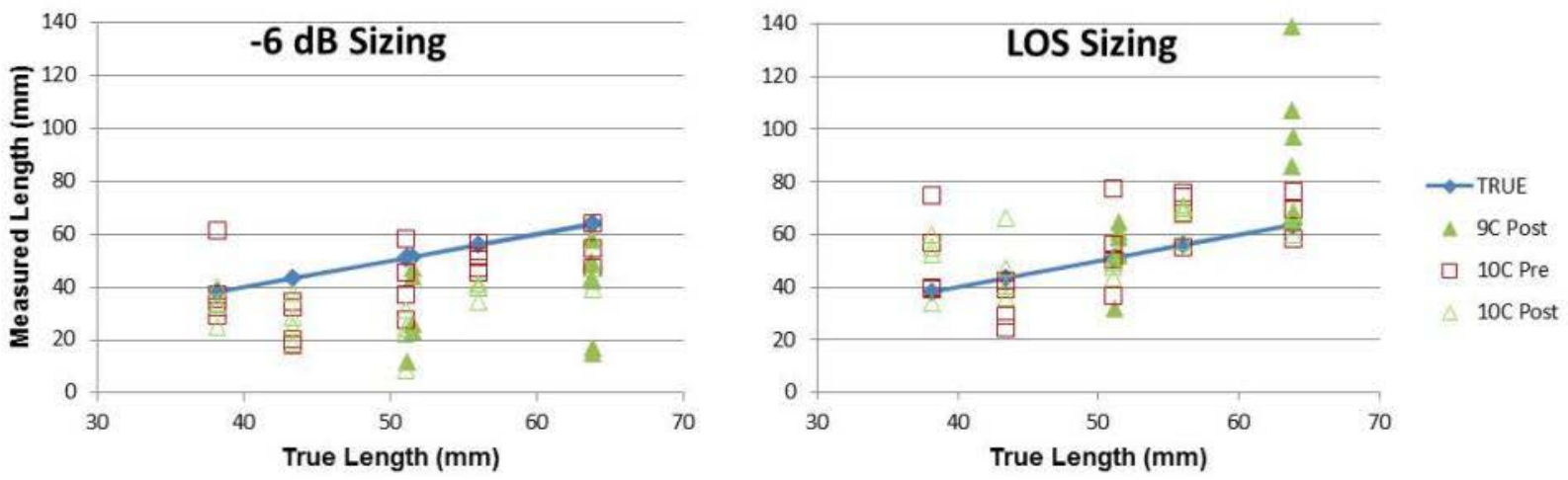

Figure 4.5. Length Sizing Results from Raster Data Acquired from the Nozzle Side at the $-6 \mathrm{~dB}$ Amplitude Level (left) and the LOS Level (right)

Table 4.6. Length Sizing RMSE Values Acquired from the Nozzle Side Data

\begin{tabular}{lcccc}
\hline & \multicolumn{2}{c}{$-\mathbf{6 ~ d B}$} & \multicolumn{2}{c}{ LOS } \\
\cline { 2 - 5 } & Line, $\mathbf{~ m m}$ (in.) & Raster, mm (in.) & Line, mm (in.) & Raster, mm (in.) \\
\hline 9C Pre & -- & -- & -- & -- \\
9C Post & $31.2(1.23)$ & $27.8(1.09)$ & $41.0(1.61)$ & $29.9(1.18)$ \\
10C Pre & $16.5(0.65)$ & $13.4(0.53)$ & $25.0(0.98)$ & $15.0(0.59)$ \\
10C Post & $22.5(0.89)$ & $19.6(0.77)$ & $10.1(0.39)$ & $10.7(0.42)$ \\
\hline
\end{tabular}





\subsection{Summary and Conclusions}

Two DMW specimens, one with shallow flaws (13\% to 31\% through-wall deep) and one with flaws in the $50 \%$ to $90 \%$ through-wall deep range, were ultrasonically examined with phased-array probes in the $0.8-$ to $2.0-\mathrm{MHz}$ frequency range. An Alloy 82/182 full structural WOL was added to each specimen and they were re-evaluated ultrasonically for flaw detection and characterization. The flaw depths with the added full structural WOL were in the 9.5 to $55.9 \%$ through-wall range.

The WOL specimens were approximately 53-mm (2.1-in.) thick and use of this thicker material suggested that a lower inspection frequency, on the order of 0.8 or $1.0 \mathrm{MHz}$, would be needed to detect and size flaws from the CASS pipe side of the weld. However, the predominantly columnar-grained microstructure in the CASS pipe, with circumferential grain sizes in the roughly $1-5 \mathrm{~mm}(0.04-0.20 \mathrm{in}$.) range, and the additional Alloy 82/182 overlay material did not prevent the effective use of probes at 1.5and 2.0-MHz in center frequency. Grain sizes in the WOL material were not determined, but are expected to be much smaller than in the CASS base material. All flaws were detected with these two higher frequency probes. On the other hand, the longer wavelengths of the two lower frequency probes, at 0.8 and $1.0 \mathrm{MHz}$, may have been a factor that prevented them from detecting the two shallowest flaws, which were less than approximately $15 \%$ in through-wall depth. The deeper flaws in these specimens, having through-wall depths of $19 \%$ to $56 \%$ in the full structural WOL thickness, were detected with all four probes.

The detected flaws had SNR values of approximately $15 \mathrm{~dB}$ which are well above a minimal level of 8 to $10 \mathrm{~dB}$ for a good detection. The depth sizing errors as calculated RMSEs were within the ASME requirements of $3.2 \mathrm{~mm}(0.125 \mathrm{in}$.) for the line scan data and a subset of the raster data where the analyst emphasized tip diffraction sizing. The remaining raster data, based more on specular reflection analyses, were above the ASME required RMSE level. Length sizing RMSEs were generally within the ASME requirements of $19 \mathrm{~mm}$ (0.75 in.) except when including the shallow flaws. The presence of a strong weld root signal that was not always separated from the flaw ID corner response contributed to the error in length sizing.

This study has shown the effectiveness of ultrasonic examinations in Alloy 82/182 overlaid DMW specimens typical of PZR surge line diameters and wall thicknesses. Phased-array probes with center frequencies in the 0.8 - to $1.0-\mathrm{MHz}$ range provide a strong coherent signal but the longer ultrasonic wavelengths and larger beam spot sizes may prevent the reliable detection of shallow flaws. However, flaws approximately $20 \%$ and greater in through-wall depth were readily detected with probes from 0.8 to 2.0 MHz. At frequencies between 1.0 and $2.0 \mathrm{MHz}$, the reflected signals are less coherent but still provide adequate signals for flaw detection and characterization. A single inspection using $2.0 \mathrm{MHz}$ phased arrays may provide minimal detection and sizing information, but a supplemental examination using 1.0 or $1.5 \mathrm{MHz}$ probes is recommended. 



\subsection{References}

Crawford SL, Cinson, A D, MT Anderson, AA Diaz and SE Cumblidge. 2009. Ultrasonic Flaw Detection of Intergranular Stress Corrosion Cracks as Observed in Austenitic Stainless Steel Piping Welds. PNNL-18334, Pacific Northwest National Laboratory, Richland, Washington. ADAMS Accession No. ML091190152.

Diaz AA, AD Cinson, SL Crawford and MT Anderson. 2009a. Technical Letter Report: An Evaluation of Ultrasonic Phased Array Testing for Reactor Piping System Components Containing Dissimilar Metal Welds, JCN N6398, Task 2A. PNNL-19018, Pacific Northwest National Laboratory, Richland, Washington. ADAMS Accession No. ML100252188.

Diaz AA, AD Cinson, SL Crawford, R Mathews, TL Moran and MT Anderson. 2009b. Assessment of Ultrasonic Phased Array Inspection Method for Welds in Cast Austenitic Stainless Steel Pressurizer Surge Line Piping, JCN N6398, Task 1B. PNNL-18596, Pacific Northwest National Laboratory, Richland, Washington. ADAMS Accession No. ML092540501. 

Appendix A

Dissimilar Metal Weld Specimen 9C-034 Phased-Array Data, Pre-WOL 



\section{Appendix A}

\section{Dissimilar Metal Weld Specimen 9C-034 Phased-Array Data, Pre-WOL}

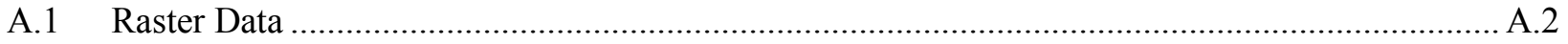

A.1.1 1.5-MHz Raster Data on Flaws 1-4 Pipe Side Pre-WOL ............................................ A.2

A.1.2 2-MHz Raster Data on Flaws 1-4 Pipe Side Pre-WOL ................................................. A.4

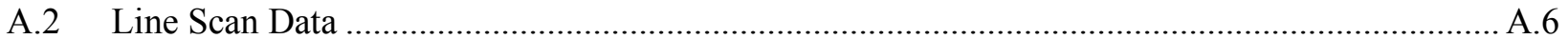

A.2.1 1.5-MHz Line Scan Data on Flaws 1-4 Pipe Side Pre-WOL ....................................... A.6

A.2.2 2-MHz Line Scan Data on Flaws 1-4 Pipe Side Pre-WOL ............................................ A.8 


\section{A.1 Raster Data}

\section{A.1.1 1.5-MHz Raster Data on Flaws 1-4 Pipe Side Pre-WOL}

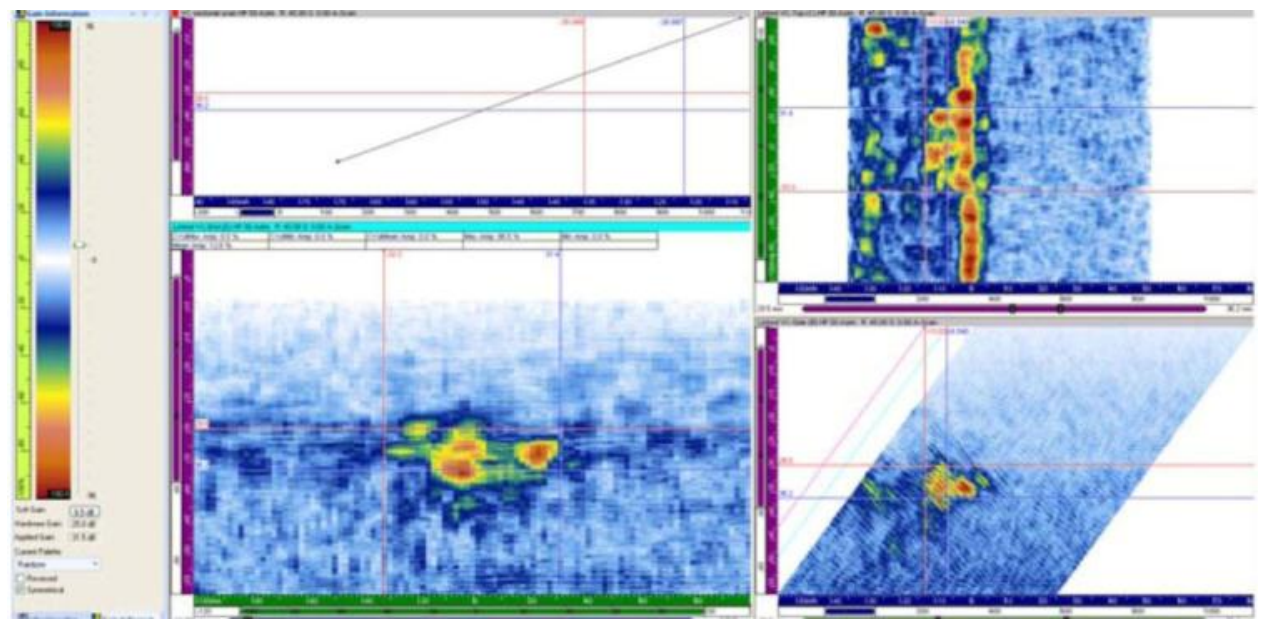

Figure A.1. Specimen 9C-034 Flaw 1 Pipe Side, Pre-WOL at 1.5 MHz, Raster Data

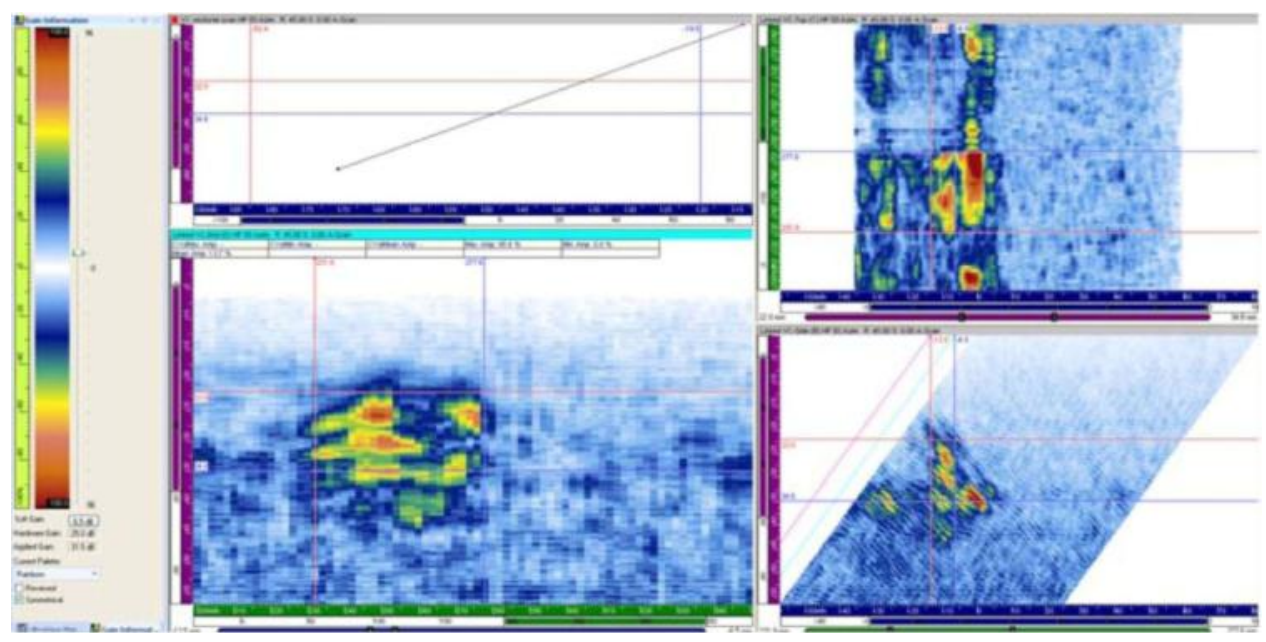

Figure A.2. Specimen 9C-034 Flaw 2 Pipe Side, Pre-WOL at 1.5 MHz, Raster Data 


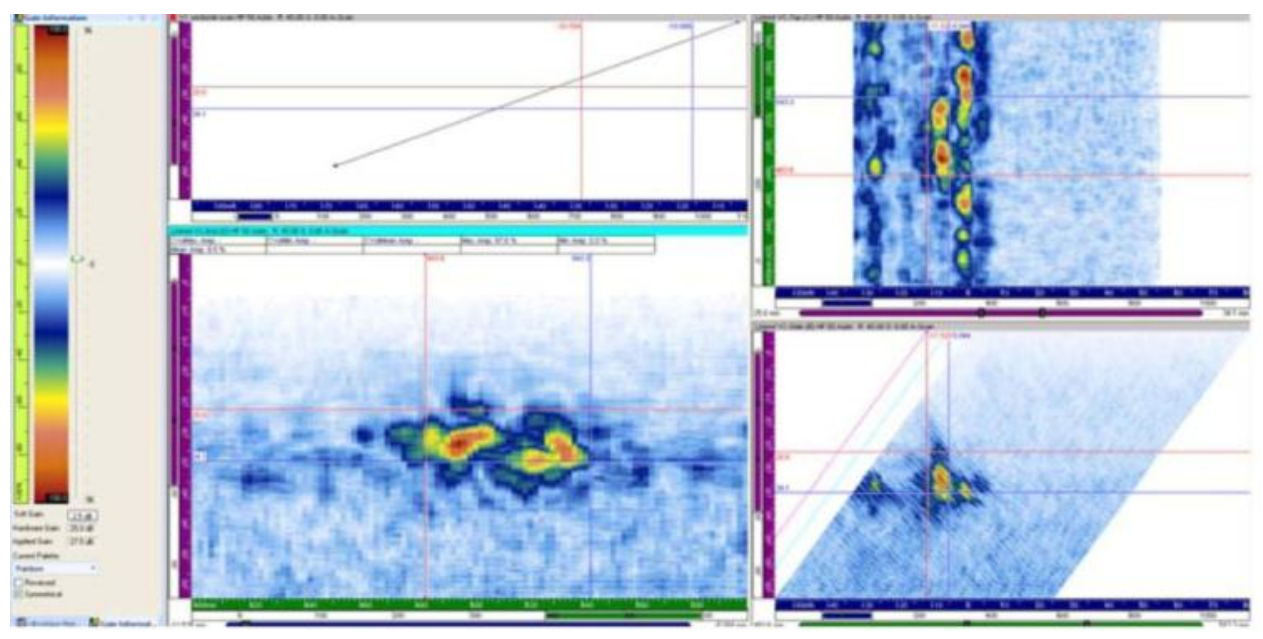

Figure A.3. Specimen 9C-034 Flaw 3 Pipe Side, Pre-WOL at $1.5 \mathrm{MHz}$, Raster Data

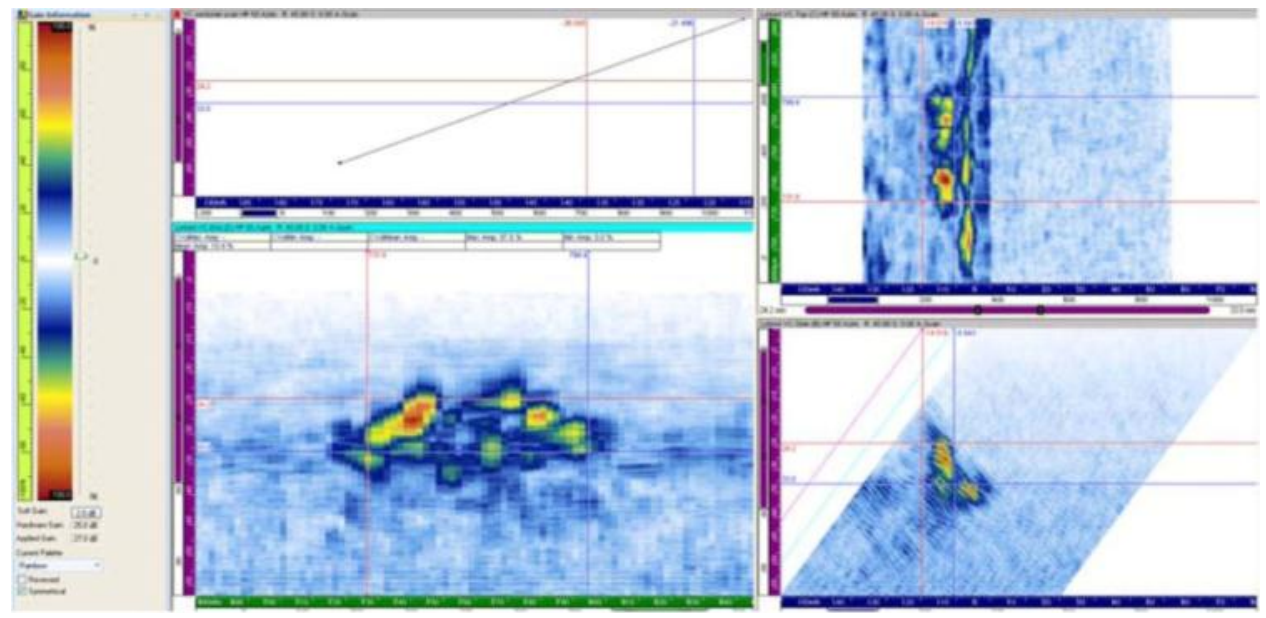

Figure A.4. Specimen 9C-034 Flaw 4 Pipe Side, Pre-WOL at $1.5 \mathrm{MHz}$, Raster Data 


\section{A.1.2 2-MHz Raster Data on Flaws 1-4 Pipe Side Pre-WOL}

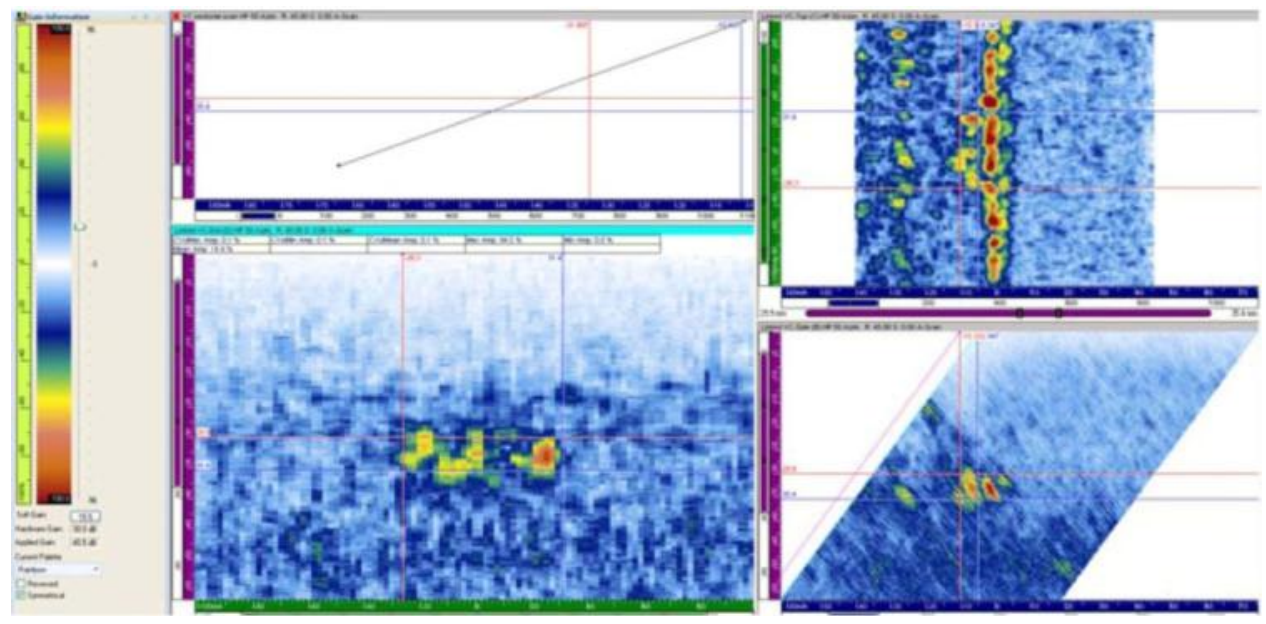

Figure A.5. Specimen 9C-034 Flaw 1 Pipe Side, Pre-WOL at 2 MHz, Raster Data

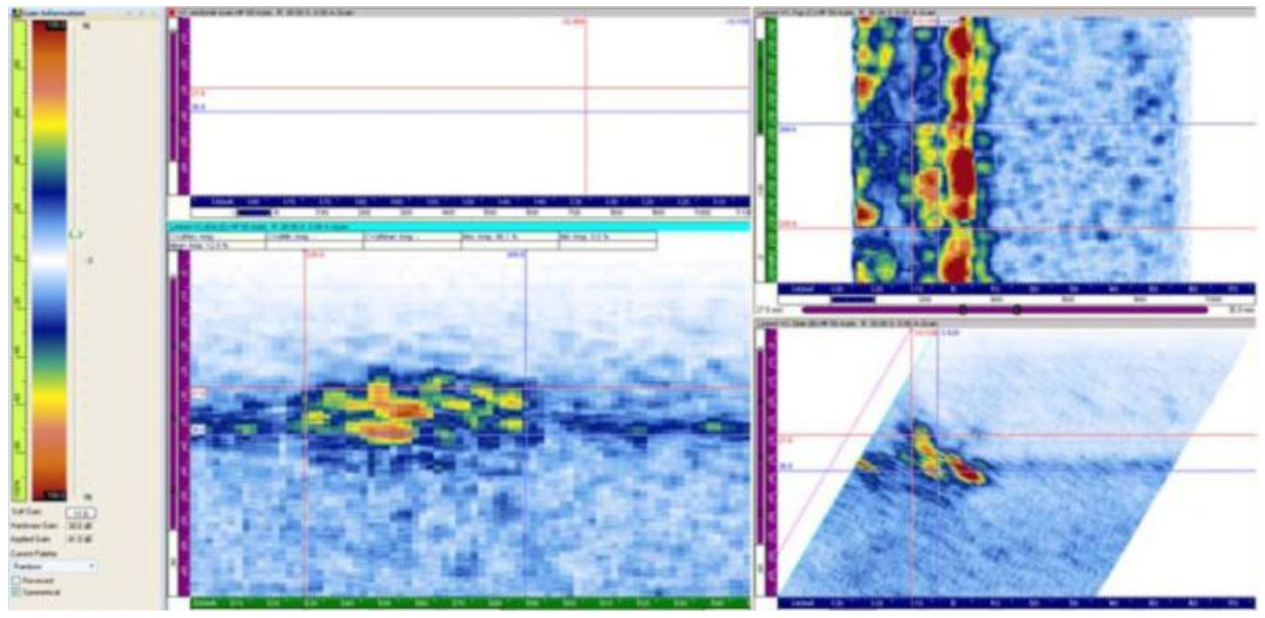

Figure A.6. Specimen 9C-034 Flaw 2 Pipe Side, Pre-WOL at 2 MHz, Raster Data 


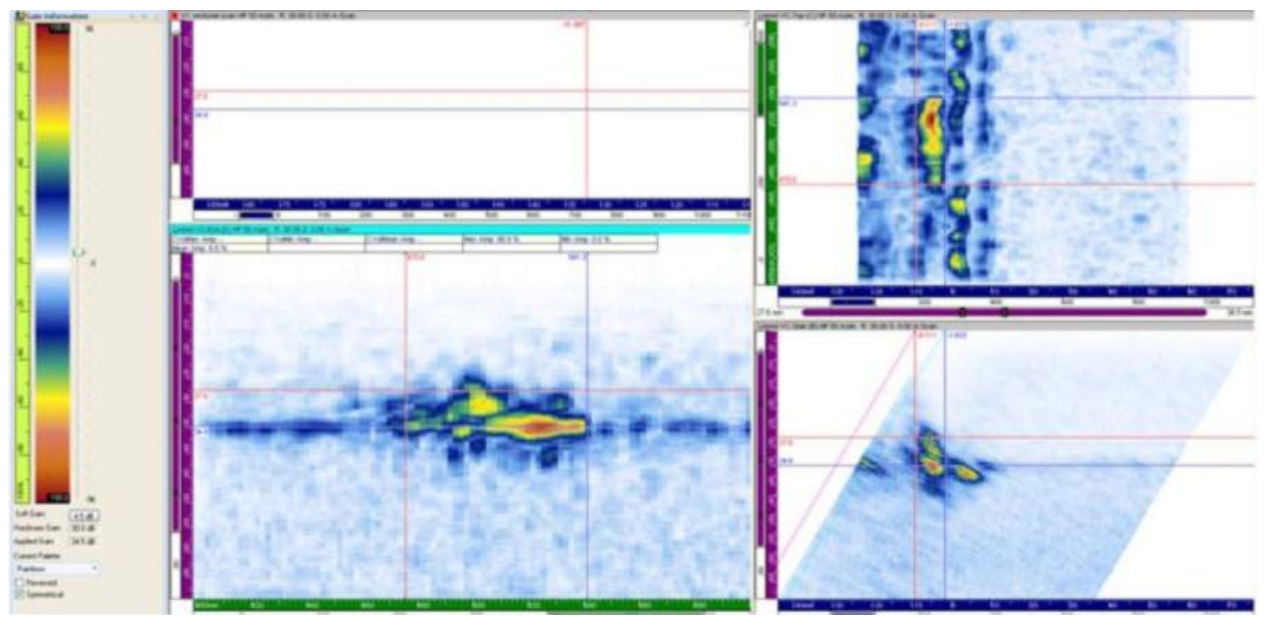

Figure A.7. Specimen 9C-034 Flaw 3 Pipe Side, Pre-WOL at 2 MHz, Raster Data

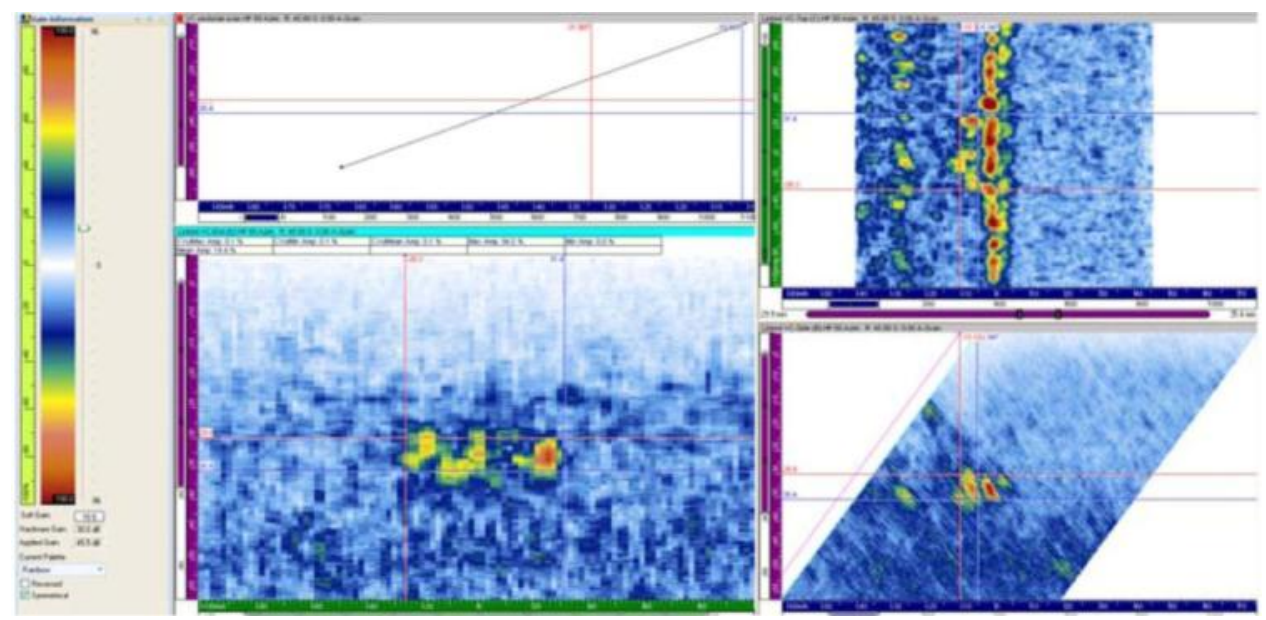

Figure A.8. Specimen 9C-034 Flaw 4 Pipe Side, Pre-WOL at 2 MHz, Raster Data 


\section{A.2 Line Scan Data}

\section{A.2.1 1.5-MHz Line Scan Data on Flaws 1-4 Pipe Side Pre-WOL}

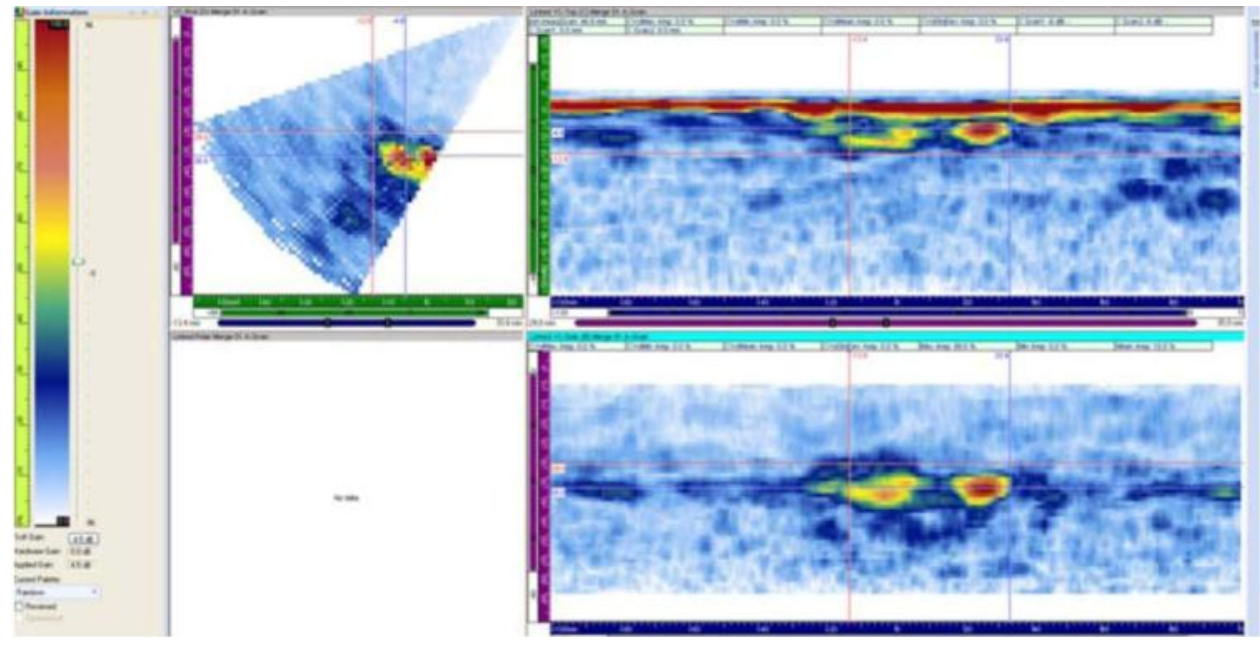

Figure A.9. Specimen 9C-034 Flaw 1 Pipe Side, Pre-WOL at 1.5 MHz, Line Scan Data

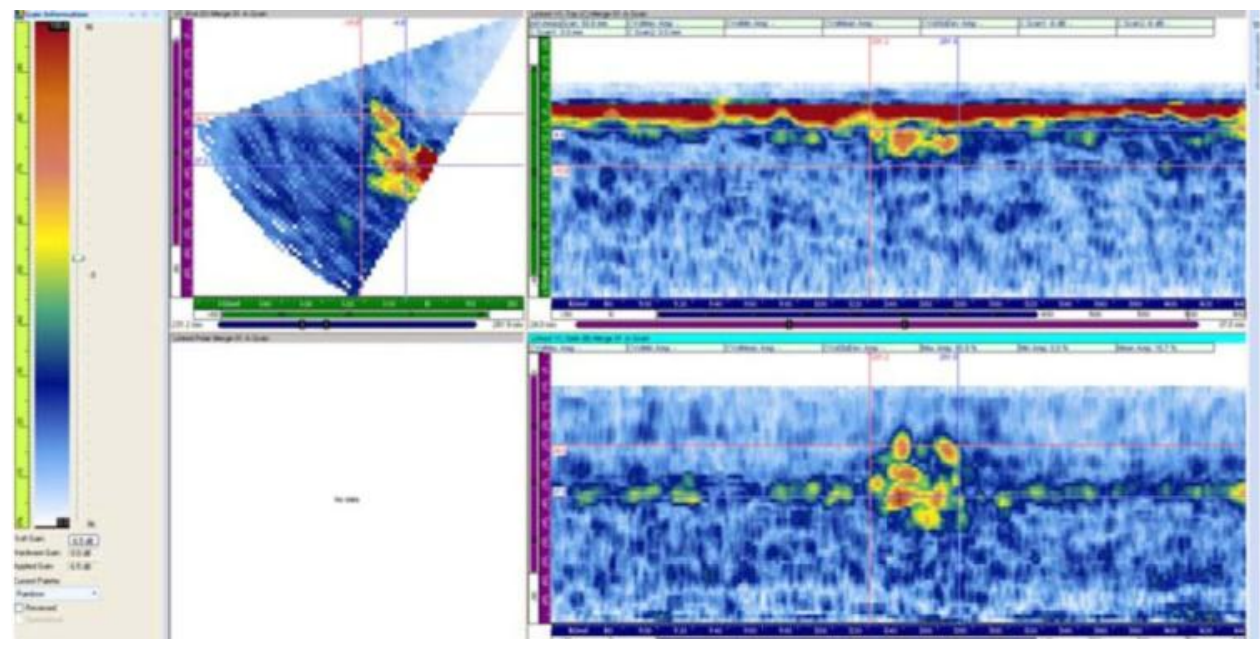

Figure A.10. Specimen 9C-034 Flaw 2 Pipe Side, Pre-WOL at 1.5 MHz, Line Scan Data 


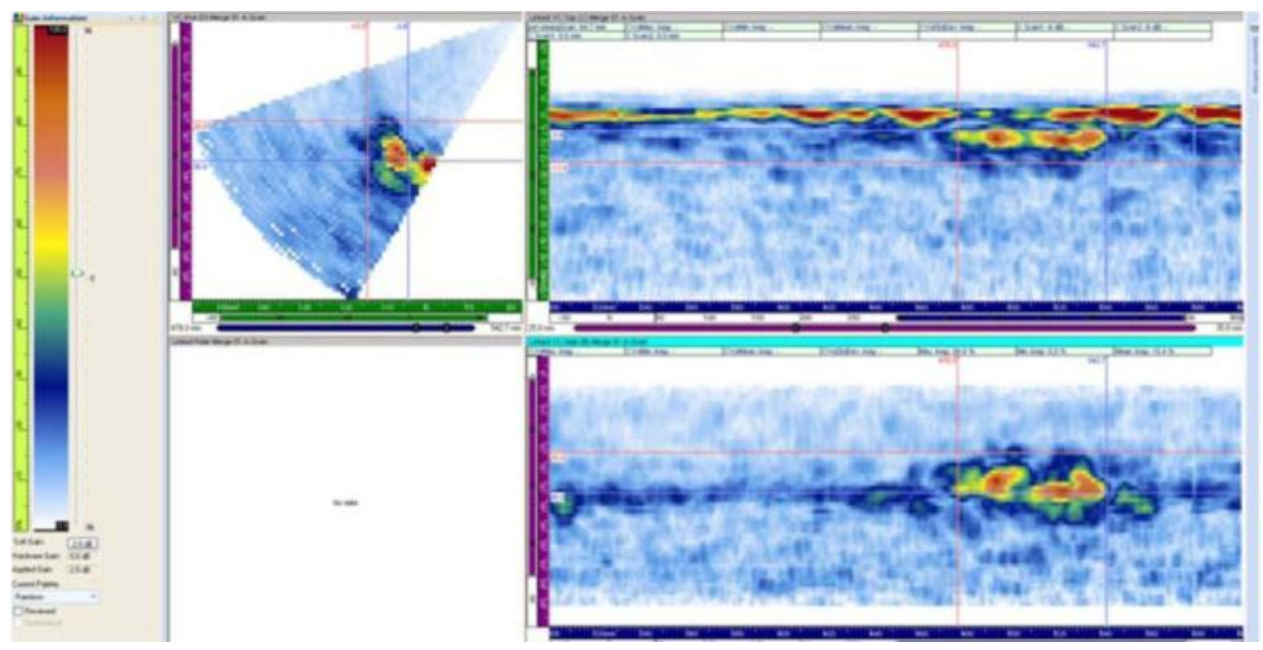

Figure A.11. Specimen 9C-034 Flaw 3 Pipe Side, Pre-WOL at 1.5 MHz, Line Scan Data

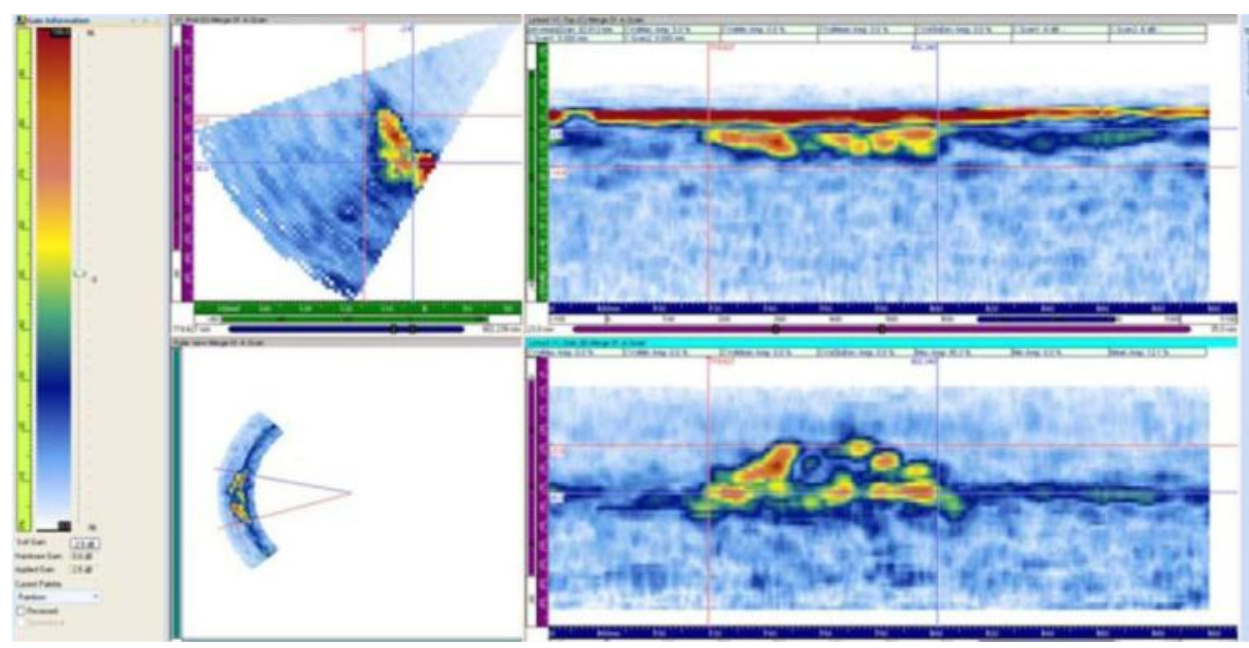

Figure A.12. Specimen 9C-034 Flaw 4 Pipe Side, Pre-WOL at 1.5 MHz, Line Scan Data 


\section{A.2.2 2-MHz Line Scan Data on Flaws 1-4 Pipe Side Pre-WOL}

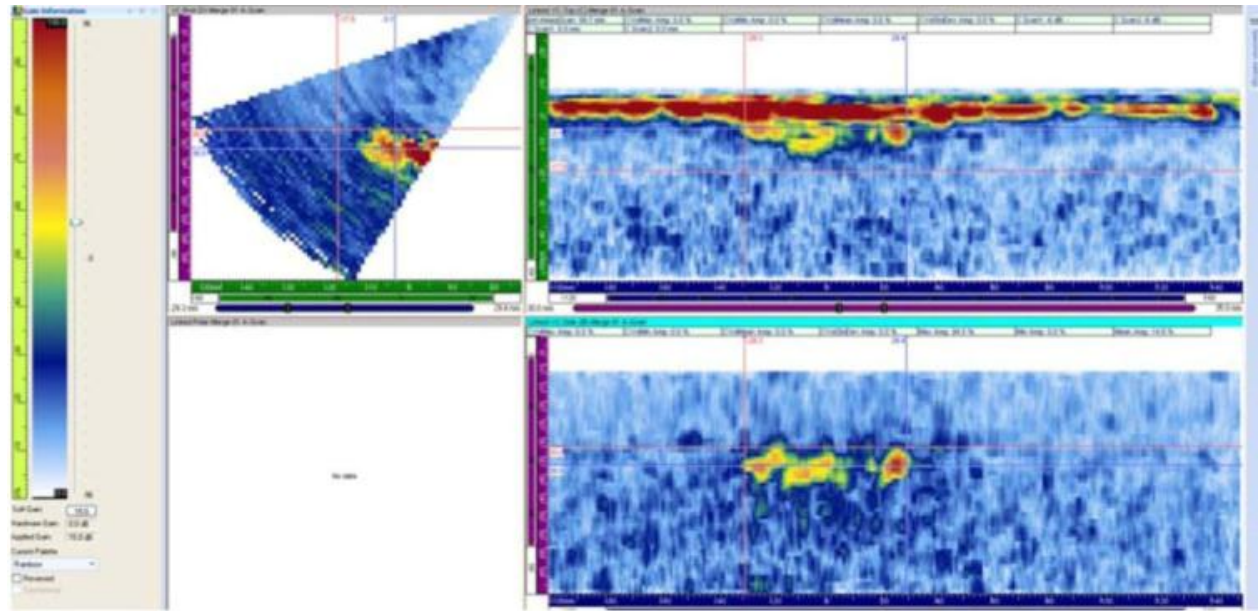

Figure A.13. Specimen 9C-034 Flaw 1 Pipe Side, Pre-WOL at 2 MHz, Line Scan Data

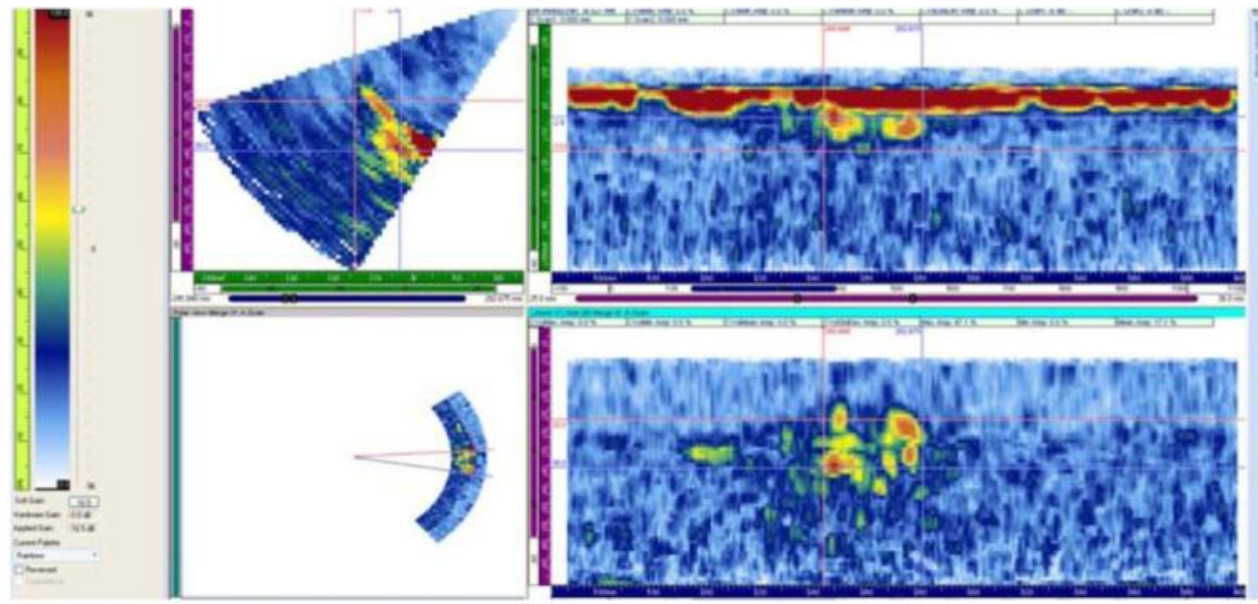

Figure A.14. Specimen 9C-034 Flaw 2 Pipe Side, Pre-WOL at 2 MHz, Line Scan Data 


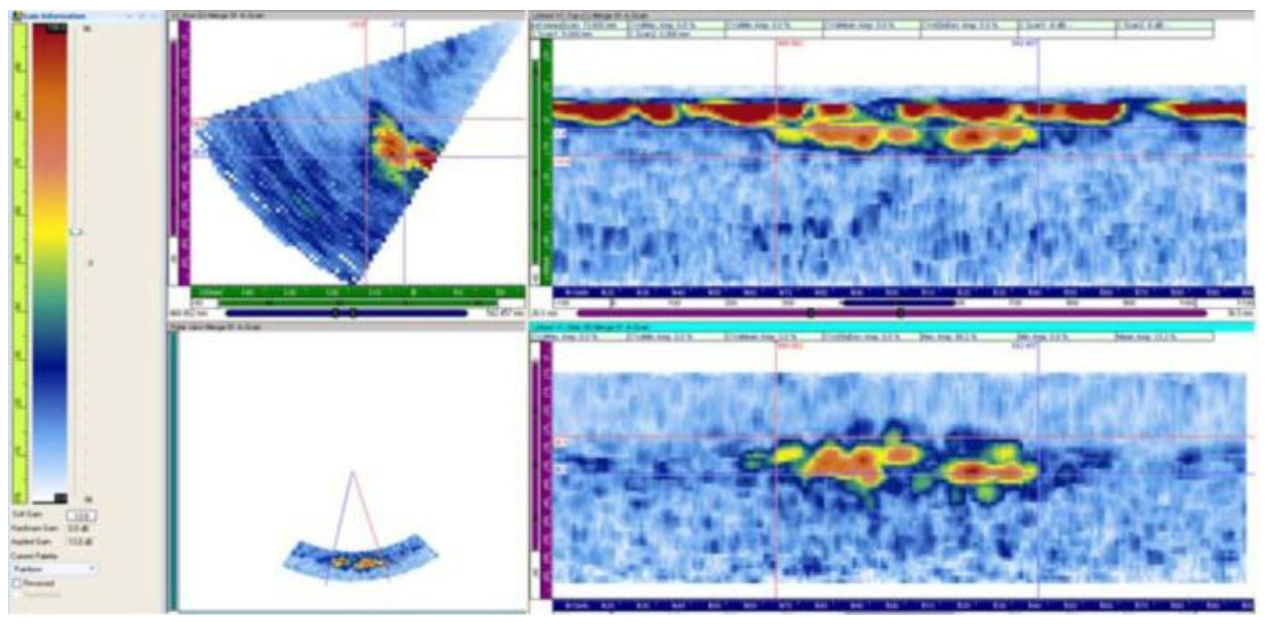

Figure A.15. Specimen 9C-034 Flaw 3 Pipe Side, Pre-WOL at 2 MHz, Line Scan Data

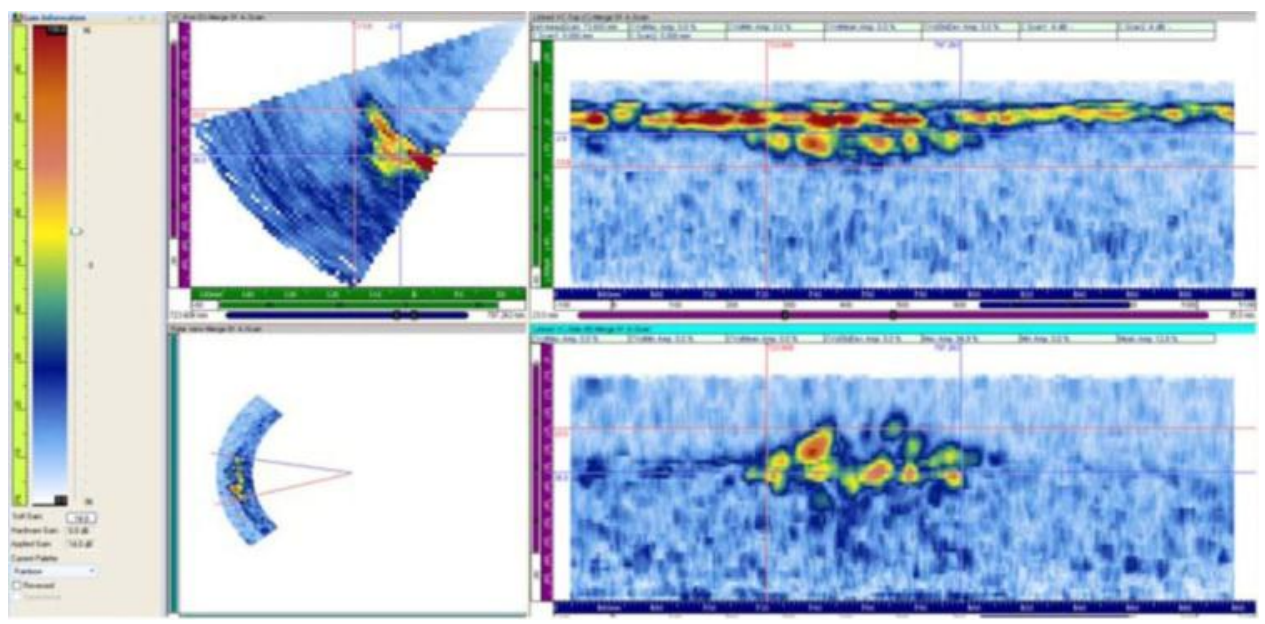

Figure A.16. Specimen 9C-034 Flaw 4 Pipe Side, Pre-WOL at 2 MHz, Line Scan Data 



\section{Appendix B}

Dissimilar Metal Weld Specimen 9C-034 Phased-Array Data, Post-WOL 



\section{Appendix B}

\section{Dissimilar Metal Weld Specimen 9C-034 Phased-Array Data, Post-WOL}

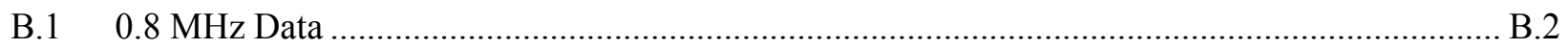

B.1.1 Line Scan Images Nozzle Side of Overlay Flaws 1-4 ..................................................2

B.1.2 Raster Scan Images Nozzle and Pipe Sides of Overlay Flaws 1-4 ...................................3

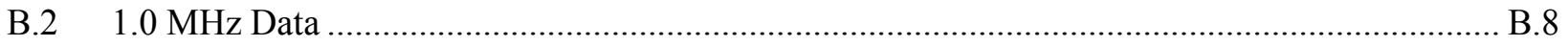

B.2.1 Line Scan Images Nozzle and Pipe Sides of Overlay Flaws 1-4 ….............................8.

B.2.2 Raster Scan Images Nozzle and Pipe Sides of Overlay Flaws 1-4..............................12

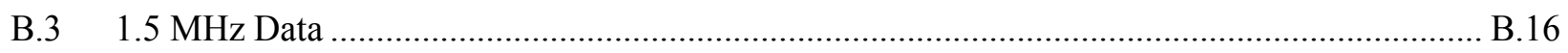

B.3.1 Line Scan Images Nozzle and Pipe Sides of Overlay Flaws 1-4 ................................16

B.3.2 Raster Scan Images Nozzle and Pipe Sides of Overlay Flaws 1-4...............................20

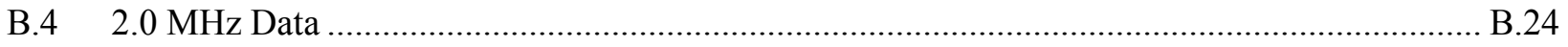

B.4.1 Line Scan Images Nozzle and Pipe Sides of Overlay Flaws 1-4 ….............................24

B.4.2 Raster Scan Images Nozzle and Pipe Sides of Overlay Flaws 1-4...............................28 


\section{B.1 $0.8 \mathrm{MHz}$ Data}

\section{B.1.1 Line Scan Images Nozzle Side of Overlay Flaws 1-4}

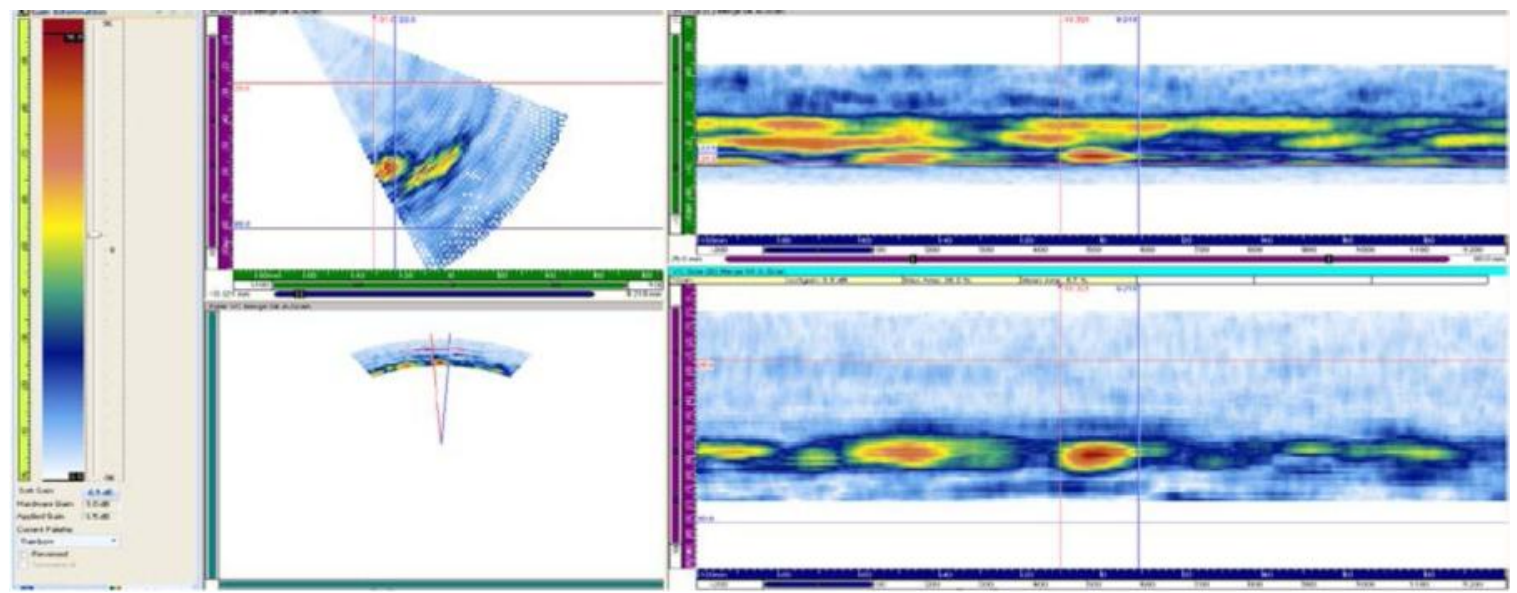

Figure B.1. Line Scan Data, Flaw 1, Nozzle Side of Overlay, 0.8 MHz, Marginal Detection

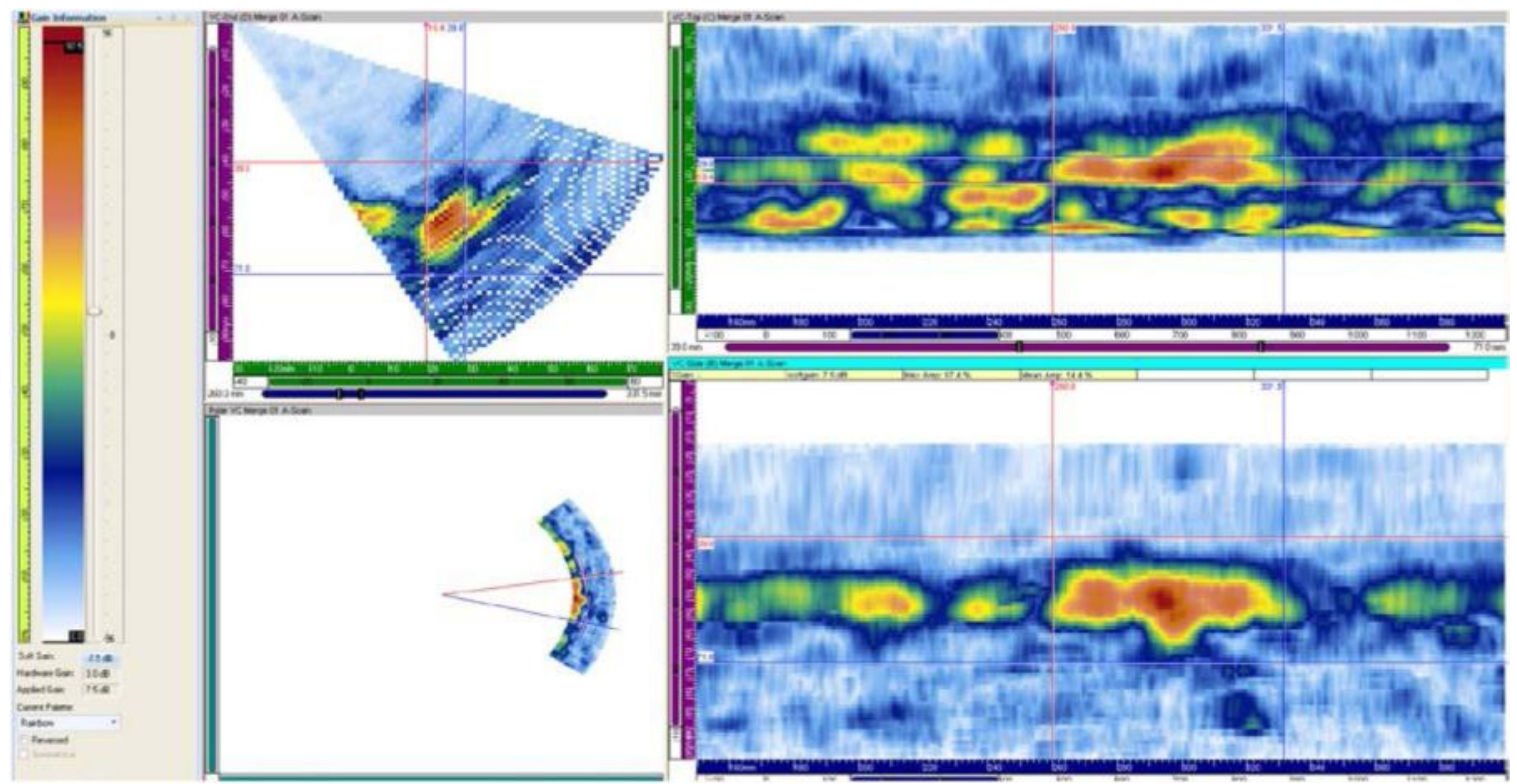

Figure B.2. Line Scan Data, Flaw 2, Nozzle Side of Overlay, 0.8 MHz, Marginal Detection 


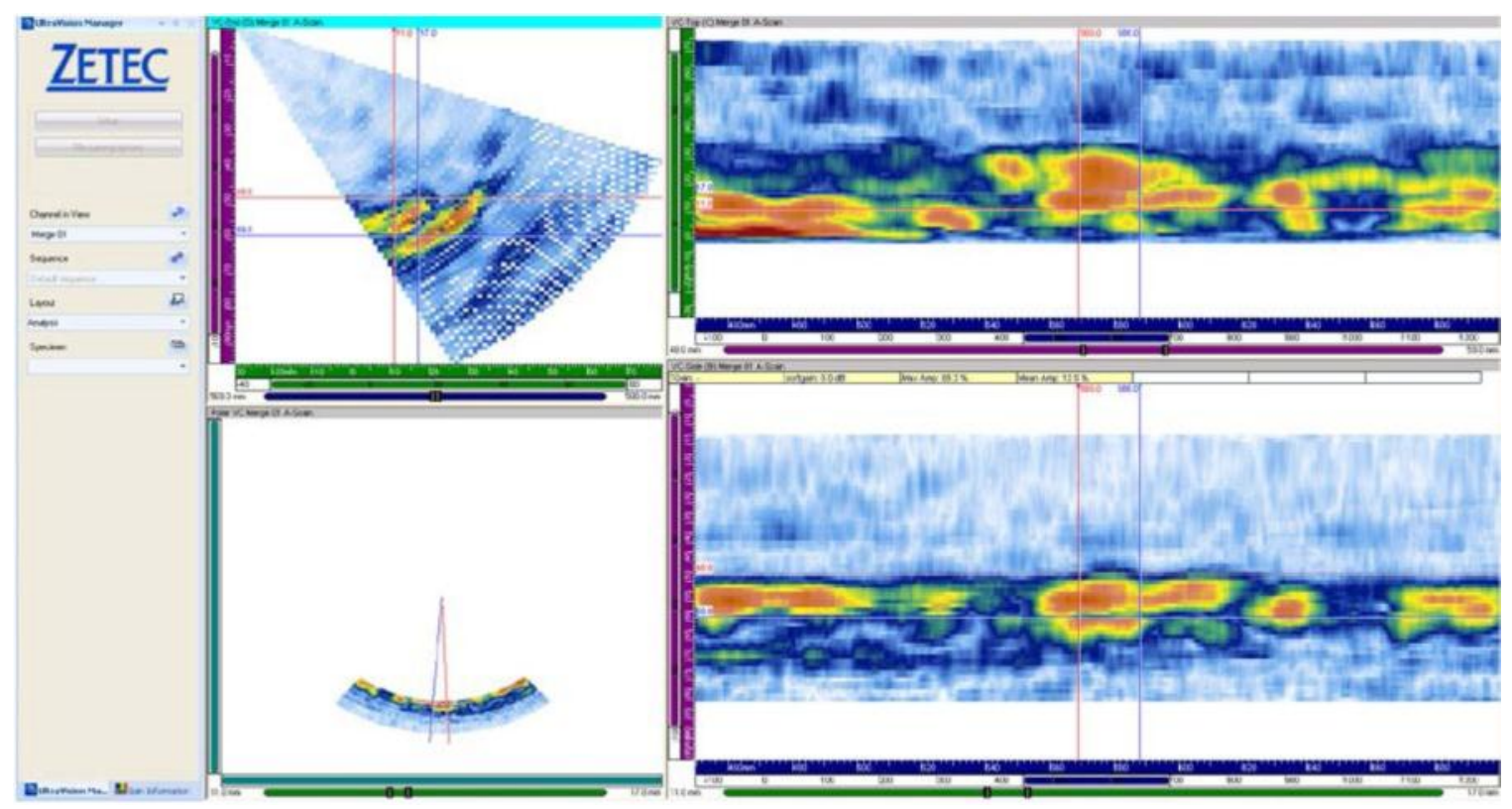

Figure B.3. Line Scan Data, Flaw 3, Nozzle Side of Overlay, $0.8 \mathrm{MHz}$, No Detection

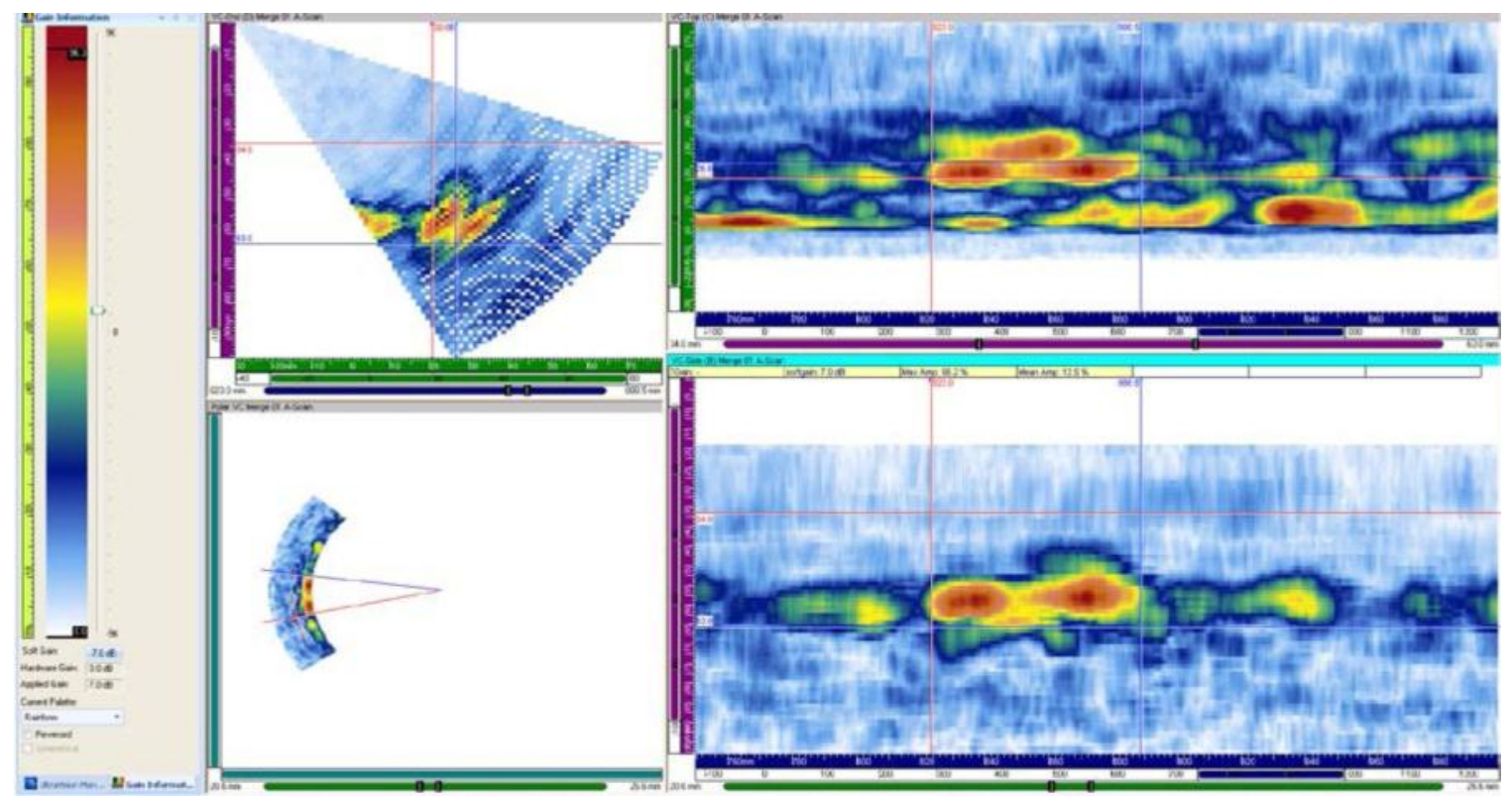

Figure B.4. Line Scan Data, Flaw 4, Nozzle Side of Overlay, $0.8 \mathrm{MHz}$, Yes Detection

\section{B.1.2 Raster Scan Images Nozzle and Pipe Sides of Overlay Flaws 1-4}




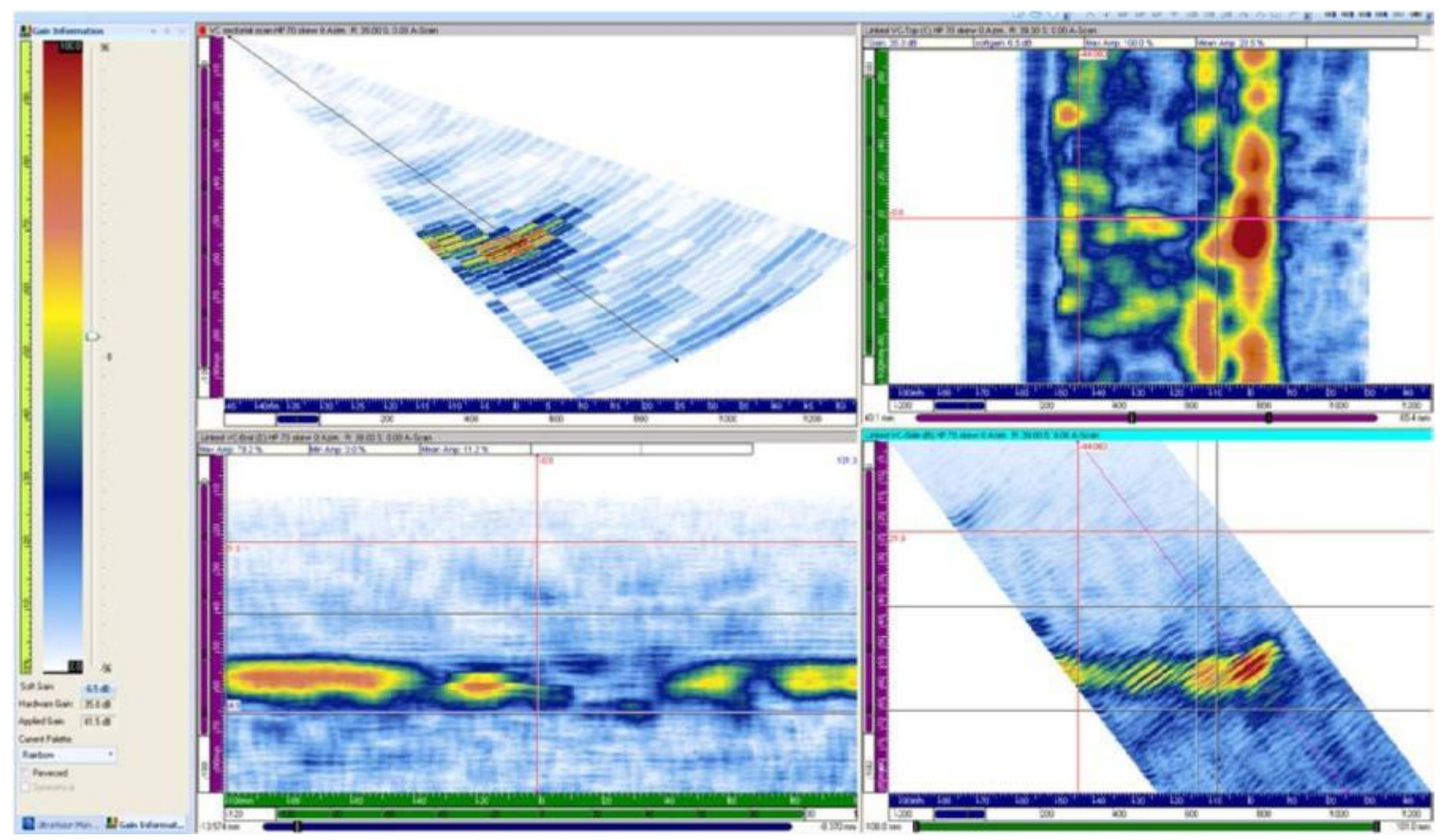

Figure B.5. Raster Data, Flaw 1 Nozzle Side of Overlay, $0.8 \mathrm{MHz}$, No Detection

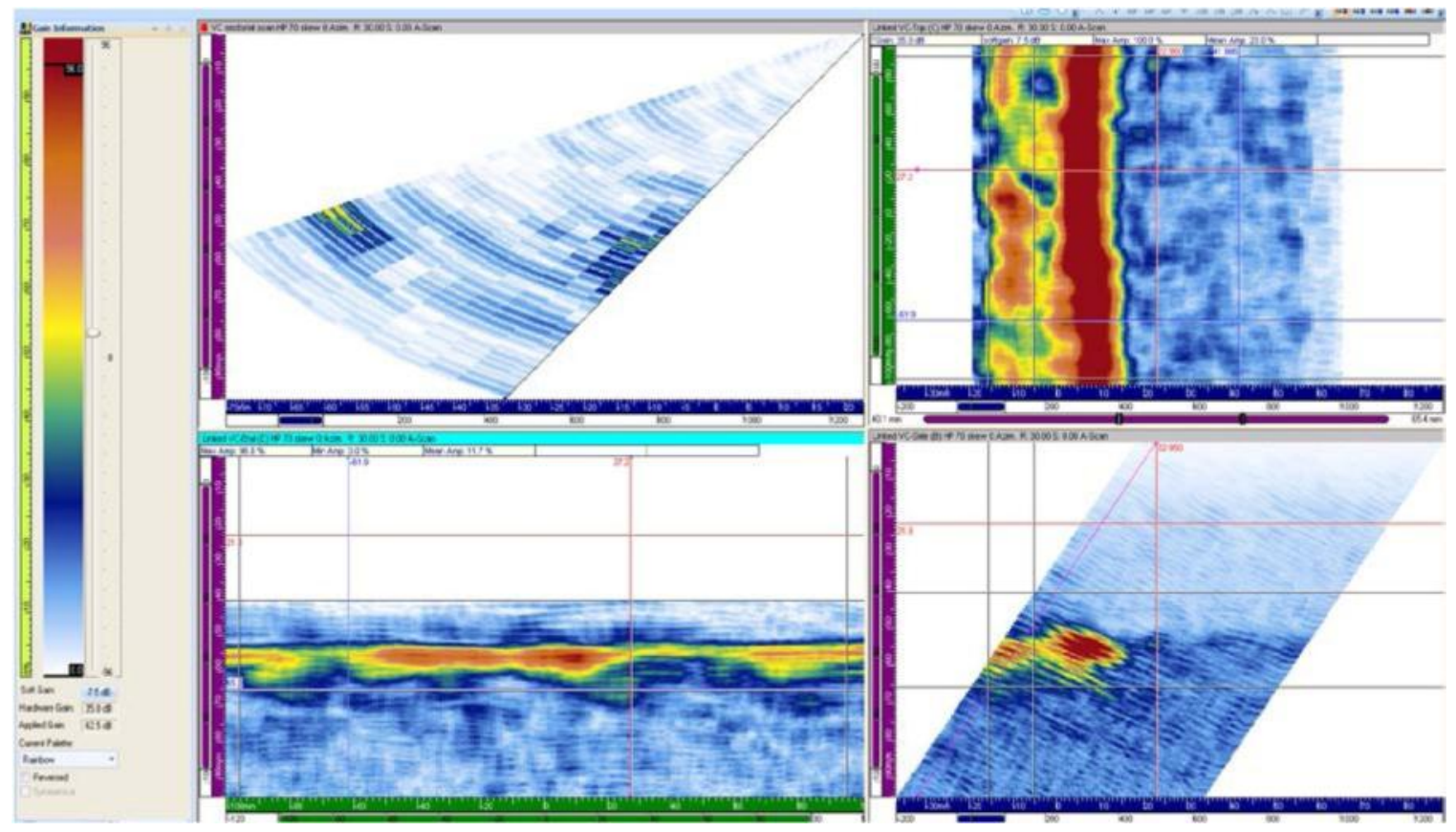

Figure B.6. Raster Data, Flaw 1 Pipe Side of Overlay, $0.8 \mathrm{MHz}$, No Detection 


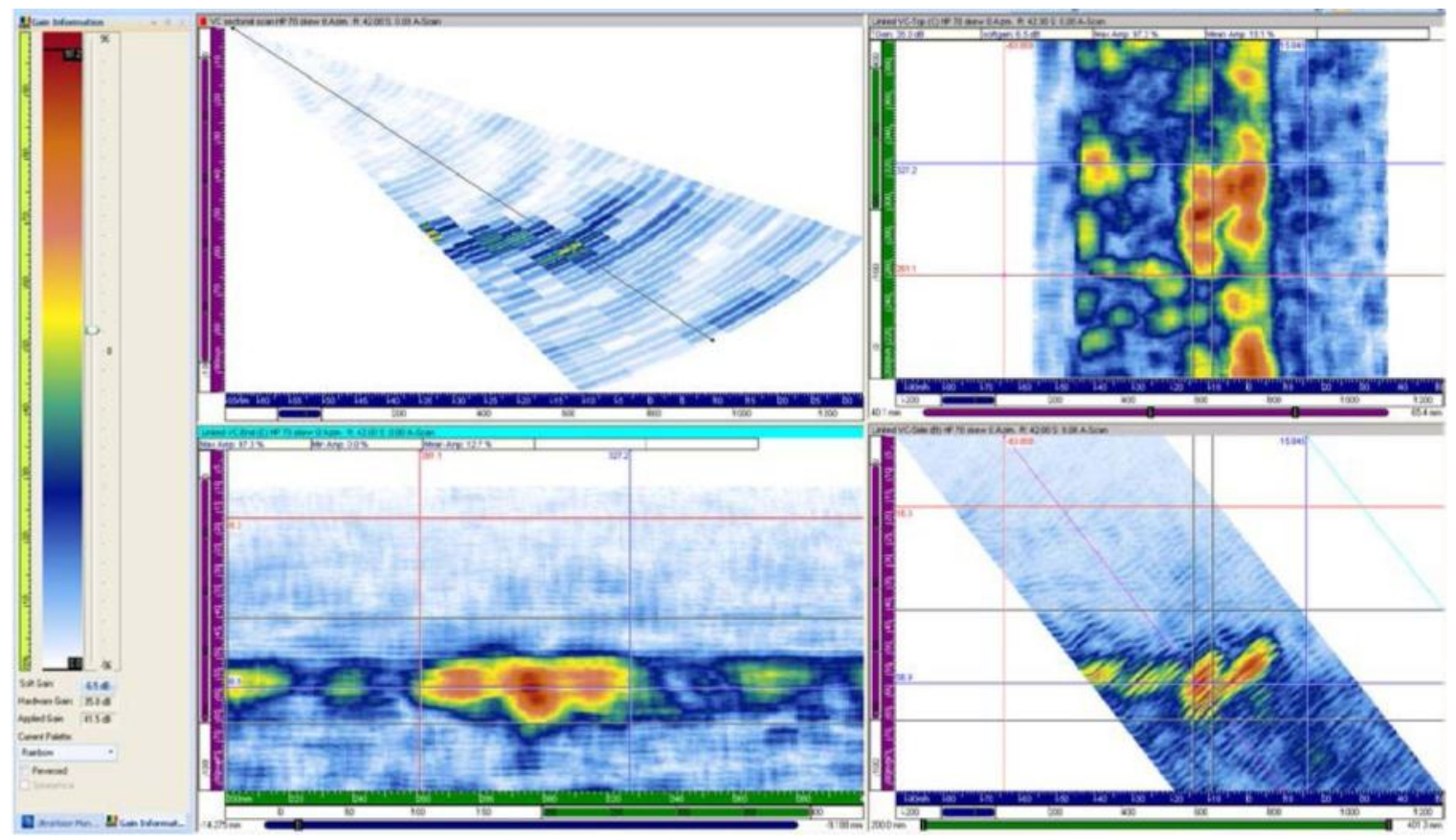

Figure B.7. Raster Data, Flaw 2 Nozzle Side of Overlay, $0.8 \mathrm{MHz}$, Yes Detection

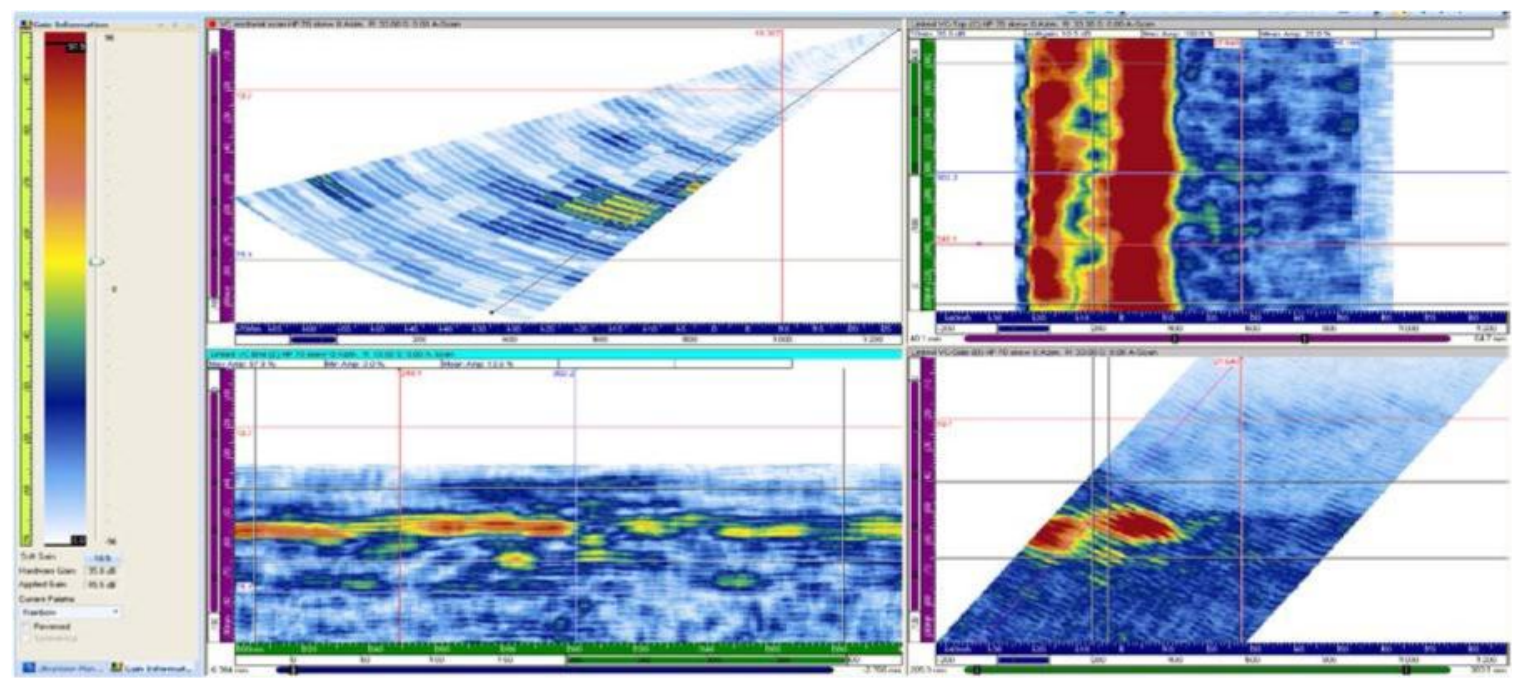

Figure B.8. Raster Data, Flaw 2 Pipe Side of Overlay, $0.8 \mathrm{MHz}$, Marginal/No Detection 


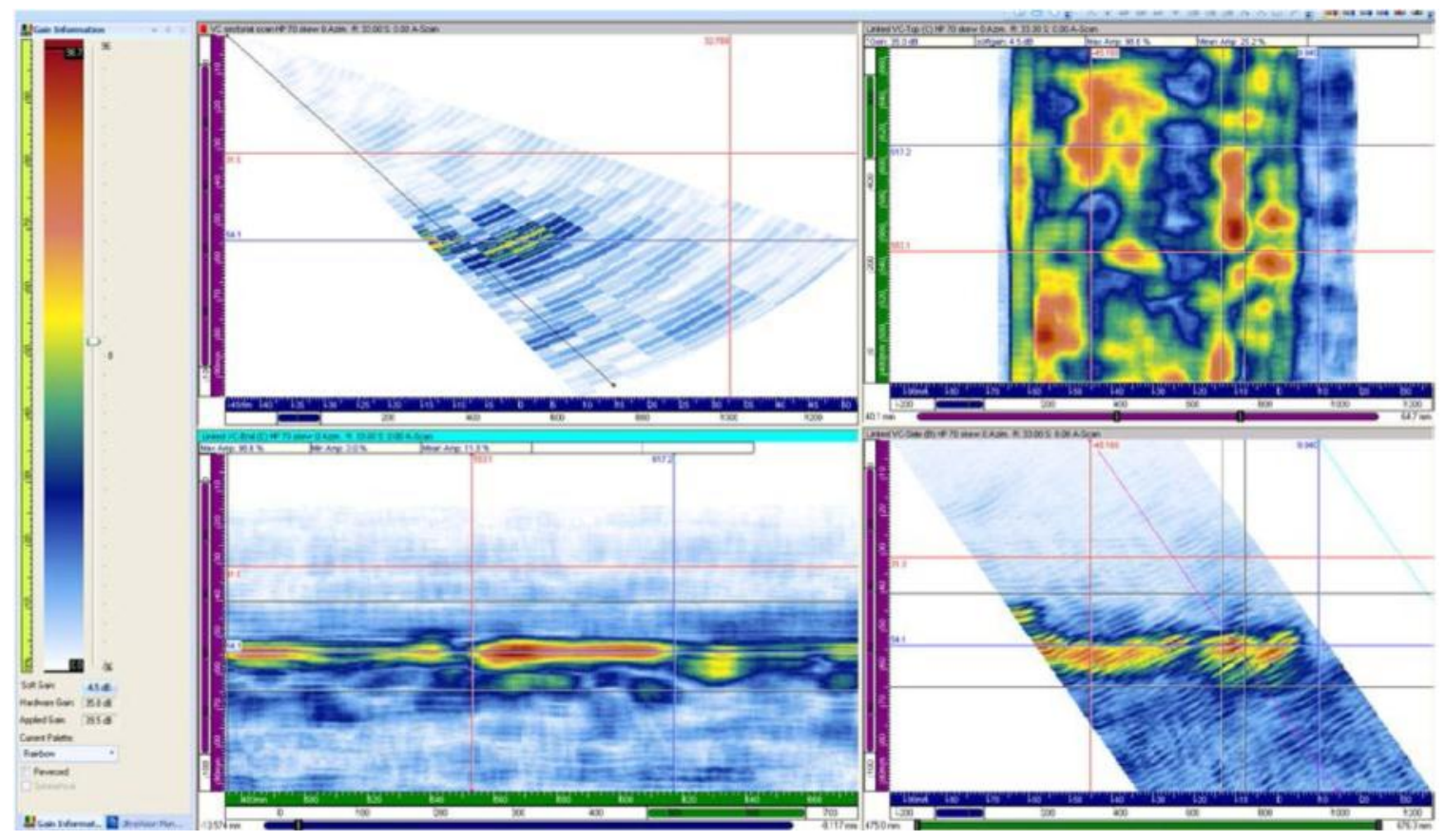

Figure B.9. Raster Data, Flaw 3 Nozzle Side of Overlay, $0.8 \mathrm{MHz}$, Marginal Detection

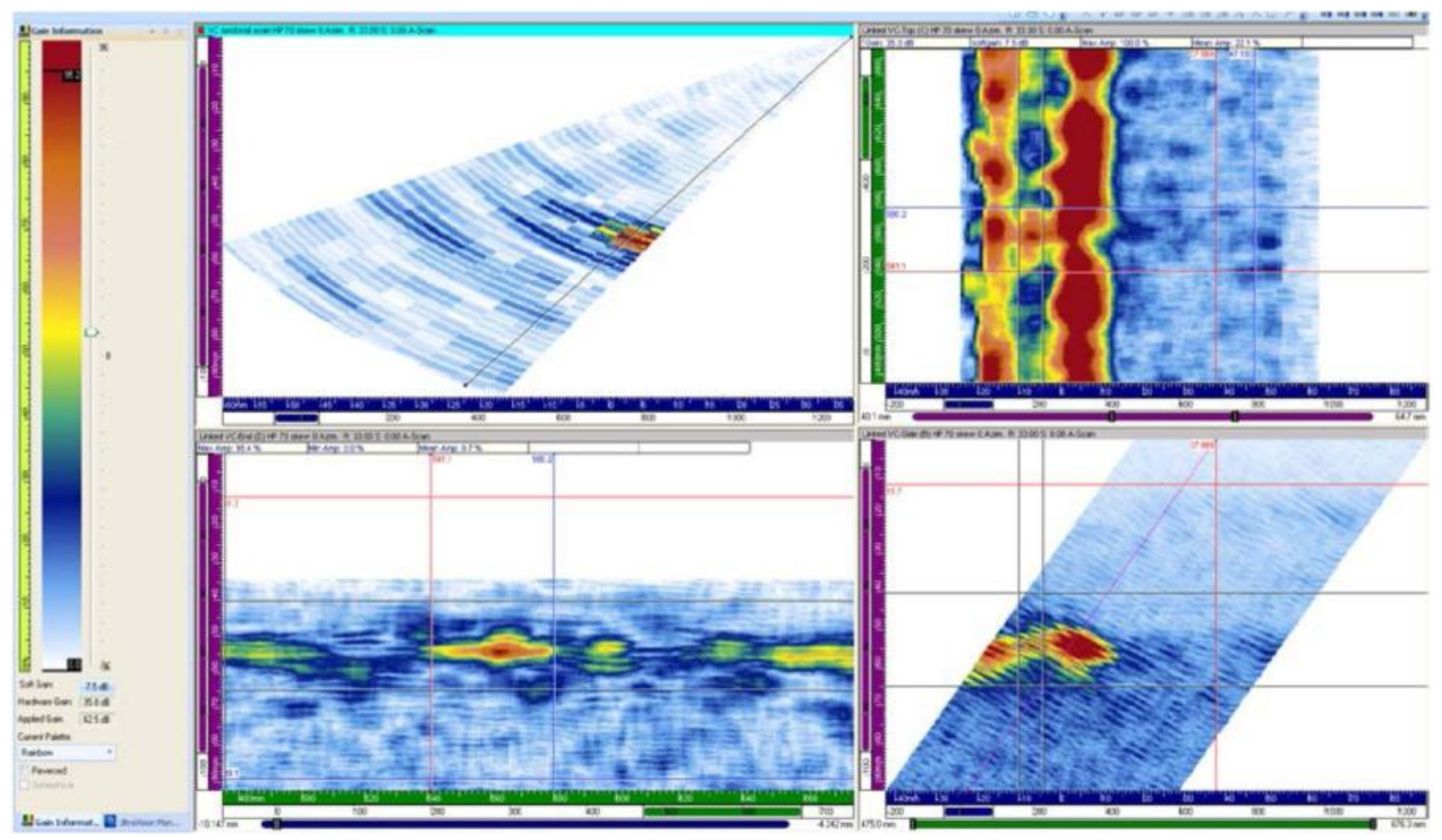

Figure B.10. Raster Data, Flaw 3 Pipe Side of Overlay, $0.8 \mathrm{MHz}$, Yes Detection 


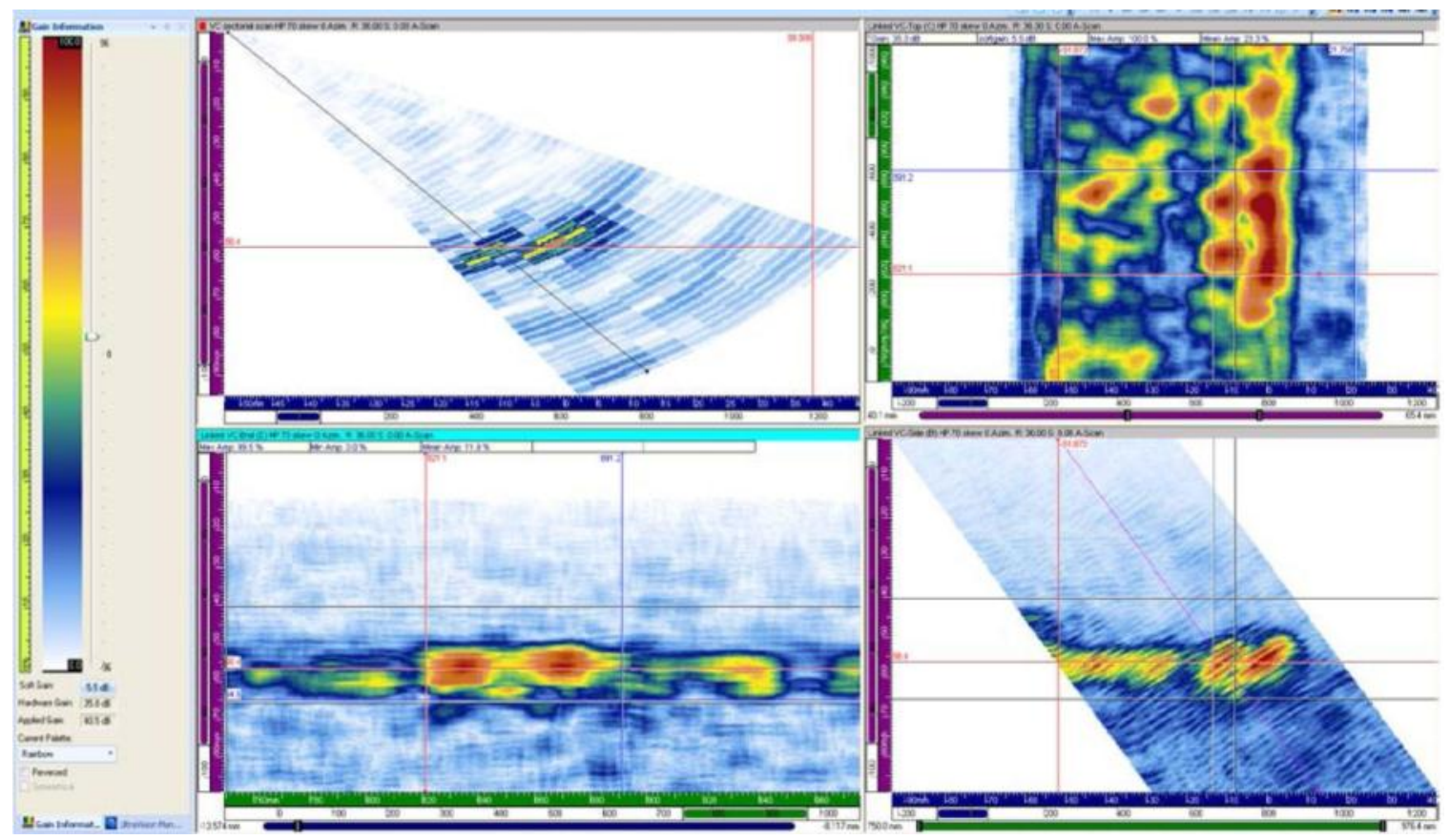

Figure B.11. Raster Data, Flaw 4 Nozzle Side of Overlay, $0.8 \mathrm{MHz}$, Yes Detection

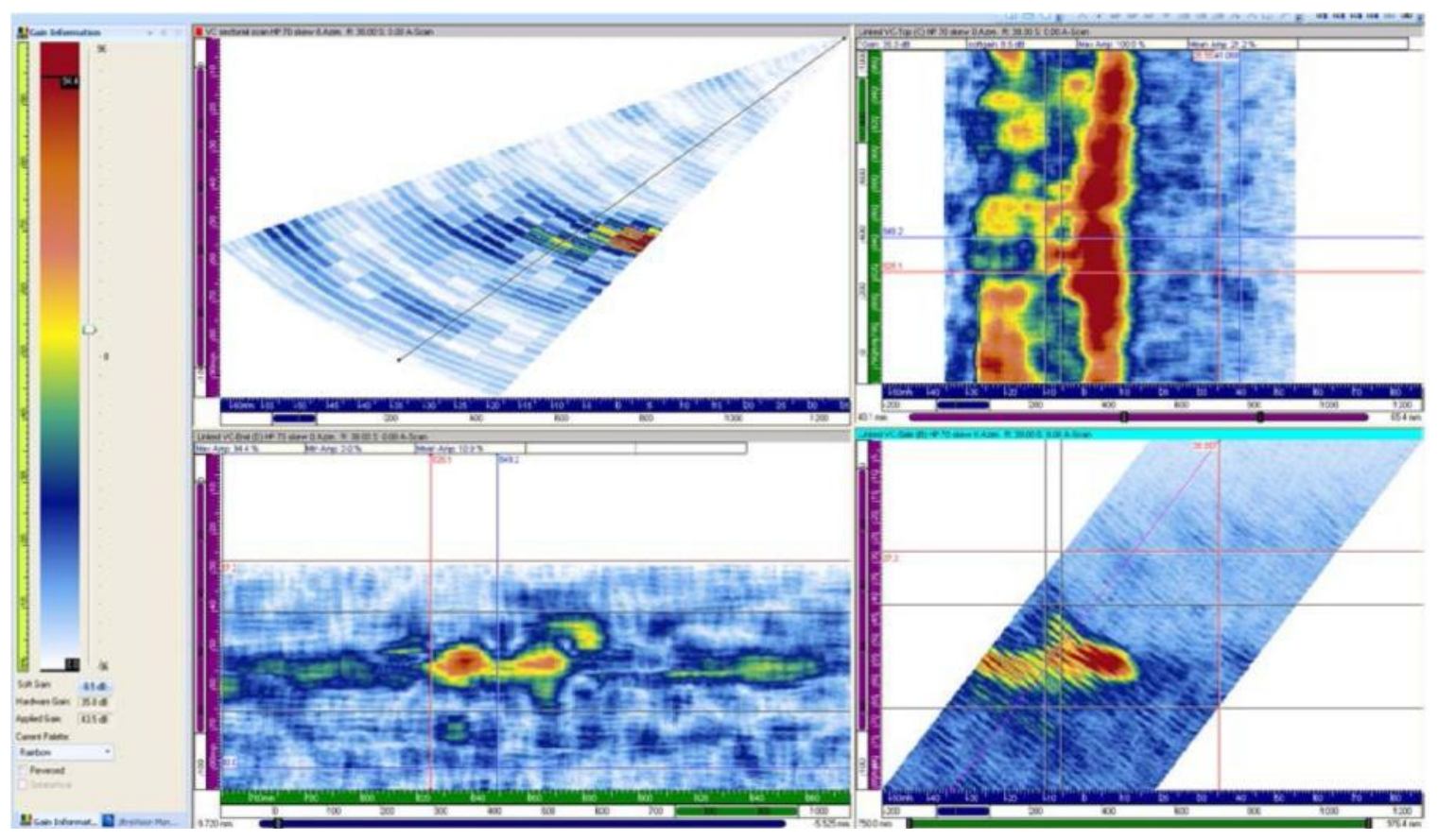

Figure B.12. Raster Data, Flaw 4 Pipe Side of Overlay, $0.8 \mathrm{MHz}$, Yes Detection 


\section{B.2 1.0 MHz Data}

\section{B.2.1 Line Scan Images Nozzle and Pipe Sides of Overlay Flaws 1-4}

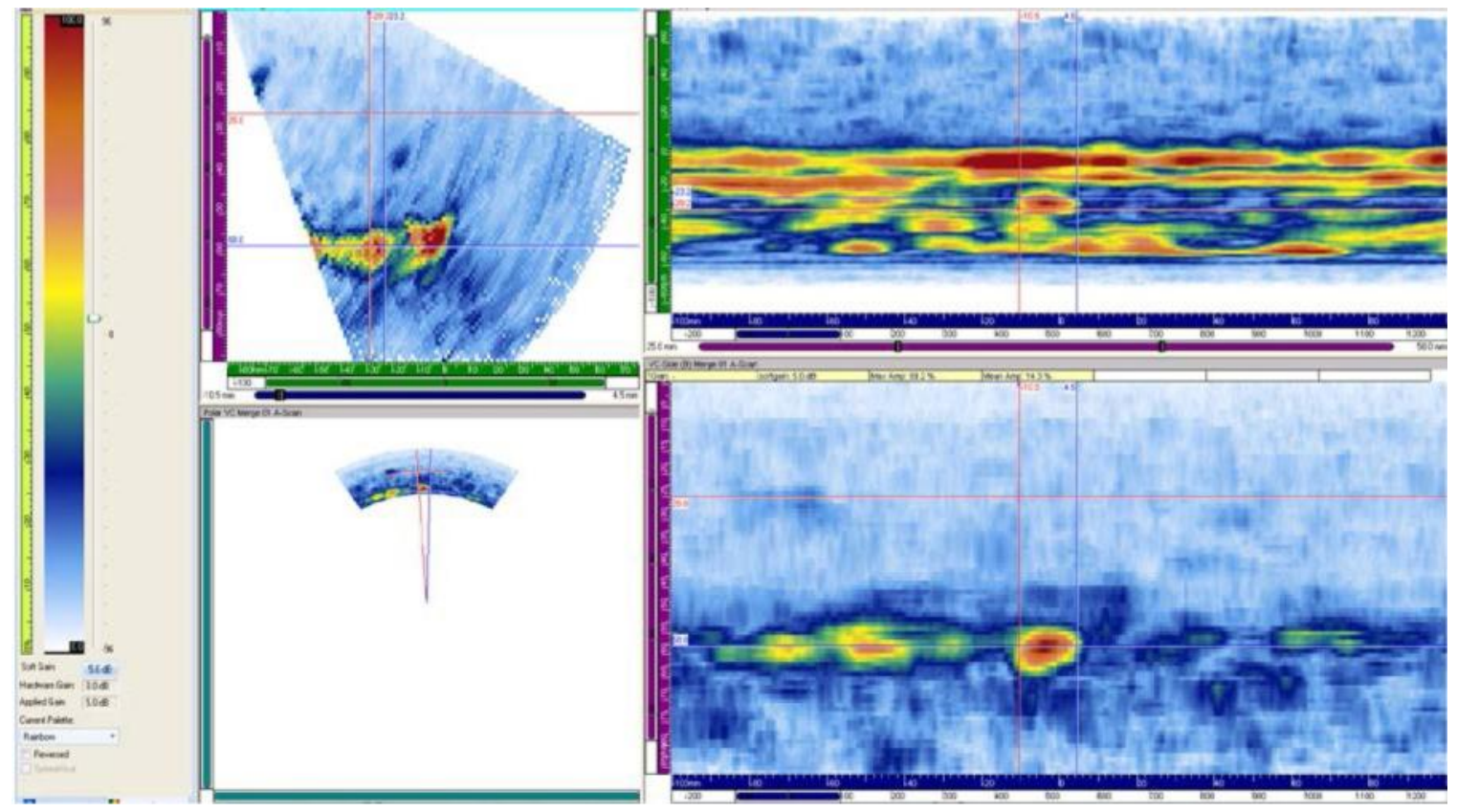

Figure B.13. Line Scan Data, Flaw 1 Nozzle Side of Overlay, 1.0 MHz, Marginal Detection

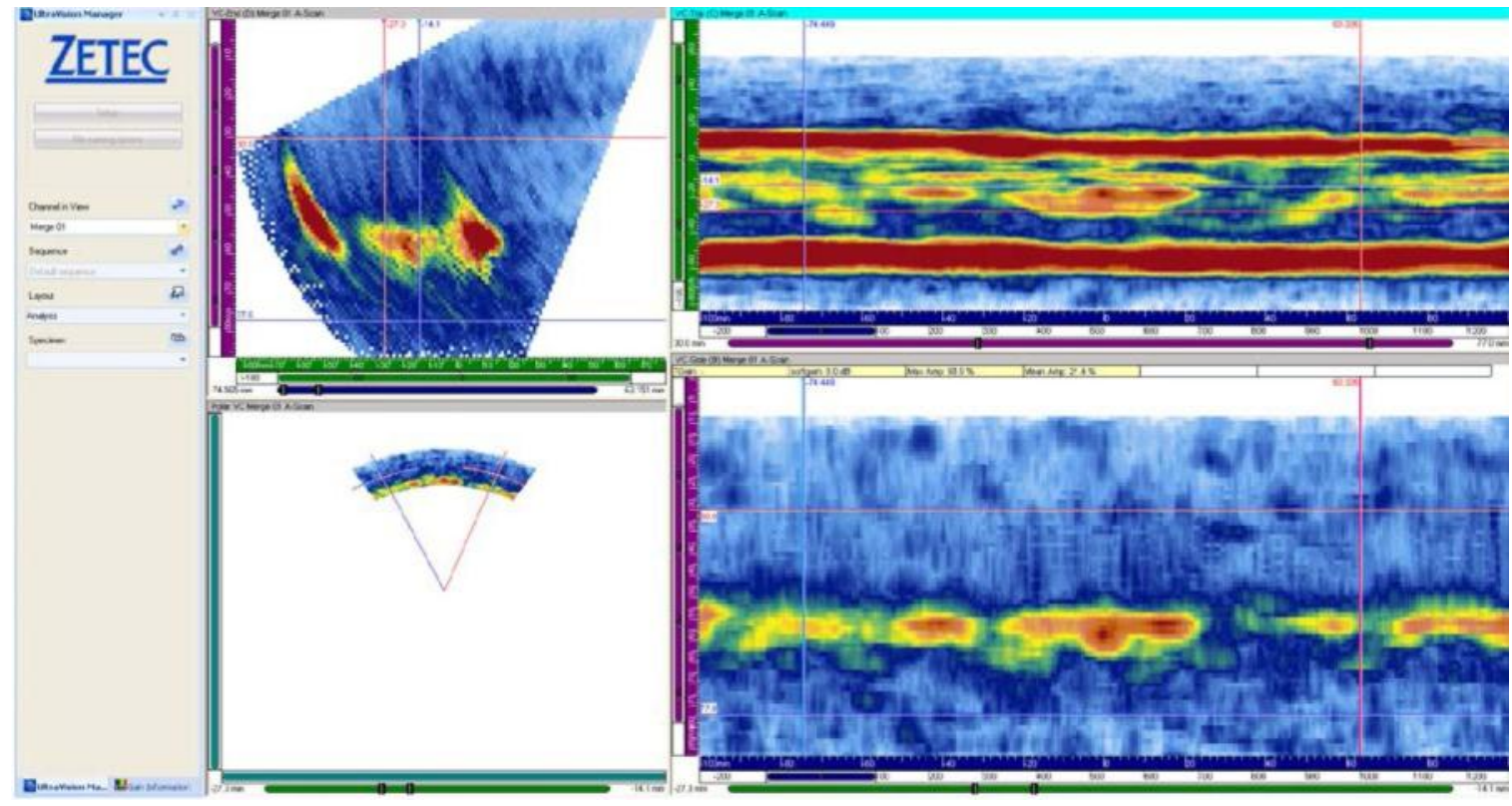

Figure B.14. Line Scan Data, Flaw 1 Pipe Side of Overlay, 1.0 MHz, No Detection 


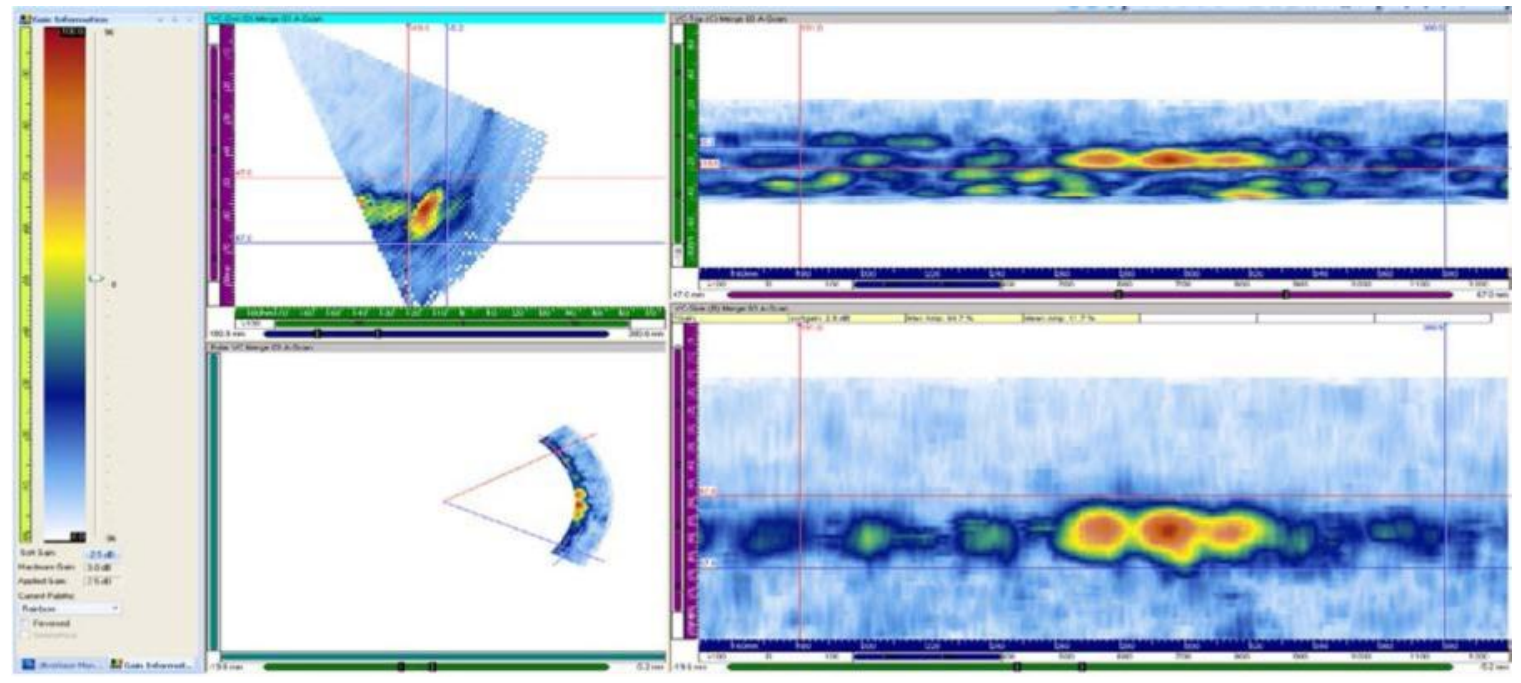

Figure B.15. Line Scan Data, Flaw 2 Nozzle Side of Overlay, 1.0 MHz, Yes Detection

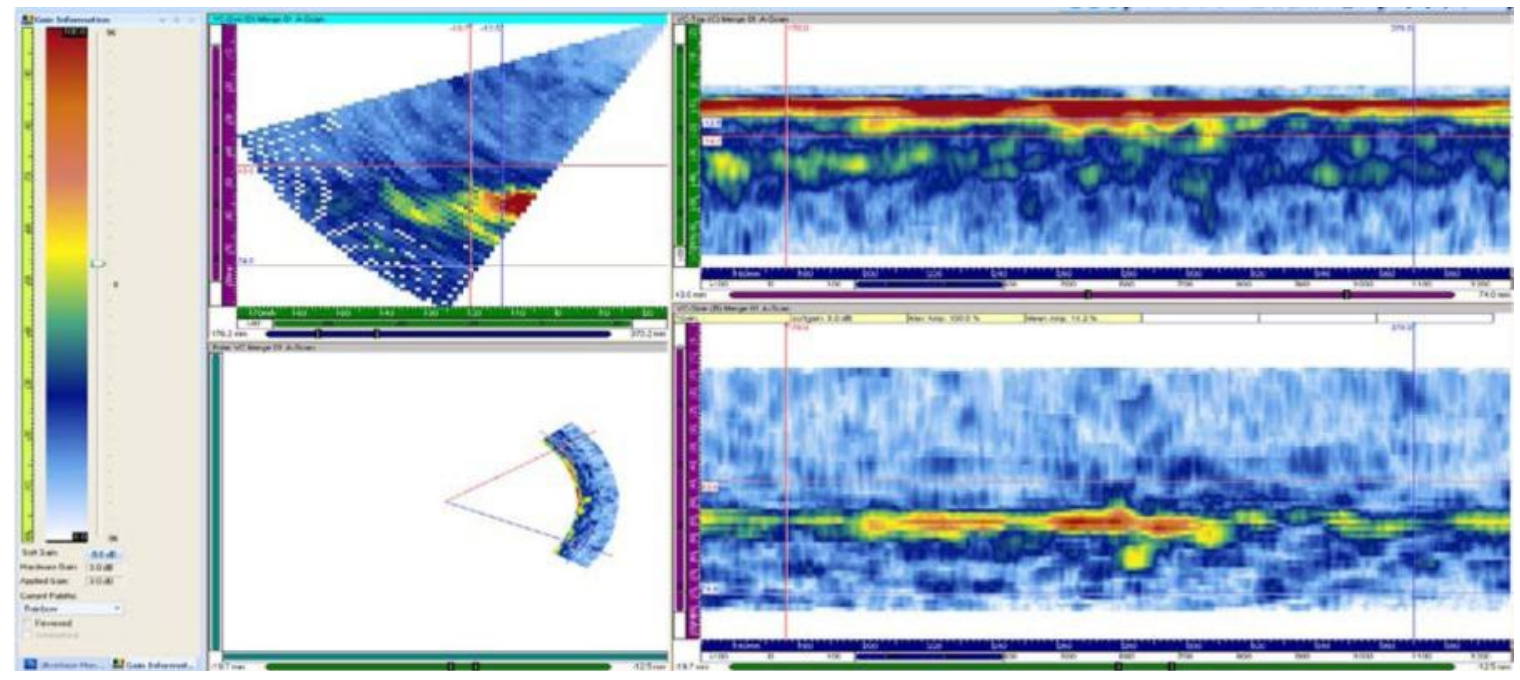

Figure B.16. Line Scan Data, Flaw 2 Pipe Side of Overlay, $1.0 \mathrm{MHz}$, No Detection 


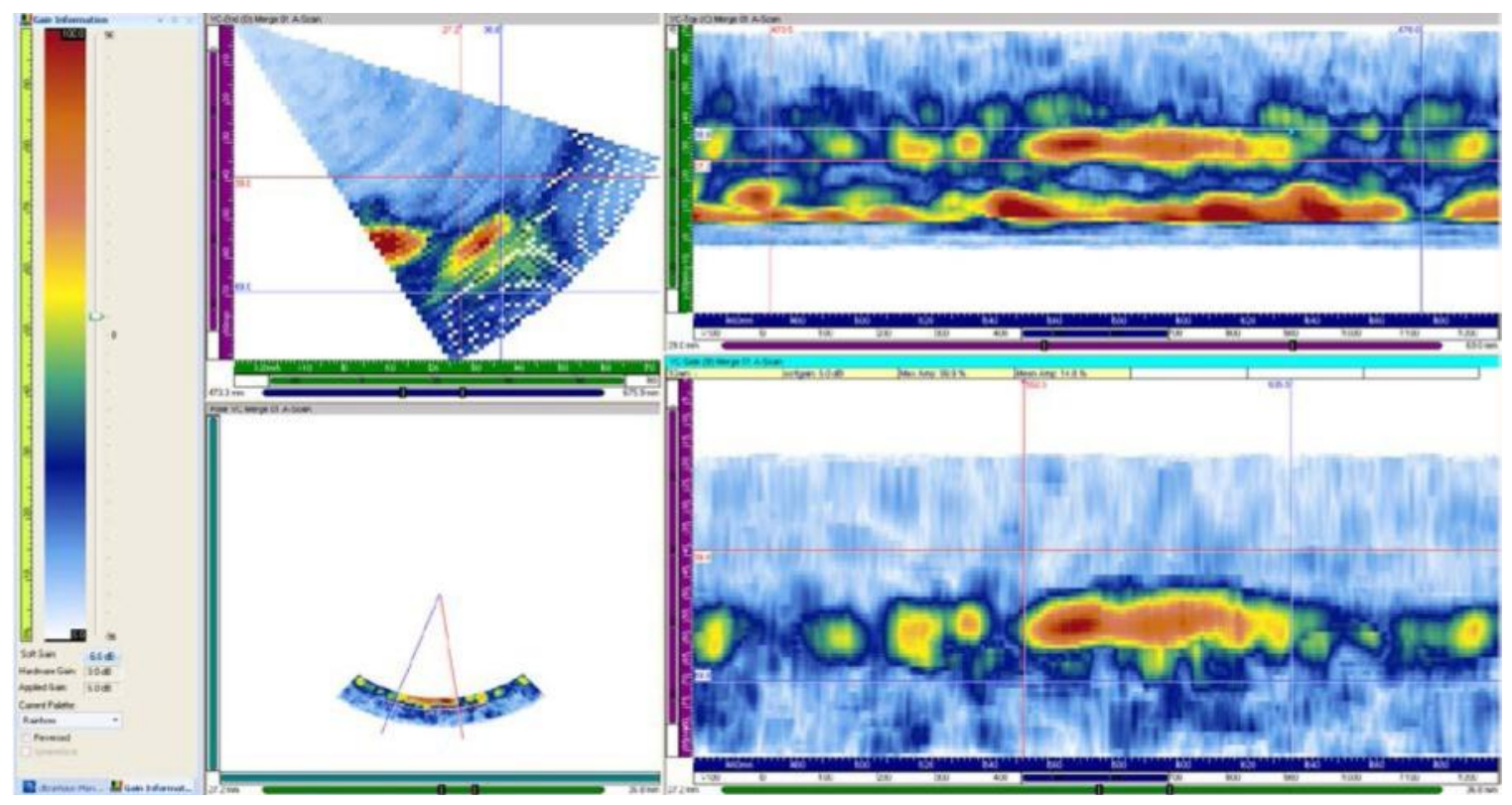

Figure B.17. Line Scan Data, Flaw 3 Nozzle Side of Overlay, 1.0 MHz, Marginal Detection

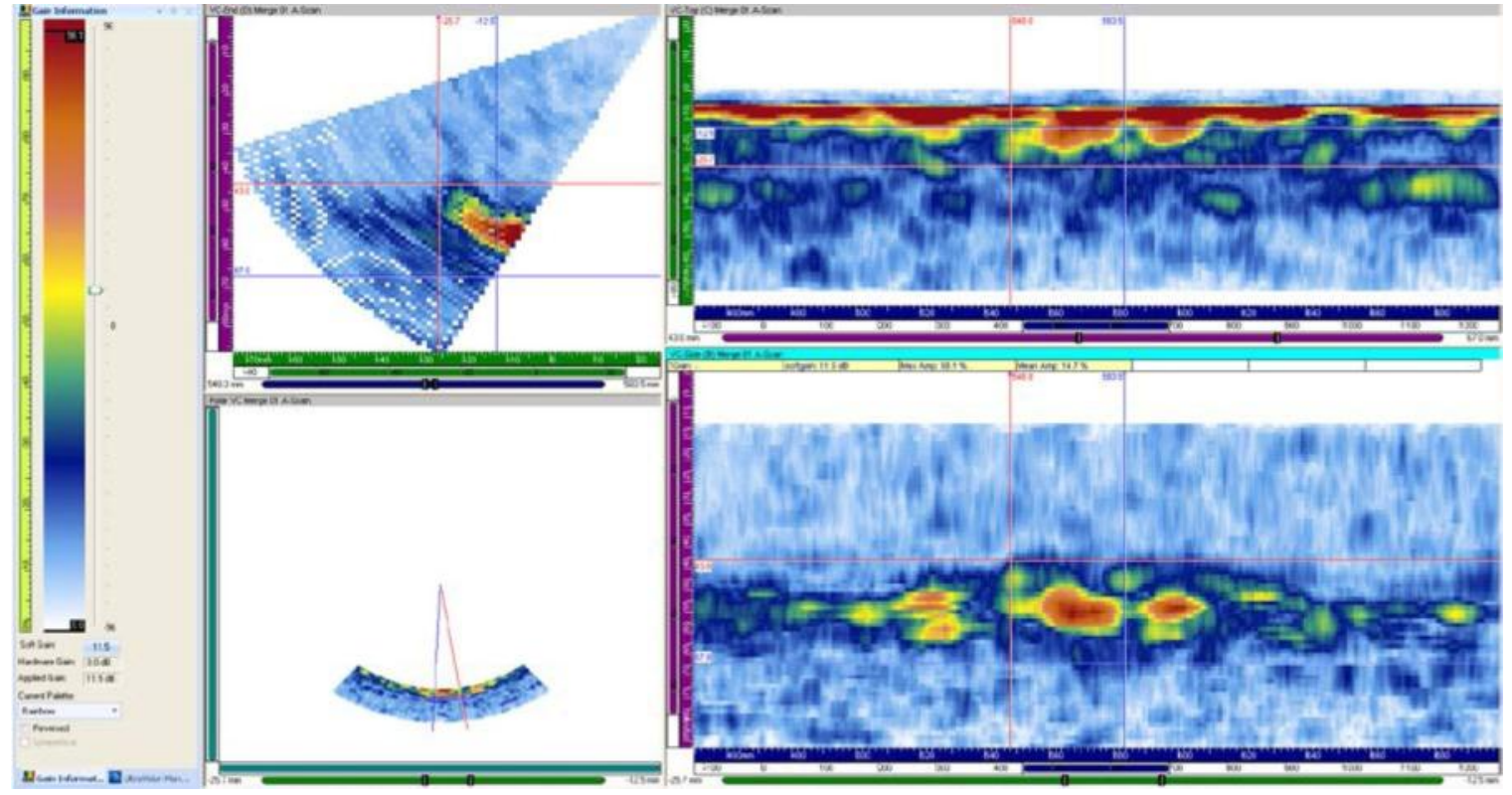

Figure B.18. Line Scan Data, Flaw 3 Pipe Side of Overlay, 1.0 MHz, Marginal Detection 


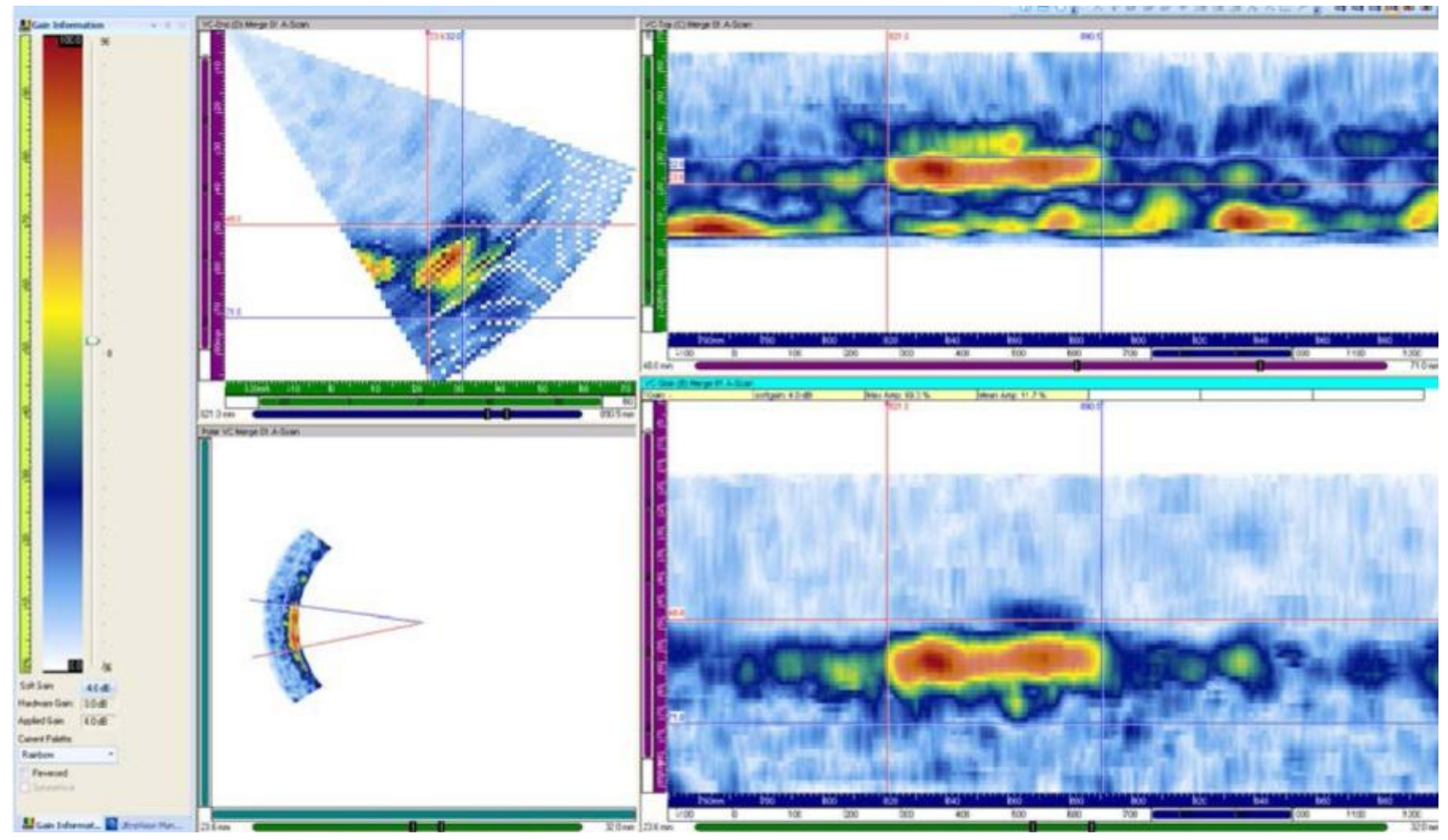

Figure B.19. Line Scan Data, Flaw 4 Nozzle Side of Overlay, 1.0 MHz, Yes Detection

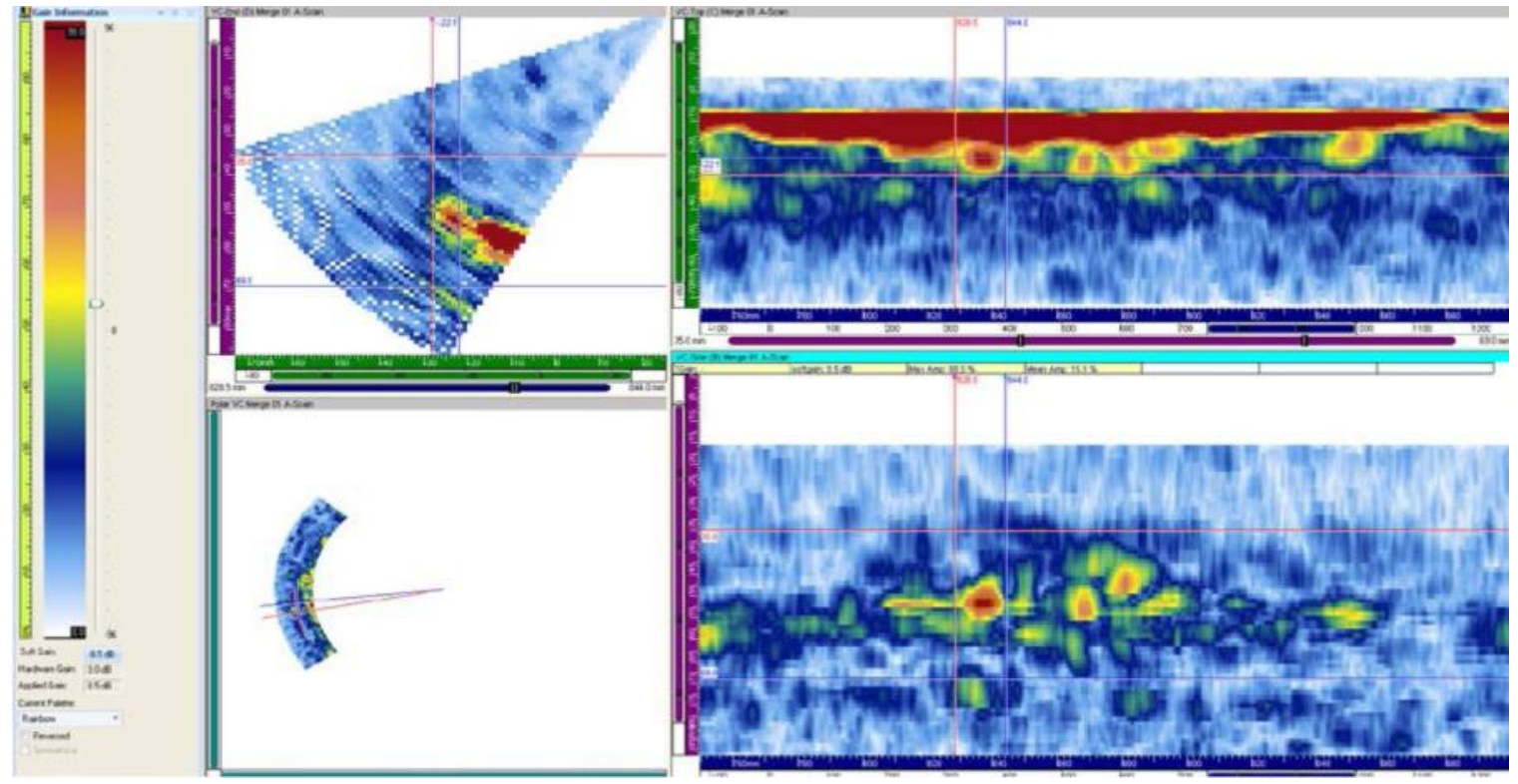

Figure B.20. Line Scan Data, Flaw 4 Pipe Side of Overlay, 1.0 MHz, No Detection 


\section{B.2.2 Raster Scan Images Nozzle and Pipe Sides of Overlay Flaws 1-4}

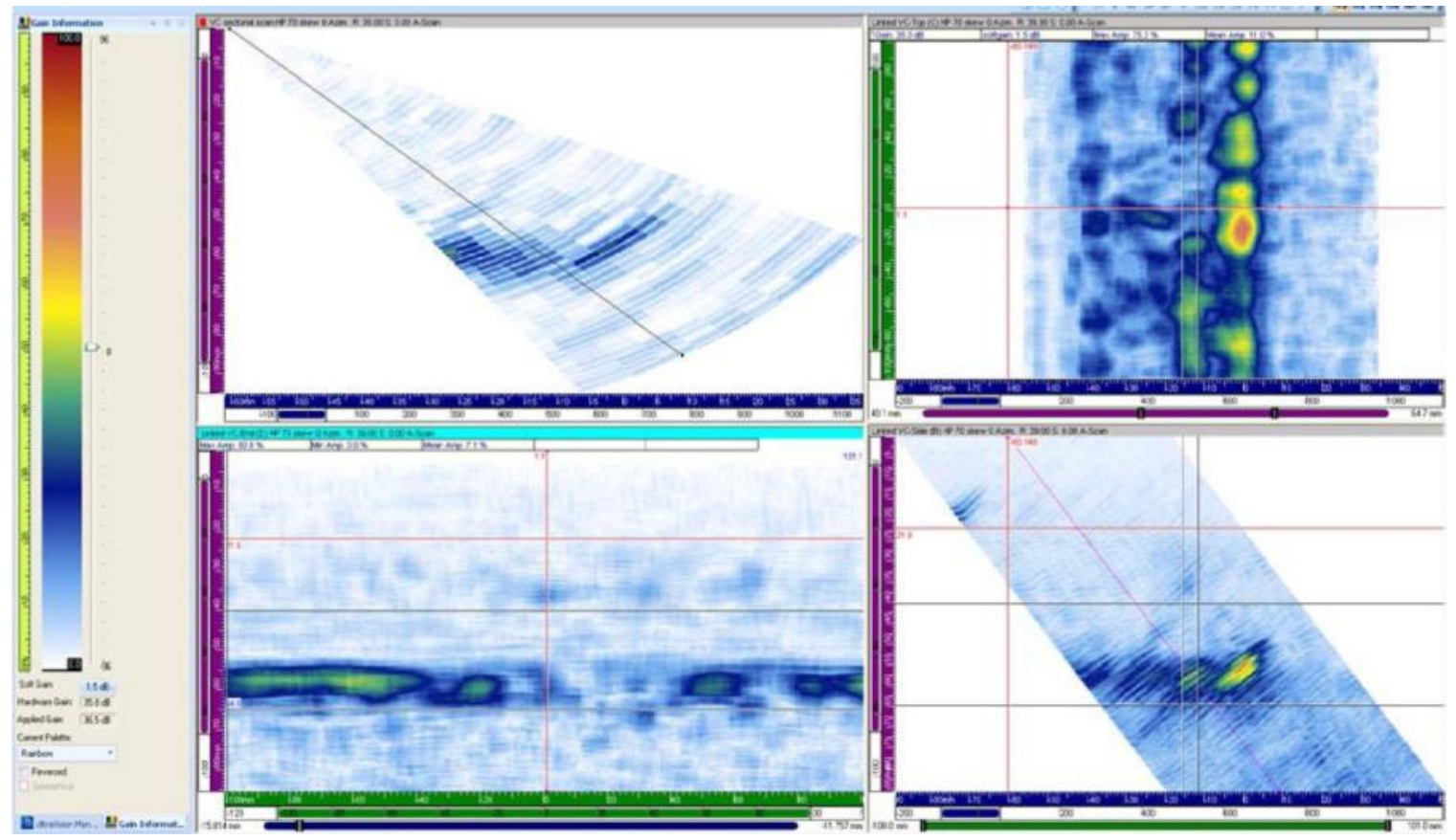

Figure B.21. Raster Data, Flaw 1 Nozzle Side of Overlay, 1.0 MHz, No Detection

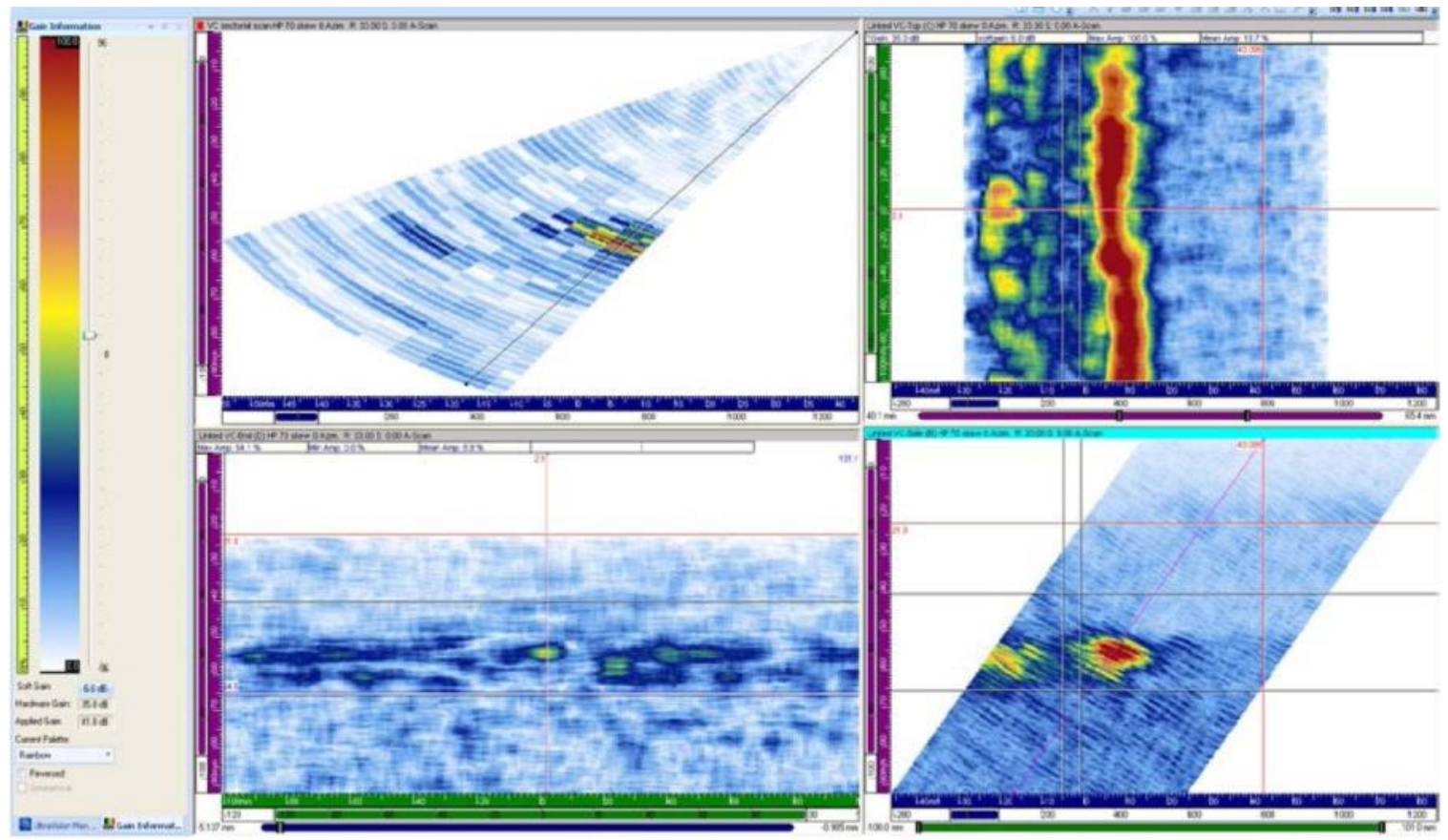

Figure B.22. Raster Data, Flaw 1 Pipe Side of Overlay, $1.0 \mathrm{MHz}$, No Detection 


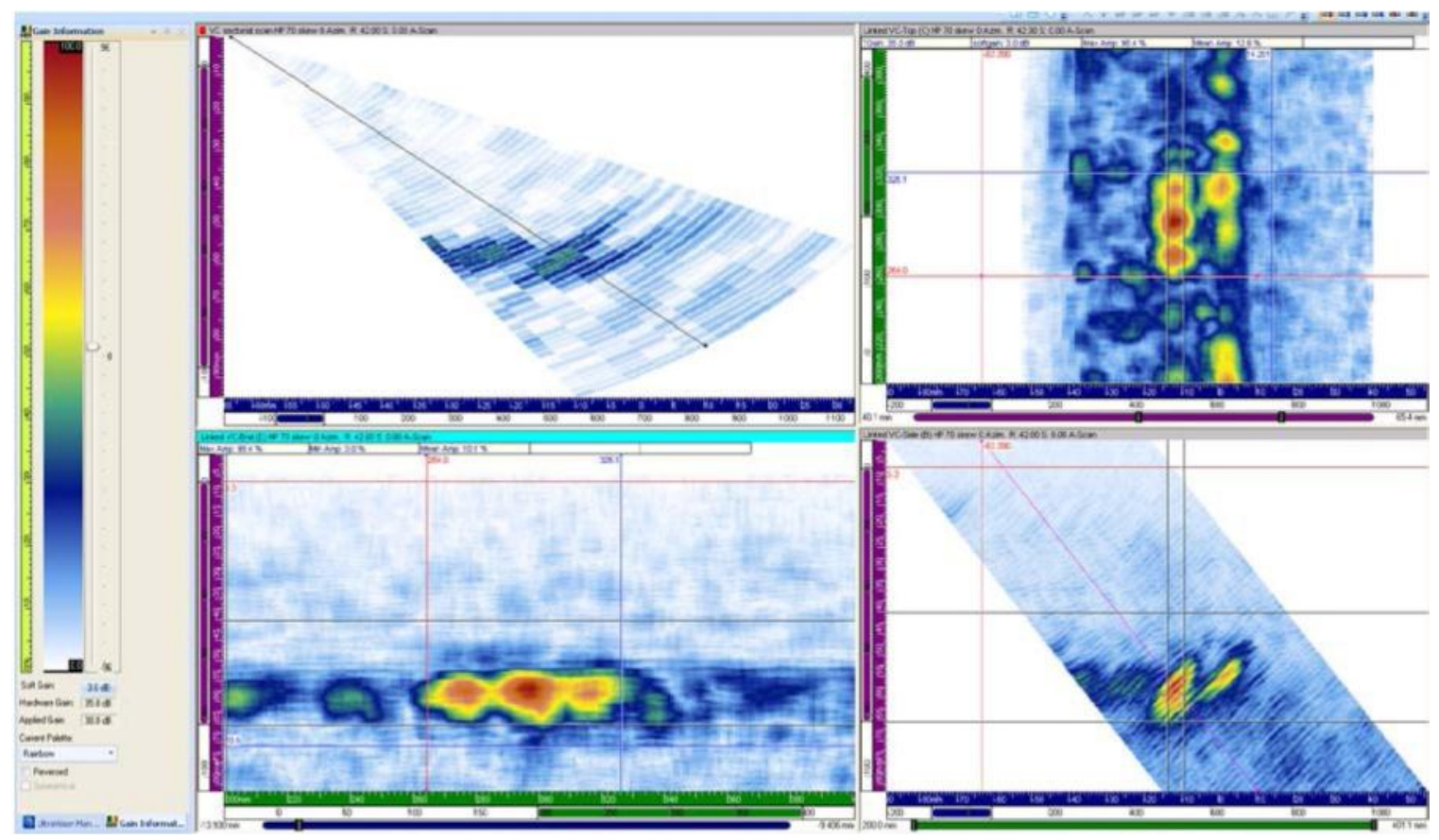

Figure B.23. Raster Data, Flaw 2 Nozzle Side of Overlay, 1.0 MHz, Yes Detection

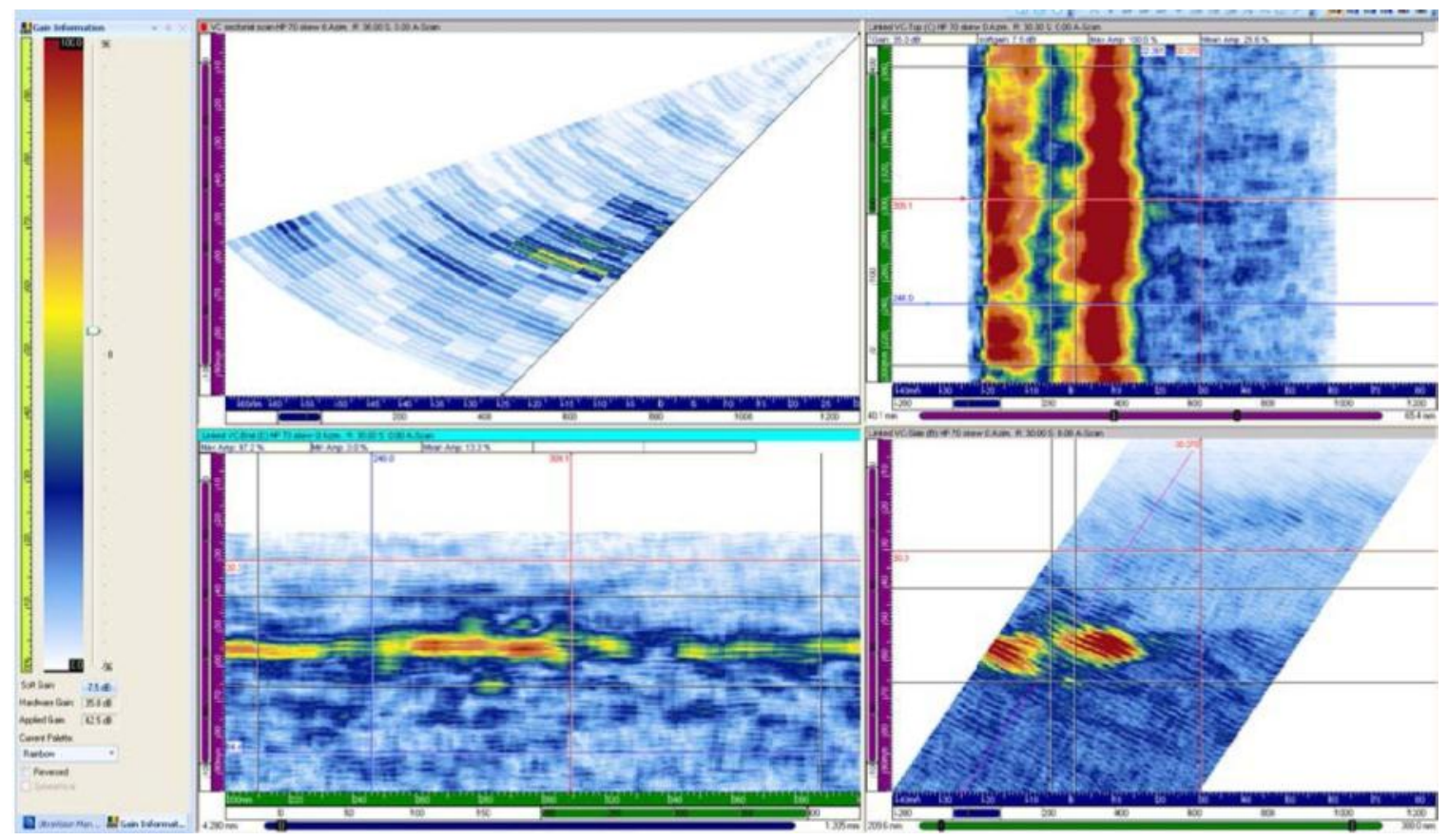

Figure B.24. Raster Data, Flaw 2 Pipe Side of Overlay, 1.0 MHz, Marginal Detection 


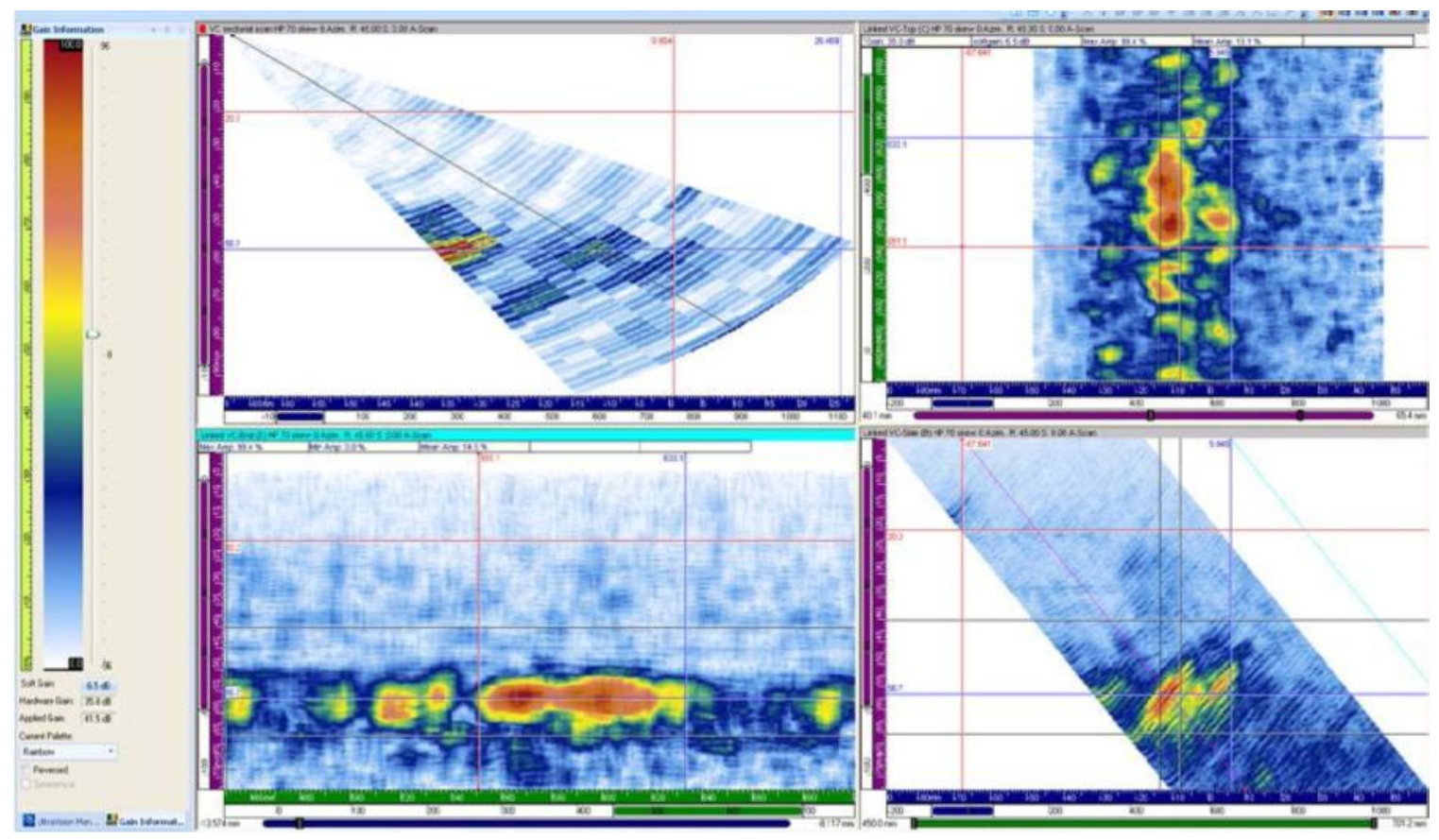

Figure B.25. Raster Data, Flaw 3 Nozzle Side of Overlay, 1.0 MHz, Marginal Detection

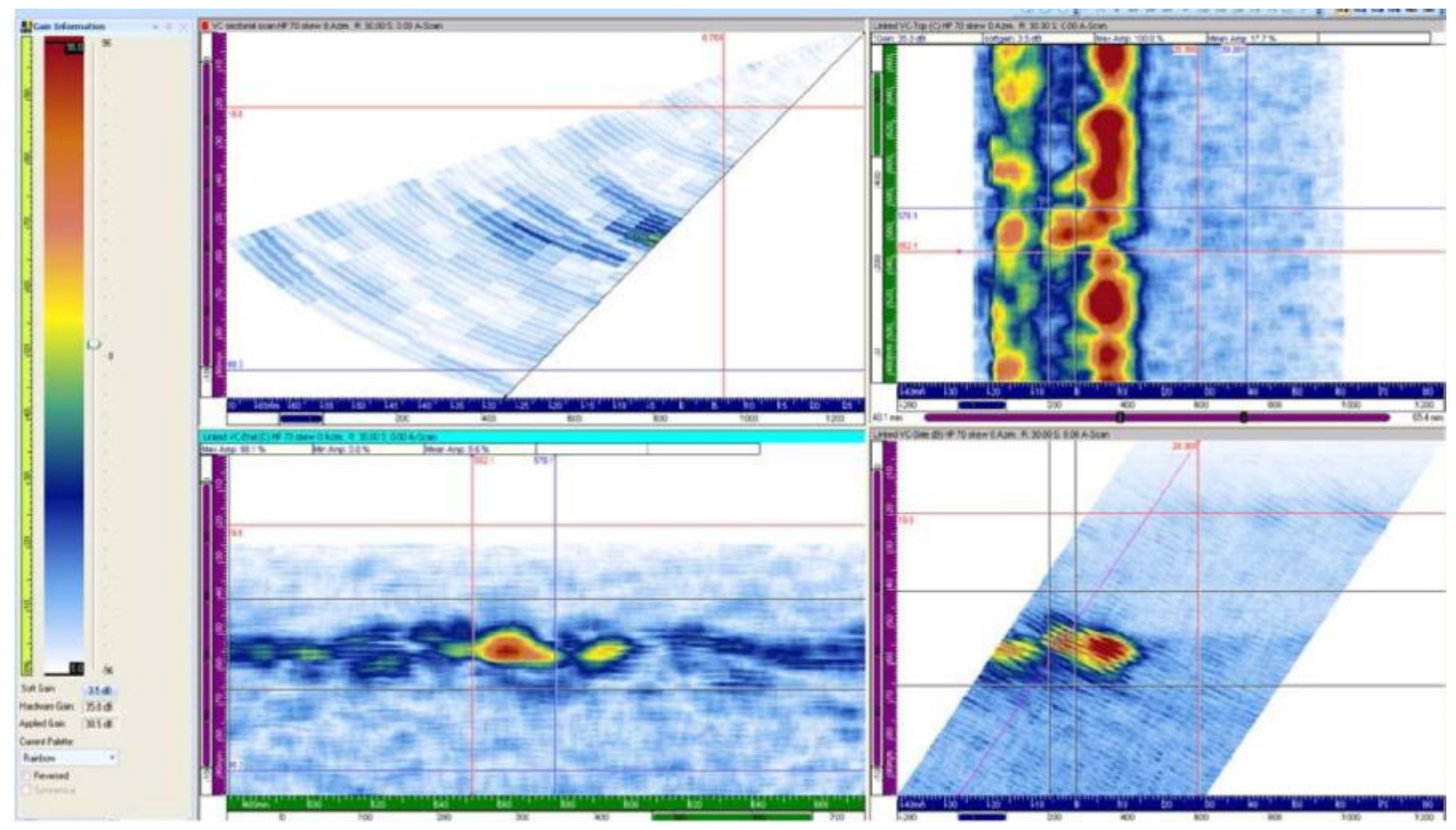

Figure B.26. Raster Data, Flaw 3 Pipe Side of Overlay, 1.0 MHz, Yes Detection 


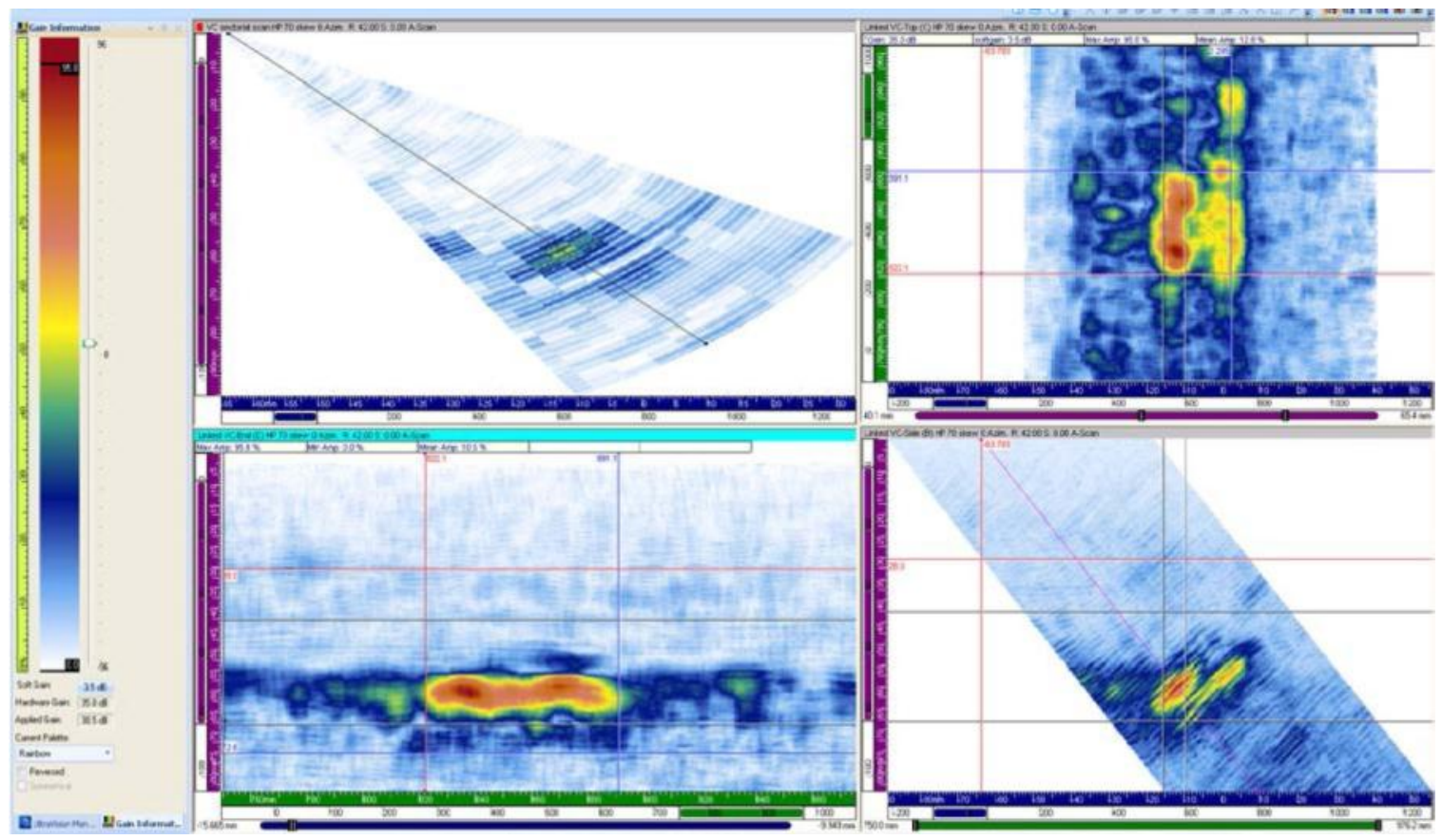

Figure B.27. Raster Data, Flaw 4 Nozzle Side of Overlay, 1.0 MHz, Yes Detection

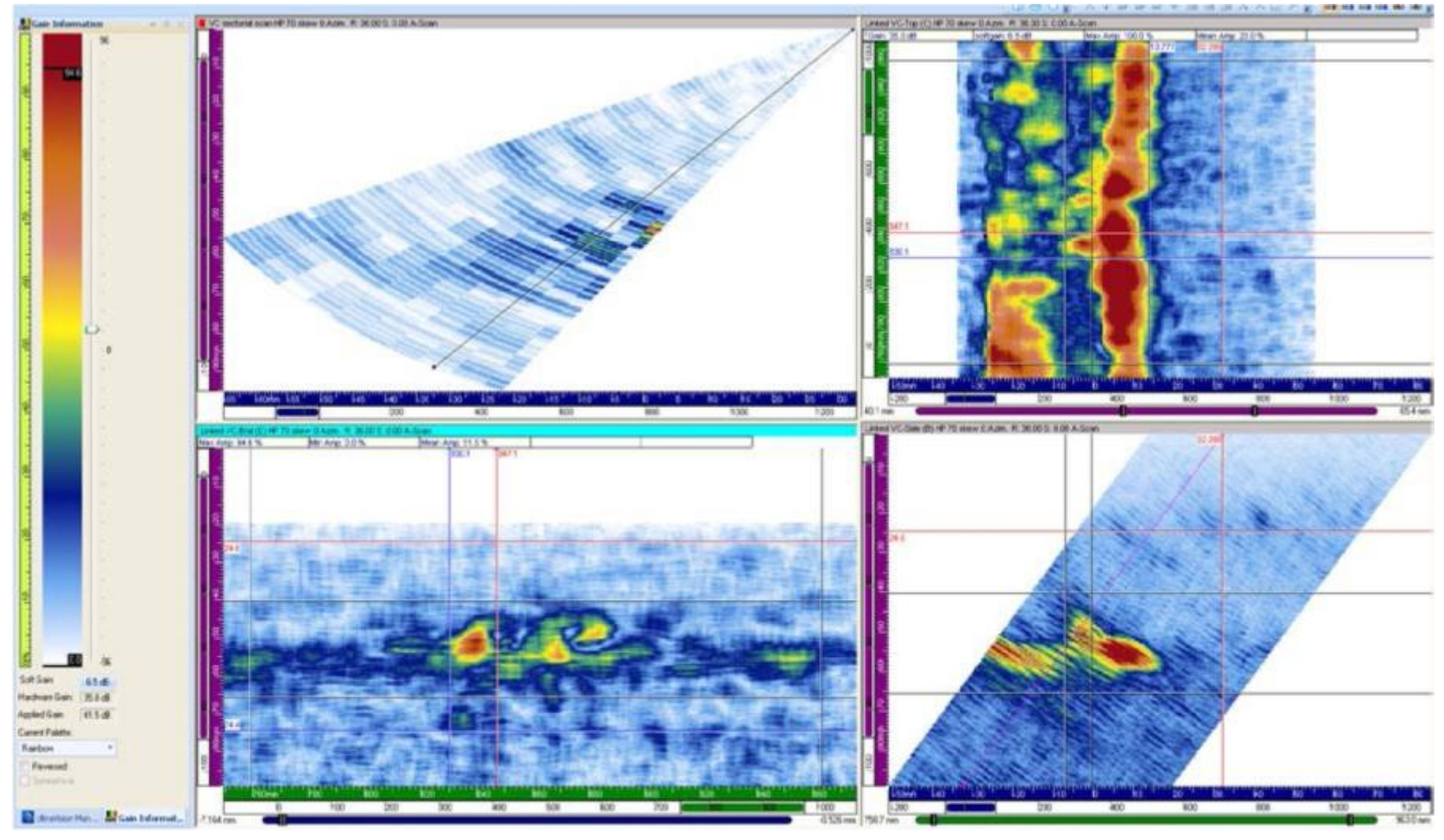

Figure B.28. Raster Data, Flaw 4 Pipe Side of Overlay, 1.0 MHz, Marginal Detection 


\section{B.3 $1.5 \mathrm{MHz}$ Data}

\section{B.3.1 Line Scan Images Nozzle and Pipe Sides of Overlay Flaws 1-4}

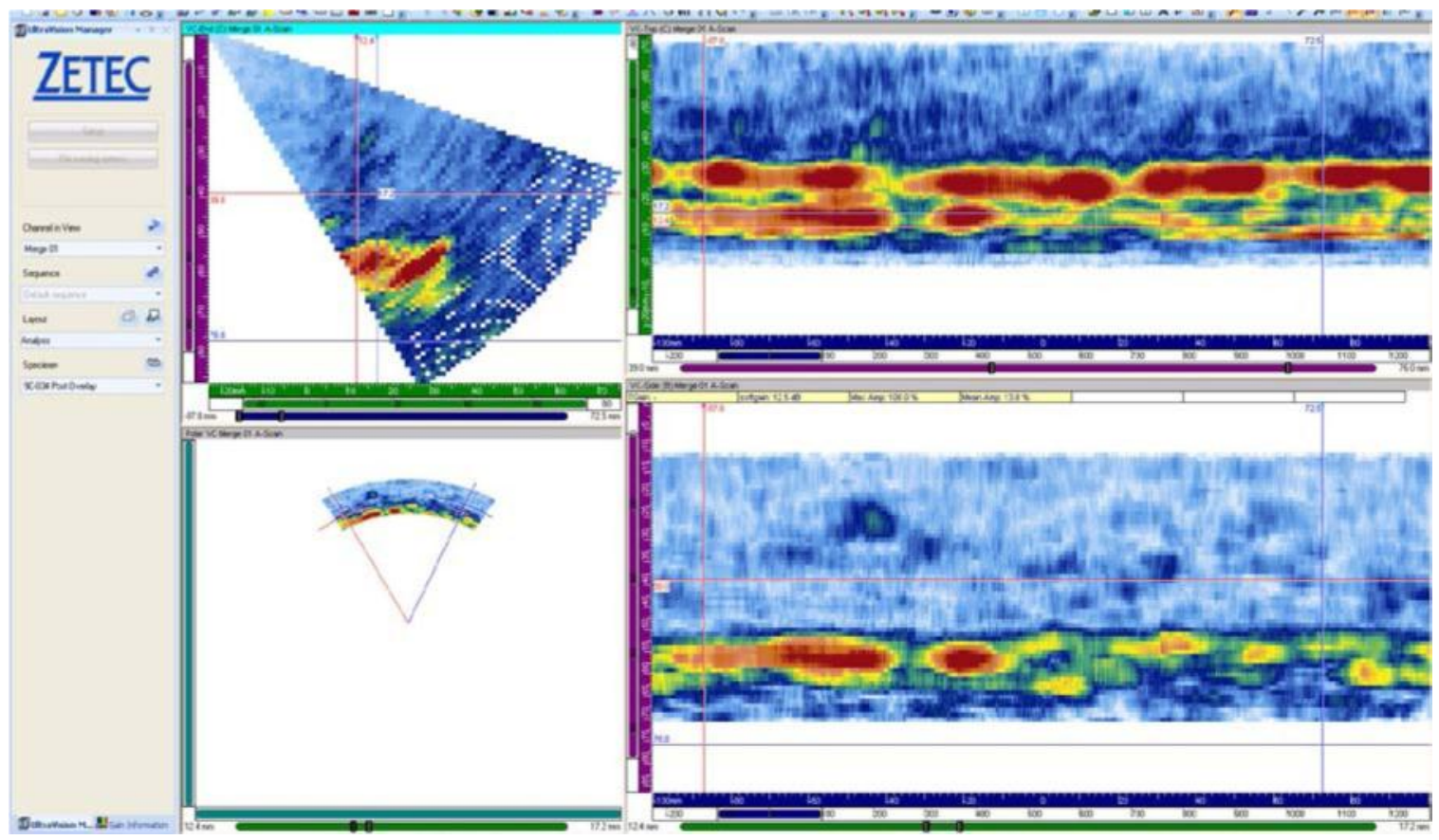

Figure B.29. Line Scan Data, Flaw 1 Nozzle Side of Overlay, 1.5 MHz, No Detection

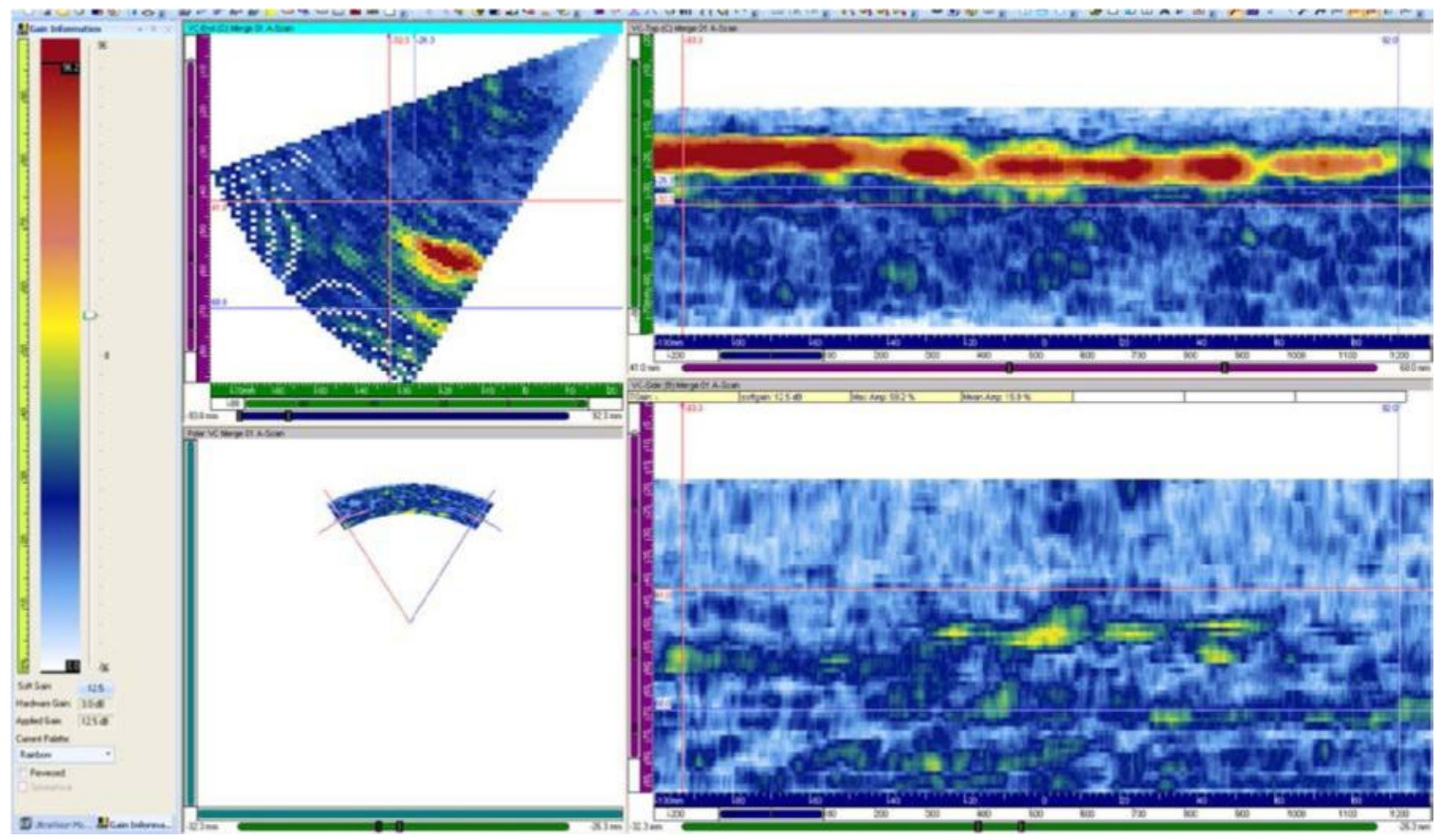

Figure B.30. Line Scan Data, Flaw 1 Pipe Side of Overlay, 1.5 MHz, No Detection 


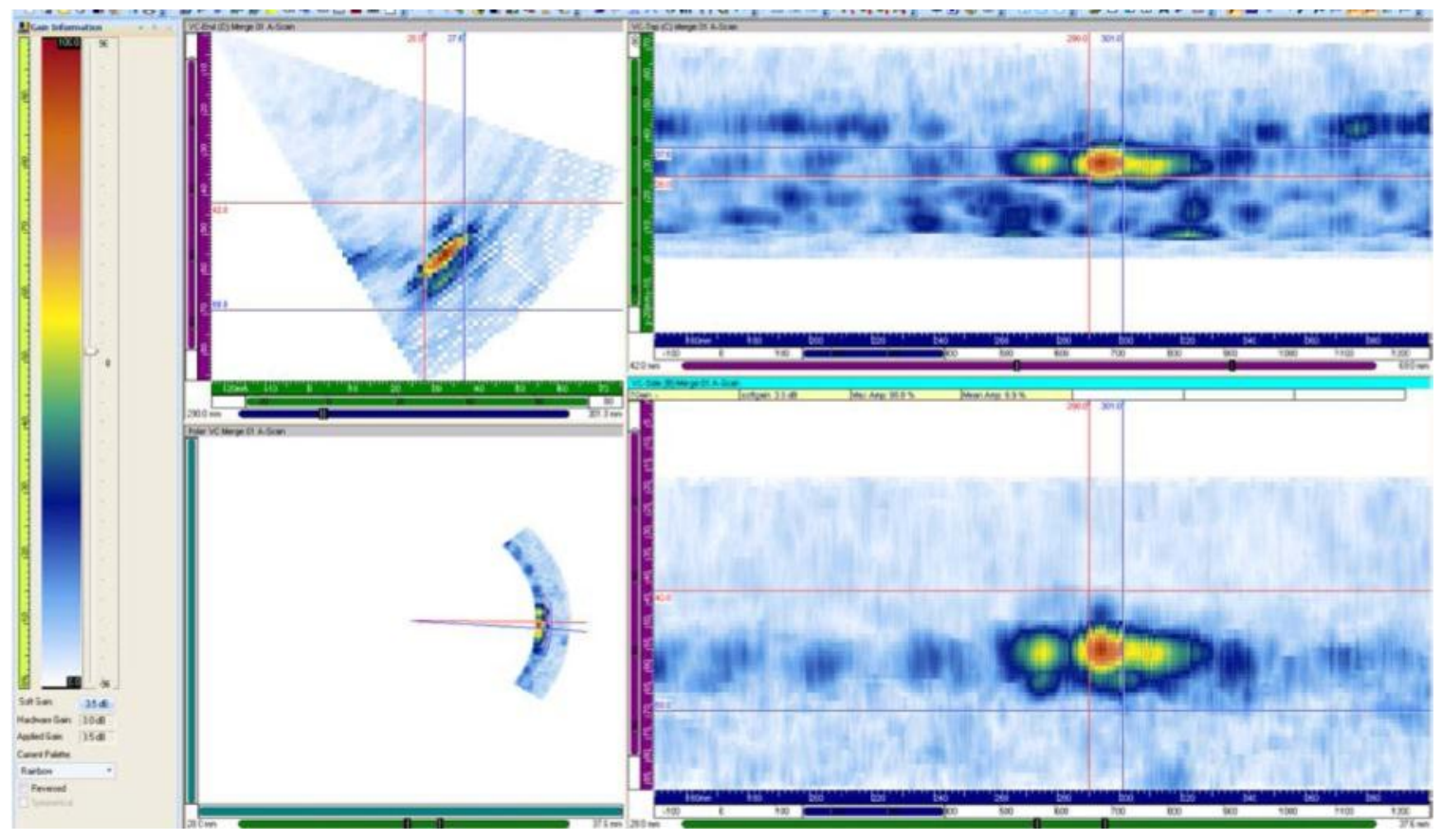

Figure B.31. Line Scan Data, Flaw 2 Nozzle Side of Overlay, 1.5 MHz, Yes Detection

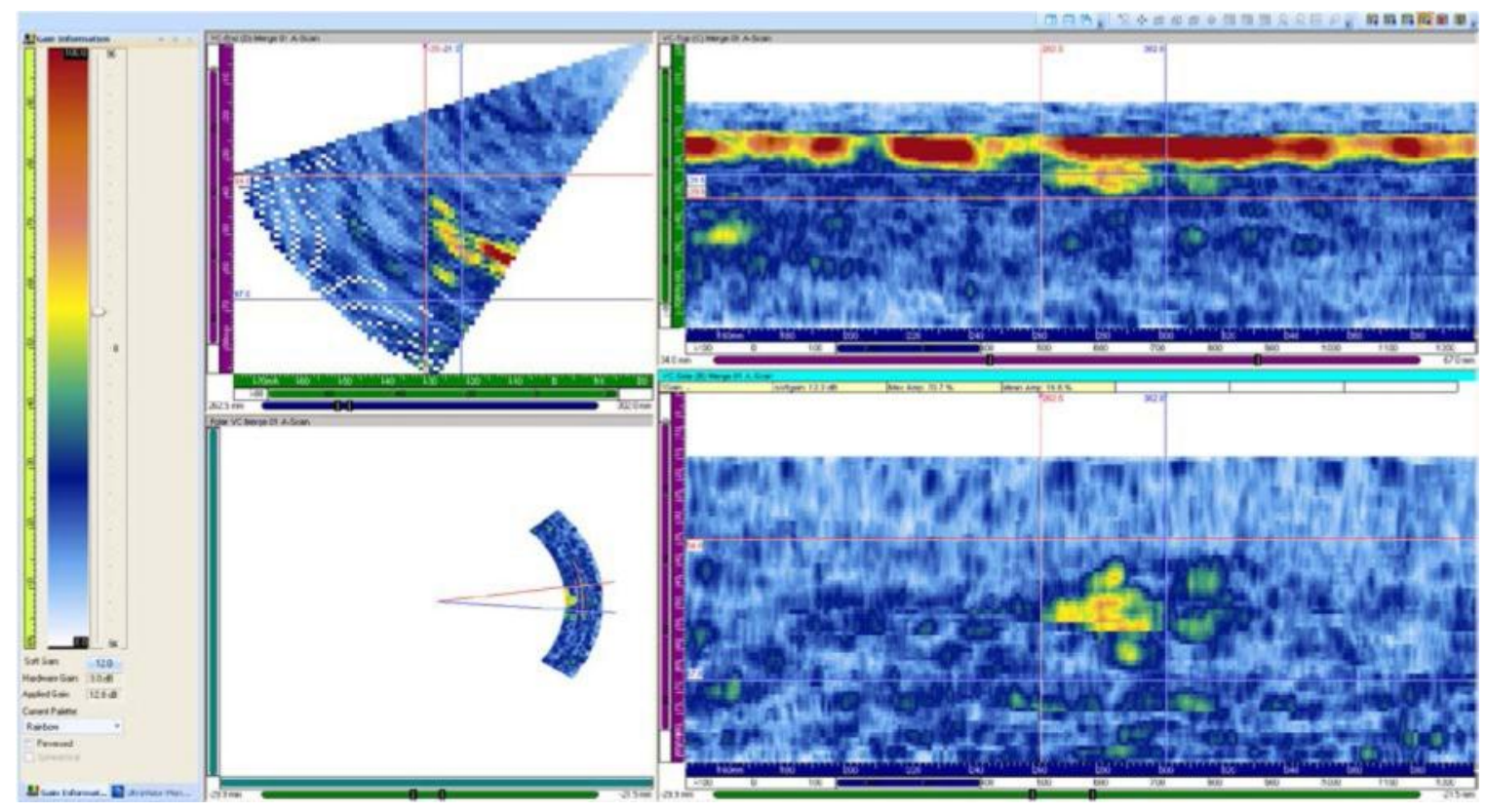

Figure B.32. Line Scan Data, Flaw 2 Pipe Side of Overlay, $1.5 \mathrm{MHz}$, Yes Detection 


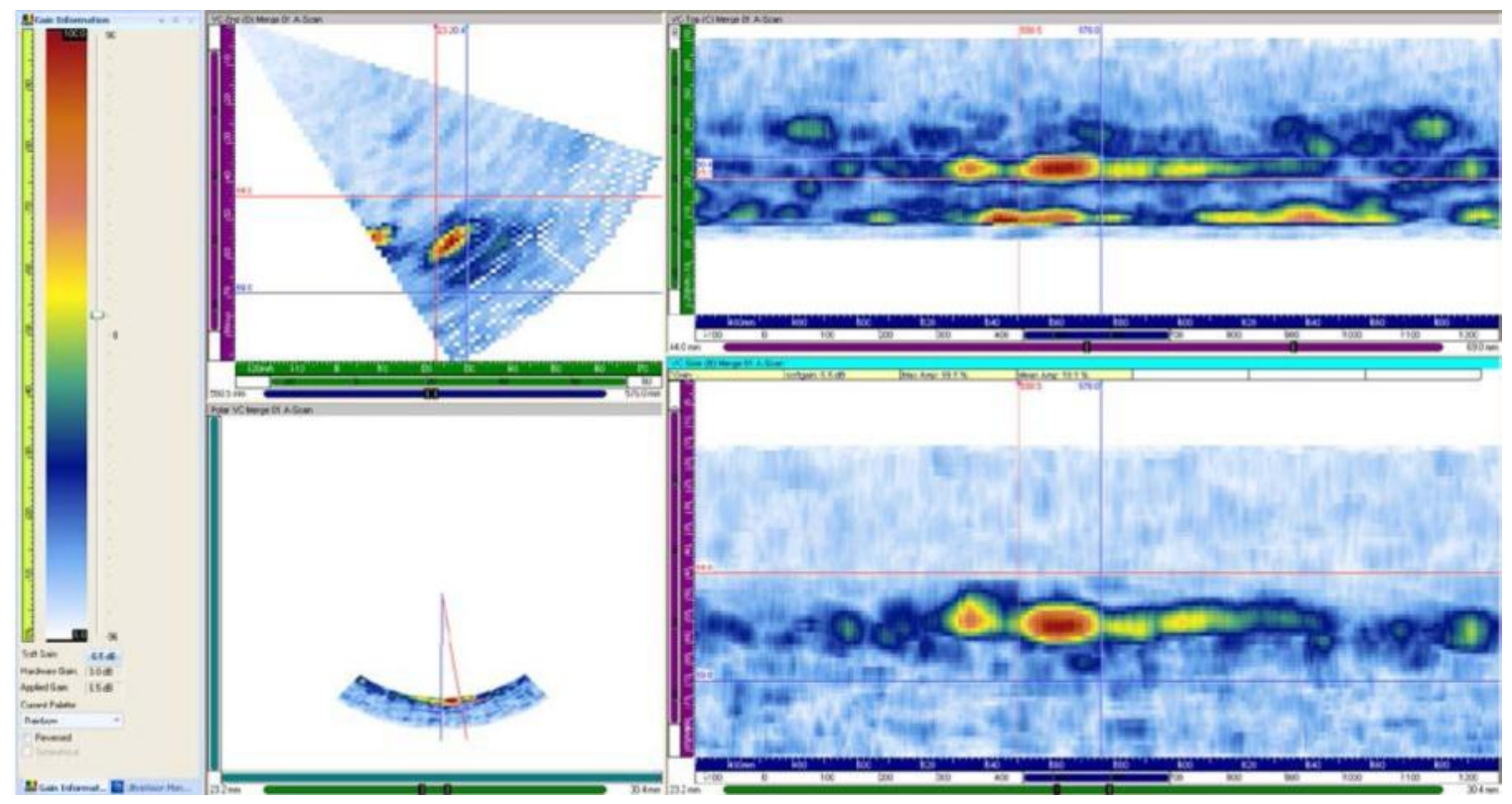

Figure B.33. Line Scan Data, Flaw 3 Nozzle Side of Overlay, 1.5 MHz, Yes Detection

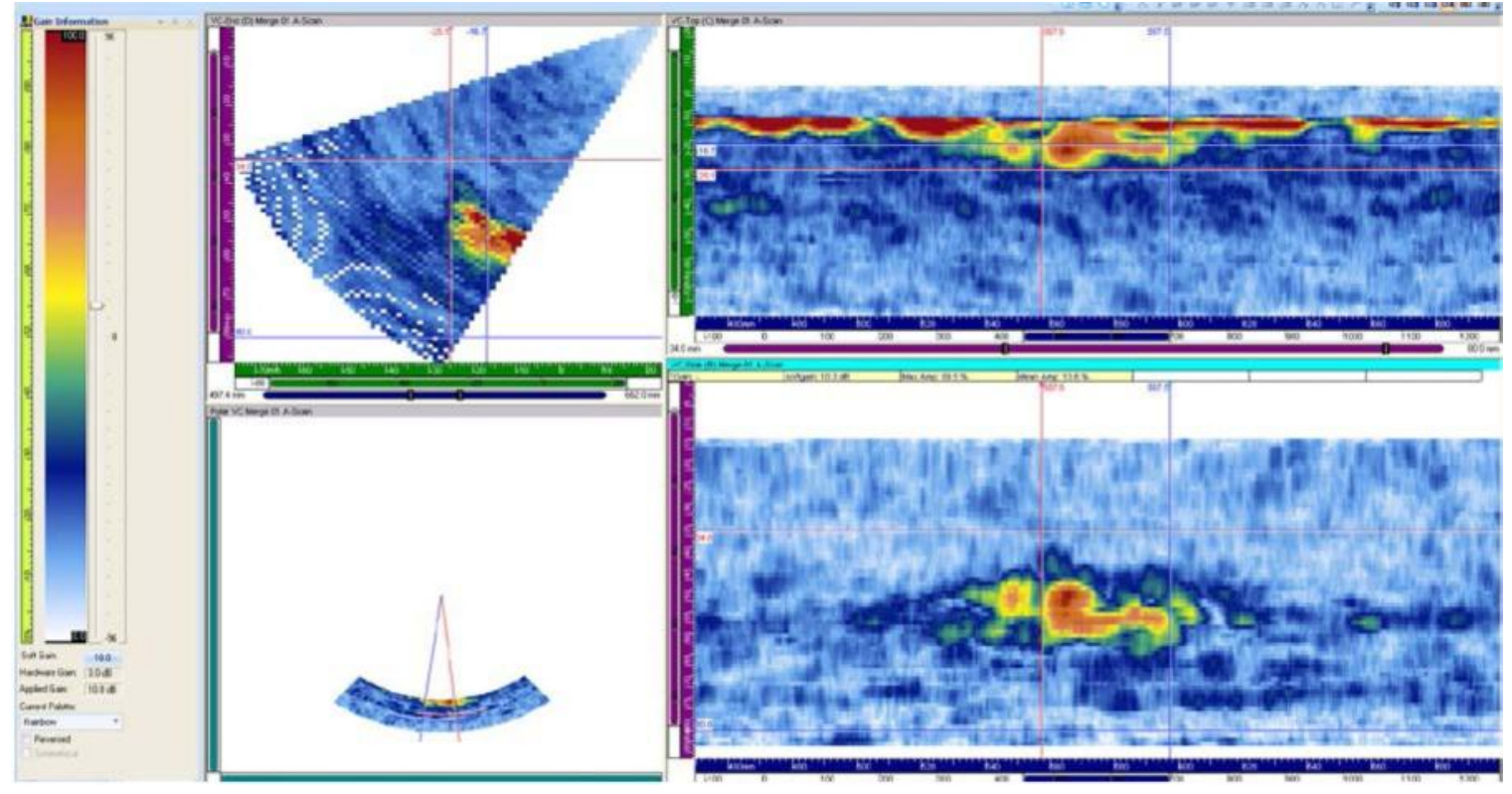

Figure B.34. Line Scan Data, Flaw 3 Pipe Side of Overlay, $1.5 \mathrm{MHz}$, Yes Detection 


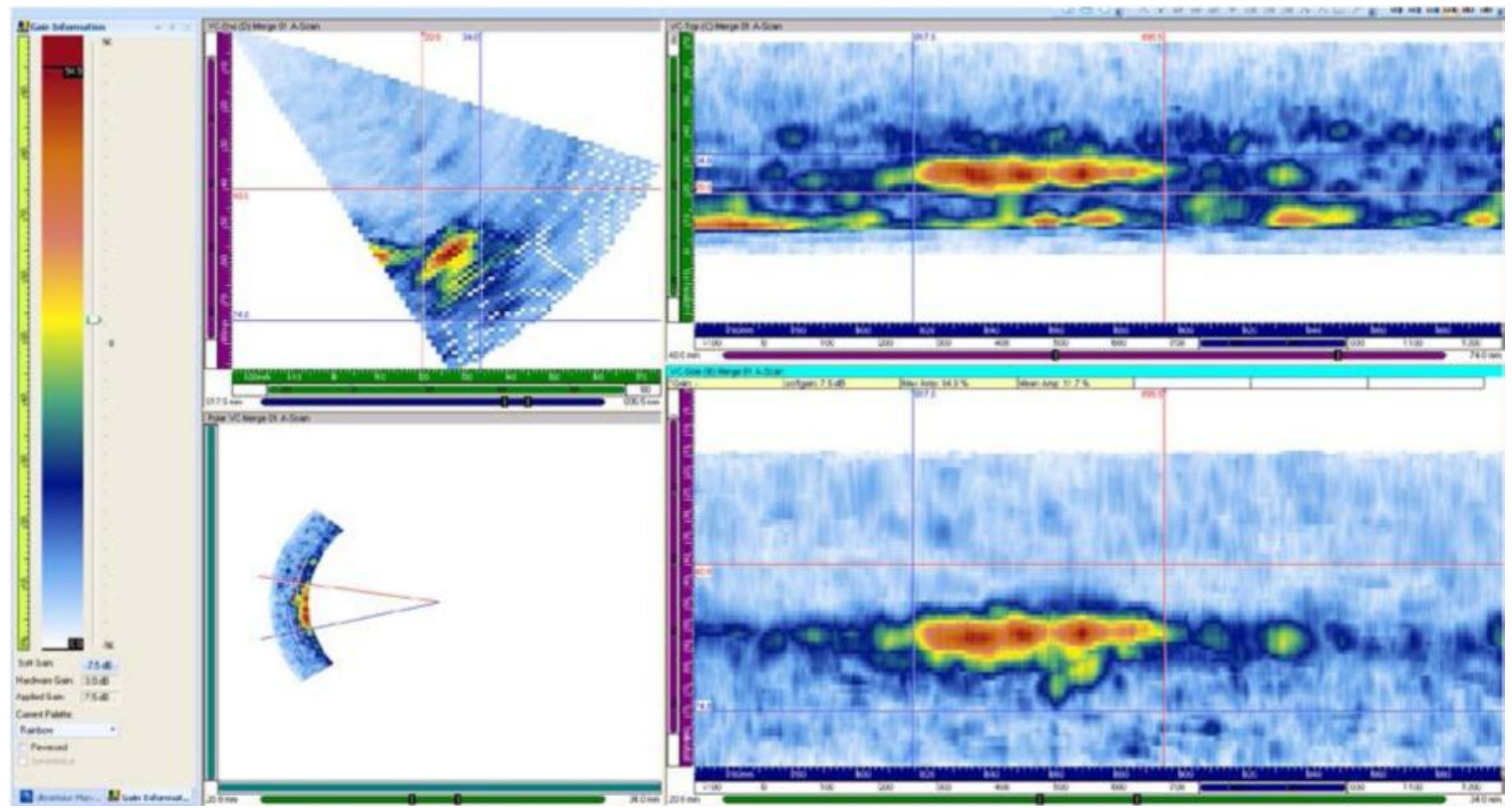

Figure B.35. Line Scan Data, Flaw 4 Nozzle Side of Overlay, 1.5 MHz, Yes Detection

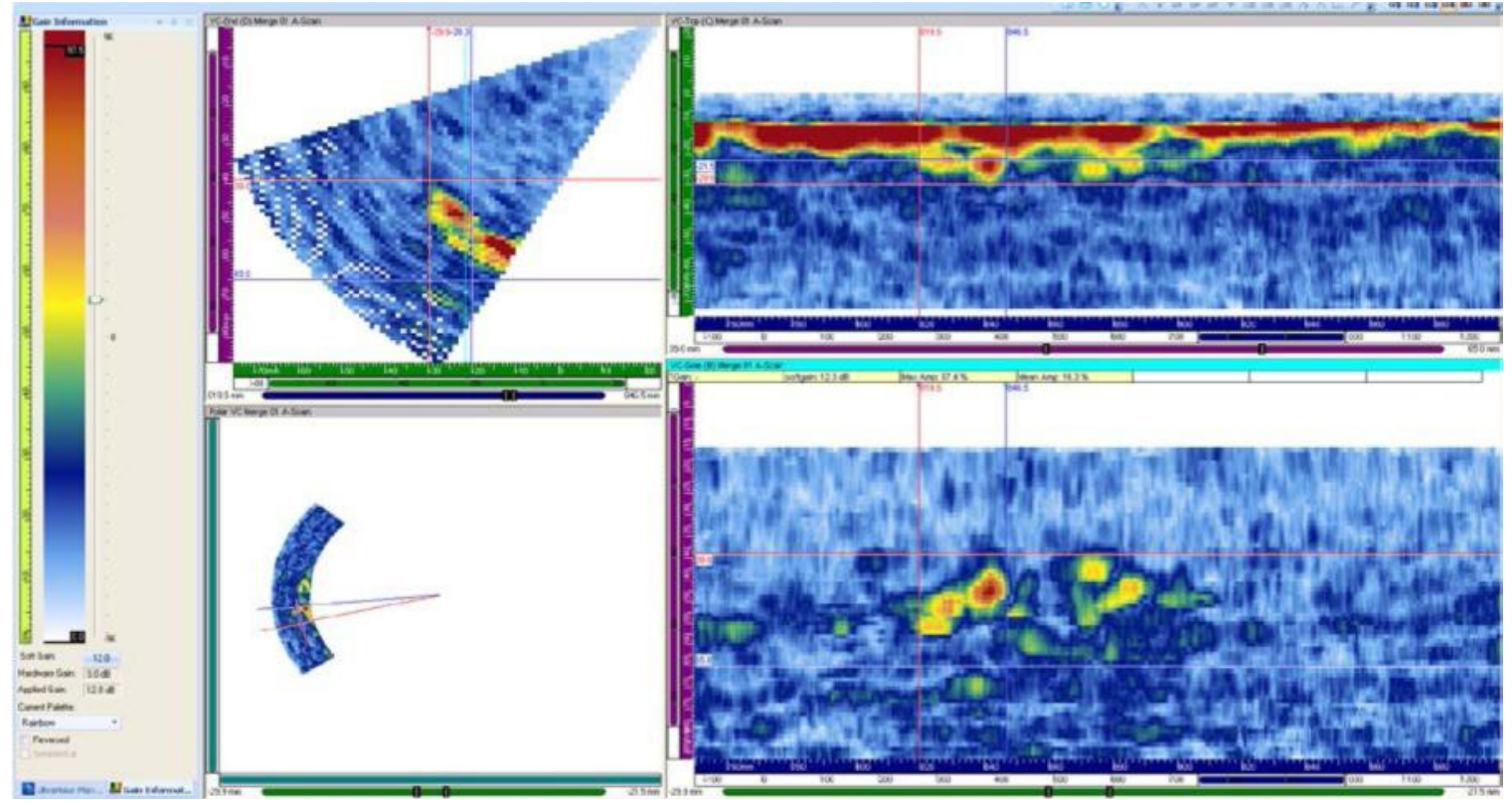

Figure B.36. Line Scan Data, Flaw 4 Pipe Side of Overlay, 1.5 MHz, Yes Detection 


\section{B.3.2 Raster Scan Images Nozzle and Pipe Sides of Overlay Flaws 1-4}

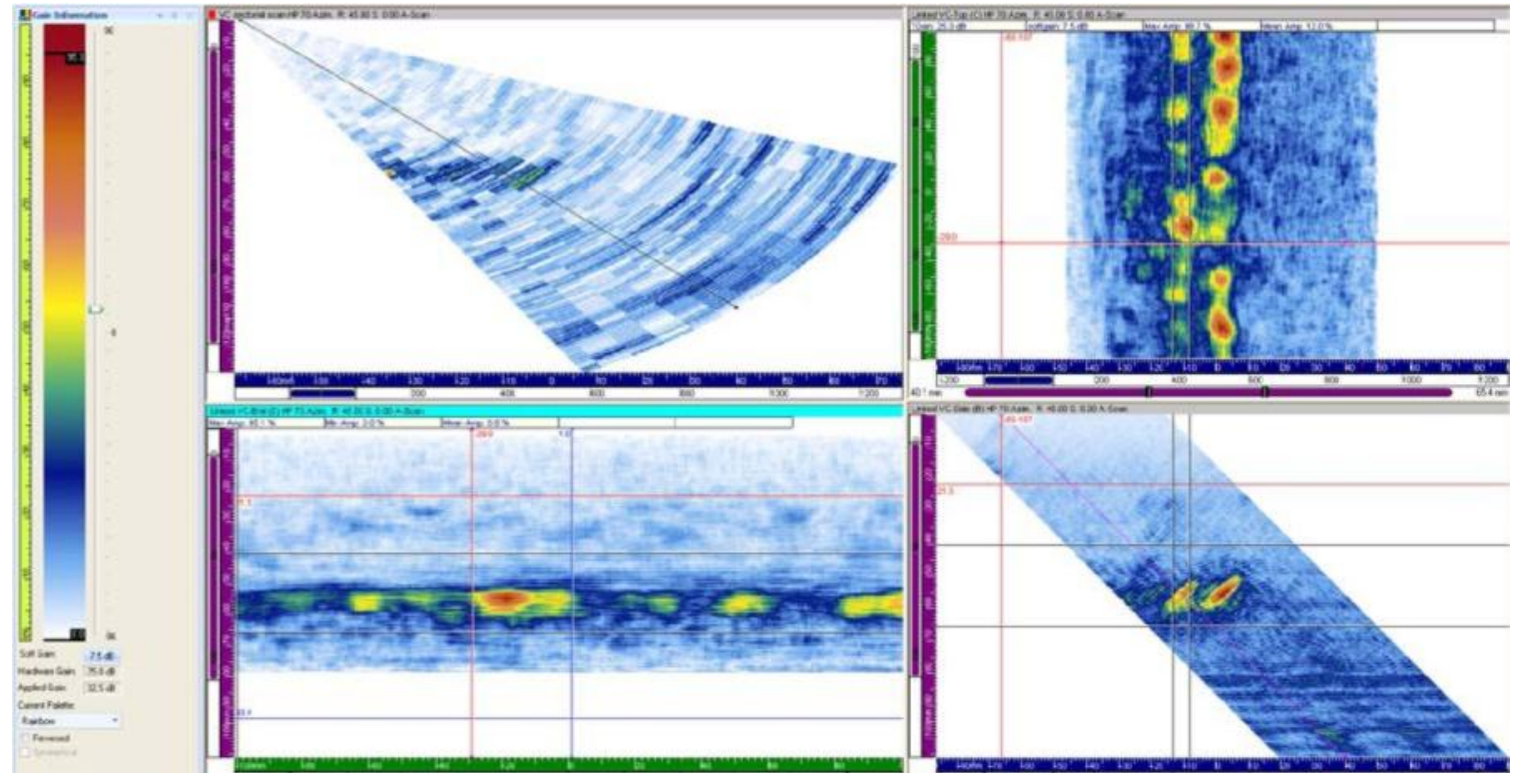

Figure B.37. Raster Data, Flaw 1 Nozzle Side of Overlay, 1.5 MHz, Marginal Detection

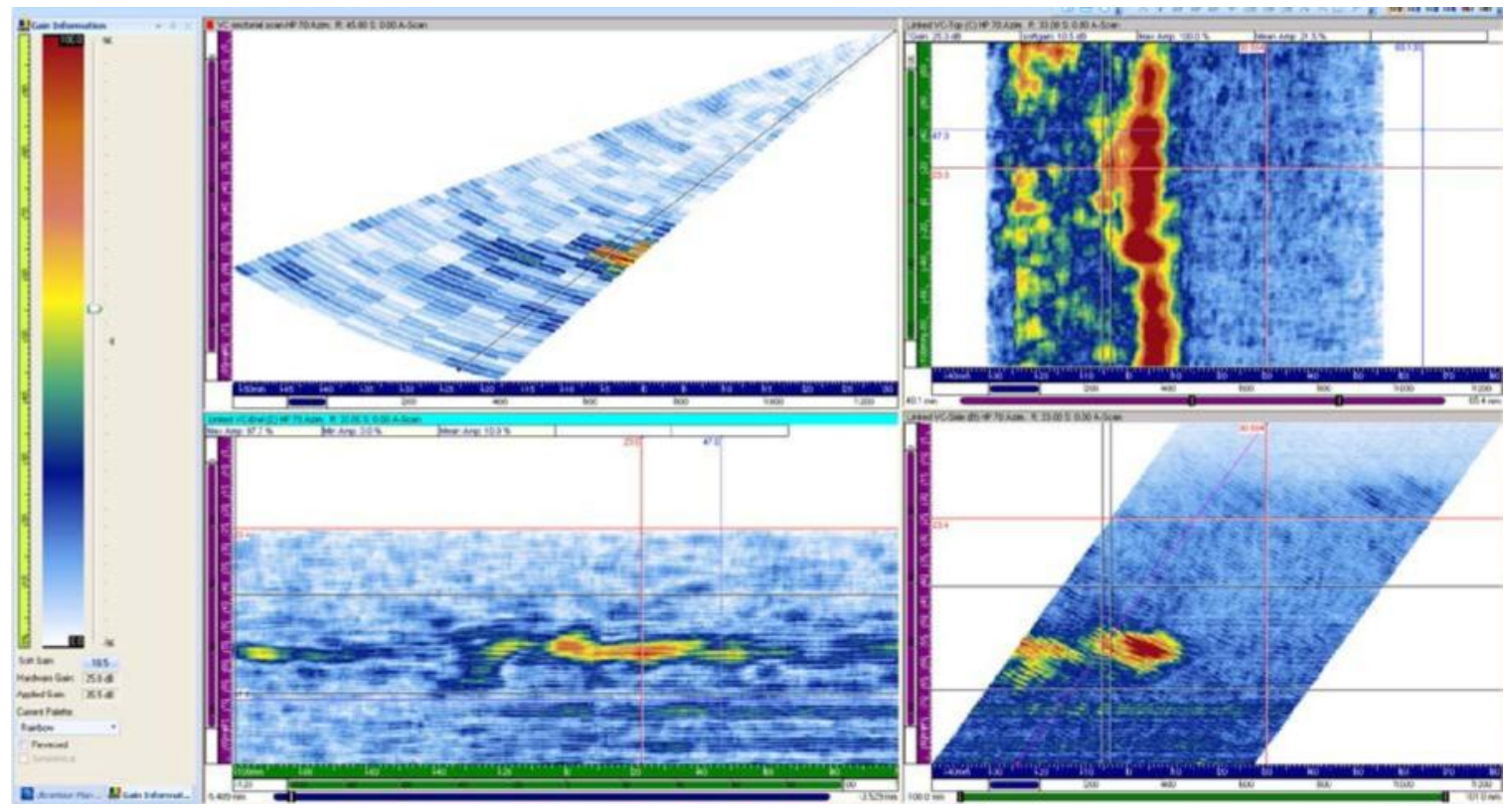

Figure B.38. Raster Data, Flaw 1 Pipe Side of Overlay, 1.5 MHz, Yes Detection 


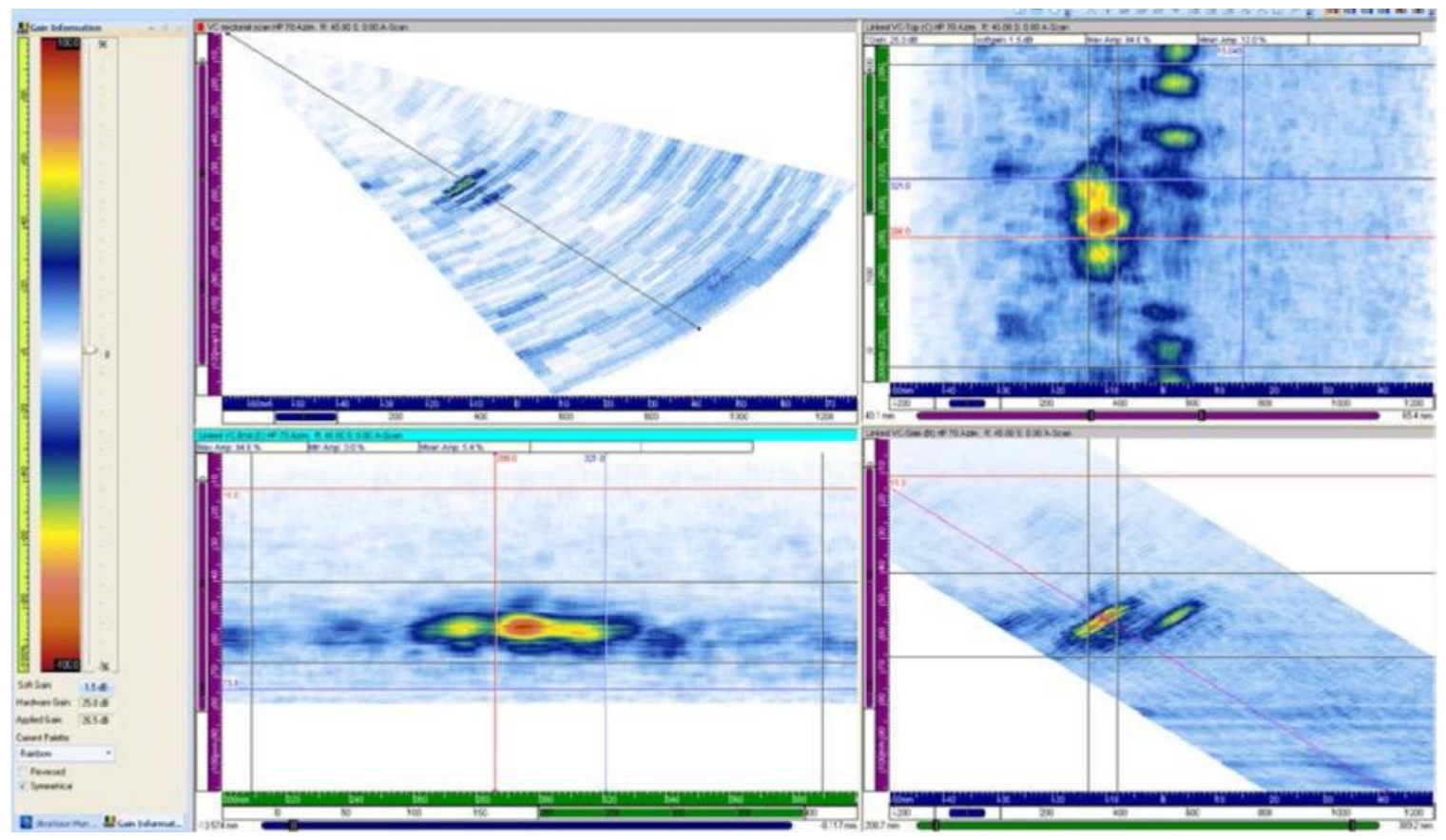

Figure B.39. Raster Data, Flaw 2 Nozzle Side of Overlay, 1.5 MHz, Yes Detection

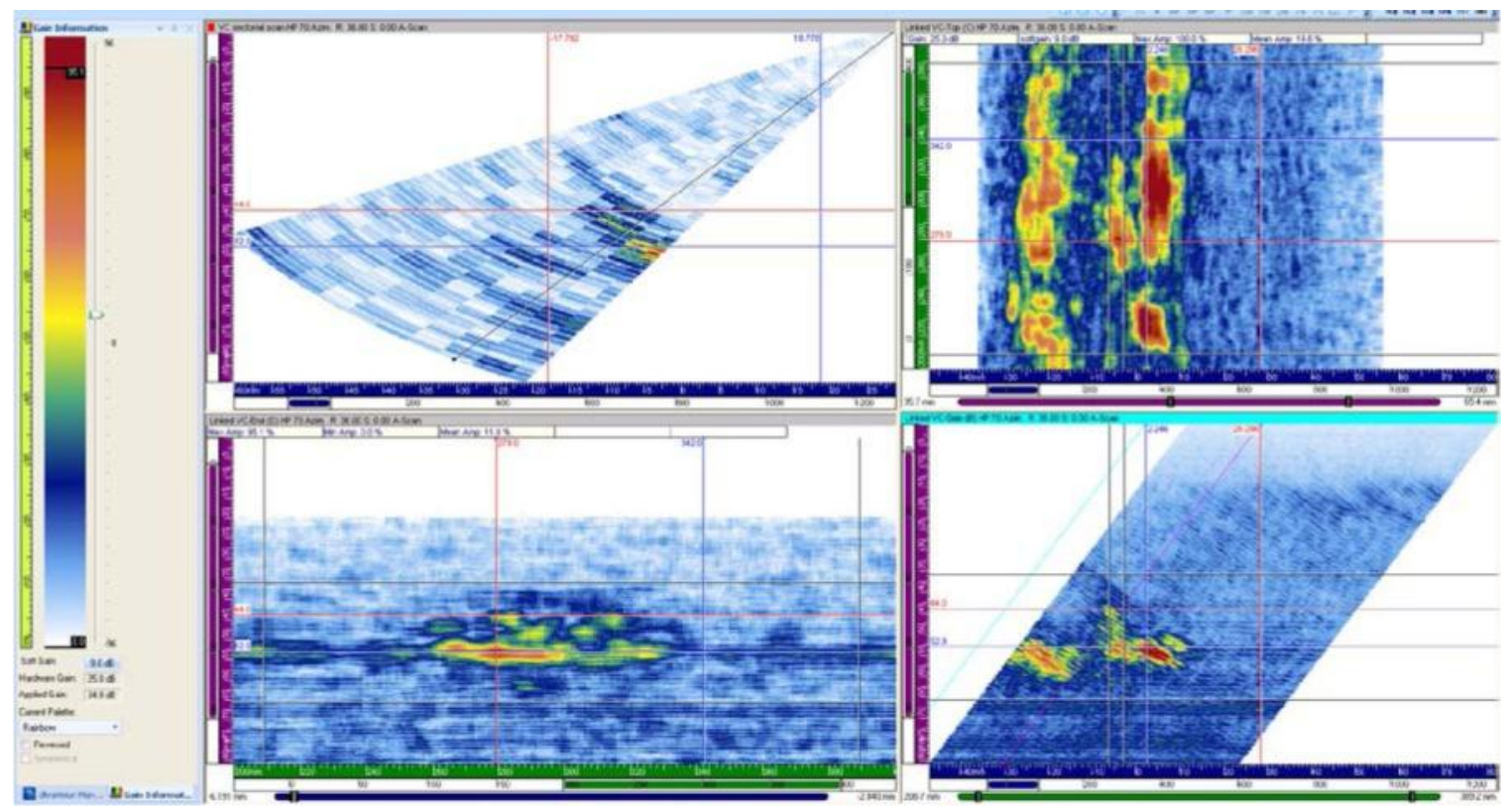

Figure B.40. Raster Data, Flaw 2 Pipe Side of Overlay, 1.5 MHz, Yes Detection 


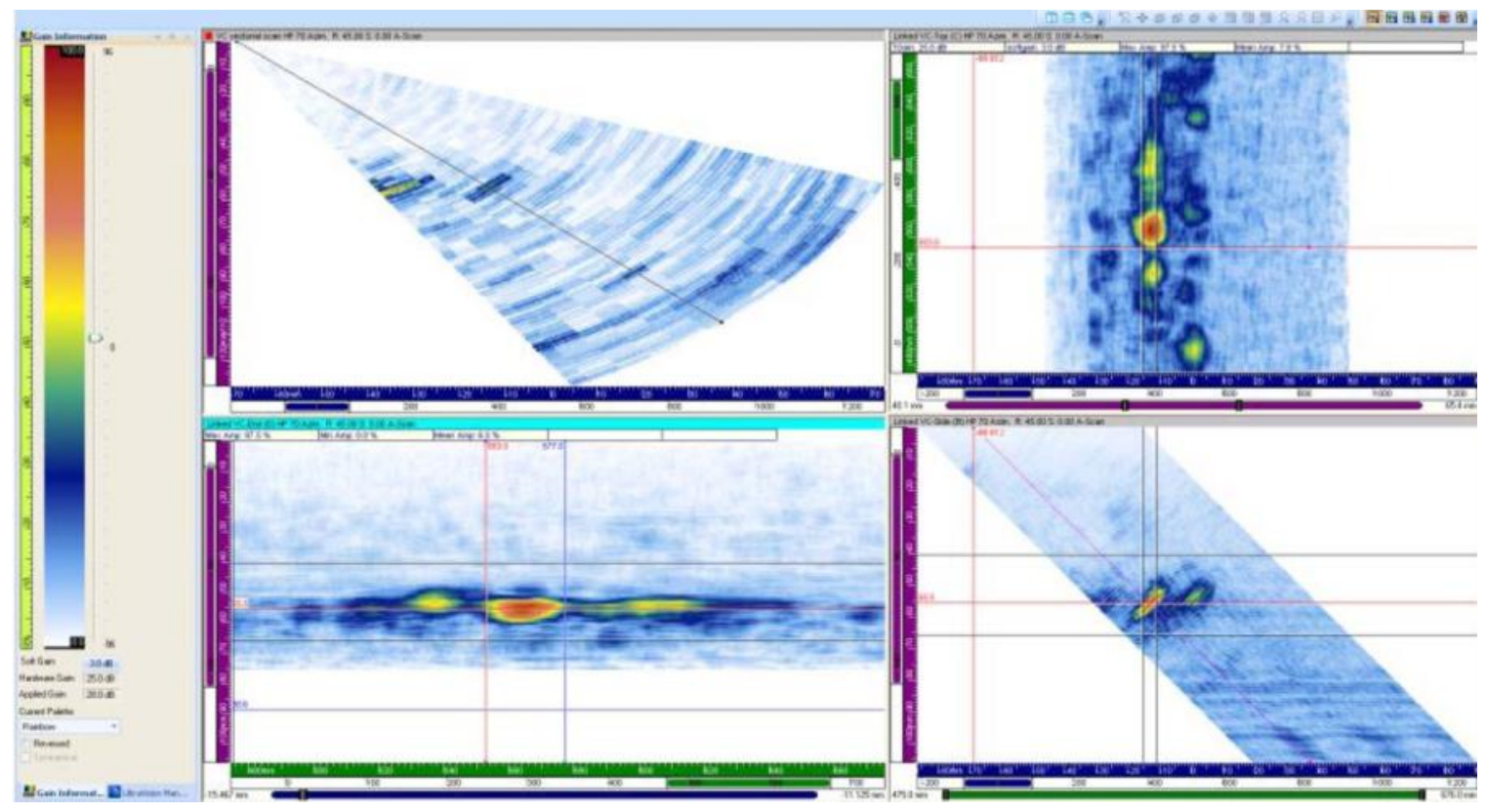

Figure B.41. Raster Data, Flaw 3 Nozzle Side of Overlay, 1.5 MHz, Yes Detection

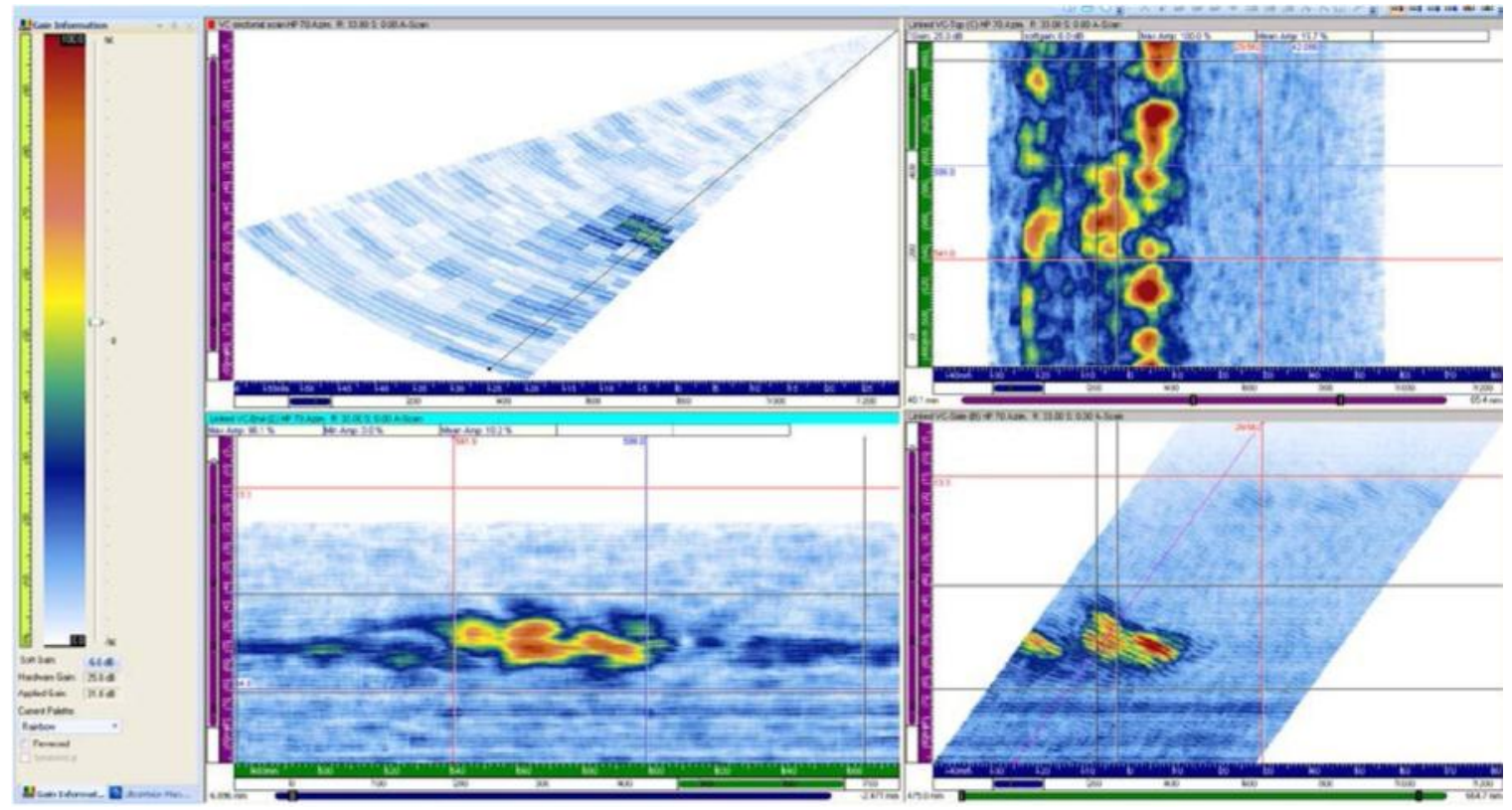

Figure B.42. Raster Data, Flaw 3 Pipe Side of Overlay, 1.5 MHz, Yes Detection 


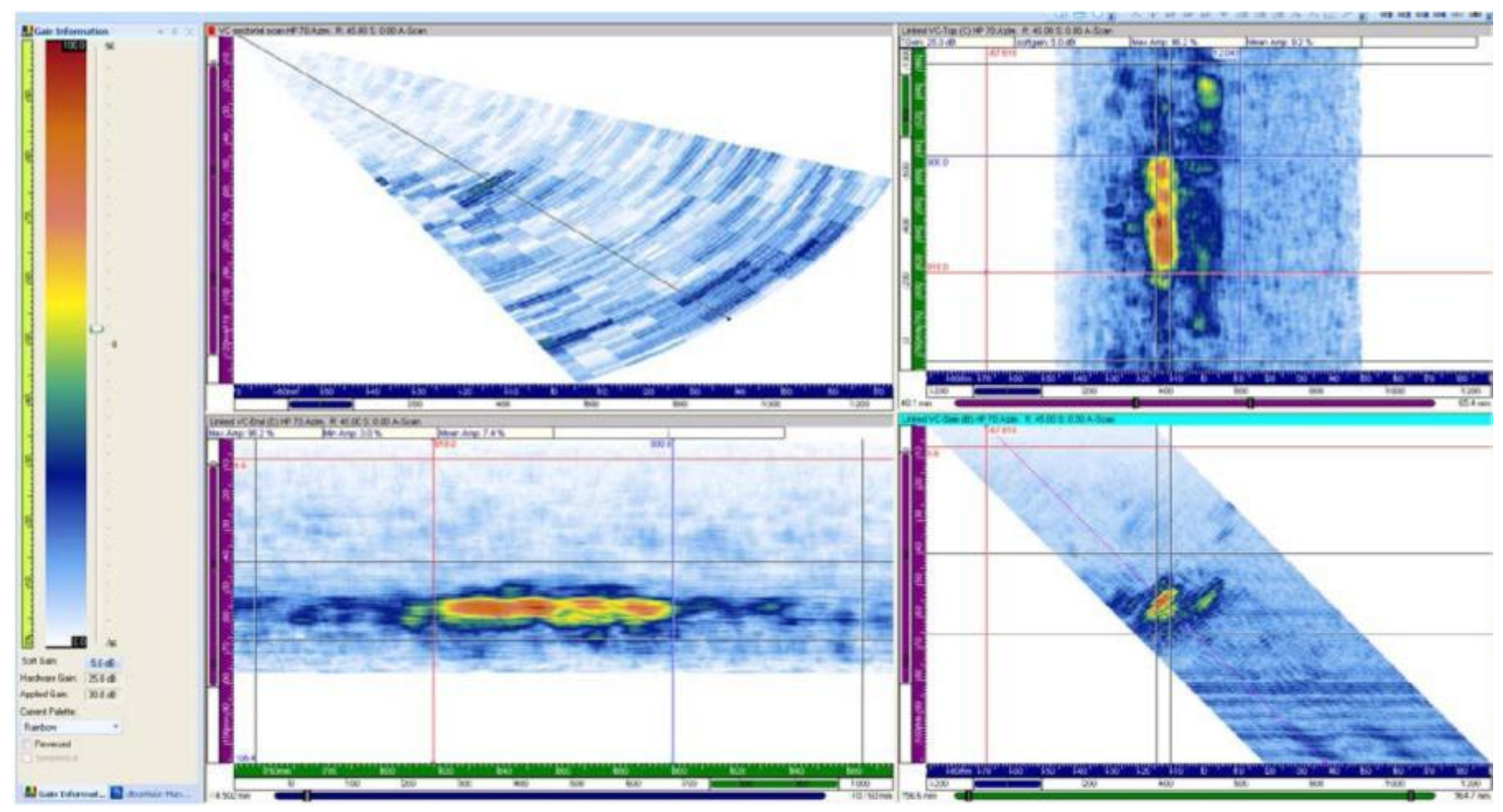

Figure B.43. Raster Data, Flaw 4 Nozzle Side of Overlay, 1.5 MHz, Yes Detection

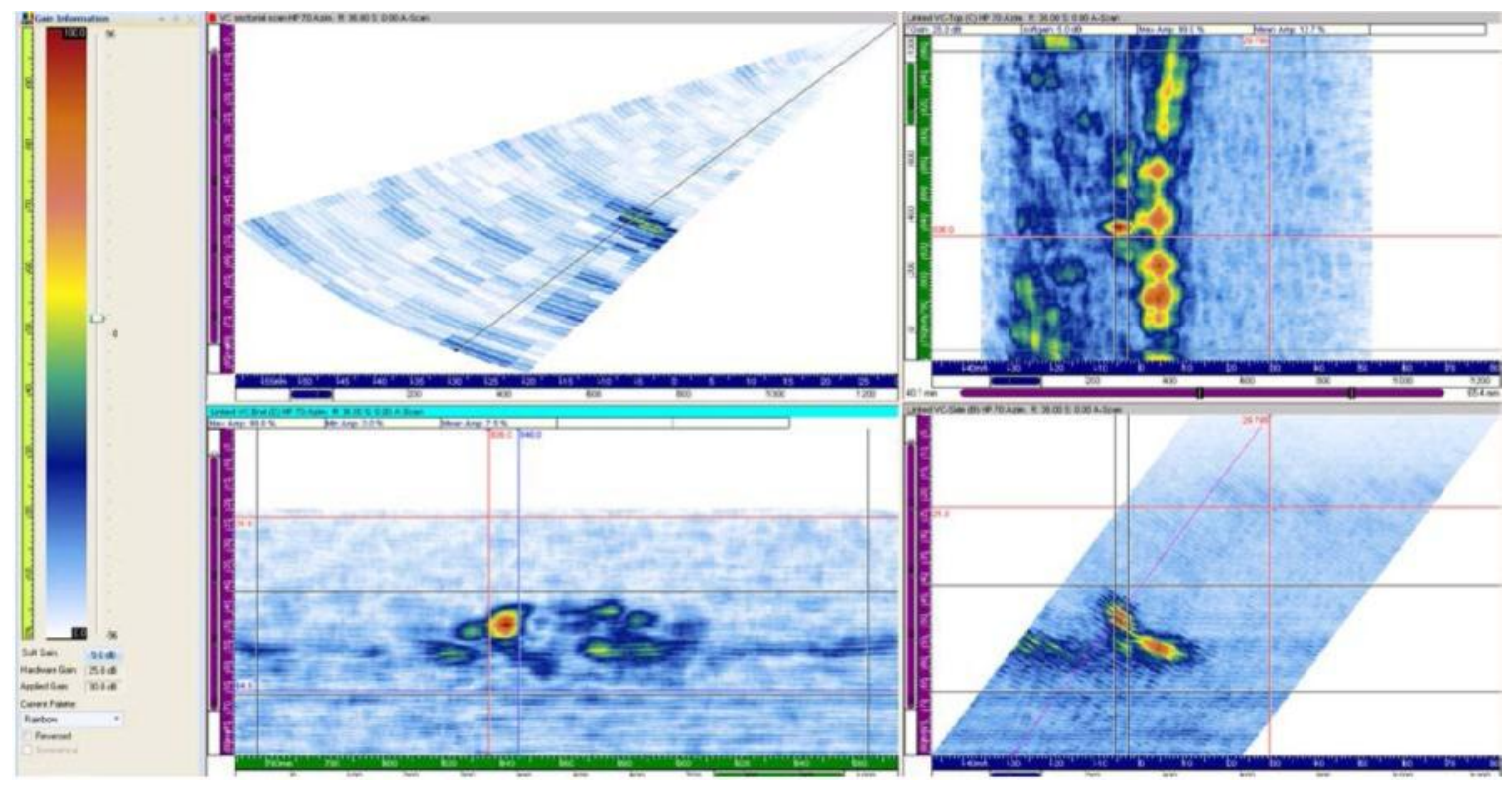

Figure B.44. Raster Data, Flaw 4 Pipe Side of Overlay, 1.5 MHz, Yes Detection 


\section{B.4 2.0 MHz Data}

\section{B.4.1 Line Scan Images Nozzle and Pipe Sides of Overlay Flaws 1-4}

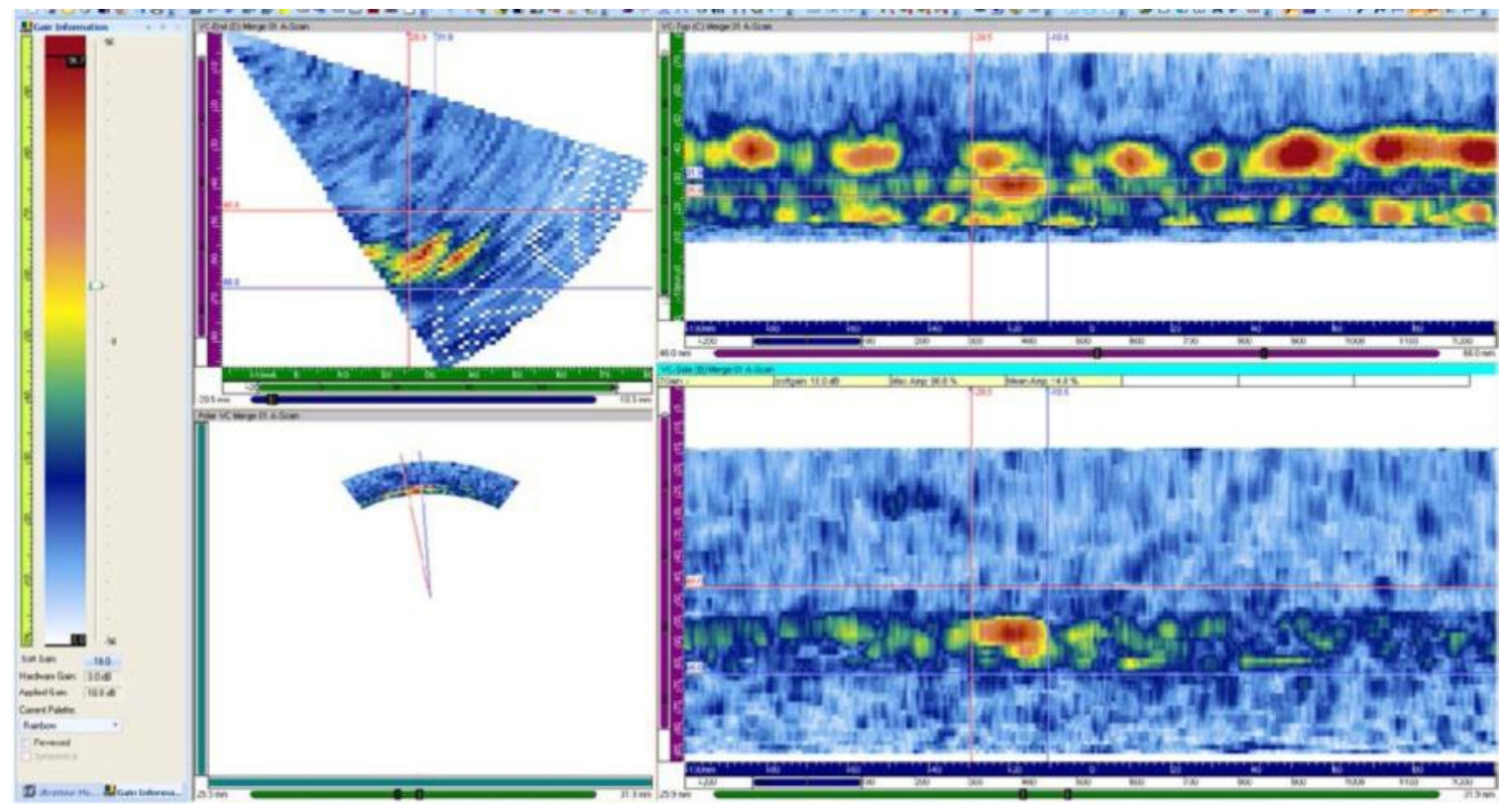

Figure B.45. Line Scan Data, Flaw 1 Nozzle Side of Overlay, 2.0 MHz, Yes Detection

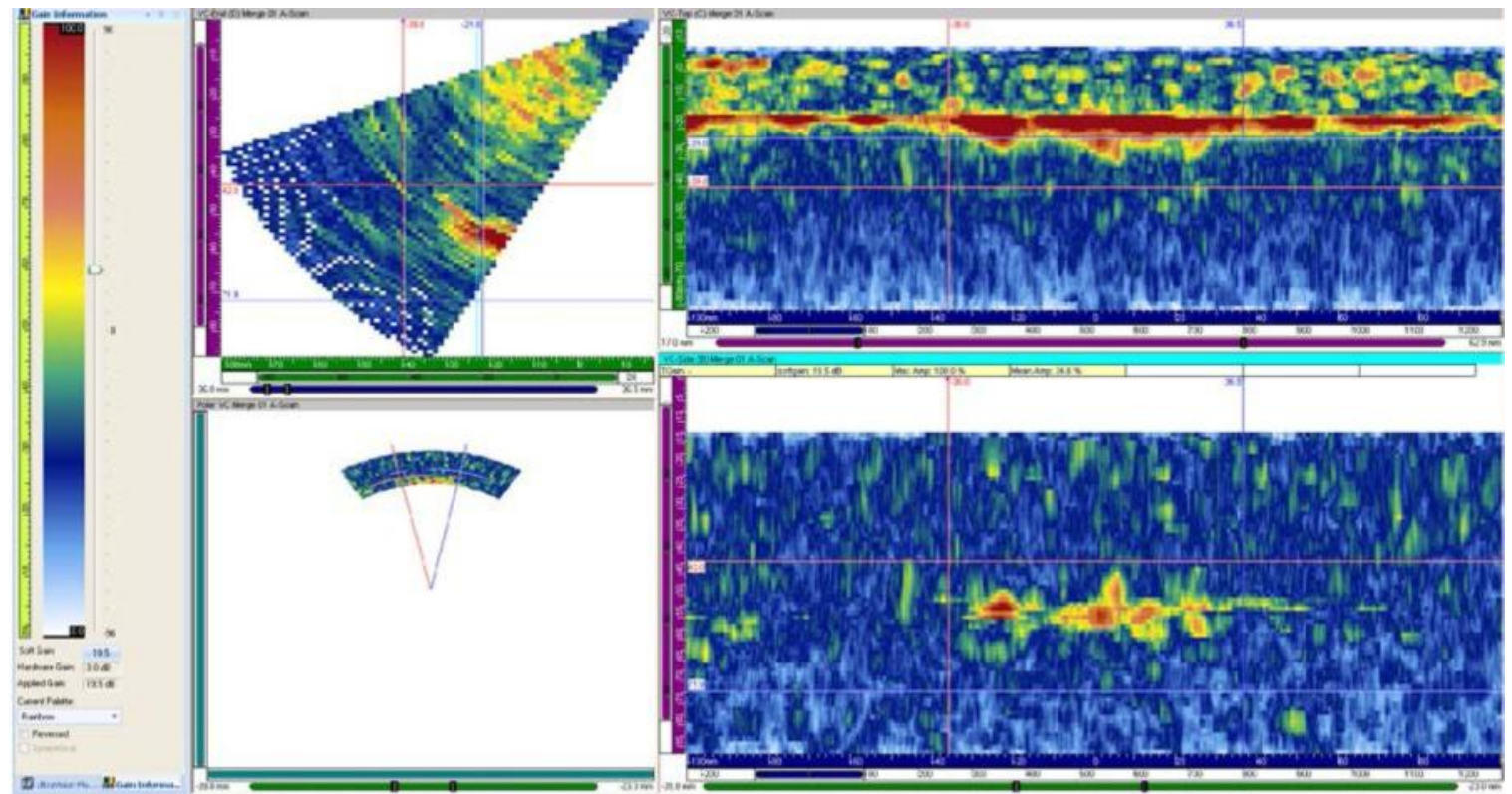

Figure B.46. Line Scan Data, Flaw 1 Pipe Side of Overlay, $2.0 \mathrm{MHz}$, No Detection. The flaw signal can't be separated from the weld root signal. 


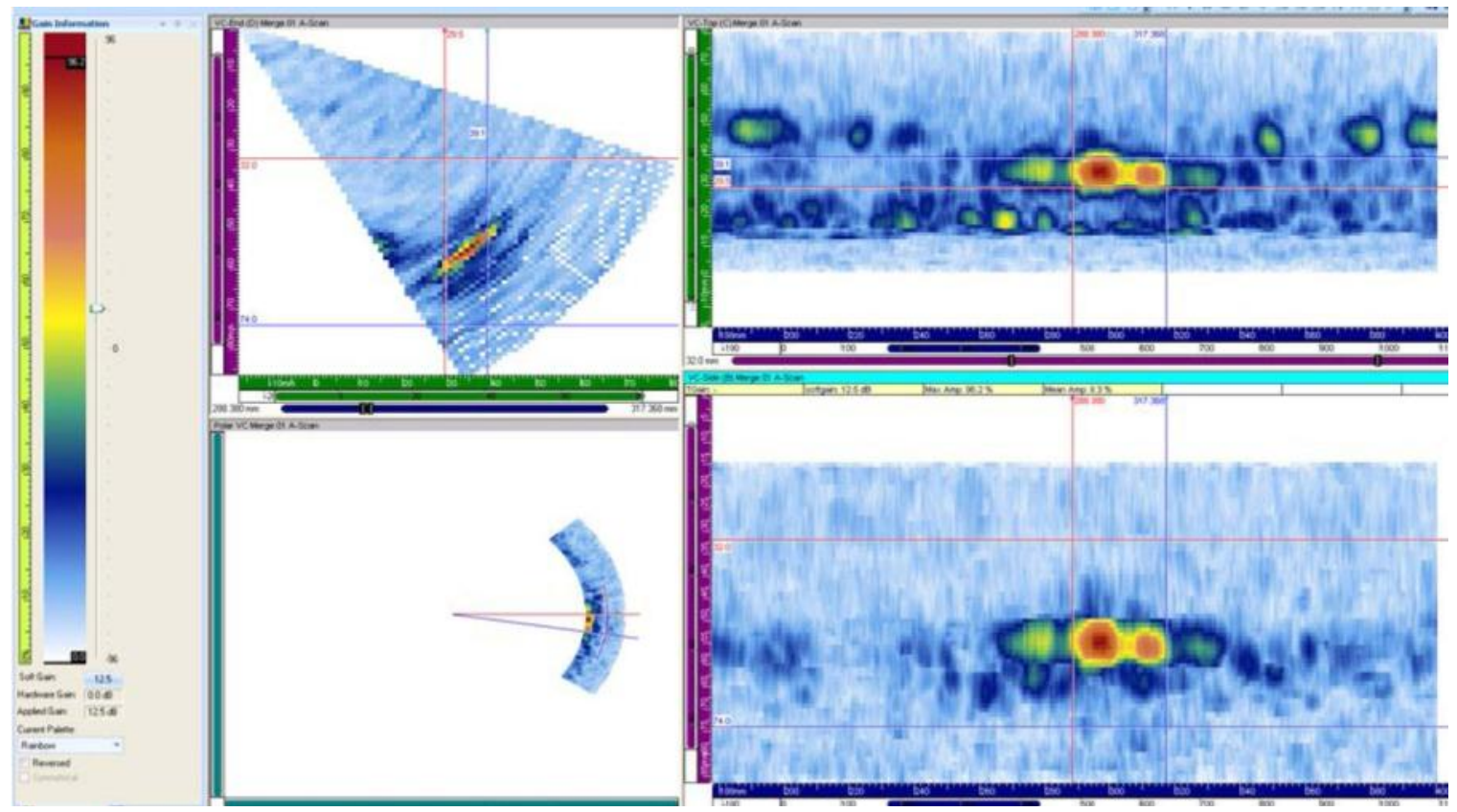

Figure B.47. Line Scan Data, Flaw 2 Nozzle Side of Overlay, 2.0 MHz, Yes Detection

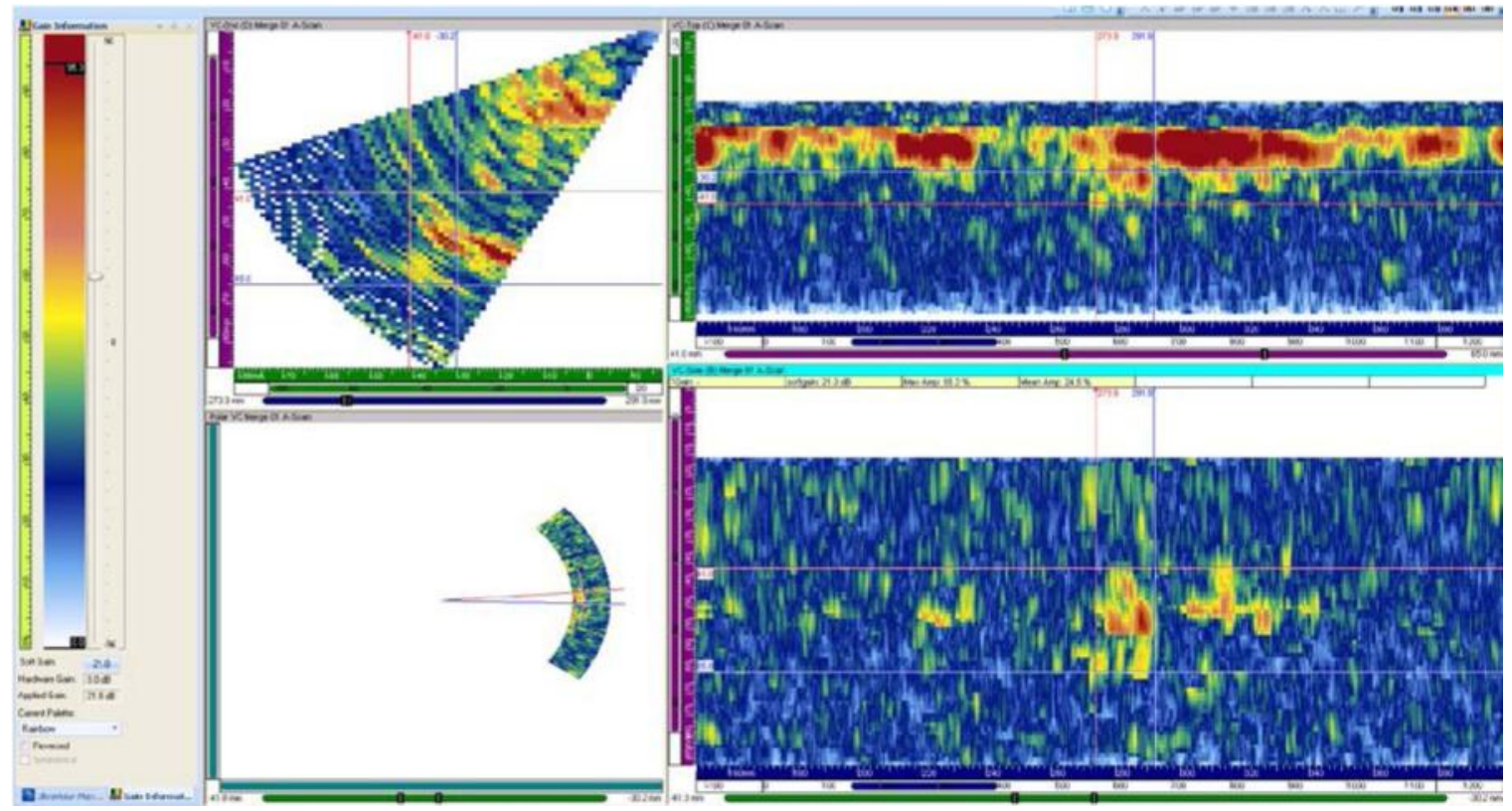

Figure B.48. Line Scan Data, Flaw 2 Pipe Side of Overlay, 2.0 MHz, Marginal Detection 


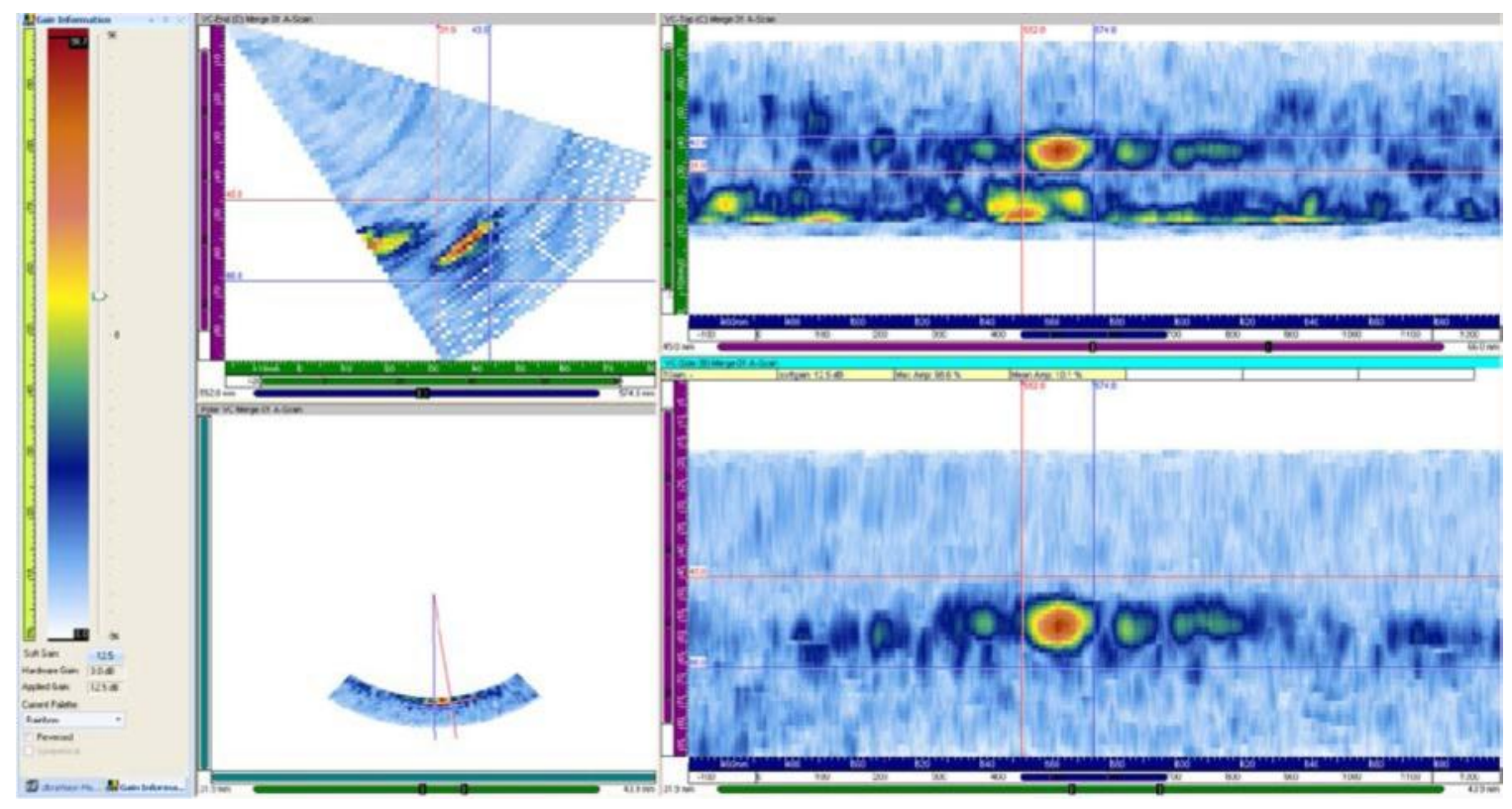

Figure B.49. Line Scan Data, Flaw 3 Nozzle Side of Overlay, 2.0 MHz, Yes Detection

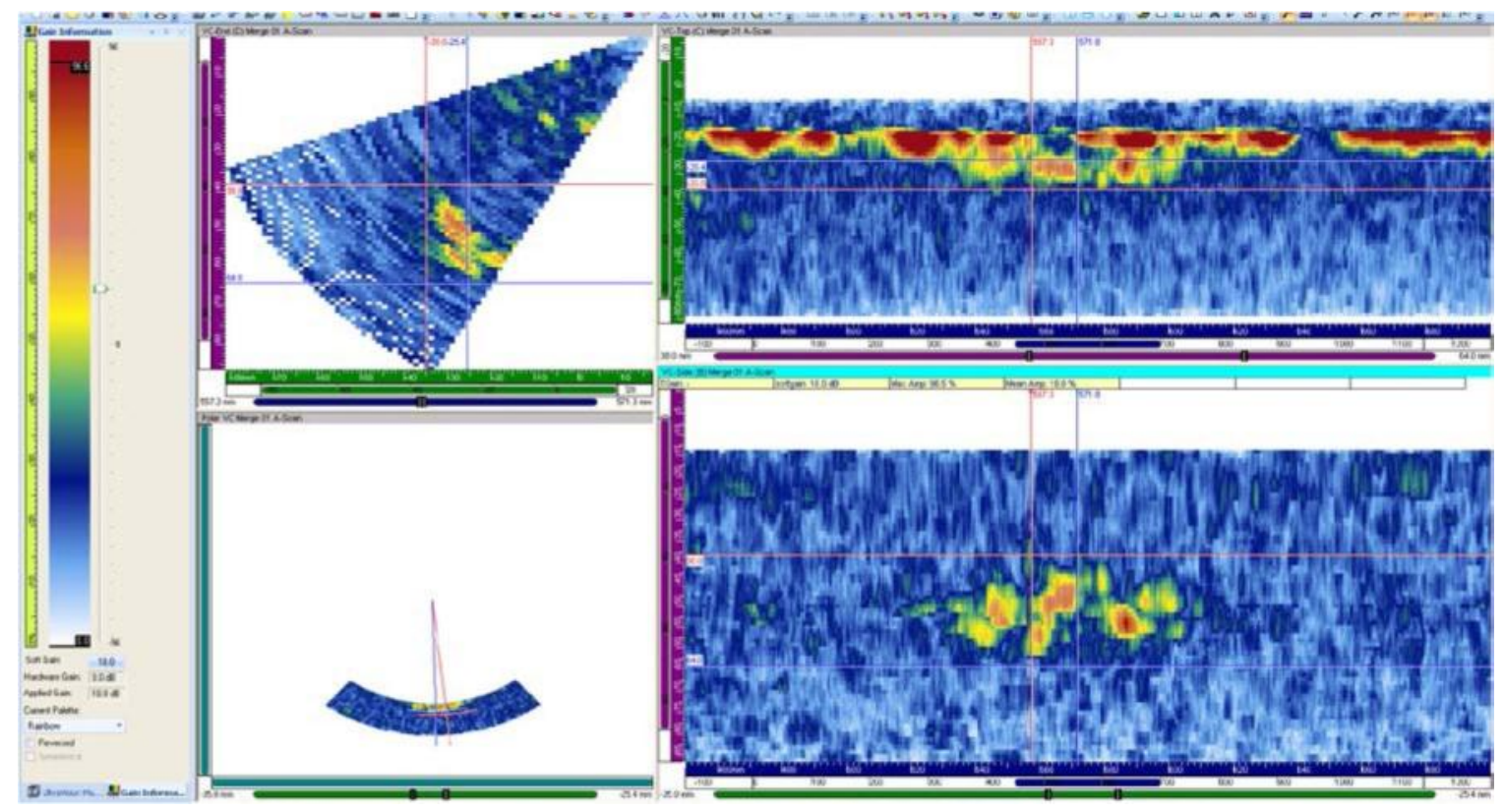

Figure B.50. Line Scan Data, Flaw 3 Pipe Side of Overlay, $2.0 \mathrm{MHz}$, Yes Detection 


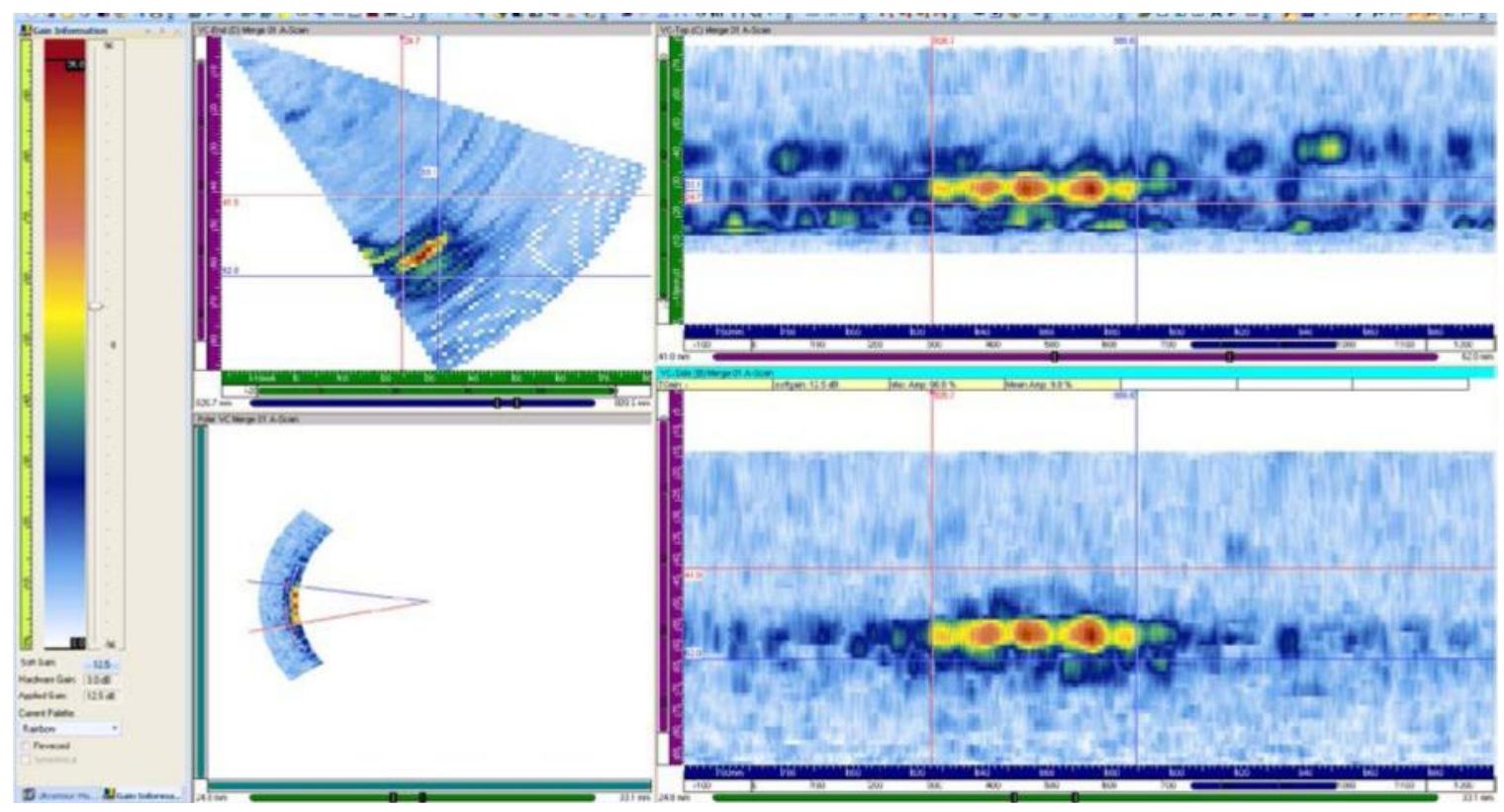

Figure B.51. Line Scan Data, Flaw 4 Nozzle Side of Overlay, 2.0 MHz, Yes Detection

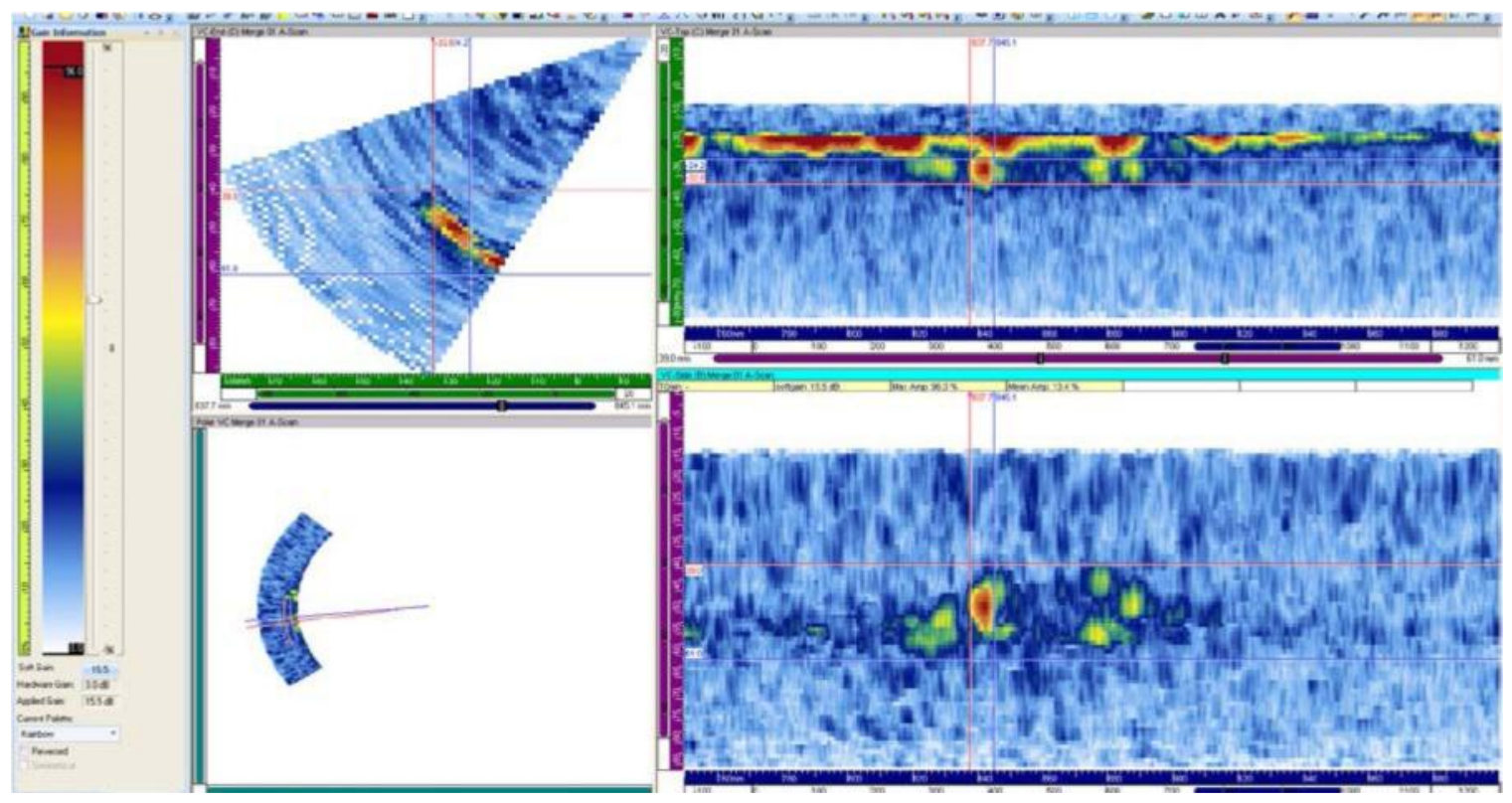

Figure B.52. Line Scan Data, Flaw 4 Pipe Side of Overlay, $2.0 \mathrm{MHz}$, Yes Detection 


\section{B.4.2 Raster Scan Images Nozzle and Pipe Sides of Overlay Flaws 1-4}

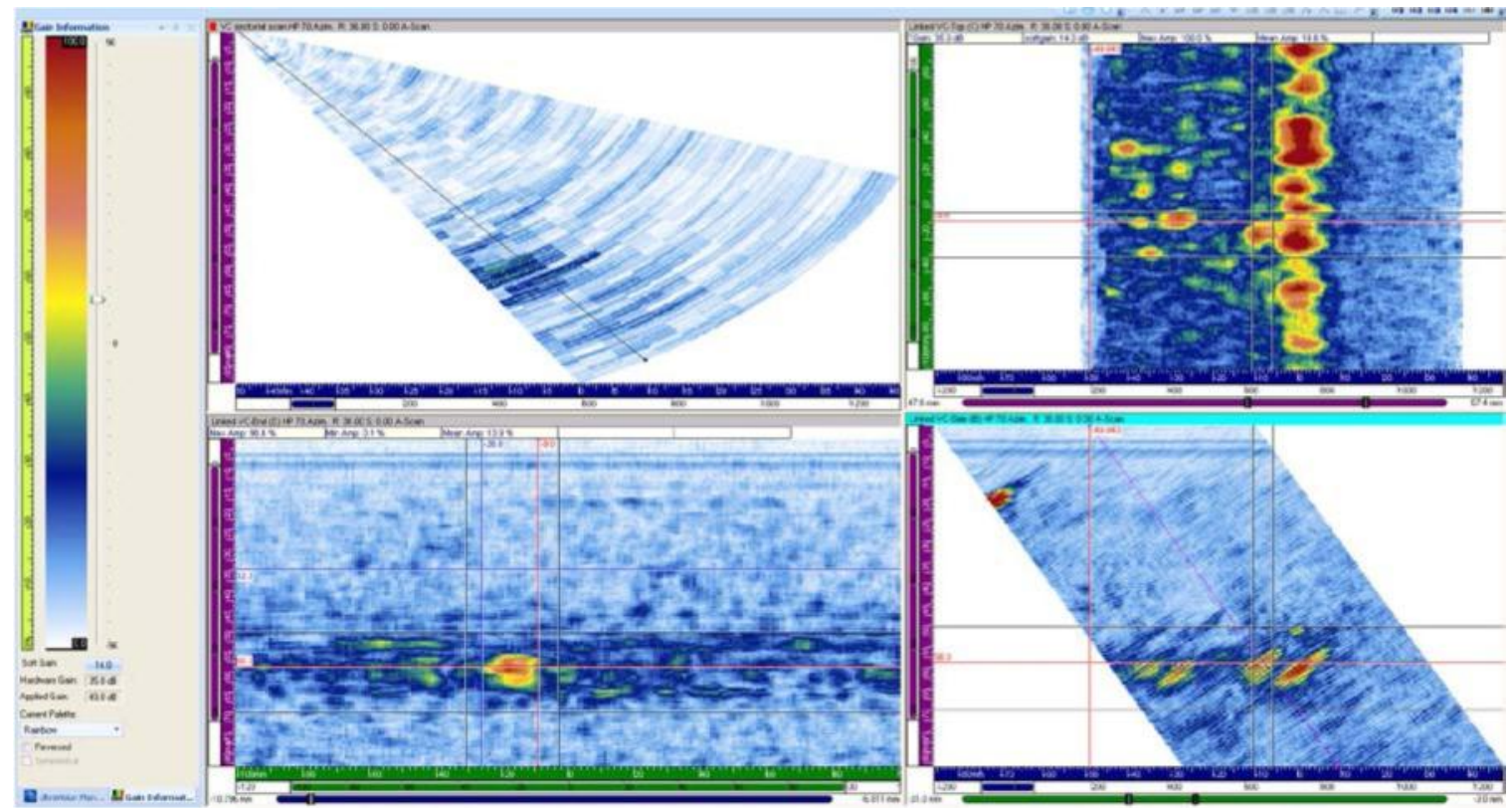

Figure B.53. Raster Data, Flaw 1 Nozzle Side of Overlay, 2.0 MHz, Yes Detection

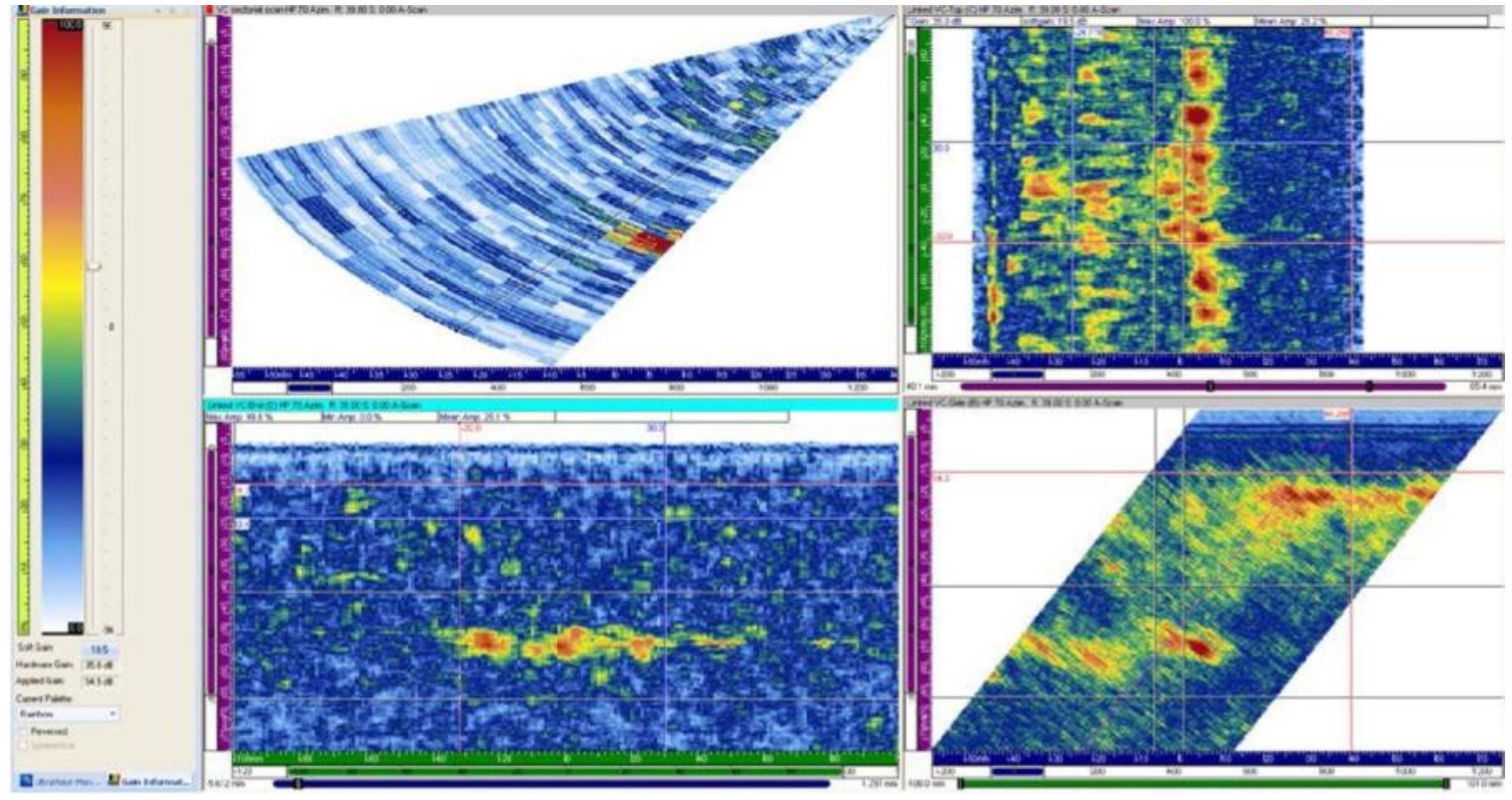

Figure B.54. Raster Data, Flaw 1 Pipe Side of Overlay, 2.0 MHz, Yes Detection 


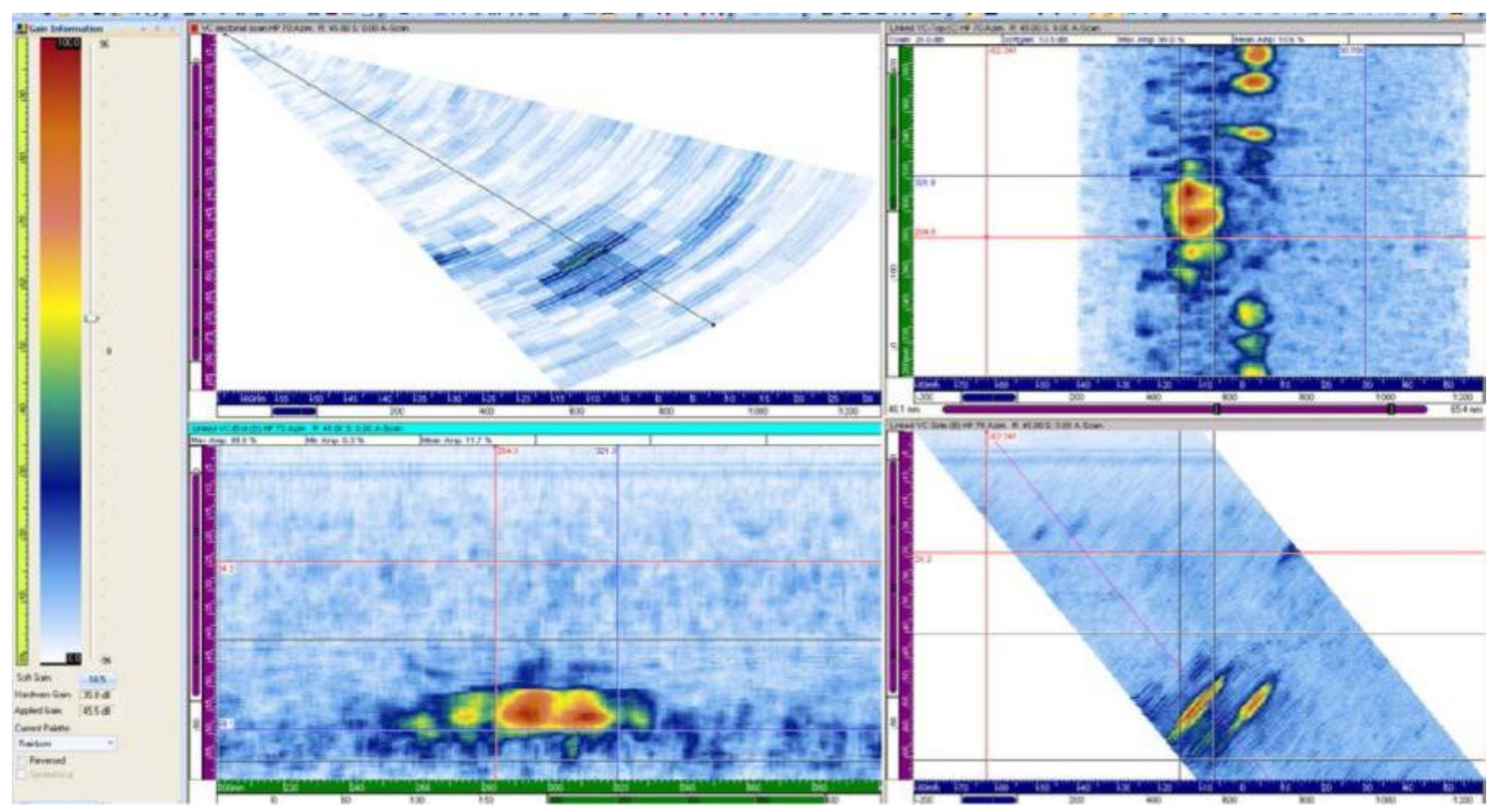

Figure B.55. Raster Data, Flaw 2 Nozzle Side of Overlay, 2.0 MHz, Yes Detection

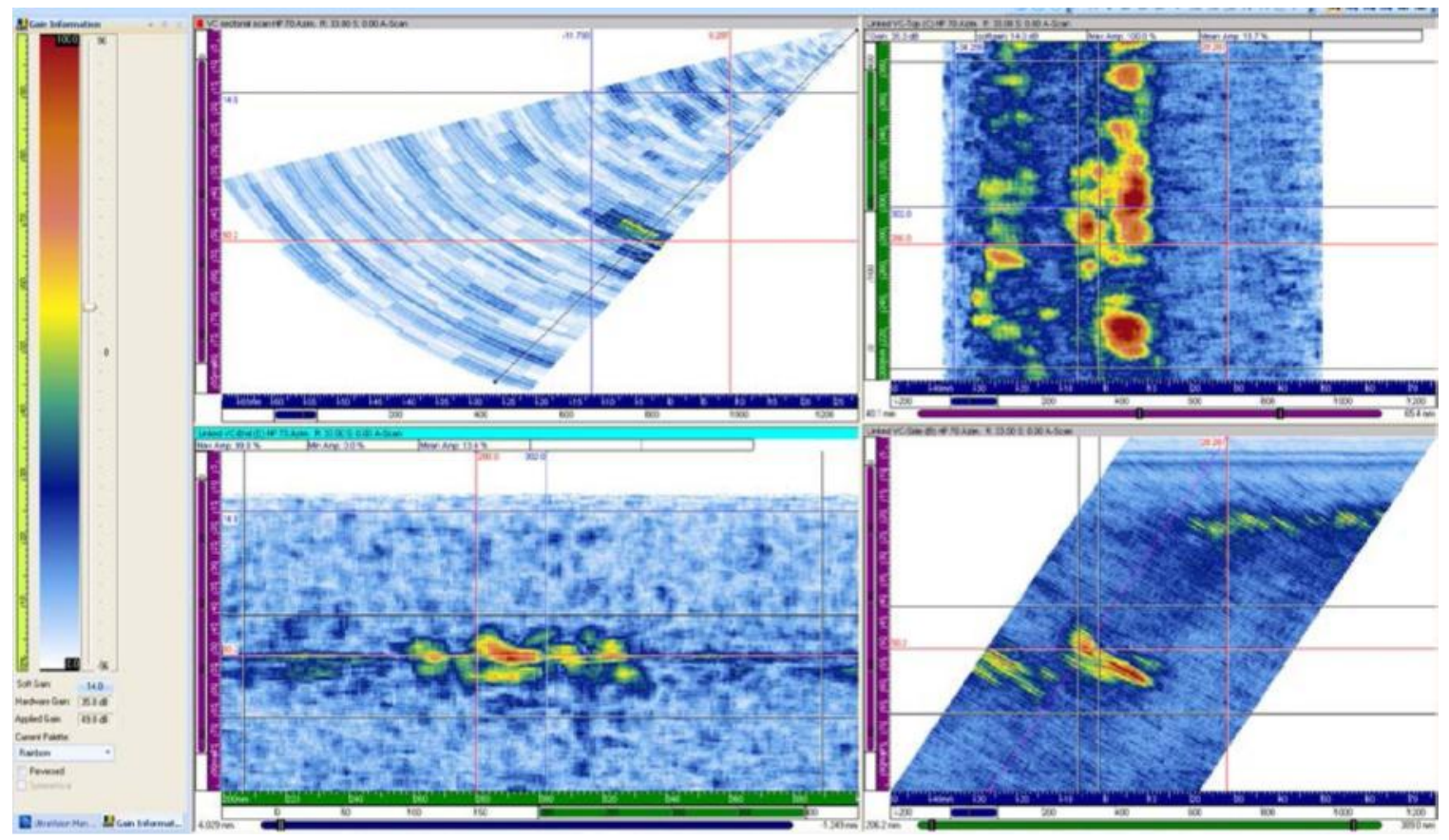

Figure B.56. Raster Data, Flaw 2 Pipe Side of Overlay, 2.0 MHz, Yes Detection 


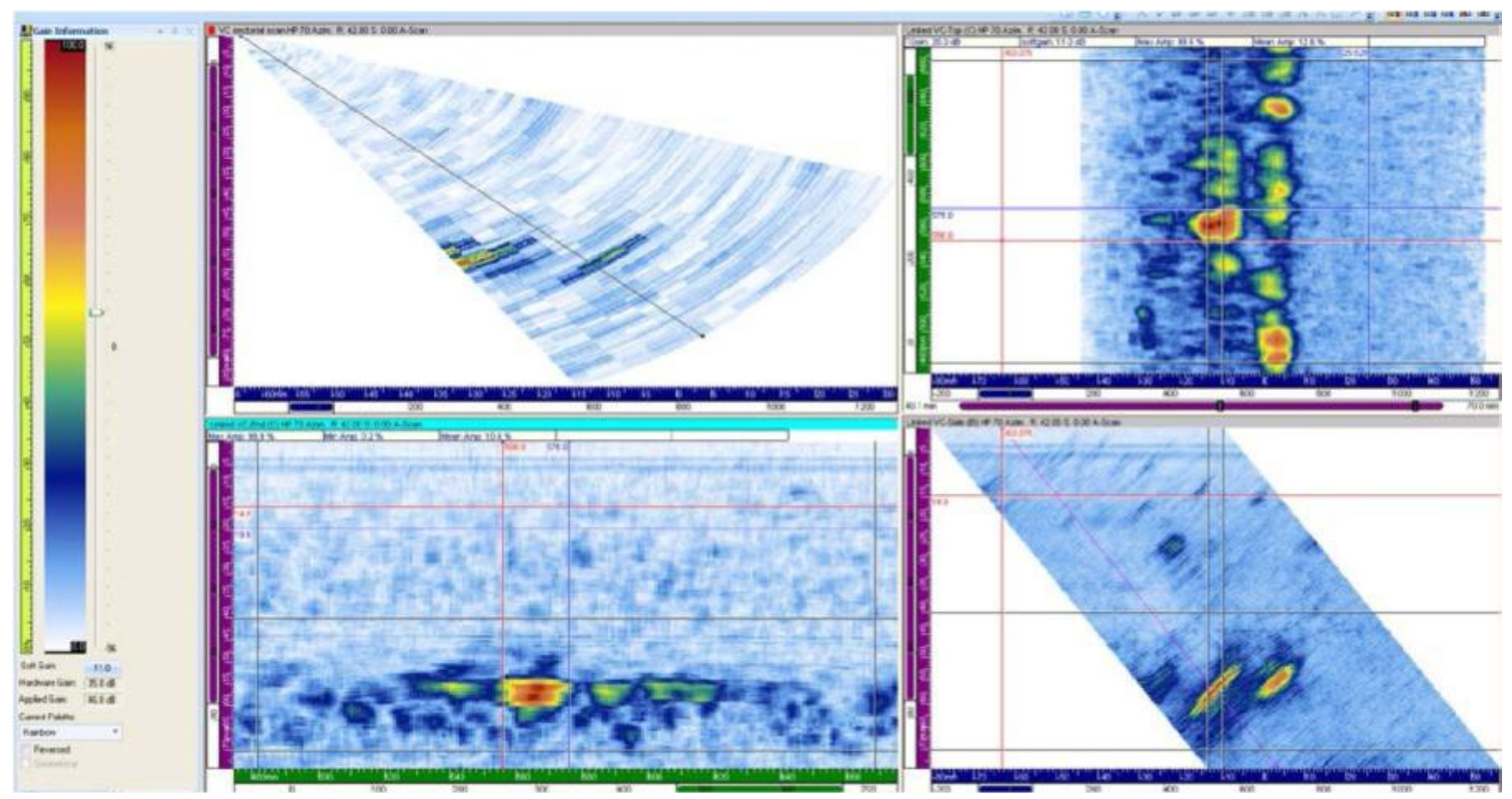

Figure B.57. Raster Data, Flaw 3 Nozzle Side of Overlay, 2.0 MHz, Yes Detection

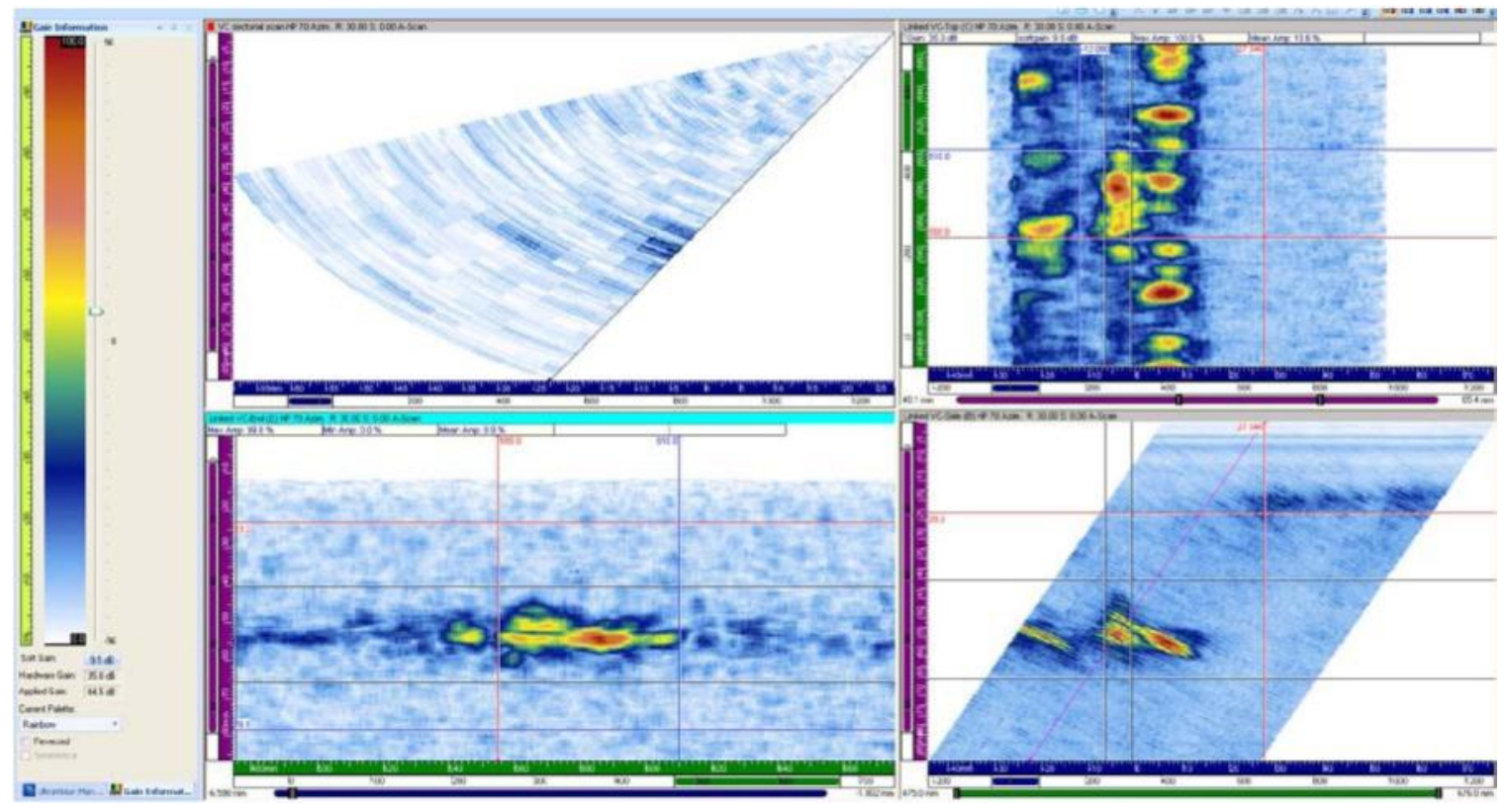

Figure B.58. Raster Data, Flaw 3 Pipe Side of Overlay, 2.0 MHz, Yes Detection 


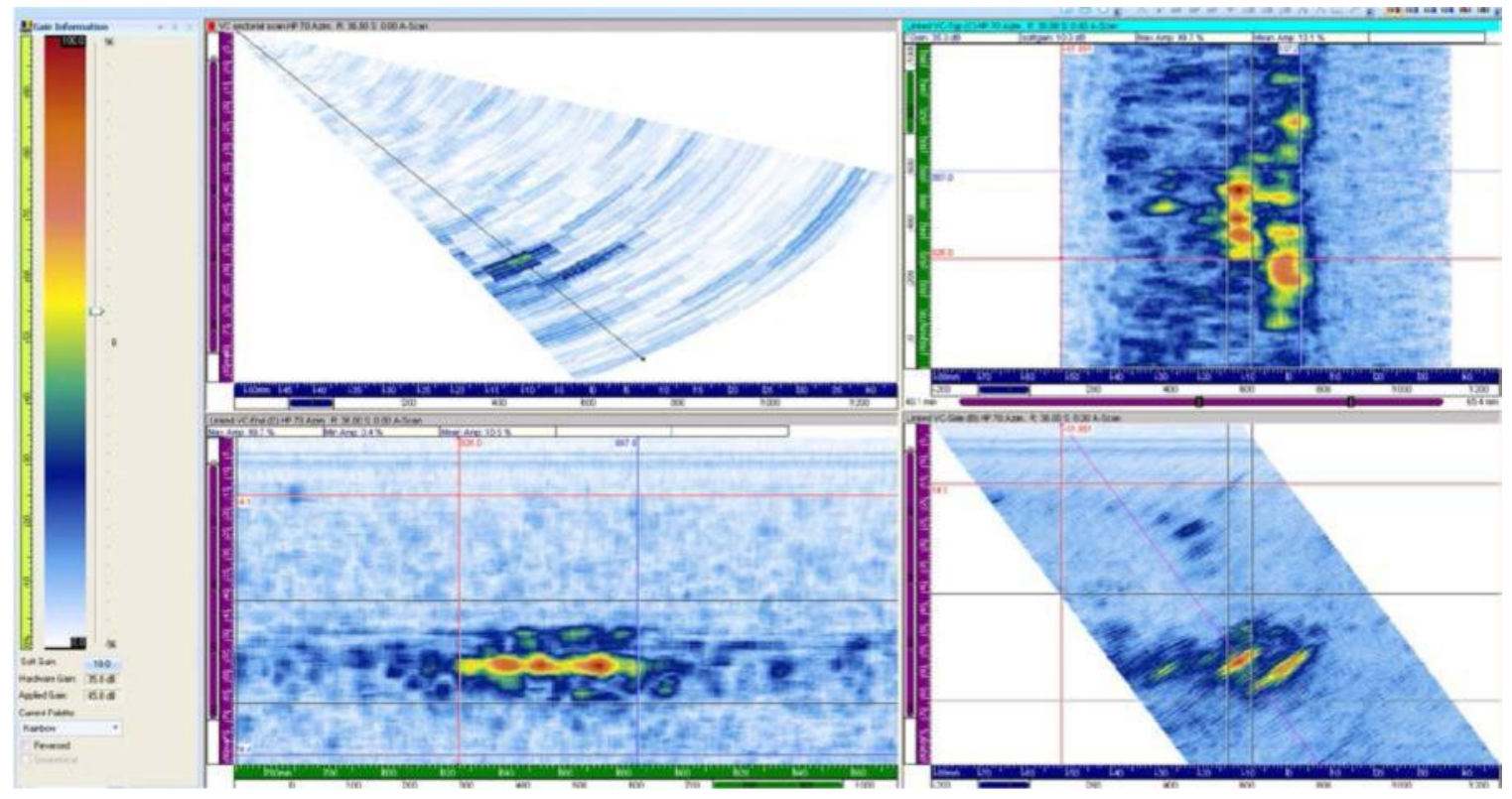

Figure B.59. Raster Data, Flaw 4 Nozzle Side of Overlay, 2.0 MHz, Yes Detection

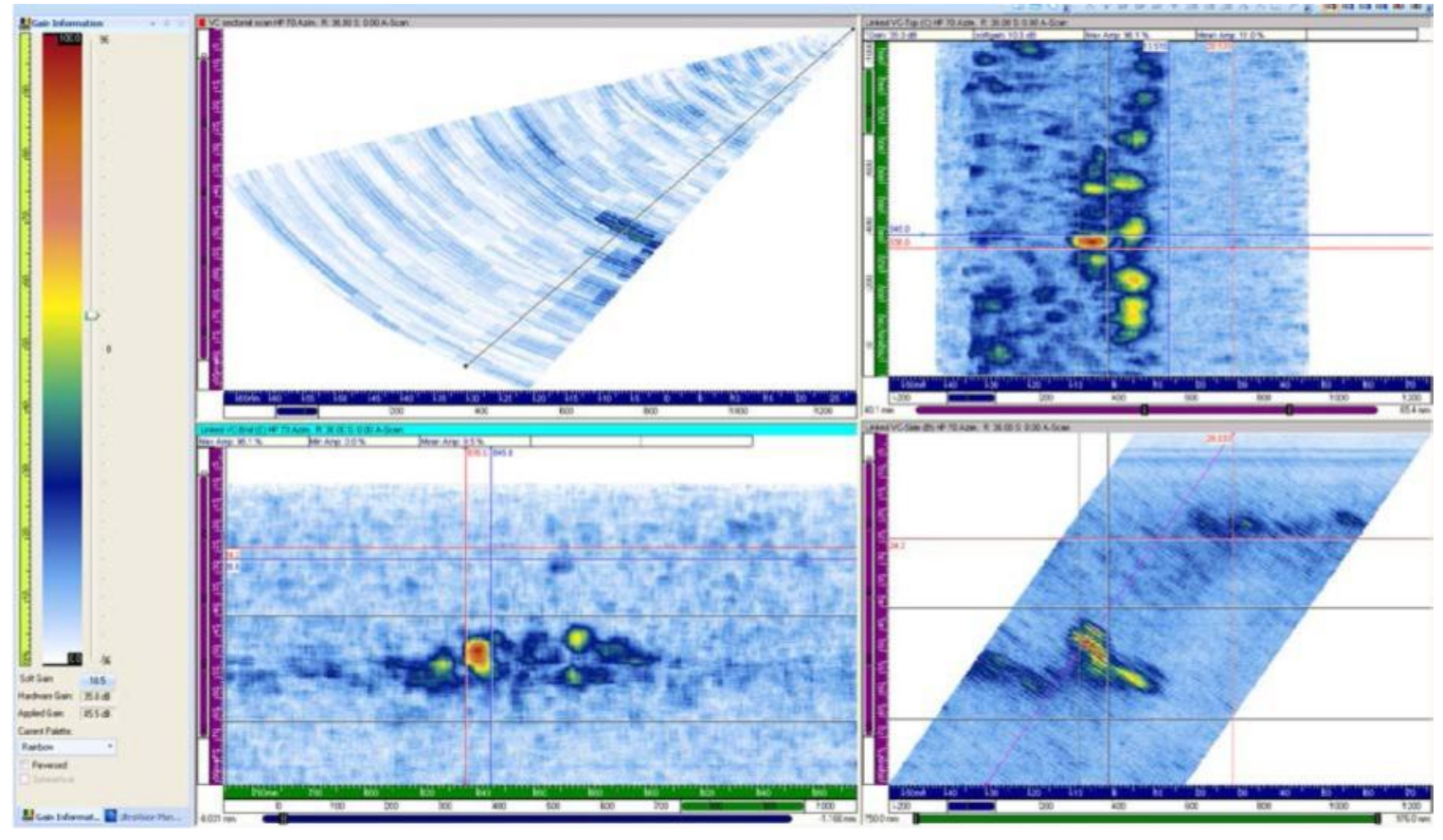

Figure B.60. Raster Data, Flaw 4 Pipe Side of Overlay, 2.0 MHz, Yes Detection 

Appendix C

Dissimilar Metal Weld Specimen 10C-011 Phased-Array Data, Pre-WOL 



\section{Appendix C}

\section{Dissimilar Metal Weld Specimen 10C-011 Phased-Array Data, Pre-WOL}

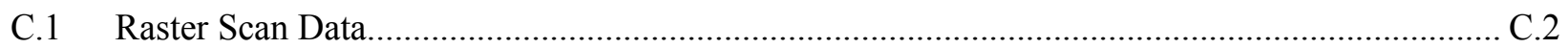

C.1.1 Raster Data at $0.8 \mathrm{MHz}$ Nozzle Side on Flaws 1-5 .....................................................2.2

C.1.2 Raster Data at $0.8 \mathrm{MHz}$ Pipe Side on Flaws 1-5 …....................................................

C.1.3 Raster Data at 1.0 MHz Nozzle Side on Flaws 1-5 .....................................................7

C.1.4 Raster Data at 1.0 MHz Pipe Side on Flaws 1-5 ….................................................. 10

C.1.5 Raster Data at 1.5 MHz Nozzle Side on Flaws 1-5 ...................................................13

C.1.6 Raster Data at 1.5 MHz Pipe Side on Flaws 1-5 Kay ..................................................16

C.1.7 Raster Scan Data at 2.0 MHz Nozzle Side on Flaws 1-5 .............................................19

C.1.8 Raster Scan Data at 2.0 MHz Pipe Side on Flaws 1-5 .............................................22

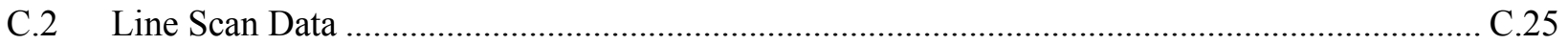

C.2.1 Line Scan Data at 0.8 MHz Nozzle Side on Flaws 1-5 ….........................................25

C.2.2 Line Scan Data at 1.0 MHz Nozzle Side on Flaws 1-5 ..............................................2.

C.2.3 Line Scan Data at 1.5 MHz Nozzle Side on Flaws 1-5 ..............................................29

C.2.4 Line Scan Data at 2.0 MHz Nozzle Side on Flaws 1-5 ................................................

C.2.5 Line Scan Data at 0.8 MHz Pipe Side on Flaws 1-5 …................................................

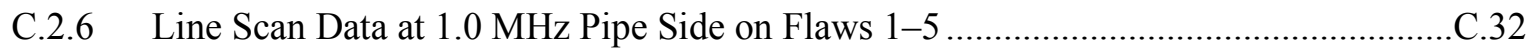

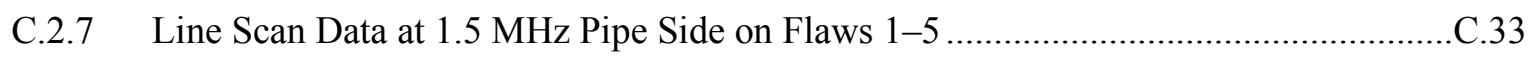

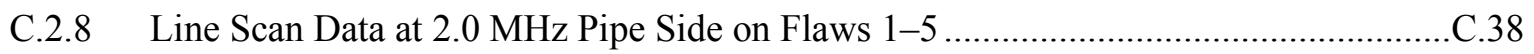




\section{C.1 Raster Scan Data}

\section{C.1.1 Raster Data at 0.8 MHz Nozzle Side on Flaws 1-5}

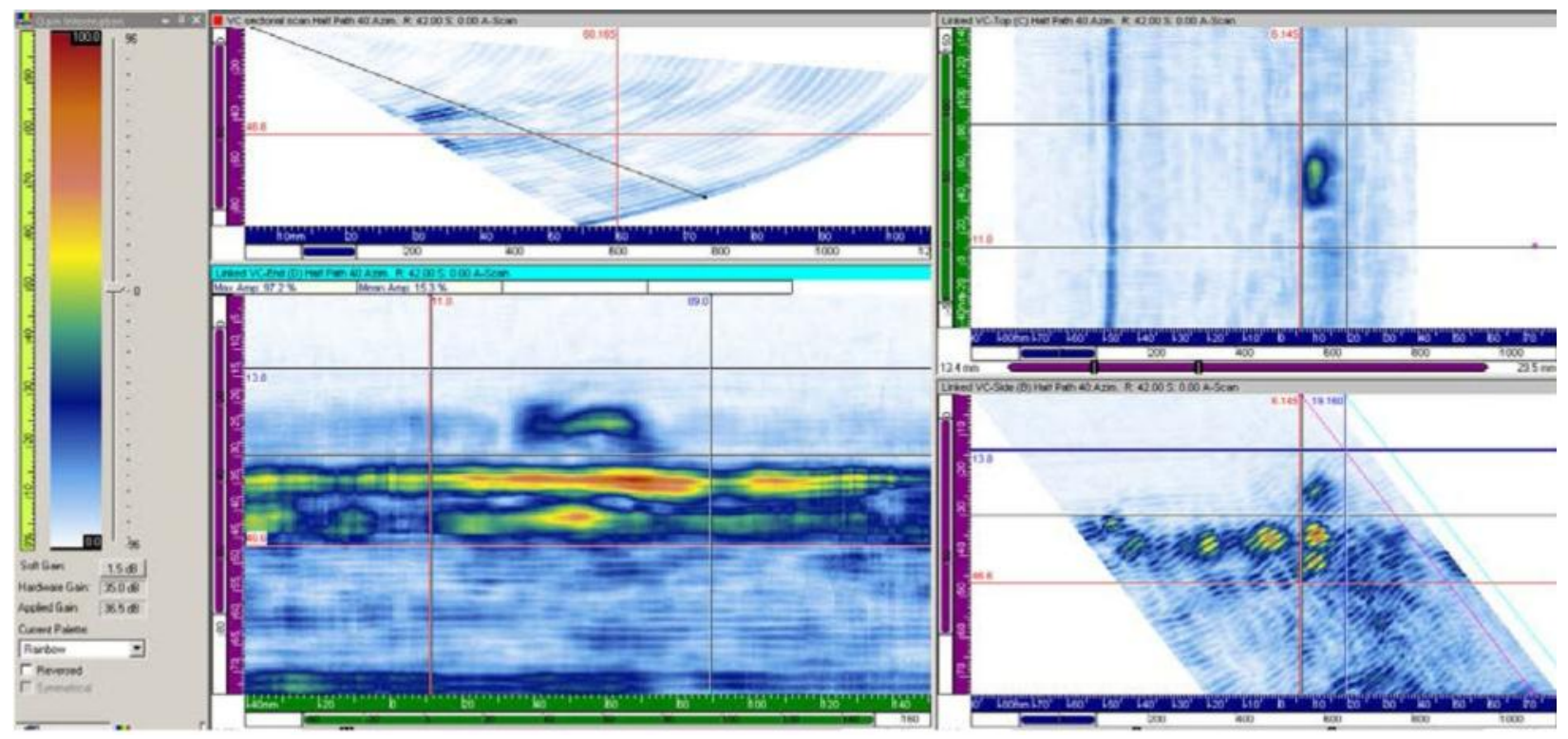

Figure C.1. 10C-011 Flaw 1 Nozzle Side Raster Data at 0.8 MHz, 42 Degrees, Pre FSWOL

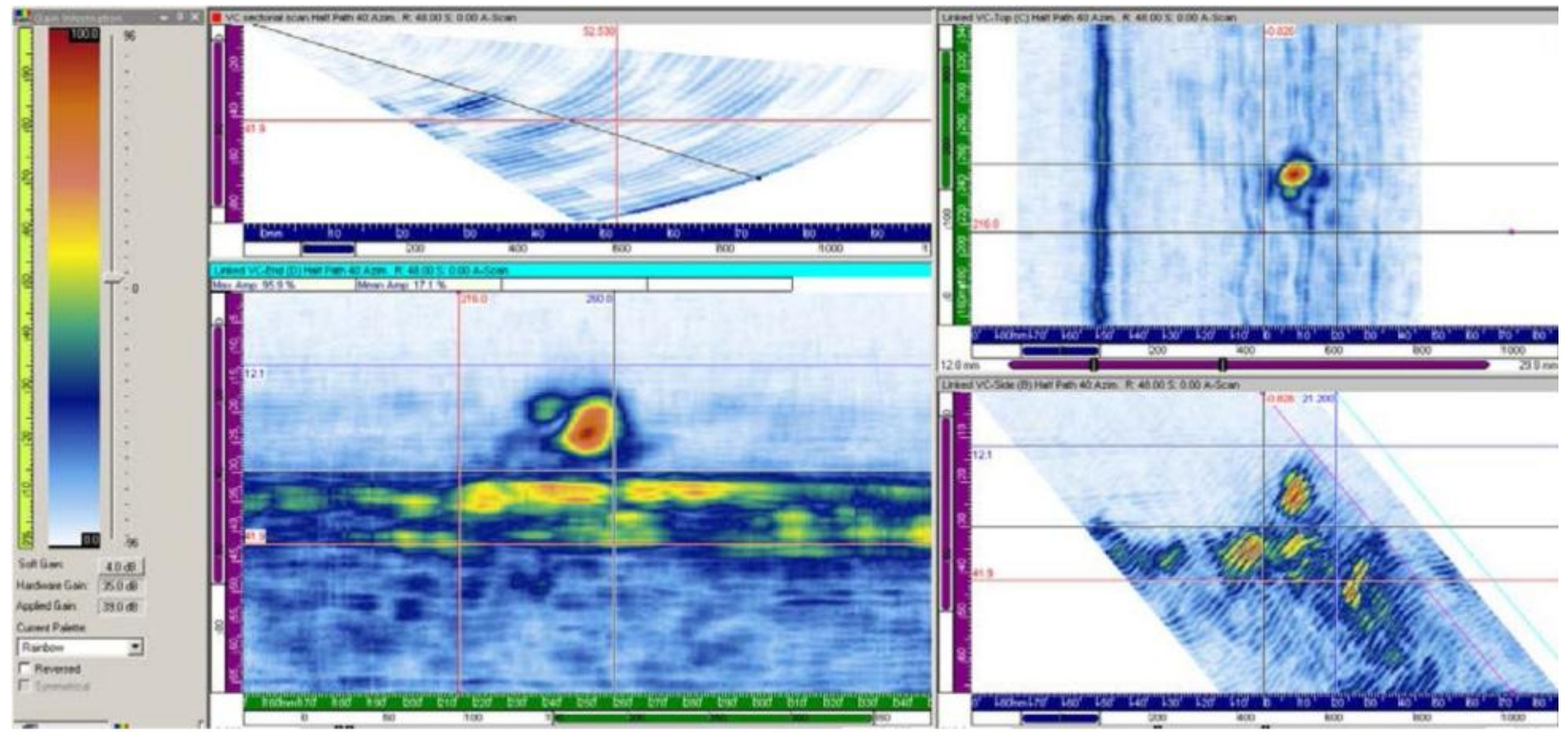

Figure C.2. 10C-011 Flaw 2 Nozzle Side Raster Data at 0.8 MHz, 48 Degrees, Pre FSWOL 


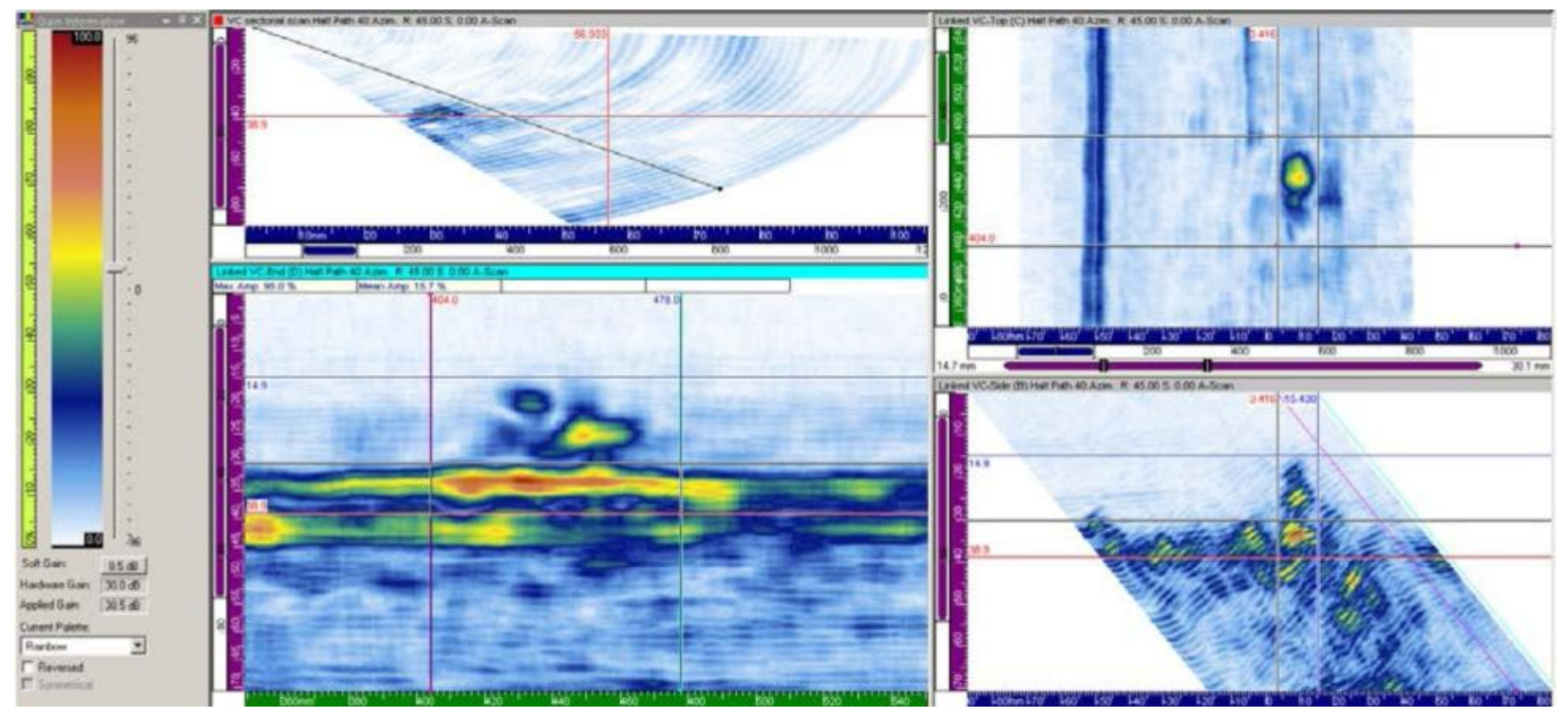

Figure C.3. 10C-011 Flaw 3 Nozzle Side Raster Data at $0.8 \mathrm{MHz}, 45$ Degrees, Pre FSWOL

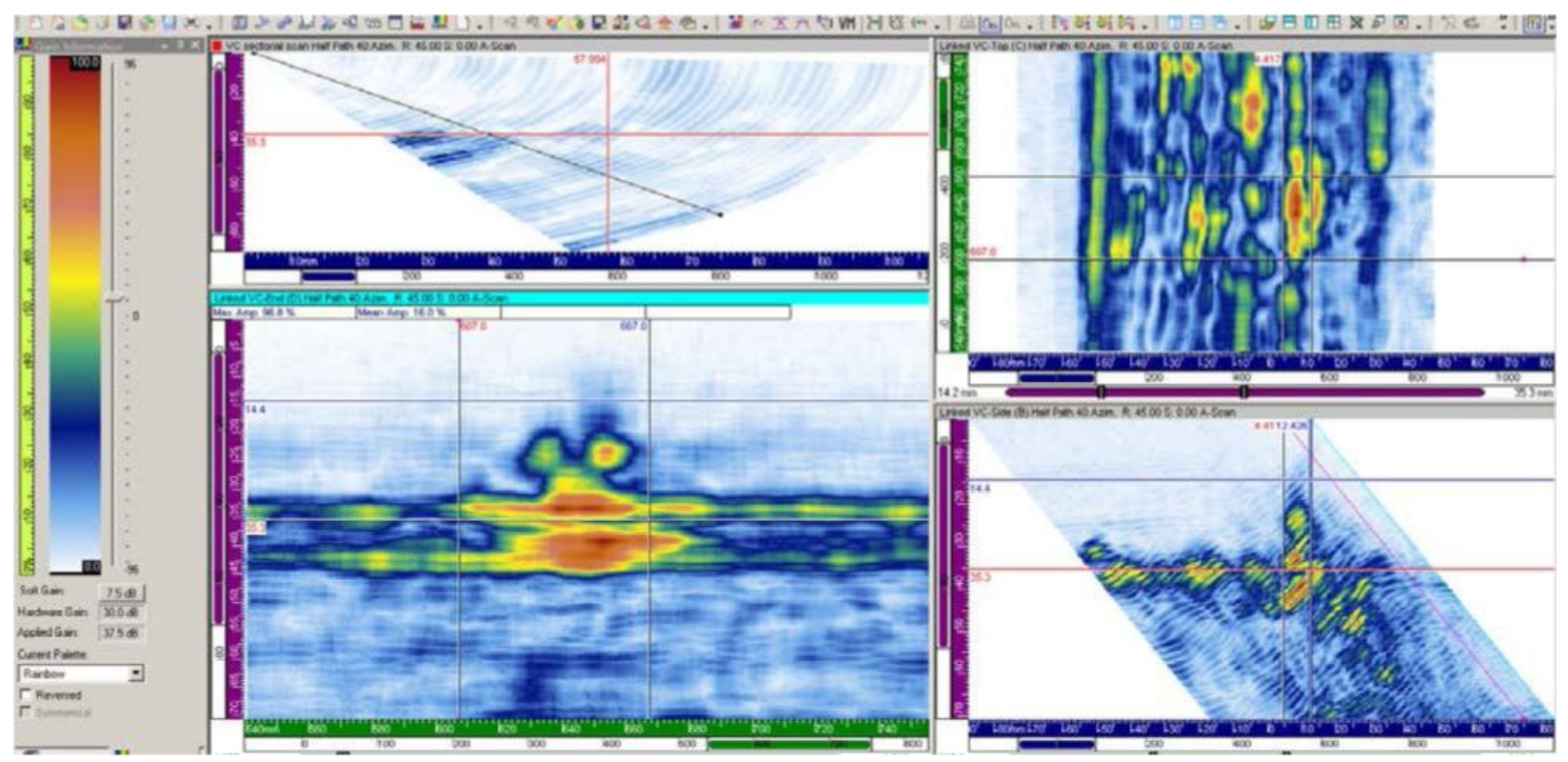

Figure C.4. 10C-011 Flaw 4 Nozzle Side Raster Data at 0.8 MHz, 45 Degrees, Pre FSWOL

\section{No Data}

Figure C.5. 10C-011 Flaw 5 Nozzle Side Raster Data at 0.8 MHz, Pre FSWOL - No Data 


\section{C.1.2 Raster Data at 0.8 MHz Pipe Side on Flaws 1-5}

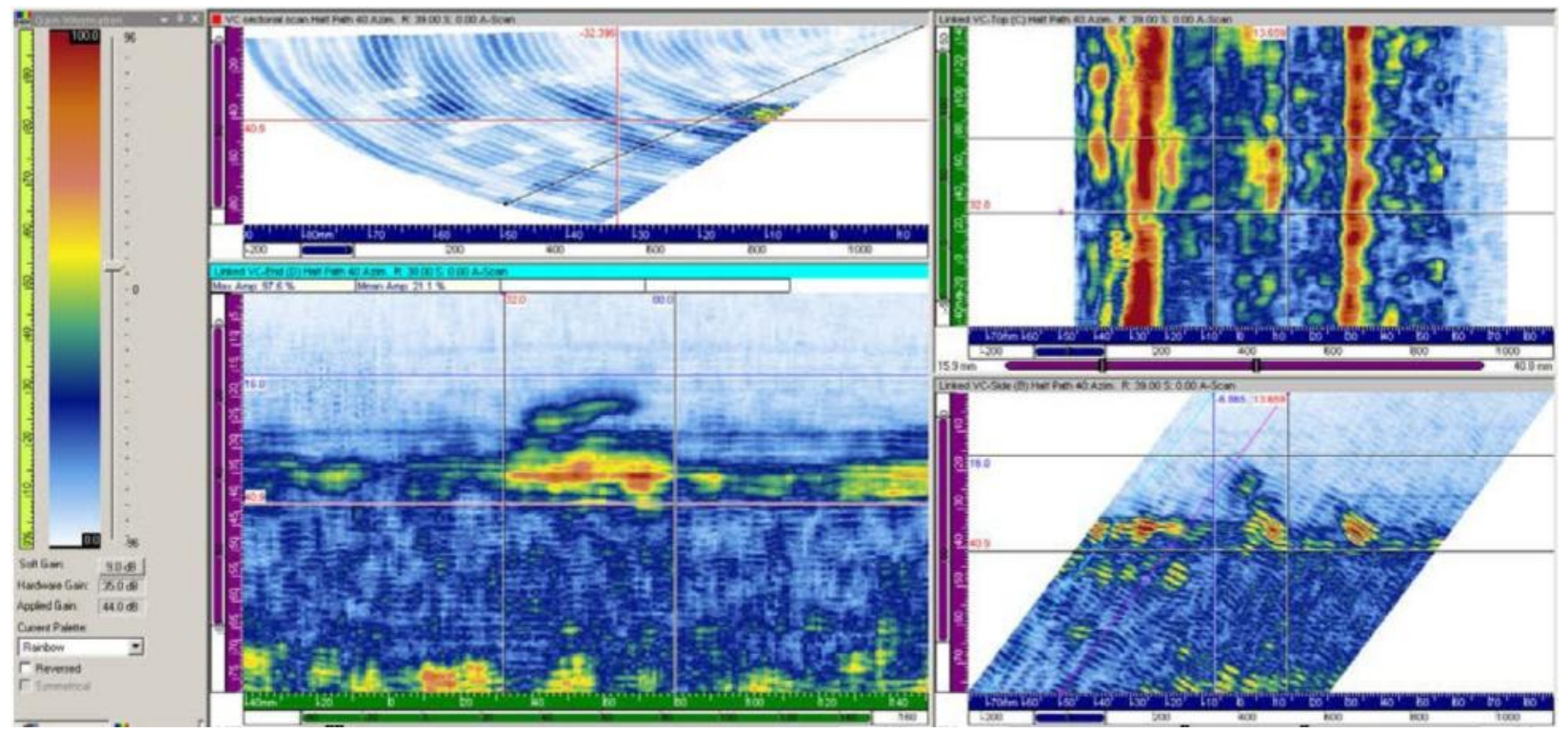

Figure C.6. 10C-011 Flaw 1 Pipe Side Raster Data at 0.8 MHz, 39 Degrees, Pre FSWOL

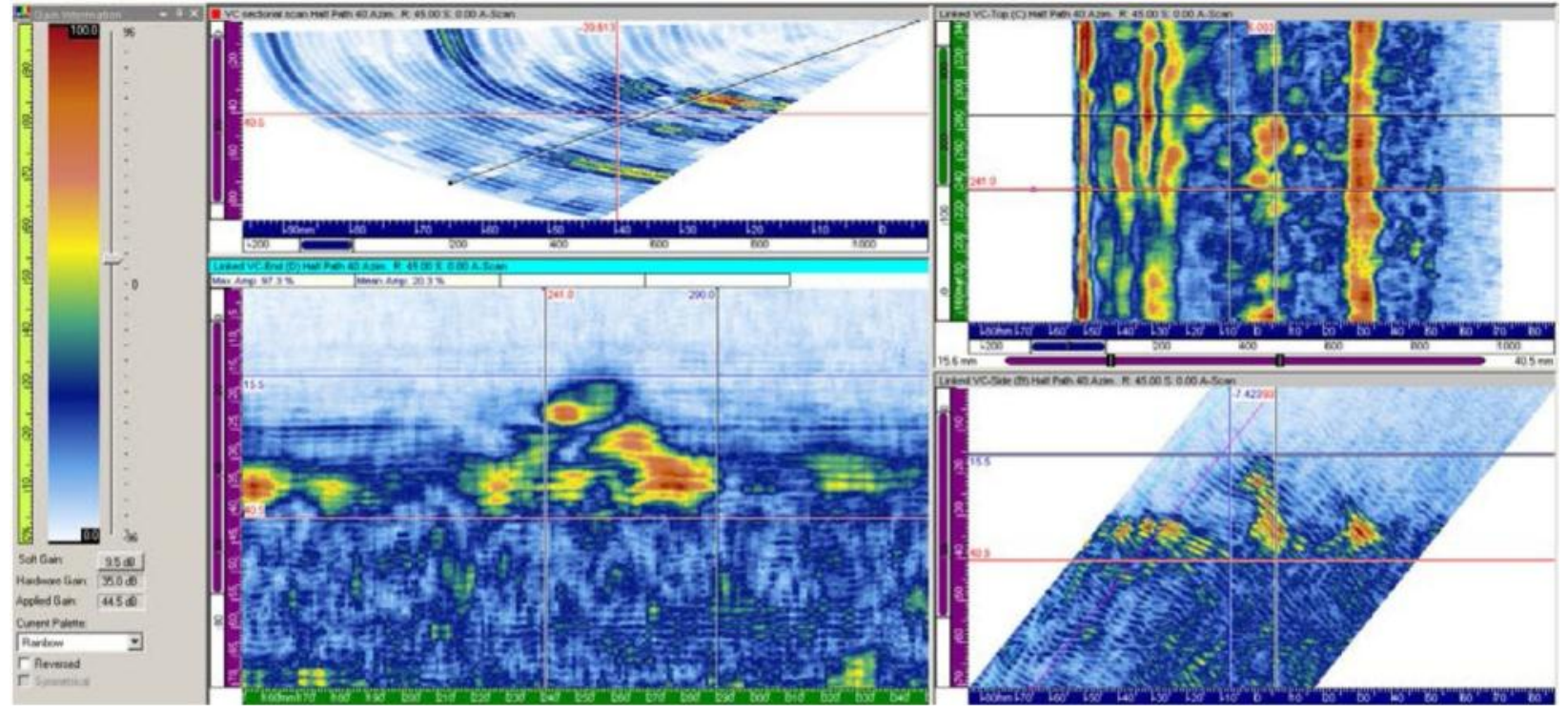

Figure C.7. 10C-011 Flaw 2 Pipe Side Raster Data at 0.8 MHz, 45 Degrees, Pre FSWOL 


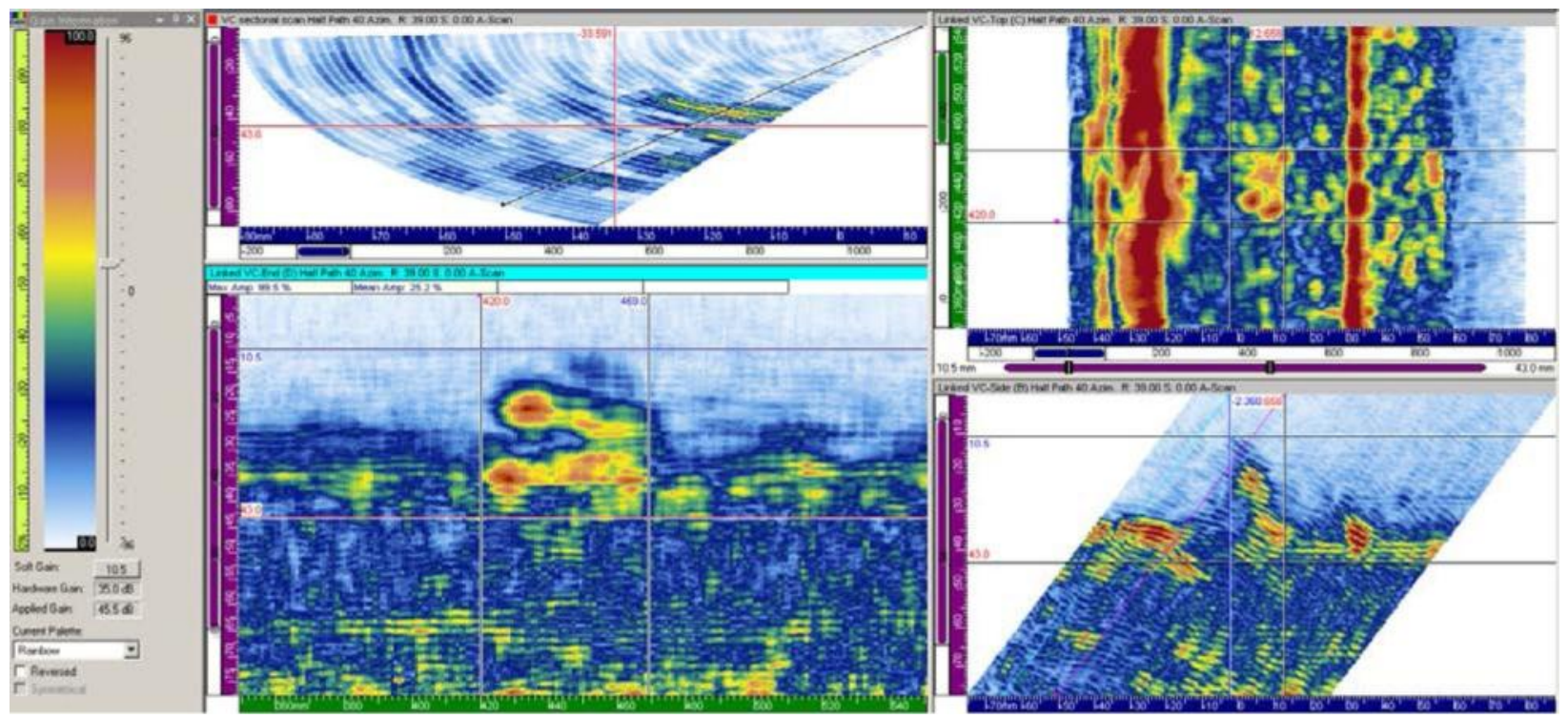

Figure C.8. 10C-011 Flaw 3 Pipe Side Raster Data at 0.8 MHz, 39 Degrees, Pre FSWOL

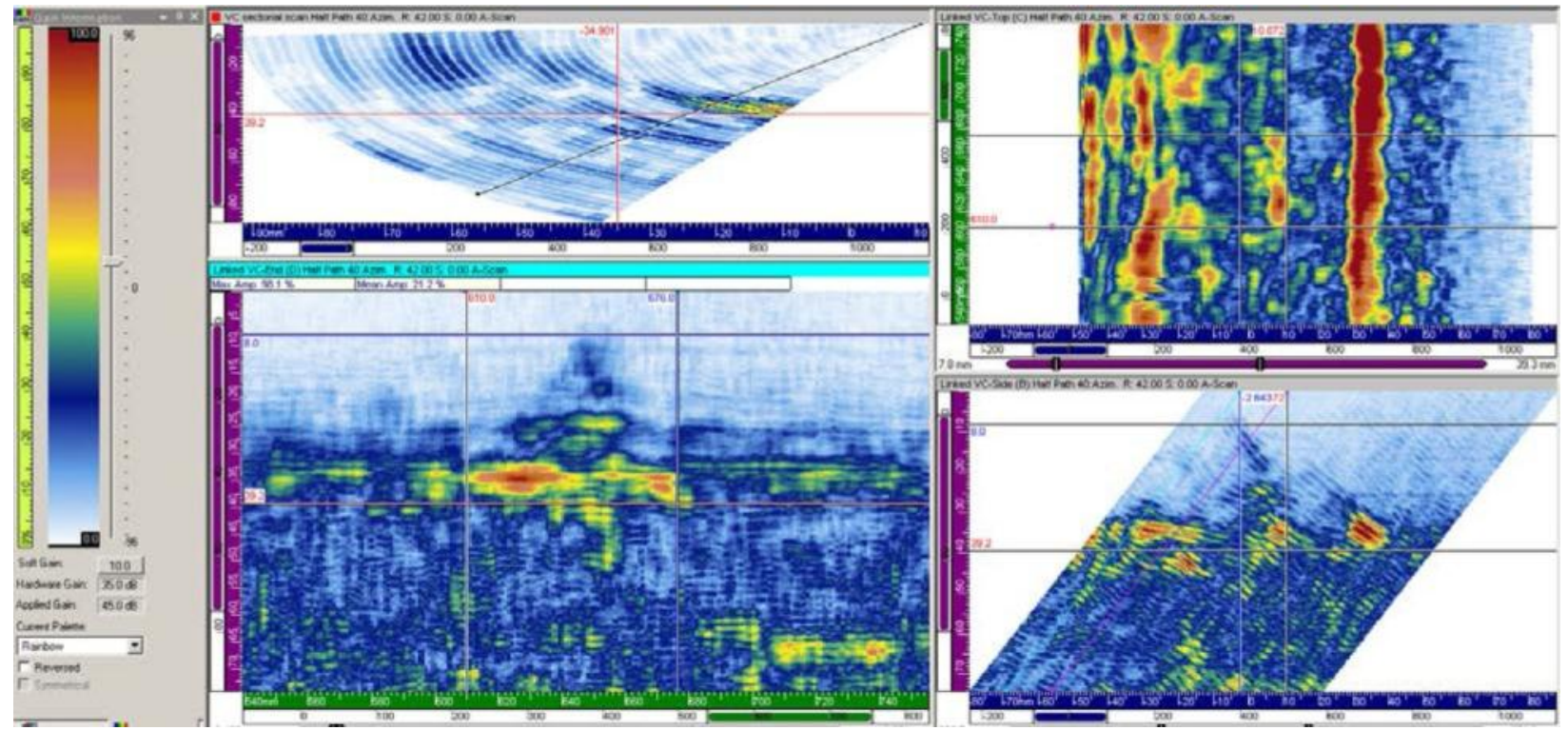

Figure C.9. 10C-011 Flaw 4 Pipe Side Raster Data at 0.8 MHz, 42 Degrees, Pre FSWOL 


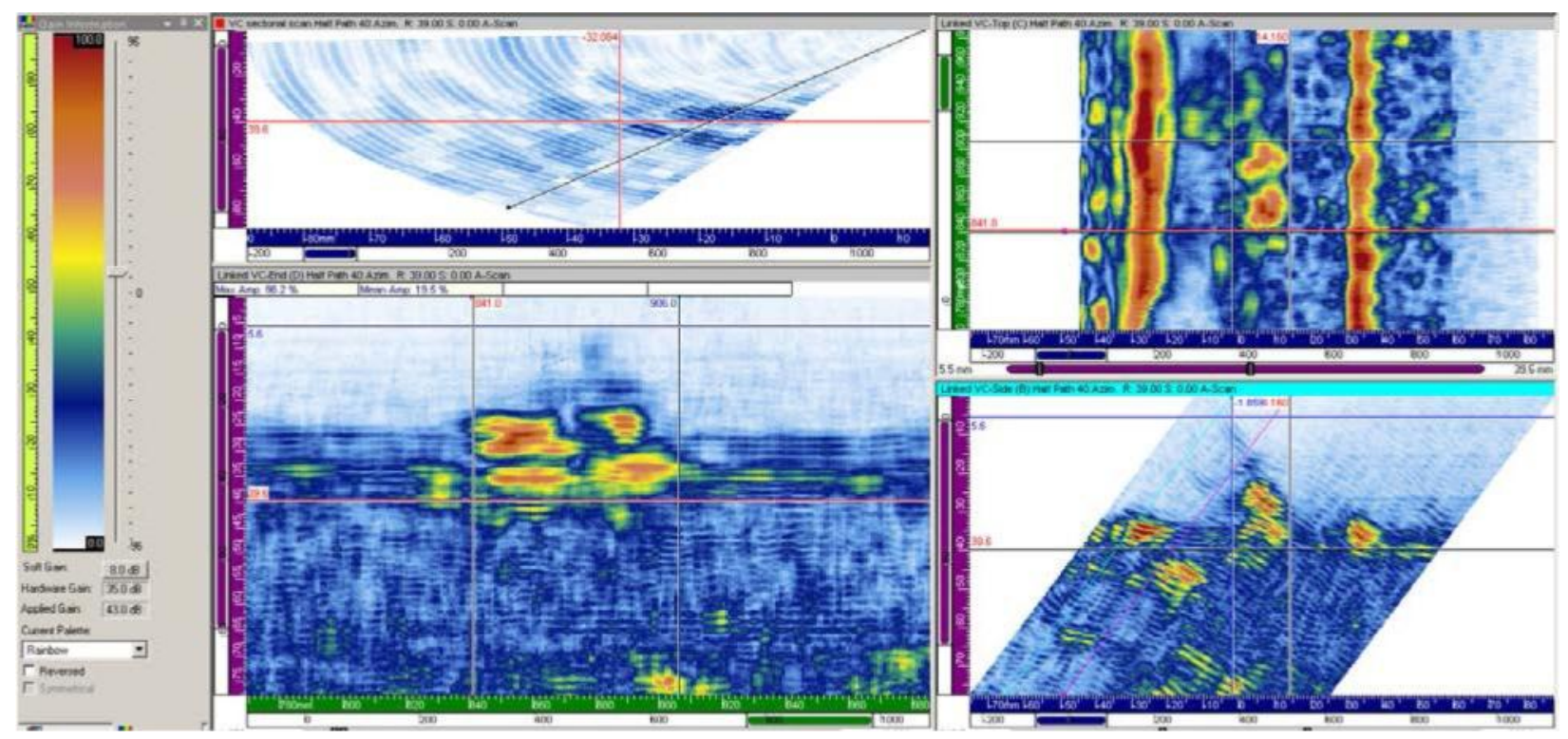

Figure C.10. 10C-011 Flaw 5 Pipe Side Raster Data at 0.8 MHz, 39 Degrees, Pre FSWOL 


\section{C.1.3 Raster Data at 1.0 MHz Nozzle Side on Flaws 1-5}

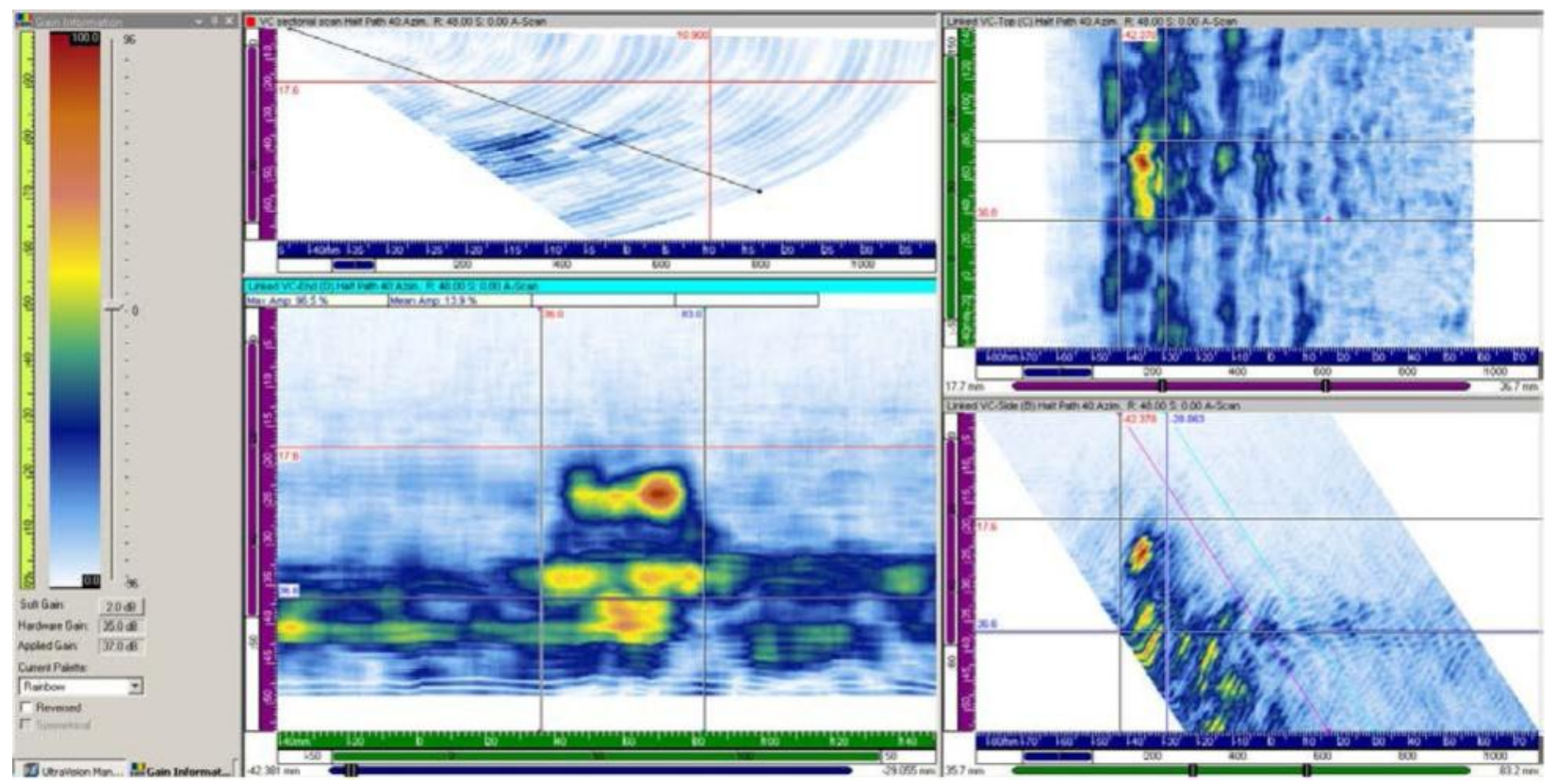

Figure C.11. 10C-011 Flaw 1 Nozzle Side Raster Data at 1.0 MHz, 48 Degrees, Pre FSWOL
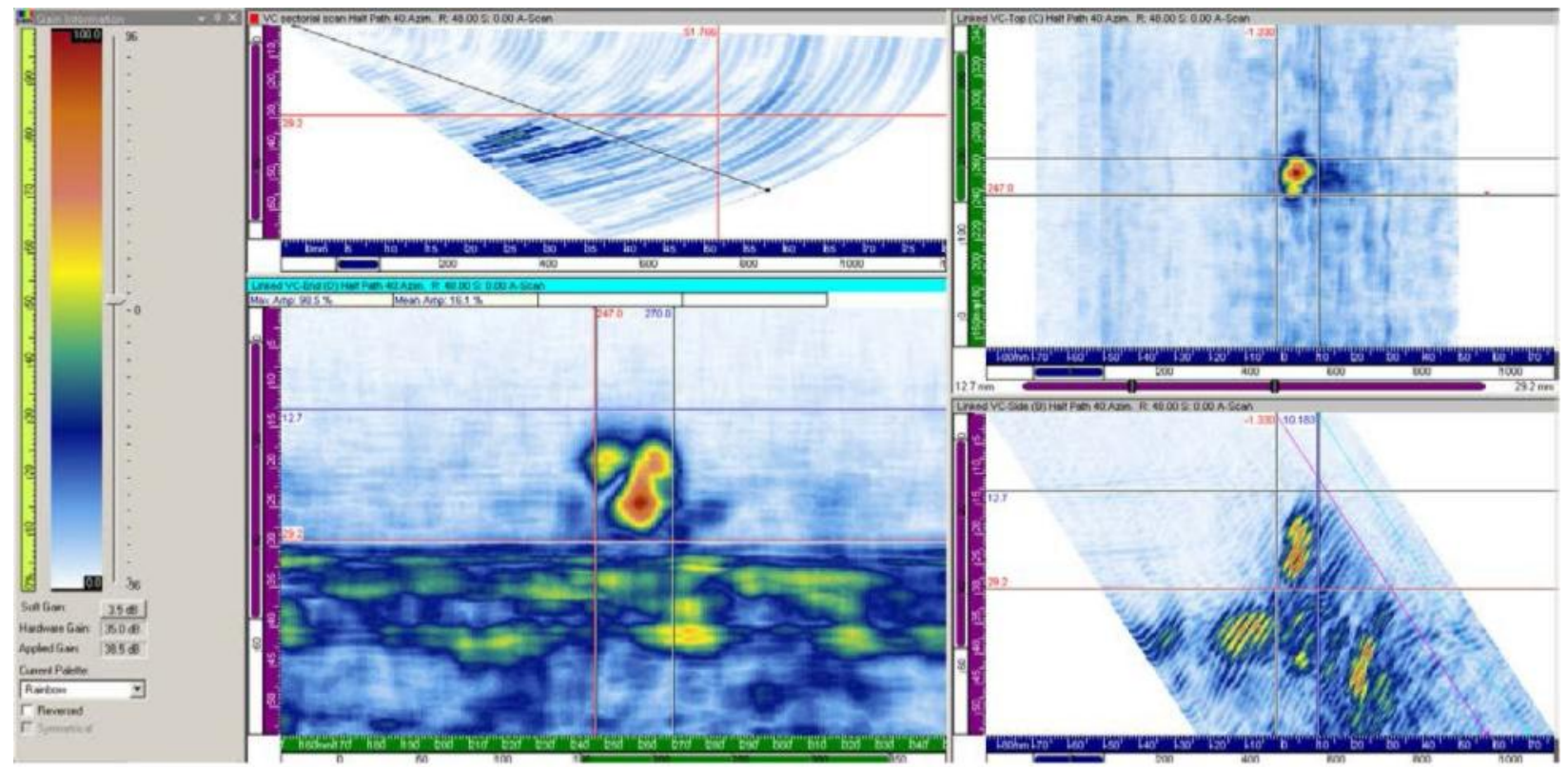

Figure C.12. 10C-011 Flaw 2 Nozzle Side Raster Data at 1.0 MHz, 48 Degrees, Pre FSWOL 


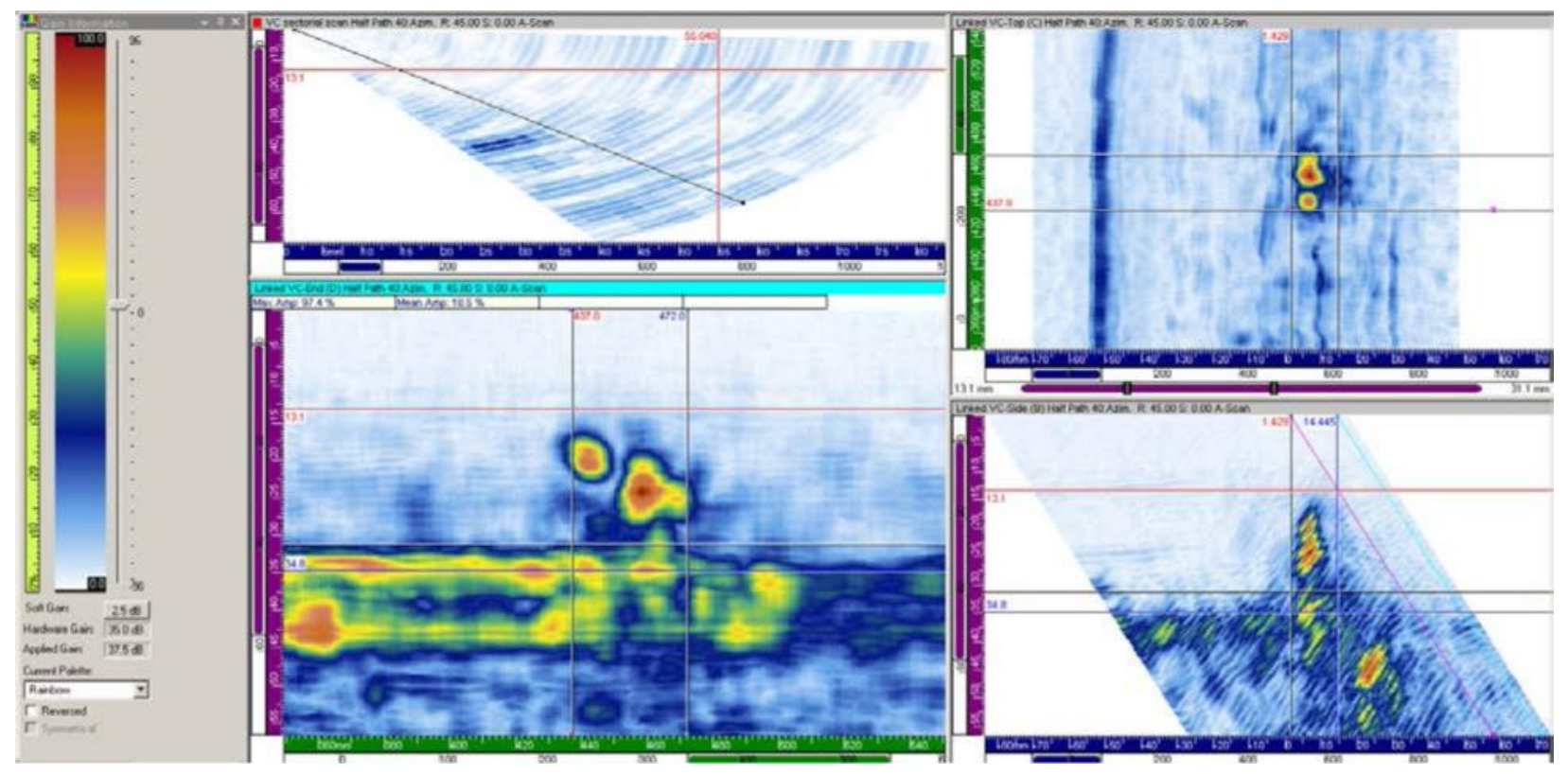

Figure C.13. 10C-011 Flaw 3 Nozzle Side Raster Data at 1.0 MHz, 45 Degrees, Pre FSWOL

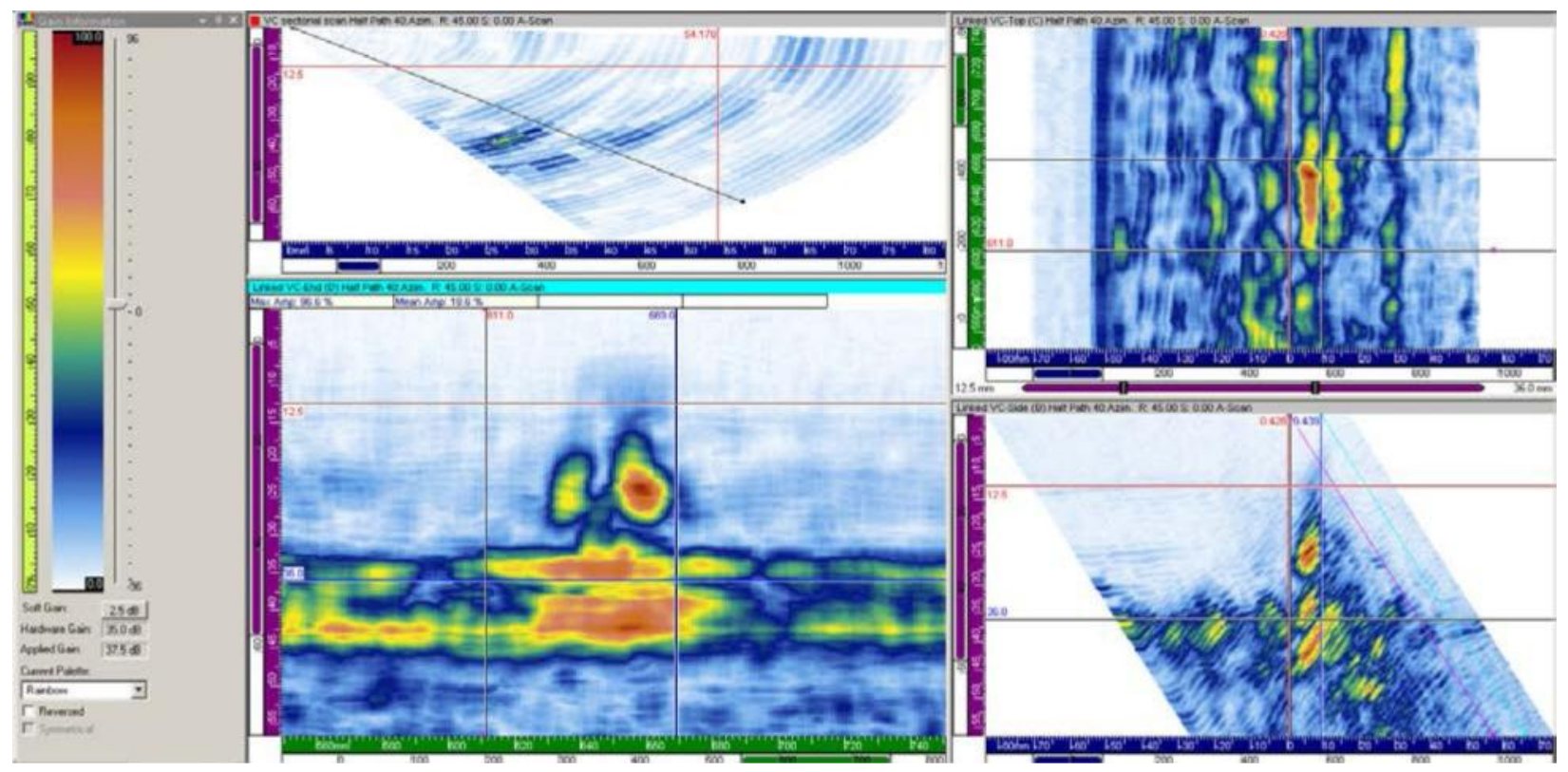

Figure C.14. 10C-011 Flaw 4 Nozzle Side Raster Data at 1.0 MHz, 45 Degrees, Pre FSWOL 


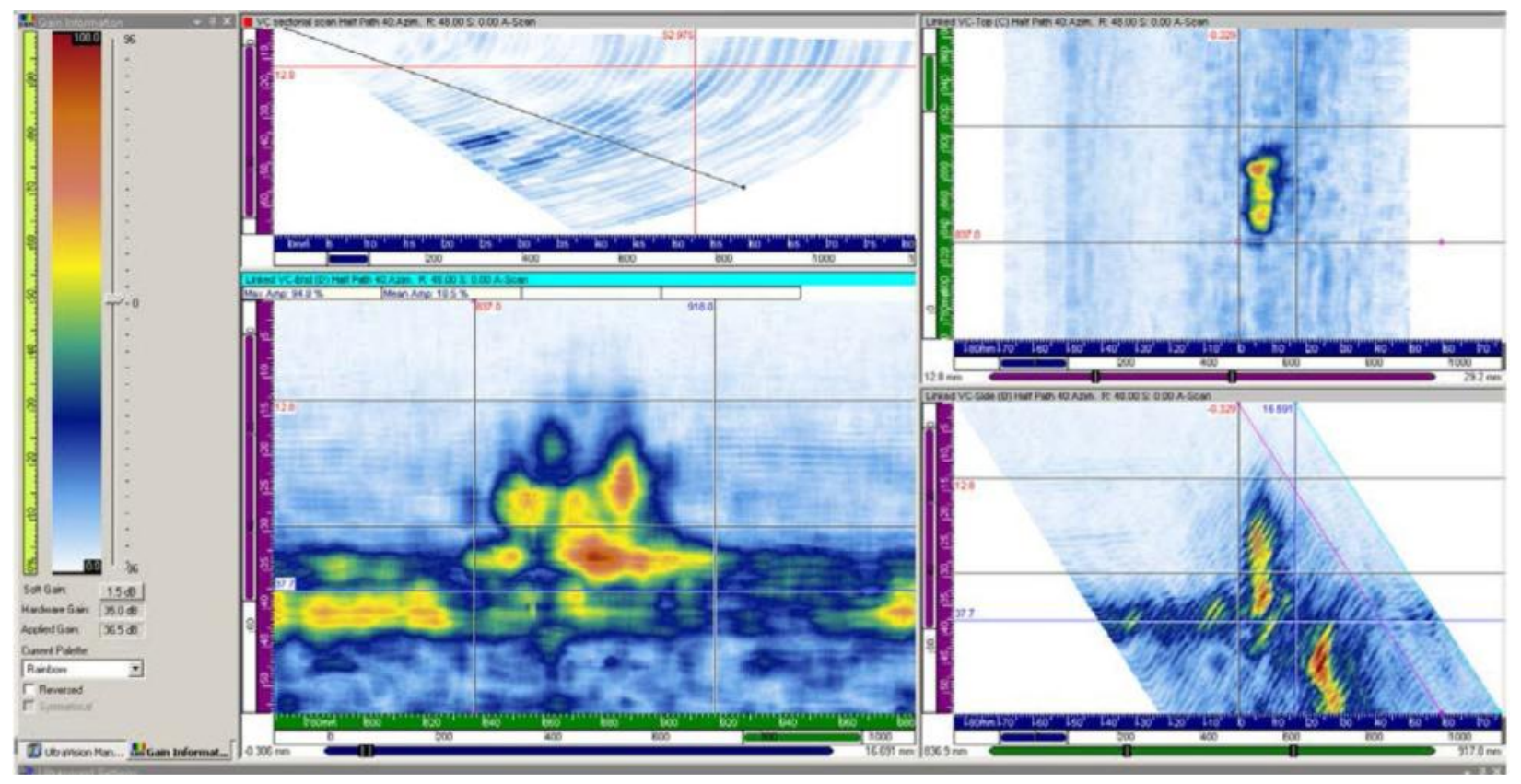

Figure C.15. 10C-011 Flaw 5 Nozzle Side Raster Data at $1.0 \mathrm{MHz}, 48$ Degrees, Pre FSWOL 


\section{C.1.4 Raster Data at 1.0 MHz Pipe Side on Flaws 1-5}

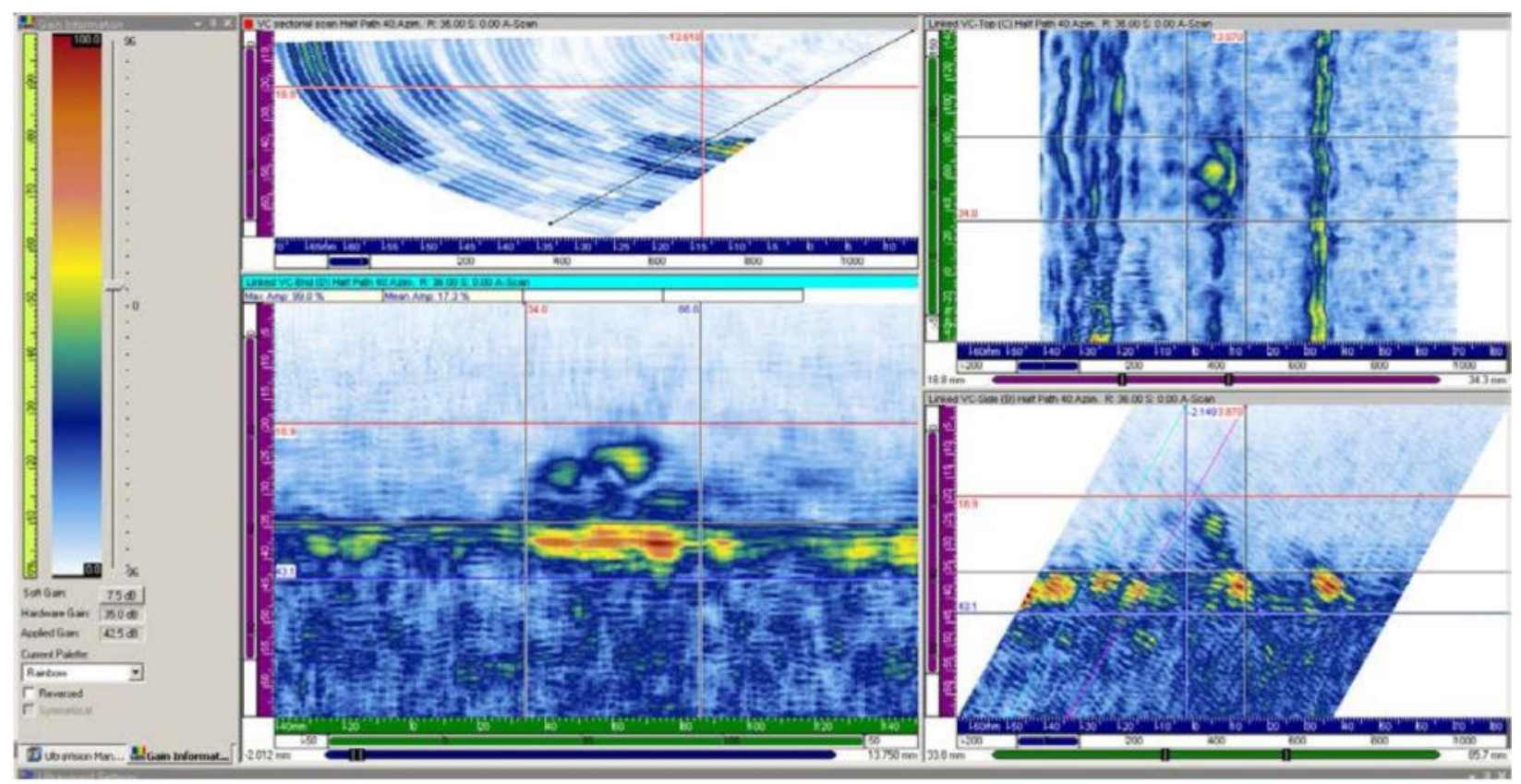

Figure C.16. 10C-011 Flaw 1 Pipe Side Raster Data at 1.0 MHz, 36 Degrees, Pre FSWOL

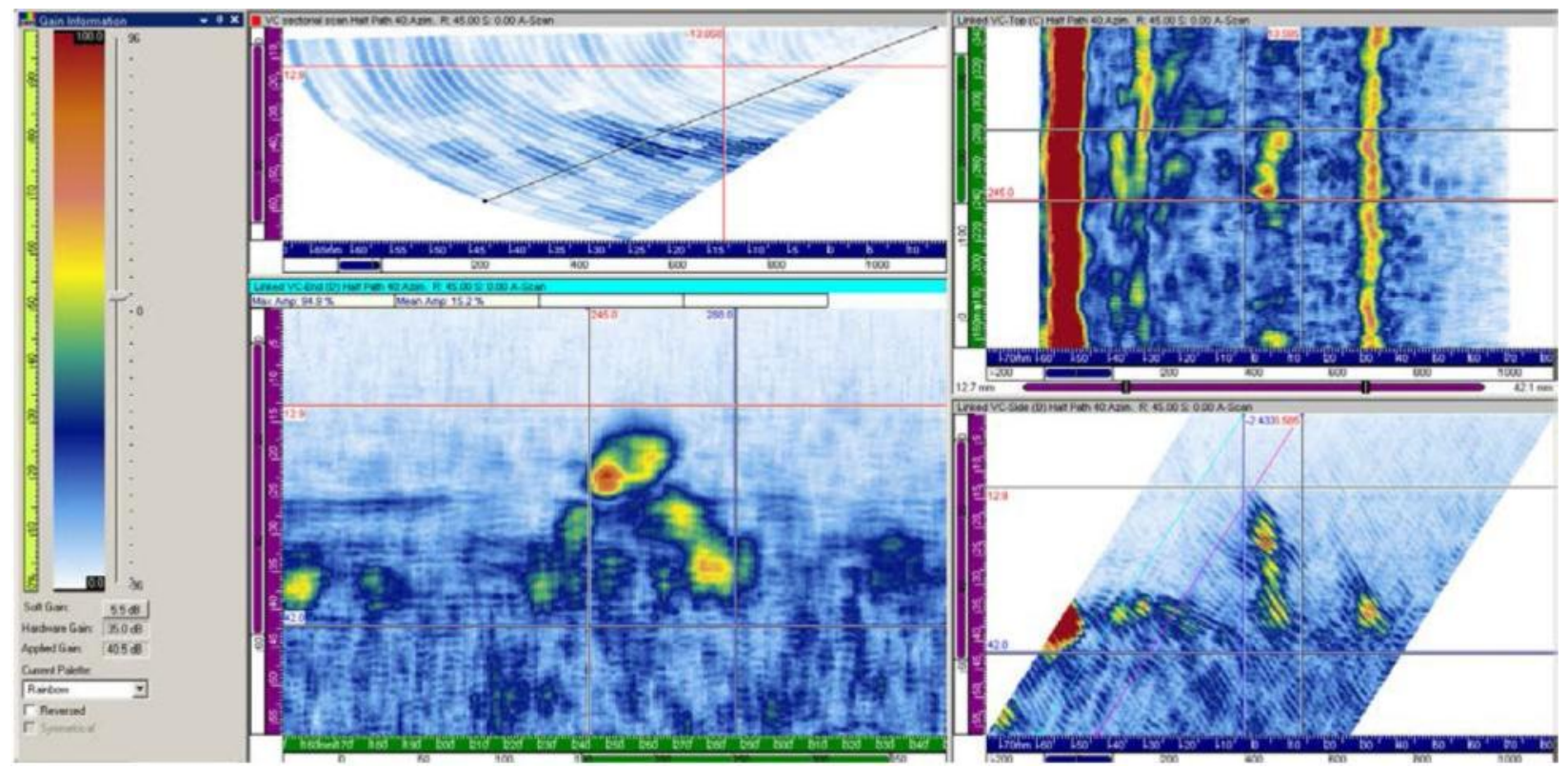

Figure C.17. 10C-011 Flaw 2 Pipe Side Raster Data at 1.0 MHz, 45 Degrees, Pre FSWOL 


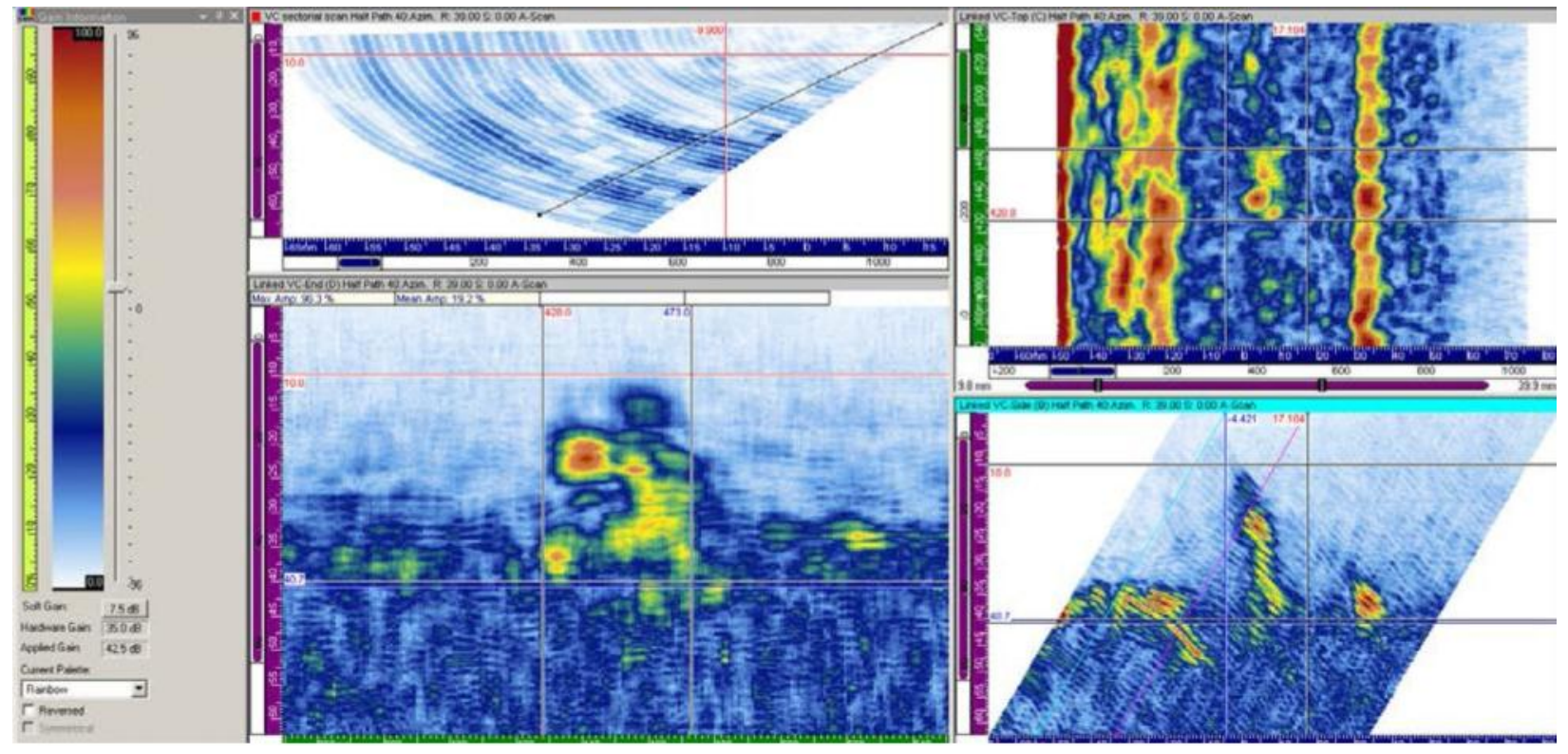

Figure C.18. 10C-011 Flaw 3 Pipe Side Raster Data at 1.0 MHz, 39 Degrees, Pre FSWOL

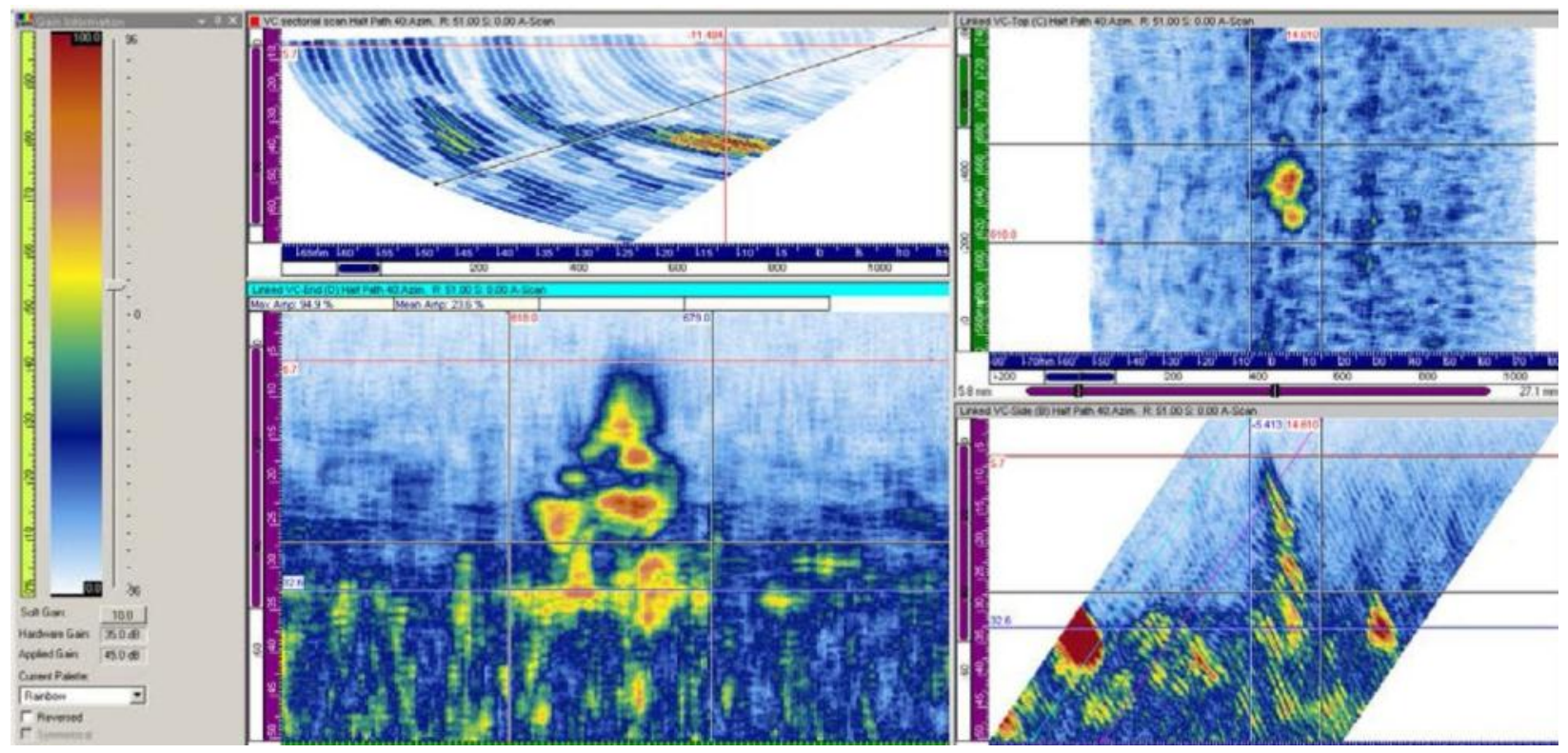

Figure C.19. 10C-011 Flaw 4 Pipe Side Raster Data at 1.0 MHz, 51 Degrees, Pre FSWOL 


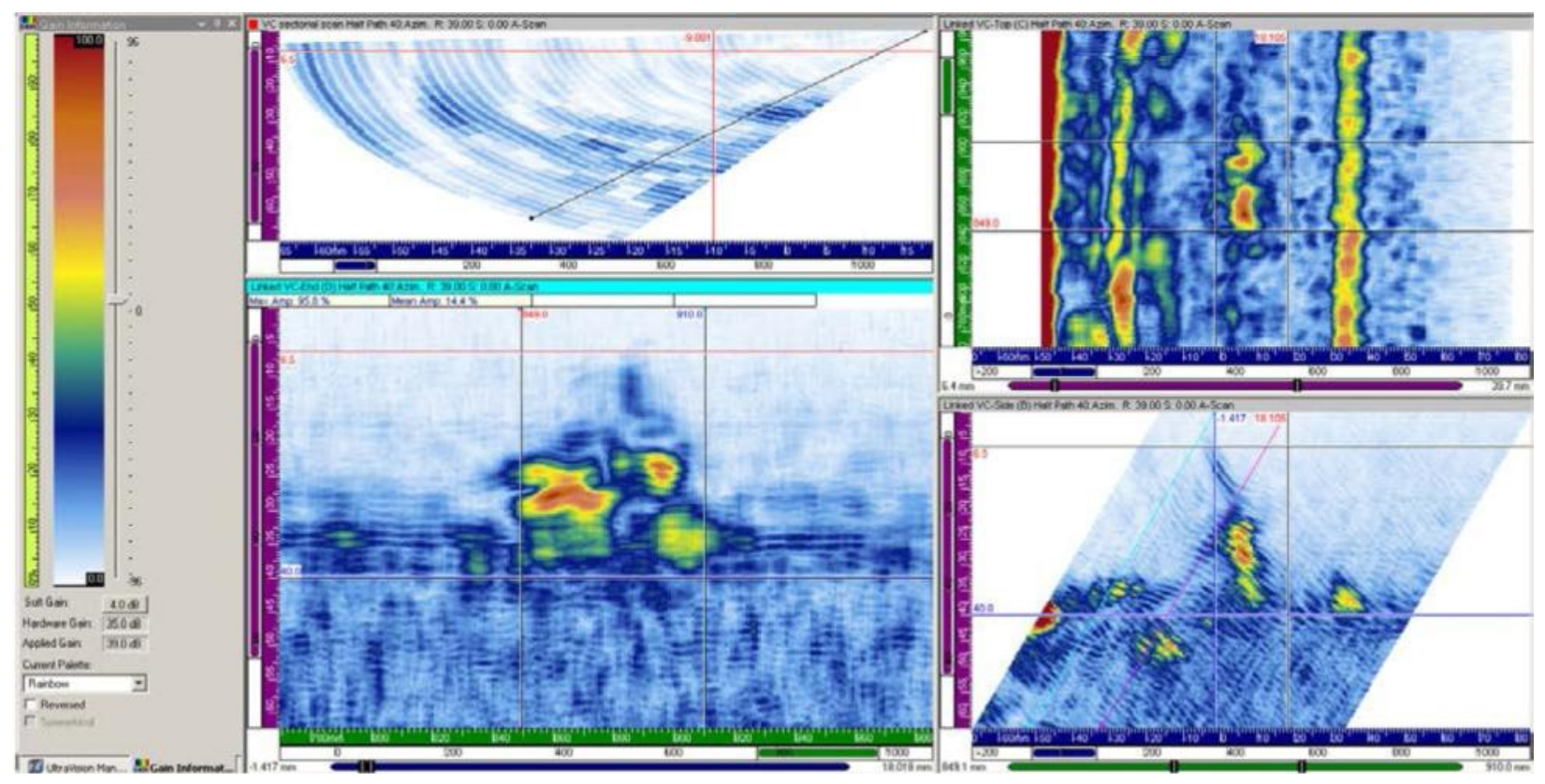

Figure C.20. 10C-011 Flaw 5 Pipe Side Raster Data at 1.0 MHz, 39 Degrees, Pre FSWOL 


\section{C.1.5 Raster Data at 1.5 MHz Nozzle Side on Flaws 1-5}

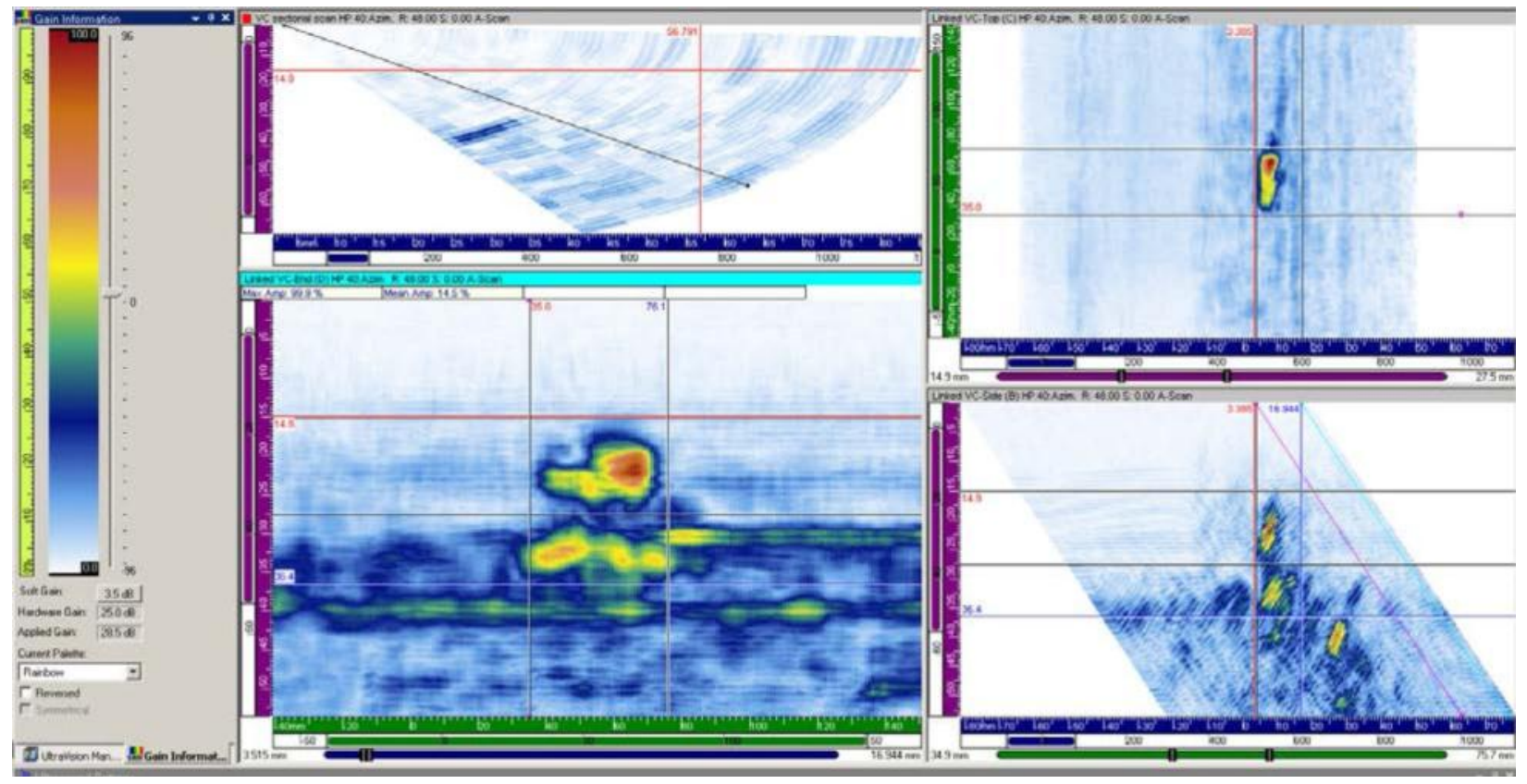

Figure C.21. 10C-011 Flaw 1 Nozzle Side Raster Data at $1.5 \mathrm{MHz}, 48$ Degrees, Pre FSWOL

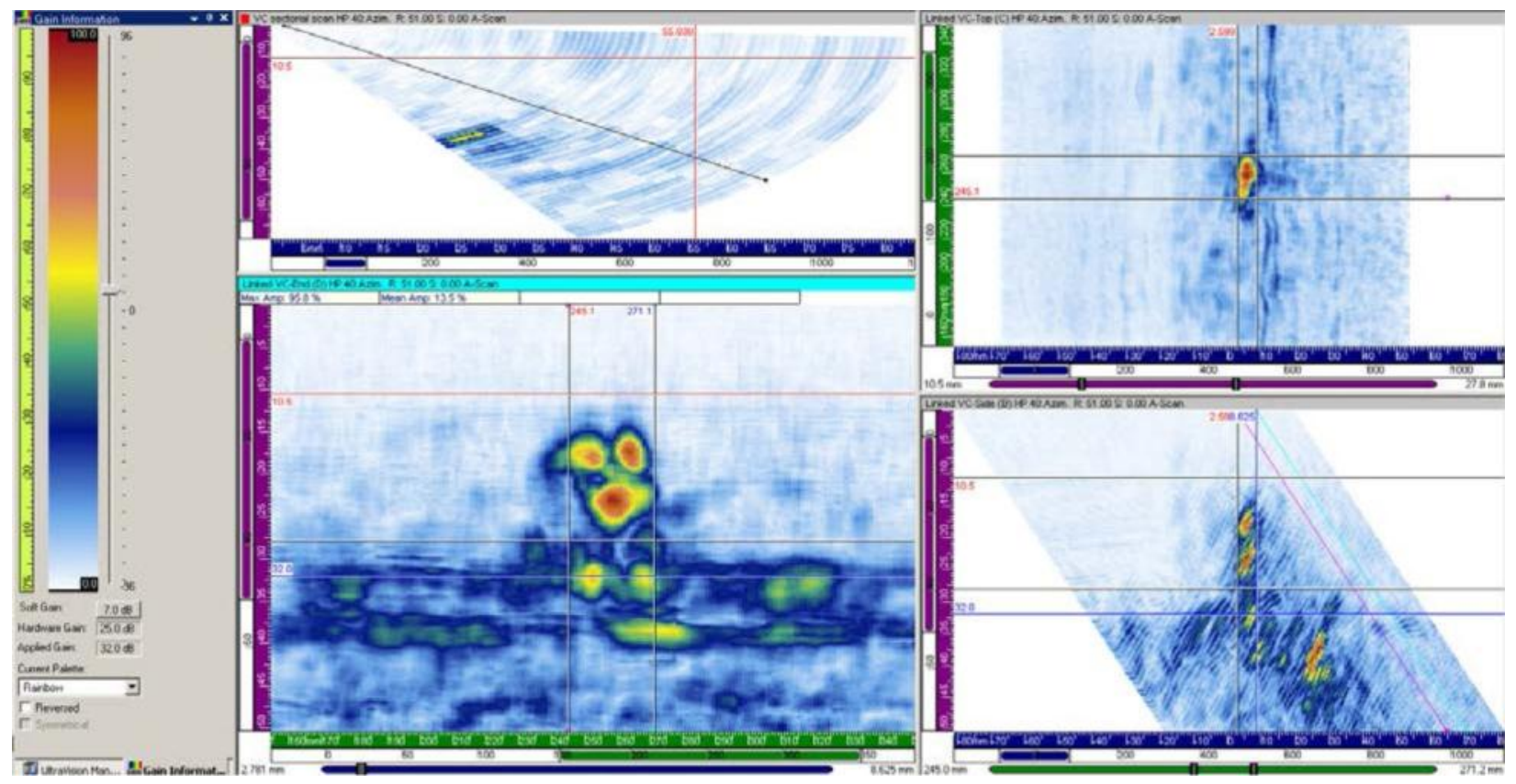

Figure C.22. 10C-011 Flaw 2 Nozzle Side Raster Data at $1.5 \mathrm{MHz}, 51$ Degrees, Pre FSWOL 


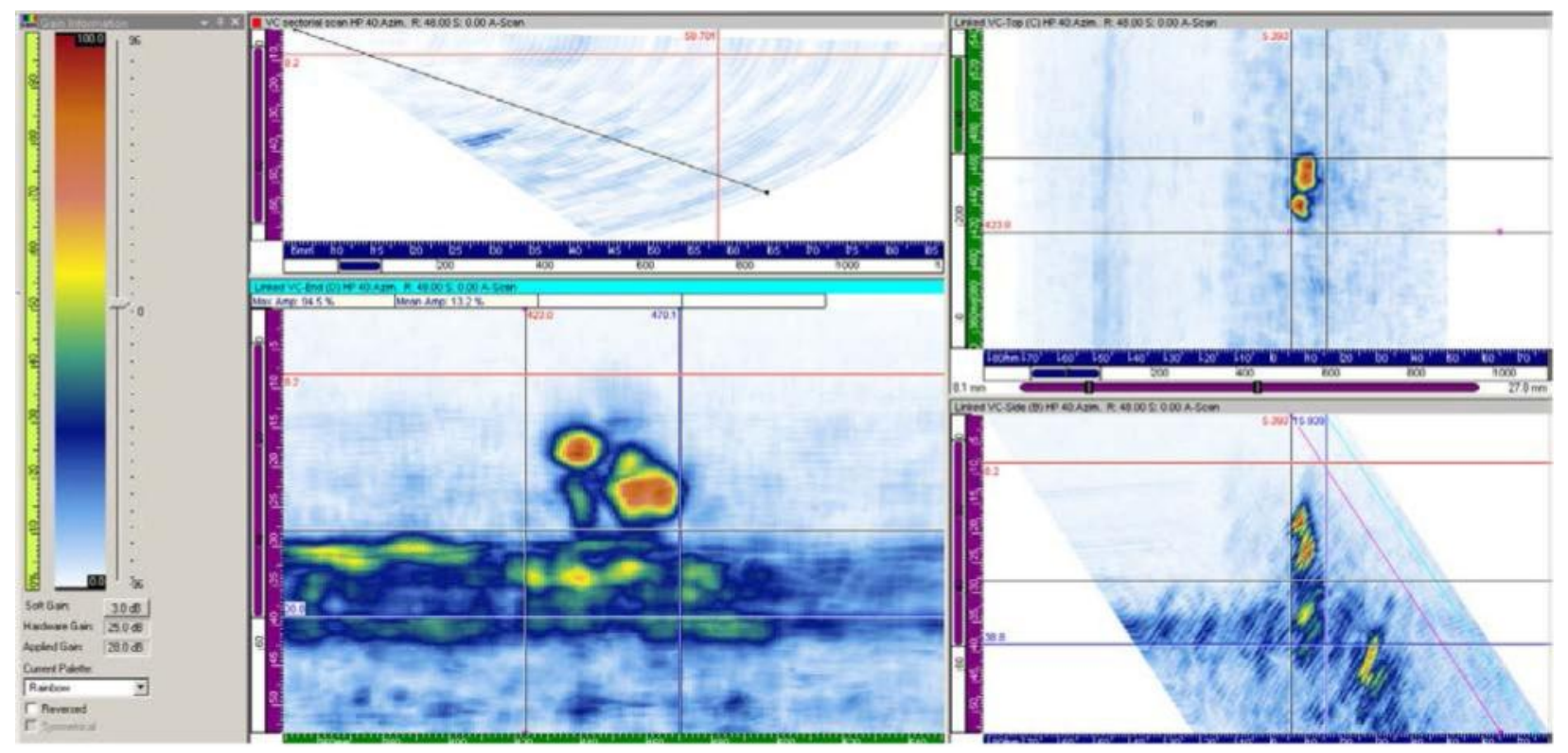

Figure C.23. 10C-011 Flaw 3 Nozzle Side Raster Data at 1.5 MHz, 48 Degrees, Pre FSWOL

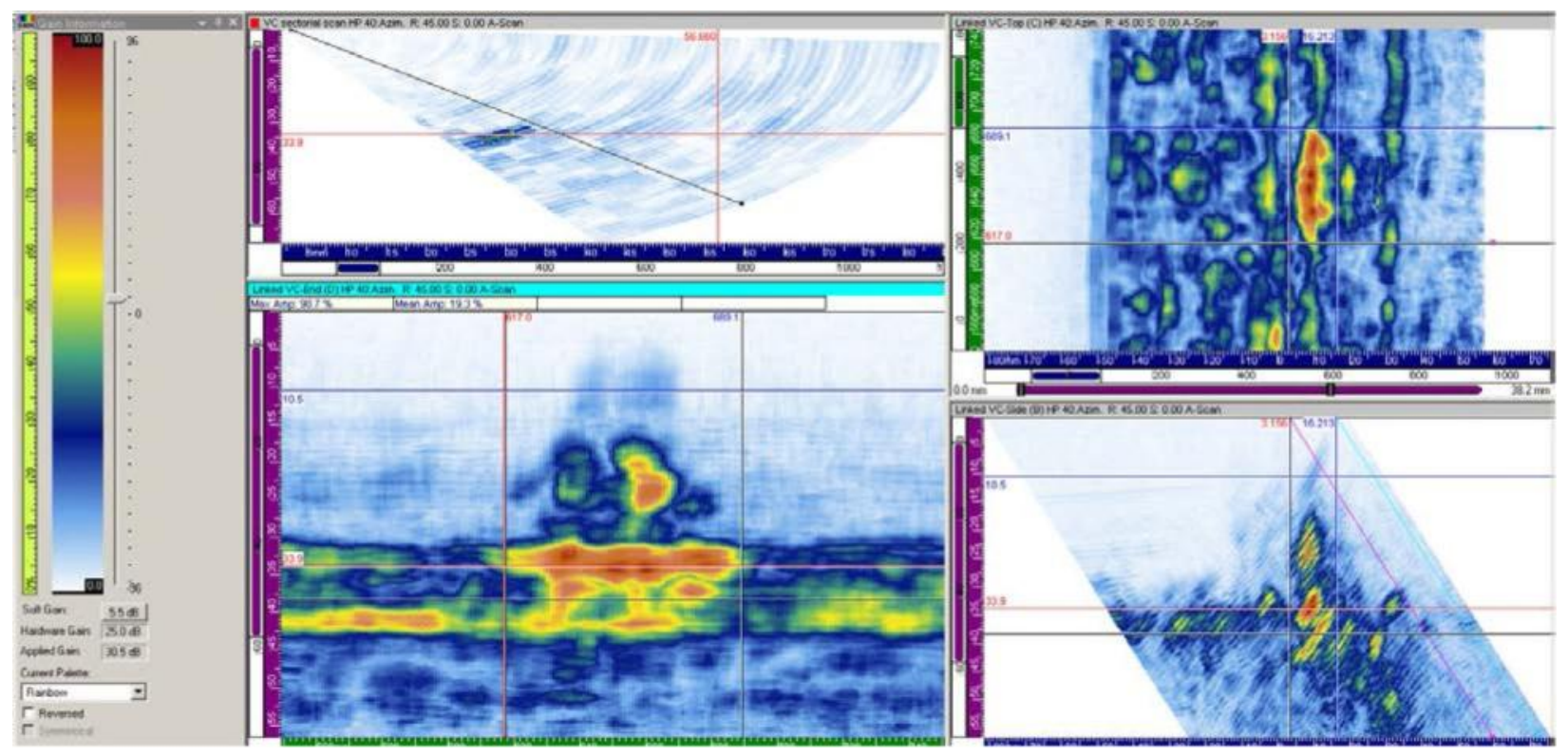

Figure C.24. 10C-011 Flaw 4 Nozzle Side Raster Data at 1.5 MHz, 45 Degrees, Pre FSWOL 


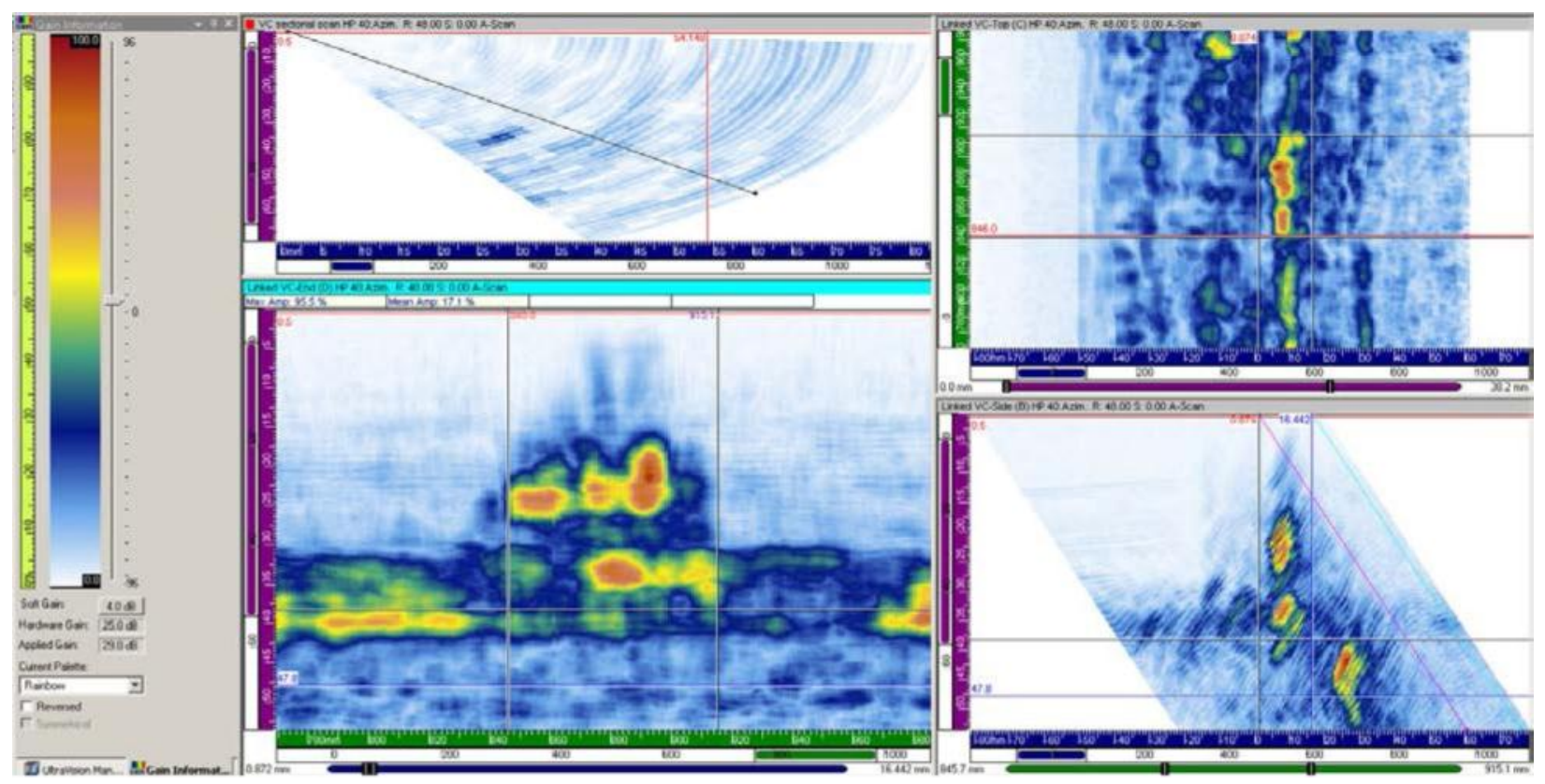

Figure C.25. 10C-011 Flaw 5 Nozzle Side Raster Data at $1.5 \mathrm{MHz}, 48$ Degrees, Pre FSWOL 


\section{C.1.6 Raster Data at 1.5 MHz Pipe Side on Flaws 1-5 Kay}

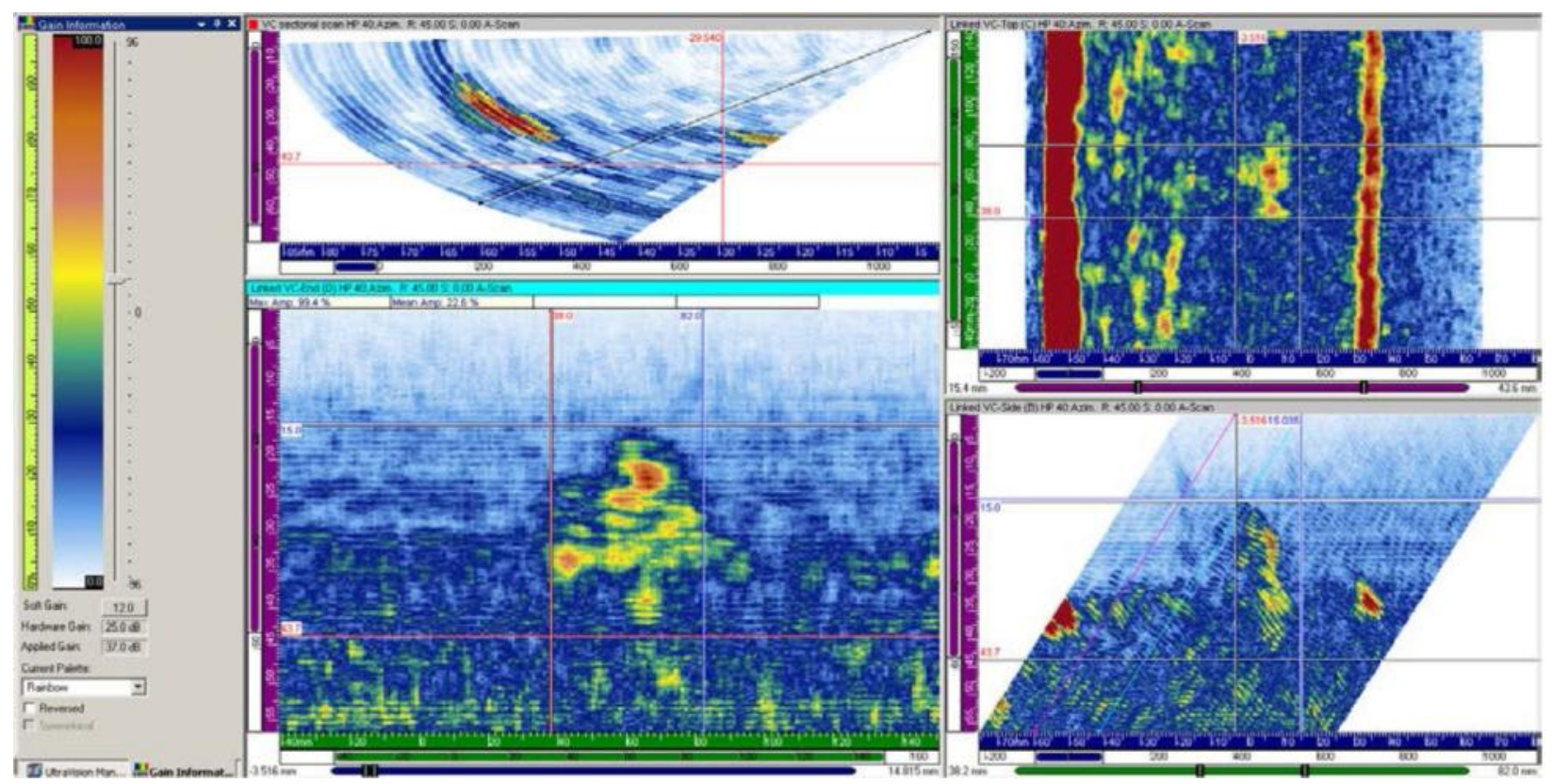

Figure C.26. 10C-011 Flaw 1 Pipe Side Raster Data at 1.5 MHz, 45 Degrees, Pre FSWOL

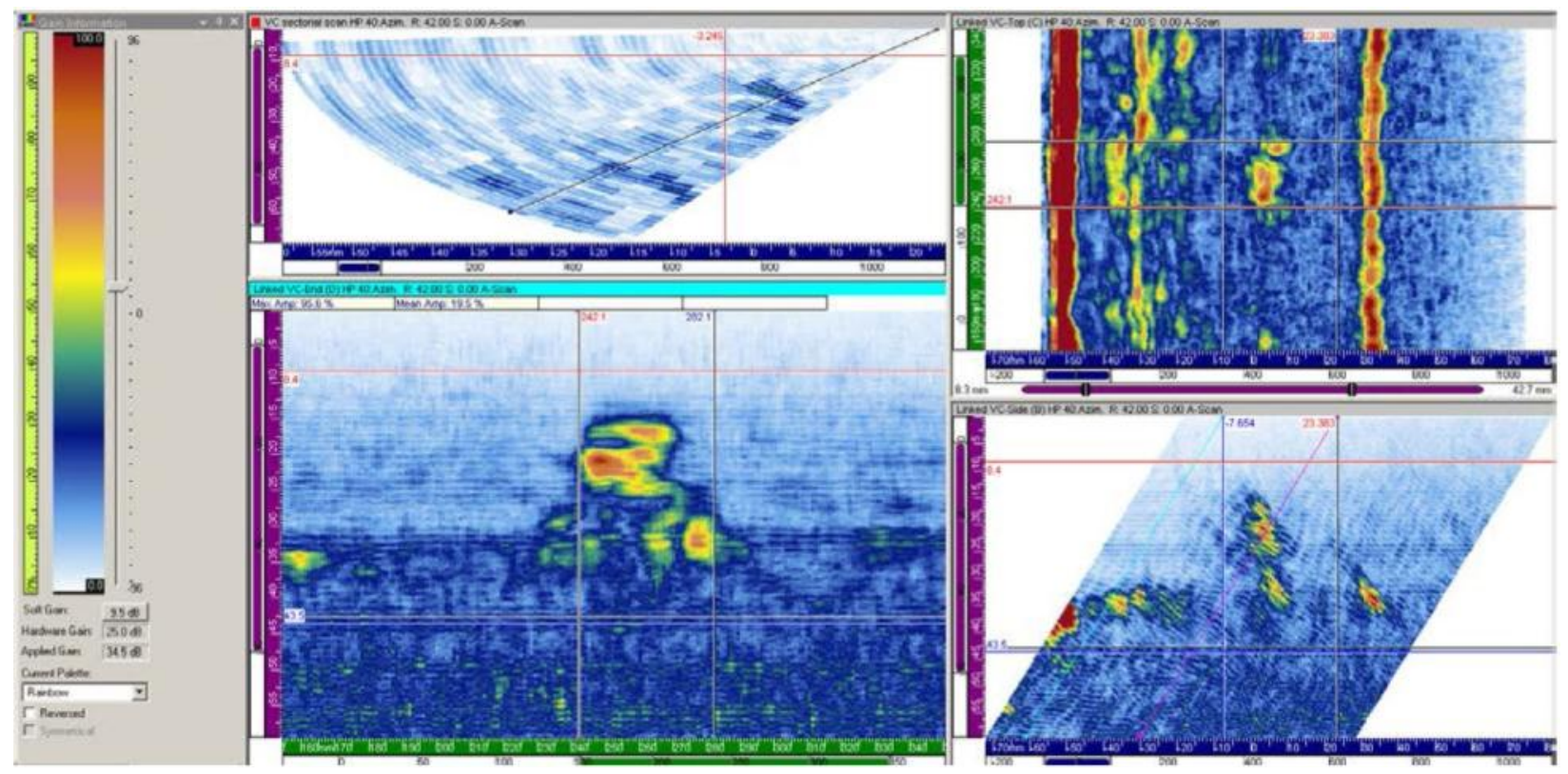

Figure C.27. 10C-011 Flaw 2 Pipe Side Raster Data at 1.5 MHz, 42 Degrees, Pre FSWOL 


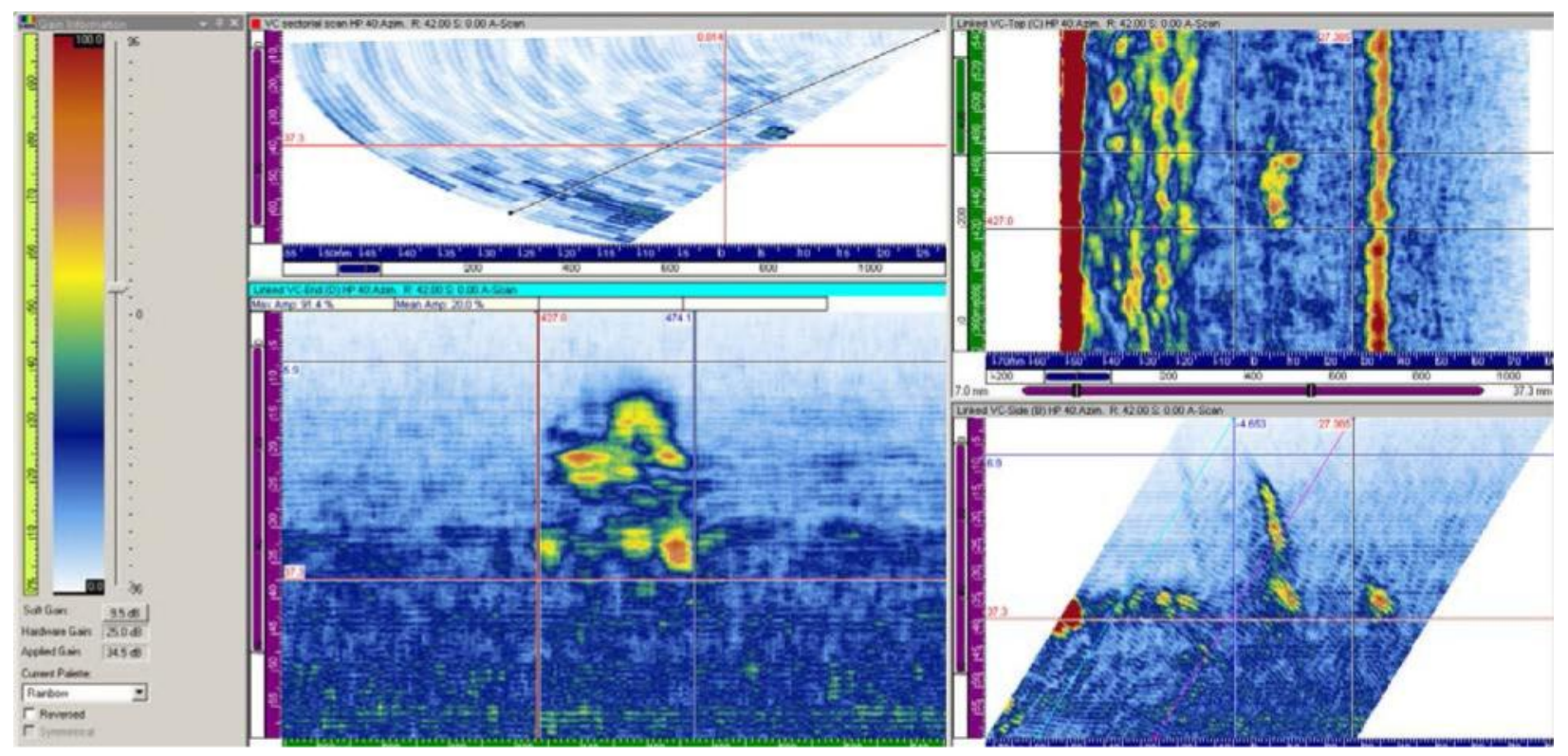

Figure C.28. 10C-011 Flaw 3 Pipe Side Raster Data at 1.5 MHz, 42 Degrees, Pre FSWOL

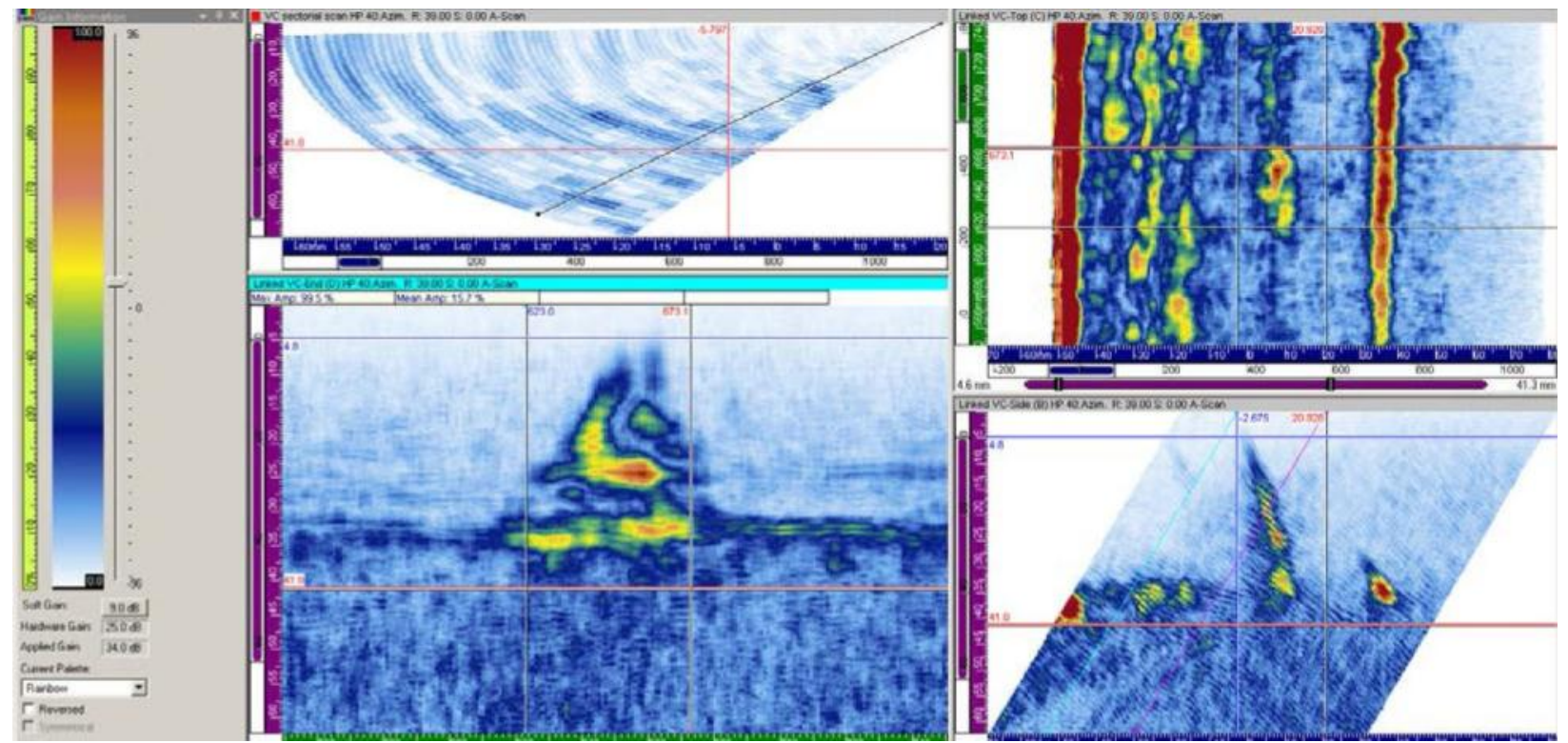

Figure C.29. 10C-011 Flaw 4 Pipe Side Raster Data at 1.5 MHz, 39 Degrees, Pre FSWOL 


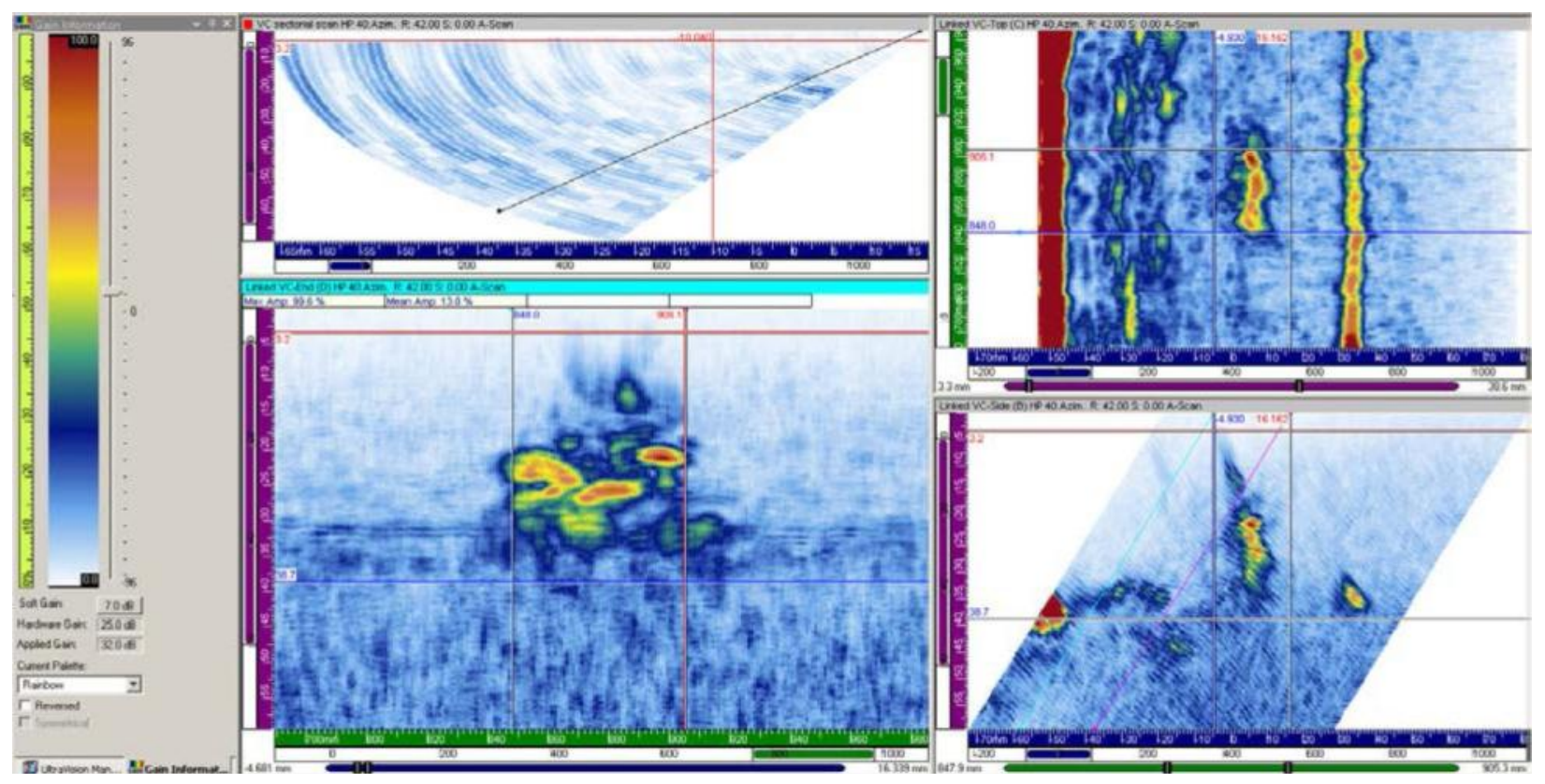

Figure C.30. 10C-011 Flaw 5 Pipe Side Raster Data at 1.5 MHz, 42 Degrees, Pre FSWOL 


\section{C.1.7 Raster Scan Data at 2.0 MHz Nozzle Side on Flaws 1-5}

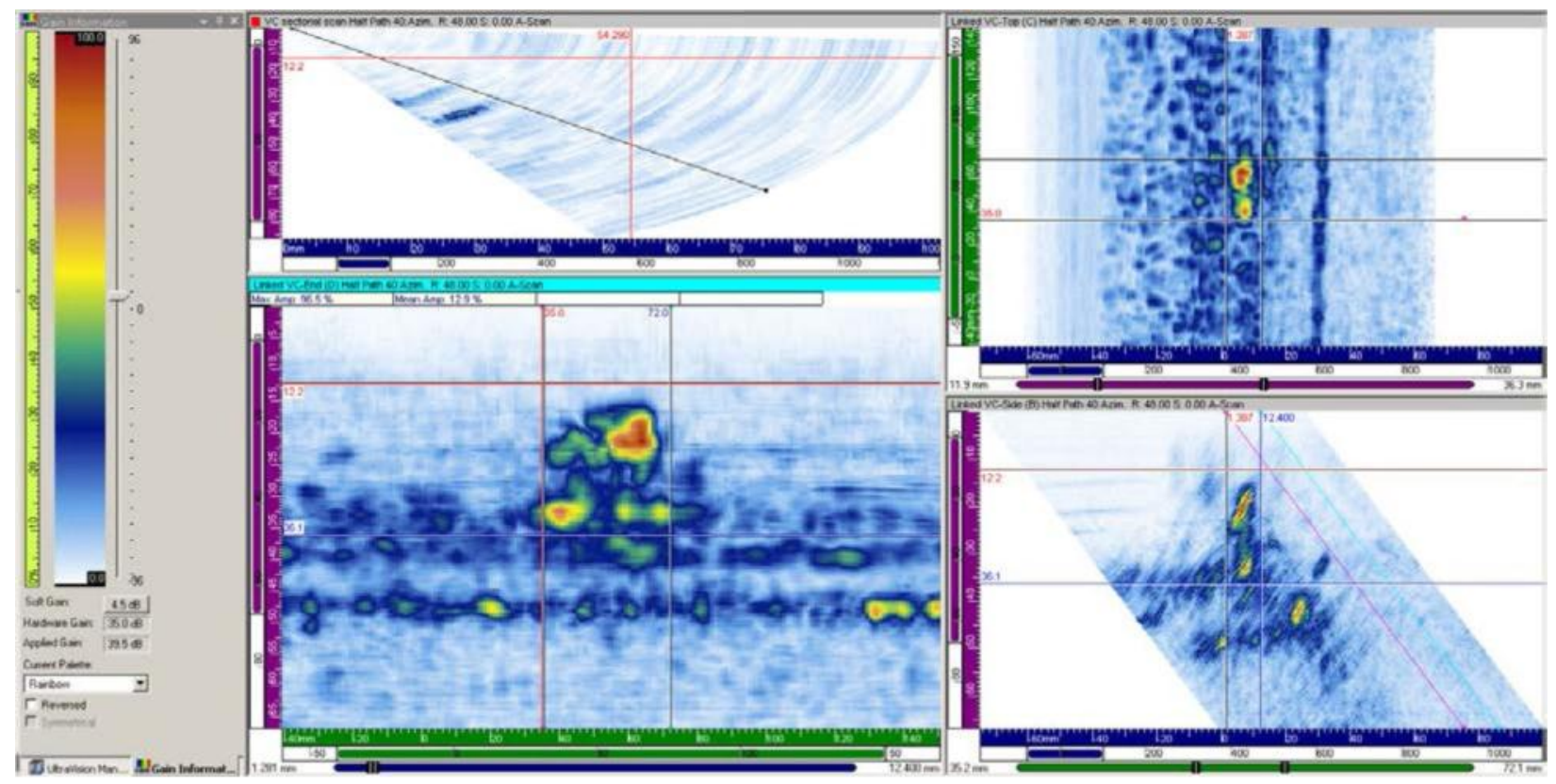

Figure C.31. 10C-011 Flaw 1 Nozzle Side Raster Data at 2.0 MHz, 48 Degrees, Pre FSWOL

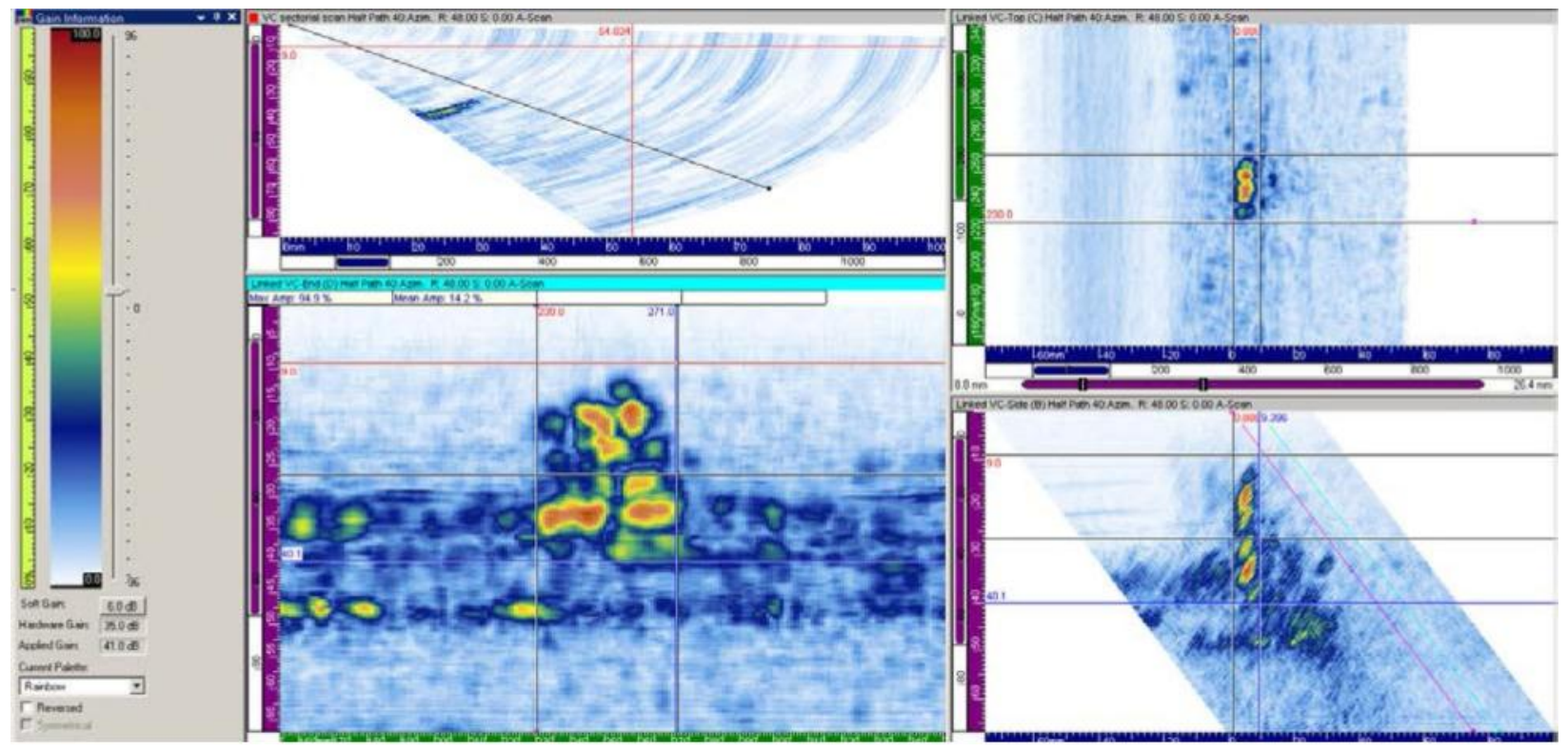

Figure C.32. 10C-011 Flaw 2 Nozzle Side Raster Data at $2.0 \mathrm{MHz}, 48$ Degrees, Pre FSWOL 


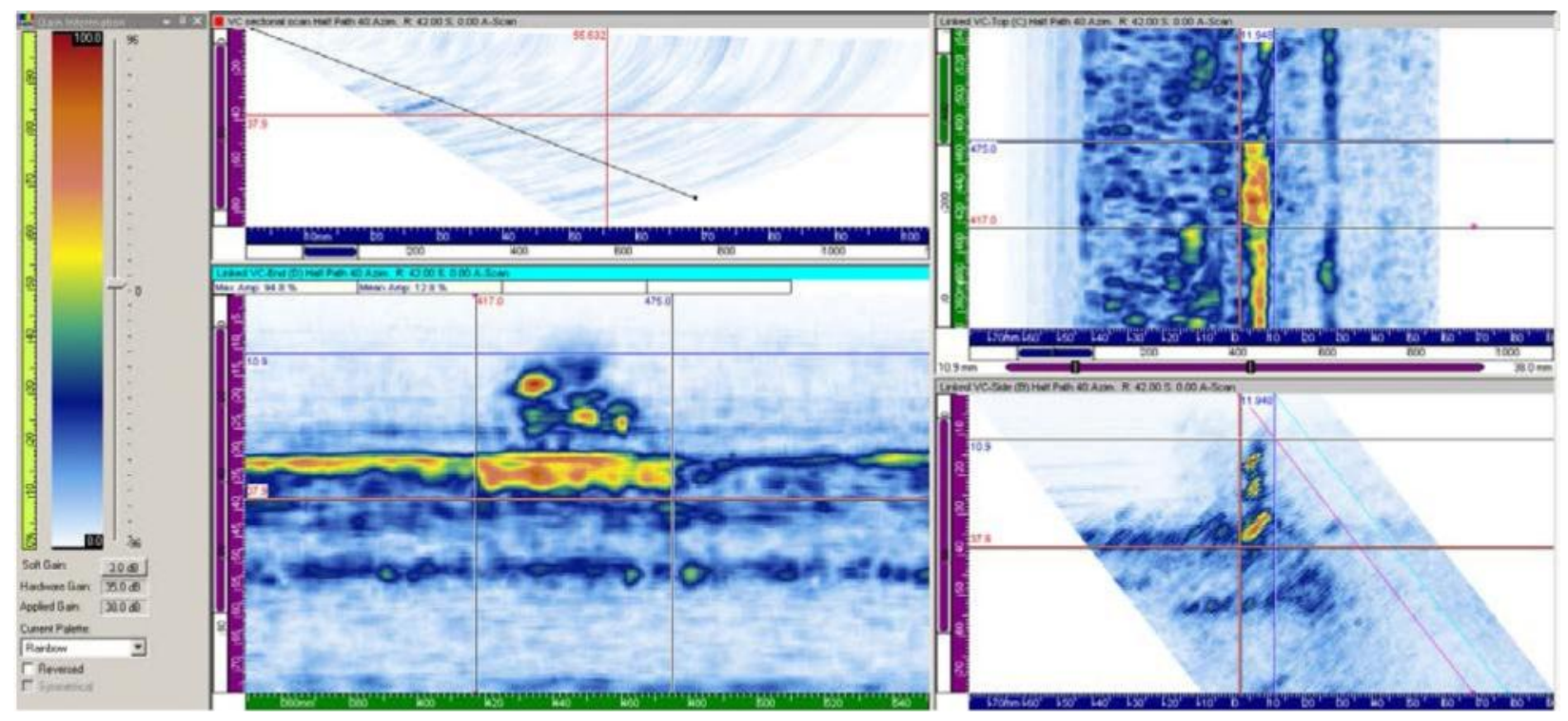

Figure C.33. 10C-011 Flaw 3 Nozzle Side Raster Data at 2.0 MHz, 42 Degrees, Pre FSWOL

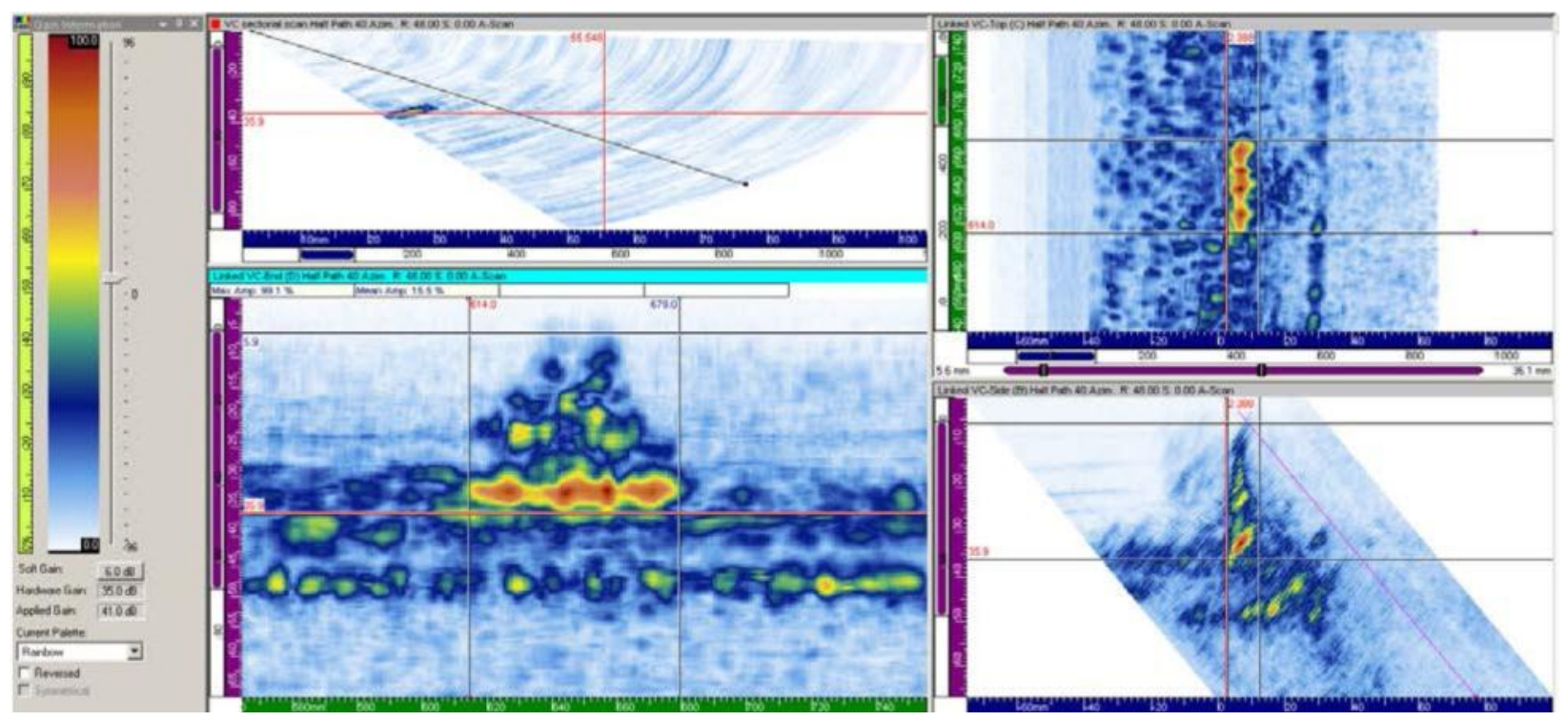

Figure C.34. 10C-011 Flaw 4 Nozzle Side Raster Data at $2.0 \mathrm{MHz}, 48$ Degrees, Pre FSWOL 


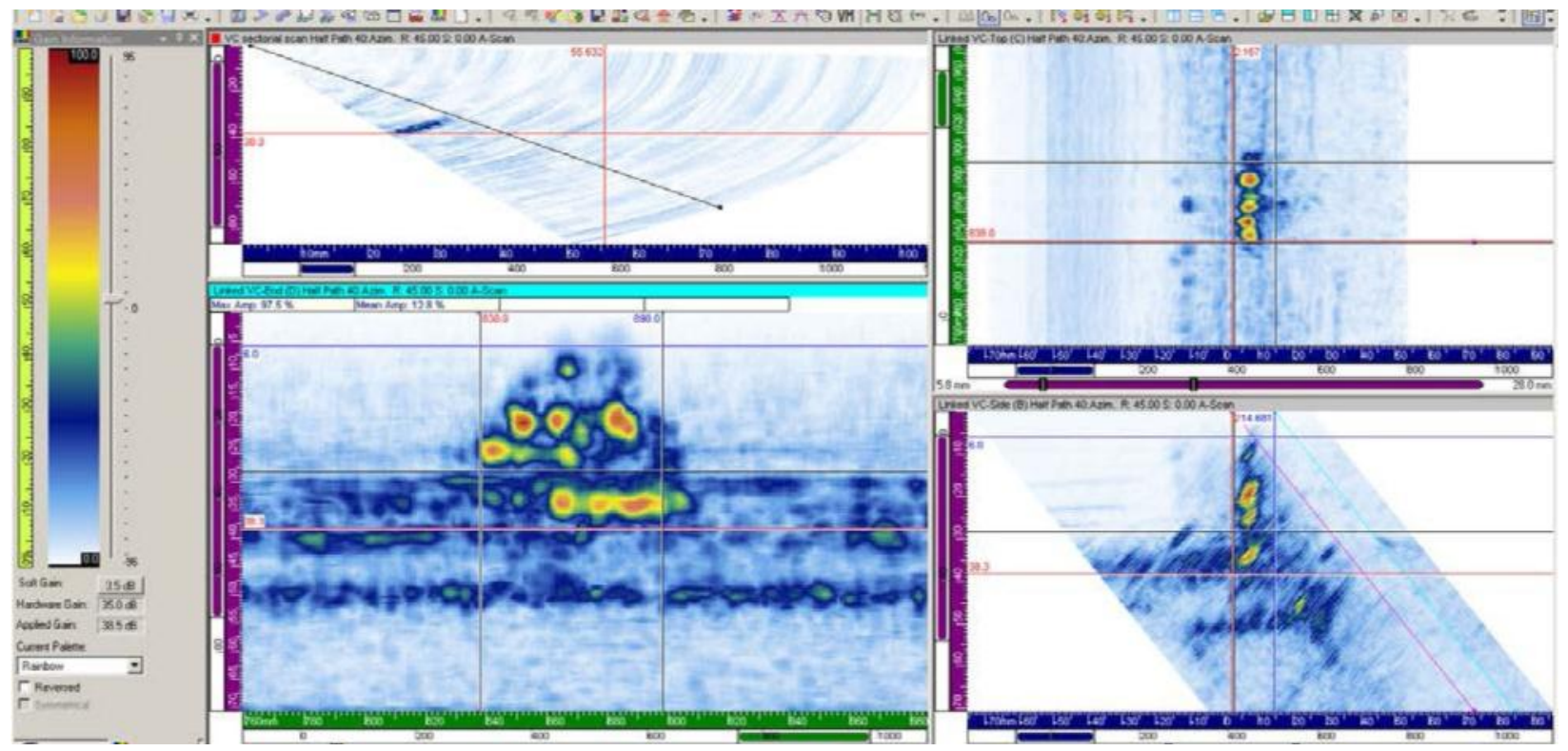

Figure C.35. 10C-011 Flaw 5 Nozzle Side Raster Data at $2.0 \mathrm{MHz}, 45$ Degrees, Pre FSWOL 


\section{C.1.8 Raster Scan Data at 2.0 MHz Pipe Side on Flaws 1-5}

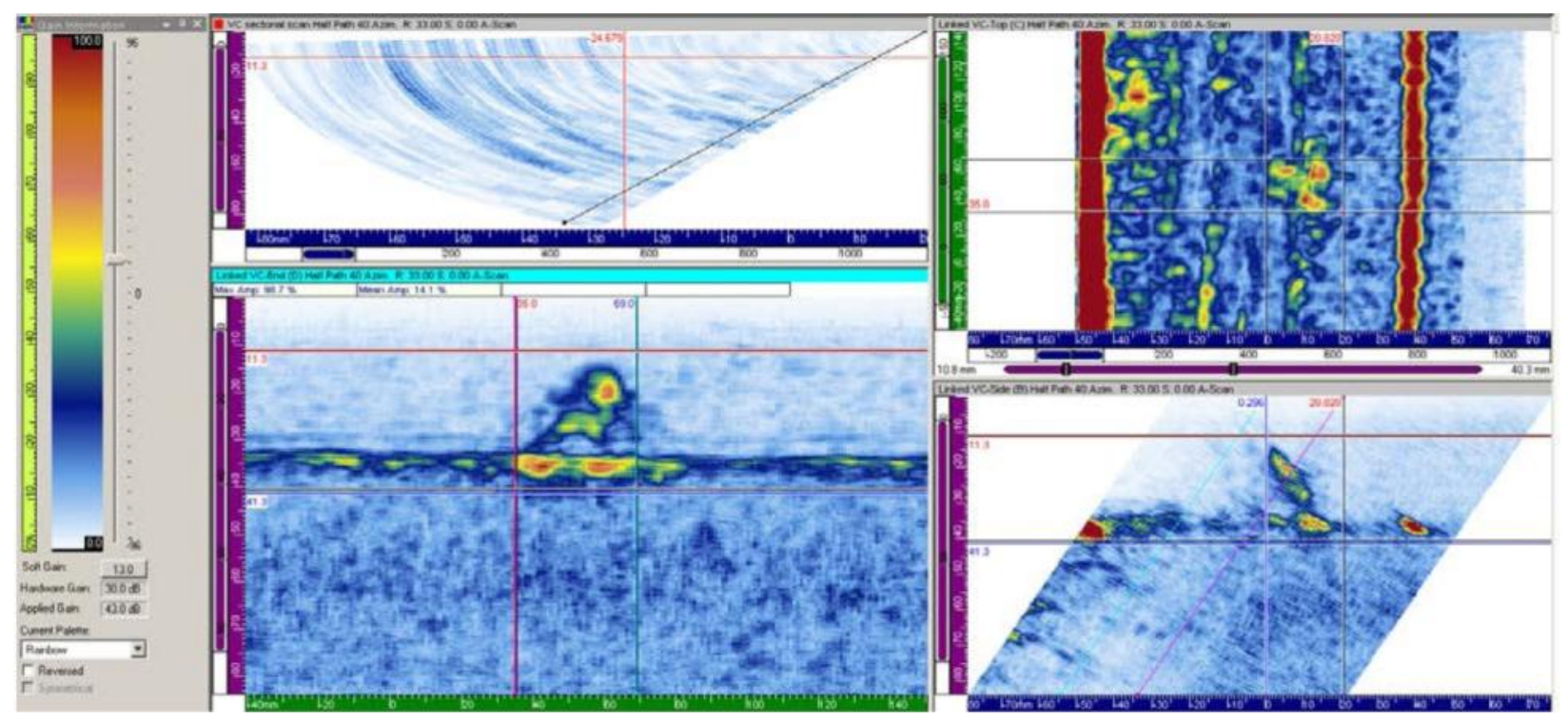

Figure C.36. 10C-011 Flaw 1 Pipe Side Raster Data at $2.0 \mathrm{MHz}, 33$ Degrees, Pre FSWOL

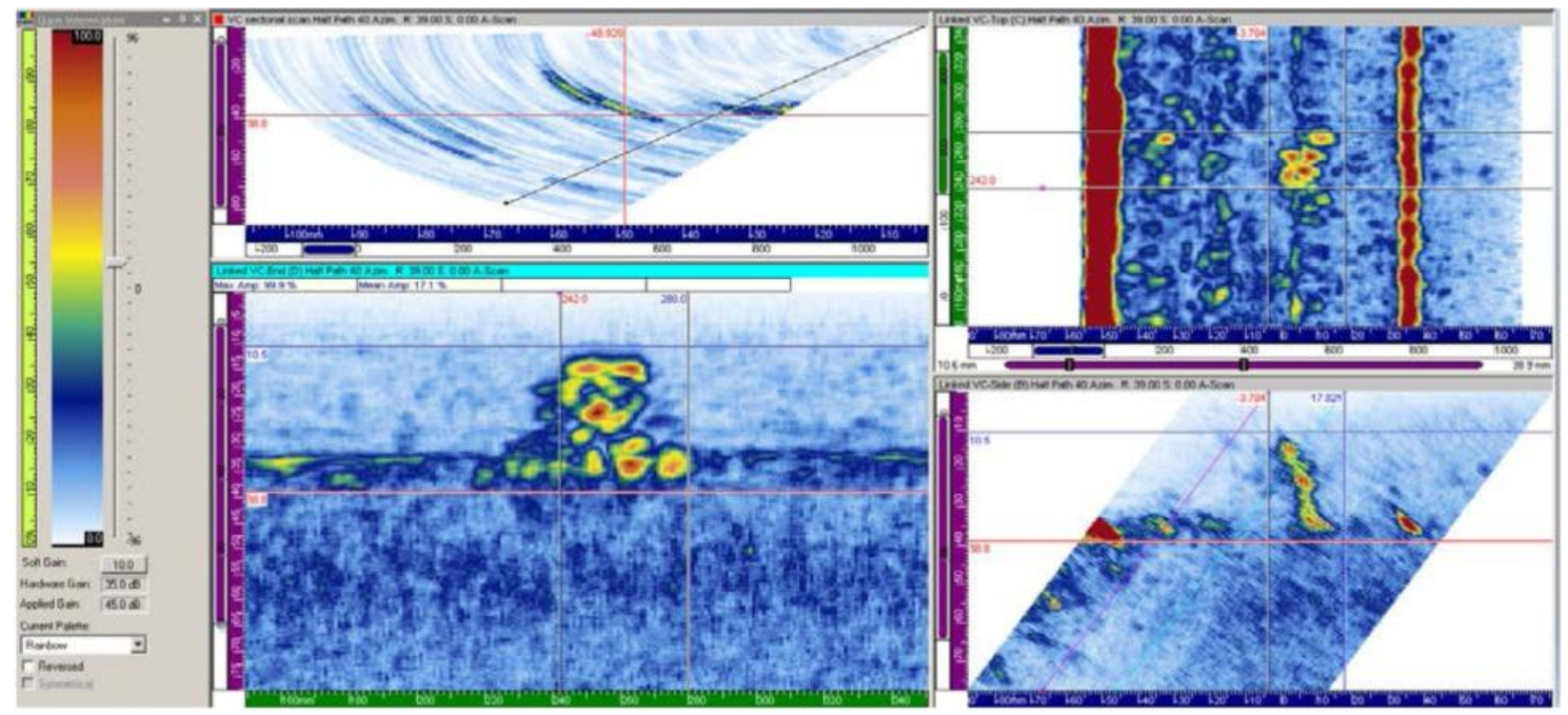

Figure C.37. 10C-011 Flaw 2 Pipe Side Raster Data at 2.0 MHz, 39 Degrees, Pre FSWOL 


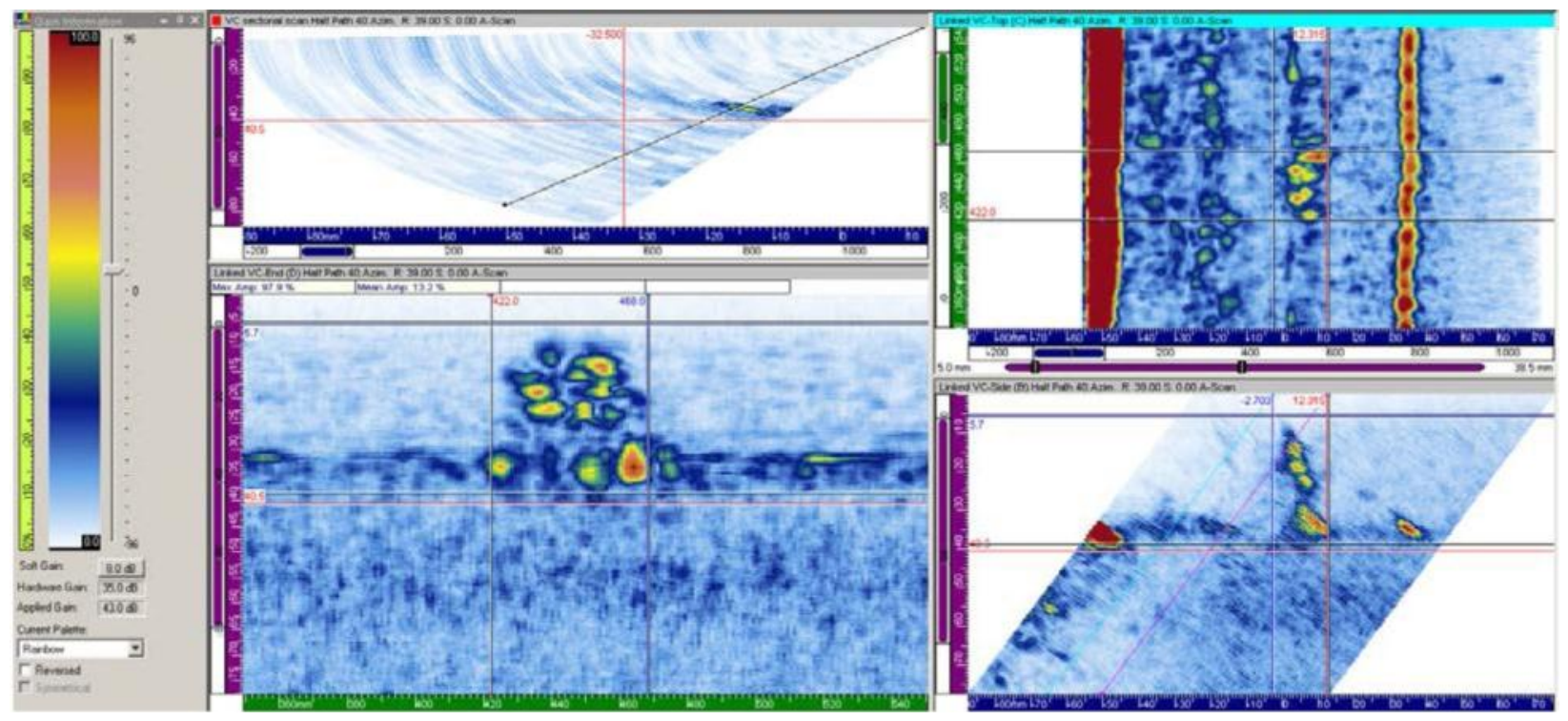

Figure C.38. 10C-011 Flaw 3 Pipe Side Raster Data at 2.0 MHz, 39 Degrees, Pre FSWOL

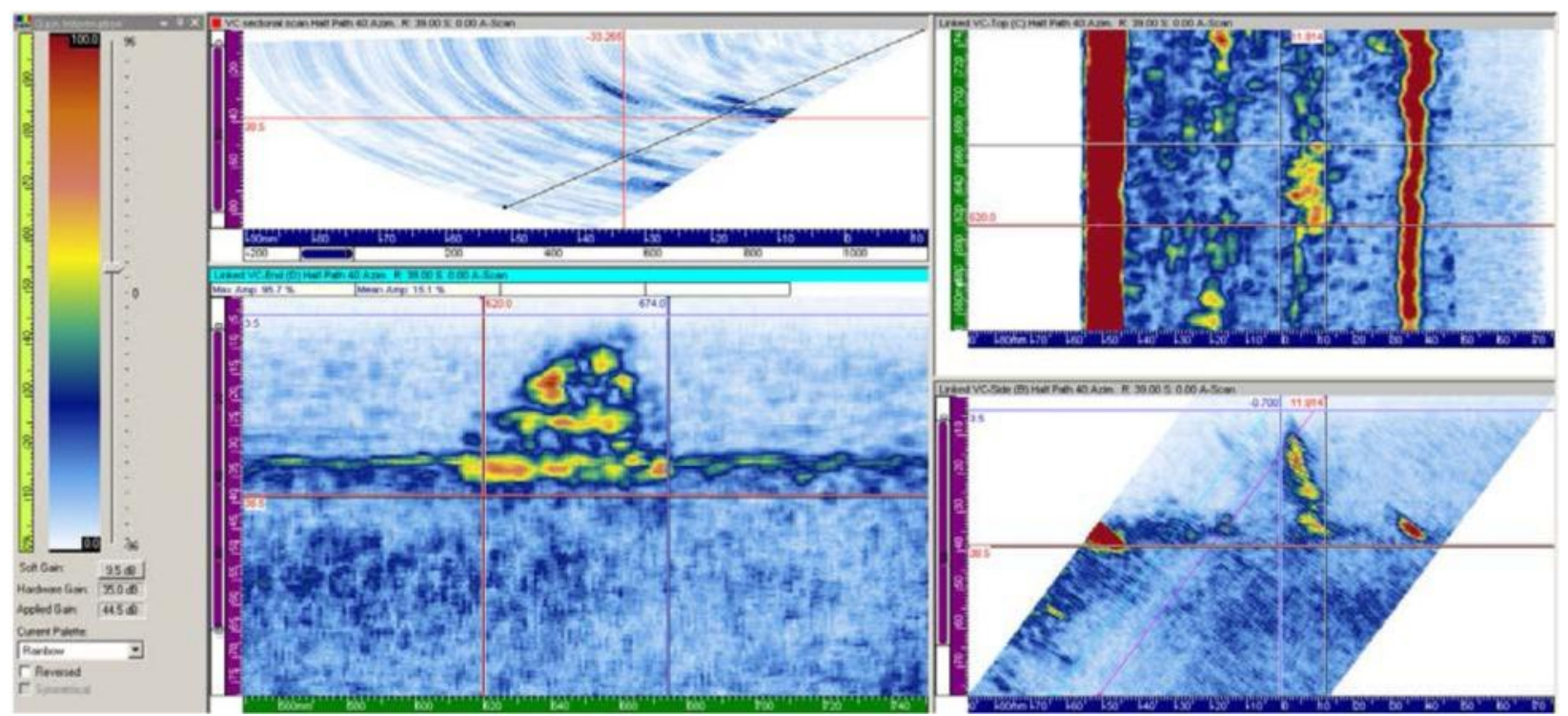

Figure C.39. 10C-011 Flaw 4 Pipe Side Raster Data at 2.0 MHz, 39 Degrees, Pre FSWOL 


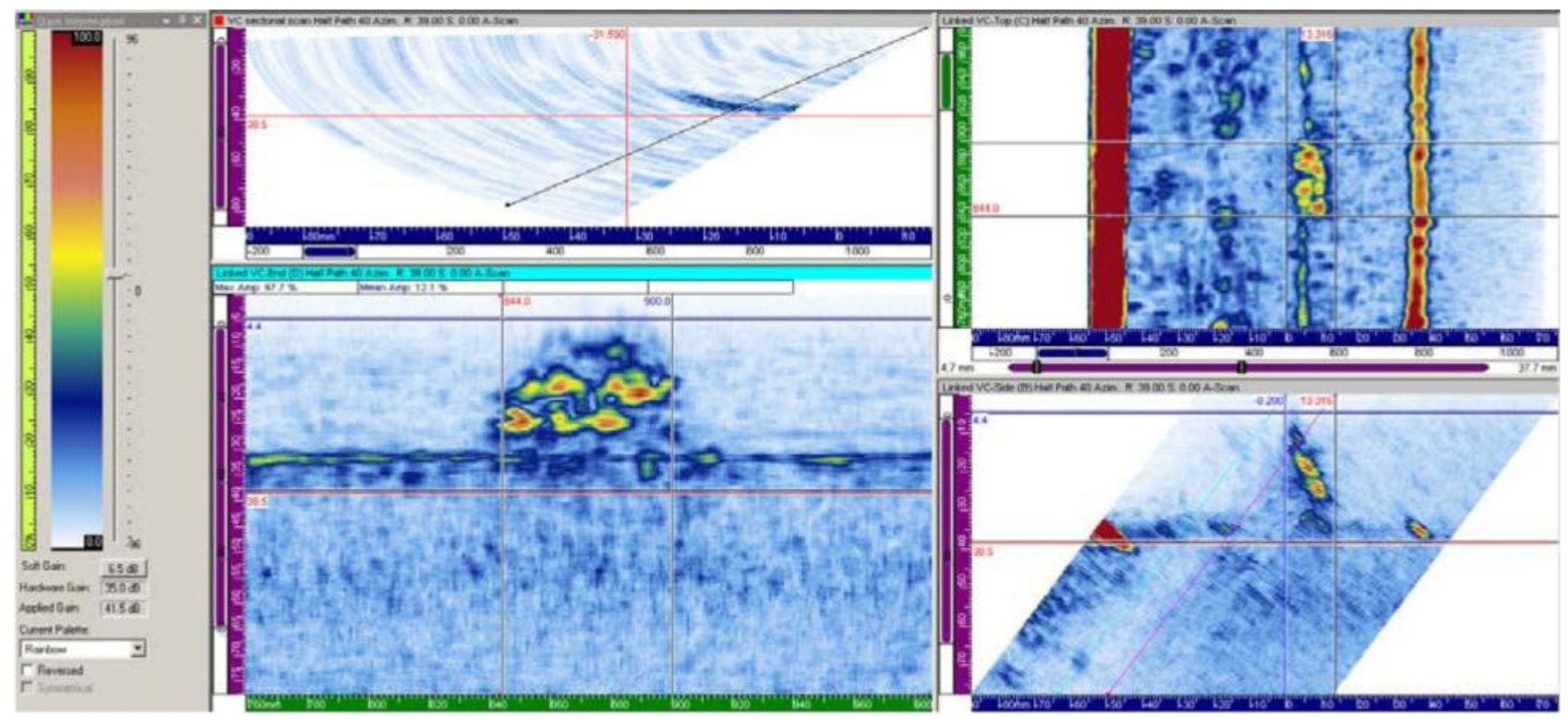

Figure C.40. 10C-011 Flaw 5 Pipe Side Raster Data at 2.0 MHz, 39 Degrees, Pre FSWOL 


\section{C.2 Line Scan Data}

\section{C.2.1 Line Scan Data at 0.8 MHz Nozzle Side on Flaws 1-5}

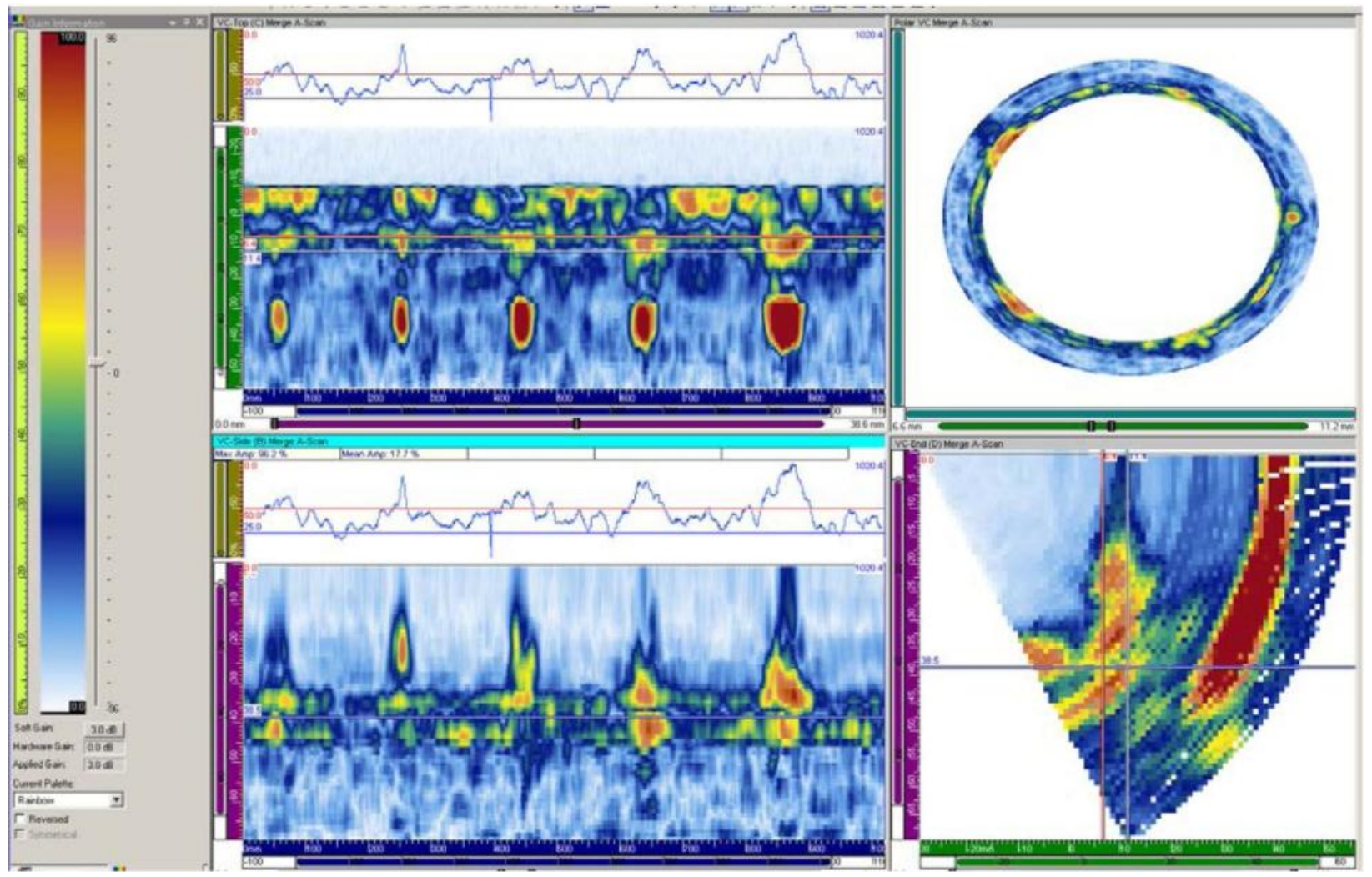

Figure C.41. 10C-011 Flaws 1-5 at 0.8 MHz from the Nozzle Side Line Scan Data, Pre FSWOL
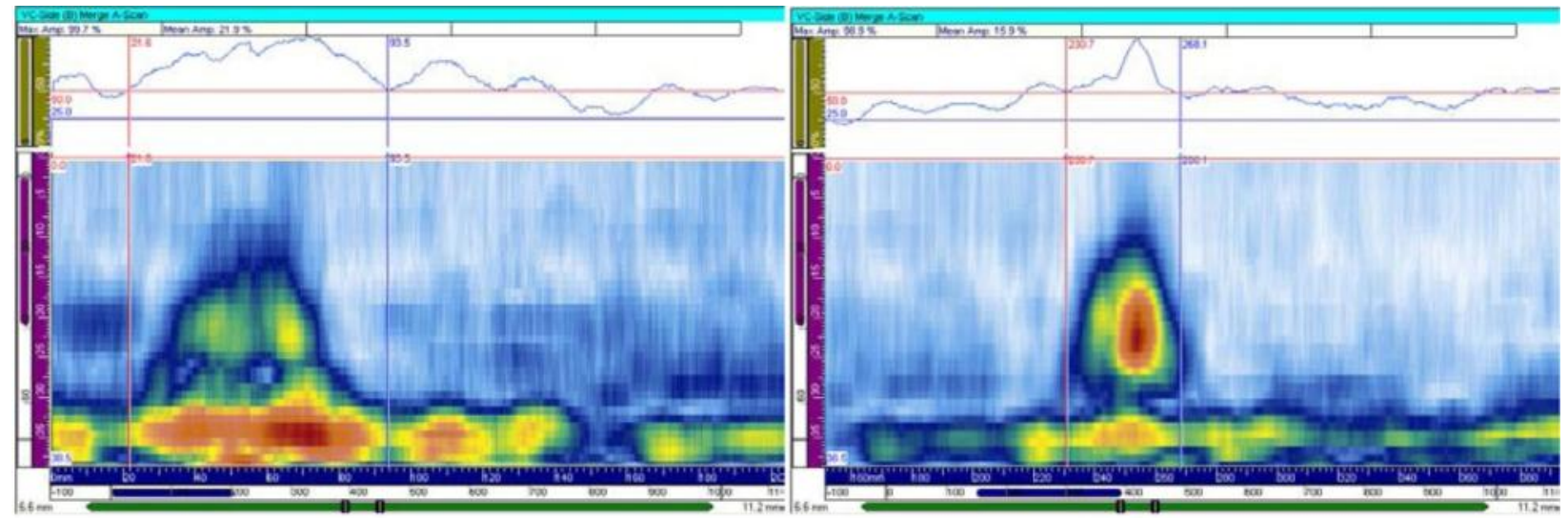

Figure C.42. 10C-011 Flaw 1 on the Left and Flaw 2 on the Right at $0.8 \mathrm{MHz}$ Obtained from the Nozzle Side with Line Scan Data, Pre FSWOL 


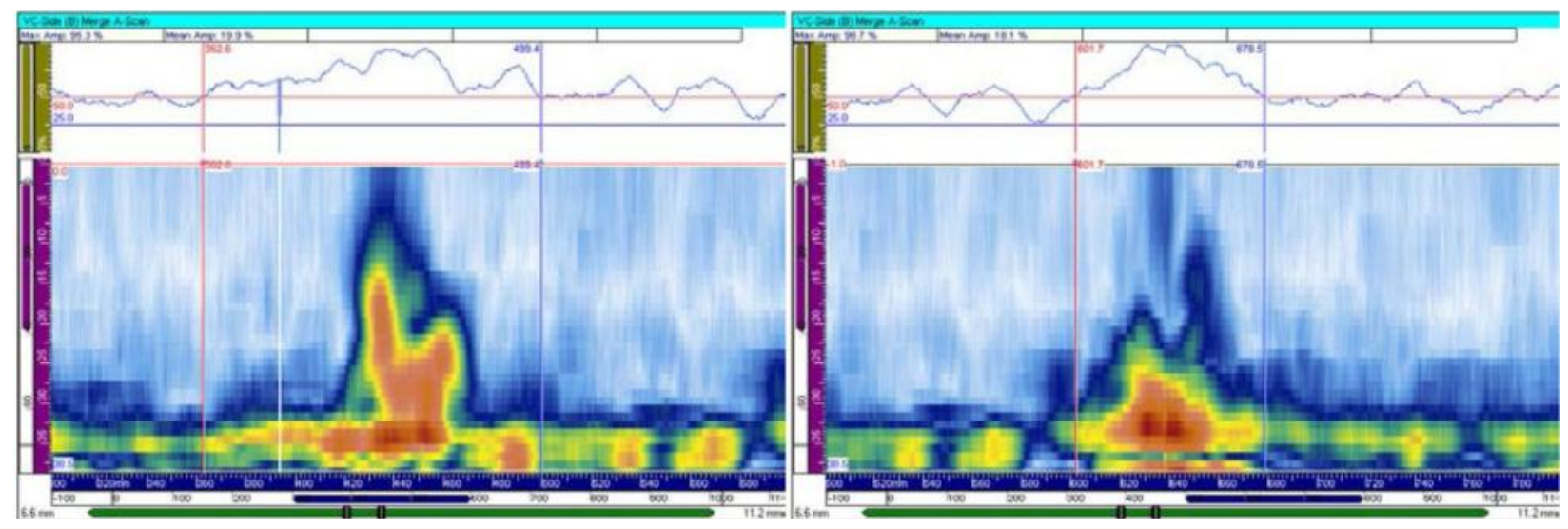

Figure C.43. 10C-011 Flaw 3 on the Left and Flaw 4 on the Right at $0.8 \mathrm{MHz}$ Obtained from the Nozzle Side with Line Scan Data, Pre FSWOL

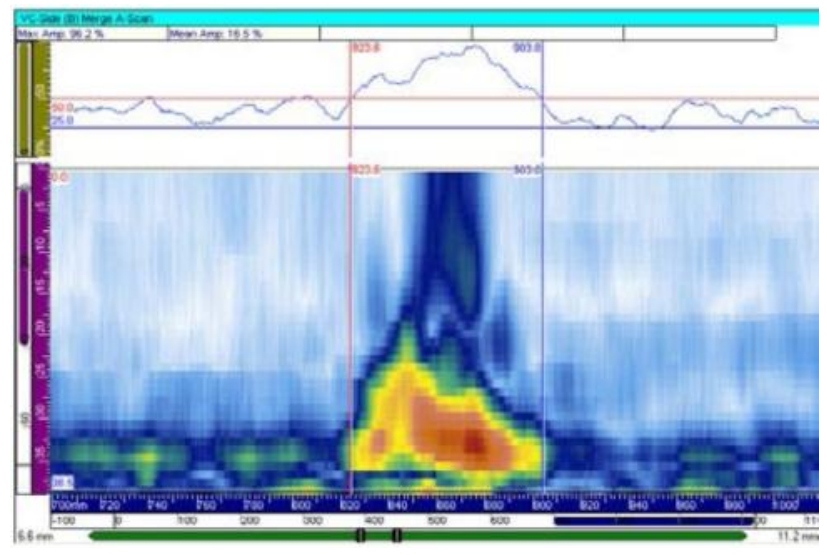

Figure C.44. 10C-011 Flaw 5 at $0.8 \mathrm{MHz}$ Obtained from the Nozzle Side with Line Scan Data, Pre FSWOL 


\section{C.2.2 Line Scan Data at 1.0 MHz Nozzle Side on Flaws 1-5}

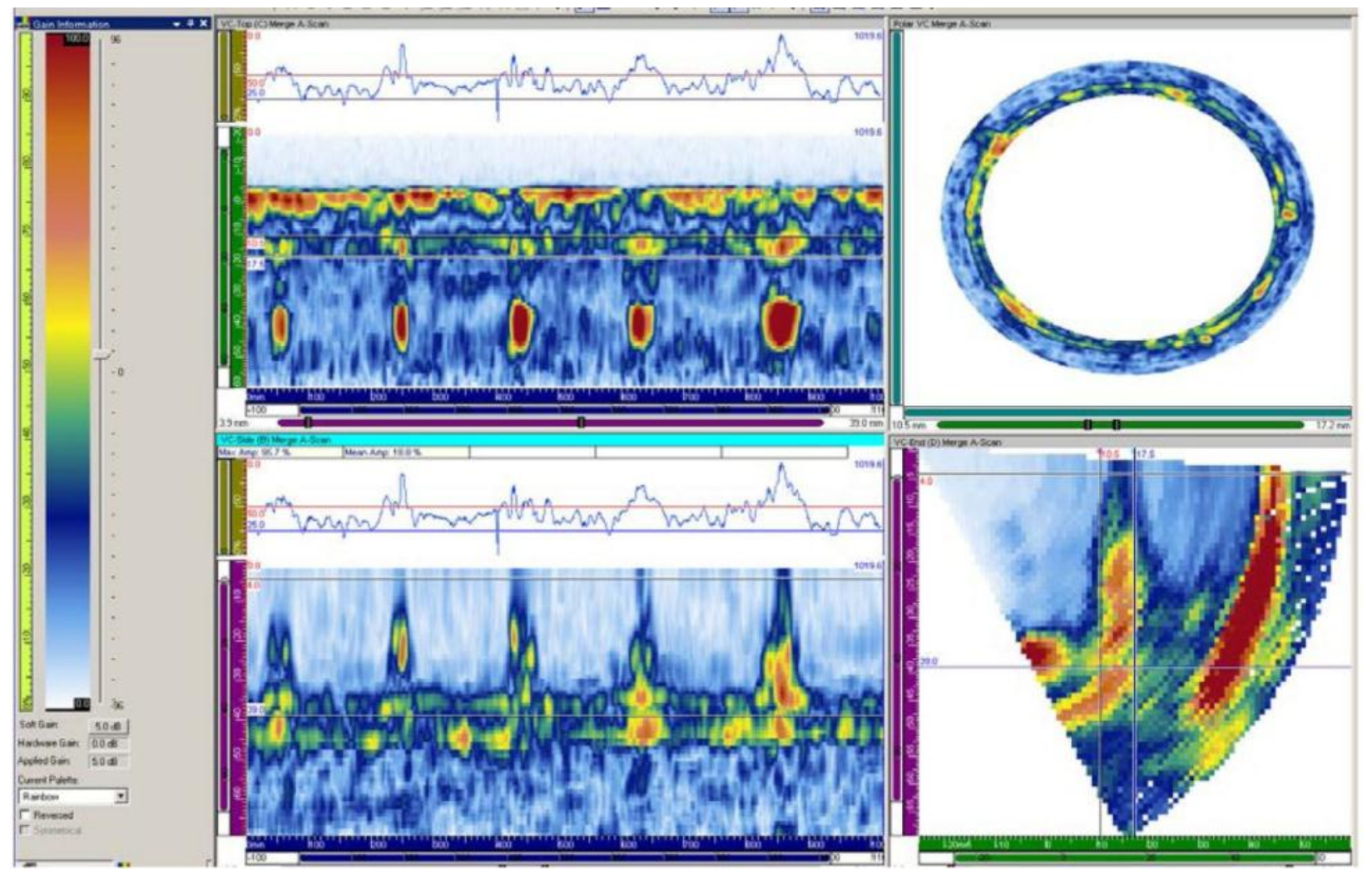

Figure C.45. 10C-011 Flaws 1-5 at 1.0 MHz from the Nozzle Side Line Scan Data, Pre FSWOL

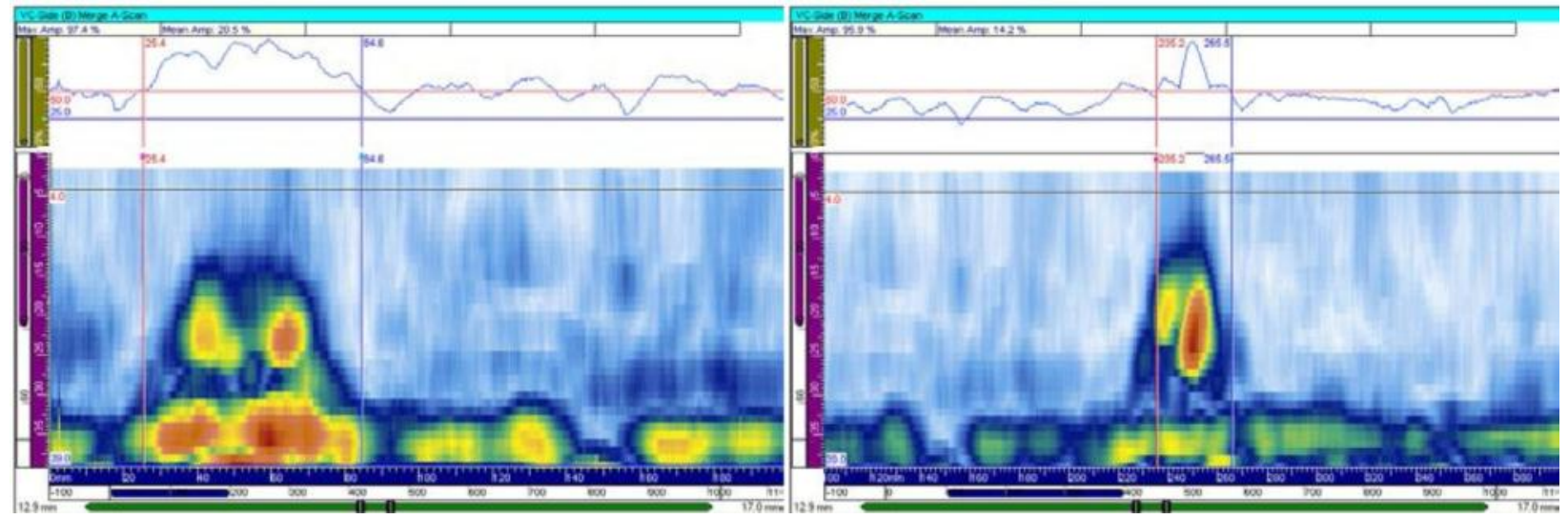

Figure C.46. 10C-011 Flaws 1 and 2 at $1.0 \mathrm{MHz}$ from the Nozzle Side Line Scan Data, Pre FSWOL 


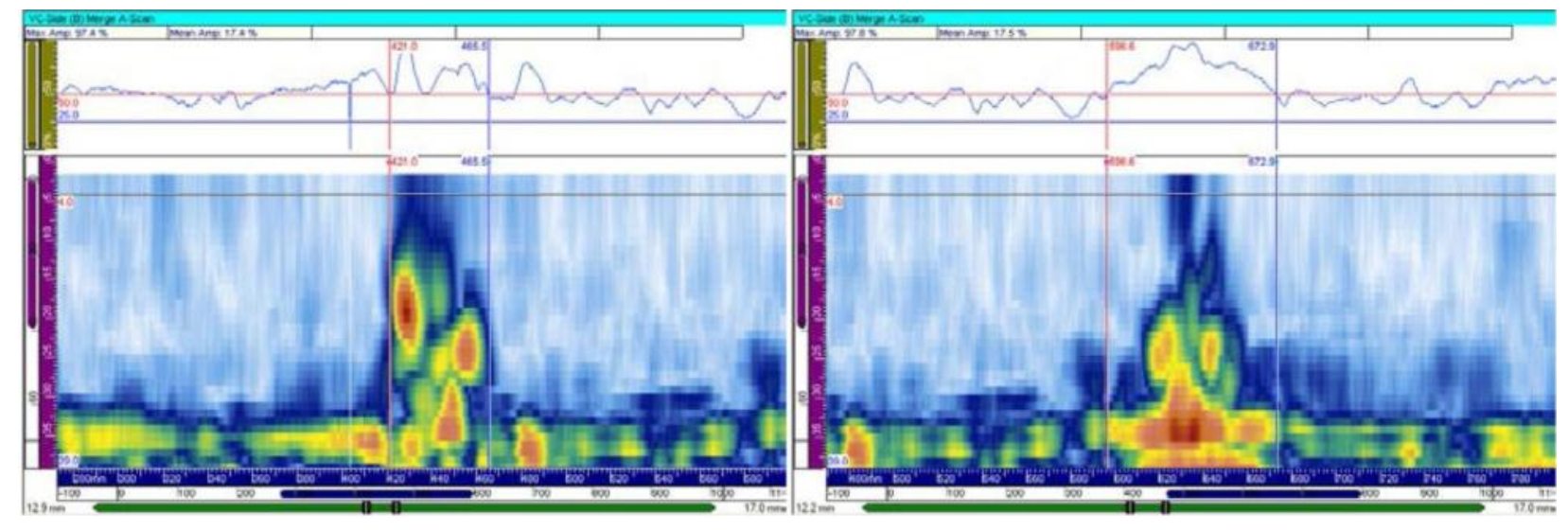

Figure C.47. 10C-011 Flaws 3 and 4 at $1.0 \mathrm{MHz}$ from the Nozzle Side Line Scan Data, Pre FSWOL

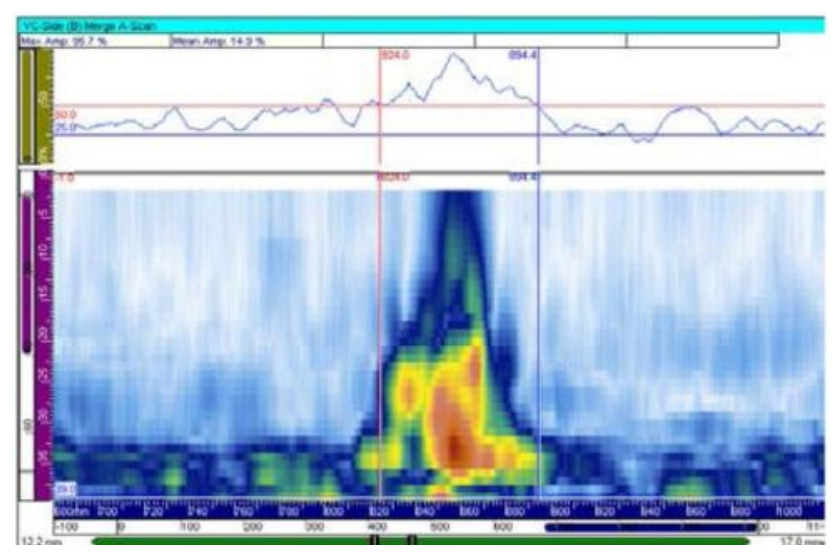

Figure C.48. 10C-011 Flaw 5 at 1.0 MHz from the Nozzle Side Line Scan Data, Pre FSWOL 


\section{C.2.3 Line Scan Data at 1.5 MHz Nozzle Side on Flaws 1-5}

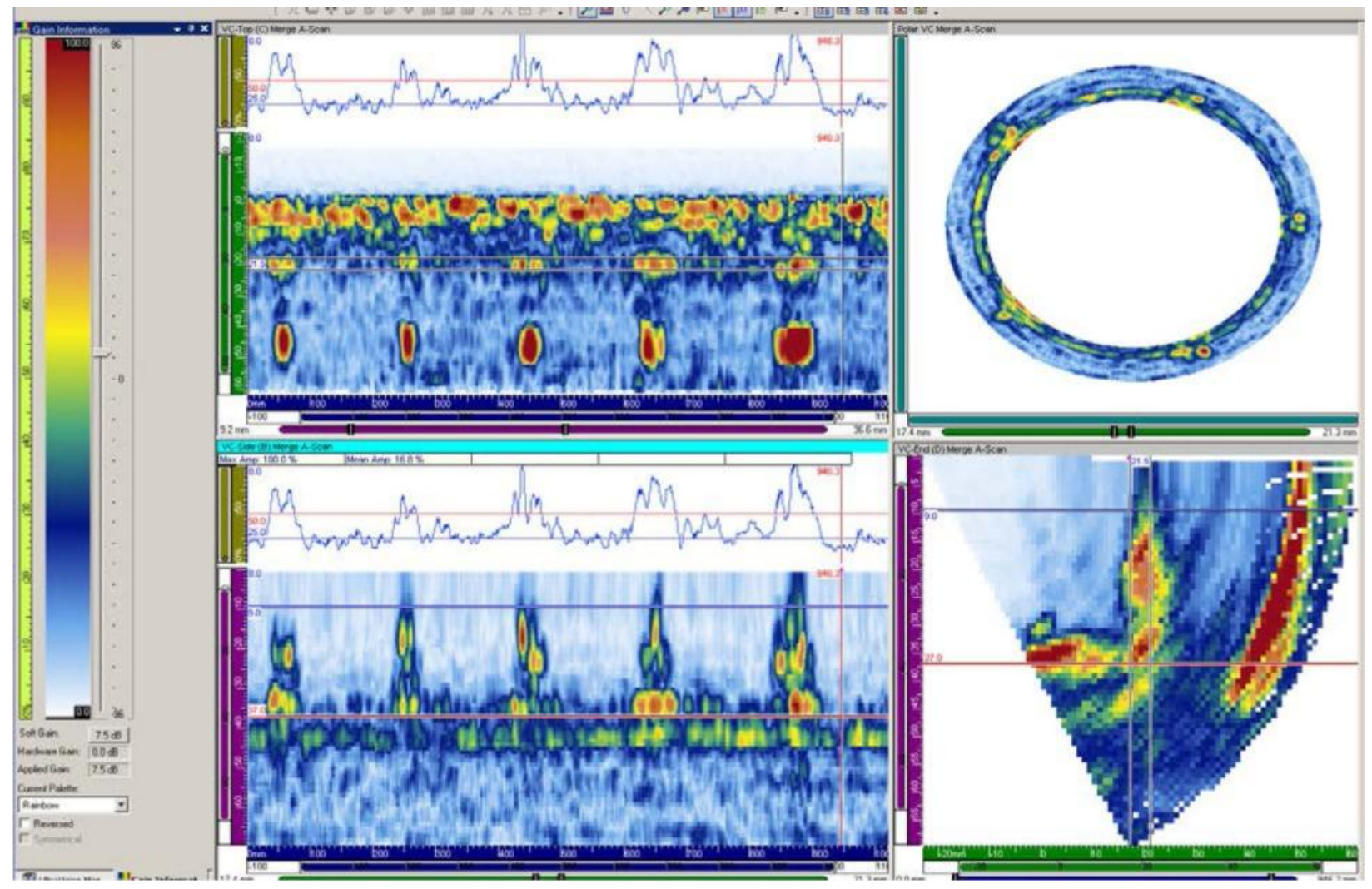

Figure C.49. 10C-011 Flaws 1-5 at 1.5 MHz from the Nozzle Side Line Scan Data, Pre FSWOL 


\section{C.2.4 Line Scan Data at 2.0 MHz Nozzle Side on Flaws 1-5}

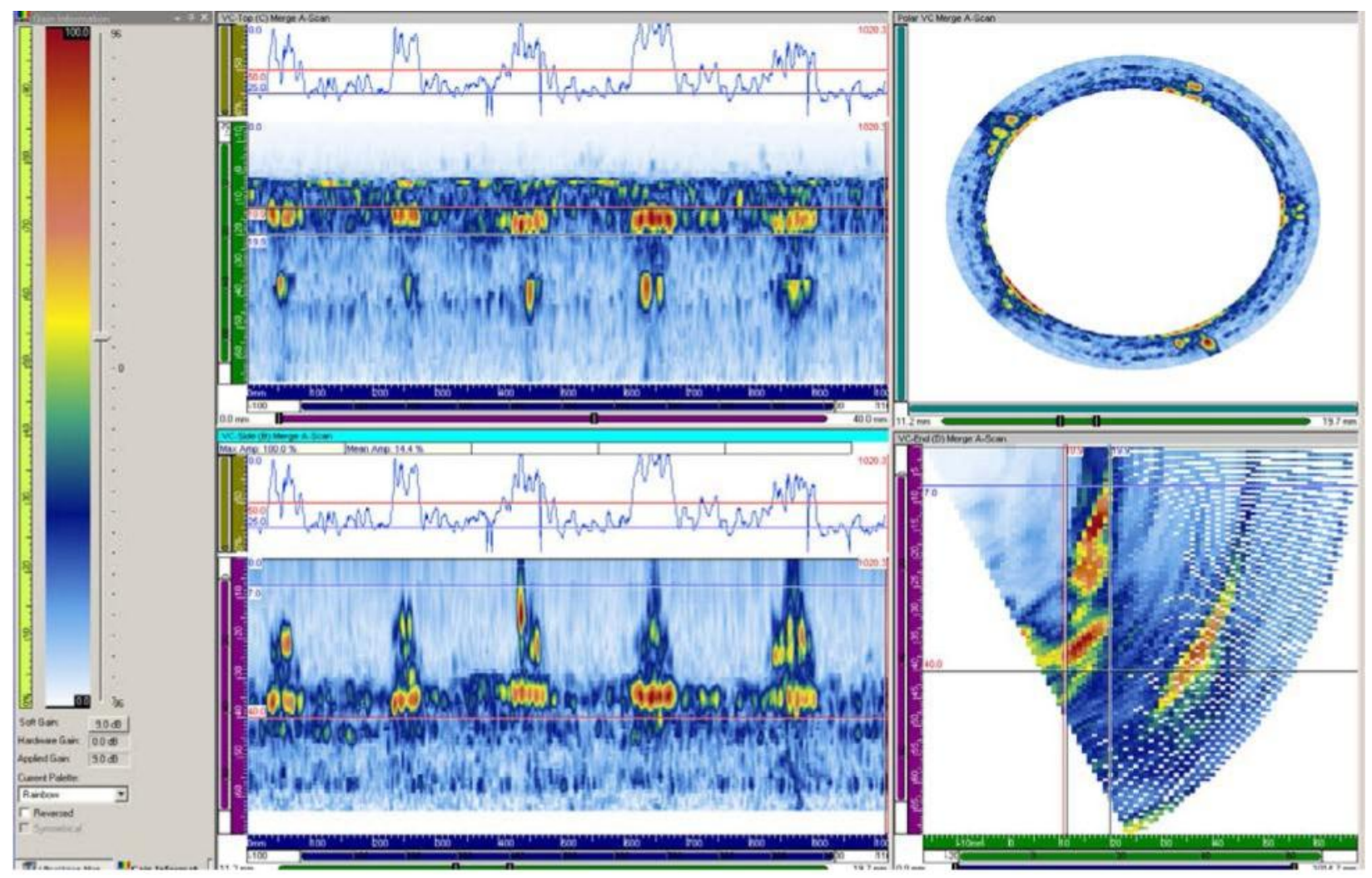

Figure C.50. 10C-011 Flaws 1-5 at 2.0 MHz from the Nozzle Side Line Scan Data, Pre FSWOL 


\section{C.2.5 Line Scan Data at 0.8 MHz Pipe Side on Flaws 1-5}

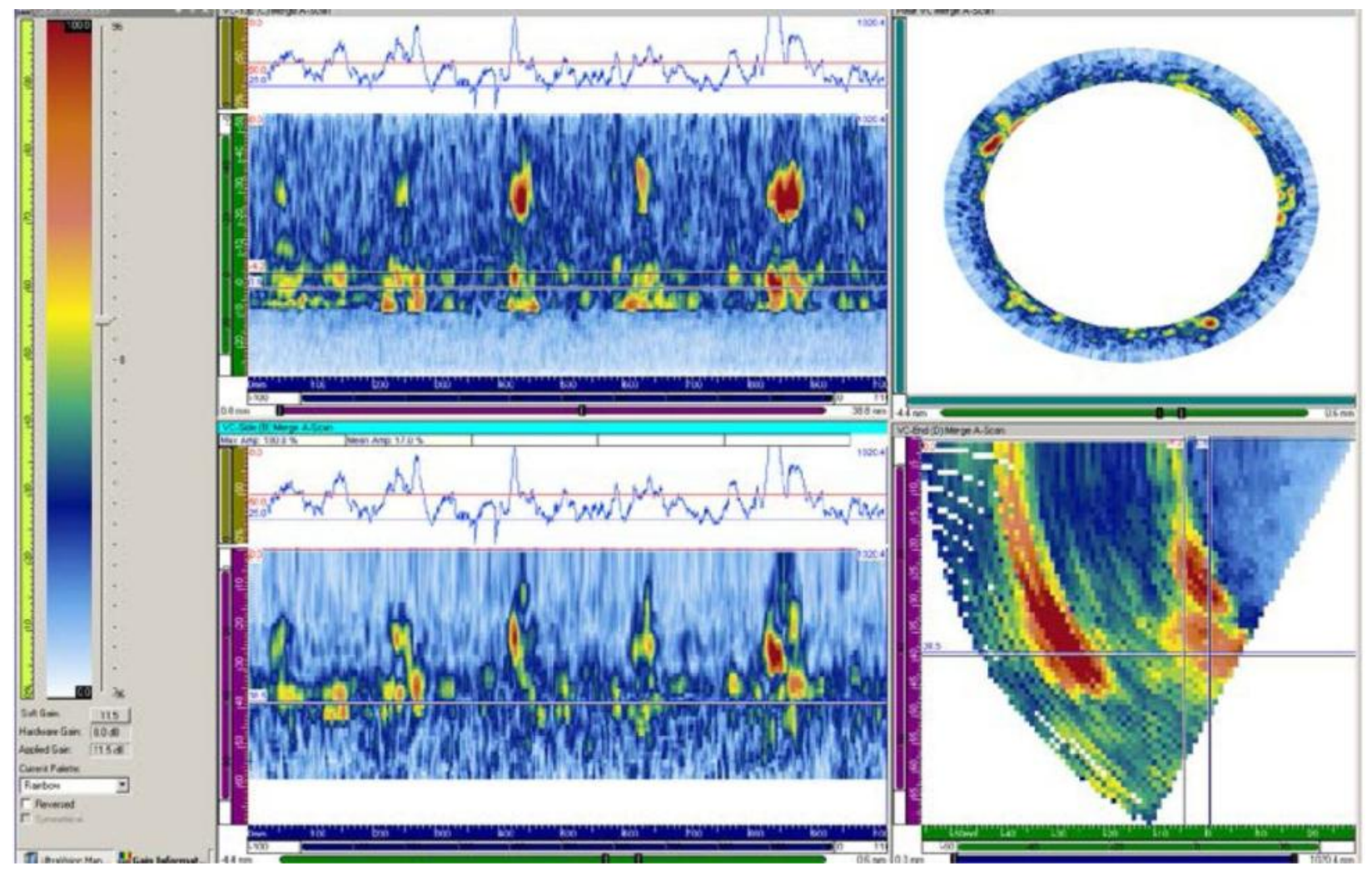

Figure C.51. 10C-011 Flaws 1-5 at 0.8 MHz from the Pipe Side Line Scan Data, Pre FSWOL 


\section{C.2.6 Line Scan Data at 1.0 MHz Pipe Side on Flaws 1-5}

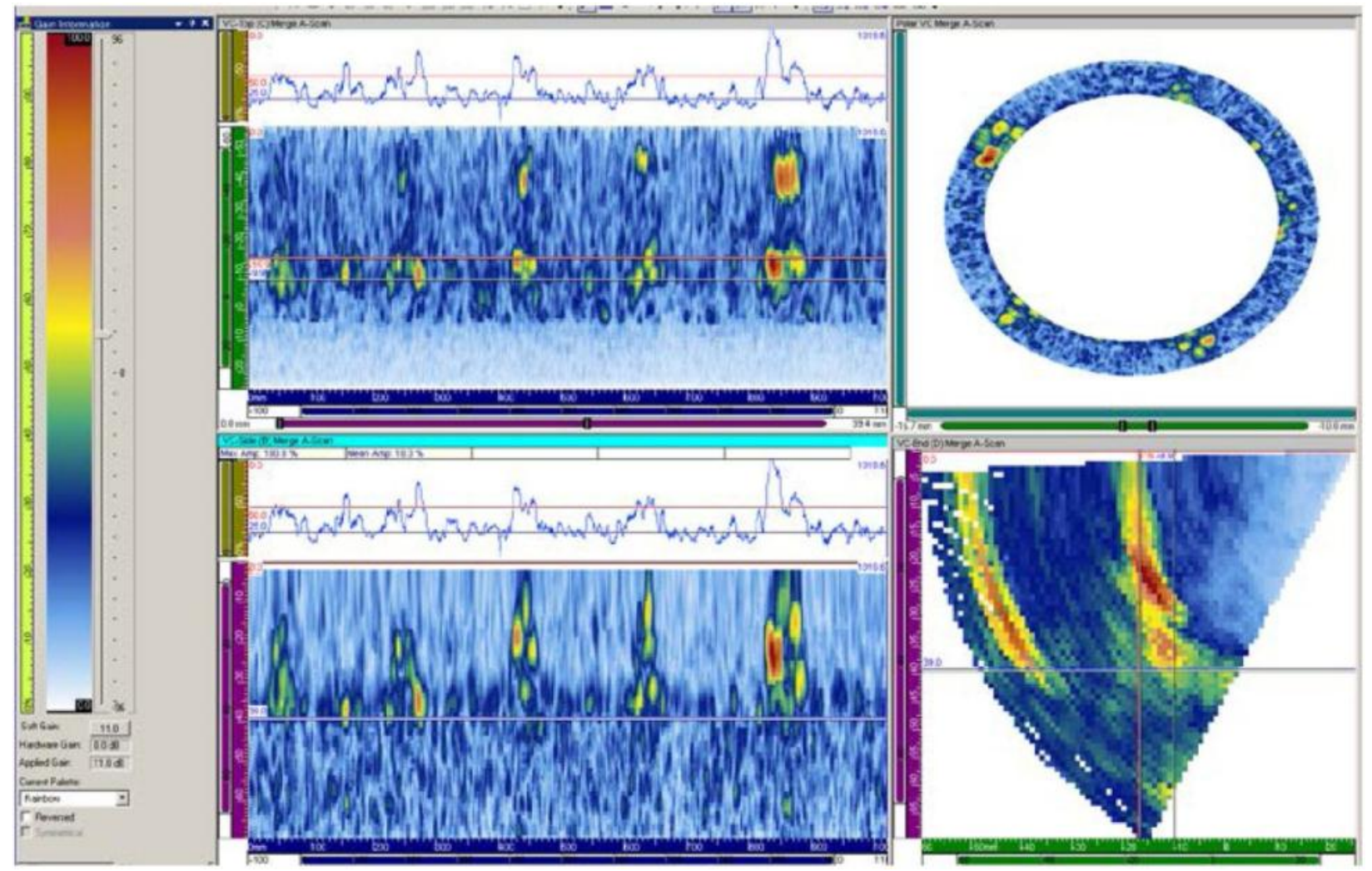

Figure C.52. 10C-011 Flaws 1-5 at 1.0 MHz from the Pipe Side Line Scan Data, Pre FSWOL 


\section{C.2.7 Line Scan Data at 1.5 MHz Pipe Side on Flaws 1-5}

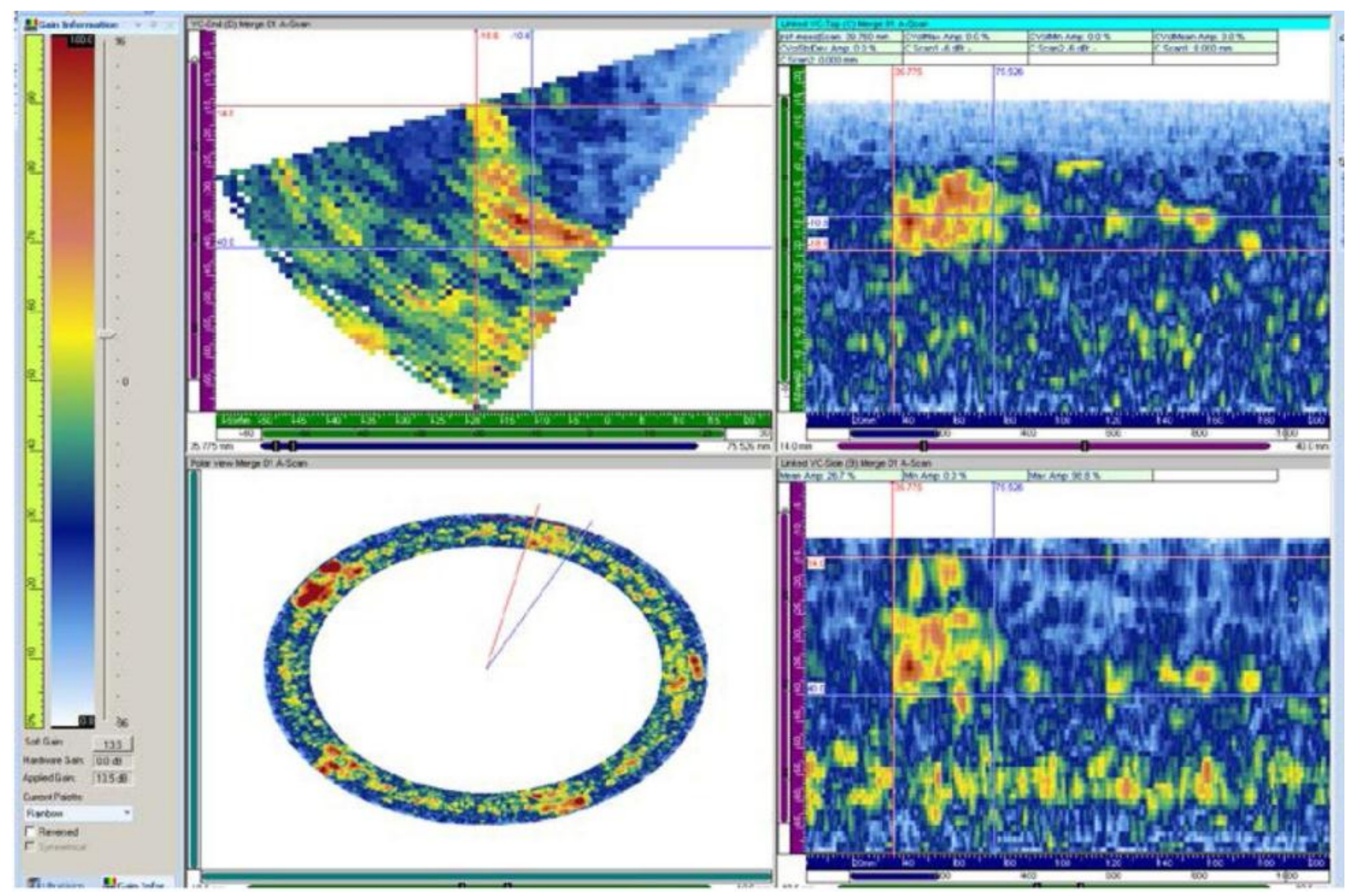

Figure C.53. 10C011 Flaw 1 Pipe Side Line Scan at 1.5 MHz, Pre FSWOL 


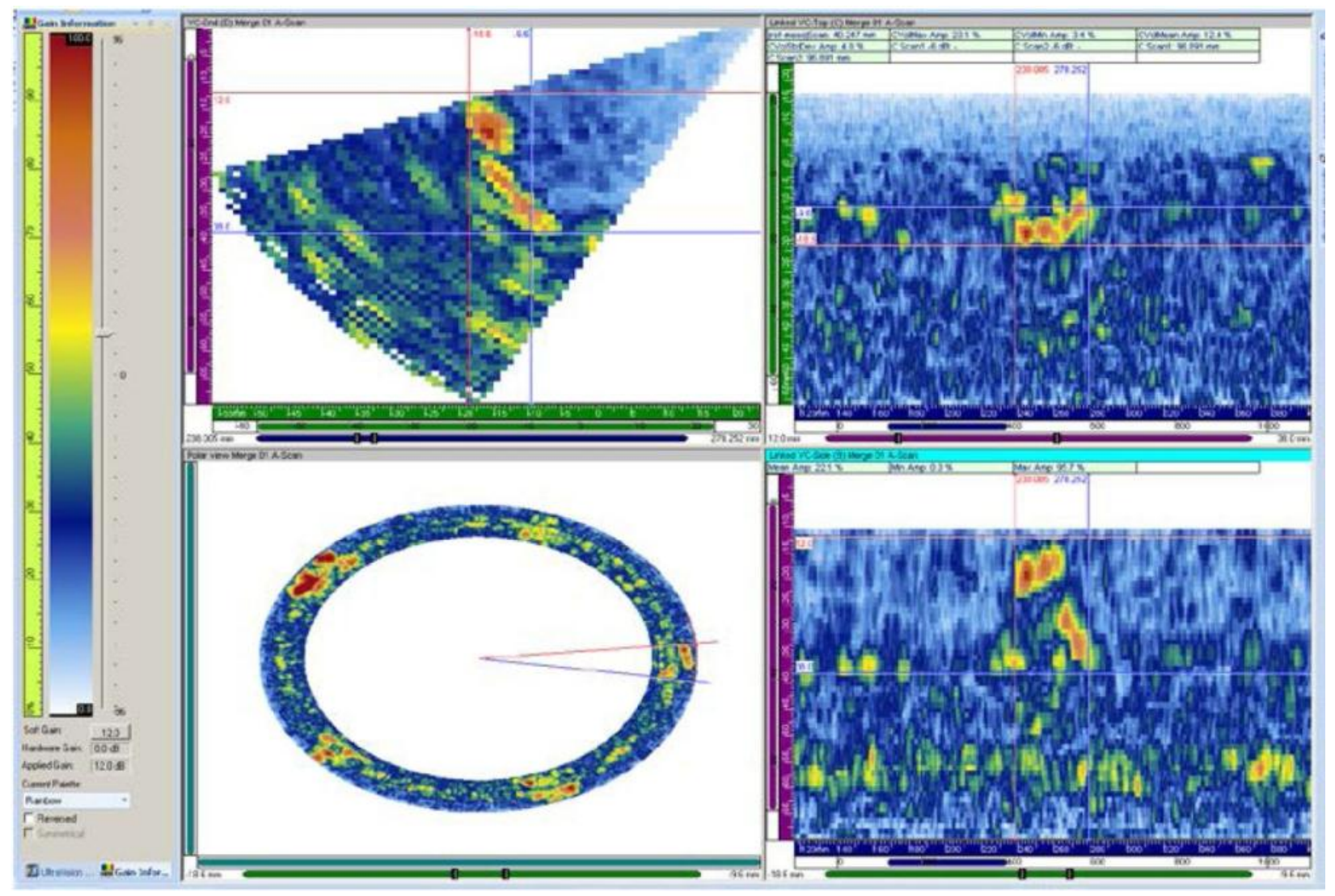

Figure C.54. 10C011 Flaw 2 Pipe Side Line Scan at 1.5 MHz, Pre FSWOL 


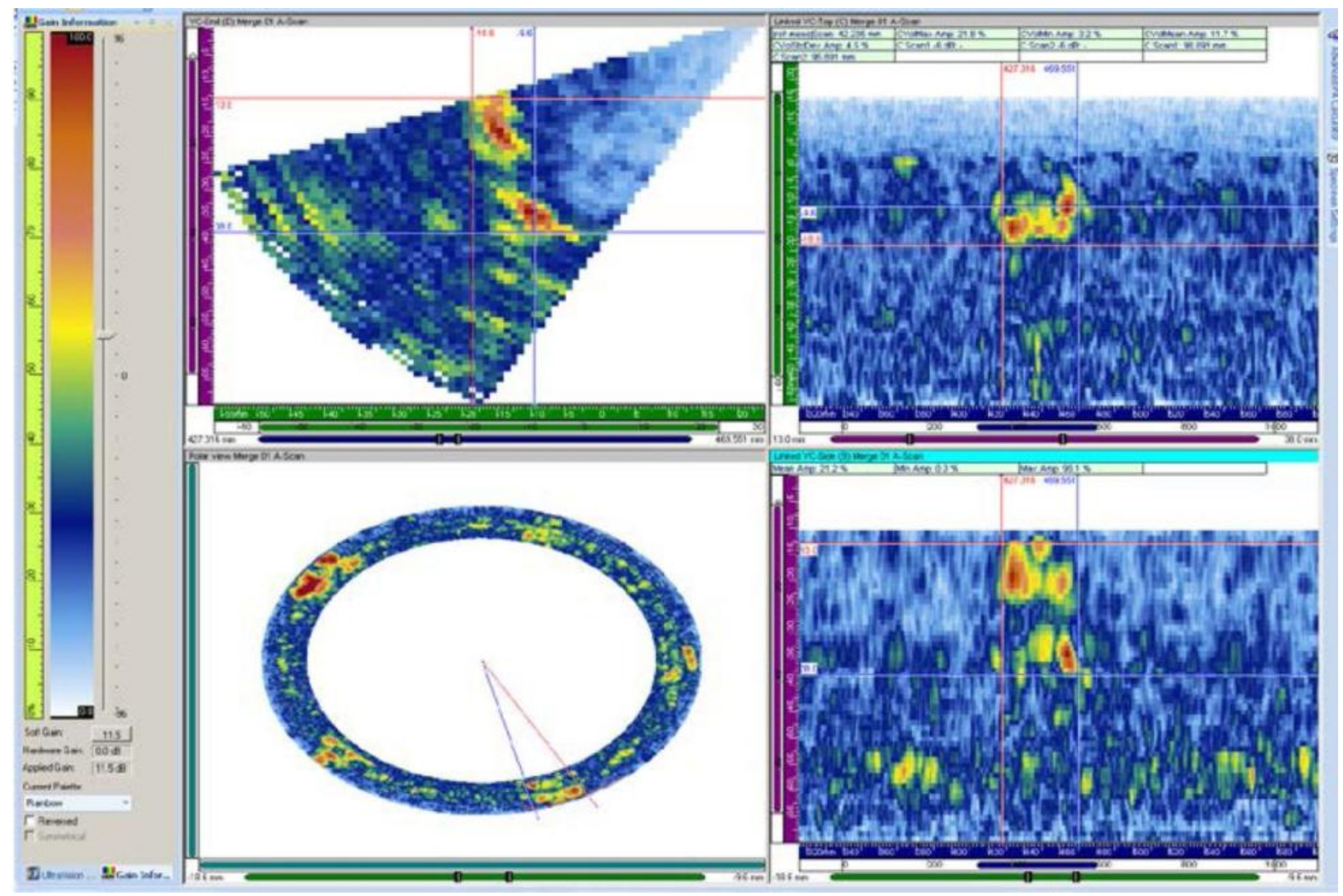

Figure C.55. 10C011 Flaw 3 Pipe Side Line Scan at 1.5 MHz, Pre FSWOL 


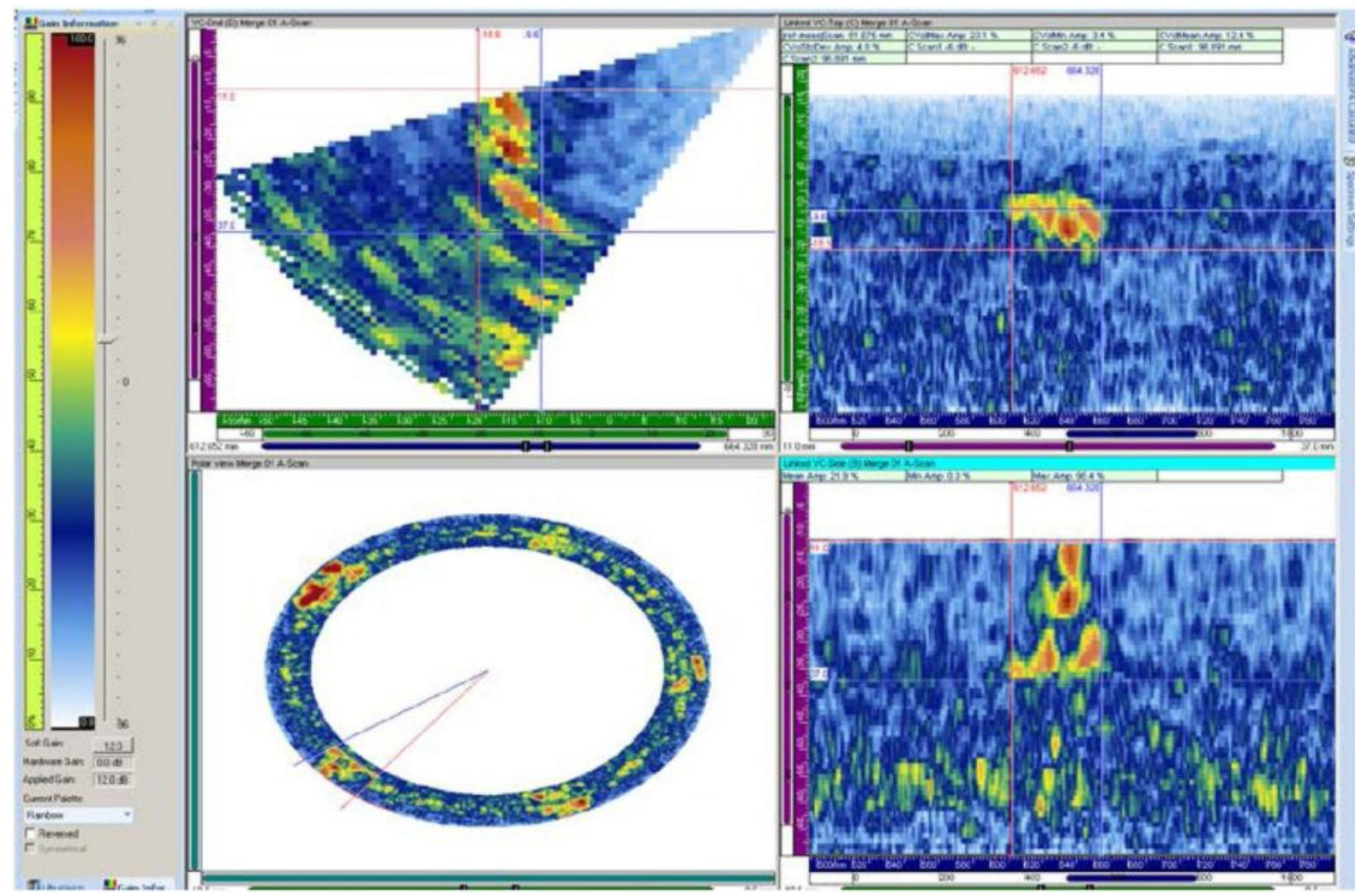

Figure C.56. 10C011 Flaw 4 Pipe Side Line Scan at 1.5 MHz, Pre FSWOL 


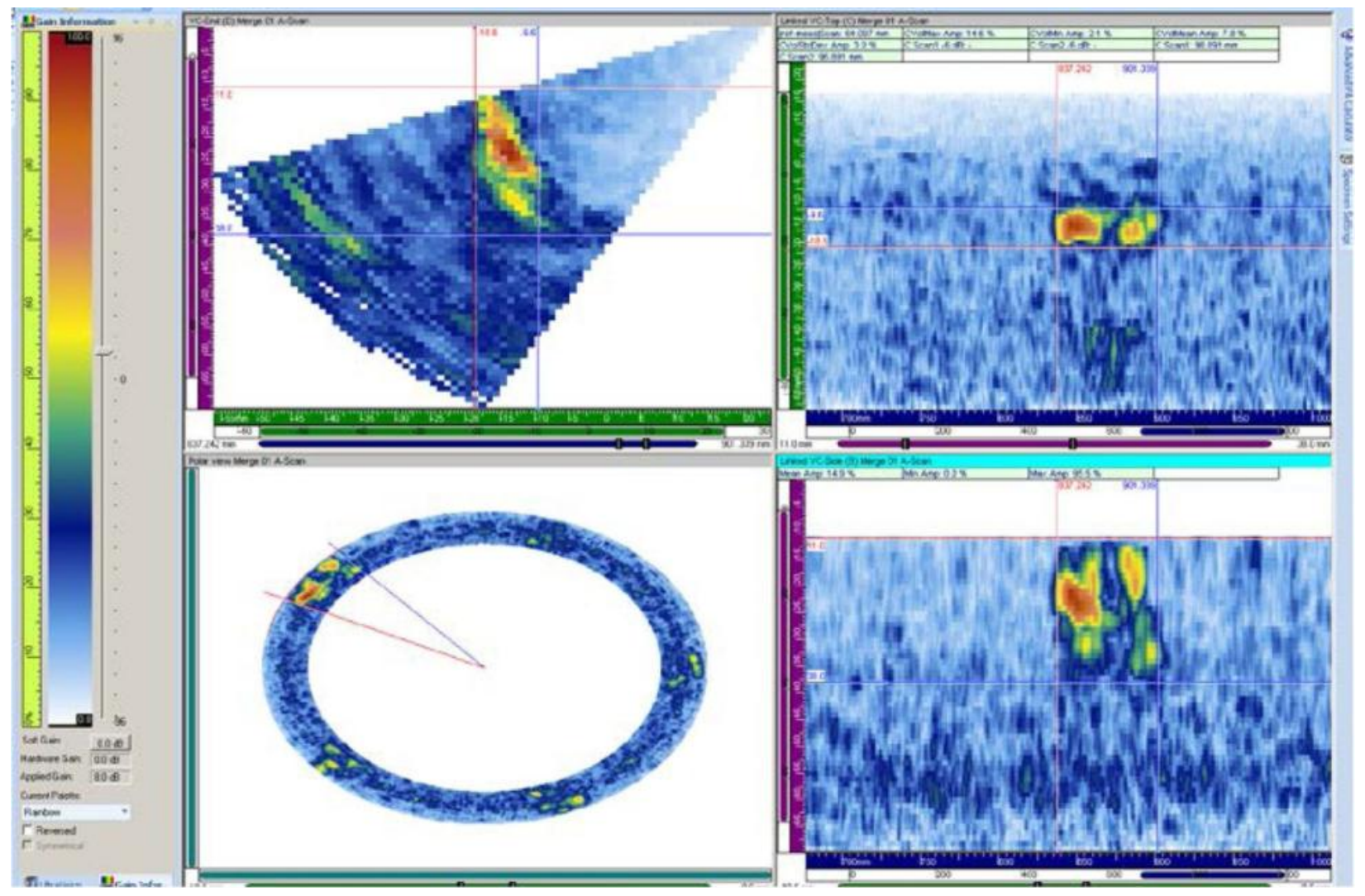

Figure C.57. 10C011 Flaw 5 Pipe Side Line Scan at 1.5 MHz, Pre FSWOL 


\section{C.2.8 Line Scan Data at 2.0 MHz Pipe Side on Flaws 1-5}

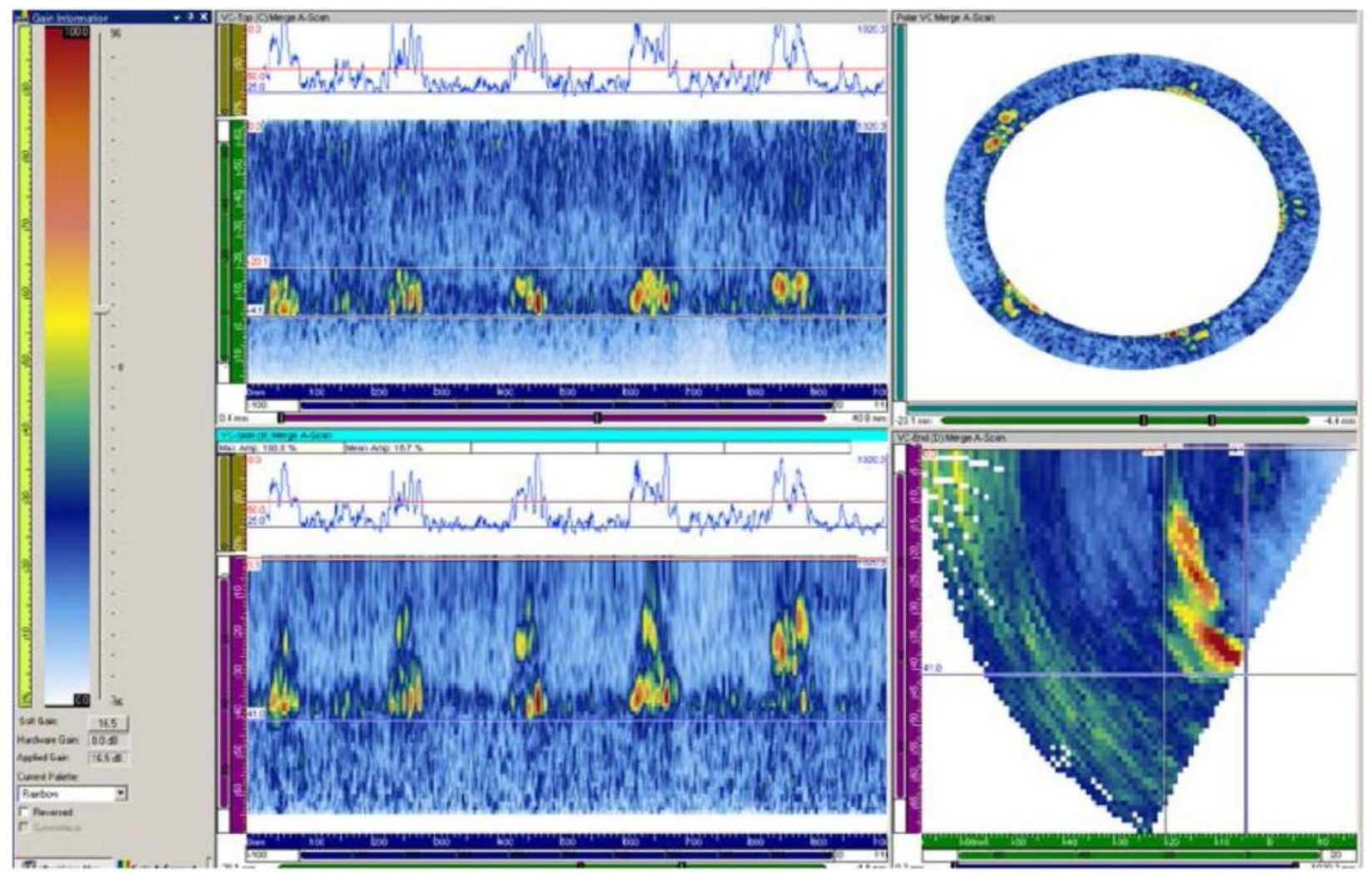

Figure C.58. 10C011 Flaws 1-5 Pipe Side Line Scan at 2.0 MHz, Pre FSWOL 


\section{Appendix D}

\section{Dissimilar Metal Weld Specimen 10C-011 Phased-Array Data,}

Post-WOL 



\section{Appendix D}

\section{Dissimilar Metal Weld Specimen 10C-011 Phased-Array Data, Post-WOL}

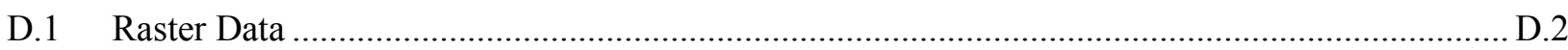

D.1.1 Raster Data at 0.8 MHz Nozzle Side of Overlay on Flaws 1-5 .................................. D.2

D.1.2 Raster Data at $0.8 \mathrm{MHz}$ Pipe Side of Overlay on Flaws 1-5 …................................... D.5

D.1.3 Raster Data at 1.0 MHz Nozzle Side of Overlay on Flaws 1-5 .................................. D.8

D.1.4 Raster Data at 1.0 MHz Pipe Side of Overlay on Flaws 1-5 …................................ D.11

D.1.5 Raster Data at 1.5 MHz Nozzle Side of Overlay on Flaws 1-5................................ D.14

D.1.6 Raster Data at 1.5 MHz Pipe Side of Overlay on Flaws 1-5 .................................... D.17

D.1.7 Raster Data at 2.0 MHz Nozzle Side of Overlay on Flaws 1-5 ................................ D.20

D.1.8 Raster Data at 2.0 MHz Pipe Side of Overlay on Flaws 1-5 …................................ D.23

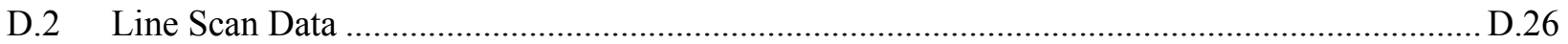

D.2.1 Line Scan Data at $0.8 \mathrm{MHz}$ Nozzle Side of Overlay on Flaws 1-5 .......................... D.26

D.2.2 Line Scan Data at 0.8 MHz Pipe Side of Overlay on Flaws 1-5 .............................. D.29

D.2.3 Line Scan Data at 1.0 MHz Nozzle Side of Overlay on Flaws 1-5 ........................... D.32

D.2.4 Line Scan Data at 1.0 MHz Pipe Side of Overlay on Flaws 1-5 .............................. D. .

D.2.5 Line Scan Data at 1.5 MHz Nozzle Side of Overlay on Flaws 1-5 ........................... D.38

D.2.6 Line Scan Data at 1.5 MHz Pipe Side of Overlay on Flaws 1-5 ............................... D.41

D.2.7 Line Scan Data at 2.0 MHz Nozzle Side of Overlay on Flaws 1-5 ............................ D.44

D.2.8 Line Scan Data at 2.0 MHz Pipe Sid of Overlay on Flaws 1-5 ................................. D.47 


\section{D.1 Raster Data}

\section{D.1.1 Raster Data at 0.8 MHz Nozzle Side of Overlay on Flaws 1-5}

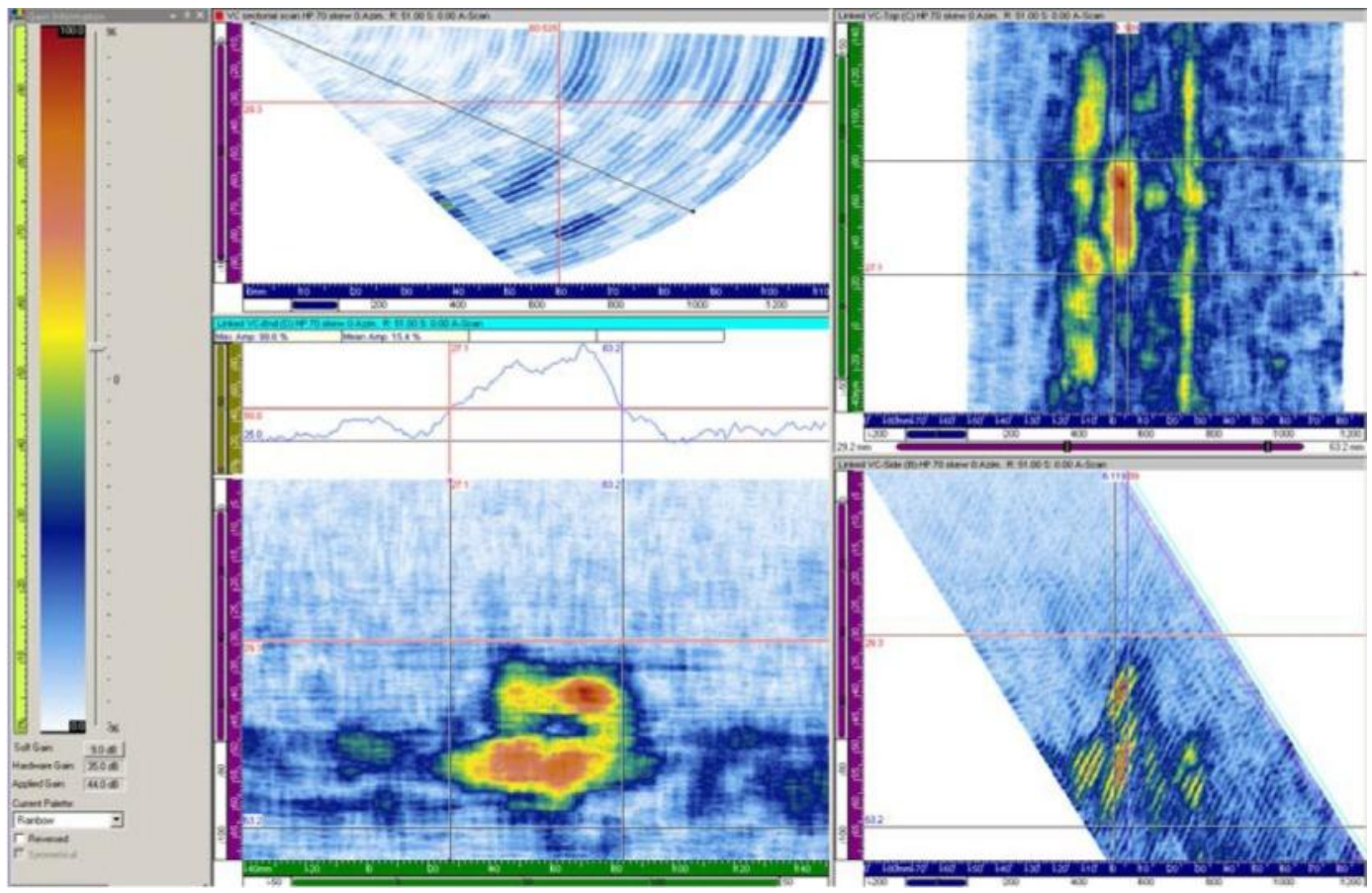

Figure D.1. 10C-011 Flaw 1 Nozzle Side of Overlay at $0.8 \mathrm{MHz}, 51$ Degrees

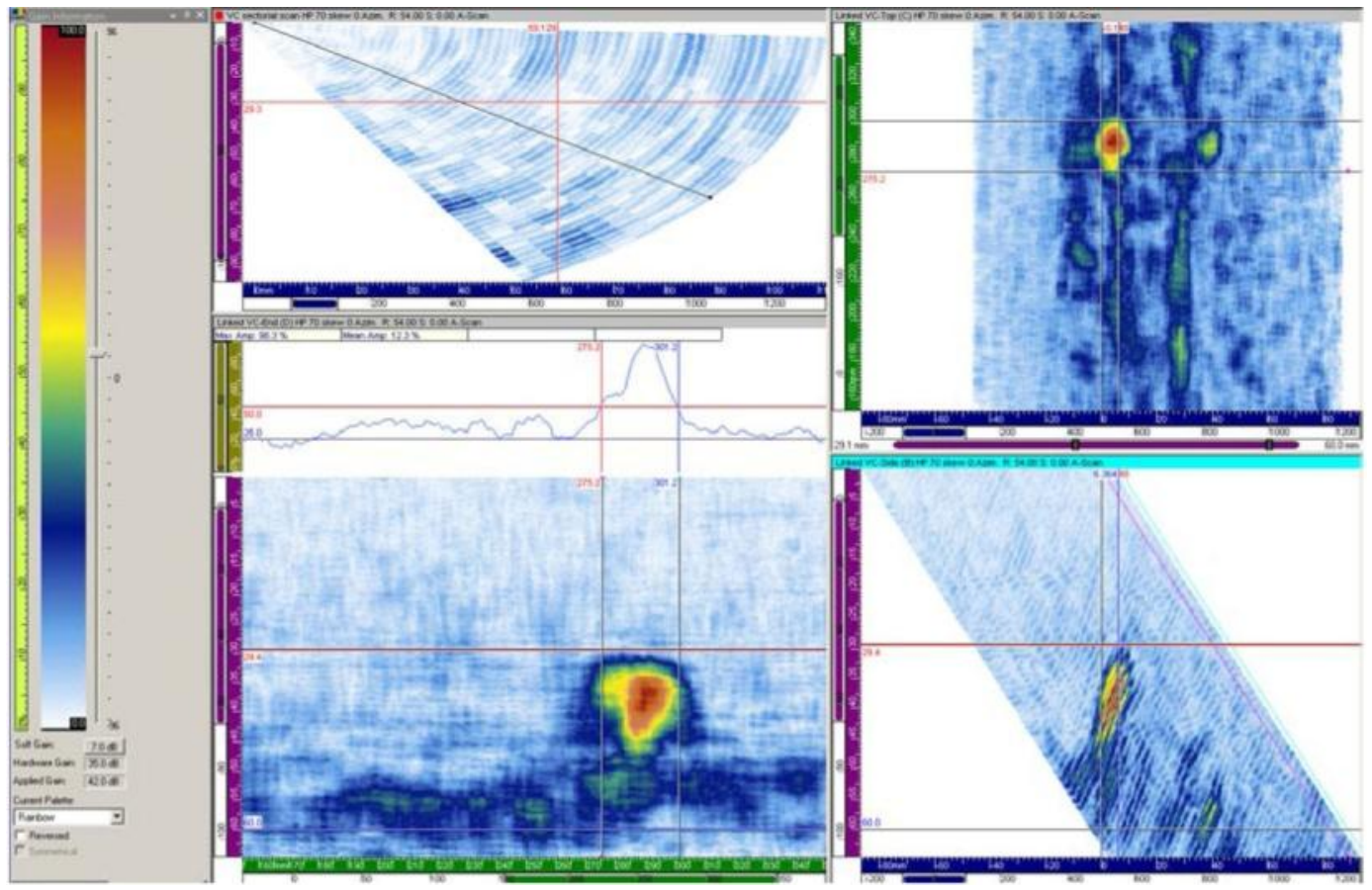

Figure D.2. 10C-011 Flaw 2 Nozzle Side of Overlay at $0.8 \mathrm{MHz}, 54$ Degrees 


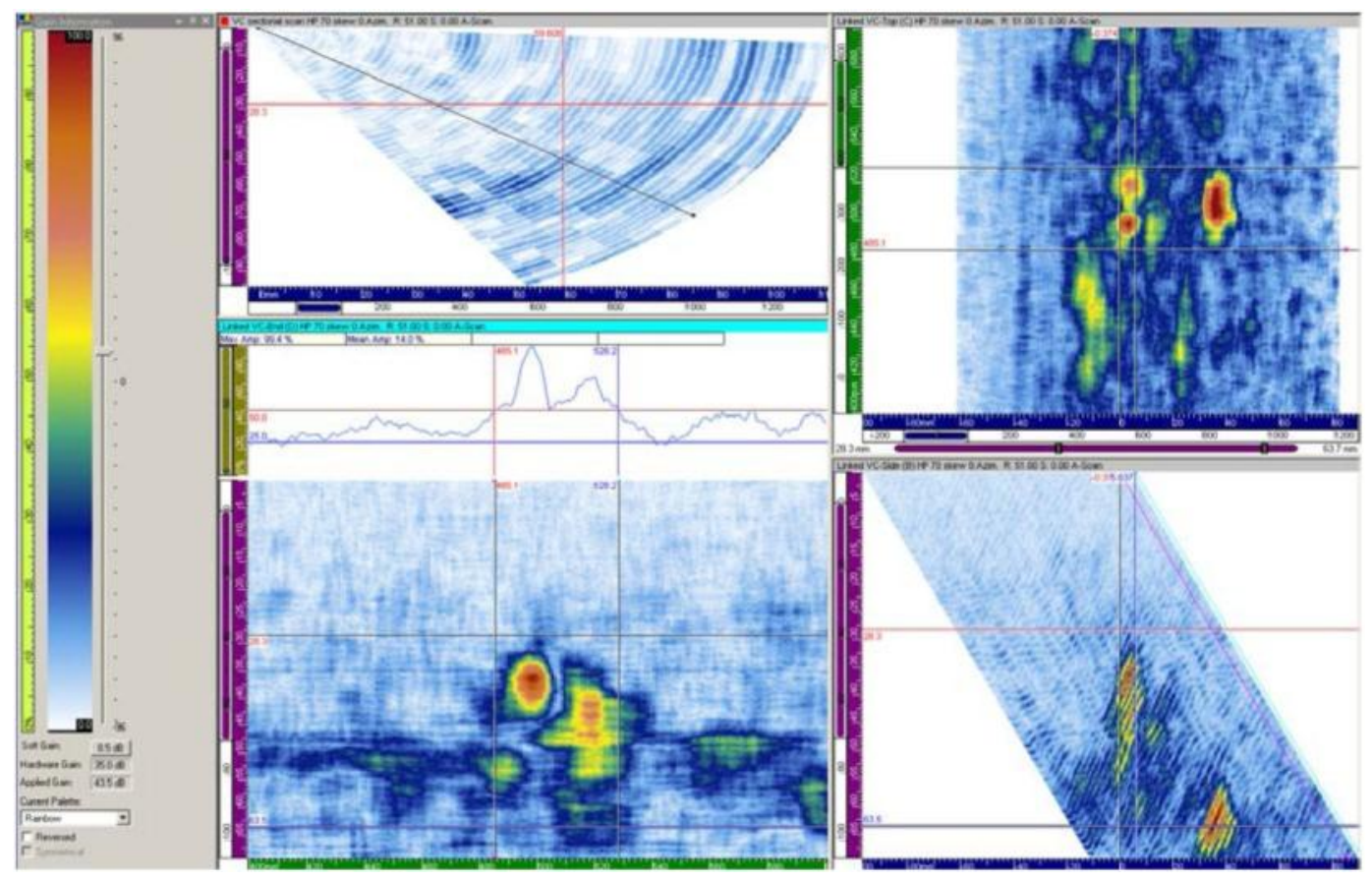

Figure D.3. 10C-011 Flaw 3 Nozzle Side of Overlay at $0.8 \mathrm{MHz}, 51$ Degrees

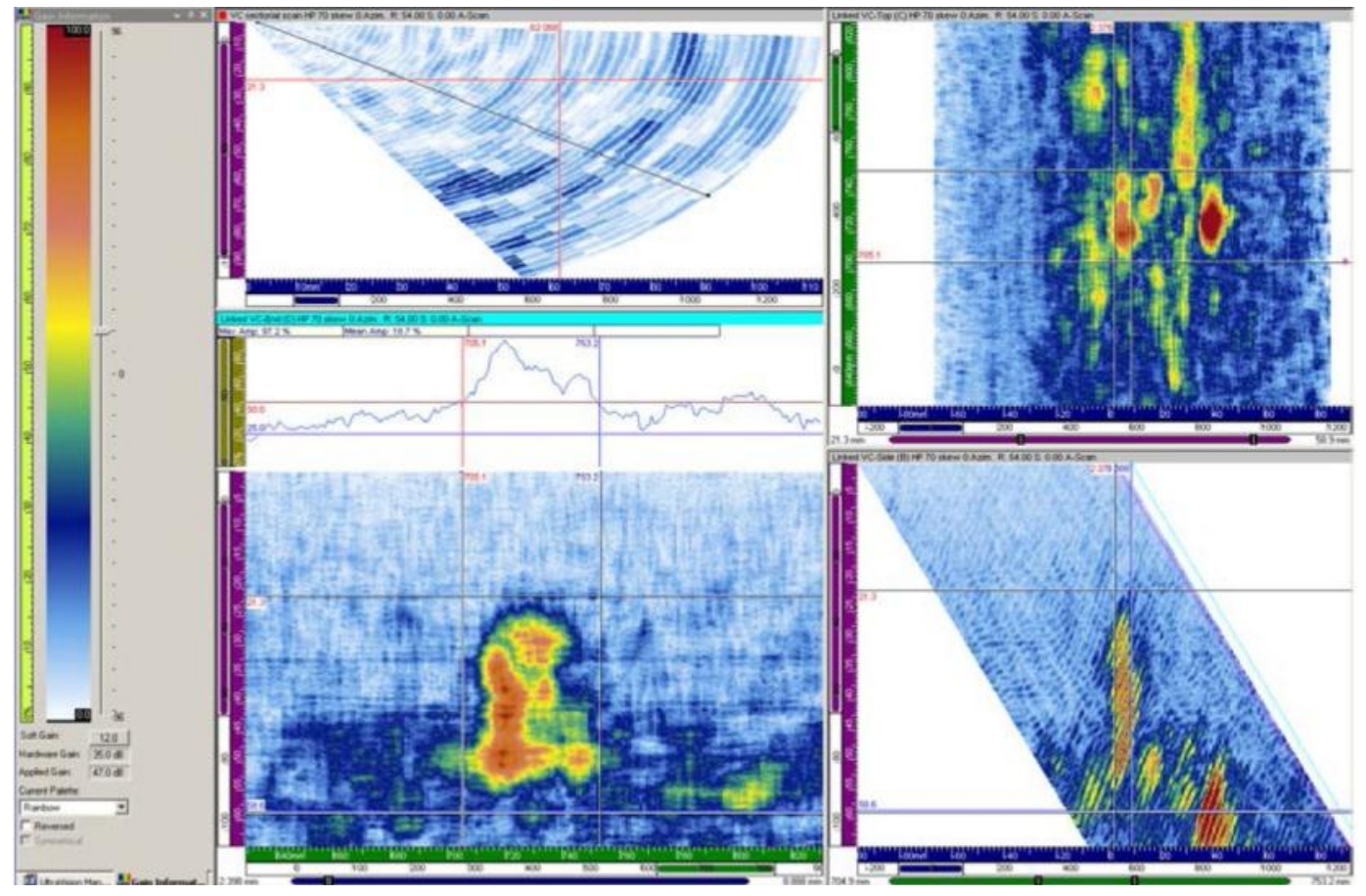

Figure D.4. 10C-011 Flaw 4 Nozzle Side of Overlay at $0.8 \mathrm{MHz}, 54$ Degrees 


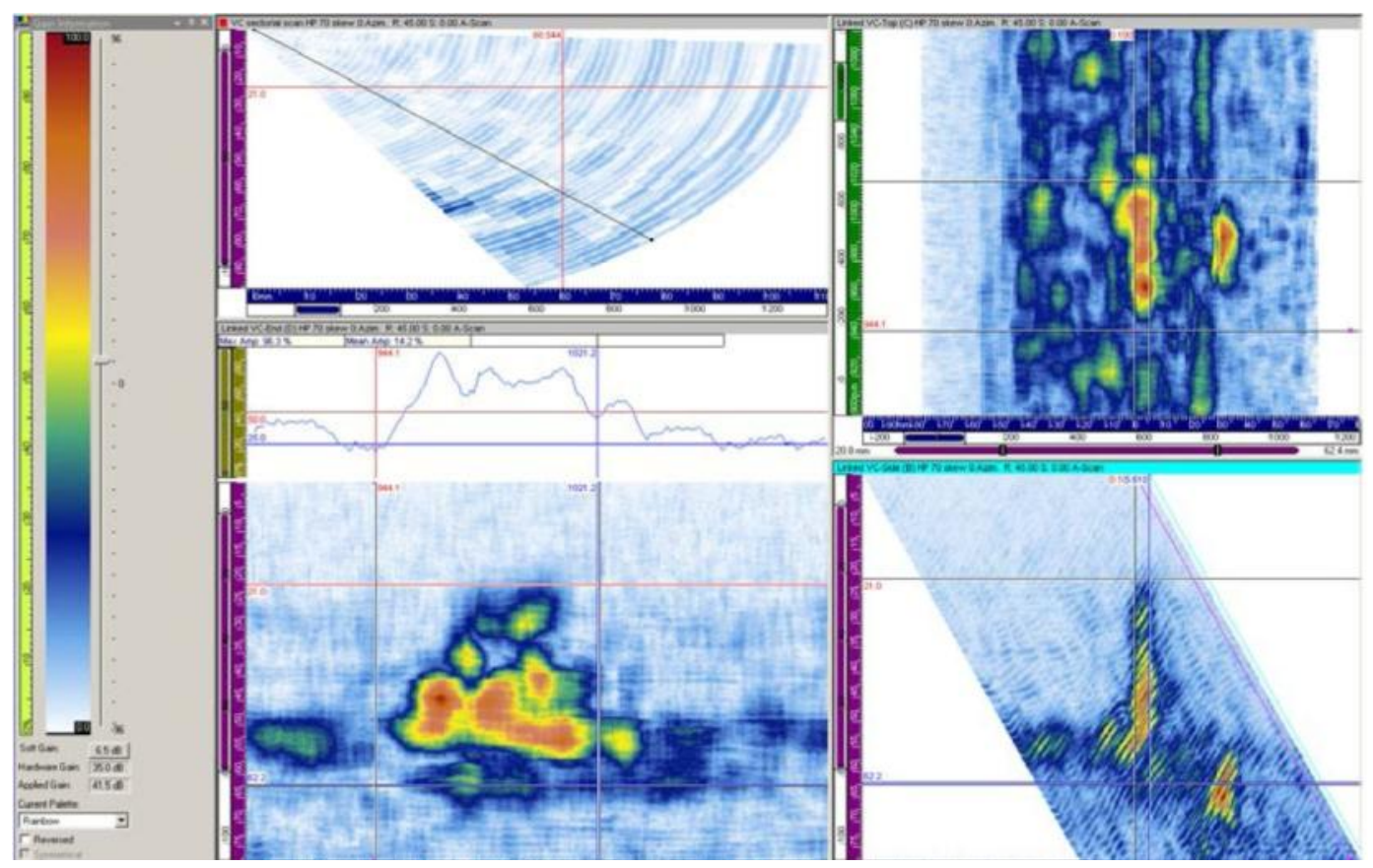

Figure D.5. 10C-011 Flaw 5 Nozzle Side of Overlay at $0.8 \mathrm{MHz}, 45$ Degrees 


\section{D.1.2 Raster Data at 0.8 MHz Pipe Side of Overlay on Flaws 1-5}

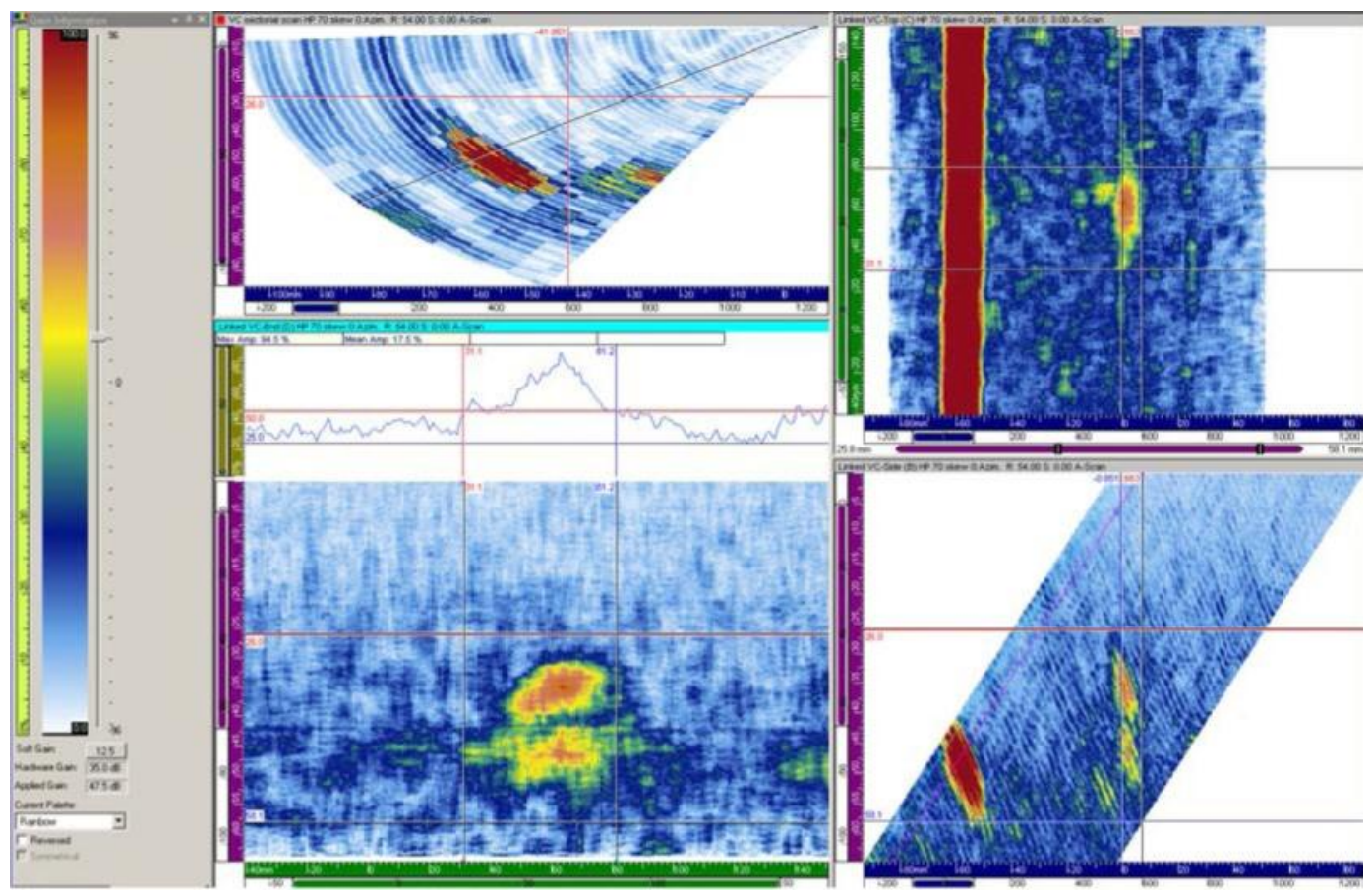

Figure D.6. 10C-011 Flaw 1 Pipe Side of Overlay at $0.8 \mathrm{MHz}$, 54 Degrees

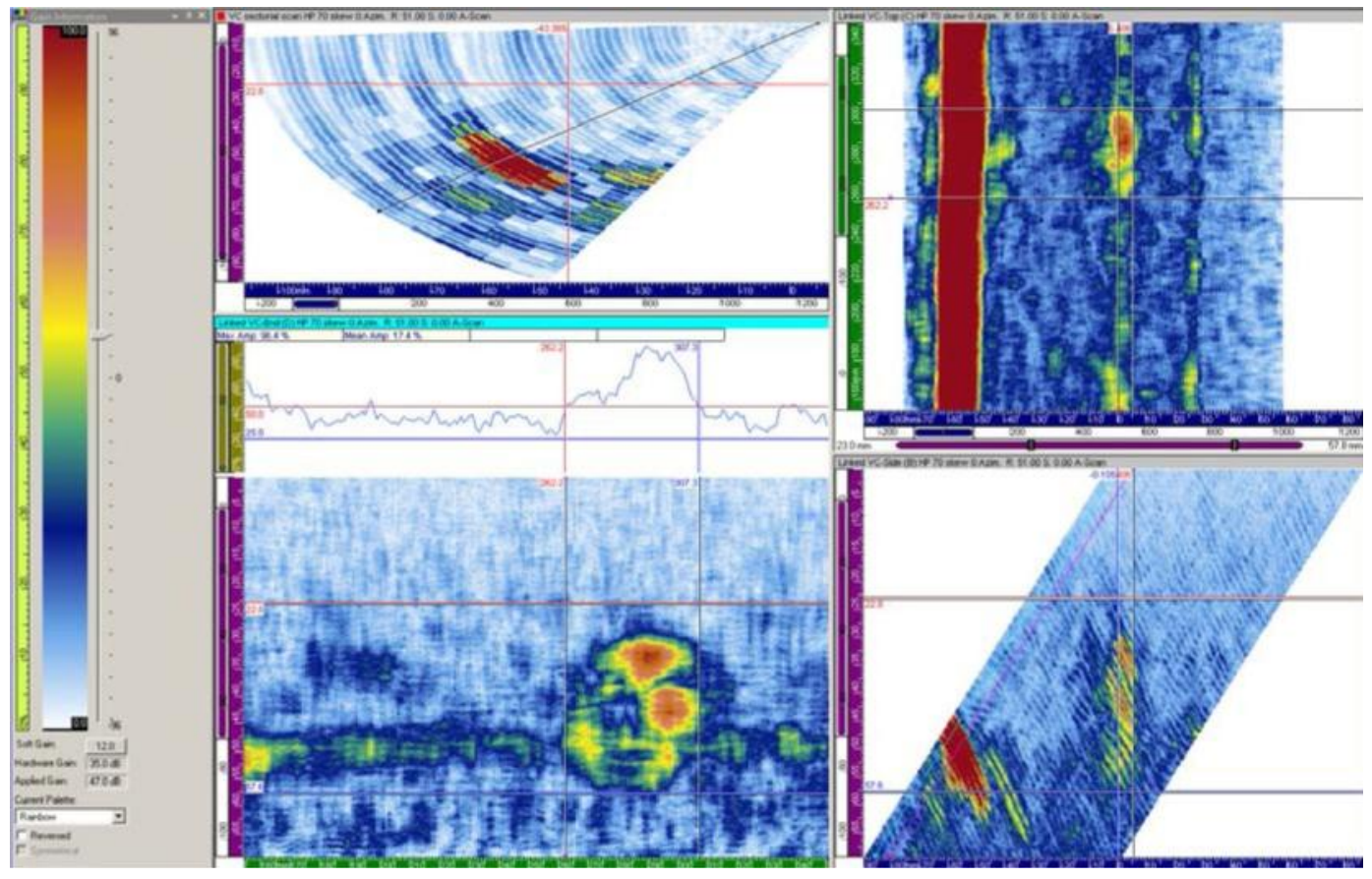

Figure D.7. 10C-011 Flaw 2 Pipe Side of Overlay at $0.8 \mathrm{MHz}, 51$ Degrees 


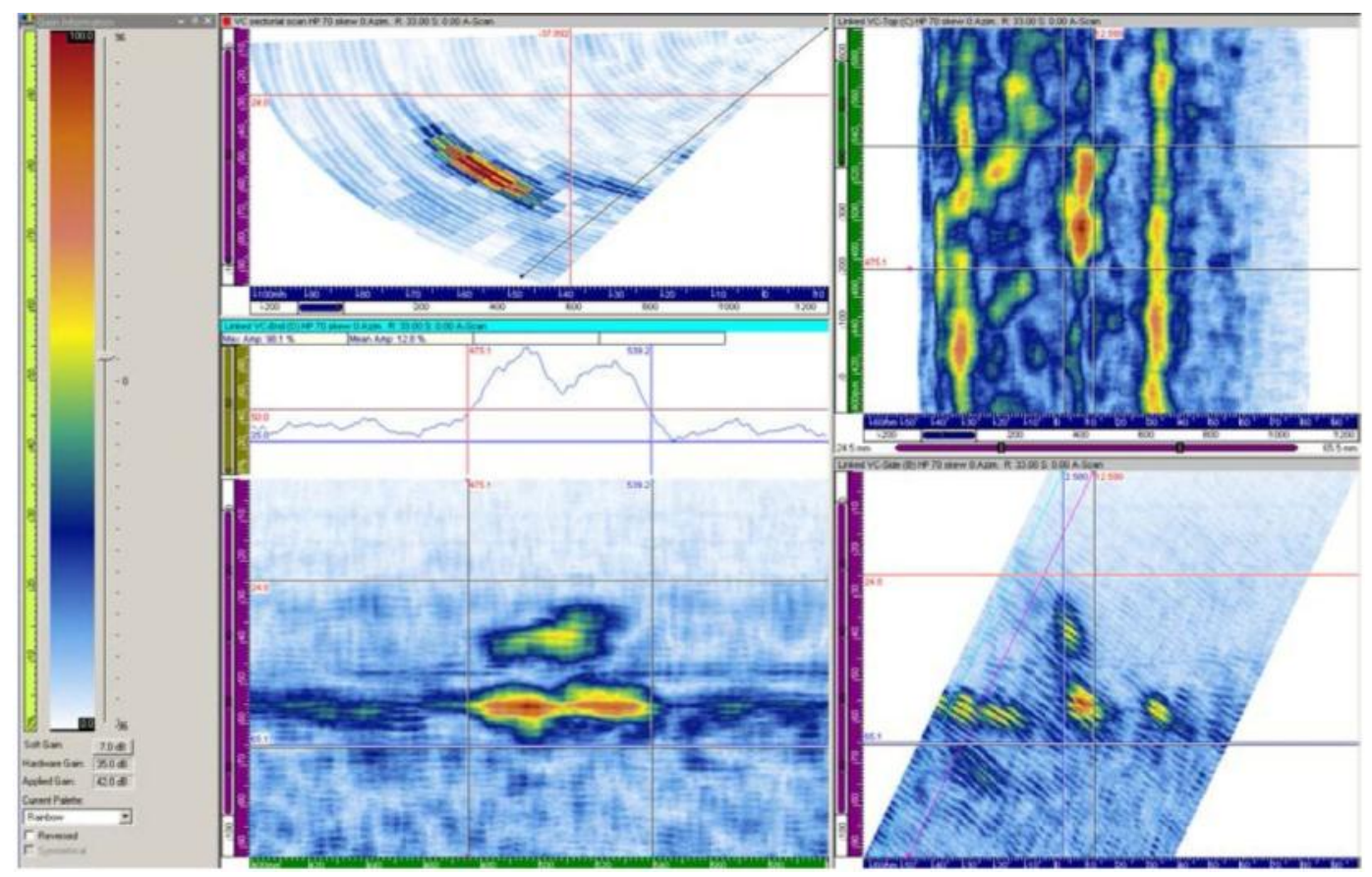

Figure D.8. 10C-011 Flaw 3 Pipe Side of Overlay at $0.8 \mathrm{MHz}, 33$ Degrees

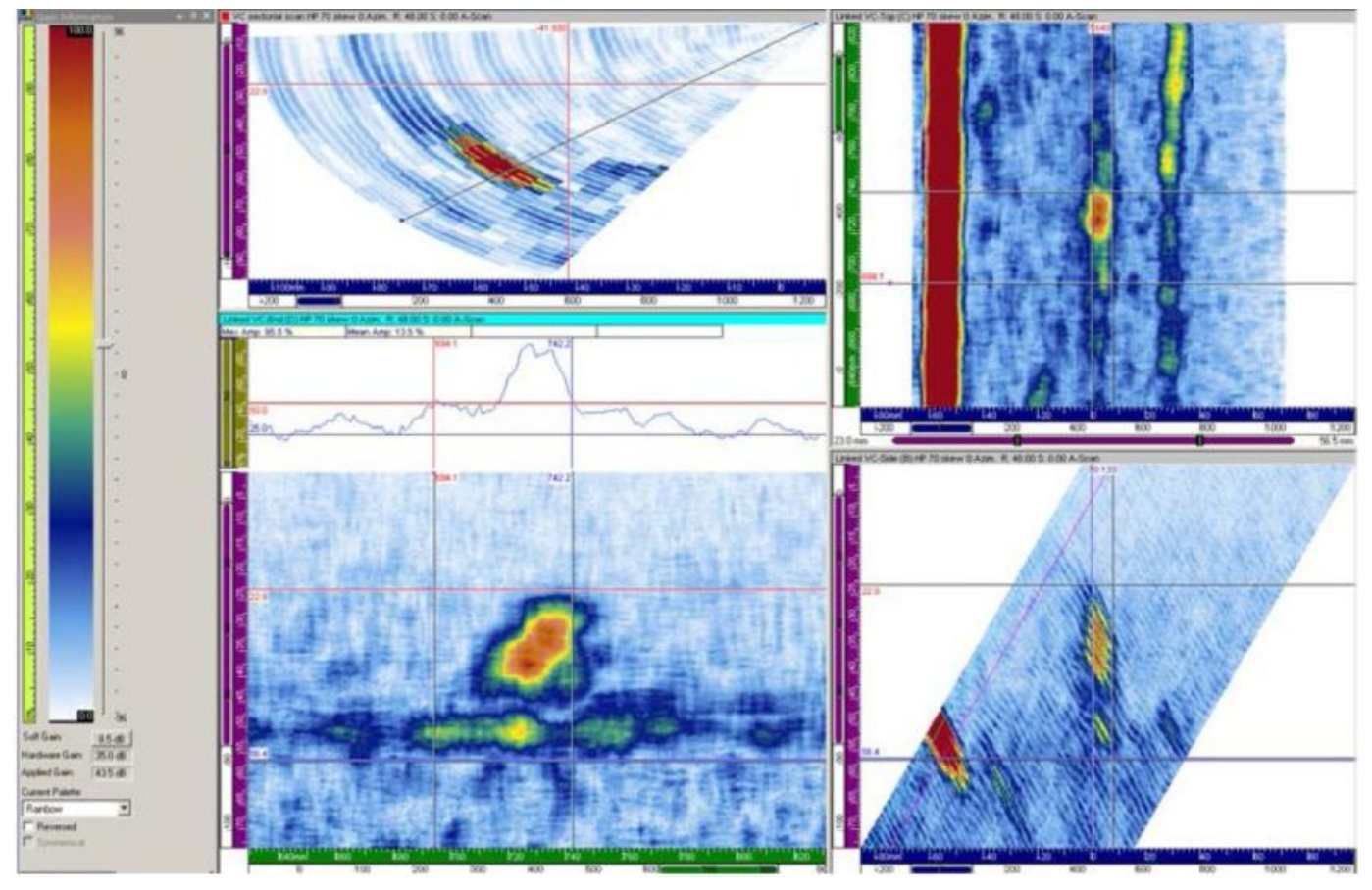

Figure D.9. 10C-011 Flaw 4 Pipe Side of Overlay at $0.8 \mathrm{MHz}, 48$ Degrees 


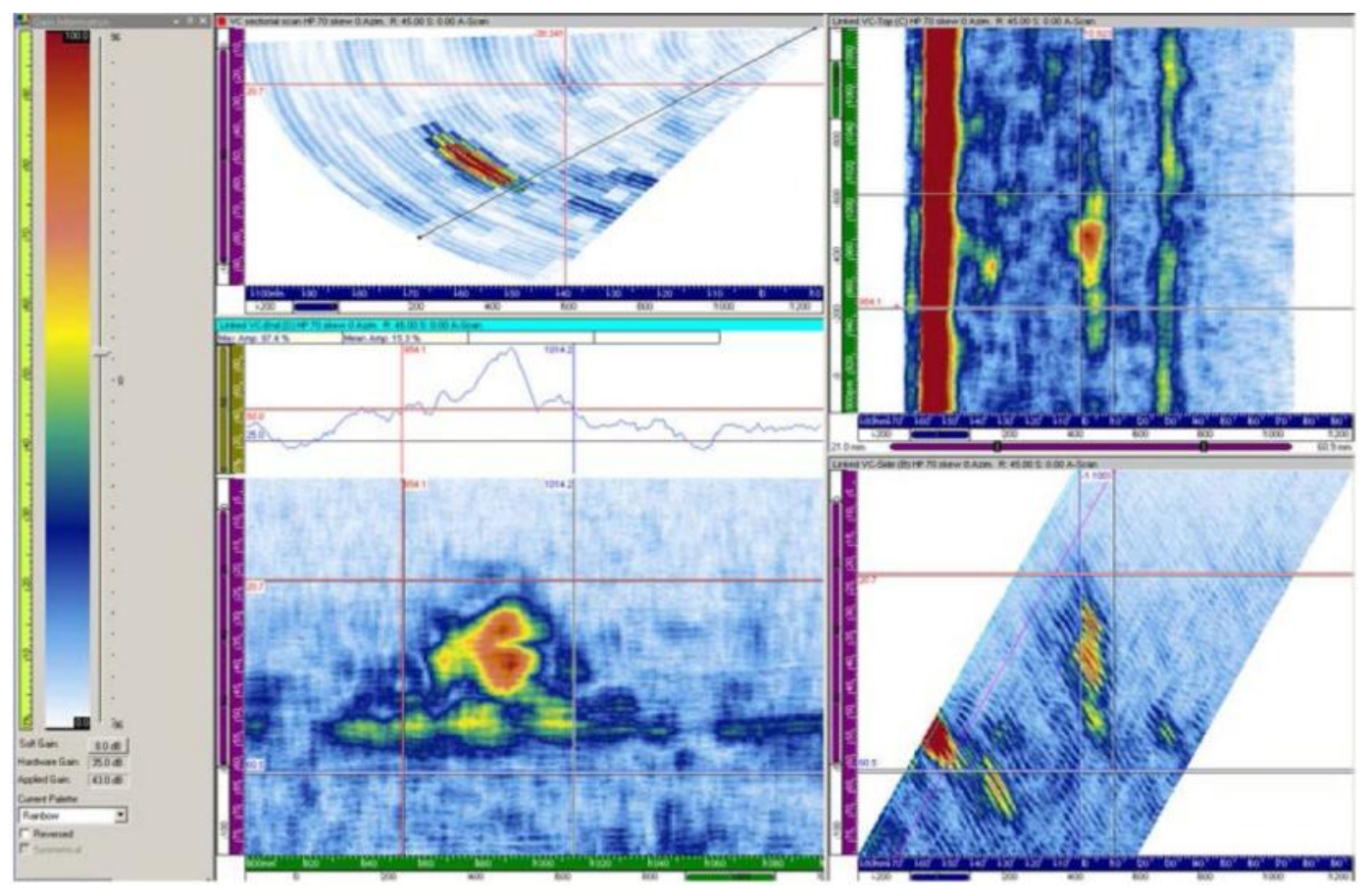

Figure D.10. 10C-011 Flaw 5 Pipe Side of Overlay at $0.8 \mathrm{MHz}, 45$ Degrees 


\section{D.1.3 Raster Data at 1.0 MHz Nozzle Side of Overlay on Flaws 1-5}

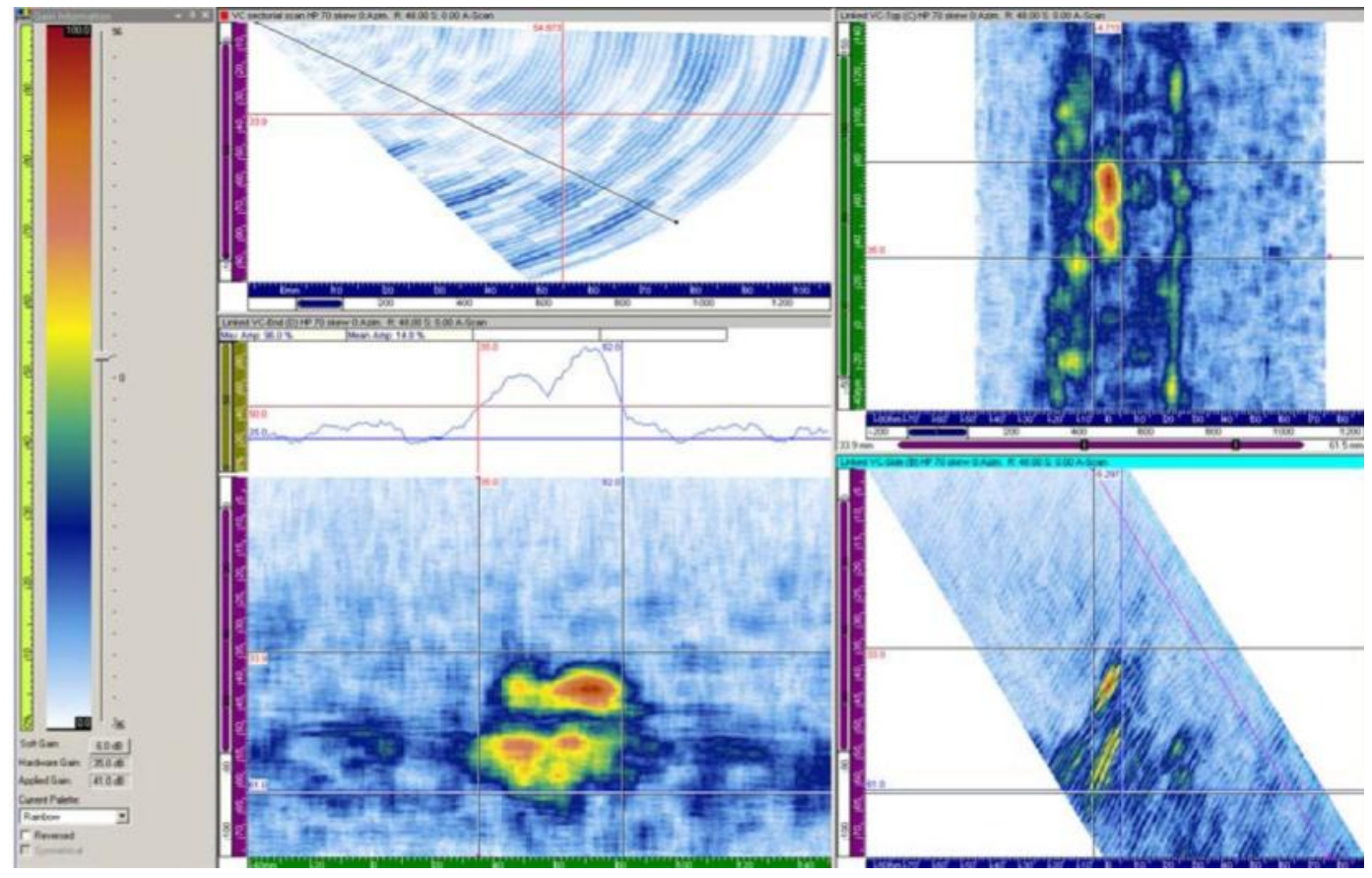

Figure D.11. 10C-011 Flaw 1 Nozzle Side of Overlay at 1.0 MHz, 48 Degrees

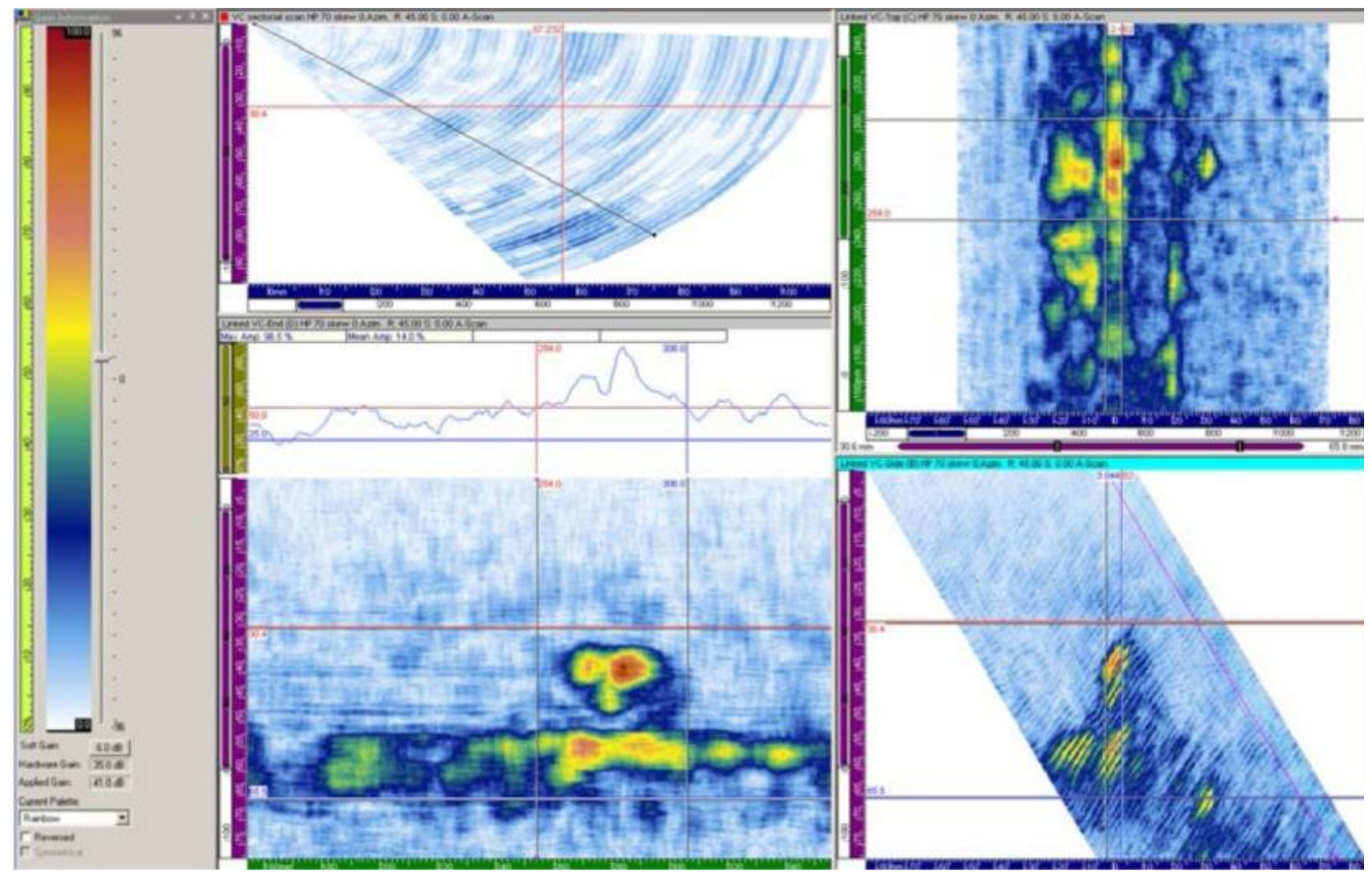

Figure D.12. 10C-011 Flaw 2 Nozzle Side of Overlay at 1.0 MHz, 45 Degrees 


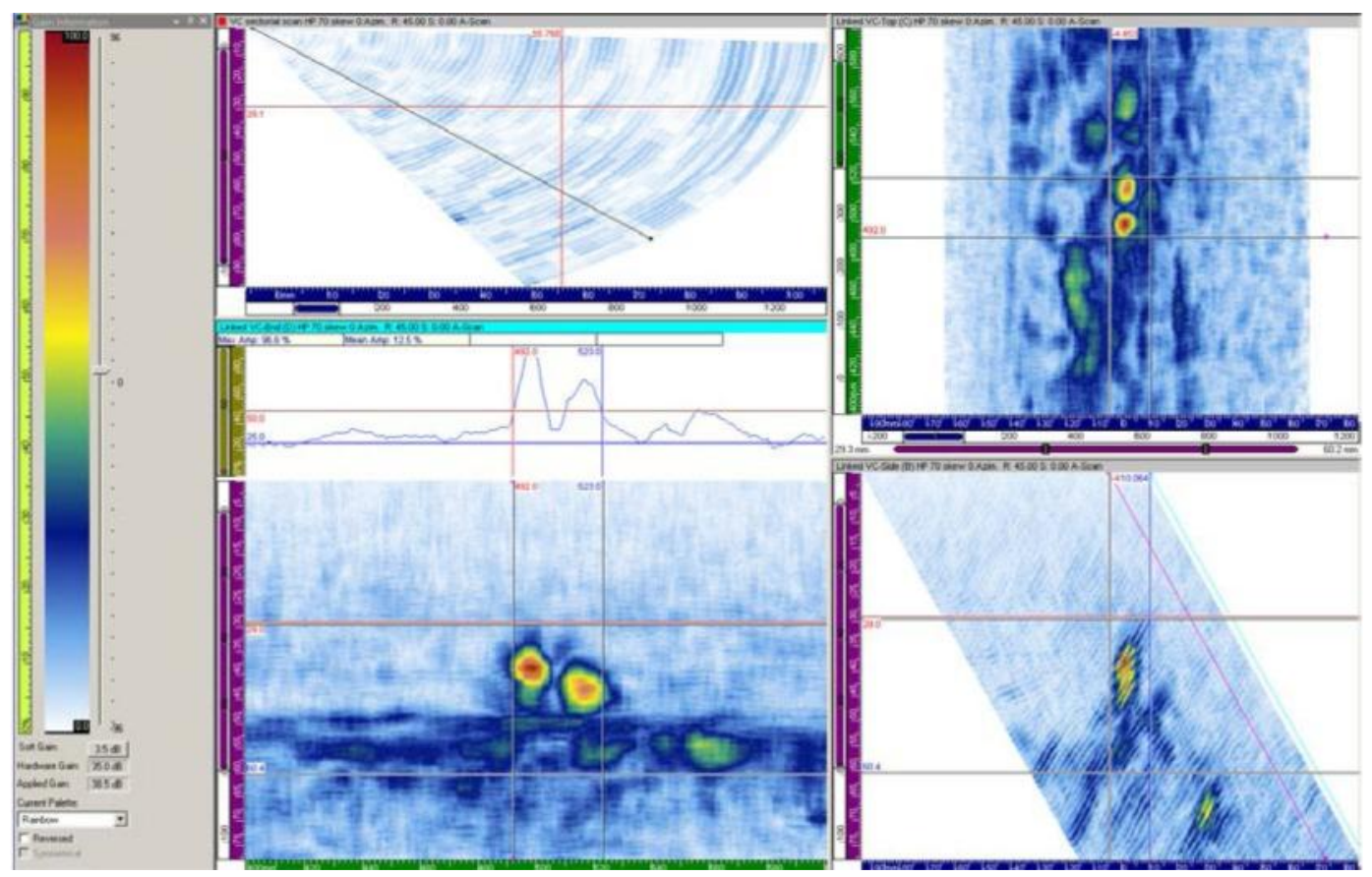

Figure D.13. 10C-011 Flaw 3 Nozzle Side of Overlay at $1.0 \mathrm{MHz}, 45$ Degrees

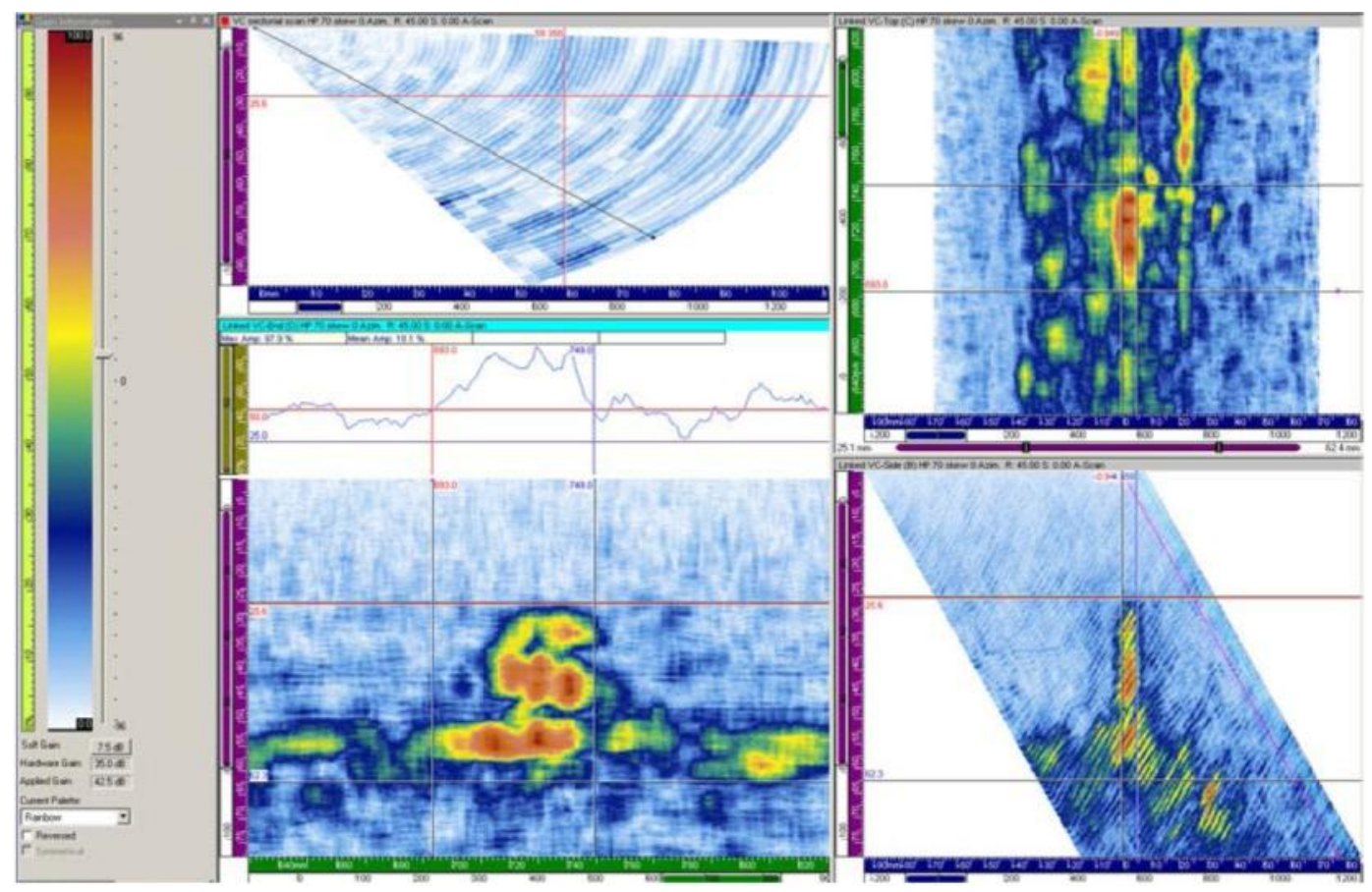

Figure D.14. 10C-011 Flaw 4 Nozzle Side of Overlay at $1.0 \mathrm{MHz}, 45$ Degrees 


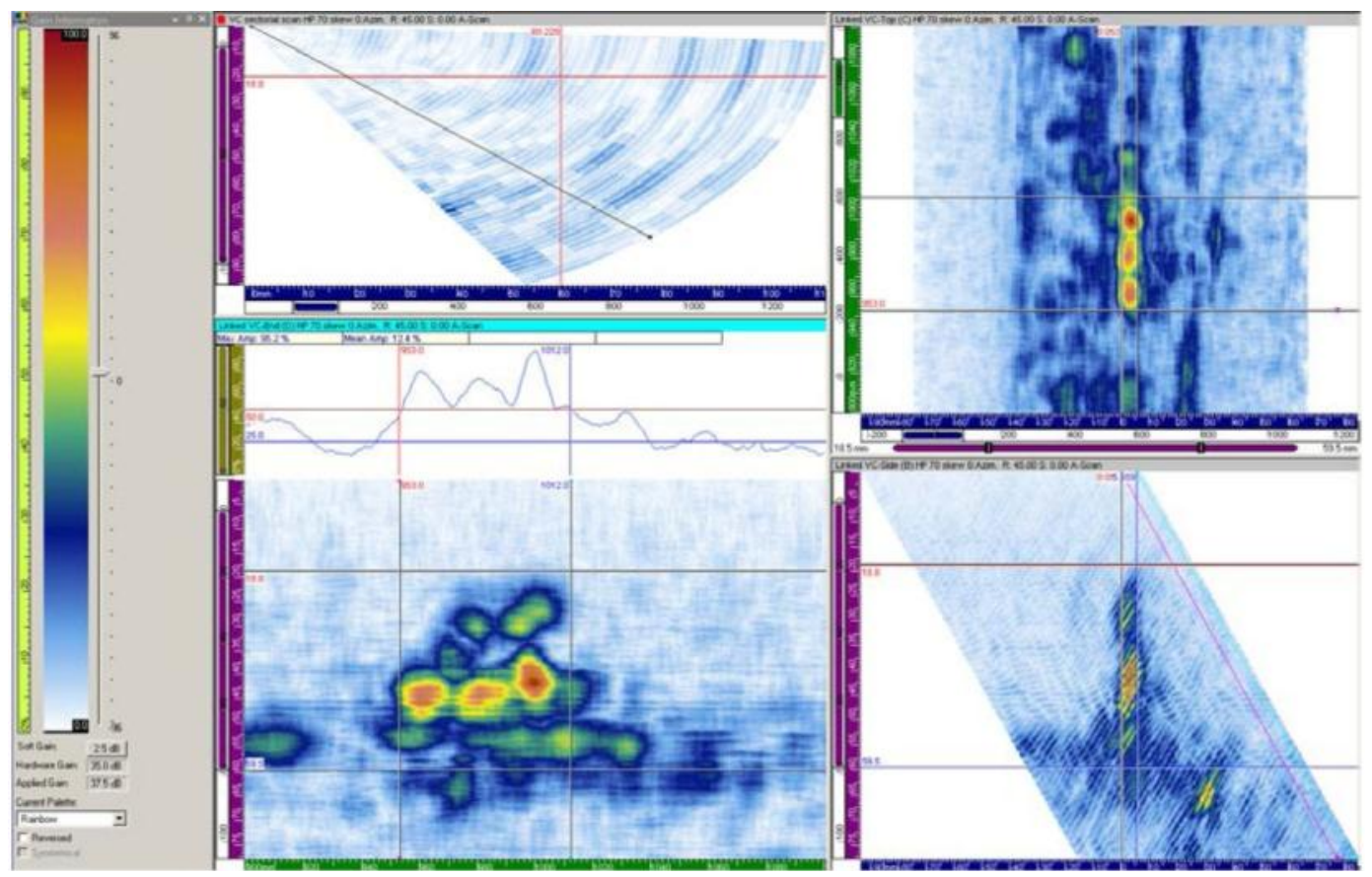

Figure D.15. 10C-011 Flaw 5 Nozzle Side of Overlay at $1.0 \mathrm{MHz}$, 45 Degrees 


\section{D.1.4 Raster Data at 1.0 MHz Pipe Side of Overlay on Flaws 1-5}

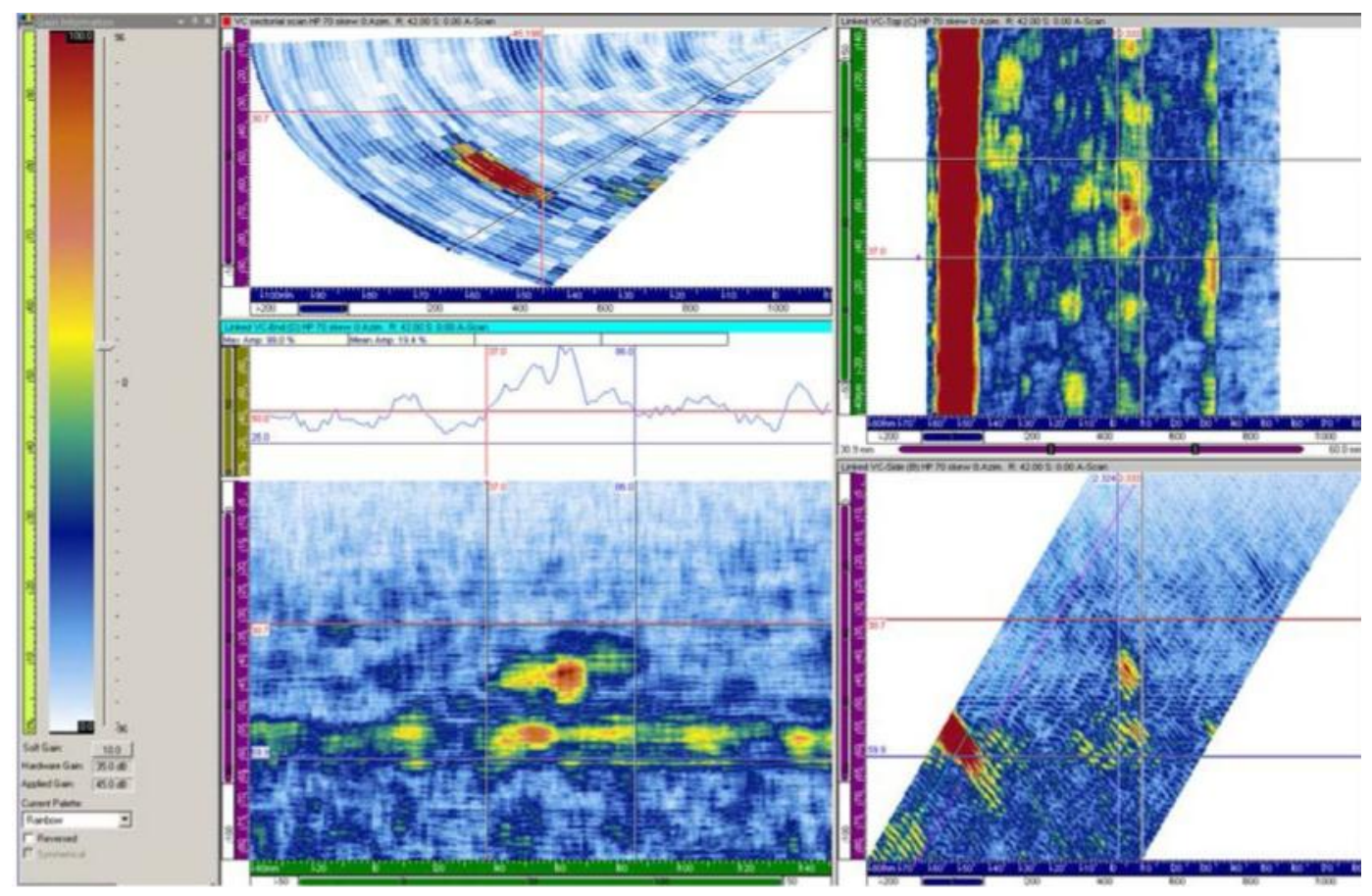

Figure D.16. 10C-011 Flaw 1 Pipe Side of Overlay at 1.0 MHz, 42 Degrees

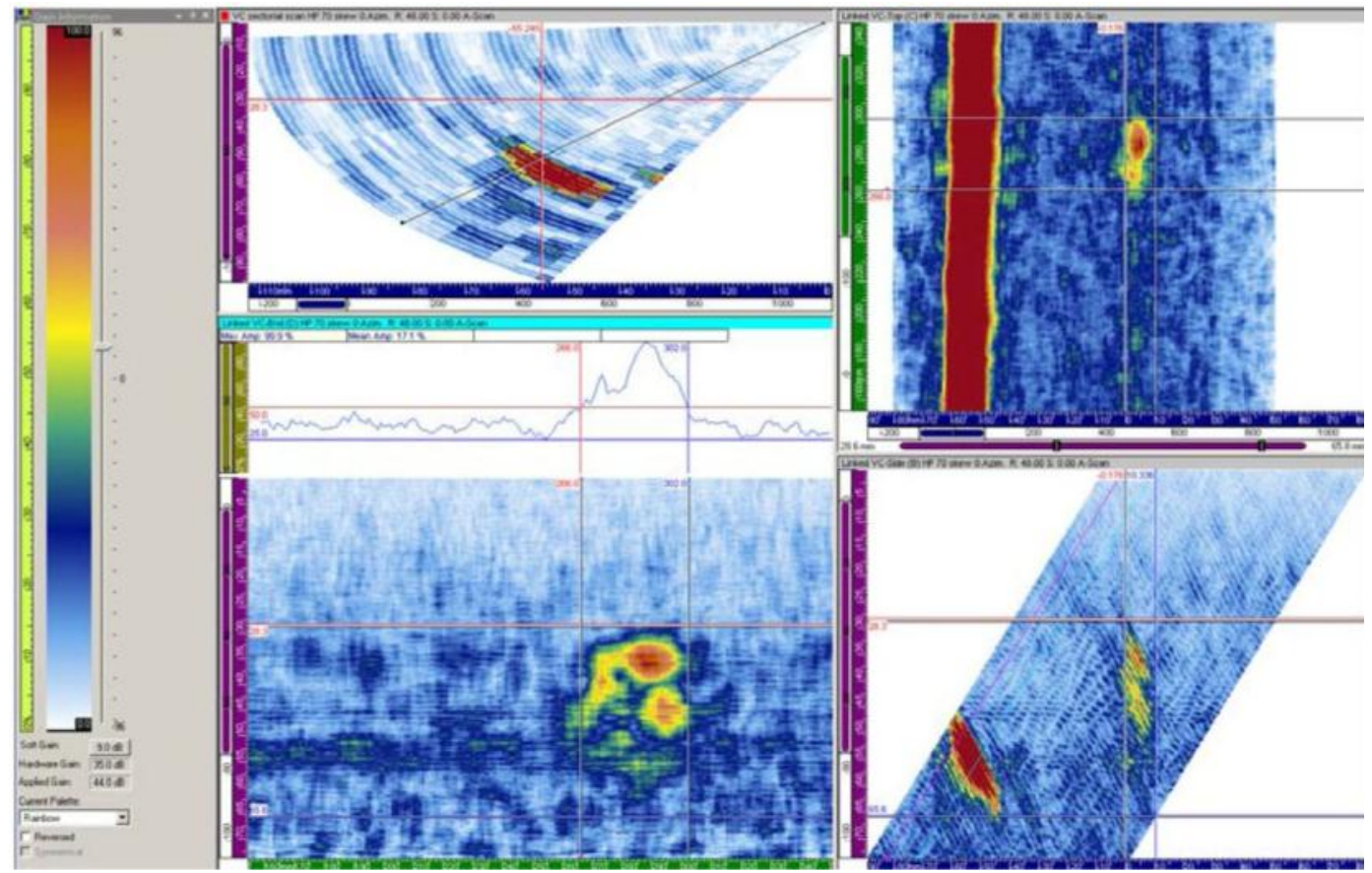

Figure D.17. 10C-011 Flaw 2 Pipe Side of Overlay at 1.0 MHz, 48 Degrees 


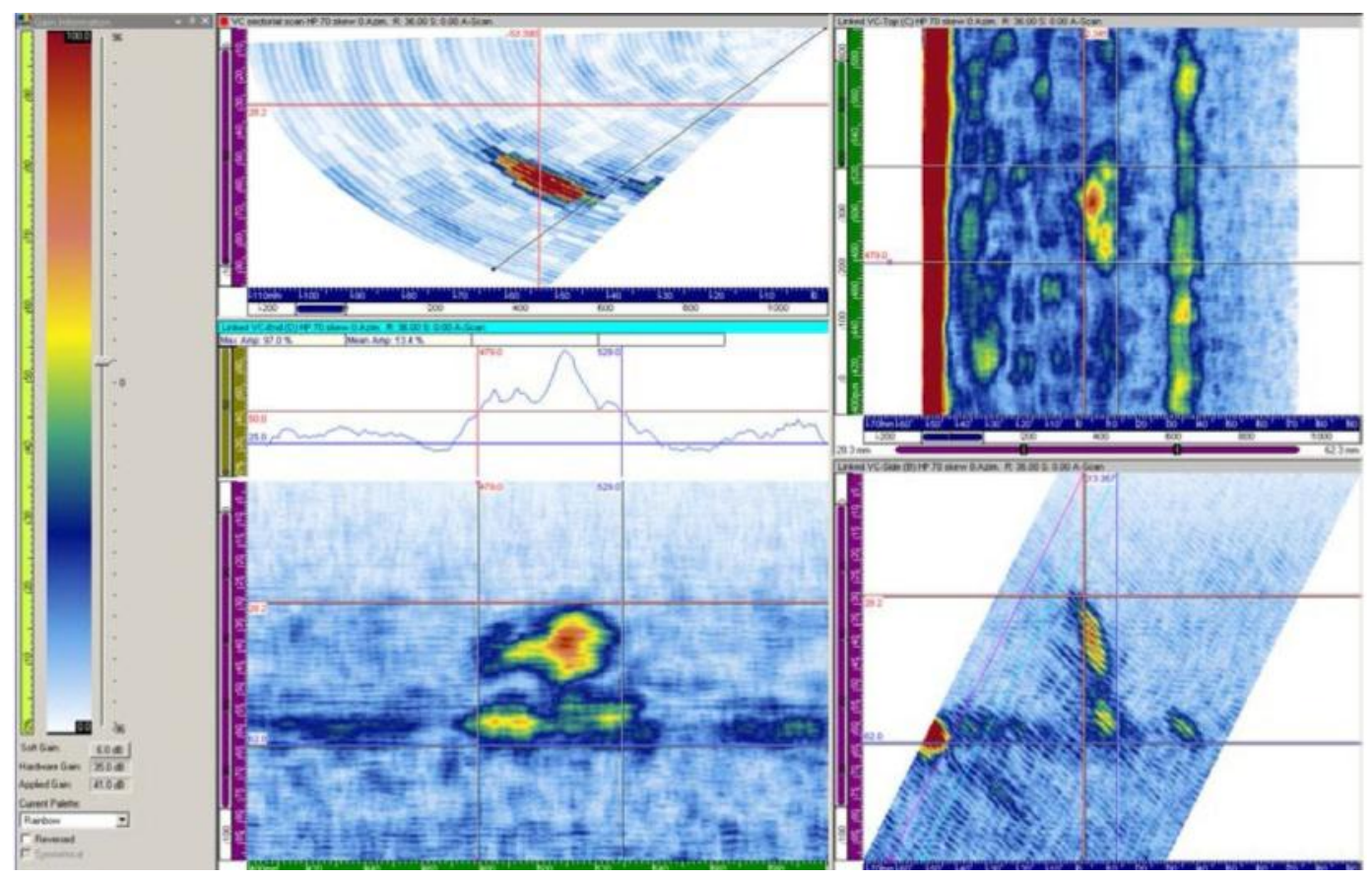

Figure D.18. 10C-011 Flaw 3 Pipe Side of Overlay at 1.0 MHz, 36 Degrees

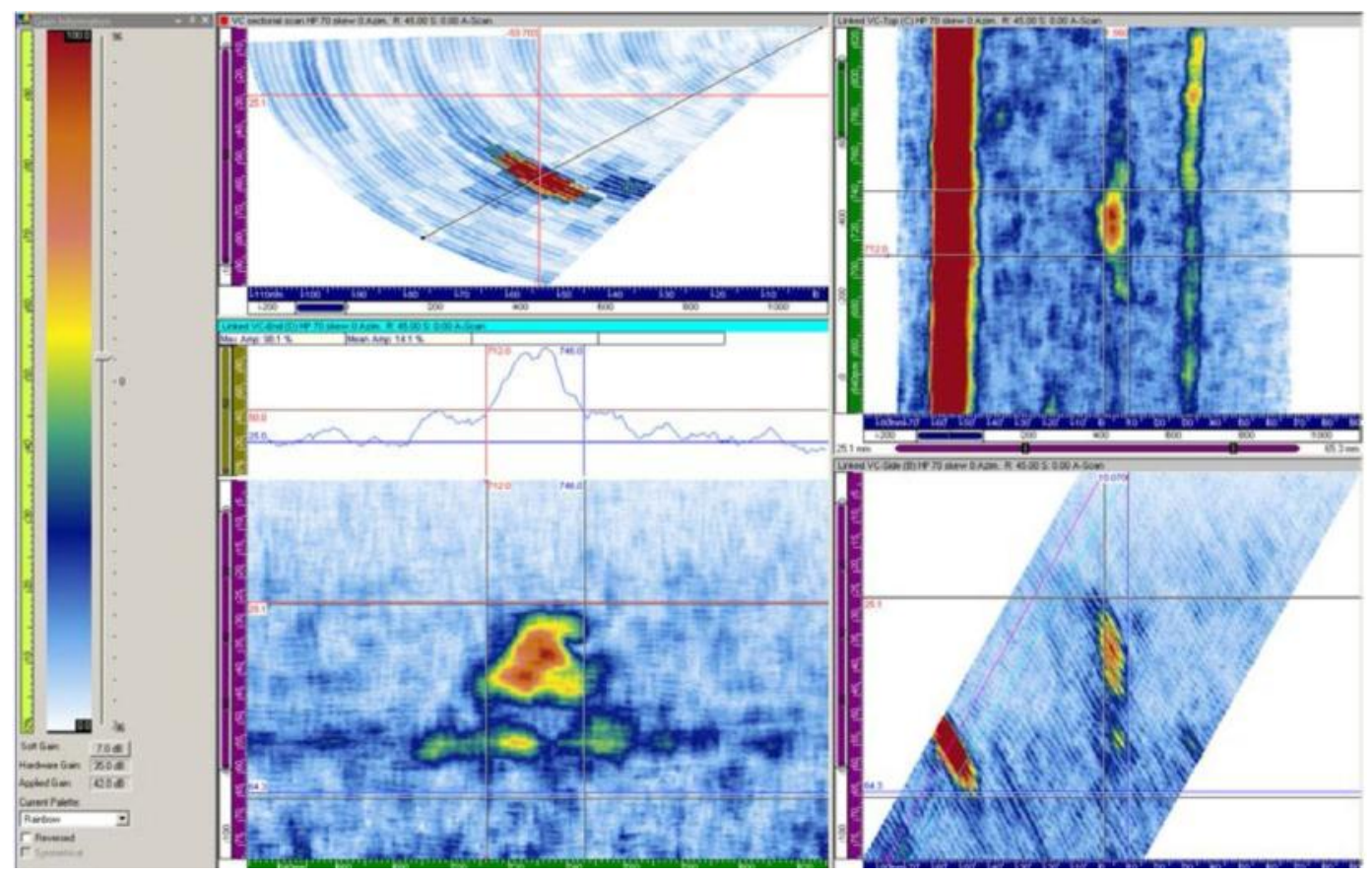

Figure D.19. 10C-011 Flaw 4 Pipe Side of Overlay at $1.0 \mathrm{MHz}, 45$ Degrees 


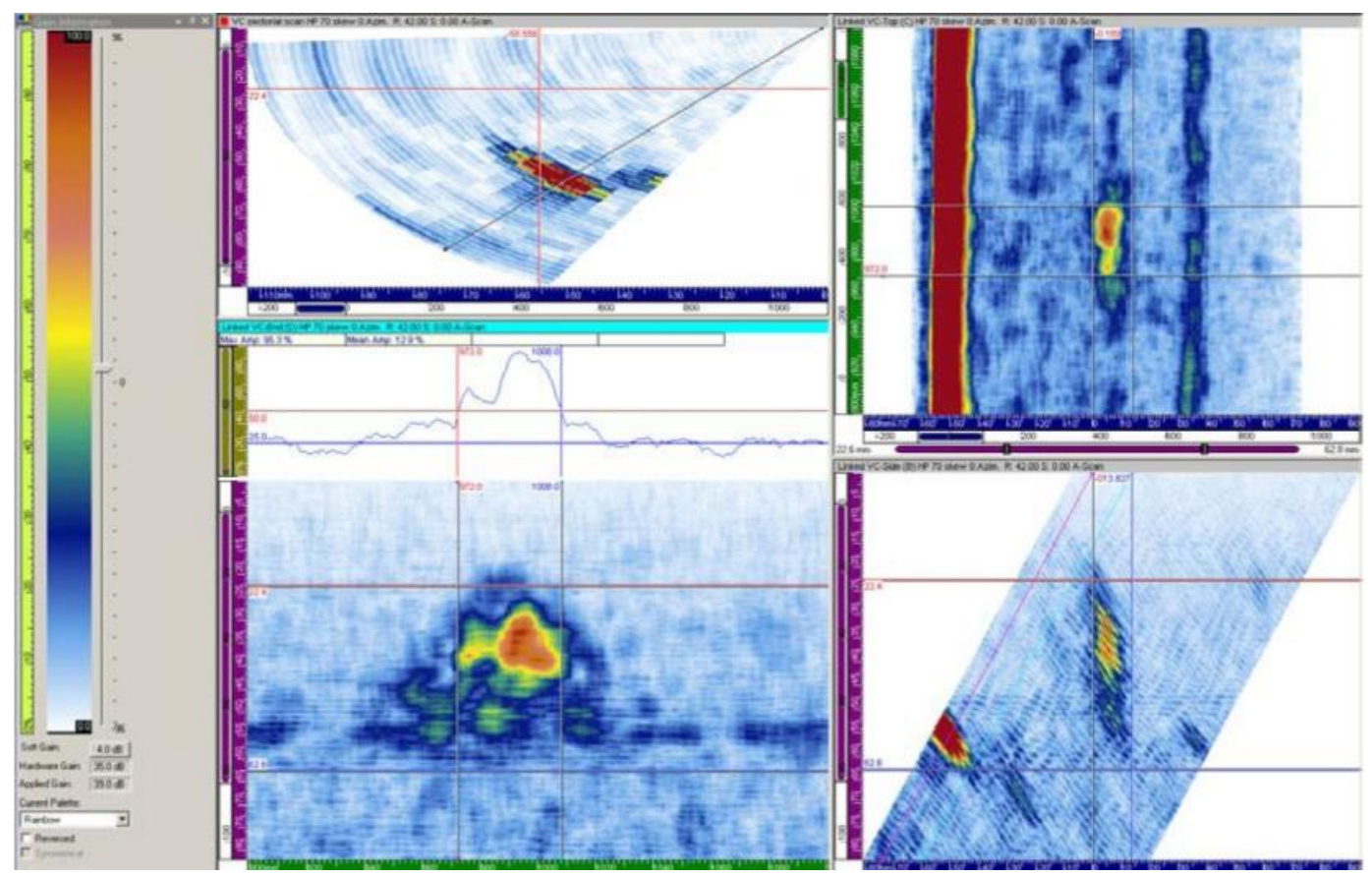

Figure D.20. 10C-011 Flaw 5 Pipe Side of Overlay at 1.0 MHz, 42 Degrees 


\section{D.1.5 Raster Data at 1.5 MHz Nozzle Side of Overlay on Flaws 1-5}

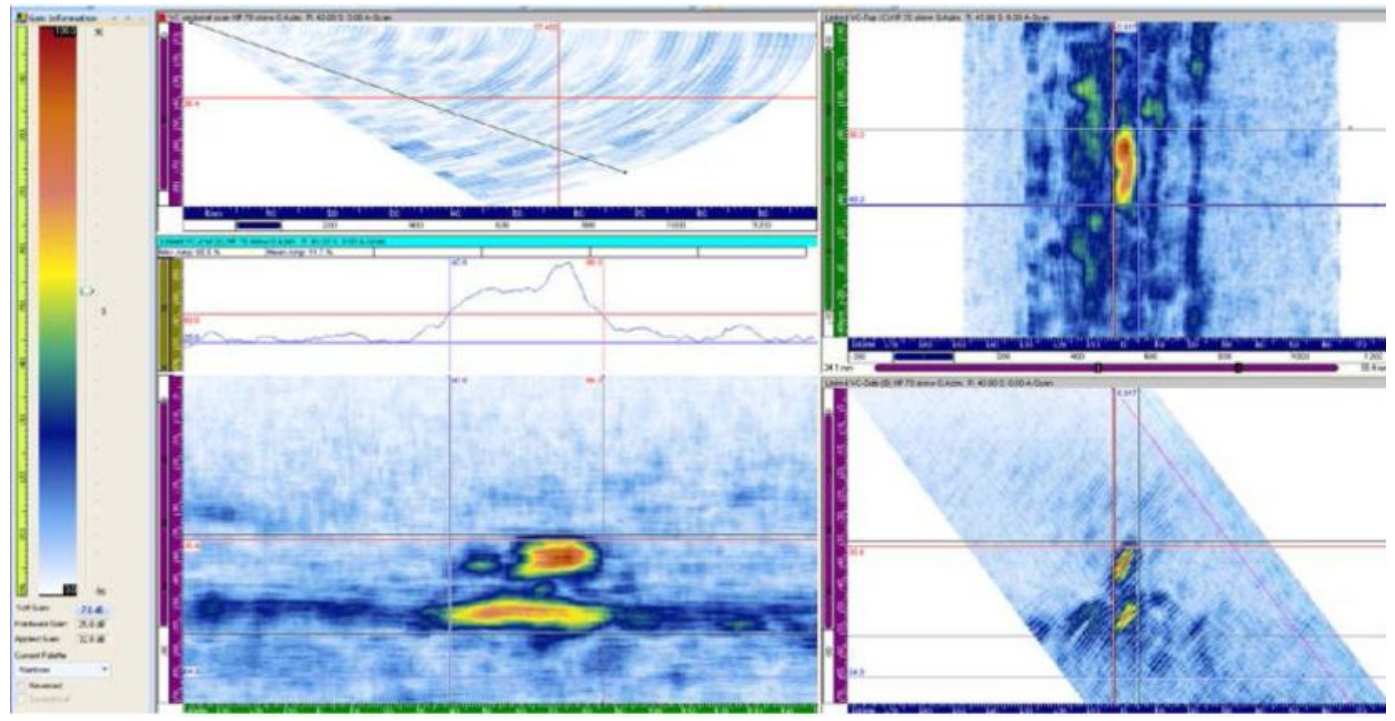

Figure D.21. 10C-011 Flaw 1 Nozzle Side of Overlay at $1.5 \mathrm{MHz}, 45$ Degrees

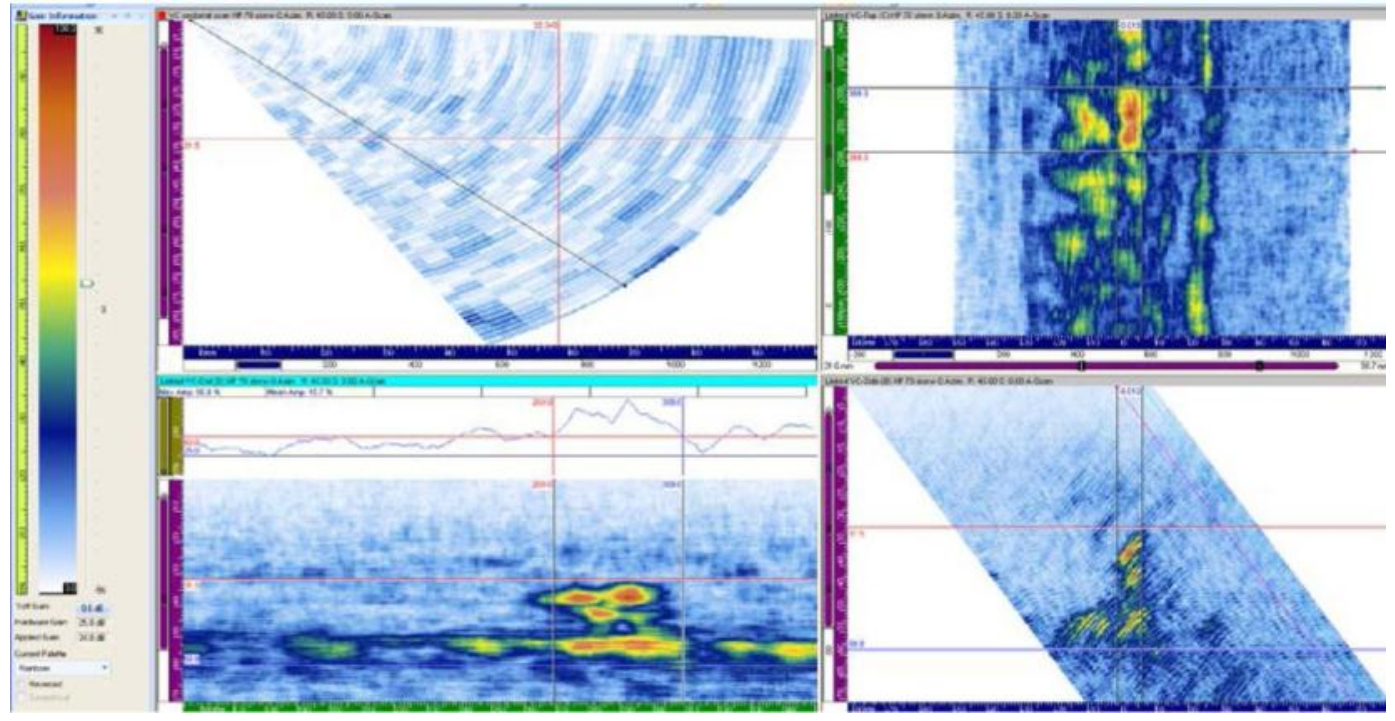

Figure D.22. 10C-011 Flaw 2 Nozzle Side of Overlay at $1.5 \mathrm{MHz}, 45$ Degrees 


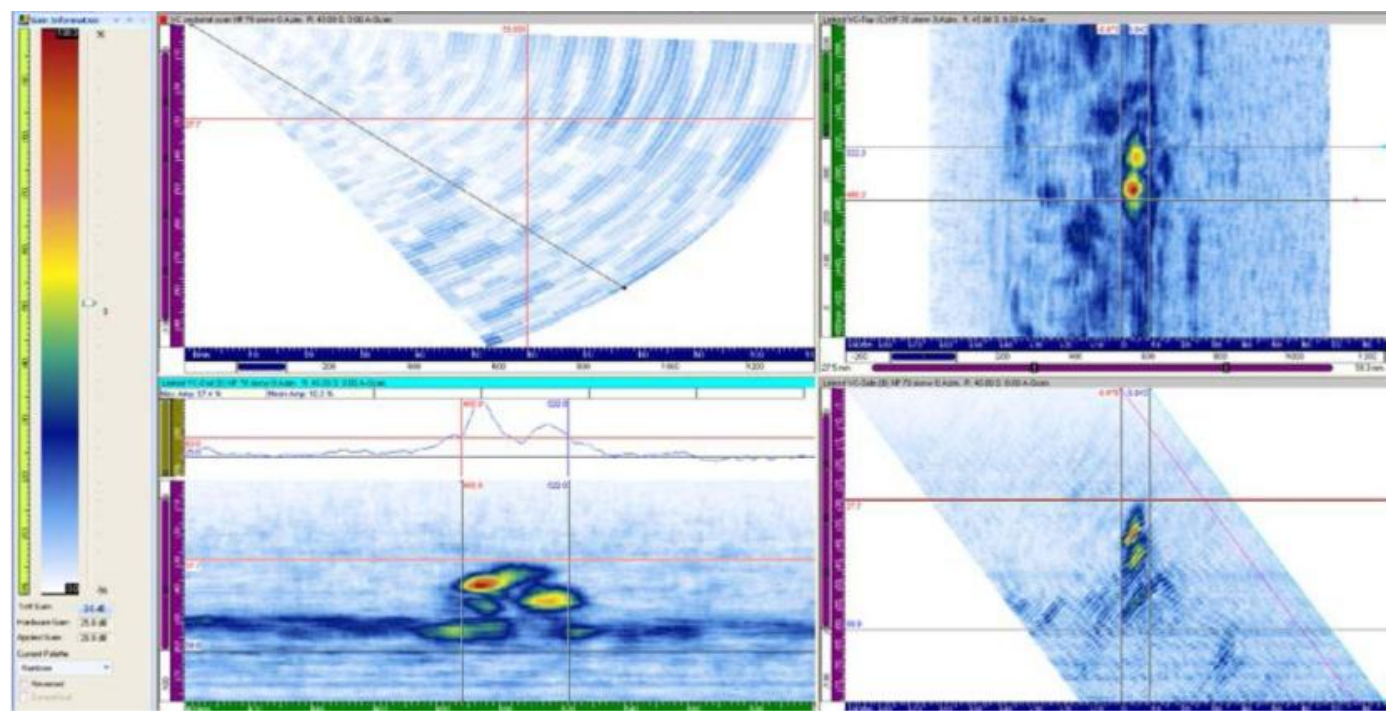

Figure D.23. 10C-011 Flaw 3 Nozzle Side of Overlay at $1.5 \mathrm{MHz}$, 45 Degrees

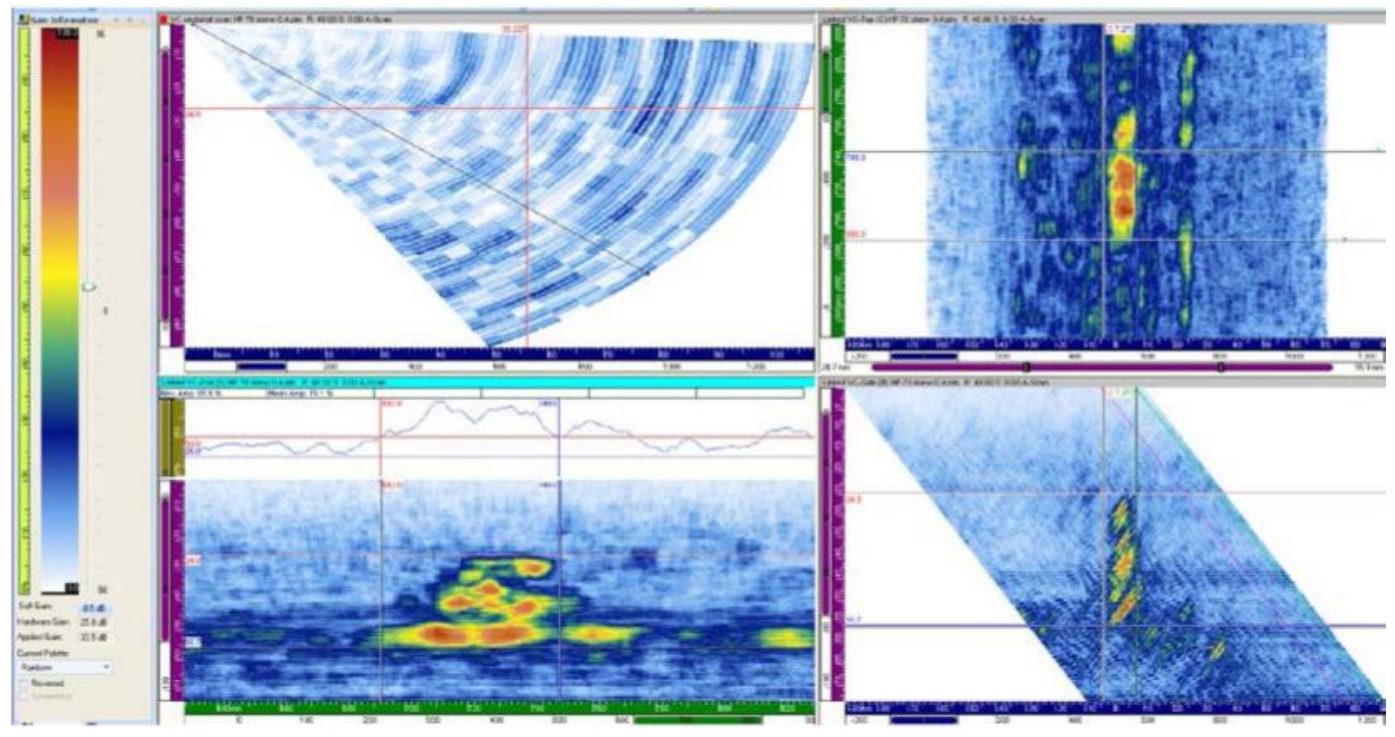

Figure D.24. 10C-011 Flaw 4 Nozzle Side of Overlay at 1.5 MHz, 48 Degrees 


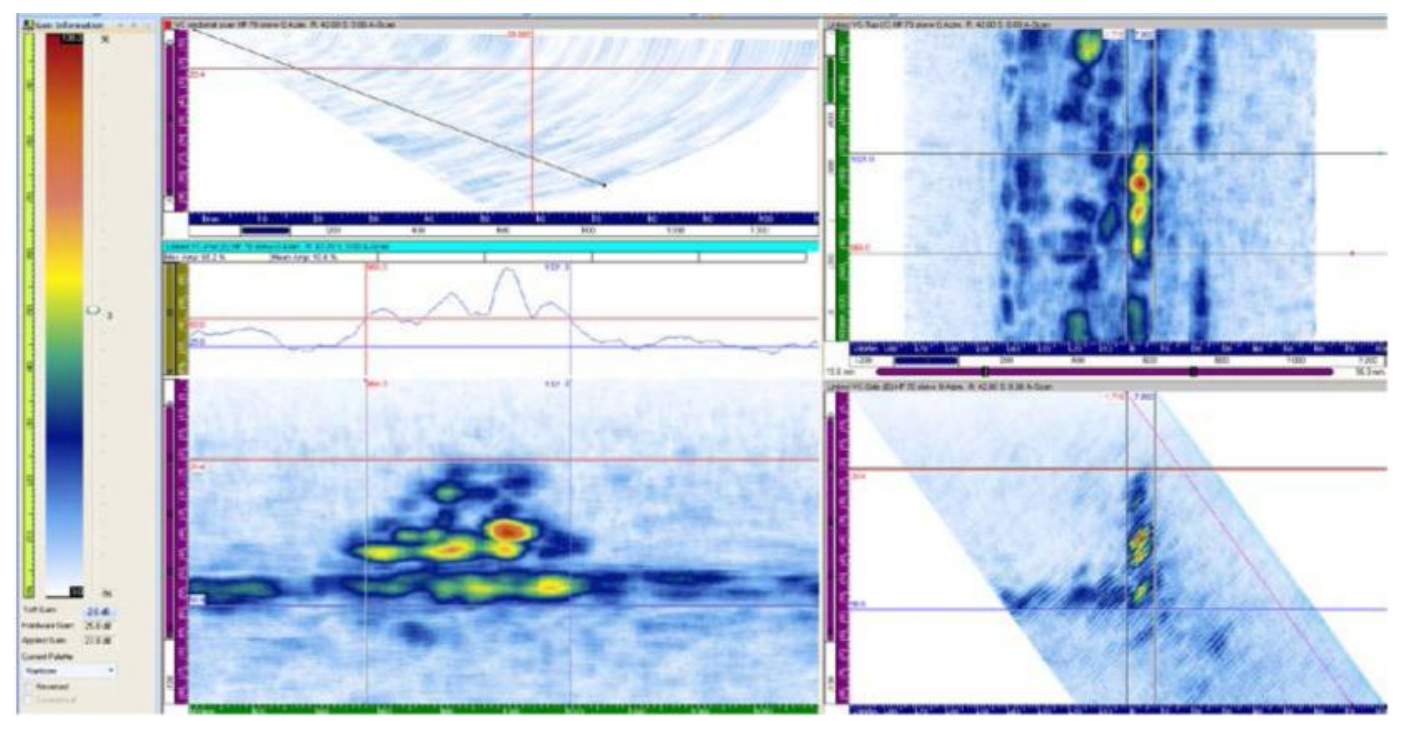

Figure D.25. 10C-011 Flaw 5 Nozzle Side of Overlay at $1.5 \mathrm{MHz}, 42$ Degrees 


\section{D.1.6 Raster Data at 1.5 MHz Pipe Side of Overlay on Flaws 1-5}

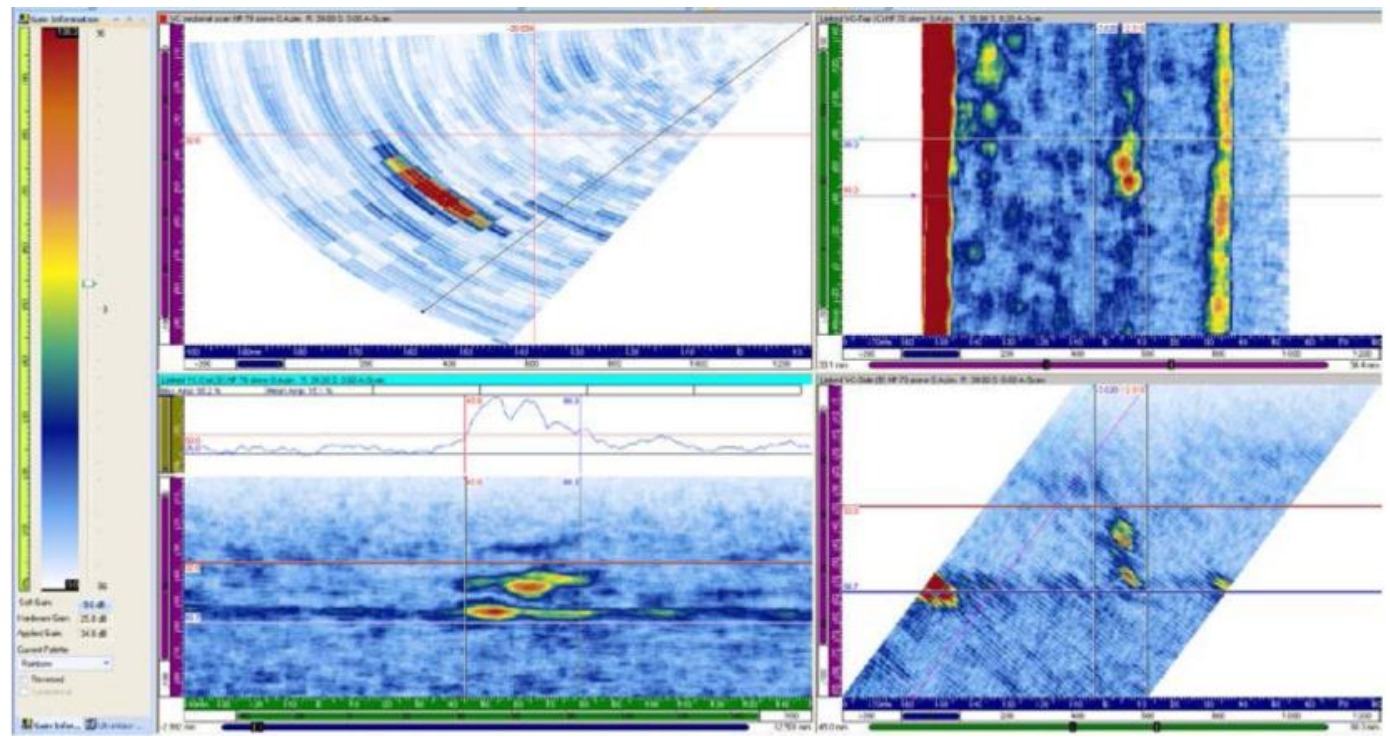

Figure D.26. 10C-011 Flaw 1 Pipe Side of Overlay at 1.5 MHz, 39 Degrees

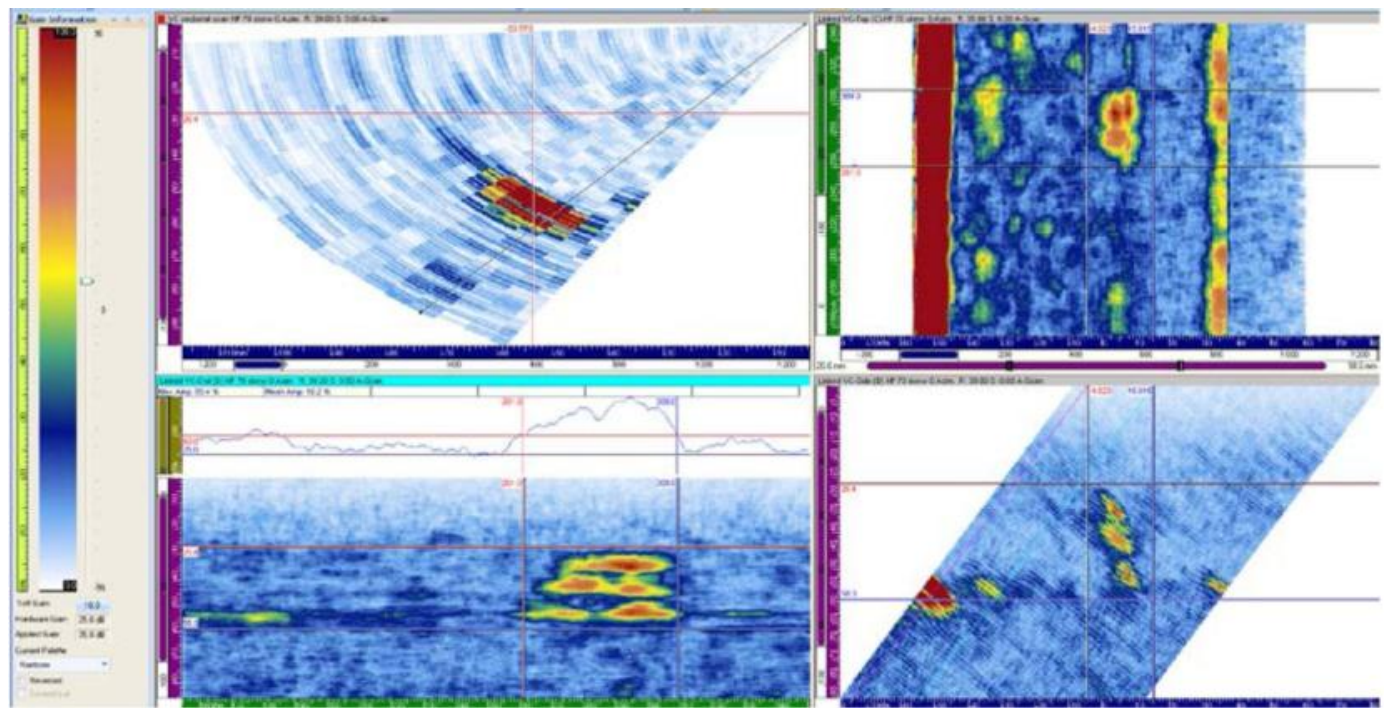

Figure D.27. 10C-011 Flaw 2 Pipe Side of Overlay at 1.5 MHz, 39 Degrees 


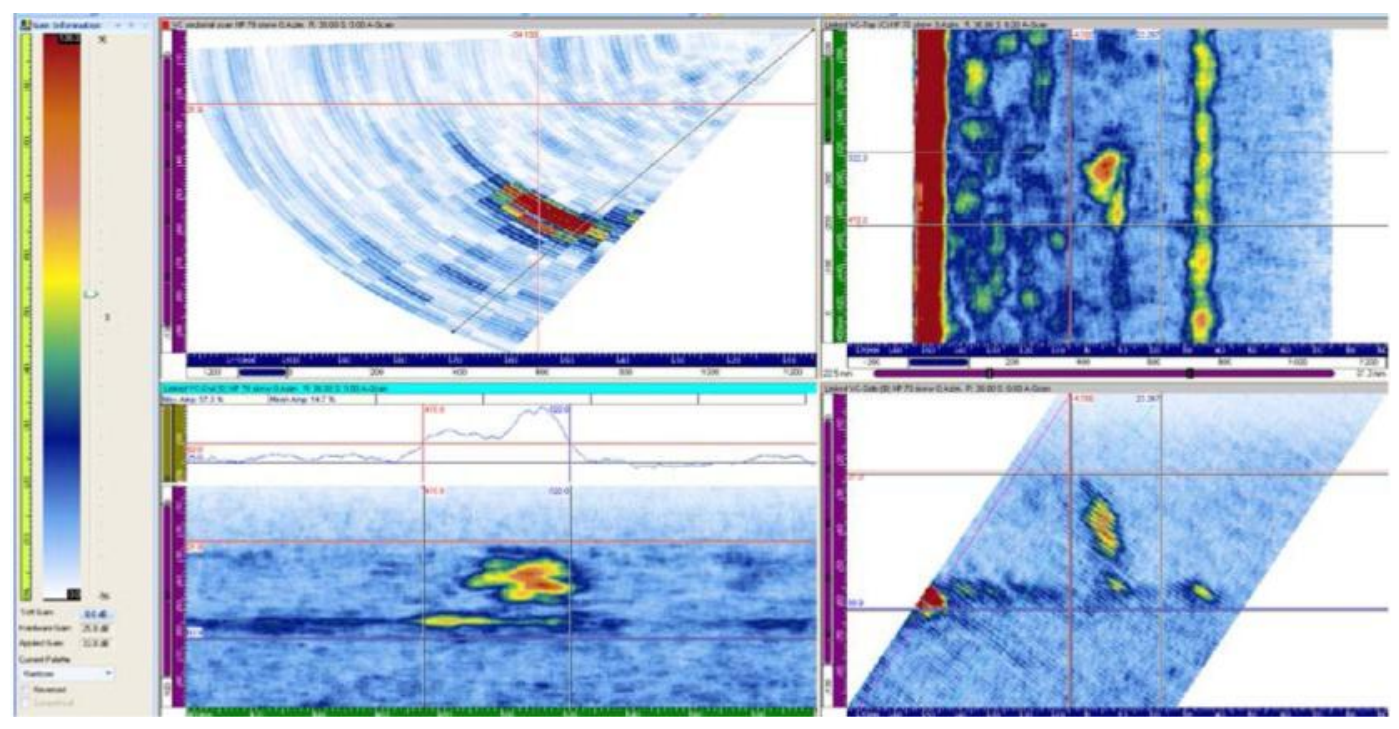

Figure D.28. 10C-011 Flaw 3 Pipe Side of Overlay at 1.5 MHz, 36 Degrees

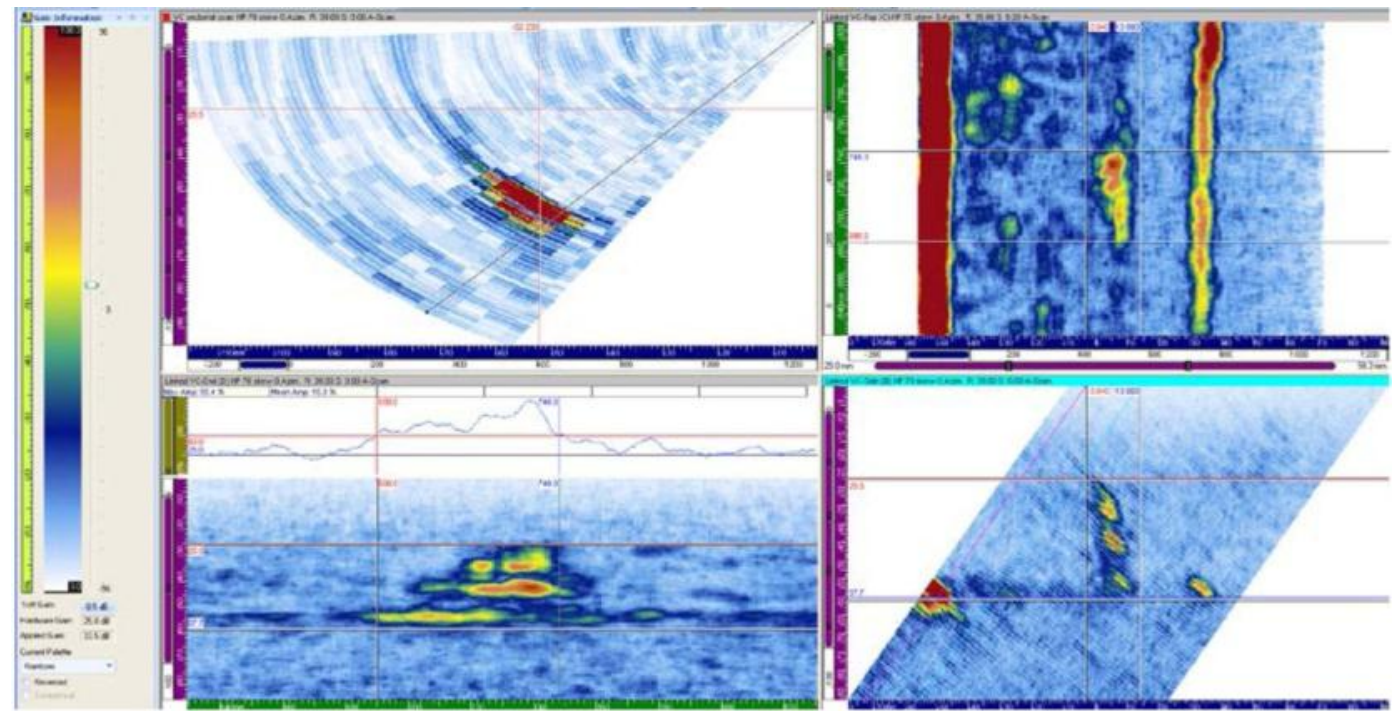

Figure D.29. 10C-011 Flaw 4 Pipe Side of Overlay at 1.5 MHz, 39 Degrees 


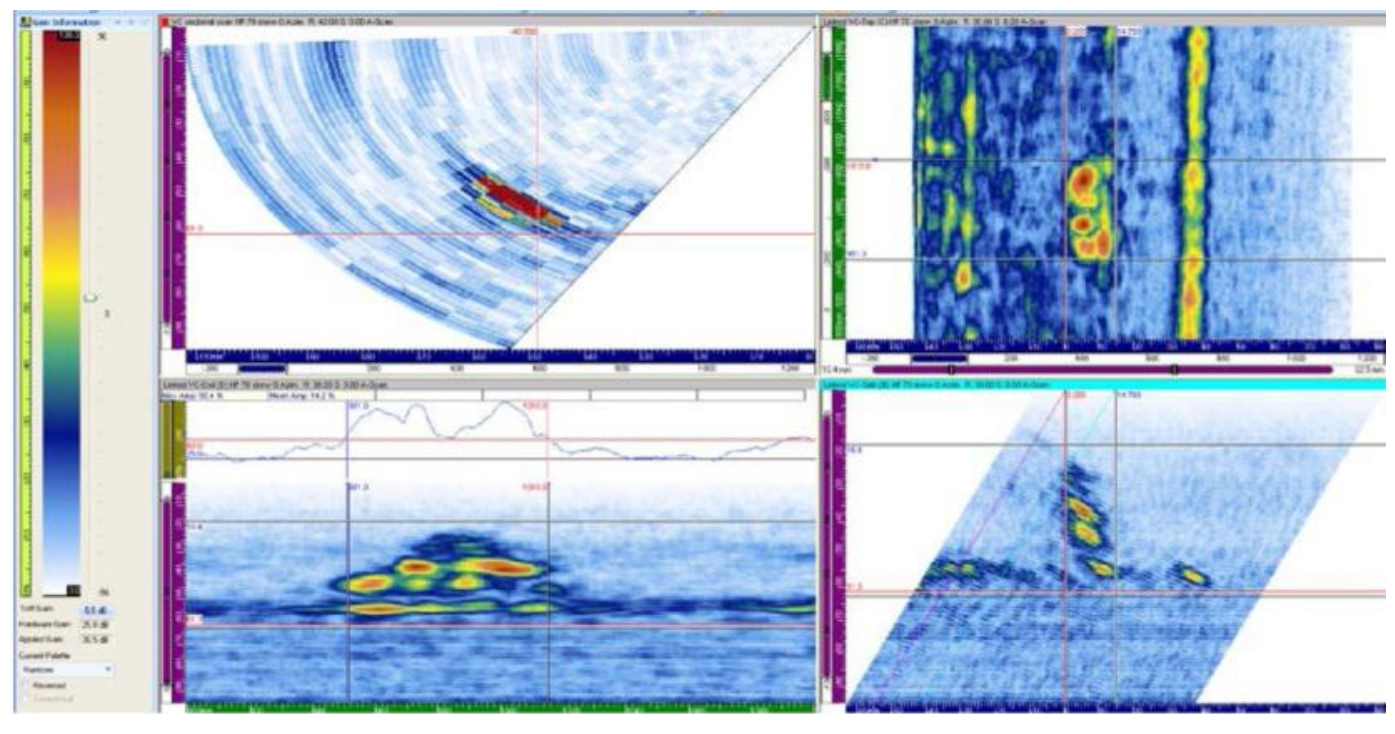

Figure D.30. 10C-011 Flaw 5 Pipe Side of Overlay at 1.5 MHz, 30 Degrees 


\section{D.1.7 Raster Data at 2.0 MHz Nozzle Side of Overlay on Flaws 1-5}

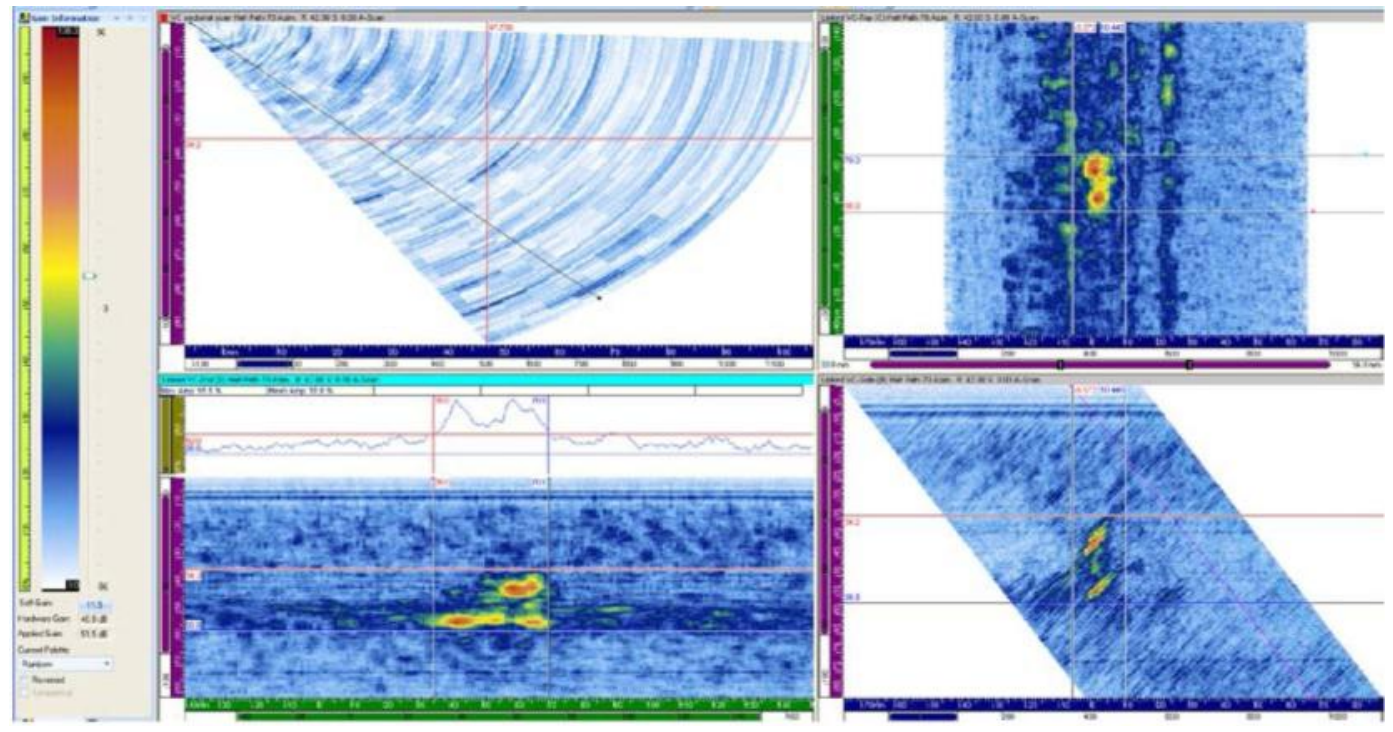

Figure D.31. 10C-011 Flaw 1 Nozzle Side of Overlay at $2.0 \mathrm{MHz}, 42$ Degrees

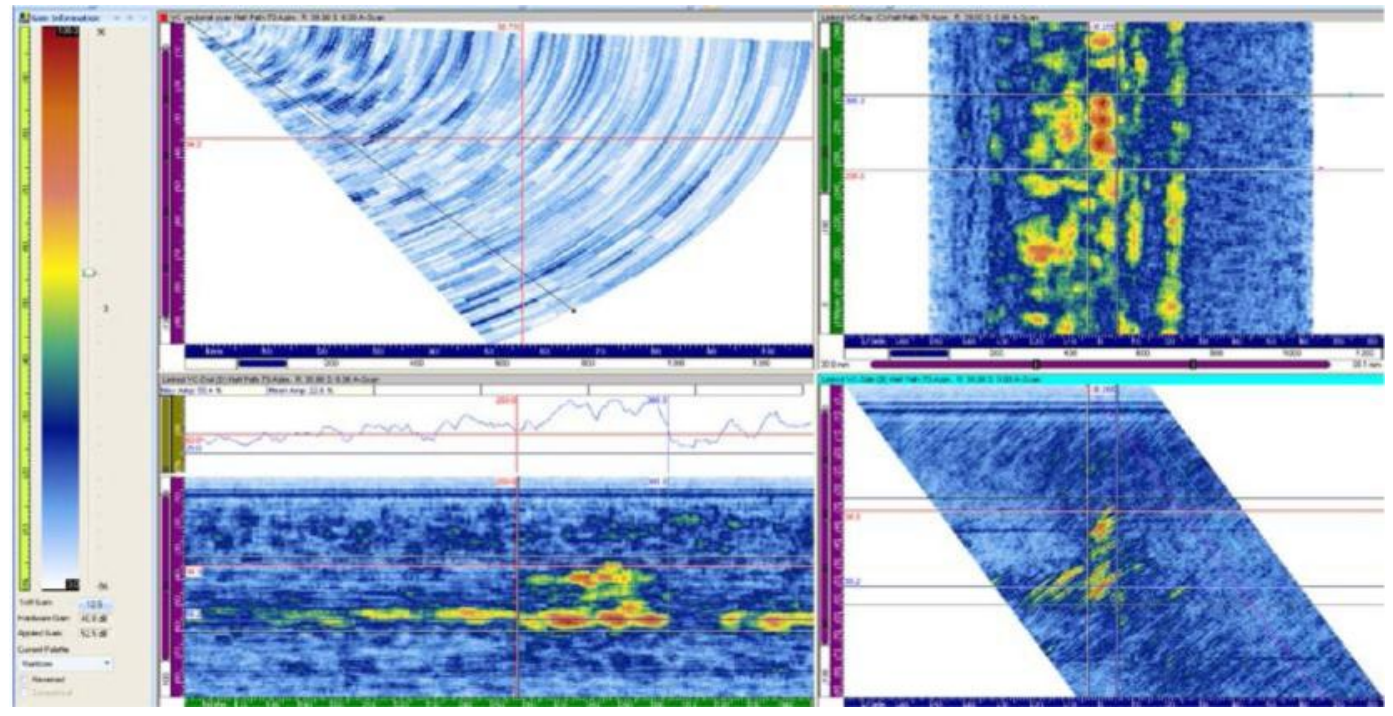

Figure D.32. 10C-011 Flaw 2 Nozzle Side of Overlay at $2.0 \mathrm{MHz}, 39$ Degrees 


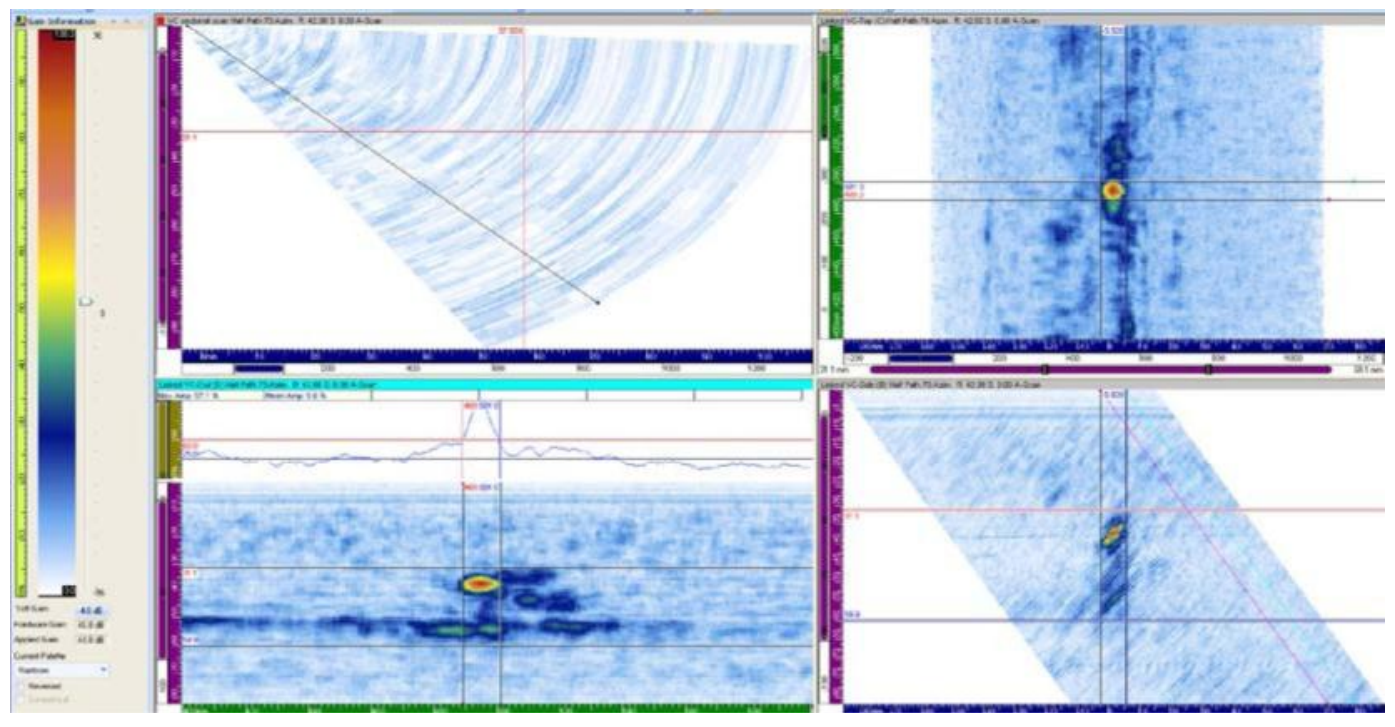

Figure D.33. 10C-011 Flaw 3 Nozzle Side of Overlay at $2.0 \mathrm{MHz}, 42$ Degrees

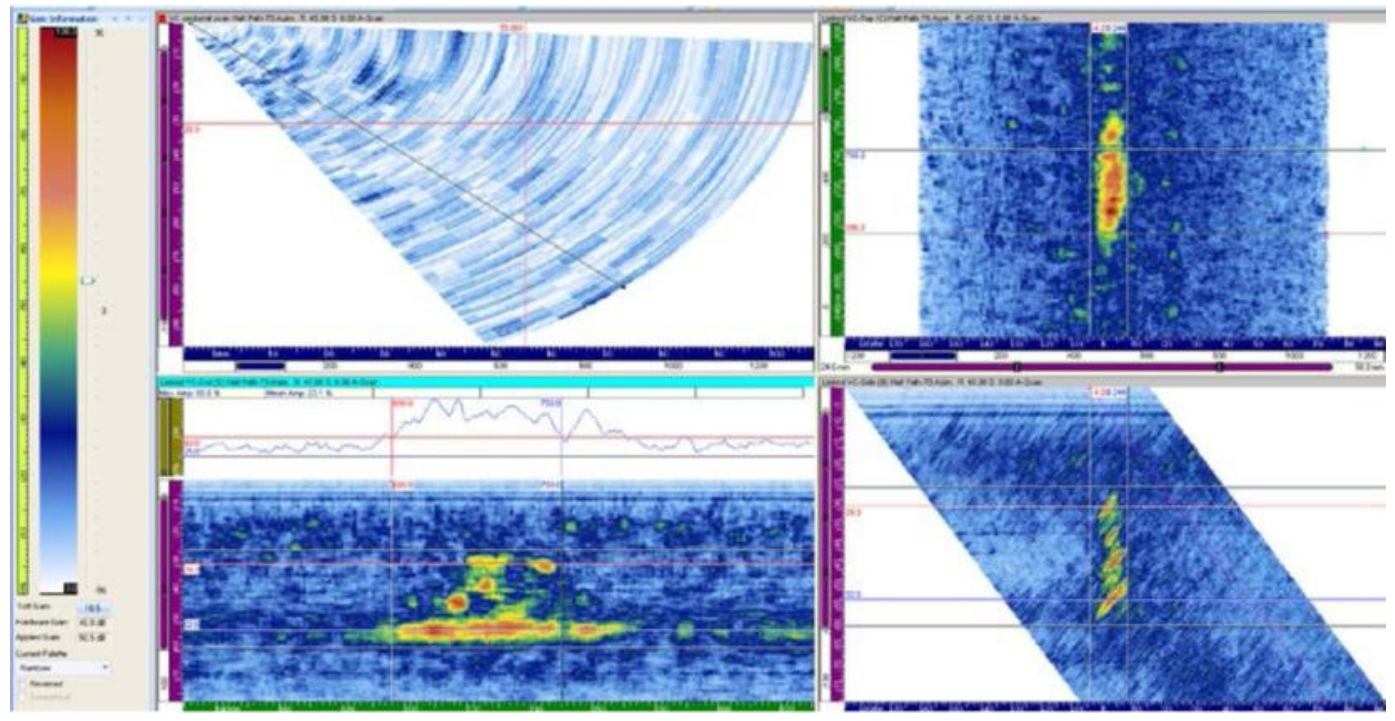

Figure D.34. 10C-011 Flaw 4 Nozzle Side of Overlay at 2.0 MHz, 45 Degrees 


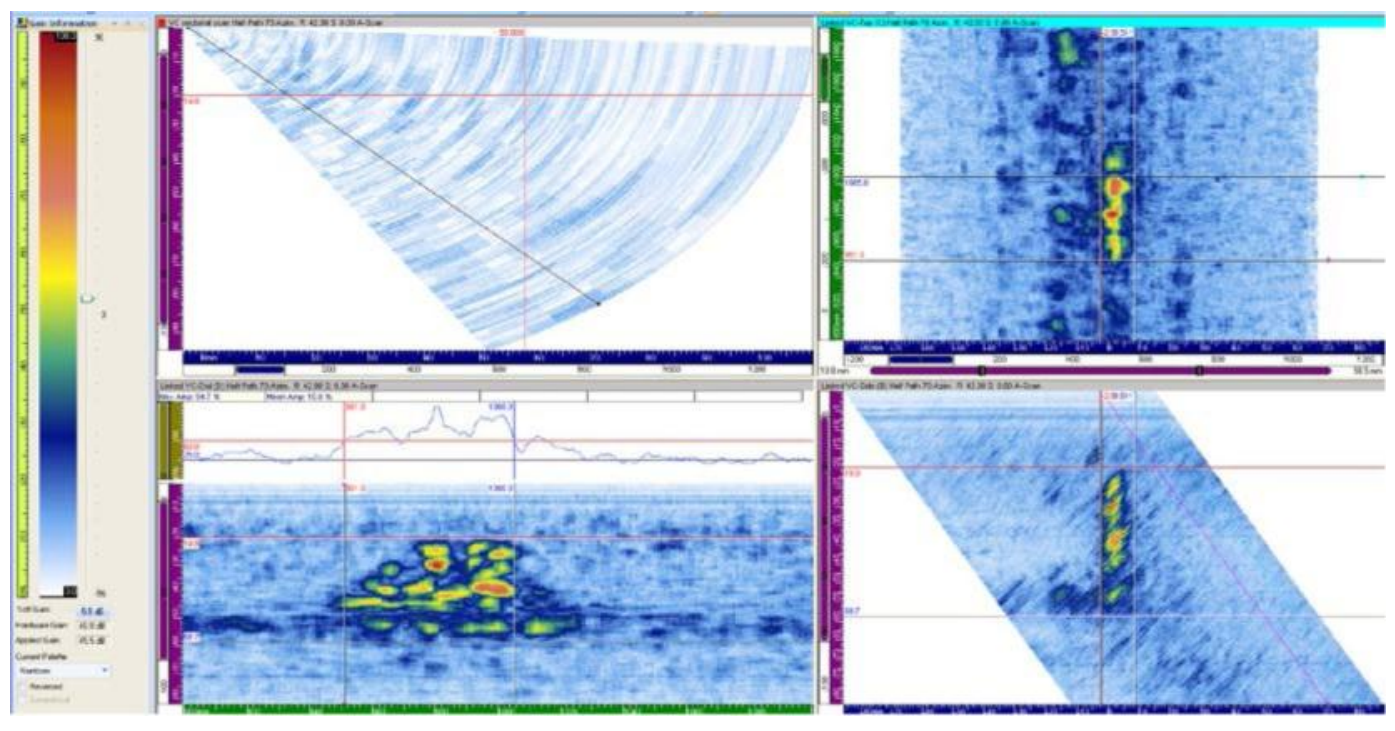

Figure D.35. 10C-011 Flaw 5 Nozzle Side of Overlay at $2.0 \mathrm{MHz}$, 42 Degrees 


\section{D.1.8 Raster Data at 2.0 MHz Pipe Side of Overlay on Flaws 1-5}

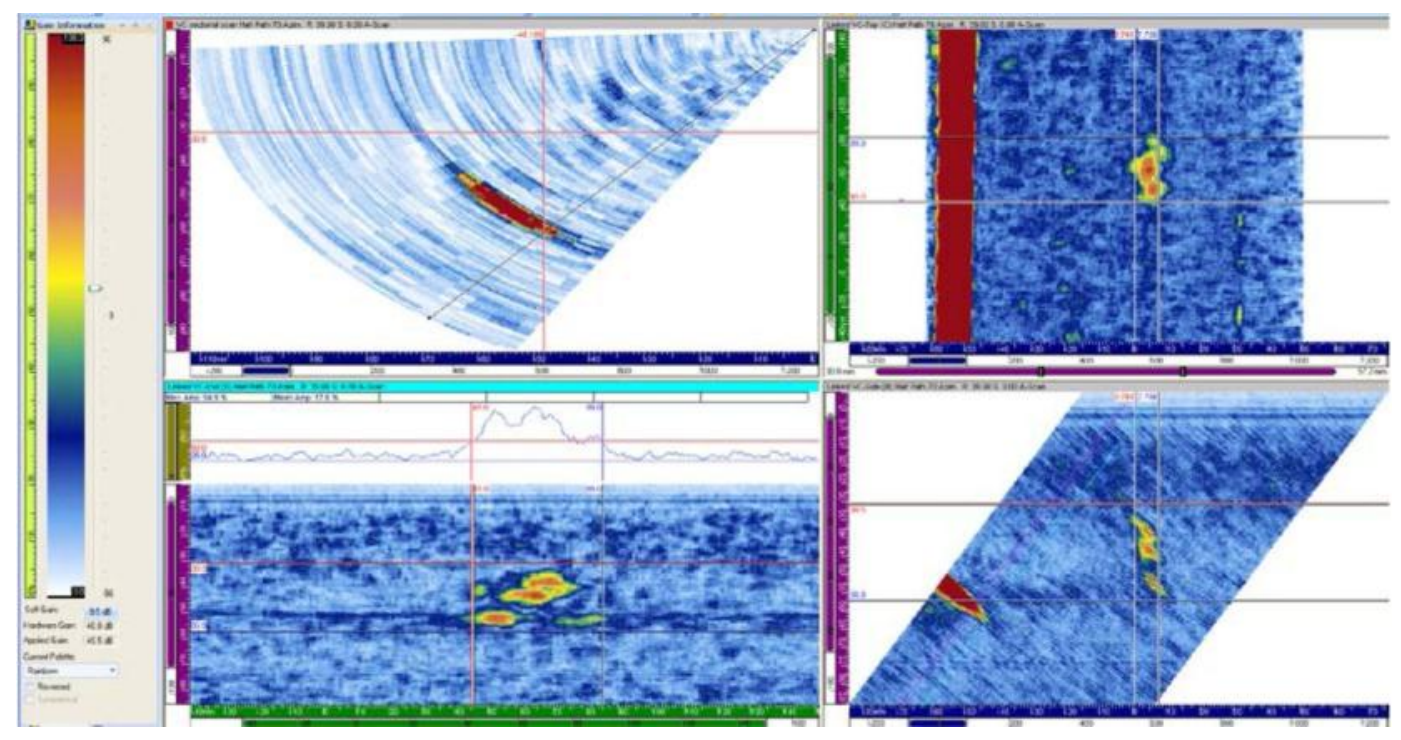

Figure D.36. 10C-011 Flaw 1 Pipe Side of Overlay at 2.0 MHz, 39 Degrees

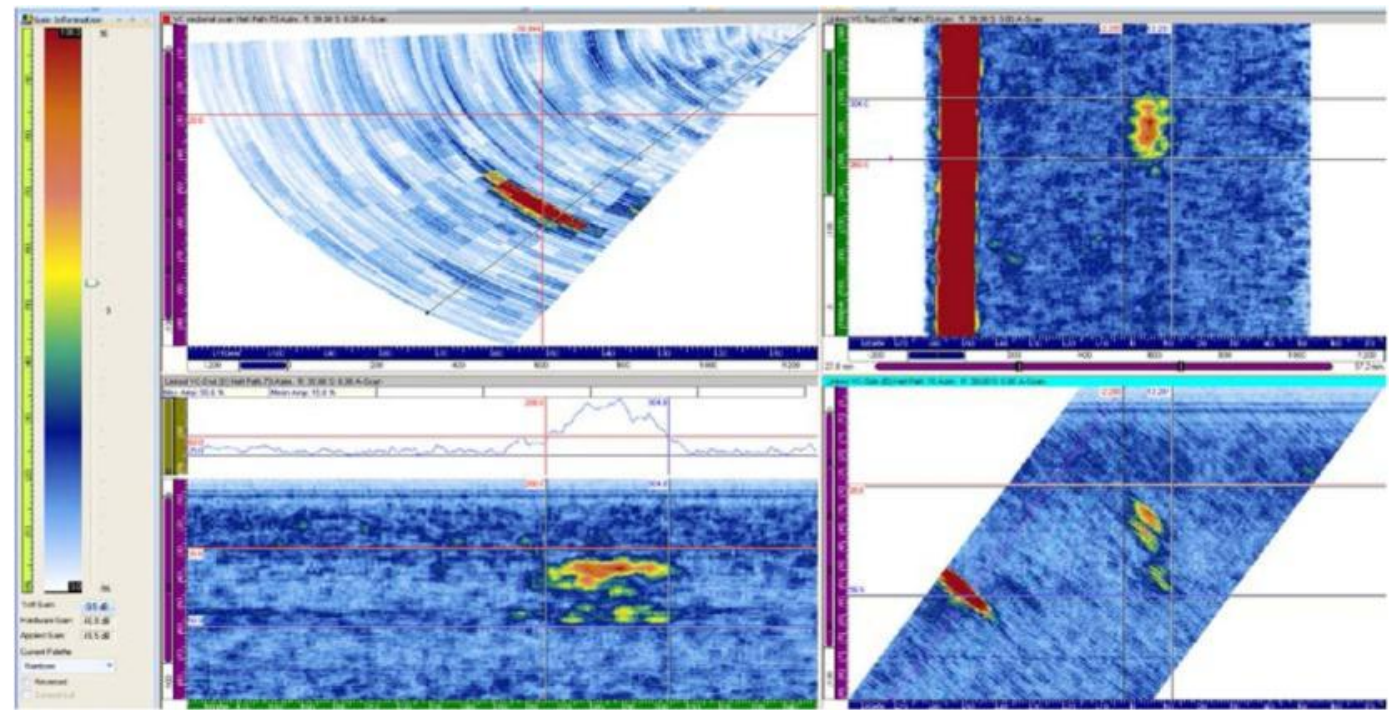

Figure D.37. 10C-011 Flaw 2 Pipe Side of Overlay at 2.0 MHz, 39 Degrees 


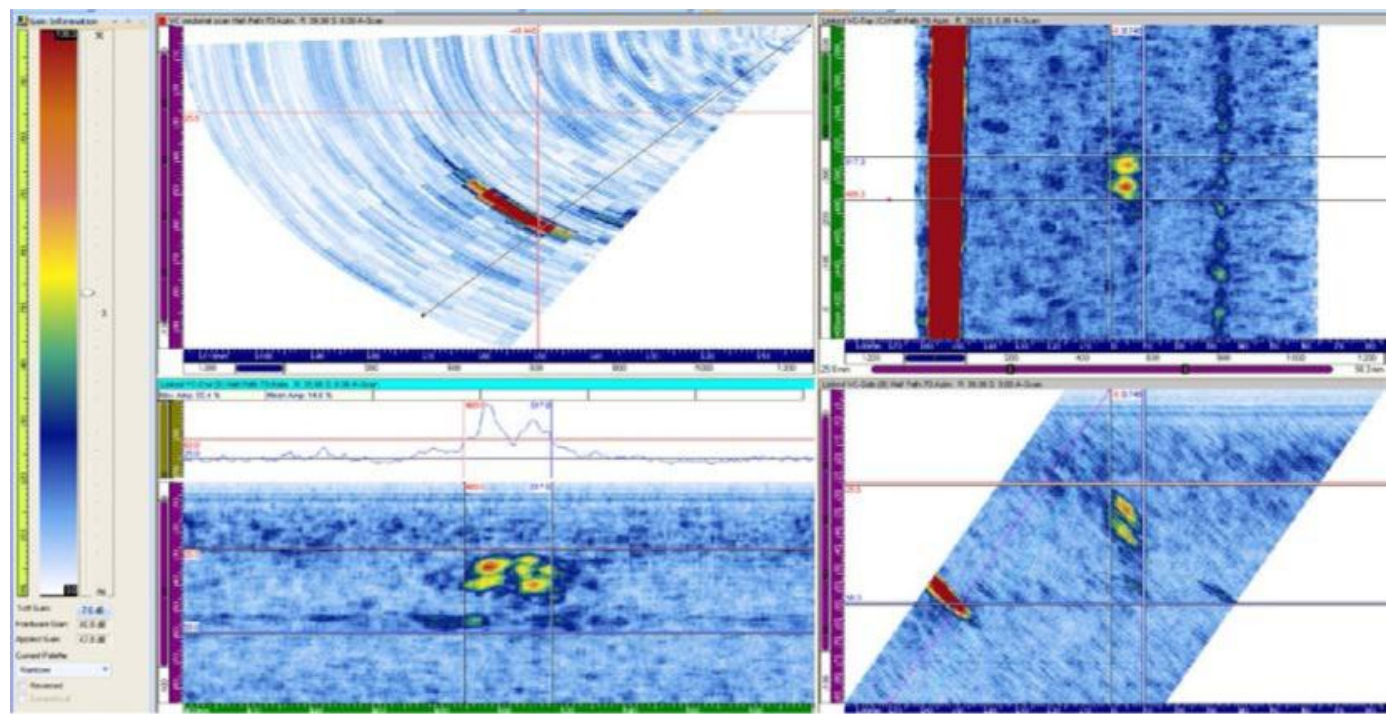

Figure D.38. 10C-011 Flaw 3 Pipe Side of Overlay at $2.0 \mathrm{MHz}, 39$ Degrees

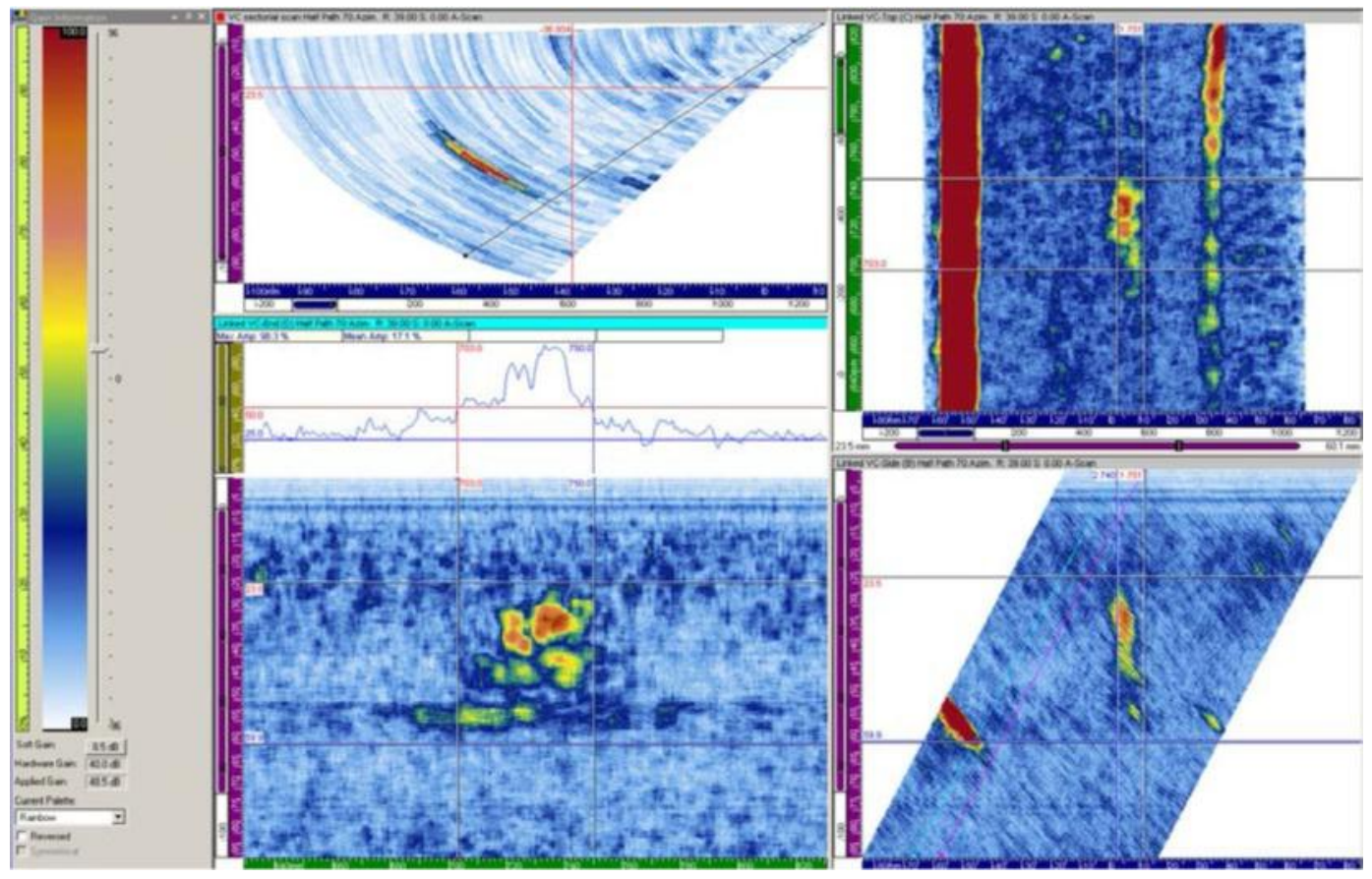

Figure D.39. 10C-011 Flaw 4 Pipe Side of Overlay at $2.0 \mathrm{MHz}, 39$ Degrees 


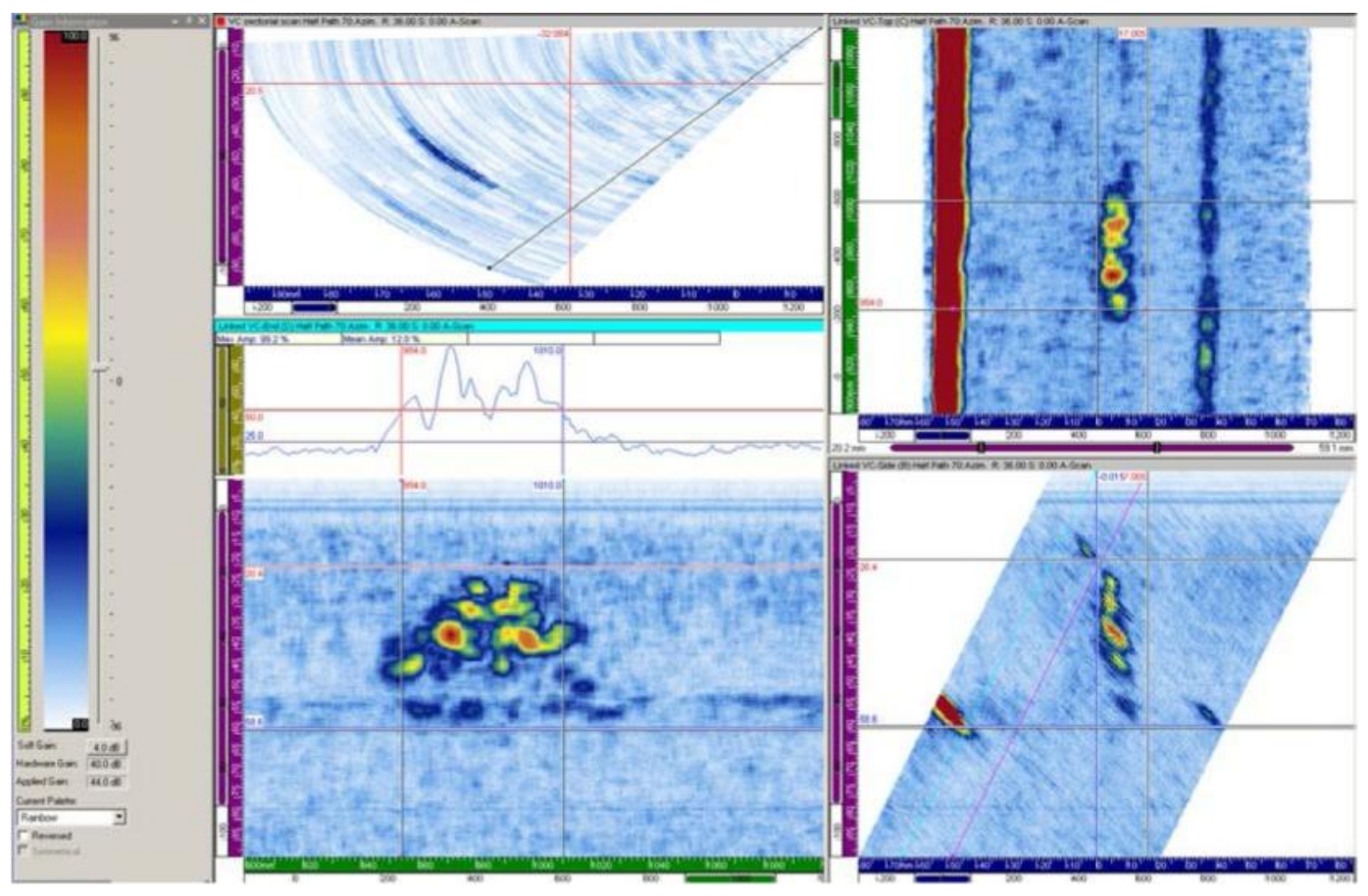

Figure D.40. 10C-011 Flaw 5 Pipe Side of Overlay at $2.0 \mathrm{MHz}, 39$ Degrees 


\section{D.2 Line Scan Data}

\section{D.2.1 Line Scan Data at 0.8 MHz Nozzle Side of Overlay on Flaws 1-5}

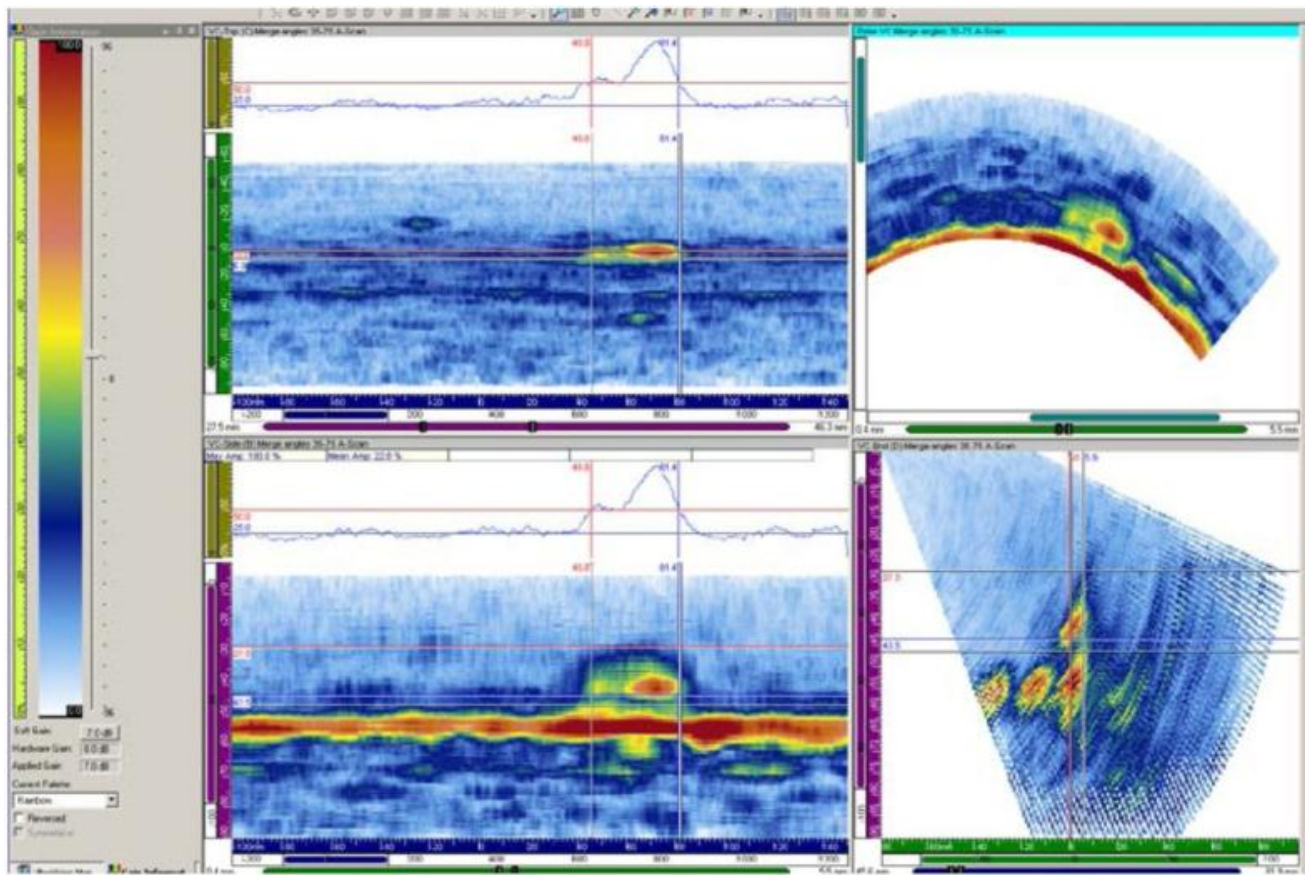

Figure D.41. 10C-011 Flaw 1 Nozzle Side of Overlay at $0.8 \mathrm{MHz}$, Line Scan

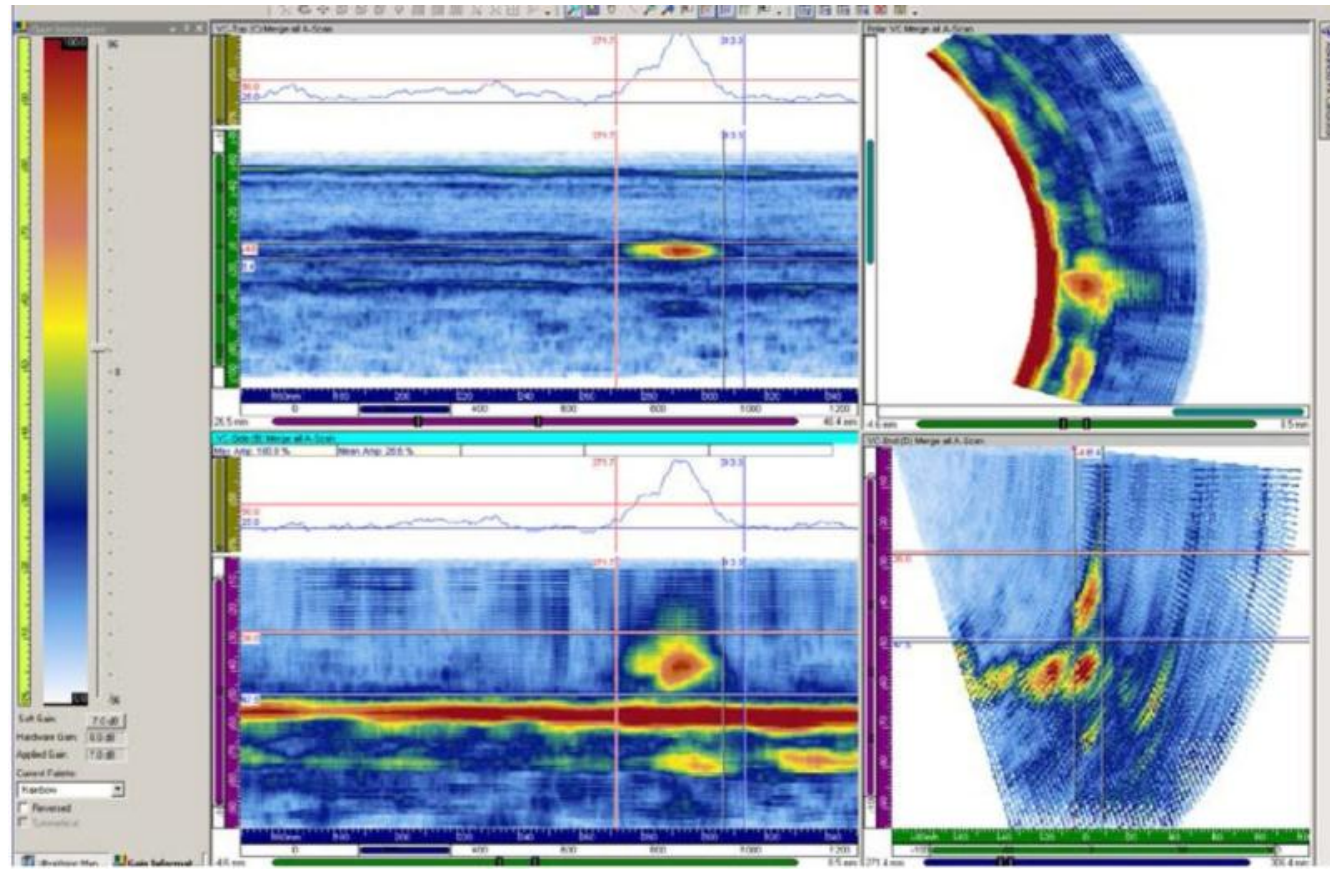

Figure D.42. 10C-011 Flaw 2 Nozzle Side of Overlay at $0.8 \mathrm{MHz}$, Line Scan 


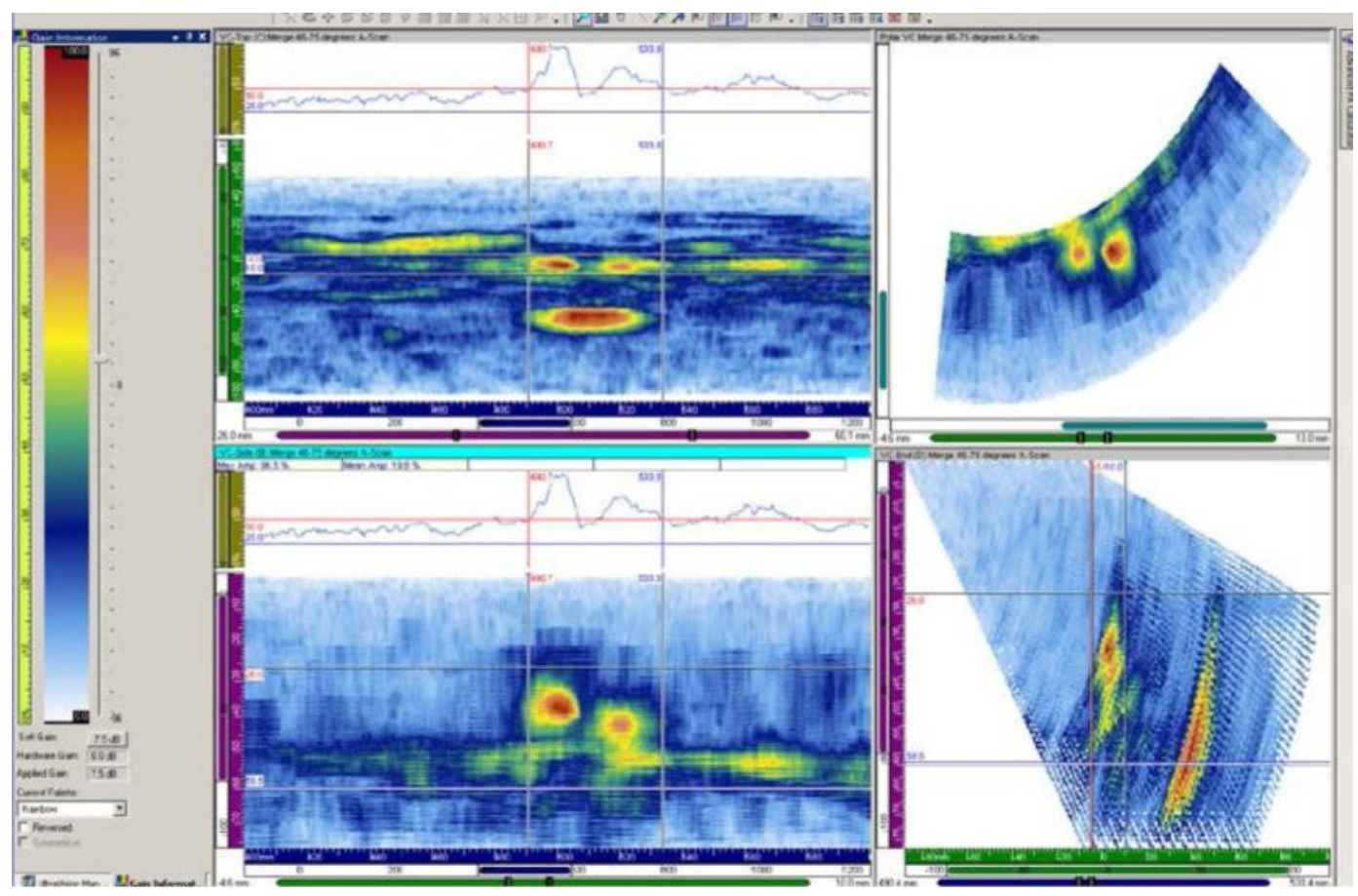

Figure D.43. 10C-011 Flaw 3 Nozzle Side of Overlay at $0.8 \mathrm{MHz}$, Line Scan

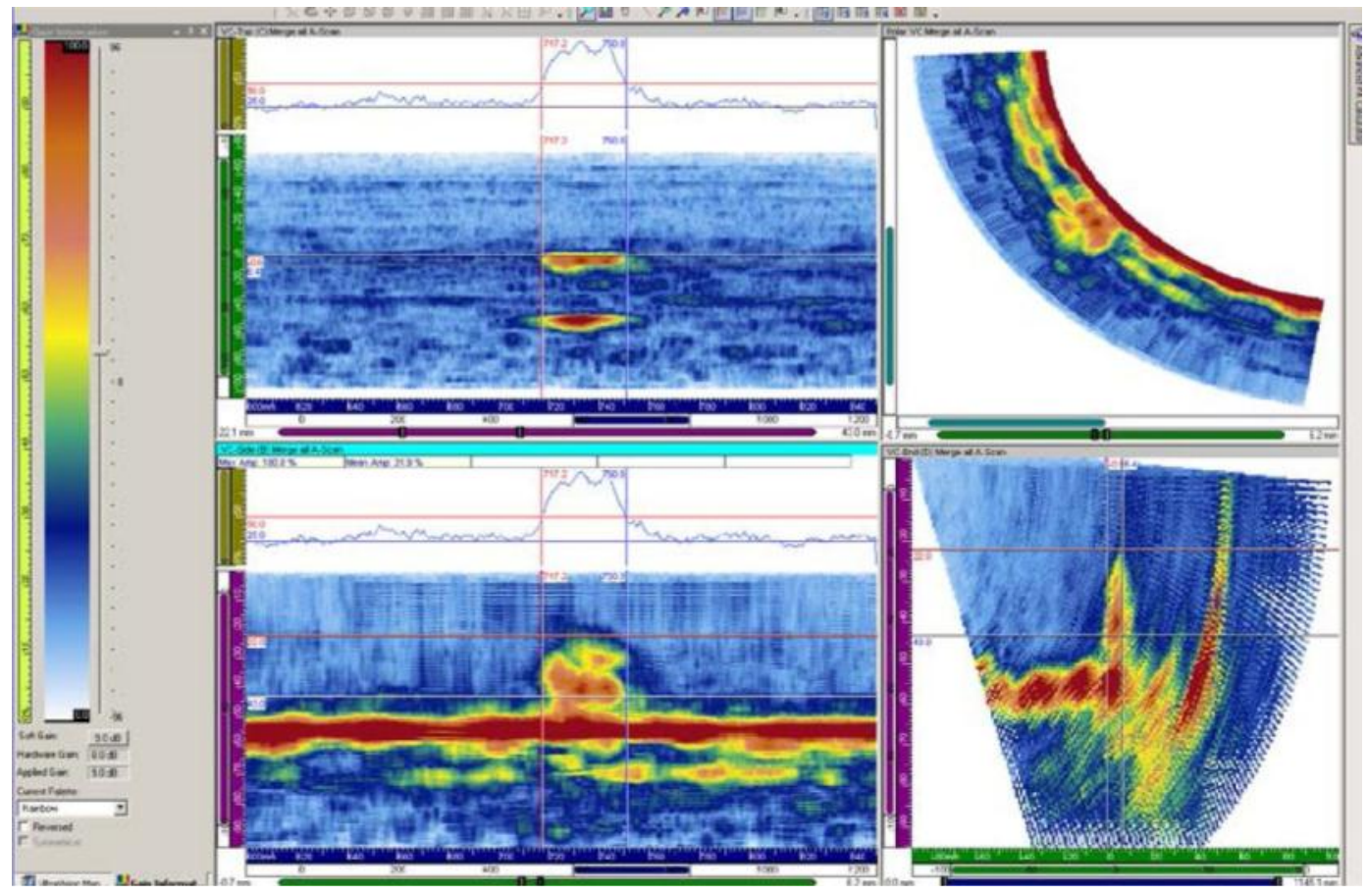

Figure D.44. 10C-011 Flaw 4 Nozzle Side of Overlay at $0.8 \mathrm{MHz}$, Line Scan 


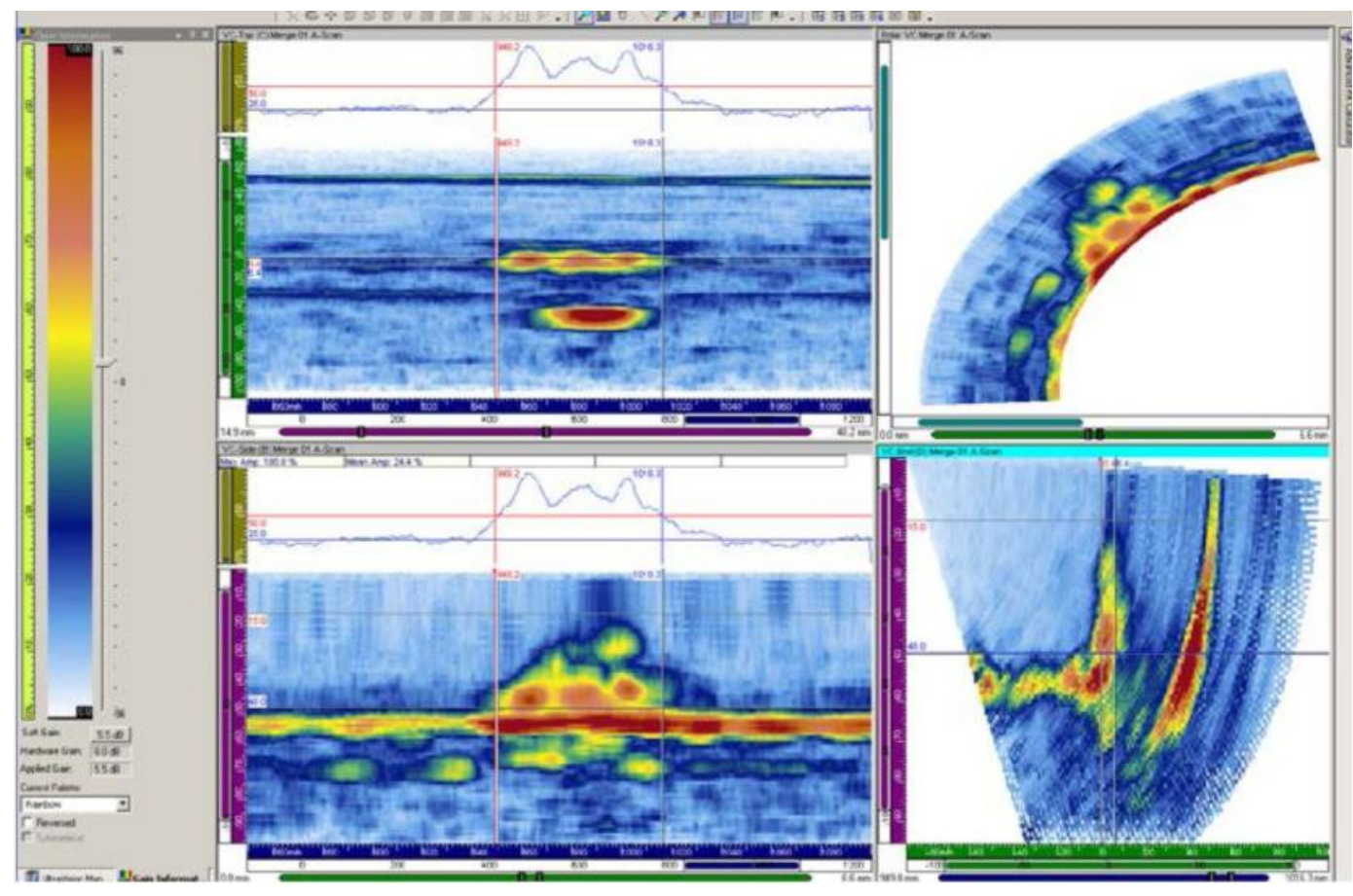

Figure D.45. 10C-011 Flaw 5 Nozzle Side of Overlay at $0.8 \mathrm{MHz}$, Line Scan 


\section{D.2.2 Line Scan Data at 0.8 MHz Pipe Side of Overlay on Flaws 1-5}

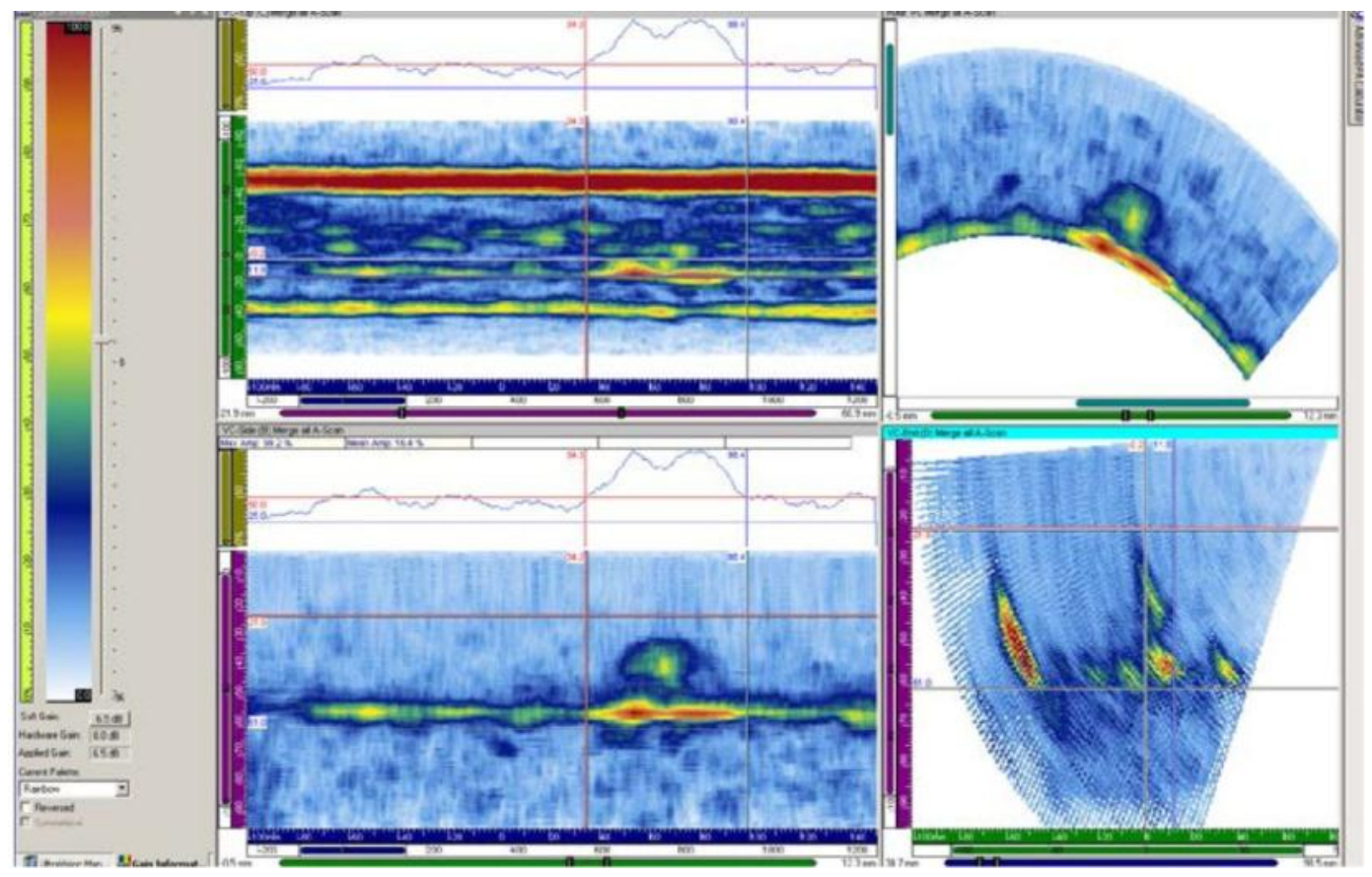

Figure D.46. 10C-011 Flaw 1 Pipe Side of Overlay at $0.8 \mathrm{MHz}$, Line Scan

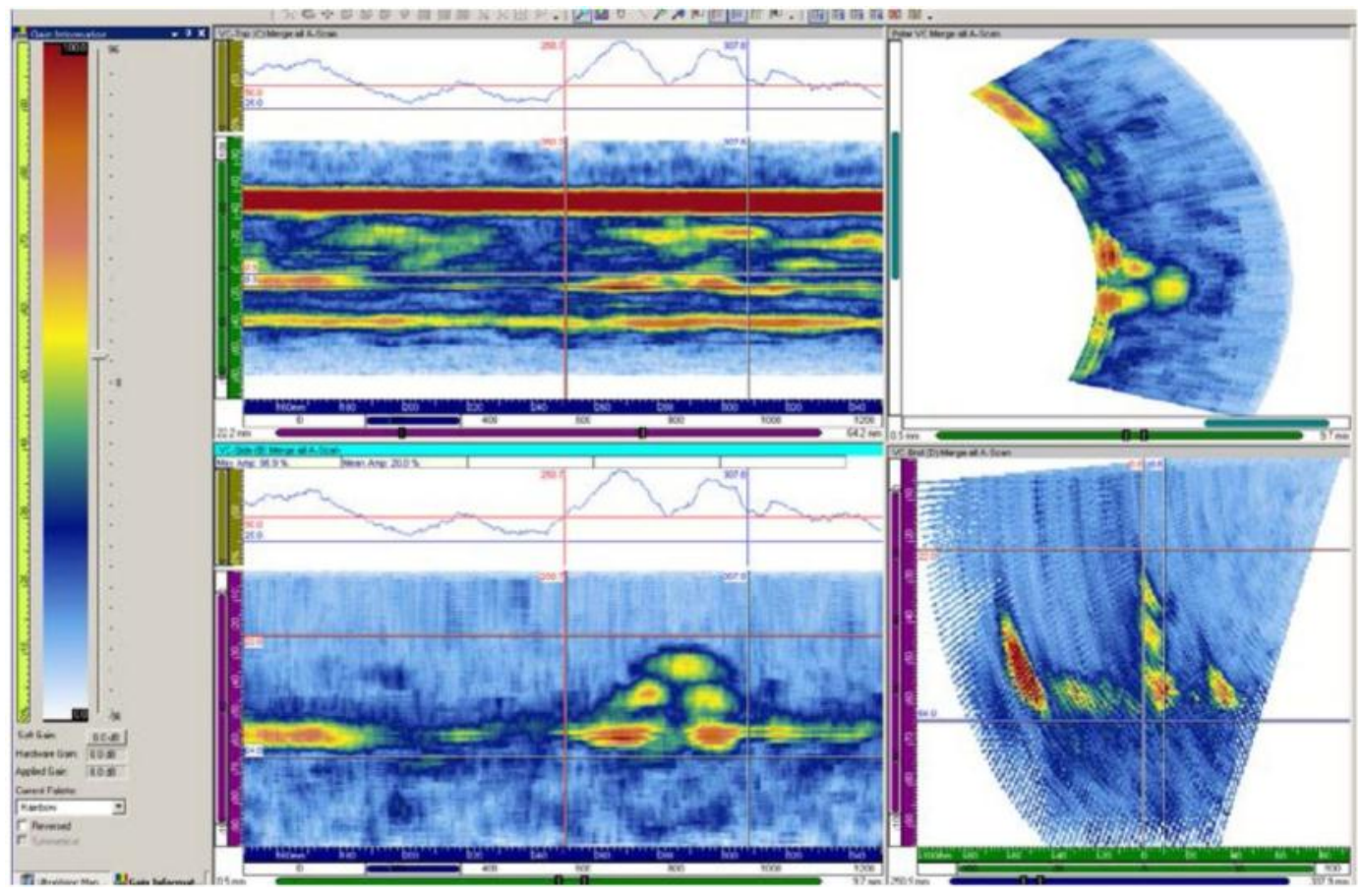

Figure D.47. 10C-011 Flaw 2 Pipe Side of Overlay at $0.8 \mathrm{MHz}$, Line Scan 


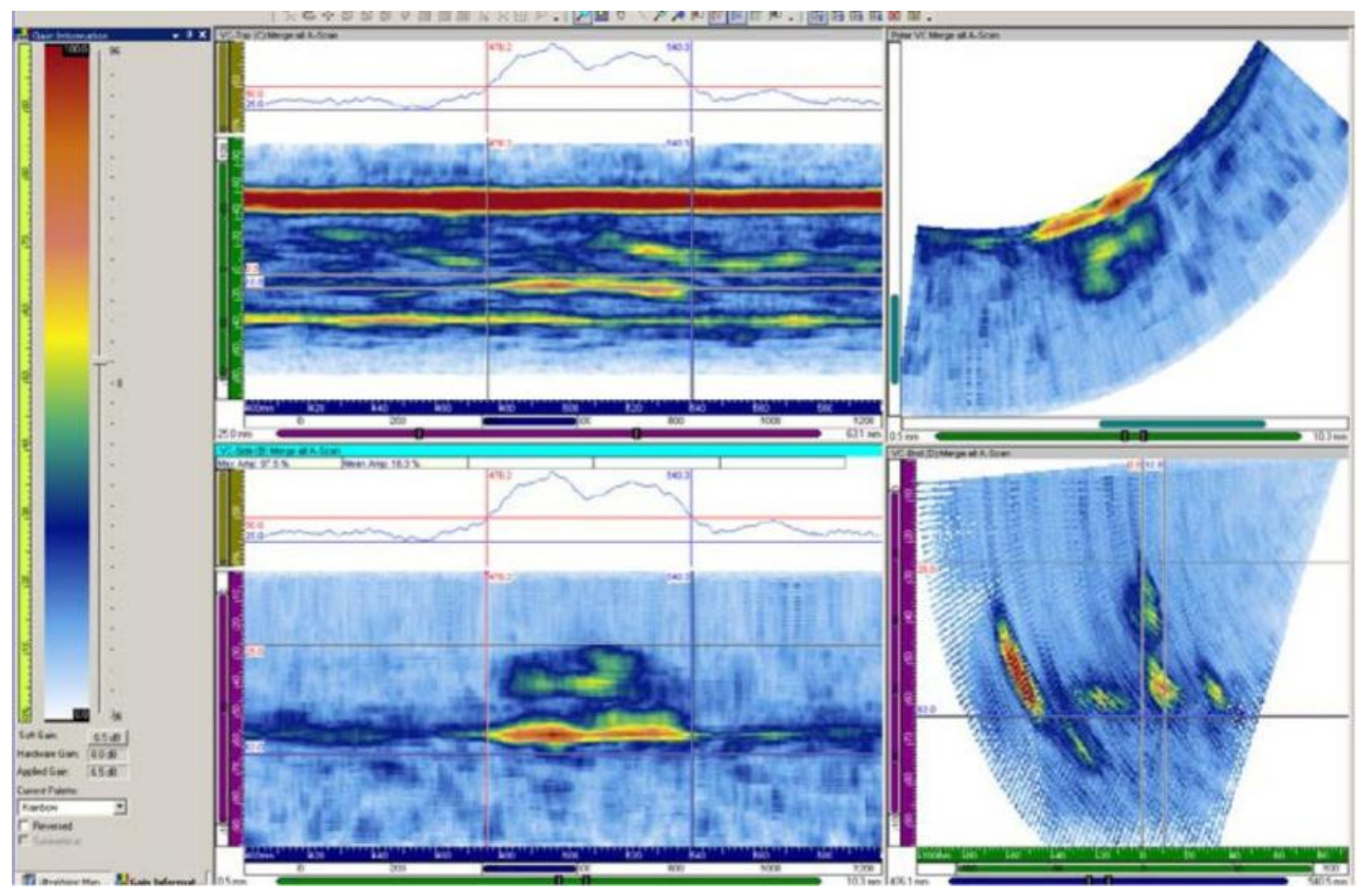

Figure D.48. 10C-011 Flaw 3 Pipe Side of Overlay at $0.8 \mathrm{MHz}$, Line Scan

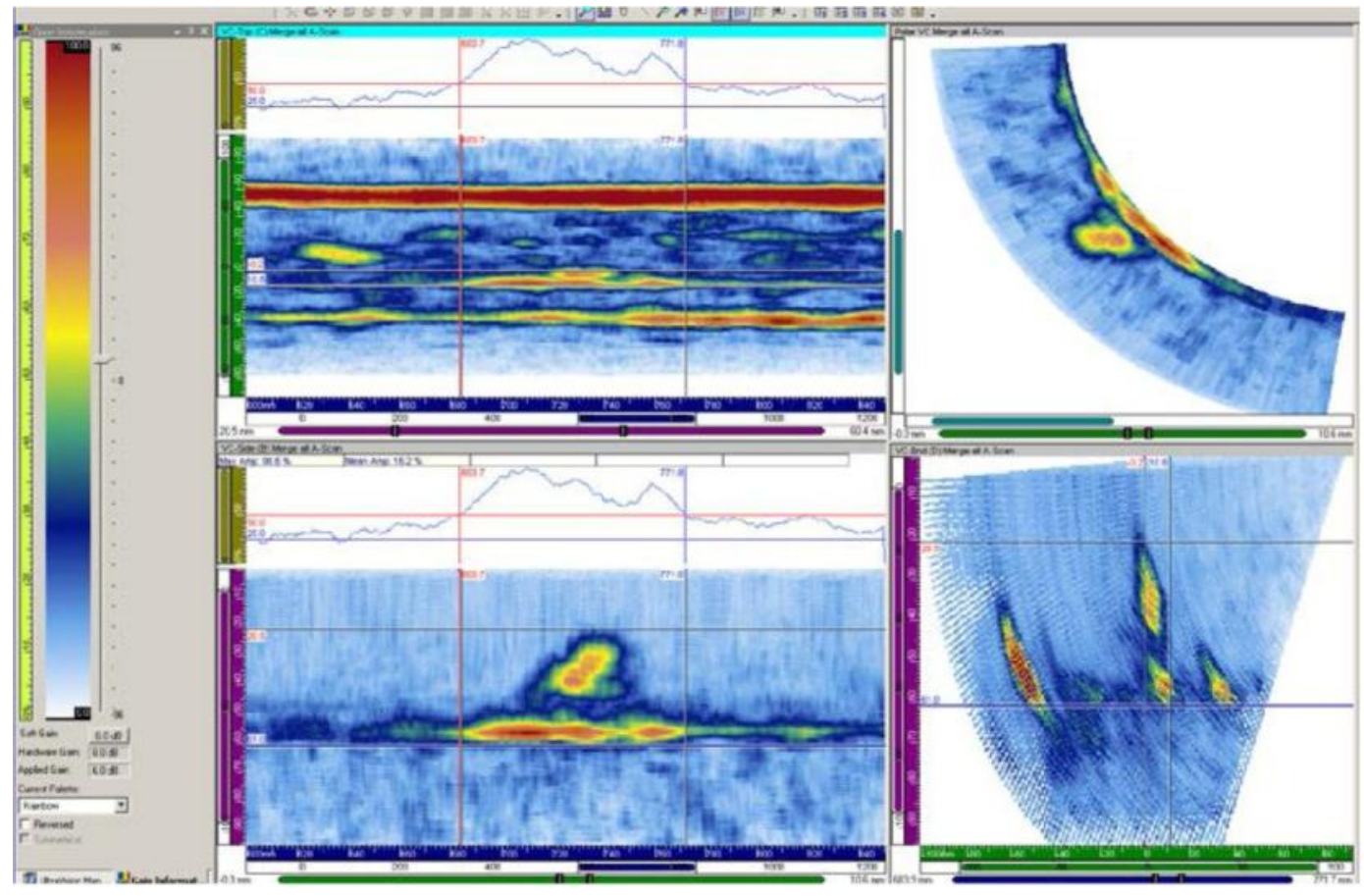

Figure D.49. 10C-011 Flaw 4 Pipe Side of Overlay at $0.8 \mathrm{MHz}$, Line Scan 


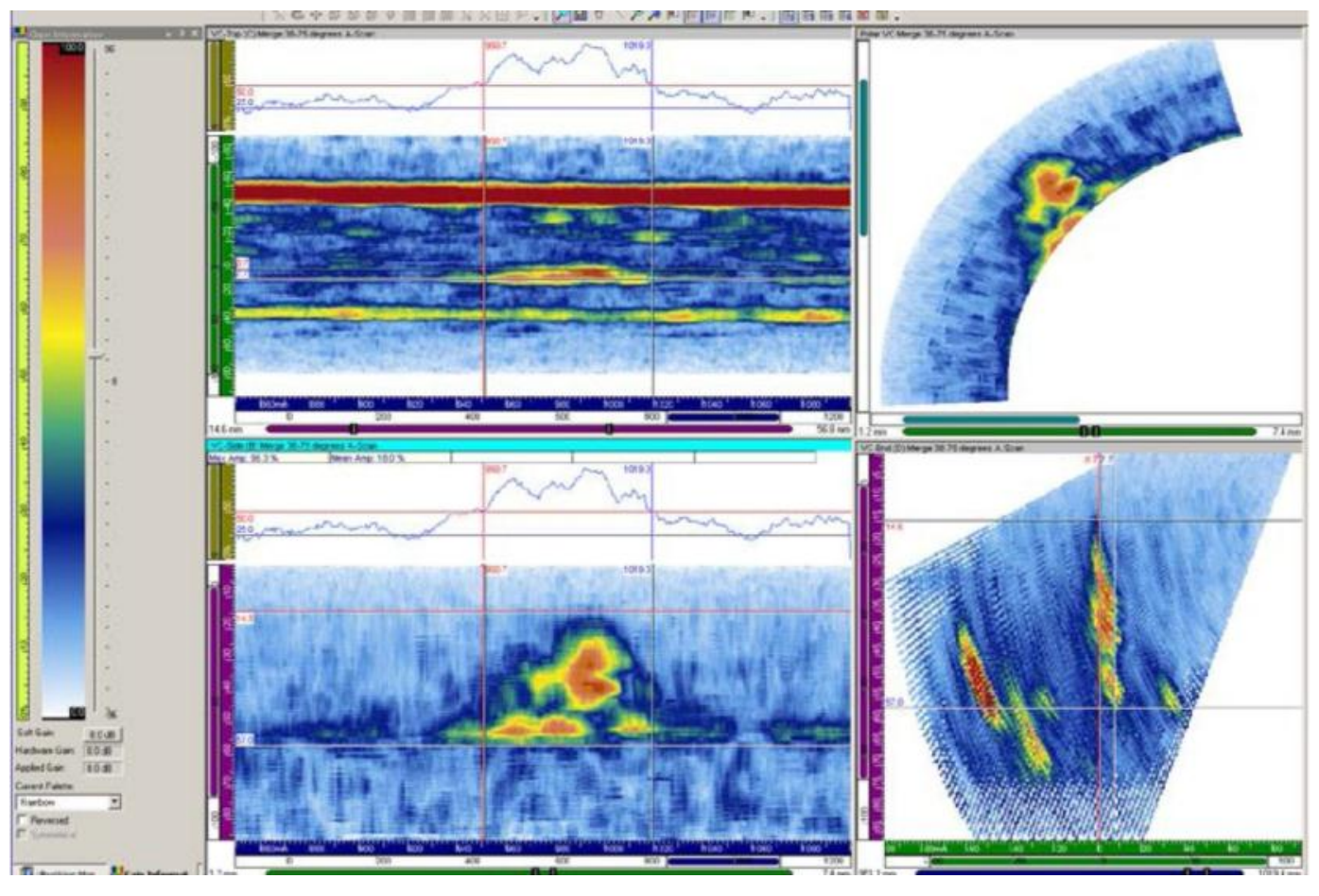

Figure D.50. 10C-011 Flaw 5 Pipe Side of Overlay at $0.8 \mathrm{MHz}$, Line Scan 


\section{D.2.3 Line Scan Data at 1.0 MHz Nozzle Side of Overlay on Flaws 1-5}

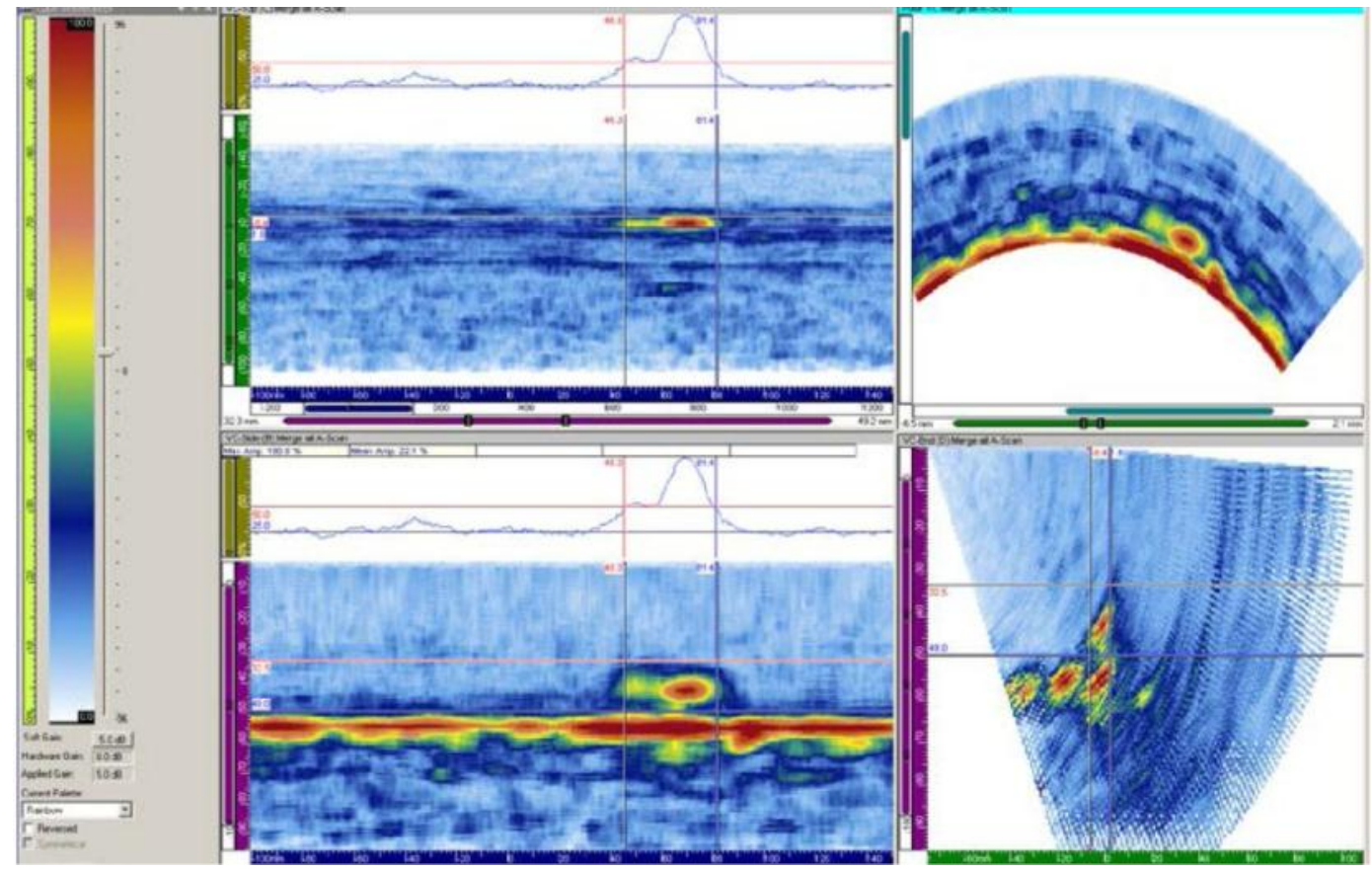

Figure D.51. 10C-011 Flaw 1 Nozzle Side of Overlay at 1.0 MHz, Line Scan

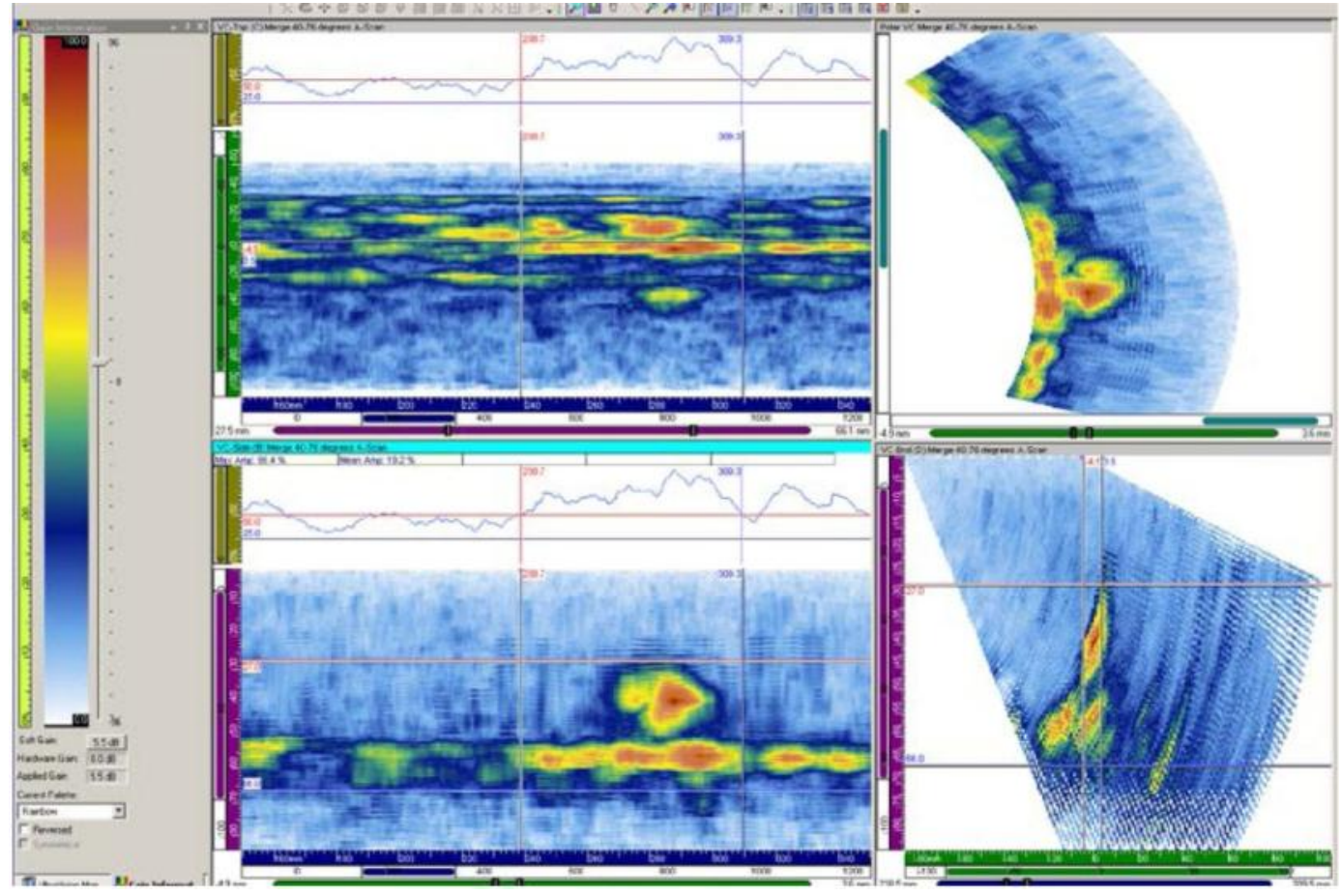

Figure D.52. 10C-011 Flaw 2 Nozzle Side of Overlay at 1.0 MHz, Line Scan 


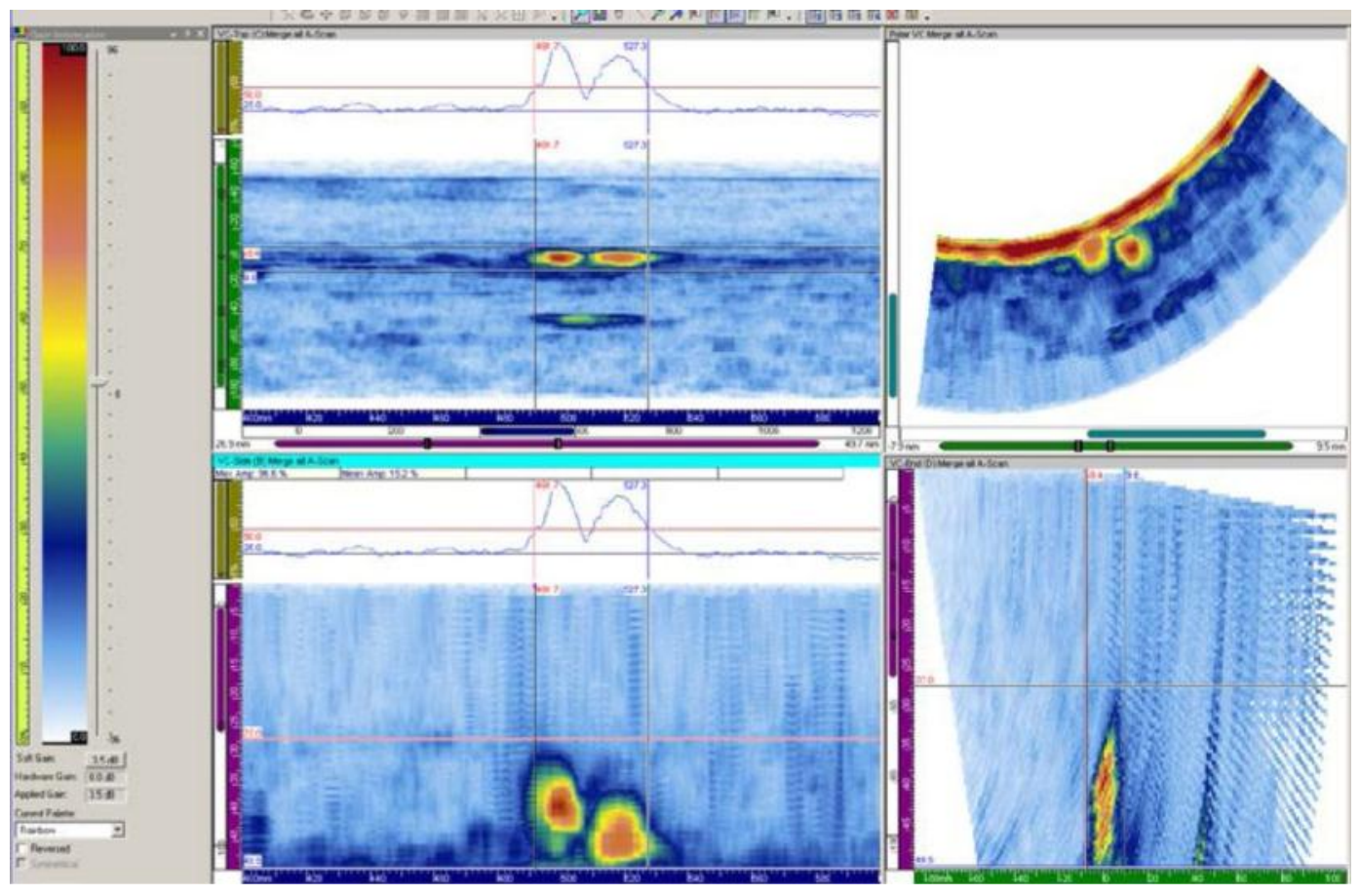

Figure D.53. 10C-011 Flaw 3 Nozzle Side of Overlay at $1.0 \mathrm{MHz}$, Line Scan

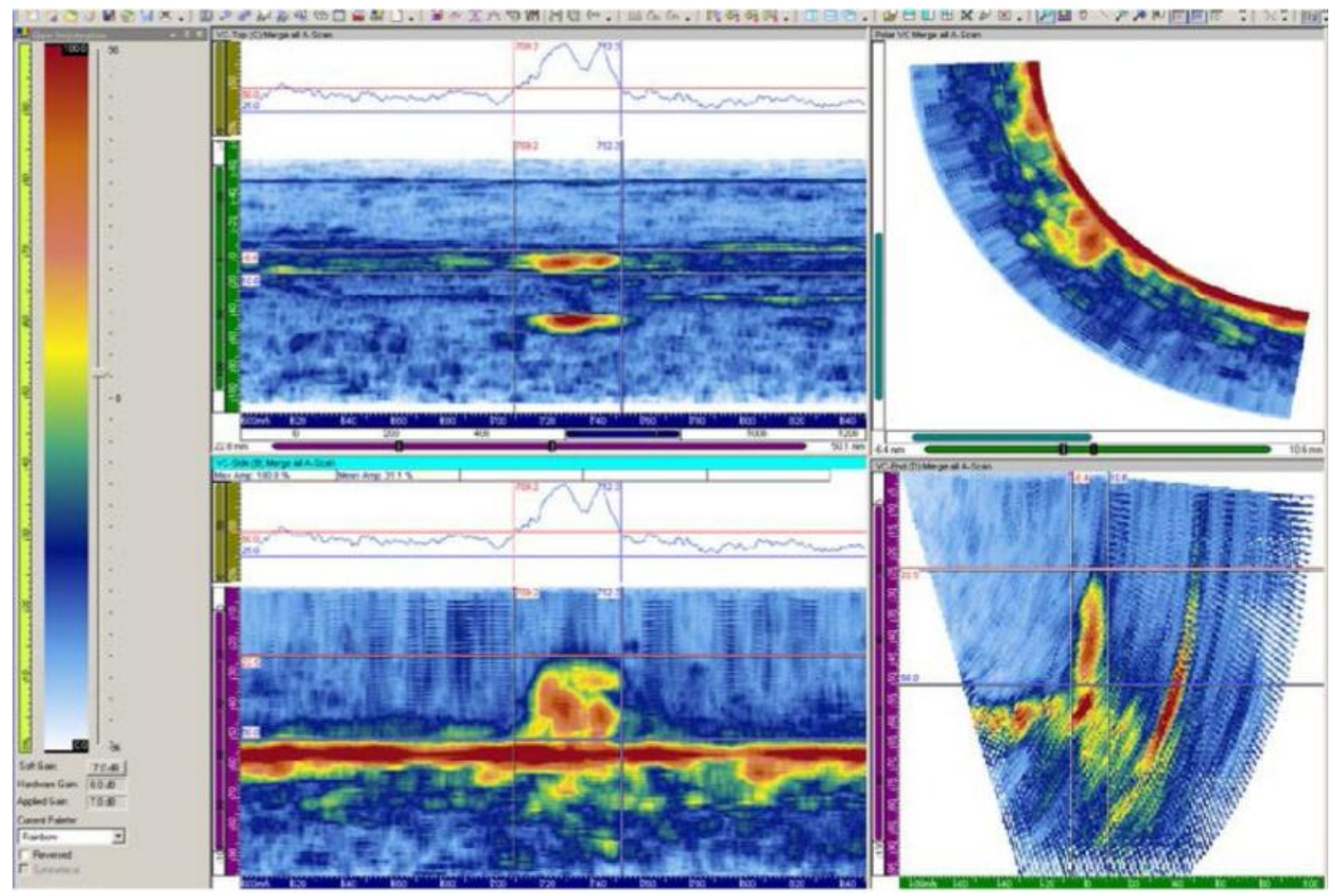

Figure D.54. 10C-011 Flaw 4 Nozzle Side of Overlay at 1.0 MHz, Line Scan 


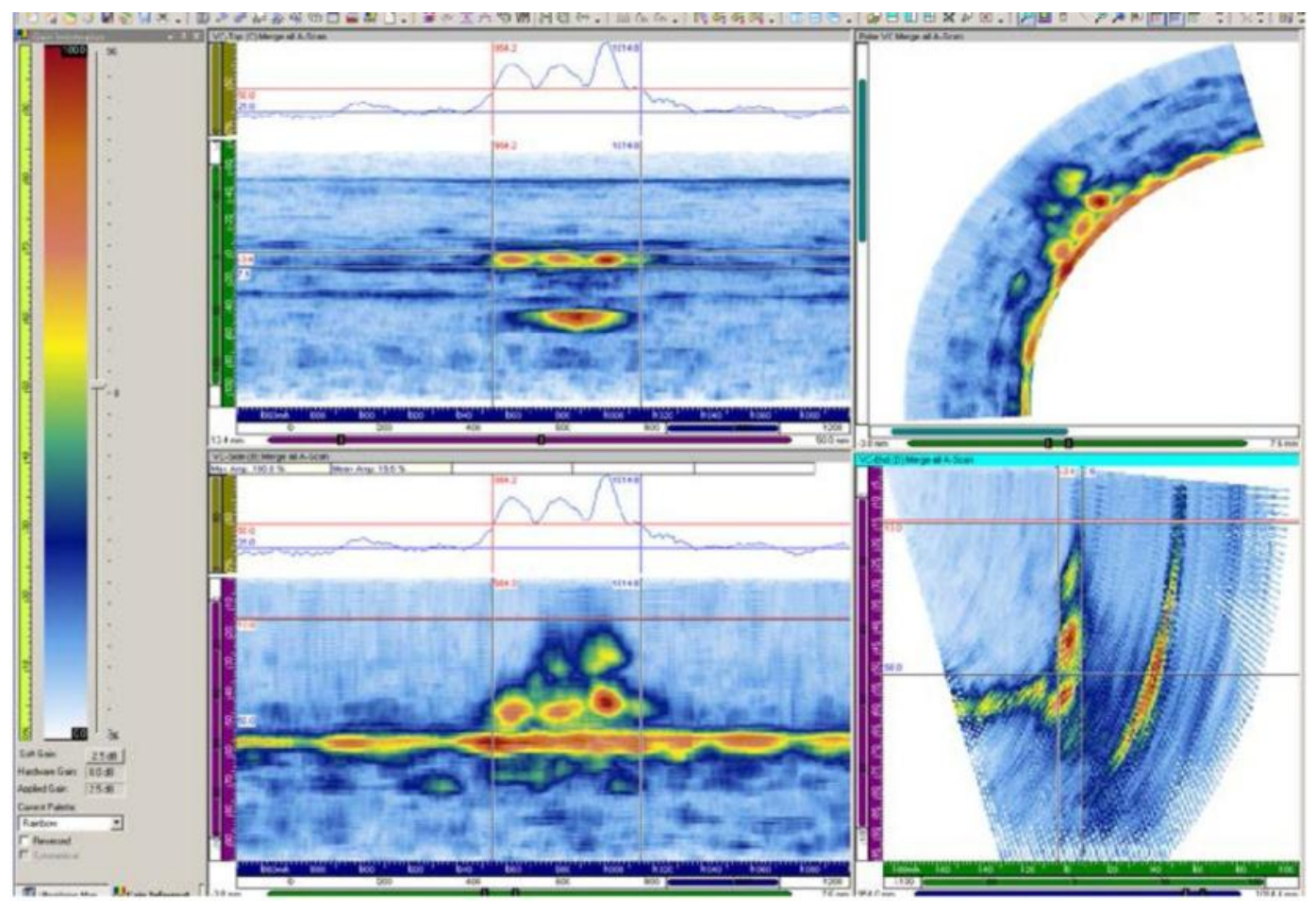

Figure D.55. 10C-011 Flaw 5 Nozzle Side of Overlay at $1.0 \mathrm{MHz}$, Line Scan 


\section{D.2.4 Line Scan Data at 1.0 MHz Pipe Side of Overlay on Flaws 1-5}

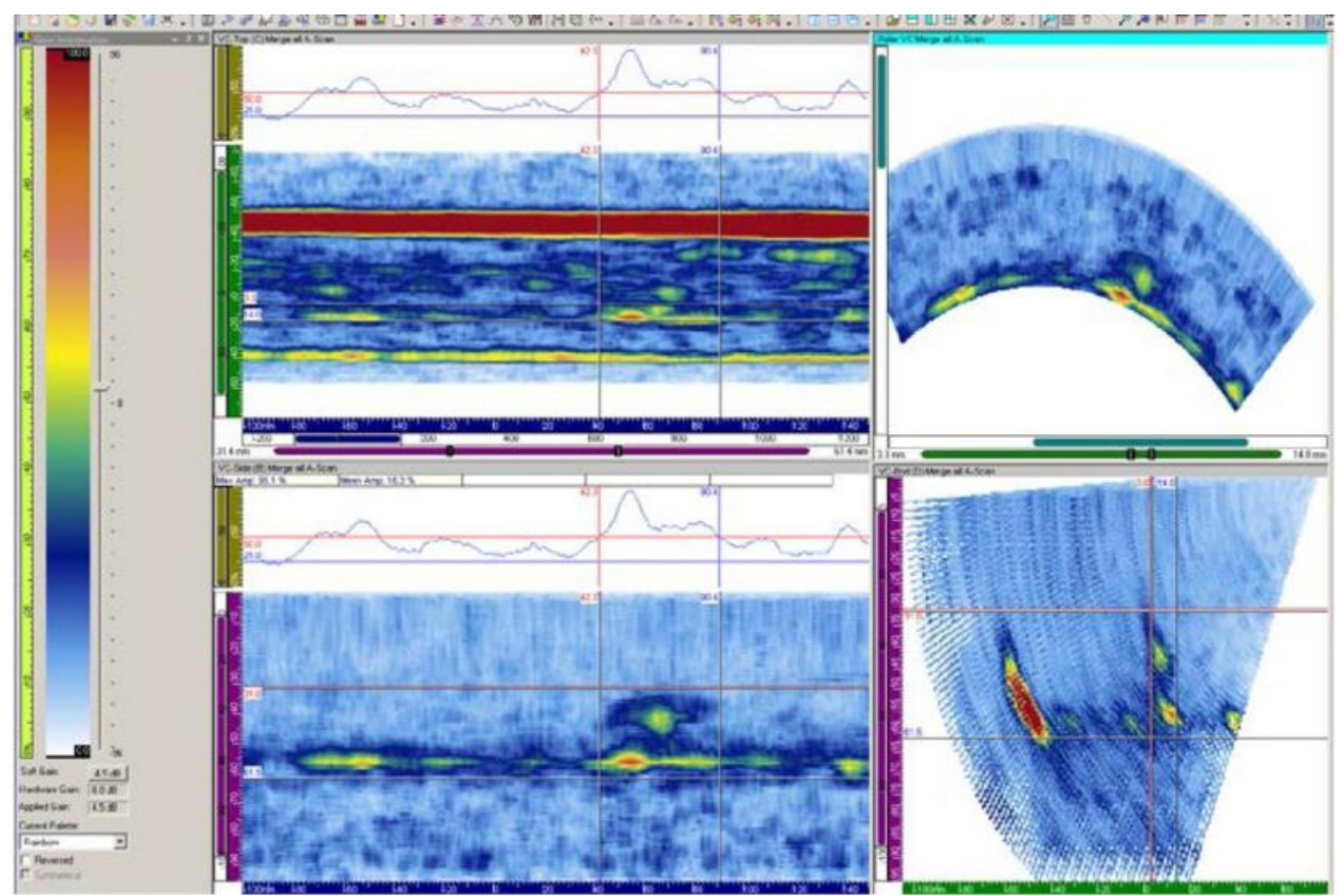

Figure D.56. 10C-011 Flaw 1 Pipe Side of Overlay at 1.0 MHz, Line Scan

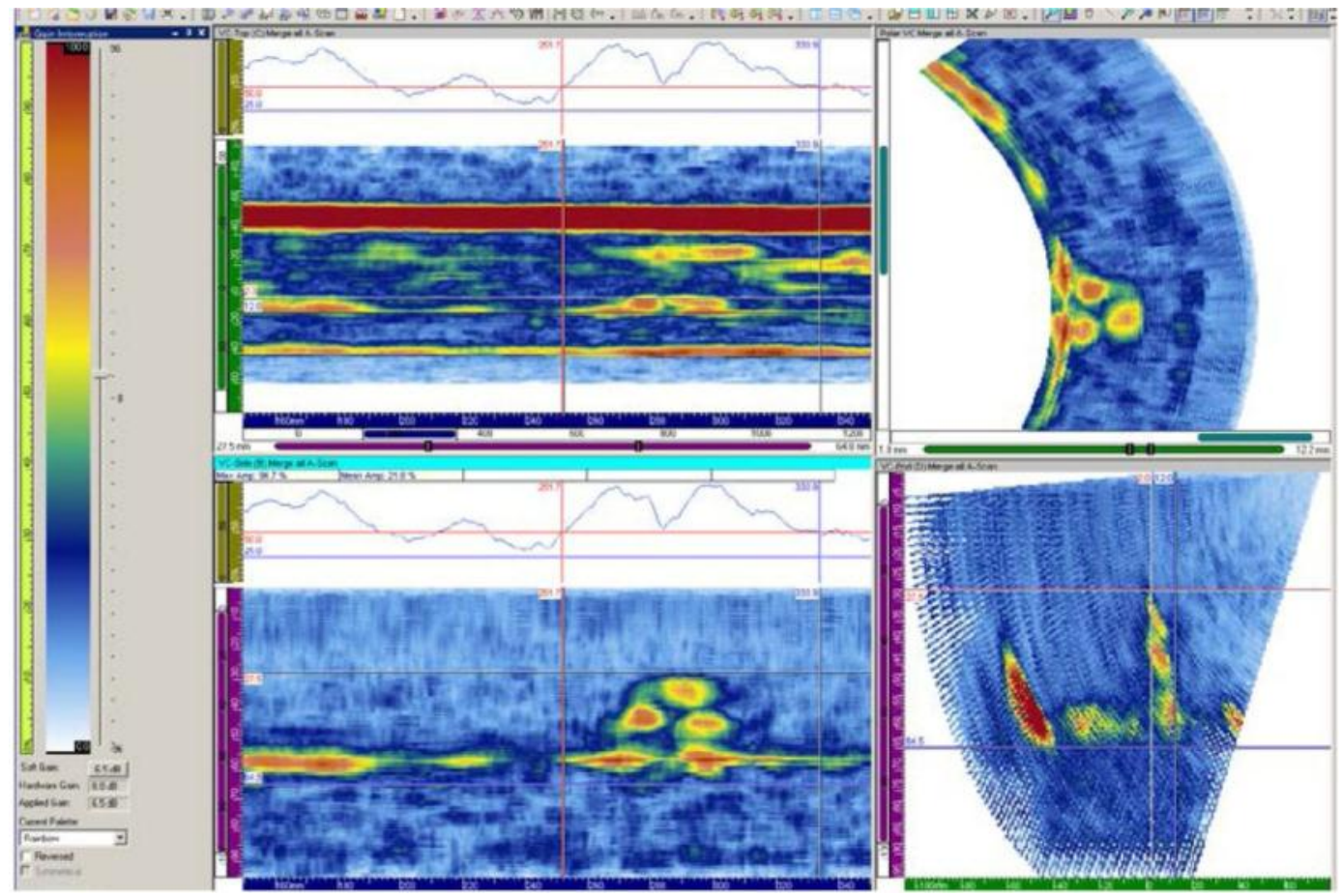

Figure D.57. 10C-011 Flaw 2 Pipe Side of Overlay at 1.0 MHz, Line Scan 


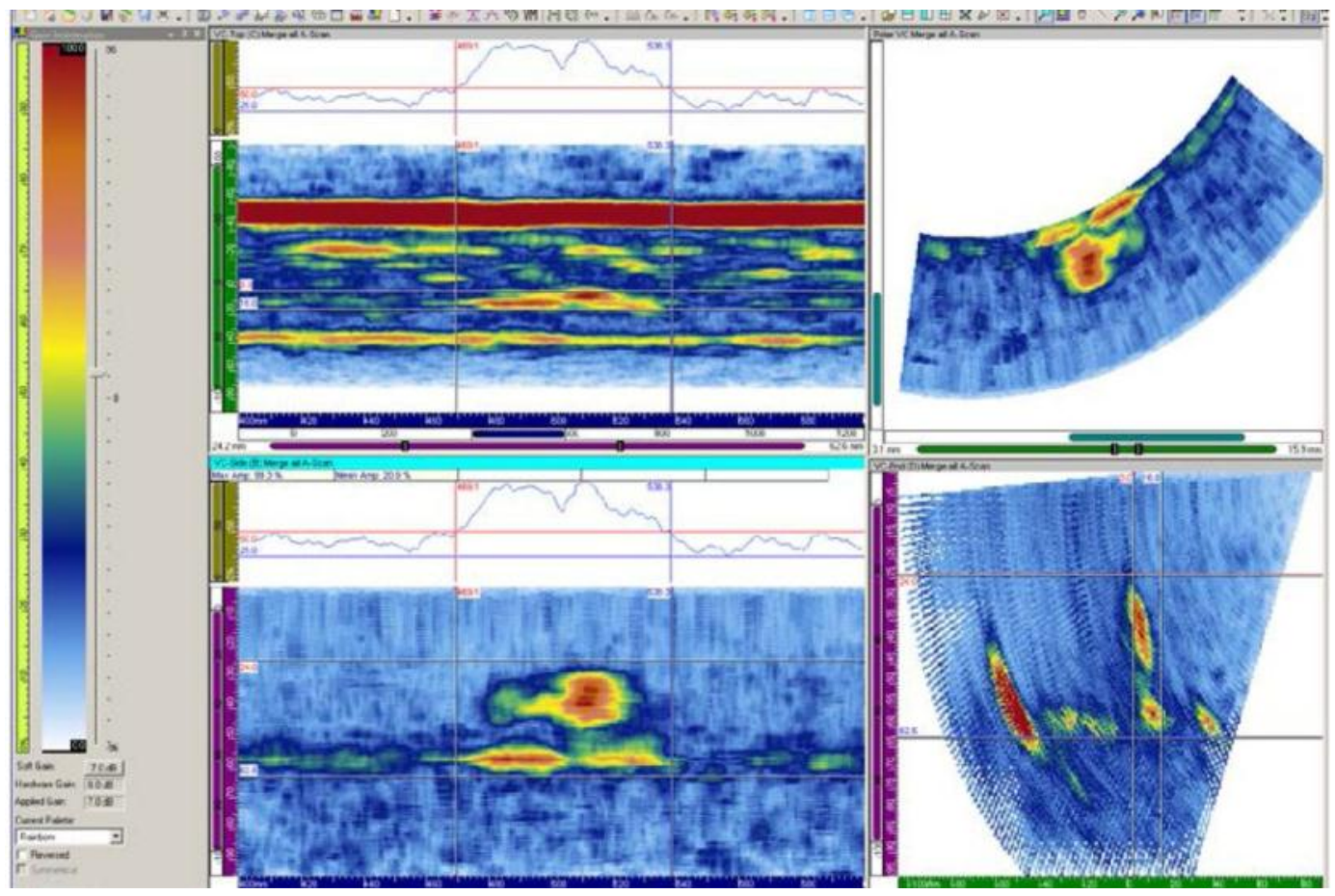

Figure D.58. 10C-011 Flaw 3 Pipe Side of Overlay at 1.0 MHz, Line Scan

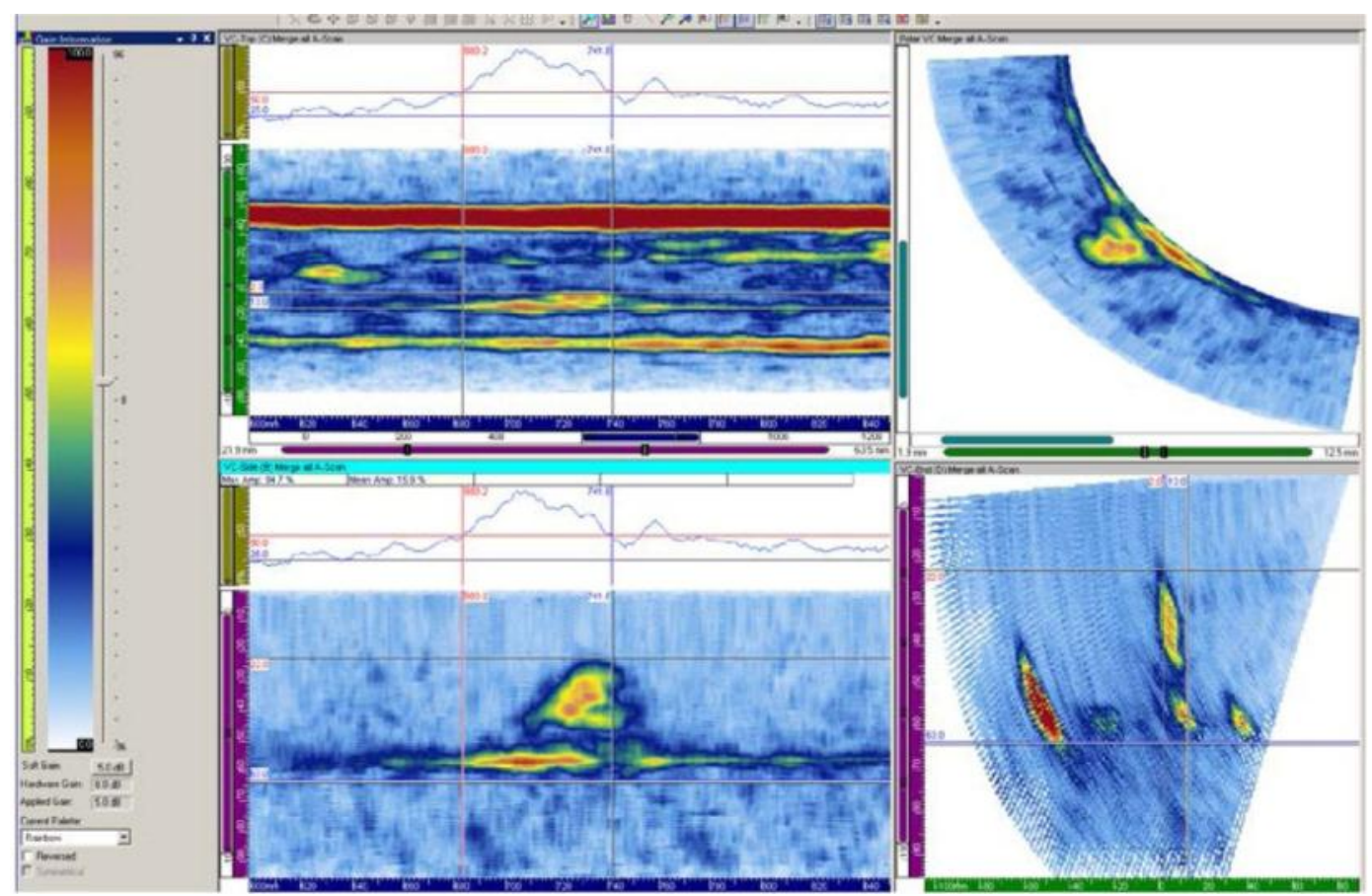

Figure D.59. 10C-011 Flaw 4 Pipe Side of Overlay at 1.0 MHz, Line Scan 


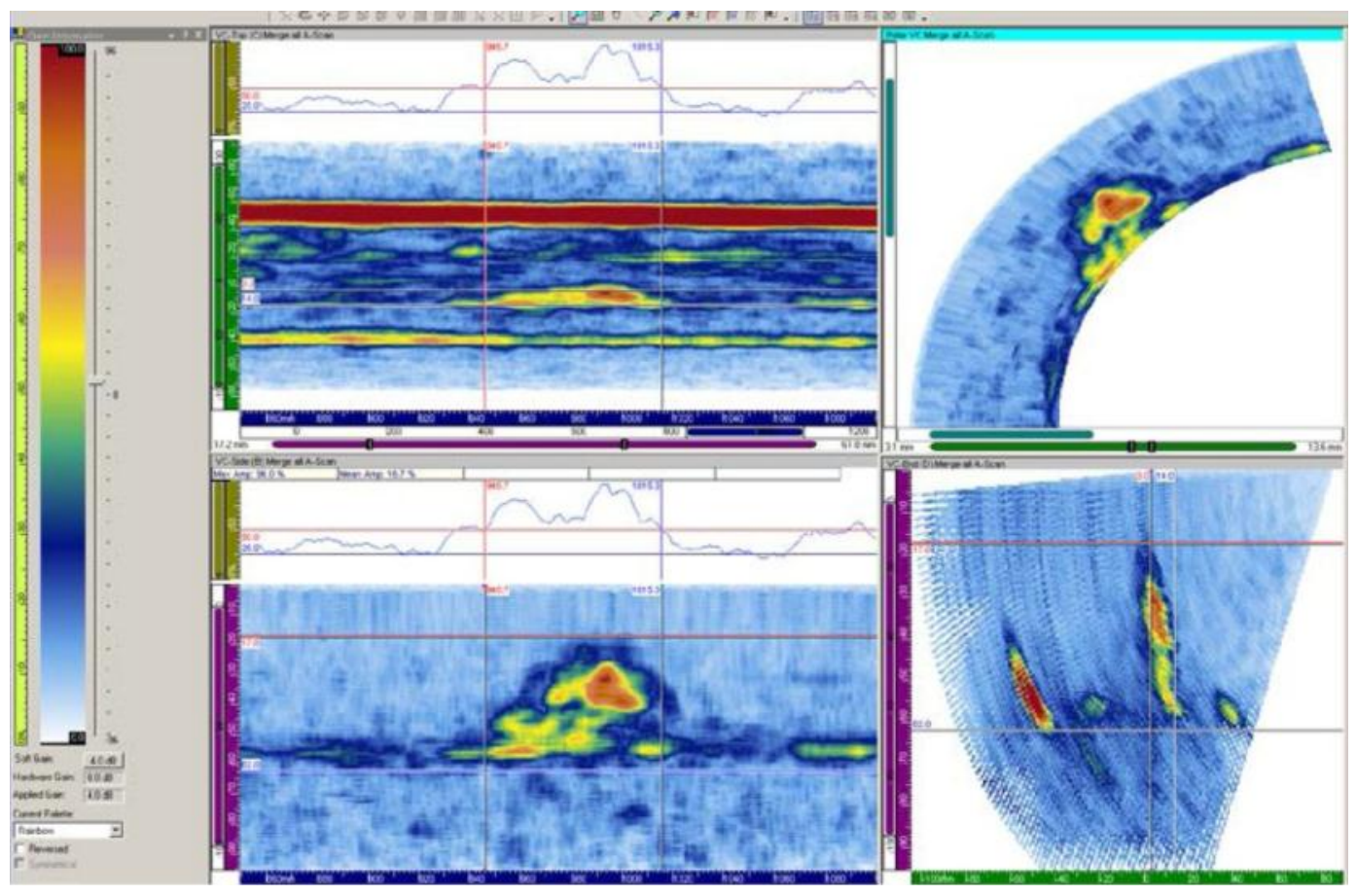

Figure D.60. 10C-011 Flaw 5 Pipe Side of Overlay at 1.0 MHz, Line Scan 


\section{D.2.5 Line Scan Data at 1.5 MHz Nozzle Side of Overlay on Flaws 1-5}

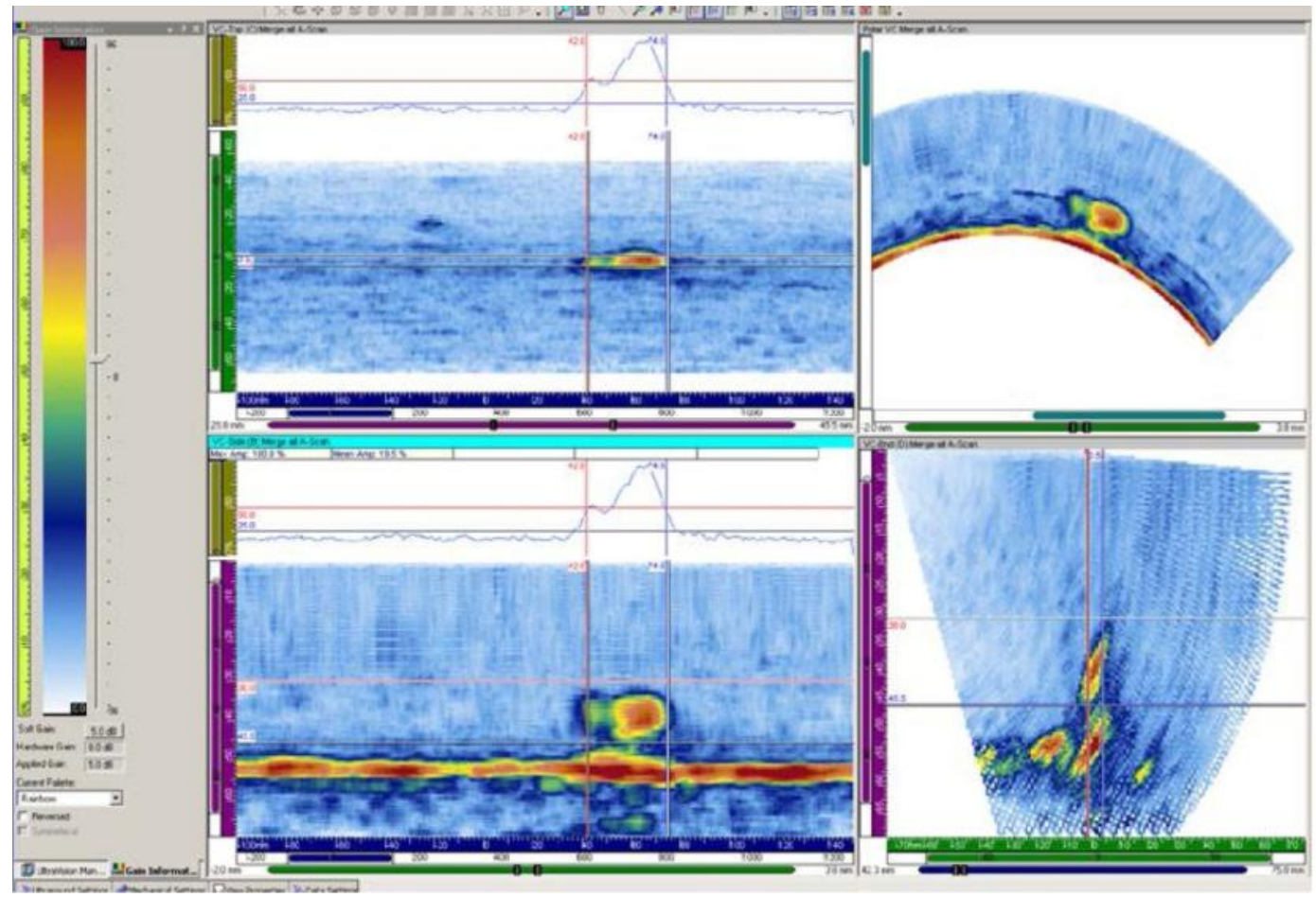

Figure D.61. 10C-011 Flaw 1 Nozzle Side of Overlay at $1.5 \mathrm{MHz}$, Line Scan

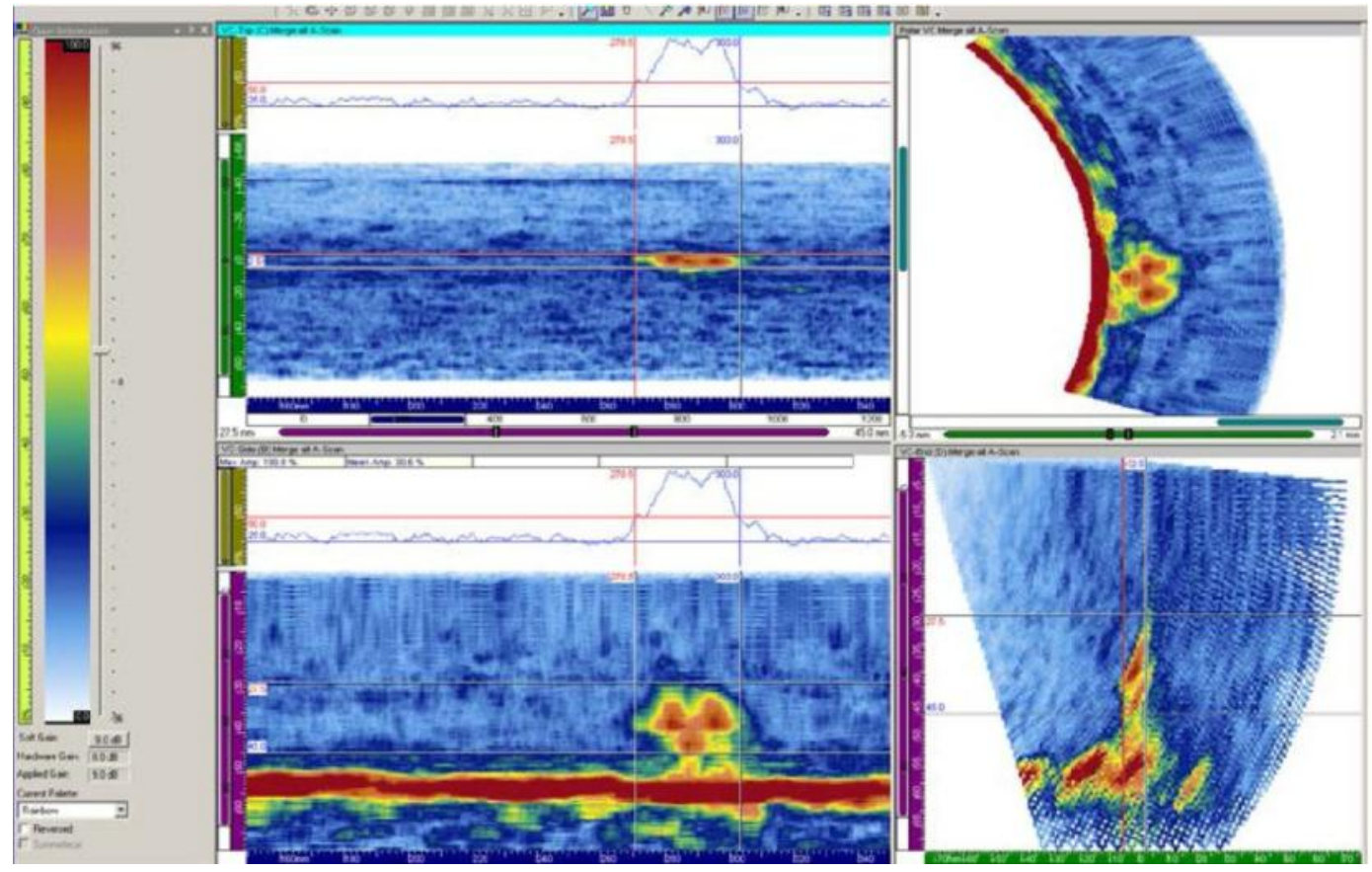

Figure D.62. 10C-011 Flaw 2 Nozzle Side of Overlay at $1.5 \mathrm{MHz}$, Line Scan 


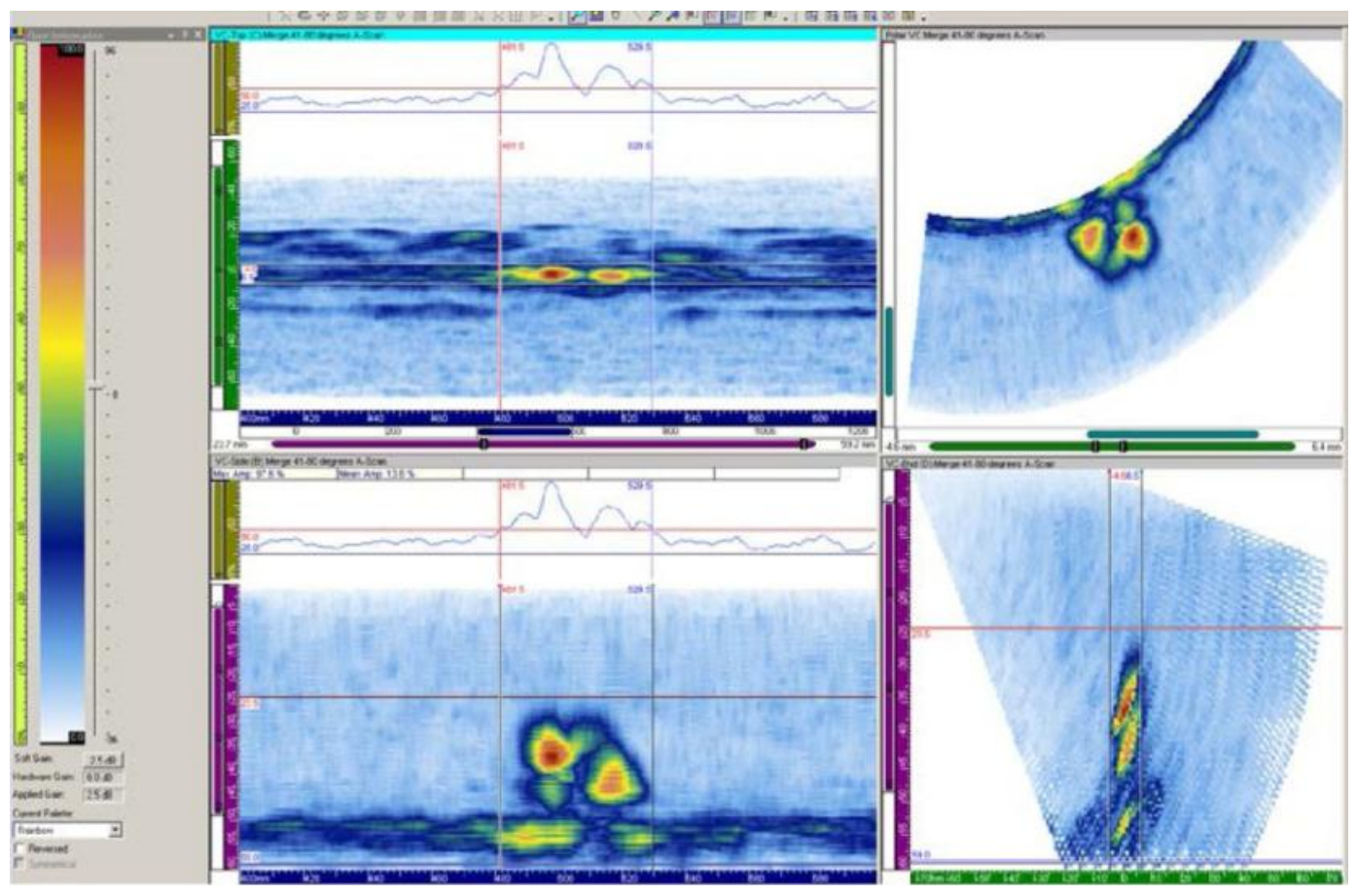

Figure D.63. 10C-011 Flaw 3 Nozzle Side of Overlay at $1.5 \mathrm{MHz}$, Line Scan

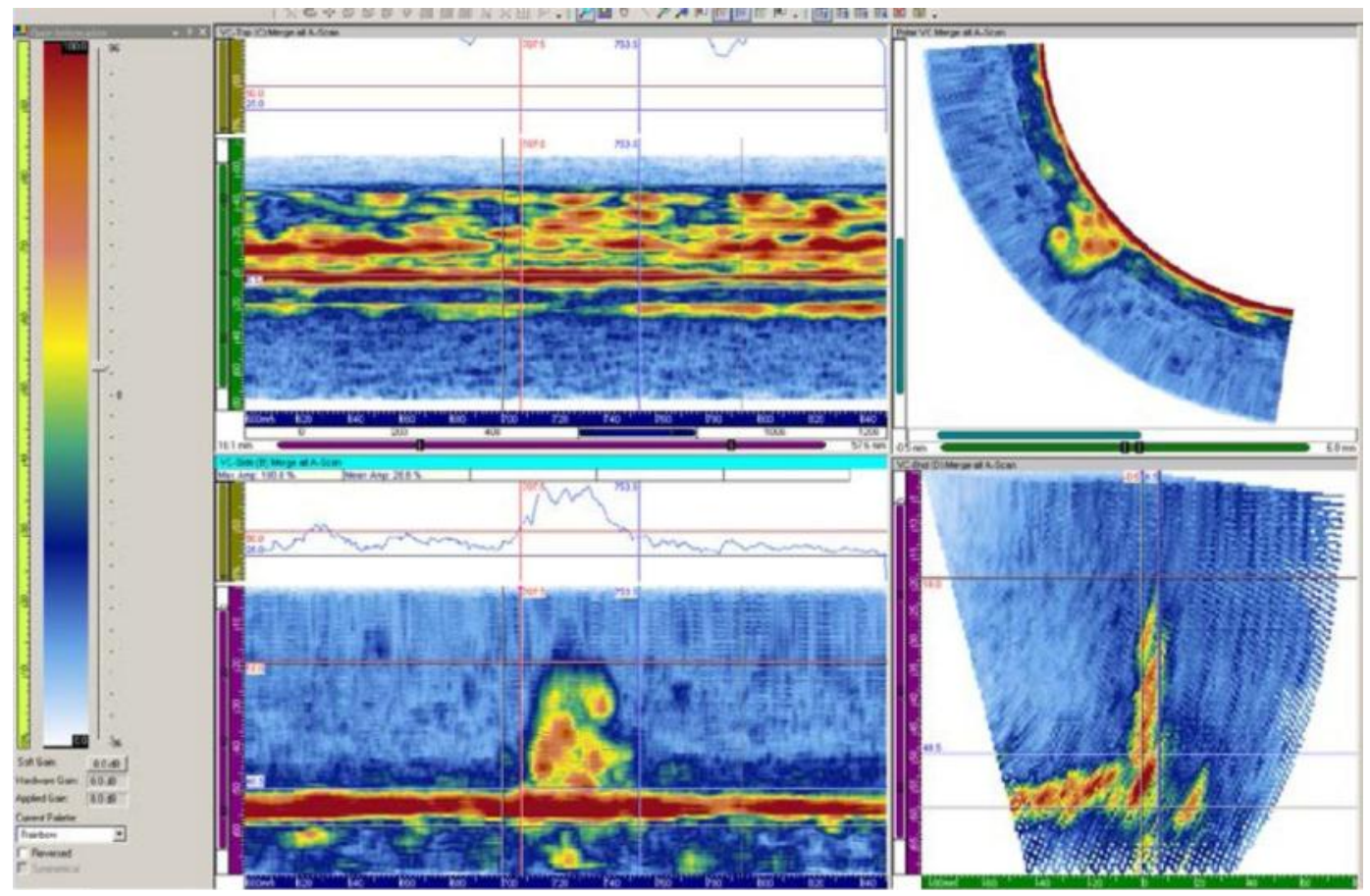

Figure D.64. 10C-011 Flaw 4 Nozzle Side of Overlay at $1.5 \mathrm{MHz}$, Line Scan 


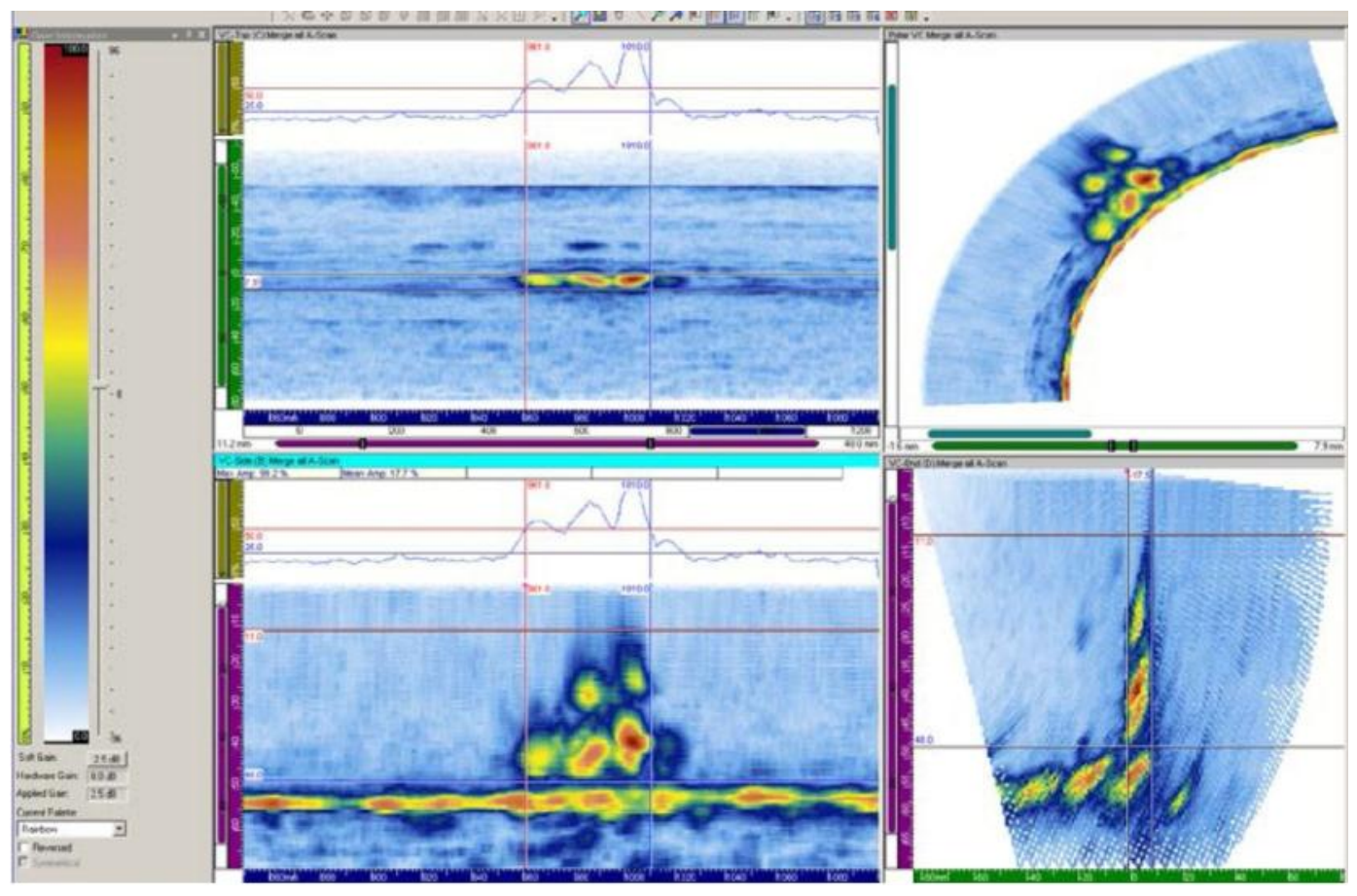

Figure D.65. 10C-011 Flaw 5 Nozzle Side of Overlay at $1.5 \mathrm{MHz}$, Line Scan 


\section{D.2.6 Line Scan Data at 1.5 MHz Pipe Side of Overlay on Flaws 1-5}

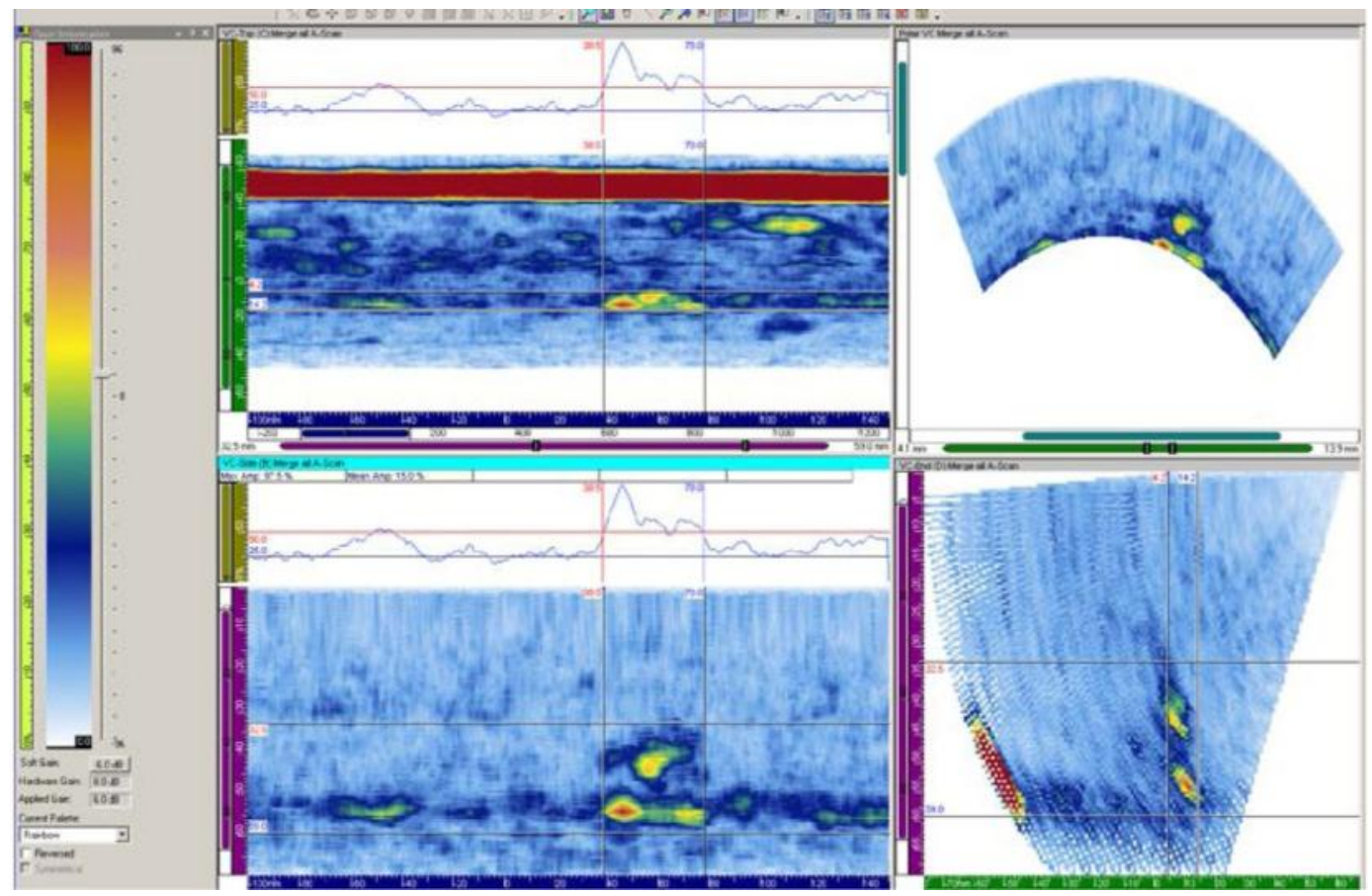

Figure D.66. 10C-011 Flaw 1 Pipe Side of Overlay at 1.5 MHz, Line Scan Post-FSWOL

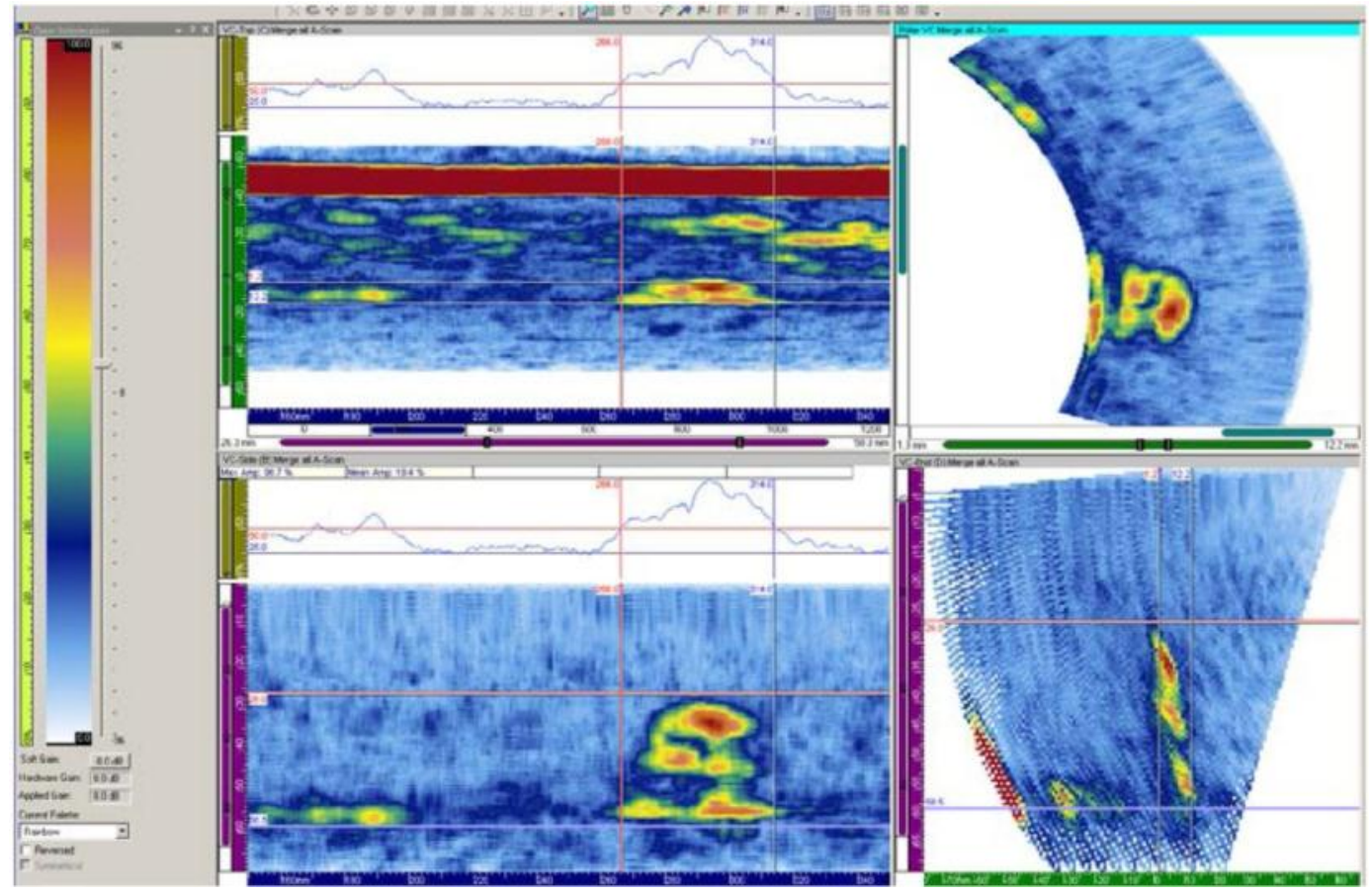

Figure D.67. 10C-011 Flaw 2 Pipe Side of Overlay at 1.5 MHz, Line Scan 


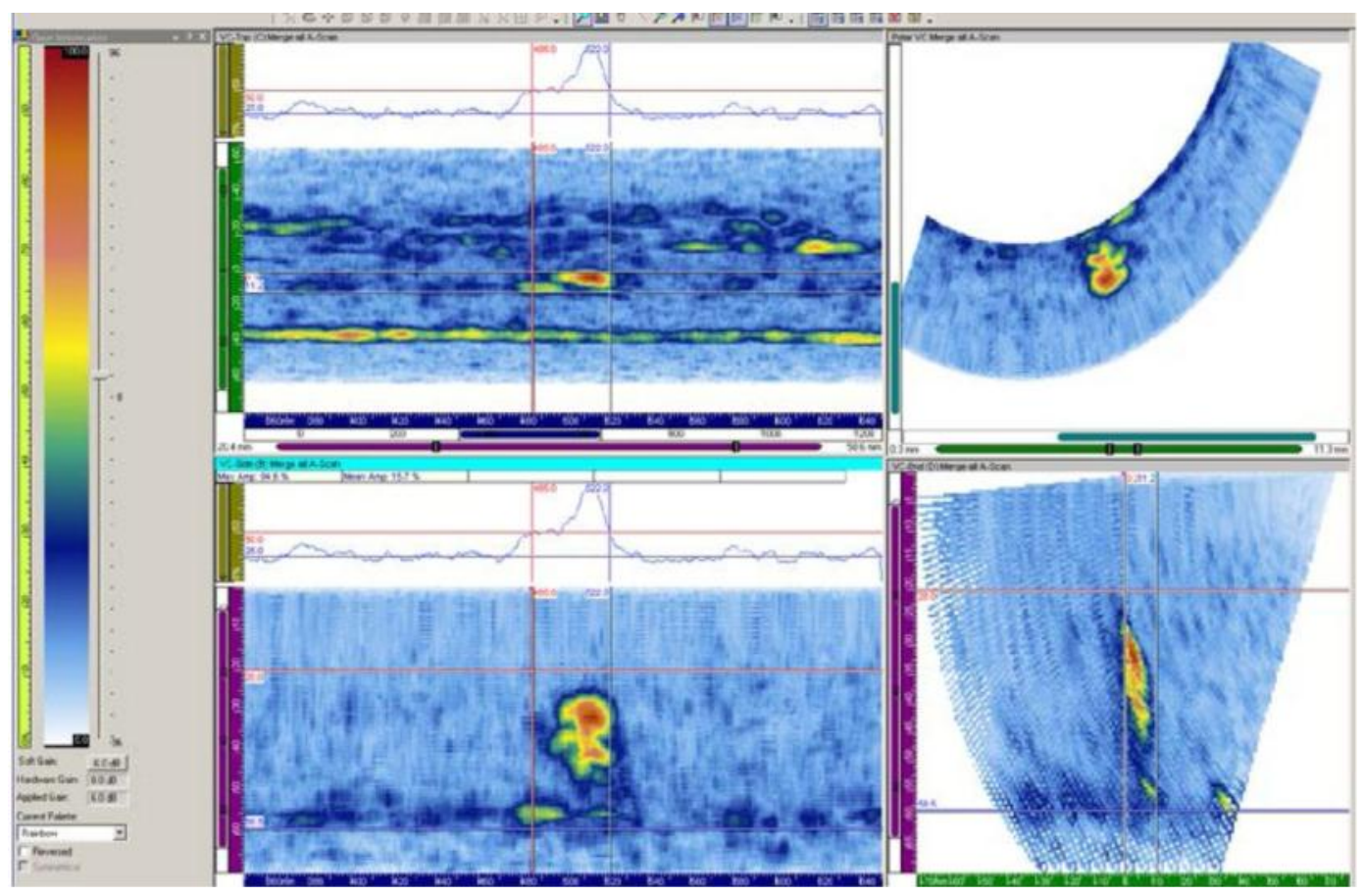

Figure D.68. 10C-011 Flaw 3 Pipe Side of Overlay at 1.5 MHz, Line Scan

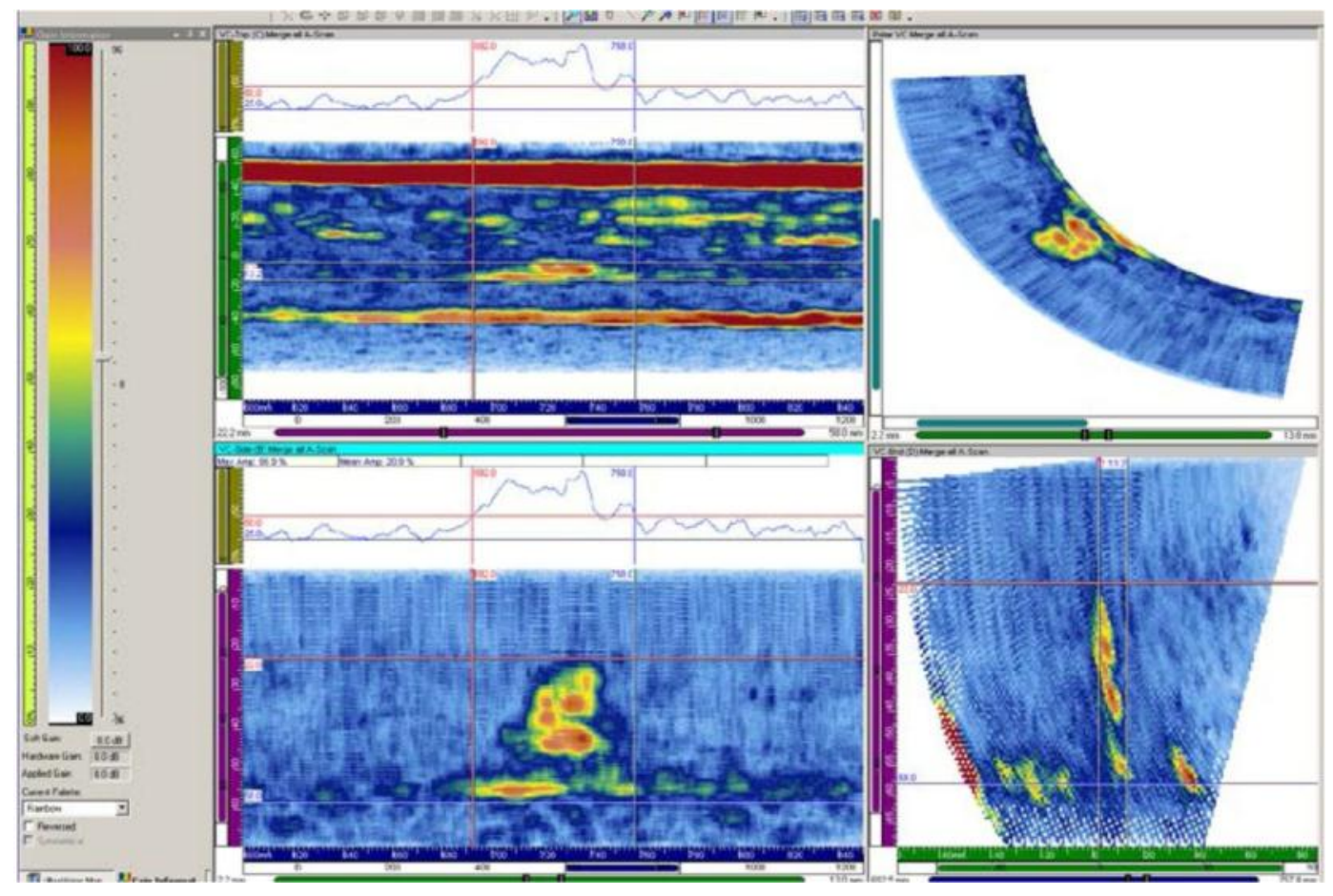

Figure D.69. 10C-011 Flaw 4 Pipe Side of Overlay at 1.5 MHz, Line Scan 


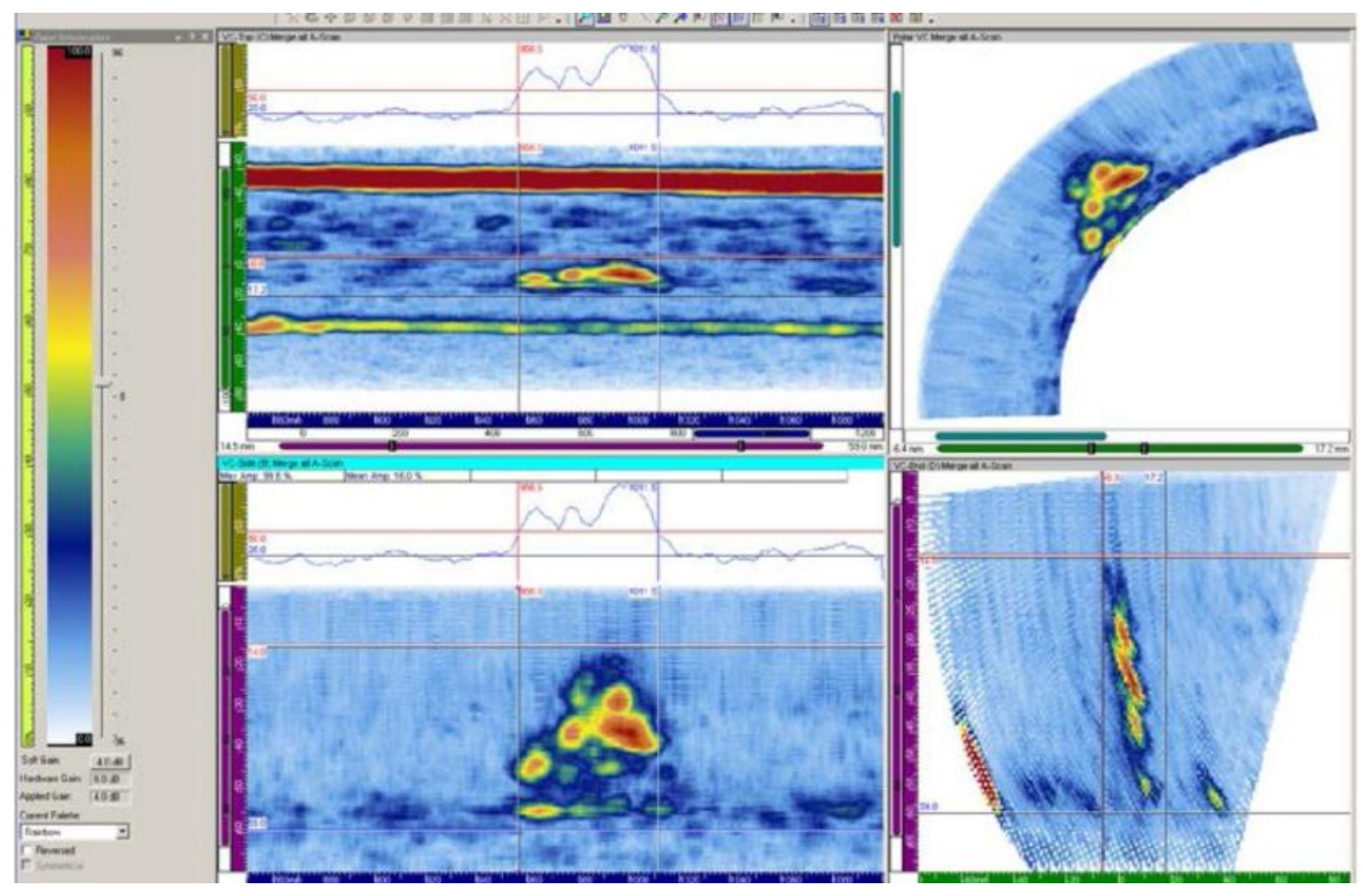

Figure D.70. 10C-011 Flaw 5 Pipe Side of Overlay at 1.5 MHz, Line Scan 


\section{D.2.7 Line Scan Data at 2.0 MHz Nozzle Side of Overlay on Flaws 1-5}

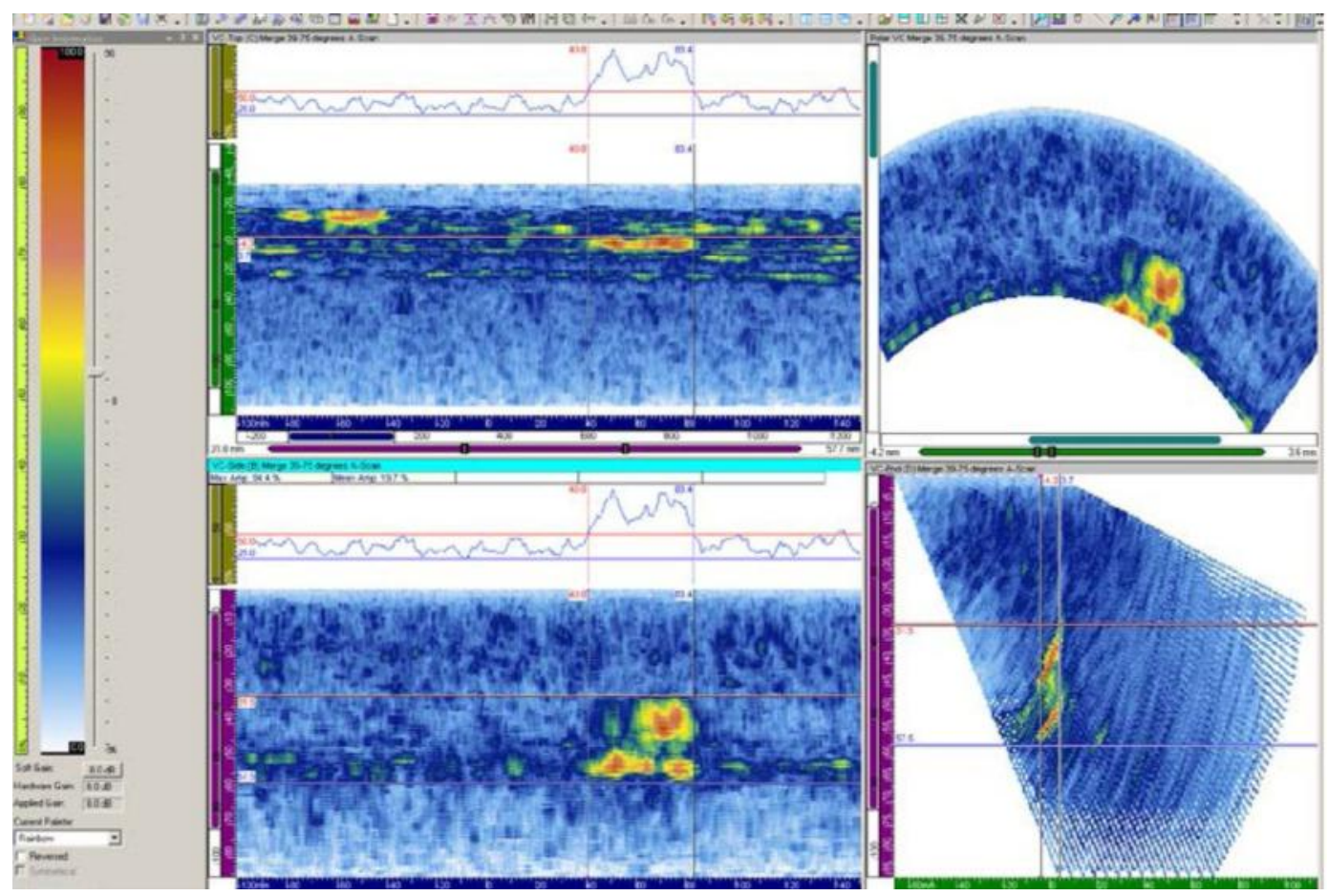

Figure D.71. 10C-011 Flaw 1 Nozzle Side of Overlay at 2.0 MHz, Line Scan

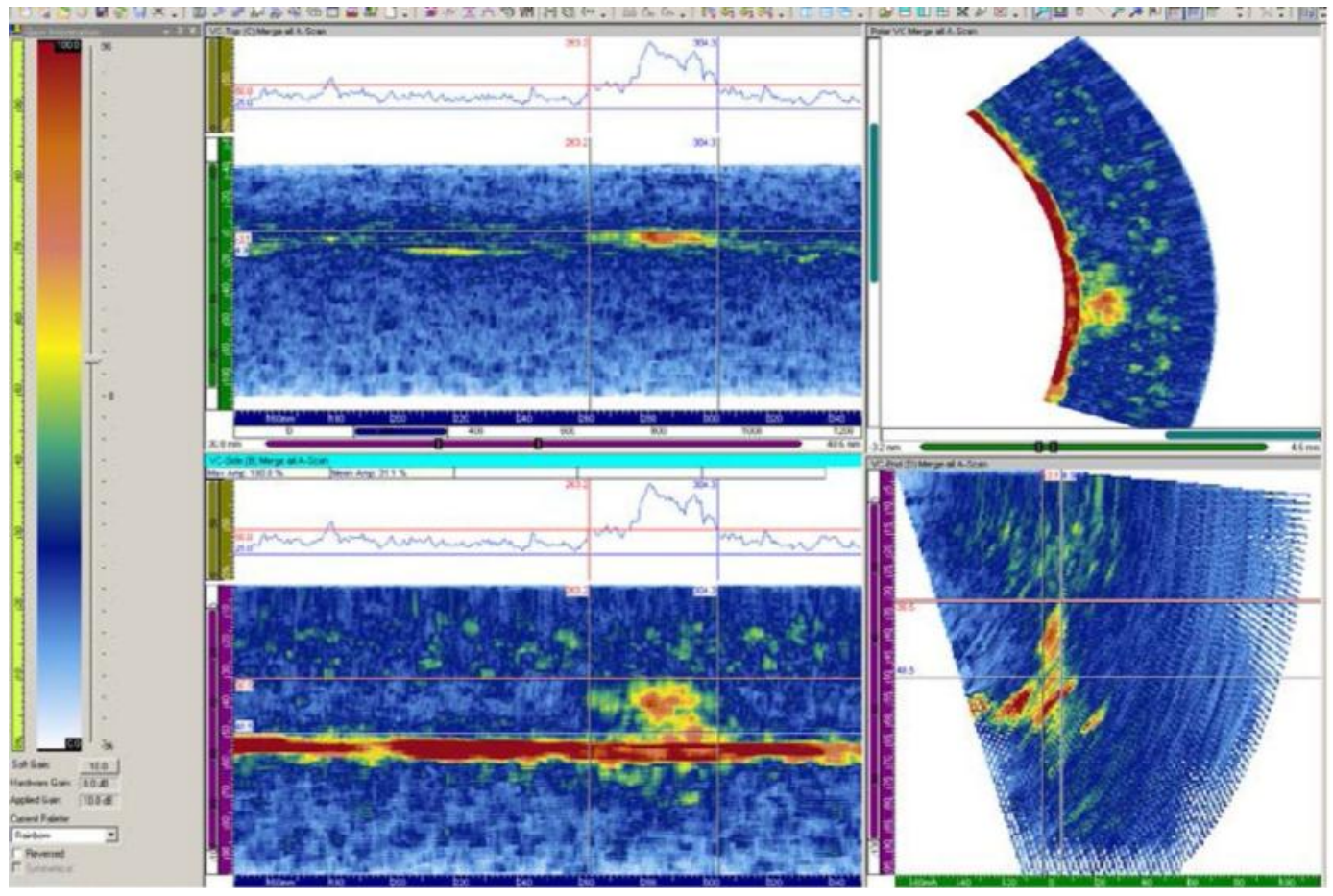

Figure D.72. 10C-011 Flaw 2 Nozzle Side of Overlay at $2.0 \mathrm{MHz}$, Line Scan 


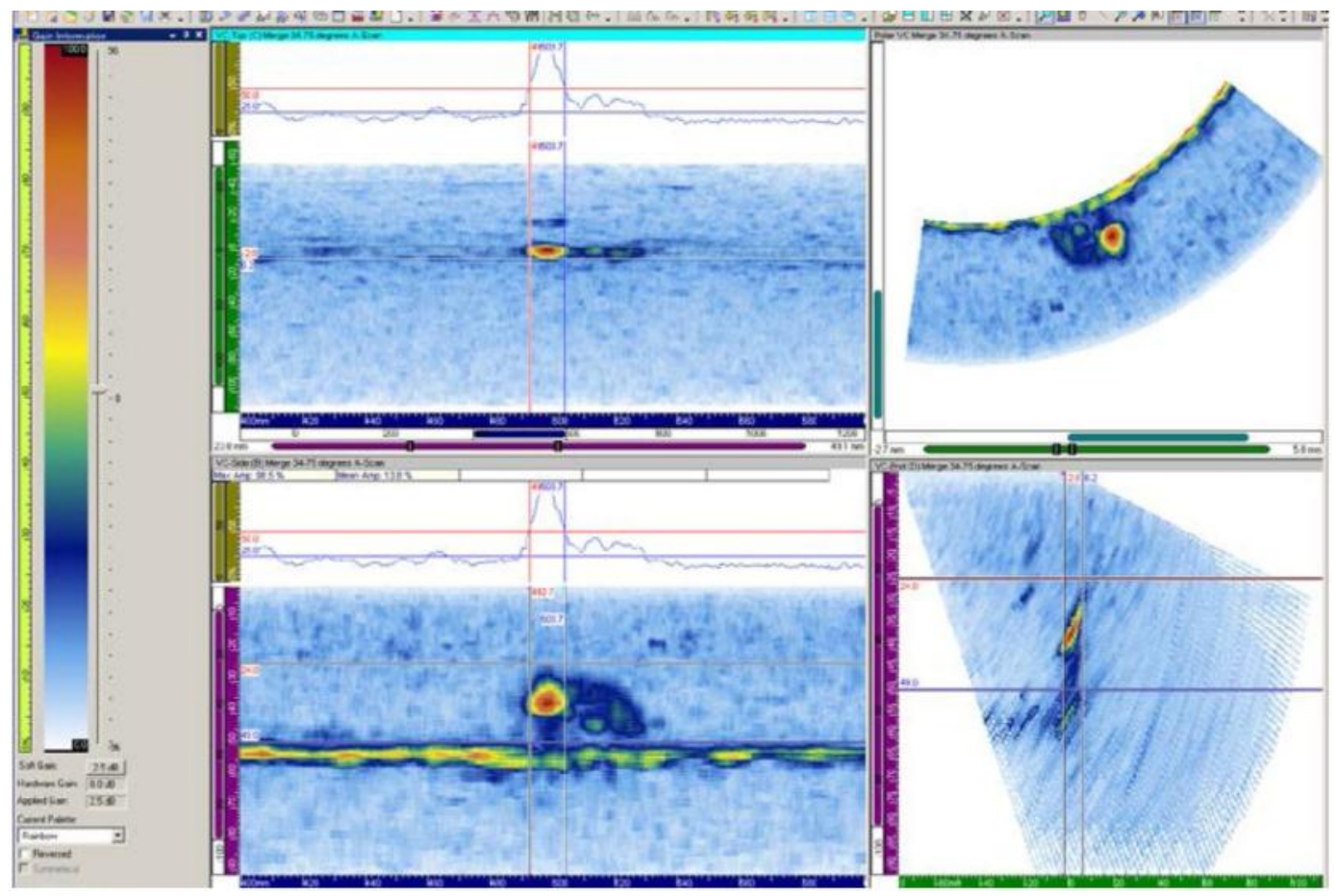

Figure D.73. 10C-011 Flaw 3 Nozzle Side of Overlay at $2.0 \mathrm{MHz}$, Line Scan

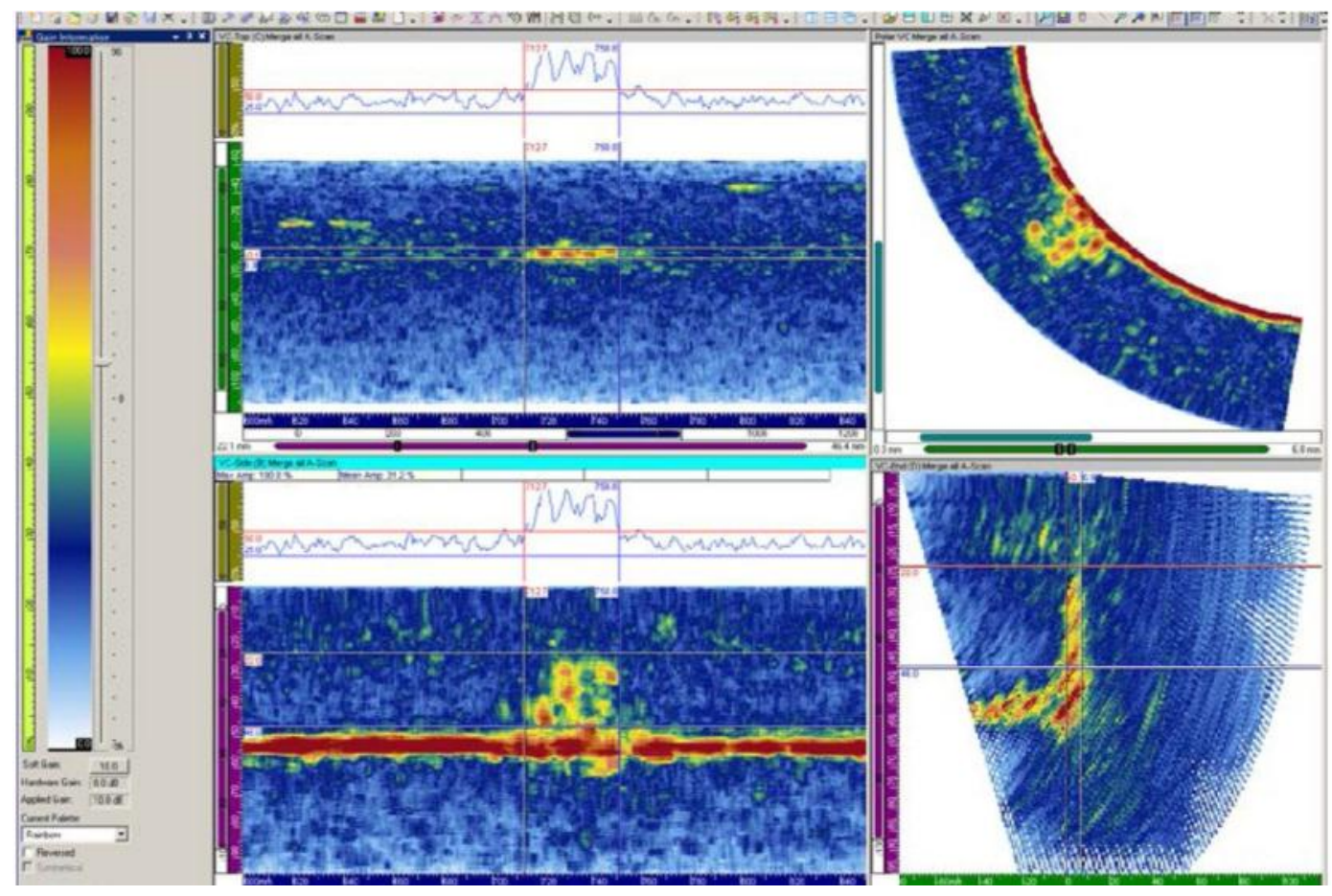

Figure D.74. 10C-011 Flaw 4 Nozzle Side of Overlay at 2.0 MHz, Line Scan 


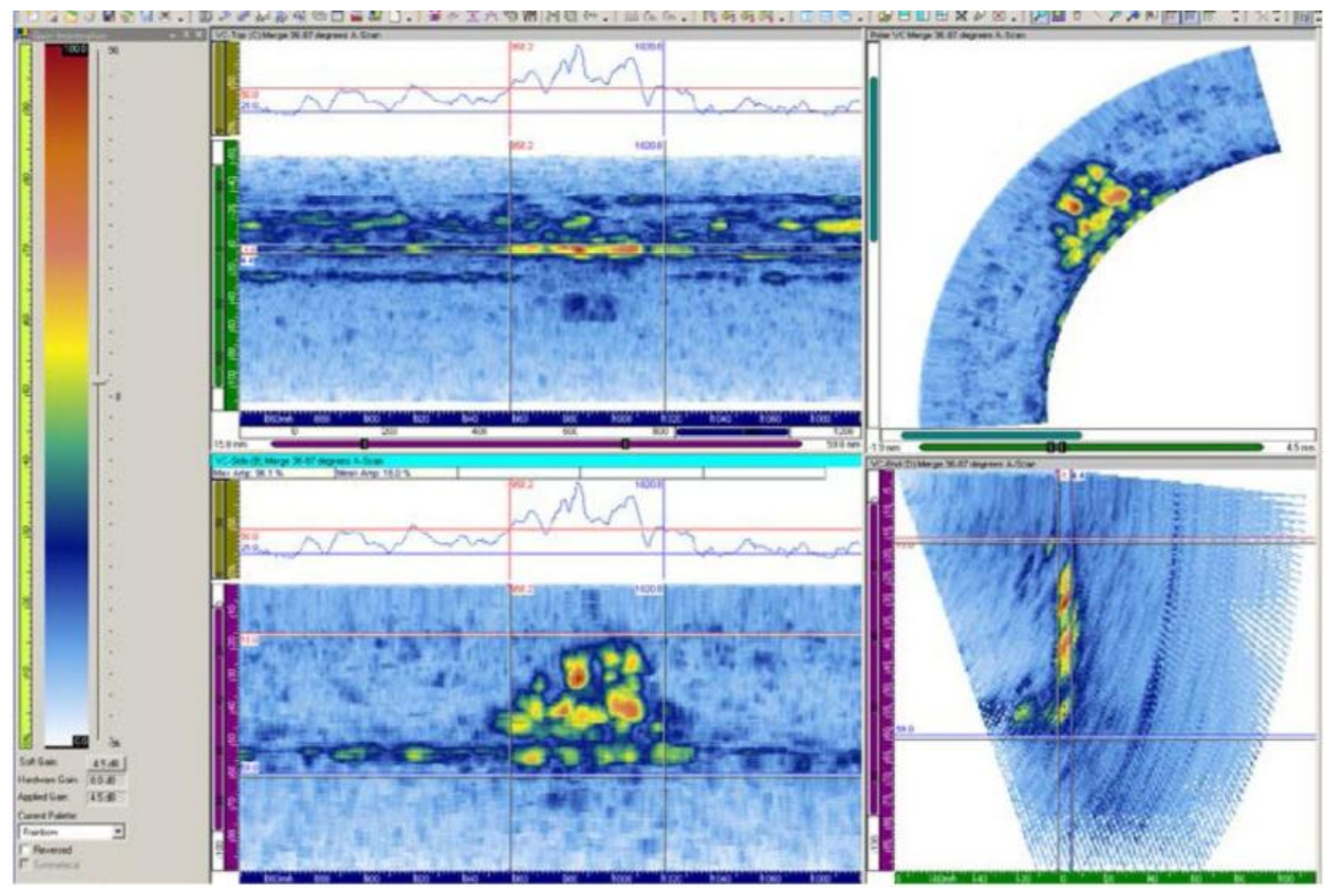

Figure D.75. 10C-011 Flaw 5 Nozzle Side of Overlay at $2.0 \mathrm{MHz}$, Line Scan 


\section{D.2.8 Line Scan Data at 2.0 MHz Pipe Sid of Overlay on Flaws 1-5}

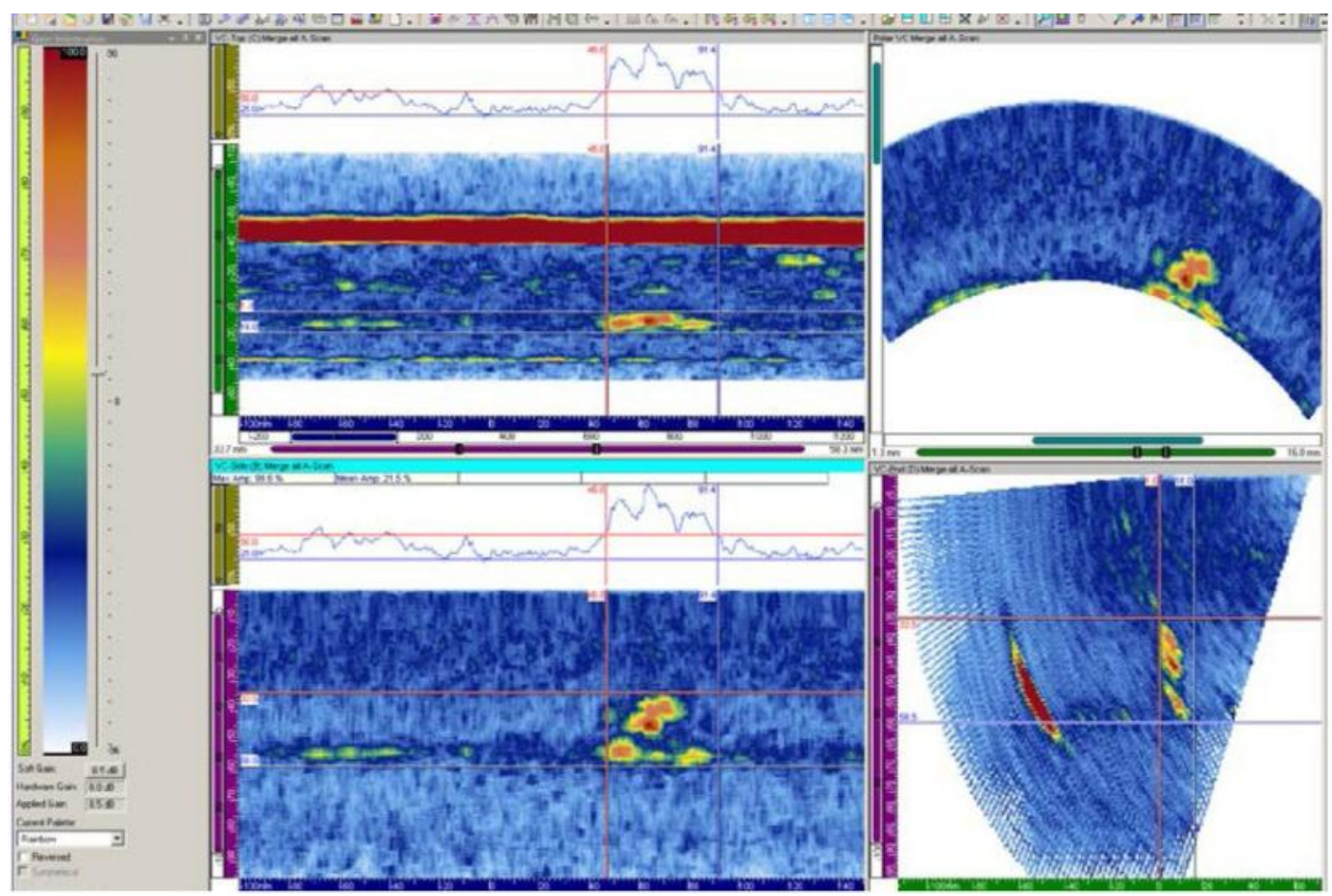

Figure D.76. 10C-011 Flaw 1 Pipe Side of Overlay at 2.0 MHz, Line Scan

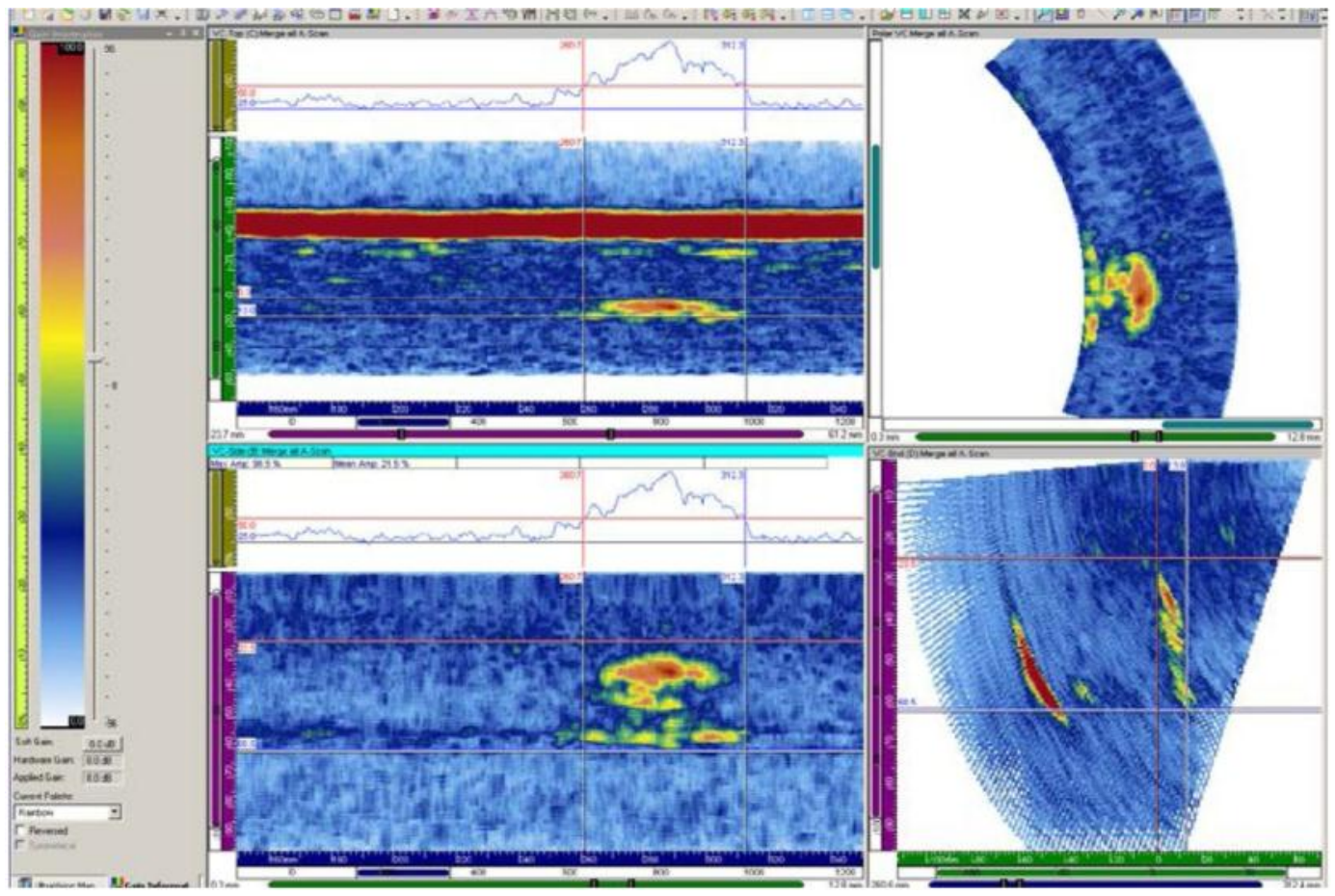

Figure D.77. 10C-011 Flaw 2 Pipe Side of Overlay at 2.0 MHz, Line Scan 


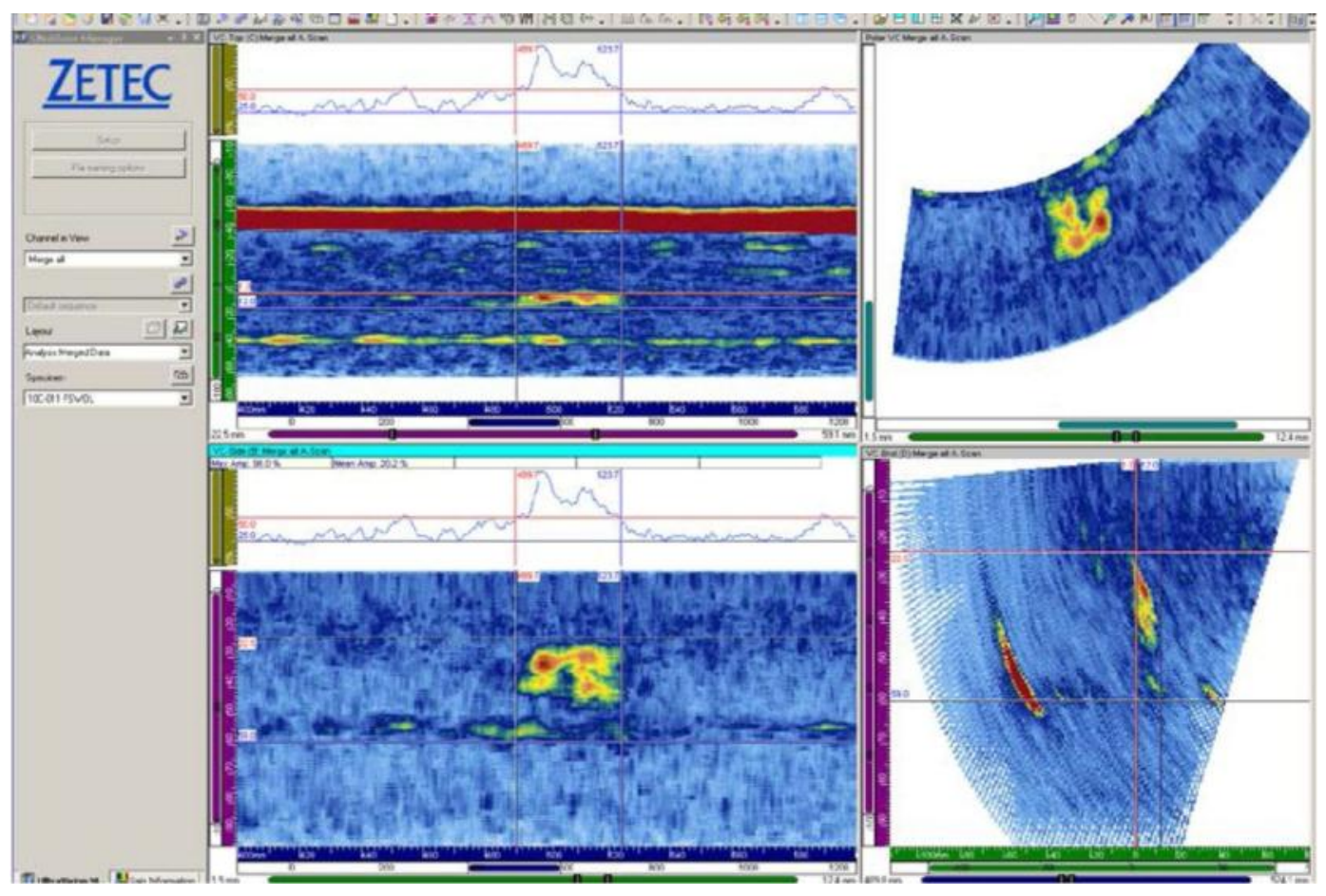

Figure D.78. 10C-011 Flaw 3 Pipe Side of Overlay at 2.0 MHz, Line Scan

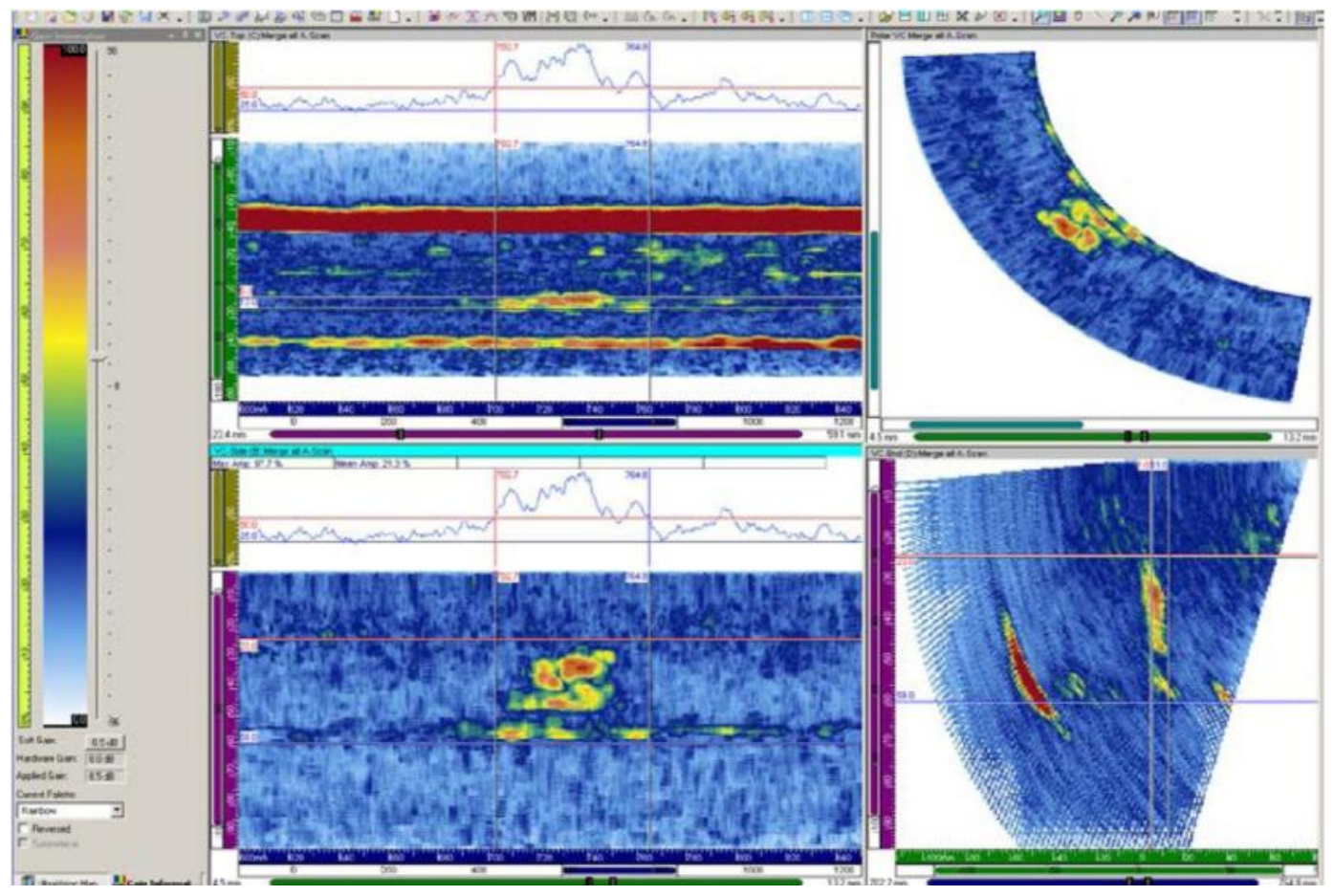

Figure D.79. 10C-011 Flaw 4 Pipe Side of Overlay at 2.0 MHz, Line Scan 


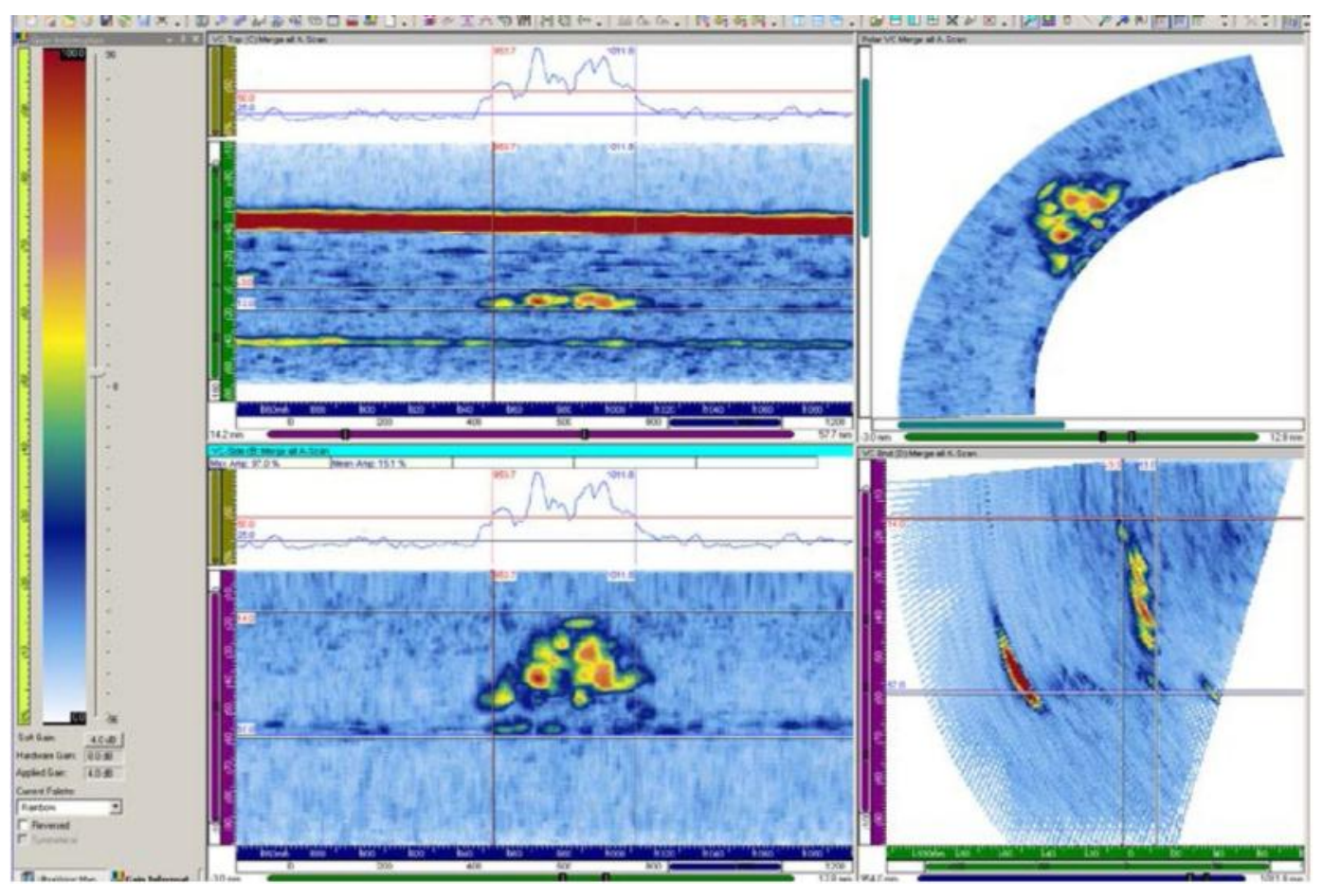

Figure D.80. 10C-011 Flaw 5 Pipe Side of Overlay at $2.0 \mathrm{MHz}$, Line Scan 

Appendix E

Length and Depth Sizing and Signal-to-Noise Ratio Tables 



\section{Appendix E}

\section{Length and Depth Sizing and Signal-to-Noise Ratio Tables}

E.1 Raster Data

E. 1

E.2 Line Scan Data

E. 4

\section{E.1 Raster Data}

Table E.1. Length Sizing -6 dB Level (mm), Raster Data, Nozzle Side of Weld

\begin{tabular}{|c|c|c|c|c|c|c|c|c|c|}
\hline \multirow[b]{3}{*}{ Flaw } & \multirow[b]{3}{*}{$\begin{array}{l}\text { True } \\
\text { State }\end{array}$} & \multicolumn{8}{|c|}{ Probe } \\
\hline & & \multicolumn{2}{|c|}{$800 \mathrm{kHz}$} & \multicolumn{2}{|c|}{$1.0 \mathrm{MHz}$} & \multicolumn{2}{|c|}{$1.5 \mathrm{MHz}$} & \multicolumn{2}{|c|}{$2.0 \mathrm{MHz}$} \\
\hline & & $\begin{array}{c}\text { Pre- } \\
\text { WOL }\end{array}$ & $\begin{array}{l}\text { Post- } \\
\text { WOL }\end{array}$ & $\begin{array}{c}\text { Pre- } \\
\text { WOL }\end{array}$ & $\begin{array}{l}\text { Post- } \\
\text { WOL }\end{array}$ & $\begin{array}{c}\text { Pre- } \\
\text { WOL }\end{array}$ & $\begin{array}{l}\text { Post- } \\
\text { WOL }\end{array}$ & $\begin{array}{c}\text { Pre- } \\
\text { WOL }\end{array}$ & $\begin{array}{l}\text { Post- } \\
\text { WOL }\end{array}$ \\
\hline $9 \mathrm{C} 034-1$ & 51.18 & & & & & & & & 12.07 \\
\hline $9 \mathrm{C} 034-2$ & 51.49 & & 46.94 & & 44.02 & & 23.43 & & 26.27 \\
\hline $9 \mathrm{C} 034-3$ & 63.88 & & & & & & 17.04 & & 14.91 \\
\hline $9 \mathrm{C} 034-4$ & 63.78 & & 49.78 & & 49.00 & & 58.23 & & 43.31 \\
\hline $10 \mathrm{C} 011-1$ & 38.15 & 61.56 & 40.53 & 37.09 & 33.95 & 32.44 & 33.23 & 29.20 & 25.28 \\
\hline $10 \mathrm{C} 011-2$ & 43.38 & 34.73 & 18.78 & 18.15 & 37.56 & 20.52 & 28.90 & 32.44 & 25.28 \\
\hline $10 \mathrm{C} 011-3$ & 51.03 & 58.40 & 31.14 & 27.62 & 22.39 & 37.17 & 24.56 & 45.78 & 8.67 \\
\hline $10 \mathrm{C} 011-4$ & 56.06 & 47.36 & 34.75 & 45.78 & 39.73 & 56.91 & 41.18 & 51.30 & 39.73 \\
\hline $10 \mathrm{C} 011-5$ & 63.86 & --- & 57.86 & 63.93 & 42.62 & 54.54 & 46.96 & 47.36 & 39.01 \\
\hline
\end{tabular}

Table E.2. Length Sizing LOS Level (mm), Raster Data, Nozzle Side of Weld

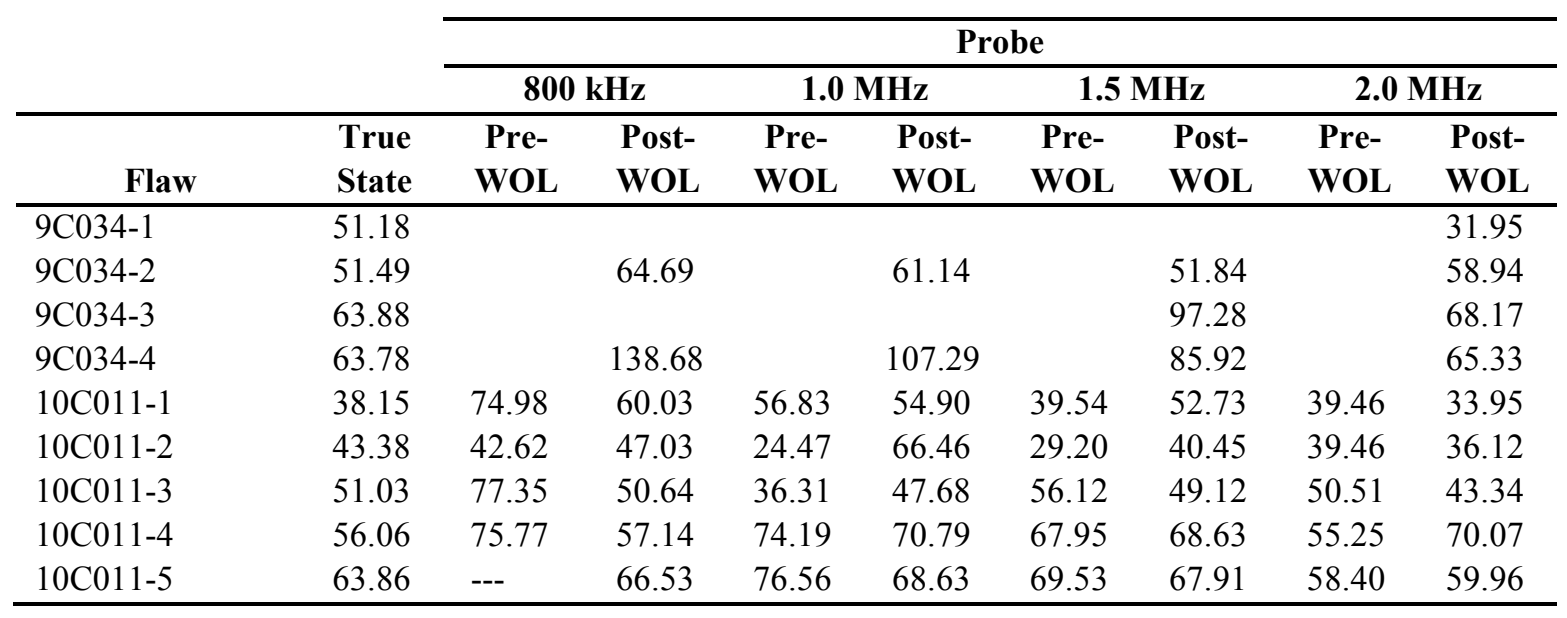


Table E.3. Depth Sizing (mm), Raster Data, Nozzle Side of Weld

\begin{tabular}{|c|c|c|c|c|c|c|c|c|c|}
\hline \multirow[b]{3}{*}{ Flaw } & \multirow[b]{3}{*}{$\begin{array}{l}\text { True } \\
\text { State }\end{array}$} & \multicolumn{8}{|c|}{ Probe } \\
\hline & & \multicolumn{2}{|c|}{$800 \mathrm{kHz}$} & \multicolumn{2}{|c|}{$1.0 \mathrm{MHz}$} & \multicolumn{2}{|c|}{$1.5 \mathrm{MHz}$} & \multicolumn{2}{|c|}{$2.0 \mathrm{MHz}$} \\
\hline & & $\begin{array}{c}\text { Pre- } \\
\text { WOL }\end{array}$ & $\begin{array}{l}\text { Post- } \\
\text { WOL }\end{array}$ & $\begin{array}{c}\text { Pre- } \\
\text { WOL }\end{array}$ & $\begin{array}{l}\text { Post- } \\
\text { WOL }\end{array}$ & $\begin{array}{c}\text { Pre- } \\
\text { WOL }\end{array}$ & $\begin{array}{l}\text { Post- } \\
\text { WOL }\end{array}$ & $\begin{array}{l}\text { Pre- } \\
\text { WOL }\end{array}$ & $\begin{array}{l}\text { Post- } \\
\text { WOI }\end{array}$ \\
\hline $9 \mathrm{C} 034-1$ & 4.55 & & & & & & & & \\
\hline $9 \mathrm{C} 034-2$ & 10.74 & & 9.7 & & 10.00 & & 8.00 & & 8.00 \\
\hline $9 \mathrm{C} 034-3$ & 6.48 & & & & & & 5.60 & & 7.50 \\
\hline $9 \mathrm{C} 034-4$ & 9.19 & & 7.4 & & 8.10 & & 7.10 & & 7.40 \\
\hline $10 \mathrm{C} 011-1$ & 16.51 & 11.20 & 14.80 & 11.00 & 13.90 & 11.60 & 11.80 & 14.50 & 12.80 \\
\hline $10 \mathrm{C} 011-2$ & 19.86 & 14.00 & 18.70 & 5.70 & 17.00 & 15.00 & 15.60 & 19.50 & 20.90 \\
\hline $10 \mathrm{C} 011-3$ & 23.11 & 15.20 & 17.80 & 16.00 & 16.10 & 16.70 & 19.60 & 20.10 & 17.50 \\
\hline $10 \mathrm{C} 011-4$ & 26.42 & 17.10 & 21.10 & 18.50 & 22.70 & 23.40 & 22.00 & 22.50 & 23.30 \\
\hline $10 \mathrm{C} 011-5$ & 29.72 & --- & 24.90 & 20.80 & 27.20 & 24.00 & 29.20 & 24.10 & 28.40 \\
\hline
\end{tabular}

Table E.4. SNR (dB), Raster Data, Nozzle Side of Weld

\begin{tabular}{|c|c|c|c|c|c|c|c|c|}
\hline \multirow[b]{3}{*}{ Flaw } & \multicolumn{8}{|c|}{ Probe } \\
\hline & \multicolumn{2}{|c|}{$800 \mathrm{kHz}$} & \multicolumn{2}{|c|}{$1.0 \mathrm{MHz}$} & \multicolumn{2}{|c|}{$1.5 \mathrm{MHz}$} & \multicolumn{2}{|c|}{$2.0 \mathrm{MHz}$} \\
\hline & $\begin{array}{c}\text { Pre- } \\
\text { WOL }\end{array}$ & $\begin{array}{l}\text { Post- } \\
\text { WOL }\end{array}$ & $\begin{array}{c}\text { Pre- } \\
\text { WOL }\end{array}$ & $\begin{array}{l}\text { Post- } \\
\text { WOL }\end{array}$ & $\begin{array}{c}\text { Pre- } \\
\text { WOL }\end{array}$ & $\begin{array}{l}\text { Post- } \\
\text { WOL }\end{array}$ & $\begin{array}{c}\text { Pre- } \\
\text { WOL }\end{array}$ & $\begin{array}{l}\text { Post- } \\
\text { WOL }\end{array}$ \\
\hline 9C034-1 & & & & & & & & 12.46 \\
\hline $9 \mathrm{C} 034-2$ & & 11.13 & & 13.17 & & 17.72 & & 17.24 \\
\hline $9 \mathrm{C} 034-3$ & & & & & & 14.21 & & 16.35 \\
\hline $9 \mathrm{C} 034-4$ & & 11.79 & & 13.74 & & 15.91 & & 16.87 \\
\hline $10 \mathrm{C} 011-1$ & 14.04 & 15.67 & 16.83 & 15.01 & 16.76 & 16.83 & 17.48 & 12.65 \\
\hline $10 \mathrm{C} 011-2$ & 15.53 & 16.21 & 15.21 & 14.44 & 17.02 & 13.92 & 16.50 & 11.34 \\
\hline $10 \mathrm{C} 011-3$ & 16.30 & 15.62 & 14.43 & 15.59 & 17.10 & 17.76 & 17.88 & 18.16 \\
\hline $10 \mathrm{C} 011-4$ & 16.20 & 12.26 & 14.31 & 9.22 & 14.18 & 11.98 & 18.41 & 11.76 \\
\hline $10 \mathrm{C} 011-5$ & --- & 15.30 & 14.19 & 17.03 & 14.94 & 17.03 & 20.04 & 15.98 \\
\hline
\end{tabular}

Table E.5. Length Sizing $-6 \mathrm{~dB}$ Level (mm), Raster Data, Pipe Side of Weld

\begin{tabular}{|c|c|c|c|c|c|c|c|c|c|}
\hline \multirow[b]{3}{*}{ Flaw } & \multirow[b]{3}{*}{$\begin{array}{l}\text { True } \\
\text { State }\end{array}$} & \multicolumn{8}{|c|}{ Probe } \\
\hline & & \multicolumn{2}{|c|}{$800 \mathrm{kHz}$} & \multicolumn{2}{|c|}{$1.0 \mathrm{MHz}$} & \multicolumn{2}{|c|}{$1.5 \mathrm{MHz}$} & \multicolumn{2}{|c|}{$2.0 \mathrm{MHz}$} \\
\hline & & $\begin{array}{l}\text { Pre- } \\
\text { WOL }\end{array}$ & $\begin{array}{l}\text { Post- } \\
\text { WOL }\end{array}$ & $\begin{array}{c}\text { Pre- } \\
\text { WOL }\end{array}$ & $\begin{array}{l}\text { Post- } \\
\text { WOL }\end{array}$ & $\begin{array}{l}\text { Pre- } \\
\text { WOL }\end{array}$ & $\begin{array}{l}\text { Post- } \\
\text { WOL }\end{array}$ & $\begin{array}{c}\text { Pre- } \\
\text { WOL }\end{array}$ & $\begin{array}{l}\text { Post- } \\
\text { WOL }\end{array}$ \\
\hline $9 \mathrm{C} 034-1$ & 51.18 & & & & & 51.0 & 32.66 & 46.2 & 13.49 \\
\hline $9 \mathrm{C} 034-2$ & 51.49 & & & & & 36.6 & 30.53 & 47.8 & 15.62 \\
\hline $9 \mathrm{C} 034-3$ & 63.88 & & 27.76 & & 18.46 & 47.8 & 41.158 & 52.6 & 29.11 \\
\hline $9 \mathrm{C} 034-4$ & 63.78 & & 17.11 & & & 54.1 & 7.10 & 65.3 & 6.39 \\
\hline $10 \mathrm{C} 011-1$ & 38.15 & 37.88 & 36.19 & 41.04 & 35.40 & 34.73 & 25.28 & 26.83 & 28.90 \\
\hline $10 \mathrm{C} 011-2$ & 43.38 & 38.67 & 32.58 & 33.94 & 26.01 & 31.57 & 34.68 & 29.99 & 26.73 \\
\hline $10 \mathrm{C} 011-3$ & 51.03 & 38.67 & 45.58 & 35.52 & 36.12 & 37.96 & 33.95 & 36.31 & 20.23 \\
\hline $10 \mathrm{C} 011-4$ & 48.93 & 52.09 & 35.47 & 48.14 & 24.56 & 39.54 & 41.90 & 42.62 & 33.95 \\
\hline $10 \mathrm{C} 011-5$ & 51.62 & 51.30 & 43.42 & 48.14 & 26.01 & 45.07 & 46.23 & 44.20 & 40.45 \\
\hline
\end{tabular}


Table E.6. Length Sizing LOS Level (mm), Raster Data, Pipe Side of Weld

\begin{tabular}{|c|c|c|c|c|c|c|c|c|c|}
\hline \multirow[b]{3}{*}{ Flaw } & \multirow[b]{3}{*}{$\begin{array}{l}\text { True } \\
\text { State }\end{array}$} & \multicolumn{8}{|c|}{ Probe } \\
\hline & & \multicolumn{2}{|c|}{$800 \mathrm{kHz}$} & \multicolumn{2}{|c|}{$1.0 \mathrm{MHz}$} & \multicolumn{2}{|c|}{$1.5 \mathrm{MHz}$} & \multicolumn{2}{|c|}{$2.0 \mathrm{MHz}$} \\
\hline & & $\begin{array}{l}\text { Pre- } \\
\text { WOL }\end{array}$ & $\begin{array}{l}\text { Post- } \\
\text { WOL }\end{array}$ & $\begin{array}{c}\text { Pre- } \\
\text { WOL }\end{array}$ & $\begin{array}{l}\text { Post- } \\
\text { WOL }\end{array}$ & $\begin{array}{c}\text { Pre- } \\
\text { WOL }\end{array}$ & $\begin{array}{l}\text { Post- } \\
\text { WOL }\end{array}$ & $\begin{array}{c}\text { Pre- } \\
\text { WOL }\end{array}$ & $\begin{array}{l}\text { Post- } \\
\text { WOL }\end{array}$ \\
\hline 9C034-1 & 51.18 & & & & & 51.0 & 74.56 & 47.8 & \\
\hline $9 \mathrm{C} 034-2$ & 51.49 & & & & & 44.6 & 75.27 & 52.6 & 61.78 \\
\hline $9 \mathrm{C} 034-3$ & 63.88 & & & & 52.62 & 60.5 & 61.07 & 58.9 & 52.55 \\
\hline $9 \mathrm{C} 034-4$ & 63.78 & & 65.40 & & & 70.1 & 17.75 & 71.7 & 13.49 \\
\hline $10 \mathrm{C} 011-1$ & 38.15 & 44.99 & 54.97 & 41.04 & 41.18 & 45.78 & & 42.62 & 37.56 \\
\hline $10 \mathrm{C} 011-2$ & 43.38 & 60.77 & 49.20 & 56.04 & 45.51 & 49.80 & 44.07 & 45.78 & 37.56 \\
\hline $10 \mathrm{C} 011-3$ & 51.03 & 42.62 & 64.37 & 44.20 & 50.57 & 42.70 & 44.79 & 40.25 & 39.73 \\
\hline $10 \mathrm{C} 011-4$ & 56.06 & 58.40 & 73.83 & 56.83 & 57.79 & 49.80 & 67.18 & 54.46 & 57.79 \\
\hline $10 \mathrm{C} 011-5$ & 63.86 & 63.14 & 93.41 & 59.98 & 62.85 & 58.48 & 65.74 & 48.93 & 53.46 \\
\hline
\end{tabular}

Table E.7. Depth Sizing (mm), Raster Data, Pipe Side of Weld

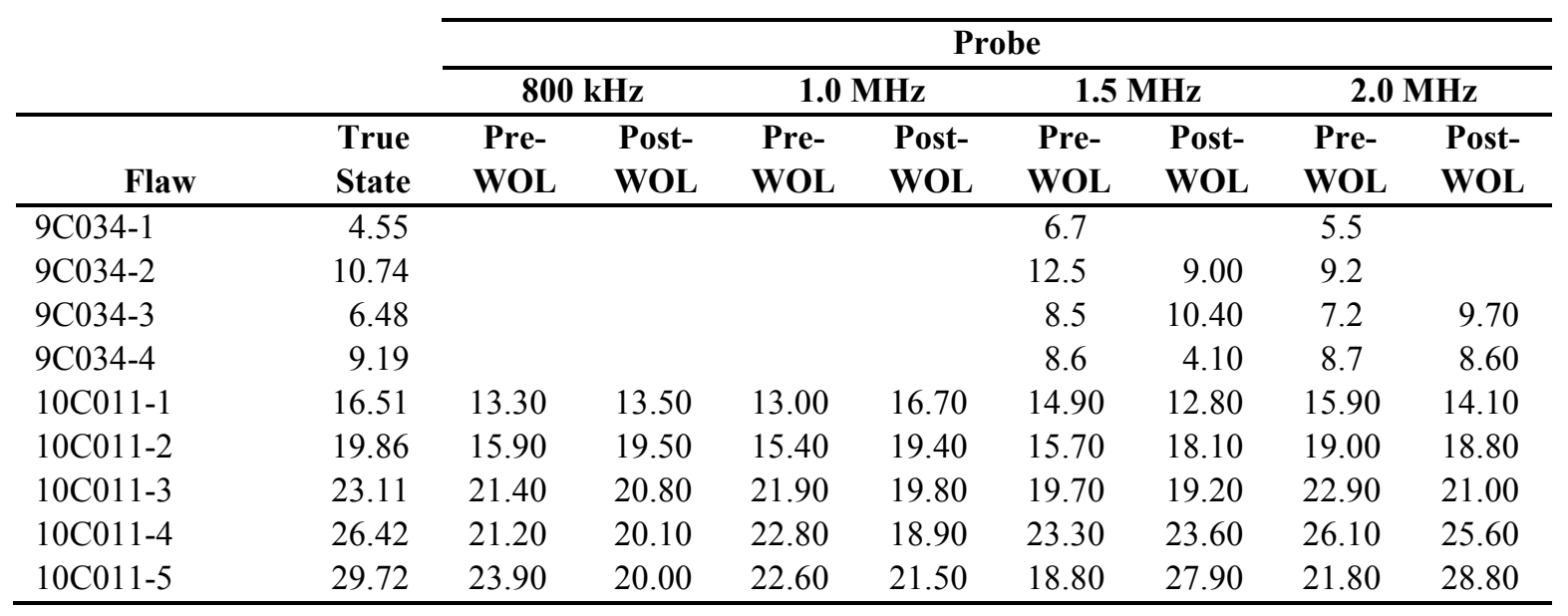


Table E.8. SNR (dB), Raster Data, Pipe Side of Weld

\begin{tabular}{|c|c|c|c|c|c|c|c|c|}
\hline \multirow[b]{3}{*}{ Flaw } & \multicolumn{8}{|c|}{ Probe } \\
\hline & \multicolumn{2}{|c|}{$800 \mathrm{kHz}$} & \multicolumn{2}{|c|}{$1.0 \mathrm{MHz}$} & \multicolumn{2}{|c|}{$1.5 \mathrm{MHz}$} & \multicolumn{2}{|c|}{ 2.0 MHz } \\
\hline & $\begin{array}{c}\text { Pre- } \\
\text { WOL }\end{array}$ & $\begin{array}{l}\text { Post- } \\
\text { WOL }\end{array}$ & $\begin{array}{c}\text { Pre- } \\
\text { WOL }\end{array}$ & $\begin{array}{l}\text { Post- } \\
\text { WOL }\end{array}$ & $\begin{array}{l}\text { Pre- } \\
\text { WOL }\end{array}$ & $\begin{array}{l}\text { Post- } \\
\text { WOL }\end{array}$ & $\begin{array}{l}\text { Pre- } \\
\text { WOL }\end{array}$ & $\begin{array}{l}\text { Post- } \\
\text { WOL }\end{array}$ \\
\hline $9 \mathrm{C} 034-1$ & & & & & 15.5 & 12.38 & 15.4 & 10.40 \\
\hline $9 \mathrm{C} 034-2$ & & & & & 16.2 & 13.99 & 14.4 & 16.39 \\
\hline $9 \mathrm{C} 034-3$ & & 11.16 & & 14.63 & 17.9 & 15.57 & 19.2 & 18.19 \\
\hline $9 \mathrm{C} 034-4$ & & 12.77 & & & 18.3 & 17.63 & 17.8 & 18.22 \\
\hline $10 \mathrm{C} 011-1$ & 13.08 & 12.98 & 15.15 & 12.04 & 12.87 & 15.41 & 18.16 & 15.30 \\
\hline $10 \mathrm{C} 011-2$ & 13.24 & 12.93 & 15.91 & 13.95 & 13.81 & 14.82 & 16.92 & 15.22 \\
\hline $10 \mathrm{C} 011-3$ & 14.20 & 13.99 & 14.01 & 16.24 & 13.19 & 16.13 & 19.35 & 17.02 \\
\hline $10 \mathrm{C} 011-4$ & 12.30 & 14.69 & 12.09 & 15.89 & 16.04 & 14.78 & 18.33 & 16.19 \\
\hline $10 \mathrm{C} 011-5$ & 15.08 & 14.59 & 16.46 & 16.48 & 17.17 & 17.19 & 20.15 & 19.47 \\
\hline
\end{tabular}

\section{E.2 Line Scan Data}

Table E.9. Length Sizing -6 dB Level (mm), Line Scan Data, Nozzle Side of Weld

\begin{tabular}{|c|c|c|c|c|c|c|c|c|c|}
\hline \multirow[b]{3}{*}{ Flaw } & \multirow[b]{3}{*}{$\begin{array}{l}\text { True } \\
\text { State }\end{array}$} & \multicolumn{8}{|c|}{ Probe } \\
\hline & & \multicolumn{2}{|c|}{$800 \mathrm{kHz}$} & \multicolumn{2}{|c|}{$1.0 \mathrm{MHz}$} & \multicolumn{2}{|c|}{$1.5 \mathrm{MHz}$} & \multicolumn{2}{|c|}{$2.0 \mathrm{MHz}$} \\
\hline & & $\begin{array}{c}\text { Pre- } \\
\text { WOL }\end{array}$ & $\begin{array}{l}\text { Post- } \\
\text { WOL }\end{array}$ & $\begin{array}{c}\text { Pre- } \\
\text { WOL }\end{array}$ & $\begin{array}{l}\text { Post- } \\
\text { WOL }\end{array}$ & $\begin{array}{c}\text { Pre- } \\
\text { WOL }\end{array}$ & $\begin{array}{l}\text { Post- } \\
\text { WOL }\end{array}$ & $\begin{array}{c}\text { Pre- } \\
\text { WOL }\end{array}$ & $\begin{array}{l}\text { Post- } \\
\text { WOL }\end{array}$ \\
\hline 9C034-1 & 51.18 & & & & & & & & 13.49 \\
\hline $9 \mathrm{C} 034-2$ & 51.49 & & & & 42.96 & & 7.81 & & 20.59 \\
\hline $9 \mathrm{C} 034-3$ & 63.88 & & & & & & 18.11 & & 15.62 \\
\hline $9 \mathrm{C} 034-4$ & 63.78 & & 46.51 & & 49.35 & & 55.39 & & 44.66 \\
\hline $10 \mathrm{C} 011-1$ & 38.15 & 56.75 & 25.72 & 46.72 & 26.08 & 35.67 & 23.48 & 33.70 & 30.77 \\
\hline $10 \mathrm{C} 011-2$ & 43.38 & 29.52 & 18.42 & 23.91 & 51.00 & 32.20 & 23.48 & 34.89 & 29.69 \\
\hline $10 \mathrm{C} 011-3$ & 51.03 & 107.97 & 31.14 & 35.12 & 25.72 & 37.25 & 34.68 & 41.91 & 7.95 \\
\hline $10 \mathrm{C} 011-4$ & 56.06 & 60.61 & 24.27 & 60.22 & 31.14 & 53.75 & 27.81 & 52.56 & 27.52 \\
\hline $10 \mathrm{C} 011-5$ & 63.86 & 63.30 & 46.67 & 55.56 & 43.78 & 46.33 & 35.40 & 58.40 & 45.22 \\
\hline
\end{tabular}


Table E.10. Length Sizing LOS Level (mm), Line Scan Data, Nozzle Side of Weld

\begin{tabular}{|c|c|c|c|c|c|c|c|c|c|}
\hline \multirow[b]{3}{*}{ Flaw } & \multirow[b]{3}{*}{$\begin{array}{l}\text { True } \\
\text { State }\end{array}$} & \multicolumn{8}{|c|}{ Probe } \\
\hline & & \multicolumn{2}{|c|}{$800 \mathrm{kHz}$} & \multicolumn{2}{|c|}{$1.0 \mathrm{MHz}$} & \multicolumn{2}{|c|}{$1.5 \mathrm{MHz}$} & \multicolumn{2}{|c|}{$2.0 \mathrm{MHz}$} \\
\hline & & $\begin{array}{c}\text { Pre- } \\
\text { WOL }\end{array}$ & $\begin{array}{l}\text { Post- } \\
\text { WOL }\end{array}$ & $\begin{array}{c}\text { Pre- } \\
\text { WOL }\end{array}$ & $\begin{array}{l}\text { Post- } \\
\text { WOL }\end{array}$ & $\begin{array}{c}\text { Pre- } \\
\text { WOL }\end{array}$ & $\begin{array}{l}\text { Post- } \\
\text { WOL }\end{array}$ & $\begin{array}{c}\text { Pre- } \\
\text { WOL }\end{array}$ & $\begin{array}{l}\text { Post- } \\
\text { WOL }\end{array}$ \\
\hline 9C034-1 & 51.18 & & & & & & & & \\
\hline $9 \mathrm{C} 034-2$ & 51.49 & & & & 61.78 & & 41.54 & & 49.71 \\
\hline $9 \mathrm{C} 034-3$ & 63.88 & & & & & & 102.25 & & 35.50 \\
\hline $9 \mathrm{C} 034-4$ & 63.78 & & 137.76 & & 124.26 & & 122.13 & & 74.13 \\
\hline $10 \mathrm{C} 011-1$ & 38.15 & 105.21 & 37.28 & 62.51 & 41.61 & 51.78 & 30.70 & 52.88 & 42.69 \\
\hline $10 \mathrm{C} 011-2$ & 43.38 & 82.71 & 32.94 & 52.88 & 58.23 & 47.43 & 36.48 & 43.88 & 40.53 \\
\hline $10 \mathrm{C} 011-3$ & 51.03 & & 41.61 & 88.00 & 40.89 & 73.40 & 49.12 & 70.64 & 29.33 \\
\hline $10 \mathrm{C} 011-4$ & 56.06 & 89.74 & 41.25 & 75.69 & 41.97 & 63.53 & 42.62 & 63.61 & 48.83 \\
\hline $10 \mathrm{C} 011-5$ & 63.86 & 86.19 & 60.75 & 75.22 & 58.30 & 66.30 & 50.21 & 78.06 & 62.27 \\
\hline
\end{tabular}

Table E.11. Depth Sizing (mm), Line Scan Data, Nozzle Side of Weld

\begin{tabular}{|c|c|c|c|c|c|c|c|c|c|}
\hline \multirow[b]{3}{*}{ Flaw } & \multirow[b]{3}{*}{$\begin{array}{l}\text { True } \\
\text { State } \\
\end{array}$} & \multicolumn{8}{|c|}{ Probe } \\
\hline & & \multicolumn{2}{|c|}{$800 \mathrm{kHz}$} & \multicolumn{2}{|c|}{$1.0 \mathrm{MHz}$} & \multicolumn{2}{|c|}{$1.5 \mathrm{MHz}$} & \multicolumn{2}{|c|}{$2.0 \mathrm{MHz}$} \\
\hline & & $\begin{array}{l}\text { Pre- } \\
\text { WOL }\end{array}$ & $\begin{array}{l}\text { Post- } \\
\text { WOL }\end{array}$ & $\begin{array}{l}\text { Pre- } \\
\text { WOL }\end{array}$ & $\begin{array}{l}\text { Post- } \\
\text { WOL }\end{array}$ & $\begin{array}{l}\text { Pre- } \\
\text { WOL }\end{array}$ & $\begin{array}{l}\text { Post- } \\
\text { WOL }\end{array}$ & $\begin{array}{l}\text { Pre- } \\
\text { WOL }\end{array}$ & $\begin{array}{l}\text { Post- } \\
\text { WOL }\end{array}$ \\
\hline $9 \mathrm{C} 034-1$ & 4.55 & & & & & & & & \\
\hline $9 \mathrm{C} 034-2$ & 10.74 & & & & & & 6.80 & & 3.30 \\
\hline $9 \mathrm{C} 034-3$ & 6.48 & & & & & & & & 4.90 \\
\hline $9 \mathrm{C} 034-4$ & 9.19 & & & & & & 5.10 & & 4.30 \\
\hline 10C011-1 & 16.51 & 13.40 & 14.40 & 12.80 & 13.60 & 13.50 & 14.70 & 15.30 & 18.30 \\
\hline $10 \mathrm{C} 011-2$ & 19.86 & 18.40 & 18.80 & 17.60 & 18.60 & 18.00 & 19.40 & 19.30 & 20.20 \\
\hline $10 \mathrm{C} 011-3$ & 23.11 & 25.90 & 19.70 & 18.00 & 20.10 & 21.70 & 22.50 & 21.90 & 21.10 \\
\hline $10 \mathrm{C} 011-4$ & 26.42 & 19.40 & 25.40 & 22.80 & 28.70 & 27.60 & 27.20 & 26.20 & 23.00 \\
\hline $10 \mathrm{C} 011-5$ & 29.72 & 29.50 & 28.30 & 30.00 & 30.10 & 29.70 & 28.80 & 28.80 & 29.70 \\
\hline
\end{tabular}

Table E.12. SNR (dB), Line Scan Data, Nozzle Side of Weld

\begin{tabular}{|c|c|c|c|c|c|c|c|c|}
\hline \multirow[b]{3}{*}{ Flaw } & \multicolumn{8}{|c|}{ Probe } \\
\hline & \multicolumn{2}{|c|}{$800 \mathrm{kHz}$} & \multicolumn{2}{|c|}{$1.0 \mathrm{MHz}$} & \multicolumn{2}{|c|}{$1.5 \mathrm{MHz}$} & \multicolumn{2}{|c|}{$2.0 \mathrm{MHz}$} \\
\hline & $\begin{array}{c}\text { Pre- } \\
\text { WOL }\end{array}$ & $\begin{array}{l}\text { Post- } \\
\text { WOL }\end{array}$ & $\begin{array}{c}\text { Pre- } \\
\text { WOL }\end{array}$ & $\begin{array}{l}\text { Post- } \\
\text { WOL }\end{array}$ & $\begin{array}{c}\text { Pre- } \\
\text { WOL }\end{array}$ & $\begin{array}{l}\text { Post- } \\
\text { WOL }\end{array}$ & $\begin{array}{c}\text { Pre- } \\
\text { WOL }\end{array}$ & $\begin{array}{l}\text { Post- } \\
\text { WOL }\end{array}$ \\
\hline $9 \mathrm{C} 034-1$ & & & & & & & & 10.87 \\
\hline $9 \mathrm{C} 034-2$ & & & & 14.6 & & 18.12 & & 16.87 \\
\hline $9 \mathrm{C} 034-3$ & & & & & & 13.11 & & 14.58 \\
\hline $9 \mathrm{C} 034-4$ & & 12.24 & & 13.21 & & 13.97 & & 15.80 \\
\hline $10 \mathrm{C} 011-1$ & 8.31 & 13.86 & 9.57 & 15.20 & 17.36 & 17.60 & 13.19 & 10.97 \\
\hline $10 \mathrm{C} 011-2$ & 14.22 & 14.46 & 15.08 & 11.83 & 16.05 & 13.60 & 12.09 & 11.20 \\
\hline $10 \mathrm{C} 011-3$ & 8.48 & 11.78 & 14.17 & 37.13 & 20.08 & 9.39 & 19.57 & 17.23 \\
\hline $10 \mathrm{C} 011-4$ & 10.16 & 12.00 & 8.67 & 12.63 & 13.29 & 12.79 & 14.06 & 11.35 \\
\hline $10 \mathrm{C} 011-5$ & 12.85 & 13.44 & 13.47 & 16.15 & 15.09 & 17.39 & 11.56 & 15.33 \\
\hline
\end{tabular}


Table E.13. Length Sizing -6 dB Level (mm), Line Scan Data, Pipe Side of Weld

\begin{tabular}{|c|c|c|c|c|c|c|c|c|c|}
\hline \multirow[b]{3}{*}{ Flaw } & \multirow[b]{3}{*}{$\begin{array}{l}\text { True } \\
\text { State }\end{array}$} & \multicolumn{8}{|c|}{ Probe } \\
\hline & & \multicolumn{2}{|c|}{$800 \mathrm{kHz}$} & \multicolumn{2}{|c|}{$1.0 \mathrm{MHz}$} & \multicolumn{2}{|c|}{$1.5 \mathrm{MHz}$} & \multicolumn{2}{|c|}{$2.0 \mathrm{MHz}$} \\
\hline & & $\begin{array}{c}\text { Pre- } \\
\text { WOL }\end{array}$ & $\begin{array}{l}\text { Post- } \\
\text { WOL }\end{array}$ & $\begin{array}{l}\text { Pre- } \\
\text { WOL }\end{array}$ & $\begin{array}{l}\text { Post- } \\
\text { WOL }\end{array}$ & $\begin{array}{c}\text { Pre- } \\
\text { WOL }\end{array}$ & $\begin{array}{l}\text { Post- } \\
\text { WOL }\end{array}$ & $\begin{array}{c}\text { Pre- } \\
\text { WOL }\end{array}$ & $\begin{array}{l}\text { Post- } \\
\text { WOL }\end{array}$ \\
\hline 9C034-1 & 51.18 & & & & & 37.4 & & 47.0 & \\
\hline $9 \mathrm{C} 034-2$ & 51.49 & & & & & 40.6 & 28.05 & 29.5 & \\
\hline $9 \mathrm{C} 034-3$ & 63.88 & & & & & 51.8 & 28.40 & 59.0 & 10.30 \\
\hline $9 \mathrm{C} 034-4$ & 63.78 & & & & & 66.1 & 19.17 & 59.0 & 5.25 \\
\hline 10C011-1 & 38.15 & 36.94 & 46.31 & 35.91 & 34.75 & 31.37 & 28.53 & 36.86 & 32.22 \\
\hline $10 \mathrm{C} 011-2$ & 43.38 & 51.30 & 41.25 & 50.20 & 59.38 & 31.77 & 34.68 & 42.78 & 37.28 \\
\hline $10 \mathrm{C} 011-3$ & 51.03 & 19.81 & 46.67 & 31.96 & 49.99 & 33.33 & 26.73 & 30.23 & 24.56 \\
\hline $10 \mathrm{C} 011-4$ & 56.06 & 48.93 & 63.64 & 48.22 & 42.33 & 40.79 & 47.68 & 47.04 & 44.86 \\
\hline $10 \mathrm{C} 011-5$ & 63.86 & 51.62 & 49.56 & 45.54 & 50.28 & 50.20 & 39.73 & 43.96 & 41.97 \\
\hline
\end{tabular}

Table E.14. Length Sizing LOS Level (mm), Line Scan Data, Pipe Side of Weld

\begin{tabular}{|c|c|c|c|c|c|c|c|c|c|}
\hline \multirow[b]{3}{*}{ Flaw } & \multirow[b]{3}{*}{$\begin{array}{l}\text { True } \\
\text { State }\end{array}$} & \multicolumn{8}{|c|}{ Probe } \\
\hline & & \multicolumn{2}{|c|}{$800 \mathrm{kHz}$} & \multicolumn{2}{|c|}{$1.0 \mathrm{MHz}$} & \multicolumn{2}{|c|}{$1.5 \mathrm{MHz}$} & \multicolumn{2}{|c|}{$2.0 \mathrm{MHz}$} \\
\hline & & $\begin{array}{c}\text { Pre- } \\
\text { WOL } \\
\end{array}$ & $\begin{array}{l}\text { Post- } \\
\text { WOL }\end{array}$ & $\begin{array}{c}\text { Pre- } \\
\text { WOL } \\
\end{array}$ & $\begin{array}{l}\text { Post- } \\
\text { WOL } \\
\end{array}$ & $\begin{array}{c}\text { Pre- } \\
\text { WOL } \\
\end{array}$ & $\begin{array}{l}\text { Post- } \\
\text { WOL }\end{array}$ & $\begin{array}{l}\text { Pre- } \\
\text { WOL }\end{array}$ & $\begin{array}{l}\text { Post- } \\
\text { WOL }\end{array}$ \\
\hline $9 \mathrm{C034-1}$ & 51.18 & & & & & 48.6 & & 50.2 & \\
\hline $9 \mathrm{C} 034-2$ & 51.49 & & & & & 47.8 & & 52.6 & \\
\hline $9 \mathrm{C} 034-3$ & 63.88 & & & & & 56.6 & 64.97 & 68.5 & 79.10 \\
\hline $9 \mathrm{C} 034-4$ & 63.78 & & & & & 72.3 & 35.50 & 71.7 & 31.53 \\
\hline $10 \mathrm{C} 011-1$ & 38.15 & 46.25 & --- & 40.57 & 64.73 & 40.39 & 40.45 & 42.78 & 49.56 \\
\hline $10 \mathrm{C} 011-2$ & 43.38 & 62.51 & 61.19 & 62.51 & 62.7 & 43.92 & 46.23 & 52.17 & 50.64 \\
\hline $10 \mathrm{C} 011-3$ & 51.03 & 48.54 & 64.44 & 40.09 & 67.33 & 43.14 & 43.34 & 49.41 & 47.10 \\
\hline $10 \mathrm{C} 011-4$ & 56.06 & 54.38 & --- & 59.43 & 61.55 & 49.41 & 63.21 & 64.72 & 69.13 \\
\hline $10 \mathrm{C} 011-5$ & 63.86 & 66.46 & 91.53 & 55.96 & 81.05 & 56.86 & 43.71 & 62.35 & 59.74 \\
\hline
\end{tabular}

Table E.15. Depth Sizing (mm), Line Scan Data, Pipe Side of Weld

\begin{tabular}{|c|c|c|c|c|c|c|c|c|c|}
\hline \multirow[b]{3}{*}{ Flaw } & \multirow[b]{3}{*}{$\begin{array}{l}\text { True } \\
\text { State }\end{array}$} & \multicolumn{8}{|c|}{ Probe } \\
\hline & & \multicolumn{2}{|c|}{$800 \mathrm{kHz}$} & \multicolumn{2}{|c|}{$1.0 \mathrm{MHz}$} & \multicolumn{2}{|c|}{$1.5 \mathrm{MHz}$} & \multicolumn{2}{|c|}{$2.0 \mathrm{MHz}$} \\
\hline & & $\begin{array}{c}\text { Pre- } \\
\text { WOL }\end{array}$ & $\begin{array}{l}\text { Post- } \\
\text { WOL }\end{array}$ & $\begin{array}{c}\text { Pre- } \\
\text { WOL }\end{array}$ & $\begin{array}{l}\text { Post- } \\
\text { WOL }\end{array}$ & $\begin{array}{c}\text { Pre- } \\
\text { WOL }\end{array}$ & $\begin{array}{l}\text { Post- } \\
\text { WOL }\end{array}$ & $\begin{array}{c}\text { Pre- } \\
\text { WOL }\end{array}$ & $\begin{array}{l}\text { Post- } \\
\text { WOL }\end{array}$ \\
\hline $9 \mathrm{C} 034-1$ & 4.55 & & & & & 6 & & & \\
\hline $9 \mathrm{C} 034-2$ & 10.74 & & & & & 13 & 12.00 & 13 & \\
\hline $9 \mathrm{C} 034-3$ & 6.48 & & & & & 10 & 6.00 & 10 & 7.00 \\
\hline $9 \mathrm{C} 034-4$ & 9.19 & & & & & 12 & & 12 & 12.30 \\
\hline $10 \mathrm{C} 011-1$ & 16.51 & 15.00 & 18.40 & 16.40 & 15.70 & 17.20 & 17.60 & 14.90 & 14.90 \\
\hline $10 \mathrm{C} 011-2$ & 19.86 & 18.90 & 23.90 & 18.50 & 20.90 & 19.00 & 19.70 & 17.20 & 22.80 \\
\hline $10 \mathrm{C} 011-3$ & 23.11 & 23.30 & 25.00 & 21.00 & 25.60 & 23.30 & 23.90 & 23.90 & 25.50 \\
\hline $10 \mathrm{C} 011-4$ & 26.42 & 26.90 & 25.30 & 27.50 & 26.90 & 26.00 & 23.80 & 27.50 & 29.40 \\
\hline $10 \mathrm{C} 011-5$ & 29.72 & 31.00 & 29.30 & 26.30 & 29.40 & 29.30 & 33.00 & 30.70 & 29.40 \\
\hline
\end{tabular}


Table E.16. SNR (dB), Line Scan Data, Pipe Side of Weld

\begin{tabular}{|c|c|c|c|c|c|c|c|c|}
\hline \multirow[b]{3}{*}{ Flaw } & \multicolumn{8}{|c|}{ Probe } \\
\hline & \multicolumn{2}{|c|}{$800 \mathrm{kHz}$} & \multicolumn{2}{|c|}{$1.0 \mathrm{MHz}$} & \multicolumn{2}{|c|}{$1.5 \mathrm{MHz}$} & \multicolumn{2}{|c|}{$2.0 \mathrm{MHz}$} \\
\hline & $\begin{array}{c}\text { Pre- } \\
\text { WOL }\end{array}$ & $\begin{array}{l}\text { Post- } \\
\text { WOL }\end{array}$ & $\begin{array}{c}\text { Pre- } \\
\text { WOL }\end{array}$ & $\begin{array}{l}\text { Post- } \\
\text { WOL }\end{array}$ & $\begin{array}{l}\text { Pre- } \\
\text { WOL }\end{array}$ & $\begin{array}{l}\text { Post- } \\
\text { WOL }\end{array}$ & $\begin{array}{l}\text { Pre- } \\
\text { WOL }\end{array}$ & $\begin{array}{l}\text { Post- } \\
\text { WOL }\end{array}$ \\
\hline 9C034-1 & & & & & 14.7 & & 15.3 & \\
\hline $9 \mathrm{C} 034-2$ & & & & & 12.2 & 10.47 & 13.7 & \\
\hline $9 \mathrm{C} 034-3$ & & & & & 15.2 & 14.20 & 16.6 & 15.08 \\
\hline $9 \mathrm{C} 034-4$ & & & & & 14.3 & 12.73 & 16.2 & 13.41 \\
\hline $10 \mathrm{C} 011-1$ & 9.61 & 9.30 & 9.42 & 10.97 & 12.08 & 12.23 & 11.92 & 12.98 \\
\hline $10 \mathrm{C} 011-2$ & 11.08 & 9.48 & 10.63 & 8.73 & 13.15 & 14.02 & 12.43 & 13.83 \\
\hline $10 \mathrm{C} 011-3$ & 13.34 & 12.07 & 12.97 & 13.54 & 14.01 & 15.17 & 15.13 & 13.83 \\
\hline $10 \mathrm{C} 011-4$ & 10.15 & 11.12 & 13.08 & 11.85 & 13.67 & 12.71 & 14.47 & 13.44 \\
\hline $10 \mathrm{C} 011-5$ & 15.06 & 14.24 & 17.41 & 15.04 & 17.35 & 16.50 & 15.45 & 16.75 \\
\hline
\end{tabular}




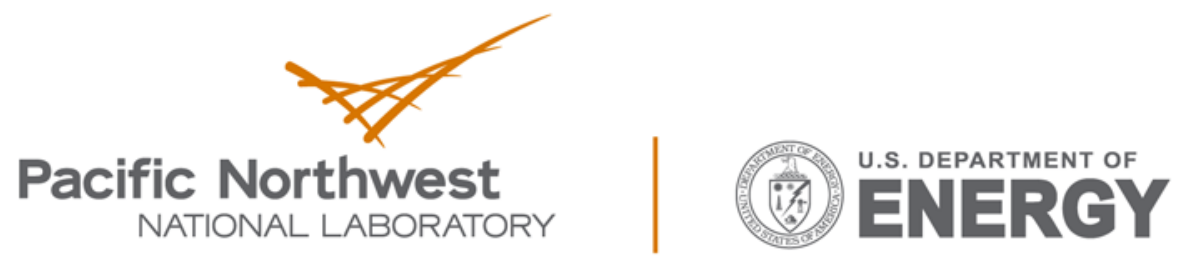

Proudly Operated by Battelle Since 1965

902 Battelle Boulevard

P.O. Box 999

Richland, WA 99352

1-888-375-PNNL (7665)

www.pnnl.gov 